\title{
RANGE AND PASTURE MANAGEMENT BY
}

ARTHUR W. SAMPSON 


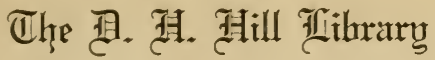

Warth Taralina State Uallege

$$
\begin{array}{r}
S F 85 \\
536 \\
\hline
\end{array}
$$


THIS BOOK IS DUE ON THE DATE INDICATED BELOW AND IS SUBJECT TO AN OVERDUE FINE AS POSTED AT THE CIRCULATION DESK.

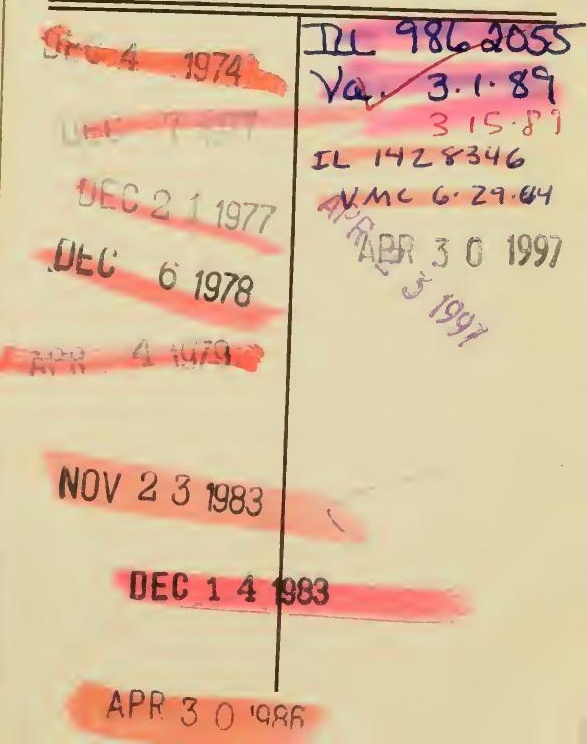







\section{RANGE AND PASTURE MANAGEMENT}




\title{
WORKS OF ARTHUR W. SAMPSON
}

\author{
PUBLISHED BY
}

\section{JOHN WILEY \& SONS, Inc.}

\section{Range and Pasture Management.}

Provides systematic instruction for those who desire a practical working knowledge of the subject, as well as for those who wish to follow technical grazing work as a profession. vii +421 pages. 6 by 9 . 129 figures, including plate showing main stock-poisoning plants in their natural colors. Cloth, $\$ 4.00$ net.

Livestock Husbandry on Range and Pasture.

A discussion of the management of range and pasture livestock. In Preparation.

\section{Native American Forage Plants.}

Treats in detail all important native forage grasses and broad-leaved plants. In Preparation. 



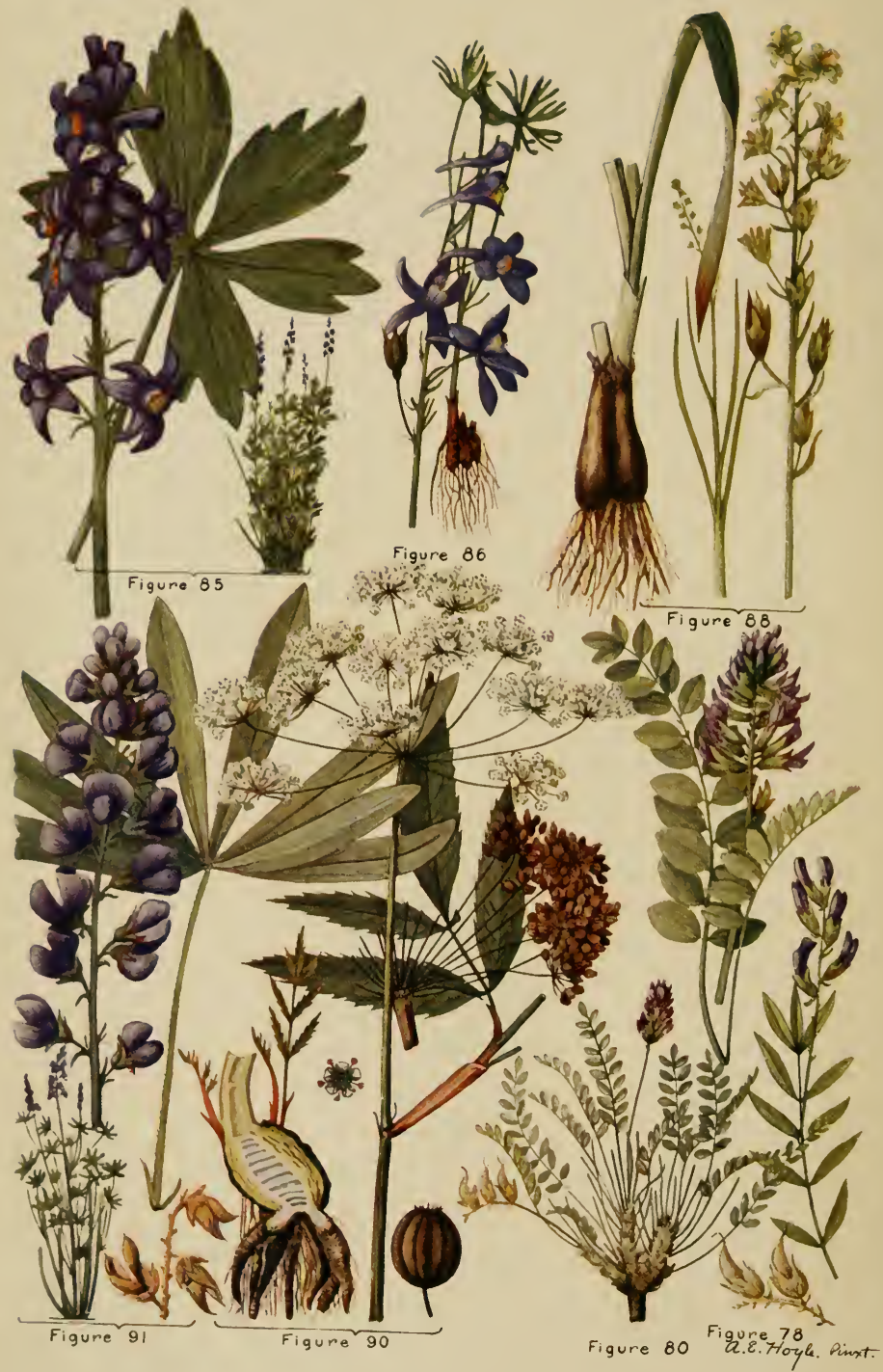




\section{RANGE AND PASTURE MANAGEMENT}

BY

ARTHUR W. SAMPSON, M.A., Ph.D. Associate Professor of Range Management and Forest Ecology University of California

Formerly Plant Ecologist, United States Forest Service, and Director, Great Basin Experiment Station

NEW YORK

JOHN WILEY \& SONS, INC.

LONDON: CHAPMAN \& HALL, LIMTTED

I923 
COPYright, I923,

BY

ARTHUR W. SAMPSON

Stanbope Press

TECHNICAL COMPOSITION COMPANY F. B. GILSON COMPANY

$$
\text { BOSTON, ס. S. A. }
$$




\title{
LIBRARY N. C. State College
}

\author{
flty 1 father \\ HAS FOR YEARS BEEN INTIMATELY ASSOCIATED WITH \\ PROBLEMS OF LIVESTOCK PRODUCTION \\ IN THE MIDDLE WESTERN UNITED STATES \\ AND \\ BY HIS PRACTICAL SENSE AND CLEAR JUDGMENT \\ HAS BEEN NOT ONLY MEASURABLY SUCCESSFUL HIMSELF \\ BUT HELPFUL TO OTHER STOCKMEN IN HIS LOCALITY
}

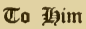

IN RECOGNITION OF HIS ACHIEVEMENTS

AND

IN GRATEFUL APPRECIATION OF

HIS PERSONAL INTEREST AND PATERNAL INSPIRATION

THIS BOOK IS

AFFECTIONATELY DEDICATED 


\section{PREFACE}

The purpose of this book is three-fold. In view of the fact that nearly everywhere in this country today the solution of pasture problems is urgently pressing, it is hoped the book may encourage agricultural colleges to include courses in pasture and range management in their curricula. It aims, also, to assist, if only in a small way, in the solution of the local pasture problems of those who have not had an opportunity to attend college. Chiefly, the book is intended to provide systematic instruction for those who desire a practical working knowledge of the subject, as well as for those who wish to follow technical grazing work as a profession and fit themselves to hold such positions as those offered by the United States Forest Service. Among these, students of professional forestry are quite as much in need of general training in this subject as are students of general agriculture.

The absolute essentials of living are supplied by four basic industries - farming, livestock production, forestry, and mining. All other business enterprises, broadly considered, are merely the result of the four basic industries. Approximately one-third of the cost of eating and a considerable part of the cost of living are expended upon meats and the by-products of the livestock industry - leather, wool, fats, and other such commodities.

For the attainment of success, no business is more dependent upon the broad application of the sciences than is that of producing livestock on range and pasture. Unfortunately, many persons are skeptical regarding the application of scientific principles to their agricultural operations, and are inclined to distinguish between what they term "practical" and what they call "scientific." Today, with a tendency toward the narrowing of the margin of profits in the production of pasture livestock, the use of "extended and systematized commonsense," as one careful thinker defines science, is essential to 
success. The happy-go-lucky range ventures characteristic of the West in the early days have been largely supplanted by orderly, business-like methods. Even so, stockmen generally throughout this country are not receiving maximum returns from the livestock industry. Evidently this is due more to overstocking during the free-for-all grazing period, which continued for so long a time in the far West, than to conspicuously destructive grazing during the last decade. The momentous results of range improvement achieved on the National Forests have proved beyond doubt the wisdom of cropping the forage on the basis of a sustained annual yield instead of overgrazing the pasture lands and taking chances of disastrous losses from poisonous plants and the caprice of the elements.

There remains now the big economic problem of revegetating the pasture and of maintaining such a nutritious forage cover as will be consistent with a maximum use of the lands. For the accomplishment of this, three things are necessary. There should be maintained at all times an effective plant cover which will bind the soil firmly and so preserve it against erosion and other destructive agencies. It is also necessary to determine which are the most important forage plants, as well as the objectionable pasture species, and how the desirable forage types may most expediently be improved. Furthermore, the foraging animals should be handled in such a way as to secure the largest percentage of offspring and of marketable stock consistent with economical production.

After fifteen years of intensive pasture investigations in the United States Forest Service, it was the author's good fortune to be called to the combined fields of instructional and investigative work in range, pasture, and livestock management. This congenial combination was of great assistance in the development of what he believes to be a logical division and treatment of so broad a subject. The present work deals chiefly with the practical care and management of range and pasture lands in this country. It discusses the character of pasture lands and the history of grazing control; the reseeding of the range; 
the recognition of the early stages of pasture-forage decline; the leading introduced forage plants and their culture; the adequate protection of timber reproduction against grazing on potential timberlands; the burning of pasture lands and its effect on forage yields; the poisonous-plant menace and its control; forage estimates and grazing capacity; methods of studying revegetational problems; and, finally, the educational phase, which embraces suggestions for instruction in pasture management and livestock production.

It is hoped that students of pasture management will avail themselves of the literature referred to in the discussion of the subject and at the end of the chapters. Although reluctant to do so, the author has been forced to cite his own writings somewhat freely, because, the critical study of range management having been so recently begun, only a small amount of literature bearing directly upon the development of the subject has been produced.

Among the most valuable features of the book are its numerous illustrations, nearly all of which are original. The plate showing the main stock-poisoning plants in their natural colors should prove especially helpful to stockmen as well as to students in the classroom.

The author takes this opportunity to express his gratitude to Mr. William A. Dayton, of the Forest Service, and others who have rendered valuable assistance by reading and criticizing portions of the manuscript. Grateful acknowledgment is made especially to Mr. Arthur Charles Watkins, of the Forest Service, who has critically read both the manuscript and proofs, and to Mrs. A. E. Hoyle, who has prepared most of the pen and ink illustrations.

Companion volumes entitled "Native American Forage Plants" and "Livestock Husbandry on Range and Pasture" are expected to appear in the near future.

ARTHUR W. SAMPSON.

The University of California, May, I923. 



\title{
CONTENTS
}

PART ONE

\section{THE GRAZING INDUSTRY AND RANGE CONTROL}

\author{
CHAPTER I \\ PASTURE LANDS AND GRAZING CONTROL IN THE \\ UNITED STATES
}

Pasture Lands. ................................... ${ }_{4}$

Range and Pasture Lands....................... 4

Forage-Crop Areas................................ 5

The Great Plains.............................. 5

The Great Basin............................. 6

The Southwest............................. 8

The Rocky Mountain Region..................... 8

Grazing Control................................ 9

Influence of the Settler......................... 9

Cause and Effect of Overgrazing................... Io

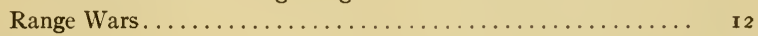

Questions................................ I5

Bibliography............................ I6

CHAPTER II

NATIONAL FOREST, STATE, AND PRIVATE GRAZING LANDS

The National Forests........................... I7

Object of Creating the National Forests.............. I7

Livestock on the National Forests. .................. I8

National Forest Grazing Policy.................... 23

The Stockmen's Protest........................ ${ }_{26} 6$

Government Rules and Regulations.................. $\quad 27$

Results of Regulated Grazing...................... $\quad 28$

State and Private Lands............................ 30

The Texas Leasing System...................... 30

The Wyoming Leasing System .................. 3 I

The Northern Pacific Railroad Leases............... 3 I 
PAGE

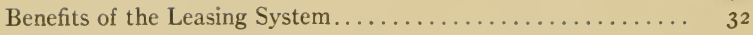

Improvement of the Pastures......................... 33

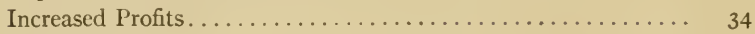

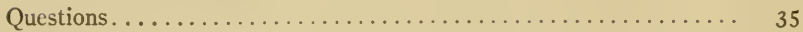

Bibliography...................................... 36

PASTURE REVEGETATION AND FORAGE MAINTENANCE

\section{CHAPTER III \\ RESEEDING WESTERN GRAZING LANDS TO CULTIVATED FORAGE PLANTS}

Plant Introduction on Arid Lands . . . . . . . . . . 4 .

Tests in Southern Arizona . . . . . . . . . . . . . . . . 40

Seeding Tests in Northern Arizona . . . . . . . . . . .

Plant Introduction on Mountain or Semi-Humid Lands......... 42

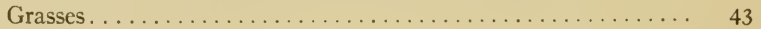

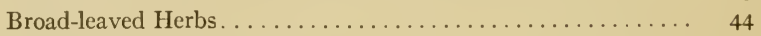

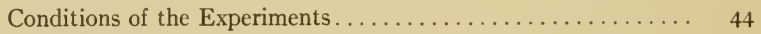

Results of the Tests. . . . . . . . . . . . 45

Success of the Various Species. . . . . . . . . . . . . . . . 45

Season for Sowing . . . . . . . . . . . . . . . . . . 47

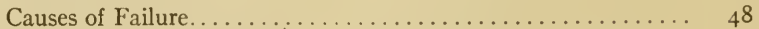

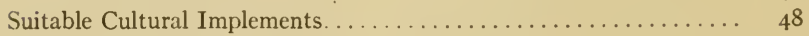

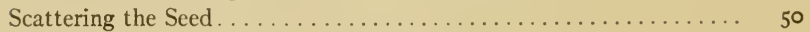

Elevational Limitations of Reseeding................. 50

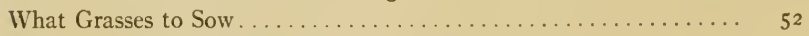

Amount to Sow and Cost of Seeding. . . . . . . $5 \ldots \ldots \ldots \ldots . \ldots \ldots$

Moisture Requirements of Cultivated Forage Plants........... 53

Seeding to a Mixture . . . . . . . . . . . . . . . . . 54

How to Graze Newly Seeded Lands.................... 55

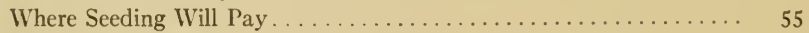

Reseeding to Native Forage Plants................. ${ }_{56}^{6}$

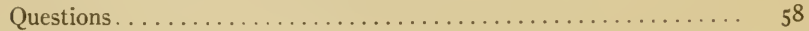

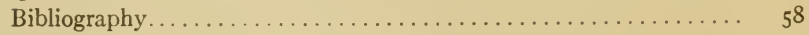

\section{CHAPTER IV}

NATURAL RESEEDING AND MAINTENANCE OF NATIVE WESTERN PASTURE LANDS

Migrations of Buffaloes Suggest Revegetation Plan........... 6 I

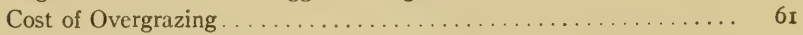

Requirements of Plant Growth................... $6_{2}$ 
Forage Production in Early Spring . . . . . . . . . . . . . $6_{2}$

Seed Production........................... 66

Scattering and Planting the Seed................. 67

Loss of Seedling Plants from Natural Agencies ............ 67

Destruction of Seedlings by Grazing. ............... 67

Grazing Systems and Forage Production............... 72

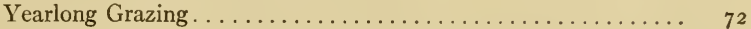

Revegetation by Yearlong Protection of Pastures........... 73

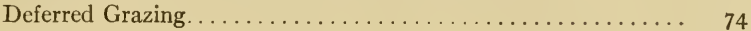

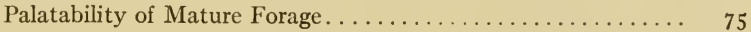

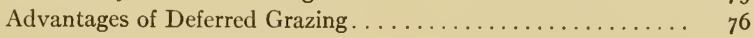

Application of Deferred Grazing. .................. 78

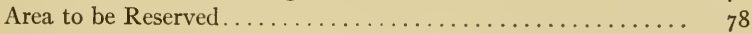

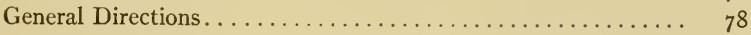

A Specific Case. . . . . . . . . . . . . . . . . . . . . 79

Deferred Grazing on Range of "Winter Annuals"............ 80

Reseeding Complications .................... 8

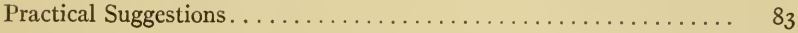

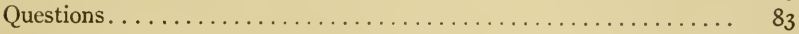

Bibliography................................... 84

\section{CHAPTER V}

\section{IMPROVEMENT AND MANAGEMENT OF FARM PASTURES}

What is Good Pasture?......................... 87

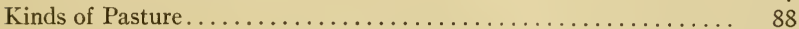

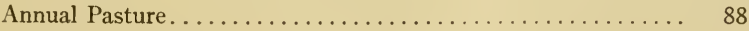

Temporary Pasture......................... 88

Permanent Pasture.......................... 88

Why Pastures "Run Out". ..................... 88

Natural Succession. . . . . . . . . . . . . . . . . . . . 89

Abnormal Changes in Autumn or Winter Weather......... 89

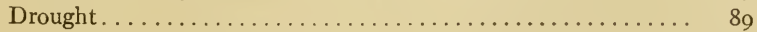

Faulty Methods of Grazing. . . . . . . . . . . . . . . 89

Growth Forms of Pasture and Hay Plants. . . . . . . . . . . . . 89

How the Farmer May Improve the Pasture............ . . . . . 90

Management of Bluegrass Pastures................. 93

Alternate versus Continuous Grazing. ................. 94

Disking and Harrowing . . . . . . . . . . . . . . . . . 95

Light versus Heavy Grazing . . . . . . . . . . . . . . 95

Management of Nonsod Pastures................. 96

Number of Stock to Graze. . . . . . . . . . . . . . . 96

Deferred Grazing. ........................... 97 
PAGE

Fertilizers for Pasture and Grassland ................... 98

Kinds of Fertilizers and Amounts to Apply .............. 99

The Eternal Battle with Weeds.................... I

Questions..................................

Bibliography.......................... 103

\section{CHAPTER VI}

RECOGNIZING AND CORRECTING A DECLINING FORAGE YIELD

How Destructive Grazing May Be Recognized ............. 104

Old or Empirical Method......................... I04

New or Scientific Method ...................... 105

Conspicuous Signs of Overgrazing ................. I06

Indicators of Slight Departures in Grazing Capacity......... I07

Type Stages of Indicator Plants................... 107

Climax Herbaceous Stage........................

Destruction of the Wheatgrass Cover................. ro 8

Forage Production......................... II I

Mixed Grass and Weed Stage...................... II I

Destruction of the Porcupinegrass-Yellowbrush Cover........ II

Forage Production........................... II

Second or Late Weed Stage......................... II

Destruction of the Foxglove-Sweet Sage-Yarrow Cover........ II 4

Forage Production........................... II

First or Early Weed Stage.......................... II 5

Forage Production............................ II5

Effect of Grazing on the Development of Vegetation.......... II7

Vegetation on Driveways and Bed Grounds.............. II9

Revegetation of Bed Grounds.................... I 20

Revegetation of Lands Grazed Each Year before Seed Maturity as Compared with That of Yearlong Protected Areas... I 24

Use of Indicator Plants........................ I 27

How to Recognize Pasture Improvement or Depletion....... I $\quad$ I27

Reliable Indicator Plants...................... I 28

Questions.................................. I30

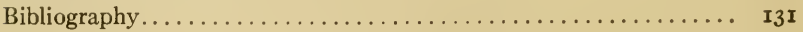

\section{CHAPTER VII}

\section{PRINCIPAL INTRODUCED FORAGE GRASSES}

Classification of Cultivated Plants..................... I32

Kentucky Bluegrass............................ I32

Canada Bluegrass.............................. I35

Bermudagrass................................ $\quad \mathrm{I}_{35}$ 
Hungarian Bromegrass.....................................

Redtop ................................ I 39

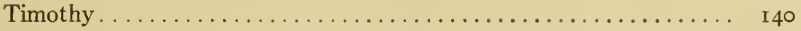

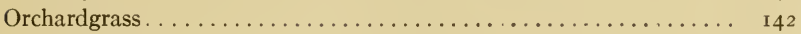

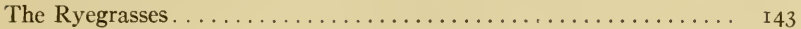

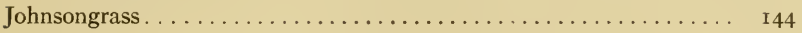

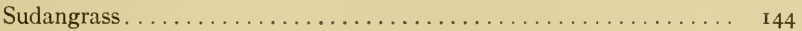

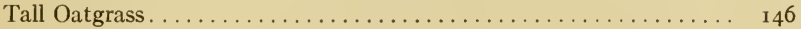

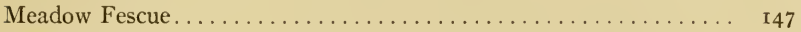

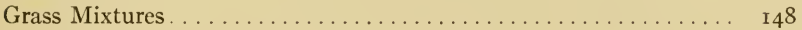

Mixtures for Temporary Pasture............... I48

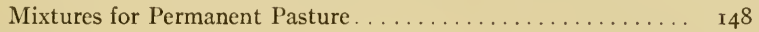

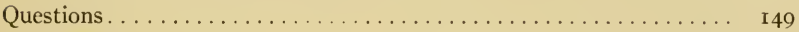

Bibliography. ........................ 149

CHAPTER VIII

PRINCIPAL INTRODUCED NONGRASSLIKE FORAGE HERBS

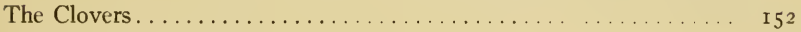

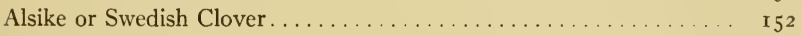

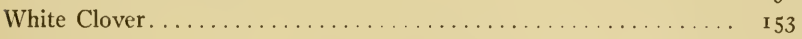

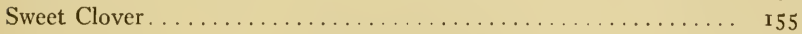

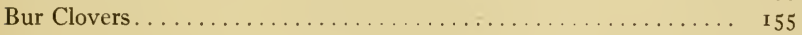

Alfalfa, or Lucerne. . . . . . . . . . . . . . . . . . . I 57

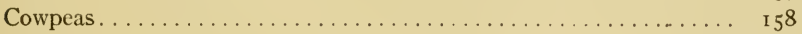

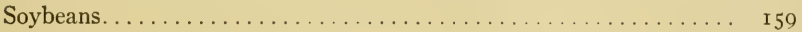

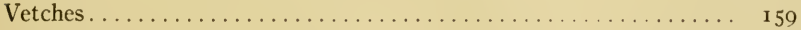

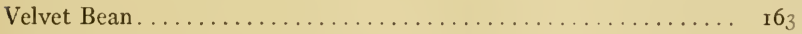

Japan Clover. ............................. ${ }^{16} 6_{4}$

Good Germination and Purity of Seed Essential. . . . . . . . . . . I $\mathrm{I}_{4}$

Questions............................ 66

Bibliography...................... 66

PART THREE

RANGE AND PASTURE PROTECTION

CHAPTER IX

CONTROL OF EROSION ON RANGE AND PASTURE

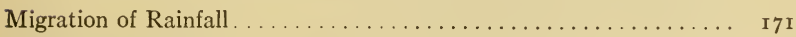

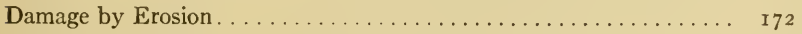

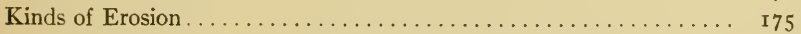

Gully Erosion..................... I76 
Sheet Erosion. ......................... I 76

Landslides....................... I 76

River-Bottom Erosion . . . . ................. I 76

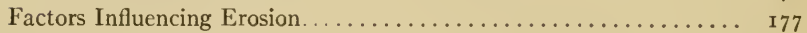

Steepness of Slope....................... I 77

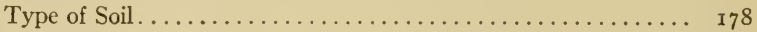

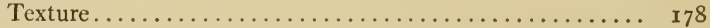

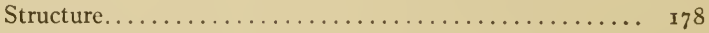

Organic Matter...................... 178

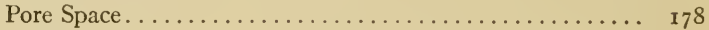

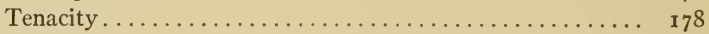

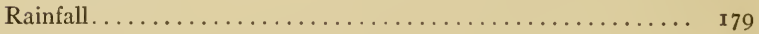

Melting Snow........................... I 80

Wind ...................... I 8 I

Vegetative Cover...................... I 82

Erosion, Plant Growth, and Revegetation.............. I82

Erosion and Plant Growth................... I 84

Erosion and Revegetation. ................... I 89

The Solution of the Erosion Problem on Pasture Lands......... I9I

Avoidance of Overgrazing . . . . . . .

Avoidance of Too Early Grazing . . . . . . . . . . .

The Practice of Deferred and Rotation Grazing .......... 192

The Control and Distribution of Livestock. . . . . . . . . 192

Terracing and Planting. ...................... 192

How More Than Half of the Erosion Battle is Won........... I94

Questions.............................. I94

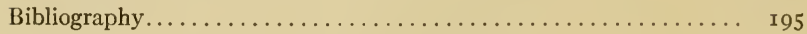

CHAPTER $\mathrm{X}$

GRAZING ON WOODLANDS AND ITS RELATION TO THE FUTURE TIMBER SUPPLY

Results of Investigations. . . . . . . . . . . . . . . . . 98

Studies in Northern California, Oregon, and Washington...... I98

Studies in Idaho . . . . . . . . . . . . . . . . . . . 200

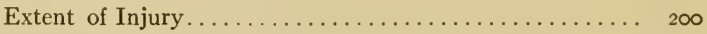

Comparative Seasonal Injury............... 201

Damage According to Intensity of Grazing and Amount of

Forage.......................... 201

Studies in Arizona and New Mexico . . . . . . . . . . . . . 202

Average Injury to Reproduction . . . . . . . . . . . . 202

Season of Injury . . . . . . . . . . $20 . \ldots \ldots \ldots . \ldots 2$

Injury in Relation to Intensity of Grazing and Character and Abundance of Forage ................... 203 
Effect of Grazing upon Aspen Reproduction ............ PAGE

Effects of Sheep Browsing..................... 206

Effects of Cattle Browsing.................... 206

Grazing Farm Woodland....................... 208

Damage Done to Tree Growth by Grazing. . . . . . . . . . . . 209

Effect of Goat Grazing on Timber Reproduction............. 210

Conclusions Based on Investigations .................. 2I I

Conclusions of General Application ................. 2 II

Conclusions of Regional Application................ 2I 2

Application of Studies to Grazing Management............. 2I 3

Questions................................. 213

Bibliography............................. $2 \mathrm{I} 4$

CHAPTER XI

BURNING OF PASTURE LANDS AND ITS EFFECTS ON FORAGE PRODUCTION

History of Burning ............................ 216

Present-Day Burning. ................... 219

A Common Delusion........................... 219

Effects of Burning on Forage Production................ 22I

Effect of Burning Grasslands....................... 222

Burning in the East, Middle West, and Far West....... 222

Burning in the South ...................... 223

Effect of Burning Brushlands.................... 225

Goats as Brush Destroyers.................. 227

Effect of Burning Wooded Pastures and Forested Ranges...... 228

Grazing and Fire Control......................... 230

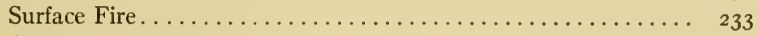

Ground Fire............................ ${ }_{233}$

Crown Fire............................... 234

Proper Control of Grazing Essential ................... 235

Summary and Conclusions.......................... ${ }_{23}{ }_{36}$

Questions.................................. ${ }_{23} 8$

Bibliography................................ $\quad 239$

\section{CHAPTER XII}

STOCK-POISONING PLANTS AND THEIR CONTROL

What is Poison?............................. 242

Important Families of Poisonous Plants............... 242

Palatability of Poisonous Plants..................... 243

Range Use and Variation in Poisonous Substances of Plants...... 244 
Proper Salting of Stock

Eradicating Poisonous Plants . ...................... 246

Driving and Herding Stock....................... 247

Questions.................................. 248

\section{CHAPTER XIII}

\section{PRINCIPAL STOCK-POISONING PLANTS}

Loco Plants (Oxytropis and Astragalus) ............... 250

Distribution and Habitat..................... 250

Losses of Stock and Animals Poisoned . . . . . . . . . . . 252

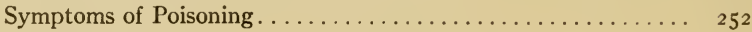

Remedies............................ 253

Control and Prevention of Losses................... 254

Larkspurs (Delphinium)............................. 255

Distribution and Habitat.................... 255

Losses of Stock and Animals Poisoned . . . . . . . . . . . 256

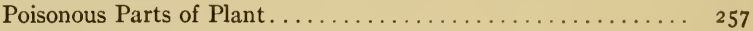

Amount Required to Cause Death.................... 257

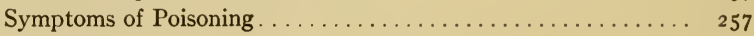

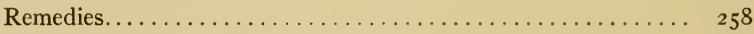

Control and Prevention of Losses. . . . . . . . . . . . . . . 259

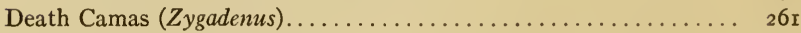

Distribution and Habitat. . . . . . . . . . . . .

Poisonous Species. . . . . . . . . . . . . . . .

Losses of Stock and Animals Poisoned. . . . . . . . . . . . 262

Poisonous Parts of Plant. . . . . . . . . . . . . . . . . ${ }_{262}$

Amount Required to Cause Death . . . . . . . . . . . . . 263

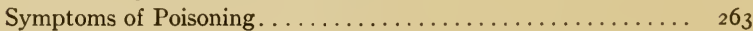

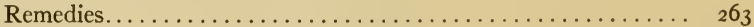

Water Hemlock (Cicuta) ............................. ${ }^{26} 4$

Distribution and Habitat. . . . . . . . . . . . . . . . . ${ }_{264}$

Losses of Stock and Animals Poisoned . . . . . . . . . . . . $2{ }_{25}$

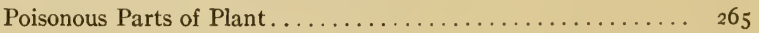

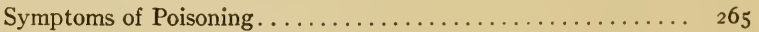

Remedies................................. ${ }_{26} 66$

Control and Prevention of Losses................... ${ }_{26} 66$

Lupines (Lupinus) . . . . . . . . . . . . . . . . . . . . . . . . ${ }_{26}^{26}$

Distribution and Habitat. . . . . . . . . . . . . . . . . . 266

Losses of Stock and Animals Poisoned ................ 267

Poisonous Parts of Plant. . . . . . . . . . . . . . . . . . . 267

Amount Required to Cause Death................. ${ }_{26} 68$

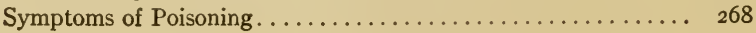


Remedies.

Control and Prevention of Losses..................... 269 269

Summary of Symptoms and Treatment of Stock Poisoned by Princi-

Questions pal Toxic Plants. . . . . . . . . .......... ${ }_{26} 69$

CHAPTER XIV

\section{POISONOUS AND MECHANICALLY IN JURIOUS PLANTS OF SECONDARY OR LOCAL IMPORTANCE}

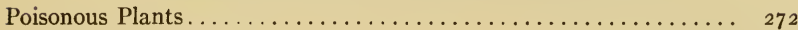

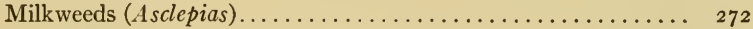

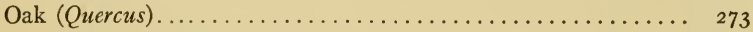

"Laurels" (Ericaceae) . . . . . . . . . . . . . . . . . 273

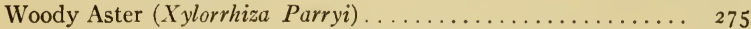

Colorado Rubberweed, or Pingué (Hymenoxys floribunda)..... . 276

Western Sneezeweed (Helenium Hoopesii) ............... 277

Aconite (Aconitum Columbianum) . . . . . . . . . . . . . 279

Wild or Choke Cherry (Prunus demissa) . . . . . . . . . 279

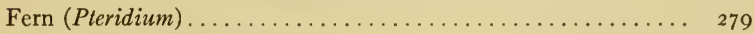

Ergot (Claviceps purpurea) . . . . . . . . . . . . . . $28 \mathbf{r}$

Fly Agaric, or Fly Amanita (Amanita muscaria)........... 283

Death Cup, or Deadly Amanita (Amanita phalloides) ....... 283

Mechanically Injurious Plants . . . . . . . . . . . . . . . 284

Bromegrasses............................... ${ }_{286}^{286}$

Barley and Squirreltail Grasses................... 286

Needlegrasses.............................. ${ }_{2} 88$

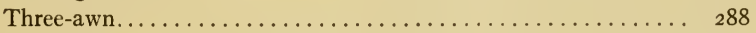

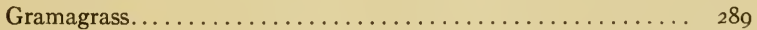

Questions................................ 289

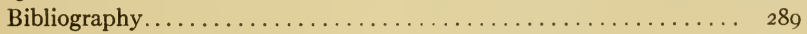

PART FOUR

PASTURE IMPROVEMENTS AND RESEARCH METHODS

\section{CHAPTER XV \\ DEVELOPMENT OF WATERING PLACES FOR RANGE AND PASTURE STOCK}

Availability of Water. . . . . . . . . . . . . . . . . . 295

Water Requirements of Livestock . . . . . . . . . . . . . . . 296

Distribution of Water. . . . . . . . . . . . . . . . . . 296

Natural Watering Places. . . . . . . . . . . . . . . . . . . . . . . 298 
Springs . PAGE

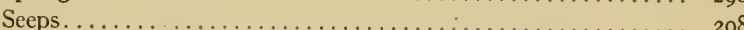

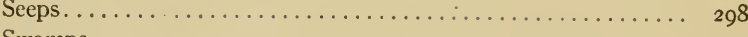

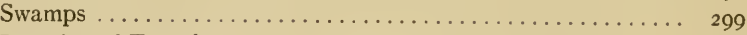

Location of Troughs......................... 299

Kinds of Troughs........................... 300

Log Troughs............................ 300

Other Wooden Troughs...................... 300

Metal, Cement, and Other Troughs................ 3 or

Trough Foundation......................... 301

Artificial Watering Places........................ 302

Reservoirs............................... 302

Wells....................................... 304

Questions...................................... 305

Bibliography.................................... 306

\section{CHAPTER XVI}

FORAGE ESTIMATES AS A BASIS FOR THE RATIONAL USE OF GRAZING RESOURCES (GRAZING RECONNAISSANCE)

Grazing Reconnaissance........................ 307

Object of Grazing Reconnaissance................... 308

History of Grazing Reconnaissance.................. 309

Data and Facts Obtained by Grazing Reconnaissance........ 3 3 I

Methods Employed in Obtaining the Data: Field Work...... 318

Gridiron Method......................... 318

Traverse-Sketching Method .................. 319

Triangulation Method........................ 320

Office Work. ............................ 320

Grazing and Timber Reconnaissance Compared........... 32I

Application of Grazing-Reconnaissance Data to Practical Pasture Management..................... 323

Accuracy and Limitations of Grazing Reconnaissance........ 323

The Forage Acre and How it is Derived............... 325

Comparative Value of a Forage Acre of Different Types...... 326

Questions................................... 327

Bibliography.................................. 327

\section{CHAPTER XVII}

\section{GRAZING CAPACITY AND PASTURE INSPECTION}

Grazing Capacity........................... ${ }_{32} 8$

Basis for Estimating Grazing Capacity................ 328

Grazing Capacity of Ranges and Farm Pastures........... $33^{\circ}$

Acreage Required for Cattle..................... $33 \mathrm{I}$ 
Acreage Required for Sheep.................... 333

Pasture Inspection . . . . . . . . . . . . . . . . . . . . . . 333

Inspection of Range and Farm Pasture............... 333

Questions..................................... ${ }_{33}$

Bibliography.................................. 337

\section{CHAPTER XVIII \\ RESEARCH METHODS IN RANGE AND PASTURE REVEGETATION}

Permanent Sample Plots.......................... 340

Kinds of Plots and Their Establishment................. 340

Chart Plot................................ 34I

Mapping Chart Plot ...................... 342

The Pantograph for Mapping Chart Plots............ 345

List Plot................................ 347

Denuded or Depopulated Plots.................... 349

Other Plots................................... 35 I

Special Sample-Plot Guide Tapes.................. 351

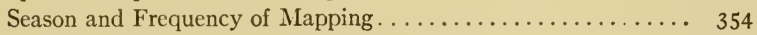

Protection Plots.............................. 355

Sample-Plot Dimensions....................... 356

Questions.................................... ${ }_{35} 8$

Bibliography................................. 359

SUGGESTIONS FOR INSTRUCTION IN PASTURE MANAGEMENT AND LIVESTOCK PRODUCTION

Outline of Grazing Course ......................... 364

General Instruction in Grazing. ..................... 389

Schools for Professional Training in Grazing. .............. 390

Bibliography................................ 39

INDEX $\ldots \ldots \ldots \ldots \ldots \ldots \ldots \ldots \ldots \ldots \ldots \ldots \ldots \ldots \ldots \ldots \ldots \ldots \ldots \ldots \ldots, 393$ 

PART ONE

THE GRAZING INDUSTRY AND RANGE CONTROL 



\section{RANGE AND PASTURE MANAGEMENT}

\section{CHAPTER I}

\section{PASTURE LANDS AND GRAZING CONTROL IN THE UNITED STATES}

The grazing animals of the ranches and farms may well be regarded as living factories that are continuously manufacturing flesh, leather, wool, mohair, motive power, and numerous other valuable products for the benefit of man. The machinery of this vast factory is run by "vegetational fuel," which, in general, can not be directly utilized as food by man. Having this prodigious livestock manufactory, we do not, like Nebuchadnezzar of old, have to subsist on grass ourselves; but we do eat it by proxy, for meat constitutes no unimportant part of our diet. The meat-eating habit will doubtless continue as long as eating remains necessary. Substitutes for meat are not popular and probably never will be.

The cellular structure of he body is composed largely of nitrogenous materials; hence foods containing an ample supply of nitrogen are an essential part of the diet. Meats are especially rich in nitrogenous substances, and in a form much more readily digested than the forms in which nitrogen is contained in cereals and vegetables. In the latter, as in string beans and other vegetable substitutes for meat, the nitrogenous materials are tied up to such an extent in cellulose, an indigestible substance, that the tissues of the body cannot be supplied with the nitrogen needed. Meat, therefore, forms an important part of the diet of all advanced nations. 


\section{PASTURE LANDS}

Range and Pasture Lands. - Of the various classes of public lands, those at present used for grazing are by far the most extensive. From the rooth meridian west to the Pacific, including the National Forests, Indian Reservations, and National Parks, there remained in 1920 approximately $375,000,000$ acres of public domain. For this vast area one of the most important economic uses is the grazing of livestock. It is not probable that any considerable proportion of these grazing lands can be irrigated with the present supply of water; and, even if this were possible, the climatic conditions do not, in most localities, favor the production of farm crops.

The total land area of the United States is $1,903,269,000$ acres, of which $878,789,000$ acres is classed as "productive," but of which only $293,794,000$ acres, or 15.4 per cent of the total area, is cultivated land. ${ }^{1}$ The remaining $584,995,000$ acres of productive land consists either of natural meadows and pastures, or of forests or woodlots, or is otherwise unimproved. Practically 65 per cent of this unimproved land lies west of the Mississippi River. The major part of the timbered lands has been cut over, or else the stand of trees is so sparse as to support a more or less luxuriant, succulent, and nutritious undergrowth, the accessible portion of which is grazed annually. East of the Mississippi, a large part of the $160,000,000$ acres of unimproved farm land remaining in 1920 is in woodlot, a considerable proportion of which is not at present grazed, notwithstanding the fact that these land produce an abundance of palatable forage. Of the unimproved farm land of the entire country, however, it is conservatively estimated that not less than $35^{\circ}, 000,000$ acres are annually used for grazing purposes.

All told, then, the acreage of land upon which our livestock is grazed is considerably greater than that which may be classed as improved farm property. The economic importance of the grazing lands, as well as of the livestock industry, is apparent from the figures given. The judicious utilization and man-

${ }^{1}$ U. S. Dept. of Agr. Yearbook, 1920, p. 834. 
agement of the public and private lands, upon which the future of the livestock industry depends, is an economic problem of tremendous importance.

\section{FORAGE-CROP AREAS}

Rainfall and temperature probably determine, more than any of the other important factors, the luxuriance of growth of forage plants, and, to a large extent, their requirements for moisture and heat determine their suitability to a given region. The following discussion deals briefly with the conditions and limitations of our forage-producing areas, with special reference to the region which now provides the greater part of the native forage crop.

The region in which timothy hay, on the one hand, and Bermudagrass, on the other, are grown commercially represents in general the tract where cultivated forage and fodder plants are largely relied upon to furnish the hay and pasture crops. The timothy area extends from New England to the southern boundary of Virginia and west through Minnesota and eastern Kansas, falling a little short of the rooth meridian. The Bermudagrass area, on the other hand, occupies the warmer southern region - the true cotton belt - and extends west to include eastern Texas. In general, the timothy-Bermudagrass expanse represents the "humid region," and thus embraces practically none of the native (arid) pasture type. There are other isolated and restricted humid areas in the western part of the United States where cultivated crops are successfully grown, but they are insignificant in extent as compared with those mentioned.

The native range lands lie almost entirely west of the rooth meridian and comprise the vast arid region. On the basis of the physical and climatic conditions, this extensive area may be divided into five well-defined regions - the Great Plains, the Rocky Mountain region, the Great Basin, the Southwest, and the Pacific coast.

The Great Plains. - This region, including the western portion of North and South Dakota, Nebraska, Kansas, Oklahoma, 
and the eastern part of Colorado, Wyoming, and Montana, comprises all the territory from the rooth meridian west to the foothills of the Rocky Mountains. In general, the Great Plains region is comparatively level, with the northwestern part sloping northward and the remainder inclining gently to the east. Although dry farming is increasing in extent in many parts, and irrigation agriculture is carried on in a limited way, the chief industry is livestock production. Failure of cultivated crops is not uncommon in this region, because of limited rainfall coupled with high normal summer temperatures, low air humidity, the prevalence of drying winds, and high evaporation. Except on the eastern border of the Great Plains, the normal annual rainfall averages less than 20 inches, with an annual variation from II to 33 inches.

The adverse climatic conditions, sometimes causing complete failure of agricultural crops, tend only to decrease, for the time being, the yield of the hardy, well-adapted native vegetation, such as the buffalograss-gramagrass association (" shortgrass" type), three-awn grasses, needlegrasses, the muhlenbergias, and sagebrush. The soil generally is rich and the grazing excellent. In many localities the ranges are not fully stocked, however, because of the distance between watering places. The water, supplied as it is by relatively few streams, is supplemented by drilled and dug wells, by artesian flows, and by dams conveniently placed to catch and store the run-off from torrential storms. The possibilities of extending the use of the forage crop in the Great Plains will depend largely upon the extent to which water for livestock purposes can be increased, to a lesser degree upon improved methods of handling the stock on the range, and upon supplemental winter feeding.

The Great Basin. - The term "Great Basin " applies to that region lying between the Rocky Mountains and the Sierra Nevada range which has no outlet to the sea. The region includes nearly the whole of Nevada and portions of Utah, Wyoming, Oregon, and California - a total area of approximately 2I 7,000 square miles. In general, the Great Basin presents a uniform appearance with respect to both topography and vege- 
tation. Much of the range region is comparatively level, lying between elevations of 4,000 and 5,000 feet, although there are some marked depressions, such as Death Valley, with a general level below the sea, and some elevated mountain ranges, such as the Wasatches, ascending to a height of more than II, $\infty 0$ feet. Because of the limited rainfall, averaging from 6 inches per annum in the most arid parts of Nevada to about 30 inches over restricted foothills and mountain lands, the vegetation is largely of a desert or semi-desert type (Fig. I). The most con-

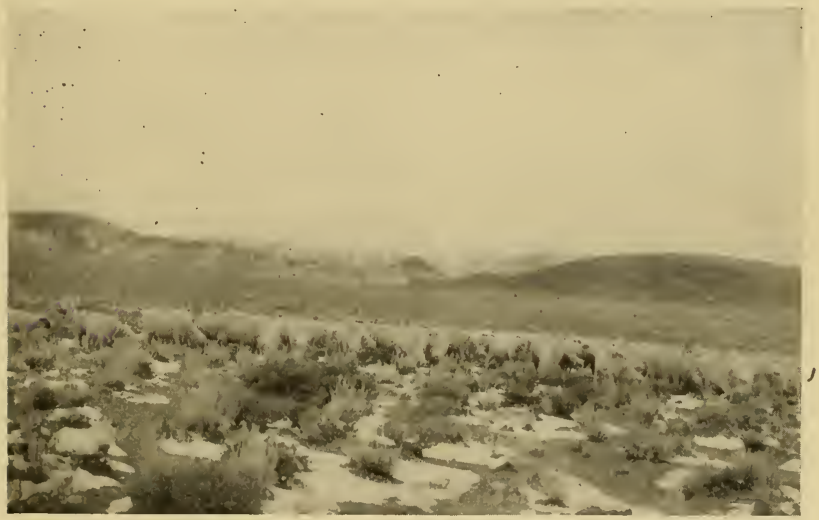

Frc. I. - TYPICAL DESERT RANGE OF THE GREAT BASIN REGION USED EXTENSIVELY IN WINTER FOR SHEEP GRAZING.

Sagebrush, shadscale, and mountain ricegrass constitute a large part of the forage.

spicuous vegetation consists of several species of sagebrush, saltbush, greasewood, scrub oak, shadscale, and a number of drought-enduring bunchgrasses.

In the Great Basin region, as in the Great Plains, dry farming is restricted to limited areas favored by deep, rich soil but having insufficient rainfall for the extensive production of farm crops. Stock grazing, therefore, must constitute the main agricultural pursuit, so far as the lands are at all suited for agricultural purposes. In those parts of Utah, however, where water is 
abundant, efficient systems of irrigation farming have been perfected.

The Southwest. - This region includes New Mexico, Arizona, and southern California, and is therefore characterized by both high temperatures and extreme aridity. In the lower valleys, citrus and similar tropical fruits, as well as other crops, are grown; in the interior there is a limited amount of dry farming, grazing constituting the chief agricultural industry. In northern Arizona the elevation (about 6,000 feet and higher) is too great for successful farming, but here the forage crop is excellent. On account of favorable climatic conditions in the high mountain region and the proximity to winter (desert) range, sheep raising is especially popular in the more rugged portions. Sheep, as well as cattle and horses, thrive well on the winter annual plants, such as plantain, alfilaria, peas, and various early grasses, particularly the highly esteemed gramas, the mesquites, the fescues, and many others.

The Rocky Mountain Region. - This region embraces Idaho, the western part of Montana, Wyoming, and Colorado, and the eastern part of Utah, Oregon, and Washington. The region is characterized by valley and basin lands from 3,000 to 7,000 feet in elevation, and by mountain ranges from 8,000 to more than I 4,000 feet above sea level (Fig. 2).

Because of the high elevation of the region as a whole and the heavy precipitation, the lands generally are well watered. The annual precipitation in the valleys and basins averages about 20 inches, but in the mountains it may exceed 30 inches. The high elevation, however, is associated with a relatively short growing season and a long, cold winter. Much of the annual precipitation, therefore, comes in the form of snow.

Except where the soil is alkaline, it is capable of good crop production. As in the Great Basin and the Southwest, the superior character of the native forage, consisting mainly of grasses and weeds, with browse in places, makes the grazing of livestock by far the most important agricultural pursuit. For the reason that the Rocky Mountain region is subject to more severe weather than the Great Basin and the Southwest, and 
thus imposes on the stockman a long winter-feeding period, it is evident that the latter regions afford the better livestock breeding grounds. It is a fact, however, that the Rocky Mountain region furnishes the tenderest and choicest of feed. Climat-

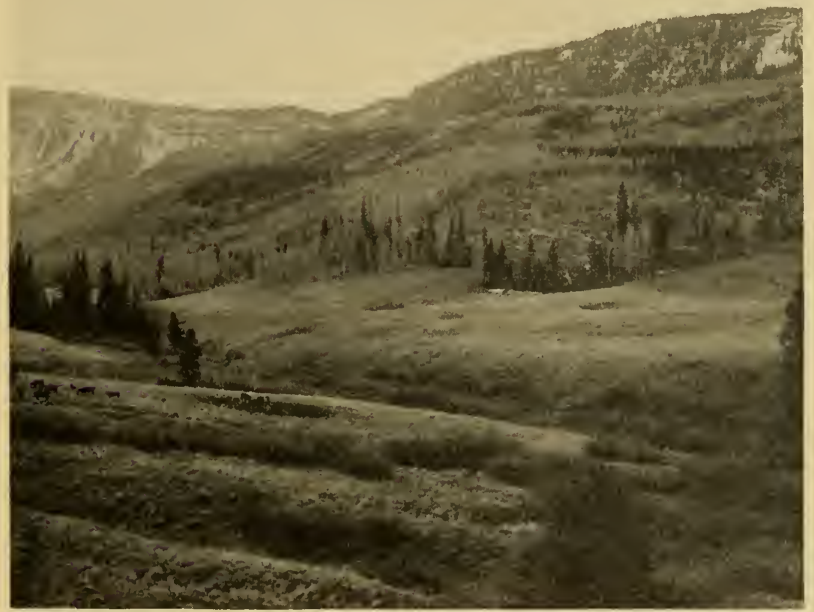

(Forest Service.)

FIG. 2. - SUMMER RANGE OF HIGH GRAZING CAPACITY IN THE ROCKIES WHERE BOTH TIMBER AND LIVESTOCK ARE PRODUCED.

ically, this region is almost ideal for stock during the spring, summer, and autumn periods; and, because of the abundance of water generally, the forage crop is well utilized.

\section{GRAZING CONTROL}

Influence of the Settler. - The farmer and ranchman are not now, as formerly, especially in the West, the monarchs of all they survey. Very recent years have brought a change in many range sections from a state of open grazing lands to settled communities, with the land in ownership or held under homestead 
entry. In the Pacific States and Western States alone, over I 23,000,000 acres of public land have been homesteaded since 1905 , more than half of which was taken up between 1909 and I9I 5.

Lands of least resistance welcome the plow and are usually the first to be settled. The best of such new lands have now become fence-enclosed farms with red barns on them. Practically all the land on which there is a remote possibility of making a living by farming has been occupied, although much of it, because of lack of ample rainfall or on account of the short growing season, should never have felt the plow.

In many localities dry farming has proved anything but successful; poverty-stricken homesteaders, no longer able to meet the financial strain, have disposed of their holdings to the larger stock breeders for what they could get, and their land has again been put to its original use - grazing. Those farmers who succeed, however, usually fence against stock and thereby often render much of the adjacent, otherwise available land inaccessible for foraging purposes.

Where good agricultural crops can be grown, settlement should be strongly encouraged; for not only will more and better stock be produced where cultivated crops can be grown, but home life will be provided. Much of the unclaimed public-domain land, which in 1922 was approximately $200,000,000$ acres - an area nearly as large as that of Germany and France combined - will be homesteaded sooner or later. Prior to their being patented, however, the greater part of the remaining public lands should be carefully classified by the Federal Government to determine for what purpose they are best suited. Following such a classification, an intelligent disposition of the lands could be made, and many a settler would be safeguarded against such serious reverses as many have already experienced; for it is a fact that a great number of homesteads, whose lands are suitable only for grazing purposes, have unfortunately been taken up for the growing of farm crops.

Cause and Effect of Overgrazing. - Range and pasture vegetation, if given adequate time in which to recuperate, is able to 
recover from the effects of a season's overgrazing, just as it will regain its vigor after a year of drought if such a season is followed by years of normal precipitation. If, however, overgrazing is persisted in for several successive years, complete barrenness is the inevitable result, and many years are required

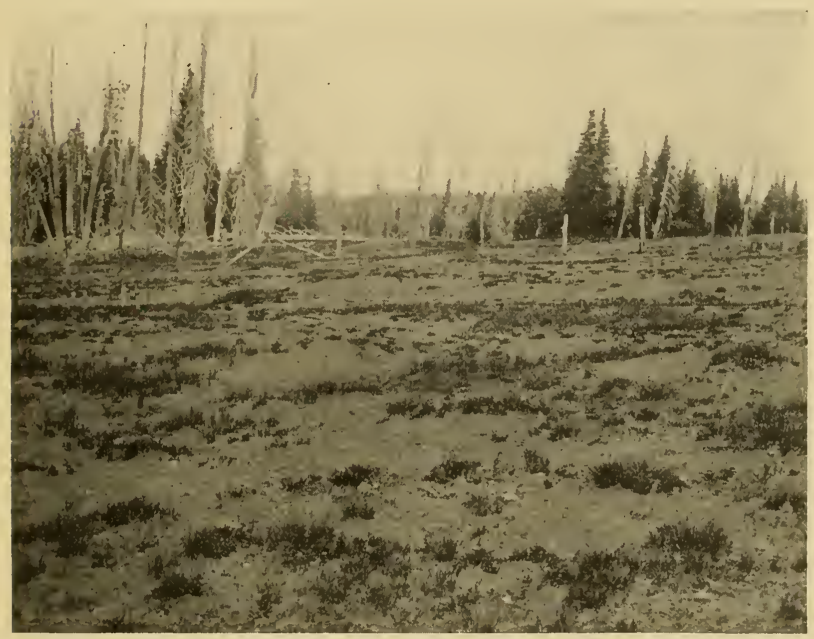

Fig. 3. - SMALL, BADLY DEPLETED AREA PROTECTED BY THE FOREST SERVICE AGAINST GRAZING FOR FIVE YEARS.

It was the aim to determine the time required for revegetation, which is usually slow on badly trampled lands, and for a long time only inferior pasture plants are seen.

in which to build up the soil and restore its original forage yield (Fig. 3).

At the time when the railroads were extended into the pasture regions of the West, the persons in the East who owned western range property began to investigate and dispose of their holdings. The western graziers soon realized that they could no longer depend entirely upon "free" grass; and, instead of this frontier country supplying "all the food for all the cows in the world," as some had formerly believed it would do, it was suddenly realized that the ranges were overcrowded. 
The stockmen were at once seized with the desire to make every dollar possible out of their opportunity, and it was not long, of course, until the lands were seriously overgrazed. Instead, therefore, of the cowmen continuing to be " cattle kings," each with a "princely kingdom," innumerable large owners were forced into bankruptcy. In the beginning, the belief having prevailed that the ranges had unlimited carrying capacity, no thought had been given to the conservation of the forage resource on a permanent business basis or for future generations. The same condition existed in Maryland and Virginia and other Eastern States prior to the western frontier movement.

Range abuses by domestic animals can invariably be traced back to overstocking. The carrying capacity of any pasture can safely be estimated only on the basis of the number of stock it will support in good condition in years of average or, preferably, slightly less than average forage yields. By proper stocking, the lands steadily increase in value, the carrying capacity is augmented, and the profits from transforming the grass into meat are increased as a result of the improved condition of the animals. But the lands could not be stocked within the limits of their carrying capacity in the absence of grazing regulations; and, before suitable regulations could be perfected, the cowmen and sheepmen insisted on having their fling.

Range Wars. - Despite the threatened depletion of the native pastures in the early nineties of the last century, still more cattle and sheep were crowded on the lands, and a desperate struggle for range ensued. Cattle owners would crowd the sheep breeders, and the latter would work their herds up the mountains in the spring as early as forage and weather conditions would permit, and the feed upon which the cattlemen were dependent would be consumed (Fig. 4). The feeling between the two livestock interests soon became extremely bitter. The sheep breeders, claiming as good a right to the free forage as anybody, would graze their bands up to the very doors of the cattle owners. The cattlemen, on account of owning property and paying taxes for the support of the Government, which many of the sheep breeders did not do, claimed prior right to 
the use of the public range in the neighborhood of their holdings.

The most intense feeling was aroused with respect to migratory sheep, which were often driven great distances to the summer ranges, coming from neighboring counties and, not uncommonly, from adjacent States. The alien sheep interests added to the

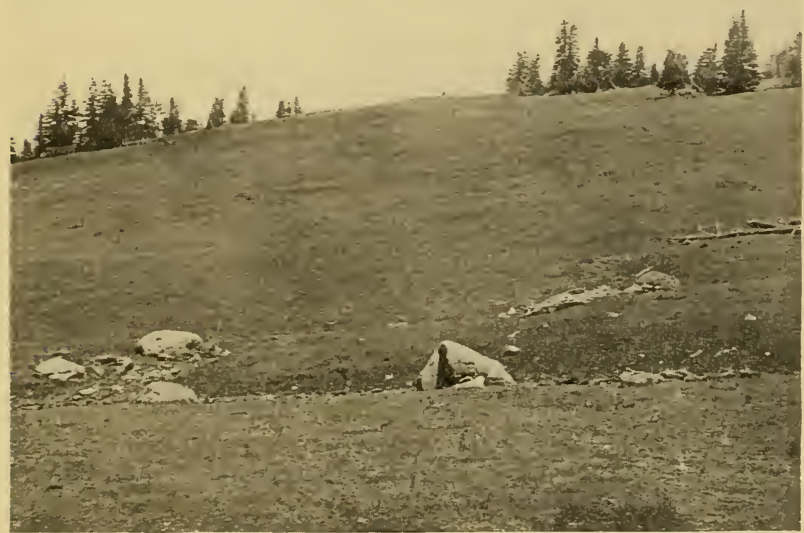

F1G. 4. - SUMMER RANGE DENUDED OF VEGETATION AS A RESULT OF COMPETITION BETWEEN SHEEPMEN AND CATTLEMEN DURING THE "FREE-FORALL" GRAZING PERIOD.

Many years of skillful livestock handling are required to reëstablish the once luxuriant growth of nutritious bunchgrasses.

controversy. In some localities the pastures were overrun by sheepmen who were not citizens and who, of course, owned no land. ${ }^{1}$ When sheepmen took their bands from the ranges in the fall they often started fires to destroy any remnant of vegetation that might be grazed by cattle. Fierce conflicts followed such action. Herders were killed and animals were shot down or so scattered that they became the prey of coyotes and other wild beasts.

1 Griffiths, David, "Forage Conditions on the Northern Border of the Great Basin.” U. S. Dept. of Agr., Bur. of Plant Ind., Bul. 15, p. $23,1902$. 
In order to protect their interests, stockmen organized associations which were empowered to act either by the persuasive force of the six-shooter or through mediators. The methods of "mediation" are well illustrated by the procedure of a certain organization of the Northwest. Following some desperate engagements in eastern Oregon in June, I904, an organization known as the "Crook County Sheep-Shooting Association of Eastern Oregon" published the following statement, which is typical of the attitude of the associations during those turbulent times.

\section{SheEP-SHOOTERS' HeAdQUARTERS, \\ Crook County, Oregon, DeCEMBER 29, I904.}

\section{MORNING OREGONIAN,}

PORTLAND, OREgON.

Mr. EdITor:- Seeing that you are giving quite a bit of publicity to the Sheep Shooters of Crook County, I thought I would lend you some assistance by giving you a short synopsis of the proceedings of the organization during the past year. . . Therefore, if space will permit, please publish the following report:

“Sheep-Shooters' Headquarters, Crook County, Oregon, December 29, r904.-Editor Oregonian: I am authorized by the association (The Inland Sheep Shooters) to notify the Oregonian to desist from publishing matter derogatory to the reputation of sheep shooters in Eastern Oregon. We claim to have the banner county of Oregon on the progressive lines of sheep shooting, and it is my pleasure to inform you that we have a little government of our own in Crook County, and we would thank the Oregonian and the Governor to attend strictly to their business and not meddle with the settlement of the range question in our province.

"We are the direct and effective means of controlling the range in our jurisdiction. If we want more range we simply fence it in and live up to the maxim of the golden rule that possession represents nine points of the law. If fencing is too expensive substitutes are readily manufactured. When sheepmen fail to observe these peaceable obstructions we delegate a committee to notify offenders, sometimes by putting notices on tent or cabin and sometimes by publication in one of the leading newspapers of the county as follows: 'You are hereby notified to move this camp within twenty-four hours or take the consequences. Signed: Committee.'

"These mild and peaceful means are usually effective, but in cases where they are not, our executive committee takes the matter in hand, and being men of high ideals as well as good shots by moonlight, they promptly enforce 
the edicts of the association. . . Our annual report shows that we have slaughtered between 8,000 and 10,000 head of sheep during the last shooting season and we expect to increase this respectable showing during the next season providing the sheep hold out and the Governor and Oregonian observe the customary laws of neutrality. In some instances the woolgrowers of Eastern Oregon have been so unwise as to offer rewards for the arrest and conviction of sheep shooters and for assaults on herders. We have heretofore warned them by publication of the danger of such action, as it might have to result in our organization having to proceed on the lines that 'Dead men tell no tales.' This is not to be considered as a threat to commit murder, as we do not justify such a thing, except where flockowners resort to unjustifiable means in protecting their property."

(Signed) Corresponding Secretary, Crook County's Sheep-Shooting Association of Eastern Oregon.

Conflicts over range territory continued until "dead lines" were established, which, by mutual agreement entered into by the livestock associations, were not to be traversed by cattle and sheep. Only occasionally after the location of "dead lines" did range wars of serious consequences occur. Many bitter range controversies were also adjusted by the policy of creating National Forests and by the leasing of pasture lands.

\section{QUESTIONS}

1. Why is meat an important constituent of the human diet?

2. (a) What was the approximate acreage of the public domain in 1920 , including reserved lands, found west of the Iooth meridian? (b) How does the acreage of grazing lands in the United States compare with that of cultivated lands? $(c)$ What is the approximate acreage of unimproved land which is used for the grazing of livestock?

3. What is the chief cause of range and pasture abuse?

4. What are the outstanding peculiarities and chief agricultural pursuits $(a)$ in the Great Plains, (b) in the Great Basin, $(c)$ in the Southwest, $(d)$ in the Rocky Mountain region?

5. What relation, if any, exists between range abuse, free range use, and range wars?

6. Discuss the value of livestock organizations in minimizing the loss of property and human lives during the period of range wars.

7. Explain what is meant by a "dead line."

8. What were the conditions that resulted in the establishment of "dead lines?" 


\section{BIBLIOGRAPHY}

Coville, Frederick V. Forest Growth and Sheep Grazing in the Cascade Mountains of Oregon. U. S. Dept. of Agr., Div. of Forestry, Bul. I 5, I 898 .

A Report on Systems of Leasing Large Areas of Grazing Lands. U. S. Public Lands Commission, Report, 1905.

Goldenweiser, E. A., and Ball, J. S. Pasture Lands on Farms in the United States. U. S. Dept. of Agr. Bul. 626, I918.

Jardine, James T., and Anderson, Mark. Range Management on the National Forests. U. S. Dept. of Agr. Bul. 790, I9I9.

Potter, Albert F. Administration of Grazing in National Forests. Amer. Nat'l Livestock Assoc'n, I913.

Public Lands Commission. Grazing on the Public Domain. U. S. Dept. of Agr., Forest Service, Bul. 62, Pt. I, I905.

SAMpson, Arthur W. Suggestions for Instruction in Range Management. Jour. of Forestry, Vol. 17, No. 5, 1919. 


\section{CHAPTER II}

\section{NATIONAL FOREST, STATE, AND PRIVATE GRAZING LANDS}

\section{THE NATIONAL FORESTS}

In $189 \mathrm{I}$, in the face of the threatened destruction of the public range and allied resources, Congress authorized the President to set aside "Forest Reserves," as the National Forests were then called, in order to develop and preserve the timber, the forage supply, and the other resources of the Forests.

The "Yellowstone Park Reserve" was the first created. Since then many others have been set aside, and on June 30 , I92I, the gross area of forest lands within the boundaries of the National Forests was $156,666,045$ acres, including the Forests in Alaska. Most of these lands lie at elevations too high for successful farming and are valuable chiefly for the timber and forage they produce, and for watershed purposes. Of the gross acreage, at least two-thirds is used each season for the grazing of livestock.

Object of Creating the National Forests. - In the creation of the National Forests the aim was so to administer their vast resources as to give all persons an equal opportunity to enjoy them, and at the same time to conserve and perpetuate their resources by proper use. That continues to be the aim. In addition to the broader economic reasons for the creation of National Forests, there are many local reasons for the Nation's possessing such Forests, as, for instance, the proper protection of the home seeker, the protection of local properties, and the prevention of unfair competition. It is only through proper control by the Government that the resources of the National Forests, estimated to have a value in the neighborhood of two billion dollars, can be rented or sold on a fair and equitable basis. The policy initiated by the Secretary of Agriculture in his letter 
to the Forester under date of February I, 1905, is so comprehensive as to warrant its inclusion here.

In the administration of the forest reserves it must be clearly borne in mind that all land is to be devoted to its most productive use for the permanent good of the whole people, and not for the temporary benefit of individuals or companies. All the resources of forest reserves are for use, and this use must be brought about in a thoroughly prompt and businesslike manner, under such restrictions only as will insure the permanence of these resources. The vital importance of forest reserves to the great industries of the Western States will be largely increased in the near future by the continued steady advance in settlement and development. The permanence of the resources of the reserves is therefore indispensable to continued prosperity, and the policy of this department for their protection and use will invariably be guided by this fact, always bearing in mind that the conservative use of these resources in no way conflicts with their permanent value.

You will see to it that the water, wood, and forage of the reserves are conserved and wisely used for the benefit of the home builder, first of all, upon whom depends the best permanent use of lands and resources alike. The continued prosperity of the agricultural, lumbering, mining, and livestock interests is directly dependent upon a permanent and accessible supply of water, wood, and forage, as well as upon the present and future use of these resources under businesslike regulations enforced with promptness, effectiveness, and common sense. In the management of each reserve local questions will be decided upon local grounds; the dominant industry will be considered first, but with as little restriction to minor industries as may be possible; sudden changes in industrial conditions will be avoided by gradual adjustment after due notice, and where conflicting interests must be reconciled the question will always be decided from the standpoint of the greatest good of the greatest number in the long run.

As the National Forests were created very largely for the proper protection and development of timber and the protection and improvement of the watersheds, great pains must be taken to harmonize the use of all the resources. The forage crop is no exception.

Livestock on the National Forests. - The yearly forage crop is harvested by livestock belonging to persons who are qualified to enjoy the privilege. As fully as is consistent with the development of all other Forest resources, the United States Forest Service seeks to utilize the forage crop on all range or timber types and at the different elevations from a few hundred feet 


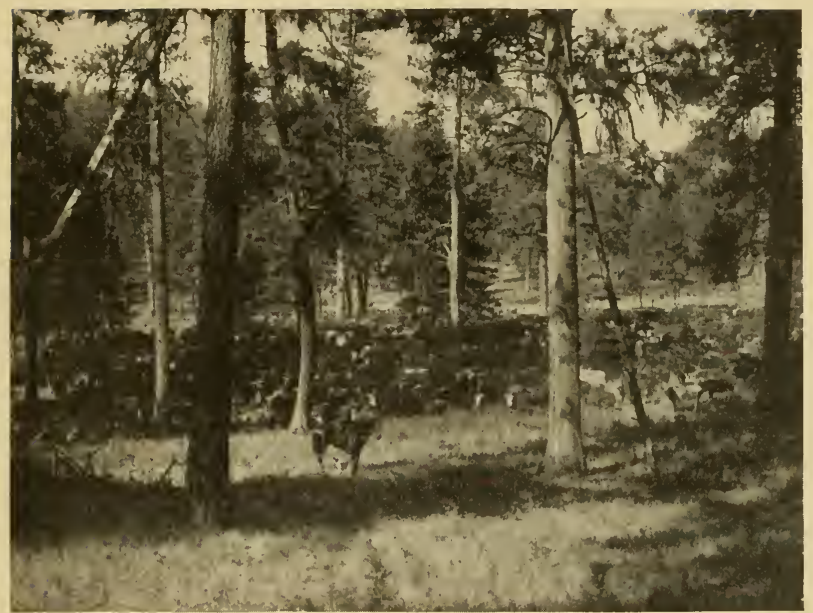

(Forest Service.)

Fig. 5. - MODERATE CATTLE GRAZING AND TIMBER PRODUCTION ON A NATIONAL FOREST IN THE YELLOW PINE TYPE.

Good pasturage and a superior quality of timber are produced on a large part of the lands controlled by the U. S. Forest Service. It is the aim of the Forest Service to utilize all of the resources the land is capable of producing.

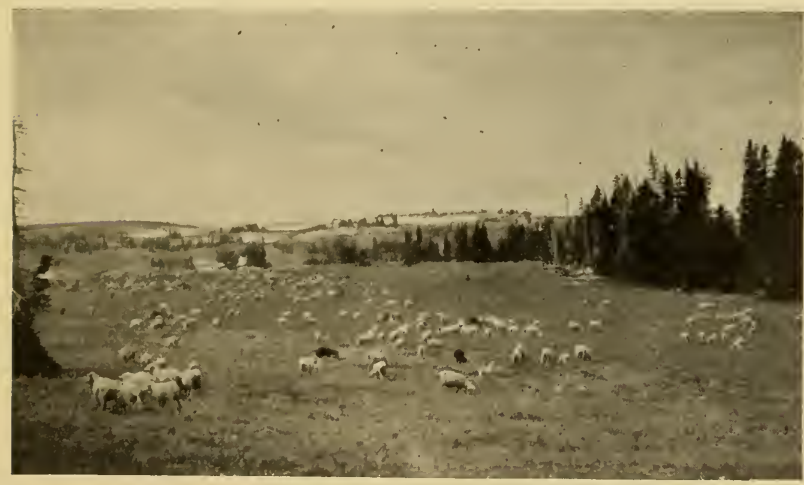

Fig. 6. - SHEEP GRAZING ON A GRASSY GLADE IN ALPINE FIR TYPE ON NATIONAL FOREST RANGE AT AN ELEVATION OF I0,000 FEET.

Few ranges are too rugged for sheep to enjoy the choice menu which they afford. 
above sea level in the foothills and valleys to 10,000 feet or more at the crest (Figs. 5 and 6). This intensive utilization is necessary because of the ever-increasing demand for range. Accordingly, therefore, the question of the proper handling of the stock without serious injury to the vegetation generally is of the greatest economic importance, and is often most perplexing. The attempt to solve the many technical and practical grazing problems with which the United States Forest Service is faced has resulted in the development of a corps of range experts, the value of whose service is very great.

The growth of the grazing industry on the National Forests has been steady and rapid since the lands came under the control of the Forest Service. The following table shows the number of cattle and sheep grazed on the National Forests in eleven western range States from 1915 to 1920 , inclusive. 
Number of Cattle and Sheep Grazed under Permit on the National Forests of Eleven of the Far Western States During the fiscal Years Ending June 30, I9I5-1920, InClusive

Cattle

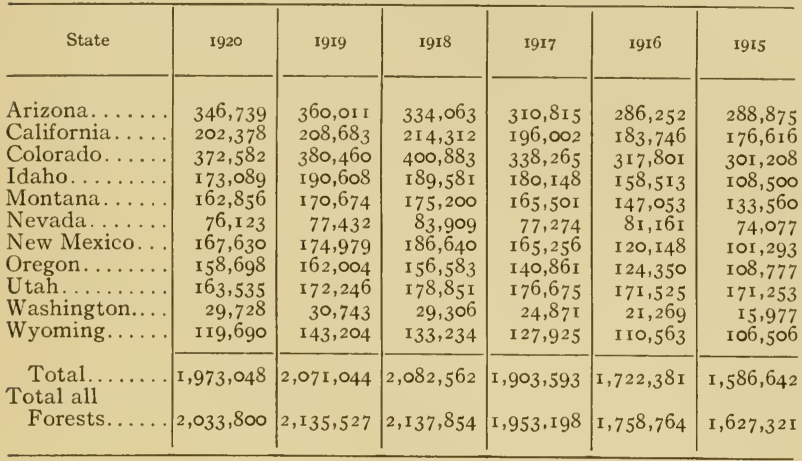

Sheep

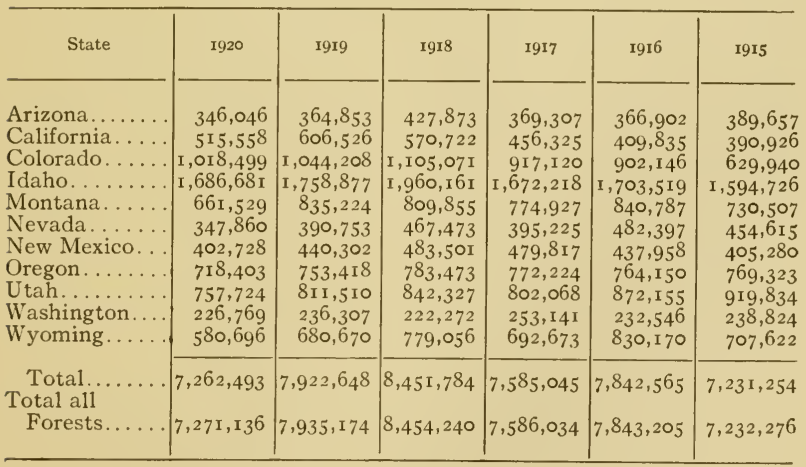


As would be expected, Colorado, with her large acreage of National Forest lands, leads in the number of cattle grazed on Forest range; Arizona is second, and California third. Idaho greatly outranks all other States in the number of sheep on National Forests; Colorado is second, and Utah third.

An idea of the influence of the National Forests on the economic welfare of communities and on the development and stabilization of the livestock industry in the West generally may be had from the fact that $9,405,499$ head of stock, all classes considered, were grazed on the National Forests in 1909, whereas a total of $10,229,895$ head were permitted on these ranges in 1919, an increase in the decade of 824,396 head. The following table shows the classes of these animals and the increase during the decade of the number grazed. With the exception of goats there has been an increase in all classes of stock grazed during the period in question.

INCREASE IN LIVESTOCK ON THE NATIONAL Forests IN I9I9 AS CoMpared WITH 1909

\begin{tabular}{|c|c|c|c|c|c|c|}
\hline Year & Cattle & Sheep & Horses & Goats & Hogs & Total \\
\hline 1919. & $2,135,527$ & $7,935,174$ & $93,25 \mathrm{I}$ & 60,789 & $5, \mathrm{I} 54$ & I0, 229,895 \\
\hline 1909. & $\mathrm{I}, 49 \mathrm{I}, 385$ & $7,679,698$ & 90, or 9 & I 39,896 & 4,501 & $9,4 \circ 5,499$ \\
\hline $\begin{array}{r}\text { Increase } \\
\text { I919... }\end{array}$ & 644,142 & 255,476 & 3,232 & $-79,107$ & 653 & 824,396 \\
\hline
\end{tabular}

These figures are especially significant in view of the fact that the increase in the number of cattle is about two and a half times greater than that of all other classes of stock. By expressing the figures on a uniform basis, say in terms of sheep, there was an increase in 1919 over 1909 of $3,413,892$ head. One cow or one horse is here considered the equivalent of five sheep, and one goat or one hog the equivalent of one sheep.

The number of stock grazed on the National Forests represents an investment by the owners of about $\$_{175}, 000,000$, from which 
the annual gross receipts are approximately $\$ 50,000,000$. In addition, the grazing fees in Igrg alone, which up to that time had been below the actual commercial value of the privileges granted, brought to the Government $\$ 2,609$, I 70 .

From the figures and facts given it is evident that the grazing business on the National Forests must receive proper protection. The continued development and prosperity of this great industry call for the closest possible harmonization of grazing with the other resources of the Forests.

National Forest Grazing Policy. ${ }^{1}$ - When the National Forests were first created, all sheep were excluded from the ranges, except in Oregon and Washington, where precipitation was abundant and tree reproduction heavy. This was because the belief prevailed that grazing was detrimental to timber production and to the control of streamflow. Although there were many glaring examples of injury caused by livestock to the timber reproduction as a result of the highly abusive grazing practices which had prevailed before the Forests were established, there was much thrifty growth of timber on long-used but moderately grazed lands (Fig. 7). The entire exclusion of stock on Forest lands generally in the early days was, in part, because of the bad results of uncontrolled grazing of stock on European forests where intensive silviculture had long been practiced. In Germany, for example, damage by livestock to the timber reproduction under intensive use of the forest was recognized as early as II $58 .^{2}$ The grazing of cattle was restricted to open parks and meadows; but the grazing of hogs on the German forests could not always be controlled by the Government because of the ancient peasant rights.

The European Governments, in the administration of their forests, failed to recognize the use of the range as a privilege;

${ }^{1}$ It is not the aim here to discuss the details of the grazing regulations as carried out in the administration of the National Forest ranges, but rather to consider briefly the broader grazing policies adopted in the harvesting of the forage crop. For a full discussion of the National Forest grazing regulations the reader is referred to "The National Forest Manual" of the U. S. Forest Service.

2 Fernow, B. E., "Economics of Forestry," p. 92. 


\section{PROPERTY LIBRARY}

N. C. rere. ringe

24 NATIONAL FOREST, STATE, AND PRIVATE LANDS

on the contrary, because of long usage the practice of grazing and of utilizing certain timber resources became a prescriptive or property right. On account of these prescriptive rights the European Governments were unable to control the grazing of

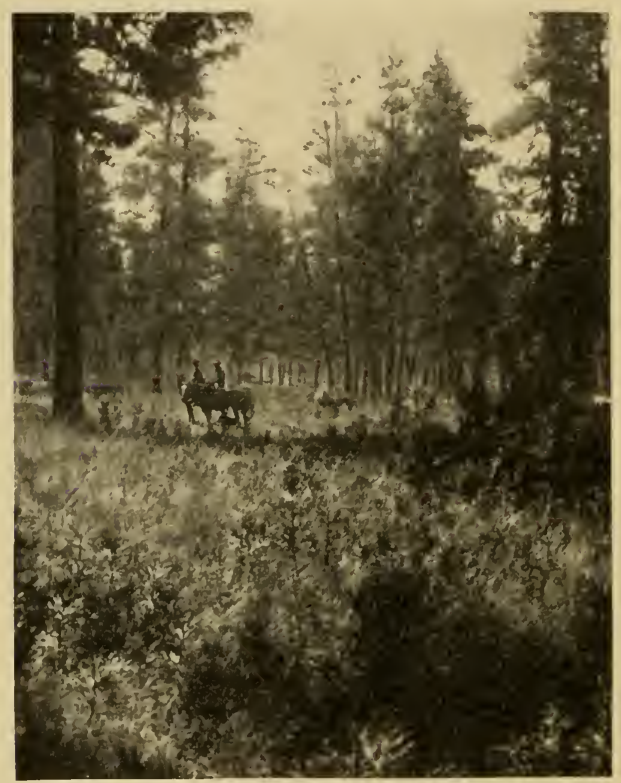

(Forest Service.)

Fig. 7. - CATTLE RANGE MODERATELY GRAZED EACH SEASON FOR A GREAT MANY YEARS SUPPORTS A DENSE, HEALTHY GROWTH OF YELLOW PINE REPRODUCTION.

Incidentally the removal of much of the palatable herbaceous vegetation protects the timber and young growth from destruction by fire.

livestock on the forest areas, even though it was known that under certain conditions serious damage resulted from excessive grazing.

In the German states the origin of the property right dates back hundreds of years under the feudal system to a time when both range and timber were abundant and of comparatively 
little value, and the large forested areas were held by the nobles, kings, and emperors as breeding grounds for game and as tracts for hunting. The peasant population that was located conveniently near these game preserves was allowed, free of charge, the privilege of grazing cattle, horses, sheep, goats, and hogs, and of cutting fuel wood and some timber under certain restrictions. No restrictions were placed upon the use of the range or the timber so long as it did not seem to interfere more or less directly with the breeding and proper protection of the game, or with hunting.

These conditions existed in Germany up to about 1800 , when the need for conserving and increasing the forest resources was keenly felt, and the practice of forestry was given serious consideration by the Government. With a rapidly diminishing supply of meat and timber and the consequent necessity of improving the productivity of the range lands and the methods of handling livestock, as well as of resorting to more intensive silvicultural methods, the free use of the forage and timber crops was found to be a great nuisance. In the Spessart Mountains in Bavaria, for instance, there are vast Government forests of oak and beech. In order to maintain a maximum stand of these timber trees, it is necessary to protect the acorn and beechnut mast, at least at periodic intervals. But this rich mast affords a most palatable and fattening feed for range hogs, and the seed crop is annually used for that purpose. The practice of running hogs on these beech and oak lands is quite extensive. As a consequence, pork is often produced, and the reproduction of the forest is prevented.

By proper regulation it is probable that both livestock and timber industries could be carried on successfully. However, as the peasants for so long a time have enjoyed the privilege of providing themselves with firewood and of using the range lands, their privileges have by law become unquestionable property rights, and the practice apparently can be overcome only in one of two ways - by the Government's purchasing the privileges from the claimants as property rights, or by the legislature's voting away prescriptive rights entirely. It is not probable that 
either will be done. The property rights could not be purchased without extremely heavy expense to the Government; hence that plan has never been given serious consideration. Likewise, no serious attempt has been made, by vote, to take away from the peasant the property right. The various legislatures have refused to vote away prescriptive rights, either feeling that these rights legitimately belong to the people, or fearing that by so doing they would lose the votes of the people deriving benefits from the forest lands.

In the light of the costly experiences of European Governments in connection with the establishment of property rights in forest lands, the United States Forest Service is justified in considering the use of the range a privilege and in no way a right. For the future welfare of the range and timber resources no recognition of the privilege, yearly becoming more valuable, should be extended by our Government which might be construed, even in the broadest sense, as establishing a property right.

On the forests of India regulated grazing of all classes of stock was permitted from the very beginning, for which a reasonable grazing fee was charged, and this is the present practice. While the grazing fees on the forests of India, as in this country, are not based on the full commercial value of the forage, the Indian Government nevertheless realizes a yearly revenue of nearly $\$ 1,000,000$. Stockmen, accustomed to using the ranges embraced within the Indian forests, like stock raisers in this country, were willing to pay for the grazing privilege.

The Stockmen's Protest. - Because of the absolute dependence of general agriculture on grazing in most localities adjoining the National Forests in the western United States, numerous and vigorous protests were raised by the sheep owners at not being allowed grazing privileges during the early administration of the National Forests. Prior to the Government's assuming control of the Forest lands the settlers had developed farms and ranches which were and still are far too remote from transportation facilities for the marketing of crude farm products, and hence the farmers were compelled first to turn the hay and 
grain into beef and mutton. In order to remain in the livestock business it was necessary for the ranchman to use the elevated, cool summer ranges of the National Forests, at least during spring, summer, and autumn. Then, as now, the Forests in many communities were indispensable to permanent and profitable settlement.

Accordingly, a thorough-going Federal investigation was arranged, which soon brought out the injustice of totally excluding sheep and of too strictly limiting the grazing of cattle and horses on some of the National Forests. In numerous localities it was found, as it is still commonly found, that the utilization of the forage crop meant very much more to the home-builder than did the timber resources. However, it was evident from the condition of the range lands that, in the interest both of timber and forage production and of the efficiency of the watershed, unregulated grazing could no longer be permitted. On the other hand, properly regulated grazing, through the removal of the forage crop, was believed to protect the Forests from destructive fires. Furthermore, it was not thought that the streamflow supplying the irrigation water for the adjoining farms would be interfered with.

Government Rules and Regulations. - Following the establishment of a more liberal grazing policy on the National Forests, the Federal Government, on June 4, I897, was empowered to promulgate rules and regulations for the proper control of livestock. All grazing was then made subject to the issuance of permits, and a small fee was decided upon for the grazing privilege. That method still obtains. The range is not leased in the ordinary sense, but the grazing is looked upon as a personal privilege or license based upon the qualifications of the individual. Local settlers and stockmen enjoy the first right to the use of the range. In this way unfair competition between large and small stock owners, which formerly caused so much trouble, is done away with. The number of animals, the season of grazing, the allotment to be grazed, and detailed rules for salting, bedding, and the like are determined and enforced by the Federal Government. Thus the functions of the Forest Service in regulating 
grazing on the National Forests may be summarized as follows:

I. The establishment of grazing allotments for the different classes of stock.

2. The location of stock driveways.

3. The establishment of the dates when the stock may be admitted, and of the period of grazing.

4. The determination of the number of stock that may be grazed without permanent injury to the resources of the Forest.

5. The determination of what persons are qualified to enjoy the grazing privileges, and of the number of stock each is entitled to graze.

6. The issuance of grazing permits, the collection of grazing fees, and the admission and proper distribution of the stock.

7. The control of trespass of stock and the collection of damages therefor.

8. The rendering of assistance to the grazier in every way possible to secure the fullest economical utilization of each type s) of forage at the proper time in the season, and the doing of the necessary improvement work to accomplish this end.

Results of Regulated Grazing. - Through the enforcement of the grazing regulations adopted by the United States Forest Service, constructive coöperation has been substituted for the old-time friction and bloodshed, and the ranges have been improved in many ways. It is estimated that the carrying capacity of the Forest ranges from 1905 to 1920 has been increased I 5 to 30 per cent, 20 per cent being the average, all localities considered. There is still room for much improvement; but, if one may judge from the remarkable advancement made in little more than a decade, the restoration of the lands to their original productiveness is only a matter of time. Just how many more stock the National Forest ranges will support in 1930 than the number carried in 1917 is difficult to say, but it is estimated that an increase of between I $_{5}$ and 20 per cent may be expected. ${ }^{1}$

1 Barnes, Will C., and Jardine, James T., "Meat Situation in the United States, Pt. 2: Livestock Production in the Eleven Far Western Range States." U. S. Dept. of Agr. Report I10, p. 17, I916. 
The increase in the production of livestock on the National Forest ranges will undoubtedly enhance the money value of the adjoining farm lands. On the other hand, as the public-range lands are further curtailed, the farms adjoining the Forests will become correspondingly more dependent on the cool summer Forest ranges than they are even at the present moment. As the productivity of the Forest ranges is increased, and as more livestock can consistently be permitted on them, increased agricultural development, in which the production of hay and concentrates suitable for the winter feeding of livestock will constitute the chief feature, is sure to follow.

The belief in such a development is based on two facts. In the first place, there is practically no more unused range possessing the essential natural facilities for the rearing of stock, upon which the industry may be extended. In the second place, stock raising on the highly improved and expensive farm lands, devoid both of summer and winter range, can not be materially increased; for under most conditions greater profits may be expected on such farms from merely finishing western-grown stock for the packer than from raising the animals for the feed yard.

The demand for grazing permits on National Forest ranges, therefore, is sure to increase, and the closest possible use of the forage crop may be expected. Without the most intensive and judicious utilization of the forage on the National Forest ranges each year, it would be impossible either to make adequate use of the feeds grown on the adjacent farms or to maintain sufficient grazing animals to make adequate use of the desert range, the forage of which, owing to the lack of water for stock purposes and because of unfavorable high temperatures, can be profitably used only during the winter months. The use of these winter ranges makes possible the running of far more stock throughout the year than could possibly be taken care of without the desert areas.

To develop, maintain, and utilize to the highest possible degree the forage resources within the National Forests is a matter of the greatest economic importance both nationally and locally. Further, the judicious management of these range re- 
sources is sure to be continued in harmony with the desired protection of the timber and the watersheds, as well as with other policies of local and national importance.

\section{STATE AND PRIVATE LANDS}

During their early.settlement certain Western States were granted tracts of agricultural and arid lands the income from which was to be used for educational and other public purposes. Furthermore, where the railroad became necessary for the development of the country, land grants were acquired from the Government by railroad companies. For example, large tracts of farm and pasture lands were granted to the Northern Pacific Railroad Company in the State of Washington. Although the railroad lands, like those in State ownership, were subject to purchase, they were at first in little demand; for, as they consisted mainly of grazing lands and had no fences, the forage crop could easily be harvested without the payment of grazing charges. During the period of free use, the State lands, like those of the public domain, soon became seriously depleted, and it was evident that some method of control was essential. A system of leasing was decided upon as a means of revenue, and also because the State and other officers believed that the trespass of stock would thereby be avoided, that the original carrying capacity of the lands would be restored, and that the land values themselves would be correspondingly increased.

The Texas Leasing System. - Prior to I879 the State lands of Texas brought in only limited revenues. This was due chiefly to faulty laws, a loose system of management, and an abundance of low-priced, privately owned lands. For a long time the ineffective laws resulted in a popular disregard of the leasing of State lands, while at the same time the pastures were being destructively utilized. It was not until I883, when the Commissioner of the Texas Land Office made effective a general law calling for the classification, sale, and lease of all State lands, that reasonable revenues were received. From then on, all accessible pasture lands were leased or sold. The rental varied according to the character of the land, the minimum charge being 
3 cents per acre, and the leases extended over a period of five to ten years. This charge for the forage crop resulted in the active purchase of the pasture lands, the price of which in 1895 was reduced from $\$ 2$ to $\$$ I per acre.

The Wyoming Leasing System. - Of the many States that were granted lands, Wyoming is an exception in that she still retains the greater part of her grants. In the administration of the Wyoming State lands, it was provided in I89r that no land should be sold at less than \$ro per acre. ${ }^{1}$ As most of the lands are arid and valuable only as pasture, purchases have been limited. Here the maximum period of rental is five years, and the lands are rarely rented for a shorter period. The usual rental fee is from $2 \frac{1}{2}$ to 5 cents per acre, depending upon the accessibility of the lands and of the water supply for livestock purposes. As a source of revenue the leasing of State lands in Wyoming has been notably successful. With the steady demand for range lands between 1892 and 1902 the rentals increased from $\$ 7,397$ to $\$ 95,925$. The funds are devoted to various public purposes.

The Northern Pacific Railroad Leases. - The Northern Pacific Railroad land grants acquired from the Government consisted of the odd-numbered sections in a strip of country 50 miles wide on each side of the railroad line. The holdings comprised of agricultural, timber, and pasture lands. In accordance with the policy of transportation development, the lands were sold as rapidly as possible. It was soon found, however, that the treeless, rocky tracts were not suited to reclamation by irrigation and were too dry for ordinary agricultural purposes. An examination by the company in 1895 showed that large areas of these arid lands had been denuded of vegetation by overgrazing. It was evident that, in order to avoid loss of traffic to the company and at the same time to dispose of the lands advantageously, something had to be done to improve and maintain their productivity. Accordingly a system of leasing was decided upon.

As the lands, previously used without cost, were now seriously 1 Revised Statutes of Wyoming, 1899, Sec. 82r. 
depleted, stockmen in the beginning refused to lease the pastures. Soon, however, sheep raisers, whose stock could readily be controlled on unfenced lands and who desired to put their industry on a firm basis, acquired the use of the lands. This naturally forced the cattle breeders also to accept the leasing system, as they feared they might ultimately have no pastures for their stock.

The first lease of Northern Pacific lands went into effect July I, I896. Six years later over 300 leases were in force covering approximately $\mathrm{I}, 500,000$ acres of pasture land. Although the leases were made for a period of five years, it was not the ultimate object of the company to establish a permanent system of leasing but rather to demonstrate that the productivity of the lands, under judicious management, could be restored, and thereby stimulate their purchase. The rental fee was a little less than 2 cents per acre, and the purchase price was proportionately low. As soon as it was seen that the lands could be revegetated, extensive sales were made, and in a few years the pastures were in private ownership. In this way the leasing system had its desired effect.

Benefits of the Leasing System. - A great many advantages have been derived from the leasing system as applied to lands owned by States and those owned by railroads. The effect was that of substituting an orderly, economical, and productive system of harvesting the natural forage crop for a precarious, wasteful, and unproductive one.

Because a large number of nomadic cattle and horses consumed much of the spring, autumn, and winter feed upon which the lessee was dependent, fencing of the leased lands was imperative to success. Fencing is one of the first steps towards stock control and permanent range improvement. With the fencing of the pasture the stockman knows exactly the acreage upon which he must depend. By supplementing this information with observations as to the character and density of the vegetation, he can closely estimate the number of animals the pasture will safely carry year after year (Fig. 8).

The leasing system, primarily because of the fencing of the 
lands, was of distinct benefit in that the productivity of the depleted pastures was improved, and the profits from the livestock business were increased.

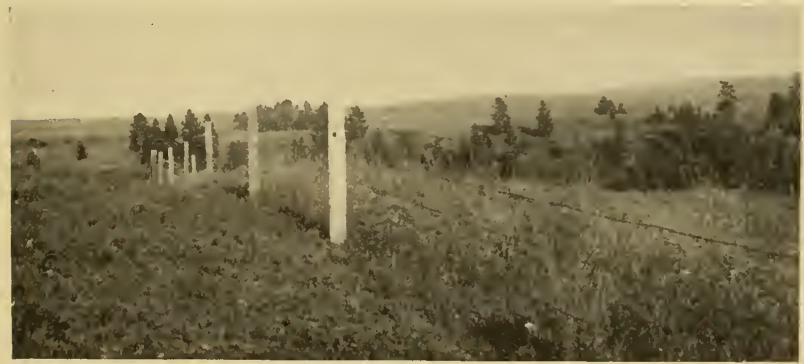

FIg. 8. - FENCING WAS THE FIRST STEP TOWARDS RATIONAL PASTURE AND LIVESTOCK MANAGEMENT THAT FOLLOWED THE ADOPTION OF THE LEASING SYSTEM.

The control of the number of stock grazed and the prevention of too early grazing soon resulted in marked improvement in the forage crop, as shown by the growth on the fenced area on the right.

Improvement of the Pastures. - The more important benefits of maintaining the productivity of the pastures were as follows:

I. The time for utilizing the forage crop was definitely controlled. The wasteful and destructive practice, in operation on the open range, of grazing the herbage early in the spring when the soil was saturated with moisture and the grasses were just starting to grow was avoided. Also, by means of division fences suitable herbage was conserved for definite seasonal periods.

2. Destructive grazing was avoided. Knowledge of the exact acreage and the character and luxuriance of the forage stand, and consequently of the number of stock the pasture would safely support, made it possible to maintain the lands in a high state of productivity. On the adjacent public-domain lands, where stock could not be controlled, the herbage was excessively grazed and trampled and in many localities completely killed out.

3. Water facilities in many localities were improved, and excessive travel of stock was avoided. Where water was inade- 
quate and the distance between watering places too remote for the best utilization of the forage, the springs, instead of being trampled into the ground as formerly, were protected, the water was conducted into troughs, wells were dug or bored, windmills were erected, and reservoirs and dams were constructed. Water development was a particularly prominent feature in the Texas leasing system, for in many localities in that State the distances between watering places were so great that it had not previously been possible to utilize the forage.

Increased Profits. - Larger profits were realized by the stockman under the lease plan than under the open-range system, chiefly for three reasons:

I. Improvement was made in the breed of stock, and the annual increase in the offspring was larger. As soon as the pastures were fenced there was apparent improvement in the quality of animals reared, especially of cattle and horses. Loss due to straying was, of course, avoided, inferior males were eliminated, and full use was made of the more desirable breeding animals. It was possible also to maintain a correct balance between males and females to insure a maximum annual increase.

2. Improved methods were employed in handling the stock and at less cost than on the open range. The fence, of course, made the herder unnecessary; and, as the stock was allowed to graze undisturbed, the animals traveled less and made better gains than when they were molested by a rider. Moreover, rounding up the stock for branding and for marketing could be done promptly and cheaply and with little disturbance to the animals.

3. Supplemental feeding and improved water facilities were provided where practicable. Many lessees made a practice of growing hay, Kafir corn, and other supplemental feeds. In this way the number of stock maintained on a leasehold was sometimes doubled. Supplemental feeding could not, of course, be practiced where the stock was not under control. As a result of the development of water facilities and the freeing of the stock from the necessity for excessive travel, better gains were made, 
less forage was trampled out, and more livestock could be supported.

\section{QUESTIONS}

1. When were the first National Forests created? What led up to this action?

2. What was the approximate acreage of the National Forests on June 30 , I92I?

3. What portion of the National Forest lands is grazed?

4. How many cattle, sheep, and horses are grazed annually on the National Forests?

5. Were sheep permitted on all the National Forests when the Forests were first created?

6. Distinguish between prescriptive rights and a license, as related to the grazing of Forest ranges, and discuss the advantages and disadvantages of each.

7. Do grazing privileges on National Forests in the United States ultimately establish property or prescriptive rights?

8. (a) Explain how the prescriptive rights became established in the German states. (b) What effect have such rights had on the reproduction and establishment of certain timber species?

9. Distinguish between a grazing permit and a range lease.

10. How and to what extent are farm lands adjacent to National Forests dependent upon the utilization of the Forest ranges?

11. What led to the adoption of the grazing-permit system on National Forest ranges?

12. Who is entitled to enjoy grazing privileges on our National Forests?

13. What has the regulation of grazing accomplished on National Forest ranges since its adoption? Why?

14. What is the probable influence of increased livestock production on National Forest ranges on the value of adjoining farm lands? Why?

15. What are the possibilities of increasing the carrying capacity of the Forest ranges? How much increase may be expected?

16. What factors were conducive to the adoption of the leasing of State and railroad lands?

17. In what state of productivity were the State and railroad lands at the time of the adoption of the leasing system?

18. (a) What rental did the State of Texas receive for the most of her lands? Wyoming? (b) For what period of time were the leases issued in the two States named?

19. Explain why Wyoming still retains much of the land originally granted her.

20. At what price can the Wyoming State lands be purchased? 
21. (a) Why were the sheep raisers first to take advantage of lands offered for lease by the Northern Pacific Railroad Company? (b) What effect did this have on the attitude of the cattle raisers relative to leasing?

22. Discuss fully what the leasing system accomplished in (a) controlling and stabilizing grazing; (b) improving the carrying capacity of the lands; (c) promoting a closer utilization of the forage crop; and $(d)$ increasing the profits from livestock.

23. How did the issuance of long-time leases affect the development of water facilities and improve the breeding of stock?

\section{BIBLIOGRAPHY}

Barnes, Will C. Western Grazing Grounds and Forest Ranges. Sanders Pub. Co. (Breeders Gaz.), Chicago, г913.

Boerker, R. H. D. Our National Forests. The Macmillan Co., N. Y., I9I8.

Fernow, B. E. A Brief History of Forestry. Univ. Press, Toronto, r9r3.

Economics of Forestry. T. Y. Crowell \& Co., N. Y., 1902.

Facts and Figures Regarding Our Forest Resources. U. S. Dept. of Agr., Div. of Forestry, Cir. I I, I 896.

Forest Service. National Forest Manual. U. S. Dept. of Agr.

Graves, Henry S. Farm Woodlands and the War. U. S. Dept. of Agr. Yearbook, 1918.

Forest Preservation. Smithsonian Institution, Annual Report, I9I0.

The National Forests and the Farmer. U. S. Dept. of Agr. Yearbook, I9I4.

A Policy of Forestry for the Nation. U. S. Dept. of Agr., Office of Secretary, Cir. 148, I9r9.

Jardine, James T., and Anderson, Mark. Range Management on the National Forests. U. S. Dept. of Agr. Bul. 790, r9r9.

Potter, Albert F. Administration of Grazing in National Forests. Amer. Nat'l Livestock Assoc'n, I9r3.

Roth, Filibert. Grazing in the Forest Reserves. U. S. Dept. of Agr. Yearbook, I901. 
PART TWO

PASTURE REVEGETATION AND FORAGE MAINTENANCE 



\section{CHAPTER III}

\section{RESEEDING WESTERN GRAZING LANDS TO CULTIVATED FORAGE PLANTS}

The native western grazing grounds for the most part are located in what is popularly known as the arid region. The vegetation varies in density from a complete cover, as on the much-restricted meadows, where ro to i 2 acres will support a cow for a year, to a growth so sparse that roo acres will barely maintain an animal the year through. Over the greater part of the range, 25 to 35 acres, waste lands included, will support a cow for a year. This low forage production is the result chiefly of limited rainfall, but overgrazing and other forms of range abuse are also responsible for the low grazing capacity.

It is natural to hope that some good forage plant may be discovered that will completely occupy the soil of this vast arid region, drive out the pestiferous weeds, and give character to the landscape. Such a plant has not as yet been found. Native pasture lands can not be made to perform miracles. Many stockmen and range investigators have learned through costly experience and wide experimentation that cultivated forage plants will not yield heavily - if, indeed, they will grow at all where the virgin native vegetation at best is sparse and composed only of drought-enduring species. To produce a good crop of clover, timothy, orchardgrass, or some other valuable grass where the annual rainfall is so low that "dry farming" of the most intensive and scientific kind fails to yield economical returns, would require a weird brand of magic.

Because of the generally low yielding capacity of the lesselevated stretches of range and the ruggedness of the more humid, elevated tracts, it is impracticable to plow the soil or otherwise put much money into the preparation of the seedbed. Clearly any practicable plan of reseeding range lands must 
find other methods and implements than those upon which the farmer ordinarily relies.

\section{PLANT INTRODUCTION ON ARID LANDS}

Many attempts have been made to grow cultivated plants on the more arid, sparsely vegetated range. That little progress has been made in reseeding such lands is evident from several carefully conducted tests.

Tests in Southern Arizona. - The most extensive tests in seeding native forage plants were conducted by Griffiths, ${ }^{1}$ Thornber, ${ }^{2}$ and Wooton, ${ }^{3}$ between 1900 and I9r6.

Griffiths's studies were confined to trials with introduced and native forage plants upon the mesa lands, where not less than 200 plant species were tested in a fenced pasture. The seeding was done in both spring and fall. In some tests the ground was worked up sufficiently to kill a goodly portion of the native vegetation. Notwithstanding these carefully conducted tests and the special soil treatment, most of the introduced plants failed even to gain a foothold. Only one introduced species, namely, alfilaria (Erodium cicutarium), gave results, and those were of limited practical value. Griffiths concludes:

The net economic results of all this foreign introduction has been practically nil. Most of the species in our experience have never come up, and the few things that did make any growth usually died before seed was produced.

Thornber, experimenting on a range reserve near Tucson, Arizona, after finding that experimental seedings failed on the drier lands, attempted a series of experiments on similar areas, some of which were irrigated. The increased water supply was procured by the construction of dams, by means of which flood water was conserved. Such valuable native species as blue grama (Bouteloua gracilis) and hairy grama (B. hirsuta) produced a fairly good cover where the lands were amply watered.

1 Griffiths, David, "A Protected Stock Range in Arizona." U. S. Dept. of Agr., Bur. of Plant Ind., Bul. 177, p. 12, r9ro.

2 Thornber, J. J., "The Grazing Ranges of Arizona." Arizona Agr. Exp. Sta. Bul. 65 , p. 3 12, 1910.

${ }^{3}$ Wooton, E. O., "Carrying Capacity of Grazing Ranges in Southern Arizona." U. S. Dept. of Agr. Bul. 367 , p. 38, I9r6. 
The stand gradually died out, however, when irrigation was discontinued. Other species gave practically the same results. Thornber reports:

No introduced forage plants, including species from cool, moist climates and the higher elevations, made any growth on the small range enclosure, and but few of them persisted in the forage garden for any considerable length of time. Both the native and Australian saltbushes failed repeatedly to secure a hold or make any growth of extended duration, though they were planted on land occasionally flooded with storm water.

Wooton's reseeding studies on the Santa Rita Range Reserve near Tucson, Arizona, substantiated the findings of Griffiths and Thornber, for practically all attempts to introduce forage plants gave negative results. In a few tests it was found that introduced plants like alfilaria and certain other aggressive annuals gave temporary promise of fair returns, but in a few years they were crowded out by the native vegetation.

Seeding Tests in Northern Arizona. - Pearson, ${ }^{1}$ between I909 and 1913, conducted a series of range reseeding experiments at the Fort Valley Forest Experiment Station near Flagstaff, Arizona. The plants tested were Hungarian bromegrass, Kentucky bluegrass, orchardgrass, Italian ryegrass, redtop, timothy, and the more drought-enduring varieties of alfalfa.

In some of the experiments the ground was thoroughly harrowed before sowing, the seed being scattered broadcast and covered by means of a brush drag. On other plots the ground was harrowed and the seed broadcasted but not covered. In still other tests the seed was sown on unprepared ground and left uncovered. The experimental plots were fenced against stock.

The area seeded was an open park in the yellow pine type, lying at an elevation of about 7,300 feet. The soil was a deep sandy to clayey loam. An adequate amount of fertile seed was used. Pearson's conclusions follow.

${ }^{1}$ Pearson, G. A., "Studies in Artificial Reseeding: Introduction of Forage Plants." U. S. Dept. of Agr., Review of Forest Service Investigations, Vol. 2, Pp. 9-13, I9I3. 
All of the species sown under range conditions proved to be failures. The establishment of timothy is of little consequence for range purposes, because it succeeded only in wet conditions, which are rarely found on the range in this region.

Timothy, alfalfa, bromegrass, and perhaps some of the other species could probably be established through persistent efforts by plowing the ground and sowing during the summer season.

It is not believed that the introduction of any of these species, either under range conditions or under cultivation, is practicable. Native grasses are hardier, and if given equal chances will produce more forage on the range than any of these species. While they might succeed under cultivation, it is doubtful whether any of the species would produce as heavily as oats or wheat, which now yield from $1 \frac{1}{2}$ to 3 tons of hay per acre without irrigation.

Since many native plants of high forage value have been proved to be adapted to this region, they should be given the preference in reseeding experiments.

Further experiments under intensive cultivation are not recommended, because such methods are not applicable to range conditions.

Like many other investigators, Pearson recognizes the importance of so husbanding the range as to foster the reproduction of the desirable native forage plants.

\section{PLANT INTRODUCTION ON MOUNTAIN OR SEMI-HUMID LANDS}

The possibilities of successfully seeding valuable forage plants on mountain meadows and similar areas where the rainfall is relatively heavy are considerably greater than on the lesselevated arid lands discussed. It is a matter of common knowledge that many portions of the seriously overgrazed mountain meadows and well-drained parks have exceedingly fertile soils and originally produced a large native forage crop of high quality, but now support few or no valuable range plants. It is evident that the native plants can not be reëstablished where the original vegetation has been completely destroyed and the land left in a denuded condition. If such land is to be restocked within a reasonable length of time, seed from forage plants adapted to the local conditions must be introduced.

These seriously overgrazed lands differed so widely in soil and growth conditions that, before any great amount of seeding was done, it was necessary, through carefully planned experiments, 
to obtain detailed information concerning the natural factors which limit the successful application of reseeding to cultivated plants, the adaptability of various species of plants to the various sets of conditions, the methods which will procure the best results, and the question of cost and returns. In other words, it was necessary to find out where reseeding can be brought about, what are the most effective means, and whether these means will pay.

In 1908 Cotton $^{1}$ reported the results of a series of reseeding experiments in mountain meadows of the Pacific coast region. These experiments showed that the grazing capacity of the betterwatered lands may be increased considerably by seeding these lands to certain cultivated grasses. The conclusions were that timothy and redtop are the most promising grasses for seeding such areas.

The artificial reseeding of mountain lands was widely extended by Sampson, ${ }^{2}$ who from 1907 to 1922 directed more than 600 reseeding experiments on the National Forest range, using various cultivated grasses and other herbaceous forage plants. These experiments have thrown considerable light on the species best suited to the different conditions, on the cost of reseeding, on the methods of scattering and planting the seed, on how to crop the lands with minimum injury to the young stand, and on the forage increment that may be expected from reseeding.

In these experiments the following I 4 grasses and 8 species other than grasses were tested: ${ }^{3}$

\section{Grasses}

I. Broomgrass (Andropogon spp.).

2. Canada bluegrass (Poa compressa).*

3. Slender wheatgrass (Agropyron tenerum).

4. Blue gramagrass (Bouteloua gracilis).

${ }^{1}$ Cotton, J. S., "The Improvement of Mountain Meadows." U. S. Dept. of Agr., Bur. of Plant Ind., Bul. I27, 1908.

${ }^{2}$ Sampson, Arthur W., "The Reseeding of Depleted Grazing Lands to Cultivated Forage Plants." U. S. Dept. of Agr. Bul. 4, I9I3.

${ }^{3}$ The asterisks indicate the ro species most frequently used in the tests because of the promise which they showed early in the experiment. 
5. Hard fescue (Festuca duriuscula).

6. Italian ryegrass (Lolium Italicum).*

7. Kentucky bluegrass (Poa pratensis).*

8. Mesquitegrass (Hilaria Belangeri).

9. Ochardgrass (Dactylis glomerata).*

Io. Perennial ryegrass (Lolium perenne).

I I. Redtop (Agrostis palustris).*

12. Hungarian brome (Bromus inermis).*

13. Tall meadow oatgrass (Arrhenatherum elatius).

14. Timothy (Phleum pratense).*

\section{Broad-leaved Herbs}

I. Alfalfa (Medicago sativa).

2. Alfilaria (Erodium cicutarium).

3. Alsike clover (Trifolium hybridum).*

4. Australian saltbush (Atriplex semibaccata).

5. Bur clover (Medicago denticulata).

6. Japanese clover (Lespedeza striata).

7. Red clover (Trifolium pratense).*

8. White clover (Trifolium repens).*

Conditions of the Experiments. - Between 1907 and I9I3 the mountain reseeding tests were conducted in every State west of the Texas and Dakota line. The plots were located where the need for forage was greatest. The areas seeded varied in elevation from about 4,000 to I I, 000 feet. Detailed studies were conducted by the author in the Blue Mountains of northeastern Oregon.

In this wide latitudinal and elevational range the more important soil types and climatic characteristics were included. The growing season varied from about six months on the lower lands to no more than two and a half months at the higher elevations.

In all experiments the seed was scattered broadcast, either by machine or by hand. In most of the tests the soil was given no culture before seeding, but generally the lands were closely cropped before the seed was scattered. The seed was usually 
worked lightly into the ground by means of a brush or woodenpeg harrow, or trampled in by sheep.

\section{RESULTS OF THE TESTS}

Success of the Various Species. - Of the 449 original widely scattered seeding tests under way at one time, I68, or 37.42 per cent, were failures; II 2 , or 24.95 per cent, were partial successes; 7I, or I5.8I per cent, were fully successful; 64, or I 4.25 per cent, were undeterminable at the end of the observational period; and in 34 experiments, or 7.57 per cent of the total, the results were not definitely declared.

By far the best results immediately following reseeding were obtained with timothy, 64.4 per cent of all trials being successful or partially successful. Next in the order of successful results were Hungarian bromegrass with 58.14 per cent, perennial ryegrass with 50 per cent, Italian ryegrass with 37.5 per cent, Kentucky bluegrass with 3 I.82 per cent, and redtop with 33.33 per cent (Figs. 9 and 10). It is significant that the more droughtenduring species, such as Hungarian bromegrass, rank among the first in the successful seeding.

Few of the broad-leaved herbs gave economical returns. White and Alsike clovers, however, did best. These clovers, like Kentucky and Canada bluegrasses, redtop, and certain other sod-formers, are slow to become established, but once they gain a foothold they are not readily killed out. In general, the best results were obtained from the tests in the Northwest, where the rainfall is moderately heavy; the poorest results followed the tests in the Southwest, notably in the lower and drier sites. ${ }^{1}$

Since the results of the original 449 reseeding tests were declared, the writer has conducted a large number of trials in the Wasatch Mountains of central Utah. The cultivated species most extensively used were Alsike and white clovers, Hungarian bromegrass, Italian ryegrass, Kentucky bluegrass, orchardgrass, redtop, and timothy.

1 As pointed out, no cultivated plant yet discovered can be successfully seeded in the hot, dry foothills, such as characterize large areas in the Southwest. 


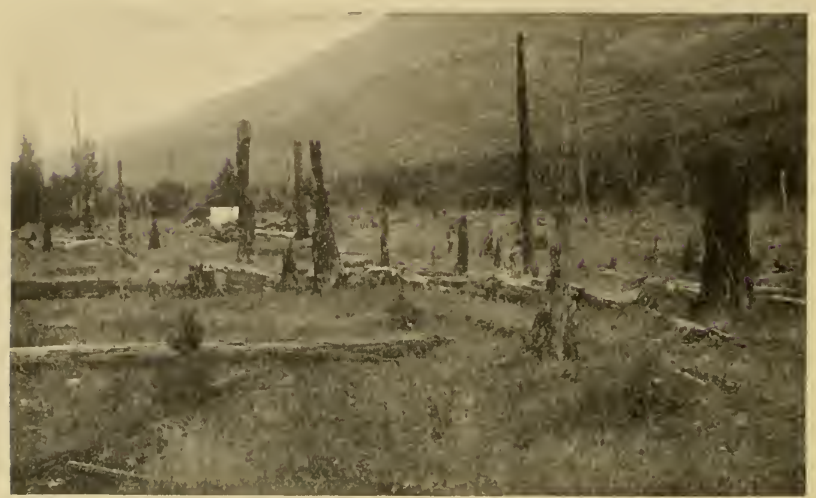

Fig. 9. - A BURNED-OVER FOREST RANGE AT AN ALTITUDE OF 5,000 FEET.

The predominating vegetation consisted of "pinegrass," or reedgrass (Calamagrostis), yarrow, and fireweed. The area was sown to timothy and redtop. The soil is rich and above the average in moisture conditions.

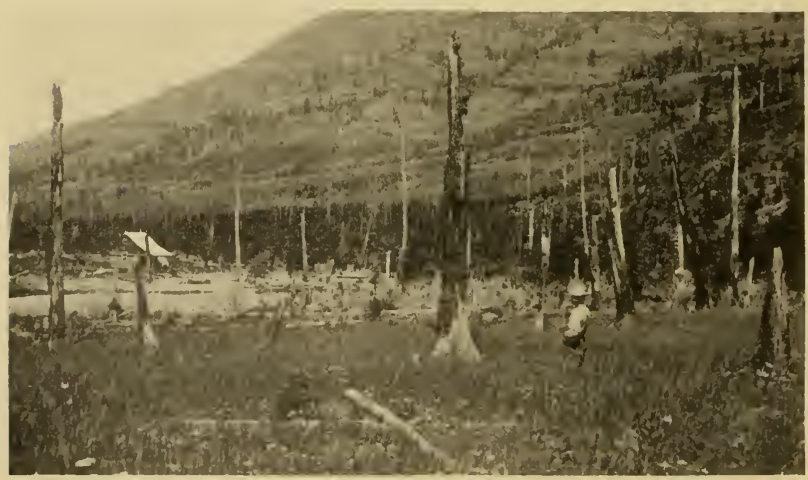

Fig. Io. - SAME AREA AS SHOWN IN FIGURE 9, TWO YEARS AFTER SEEDING.

The native vegetation has been almost completely replaced by the introduced grasses. Two-thirds of the cover is composed of timothy. A brush harrow was dragged over the area to cover the seed. 
Approximately 60 per cent of all the tests here conducted, as analyzed in 1922 , were successful or partially successful. It is significant that Hungarian bromegrass, with 76 per cent of the trials successful or partially successful, outranked timothy, which, however, was second best in yielding capacity. These species were followed, in the order named, by Kentucky bluegrass, Canada bluegrass, white clover, redtop, and orchardgrass.

Season for Sowing. - In the Northwest, and as far south as Utah and northern Nevada, seeding in the fall appeared to give better results than at any other season. The autumn-sown areas were superior to those seeded in the spring in that (I) germination took place more promptly, (2) the development of the seedlings was more uniform, and (3) the loss of seedlings from adverse conditions was less (Fig. II).

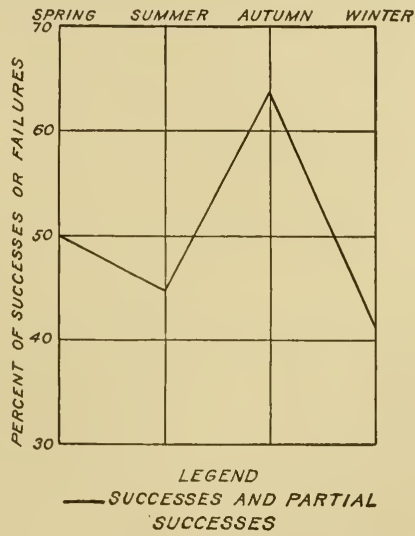

Fig. II. - RESULTS OF SEASONAL RESEEDING TESTS ON MOUNTAIN RANGE LANDS IN THE WEST.

In the mountains, from central Utah and central Nevada, and throughout the Southwest, spring or early-summer seeding gave better results than did autumn seeding. In this region the soil usually becomes so dry late in the spring that a goodly proportion of the seedlings originating from seed scattered in 
the autumn are killed before the summer rains come. When the seed is scattered shortly before the summer rains begin, say early in July, a good stand may be expected.

Causes of Failure. - An analysis of the causes of failure in the unsuccessful tests may aid the stockman to avoid seeding unfavorable sites. The chief causes of failure, given in the order of importance, are as follows: (I) Lack of soil treatment; (2) drought; (3) unsuitable species; (4) failure of the species sown to compete successfully with the native vegetation; (5) wrong time of sowing; (6) overgrazing.

It is encouraging to note that the factors which are generally responsible for the failures are largely controllable. Failure due to excessive drought, for instance, may be largely avoided by seeding only those lands which are so located as to receive more than average rainfall. The wrong selection of species is avoidable if the requirements of the species with respect to soil, moisture, altitude, and growth are known. Clearly, such matters as soil treatment, season of sowing, and avoidance of overgrazing are within the control of man.

Suitable Cultural Implements. - The proper treatment of the soil, following the scattering of the seed, is so important as to warrant a consideration of the use of suitable implements for this purpose.

If timber is available, a brush harrow constructed from a few saplings or the tops of pine or some other stiff-leaved tree, cut into lengths of about 6 feet and laid parallel to each other at intervals of about a foot, is an effective implement. The brush is held together, as in a vise, between the parts of a 5 -foot crosspiece. Such a harrow can be dragged readily over the ground by a rope attached to the saddle horn (Fig. 12).

On lands where the soil tends to become baked, the use of a wooden-peg "A " harrow is satisfactory (Fig. 13). The framework is made from a log about 6 inches in diameter, cut into three lengths of about 5 feet. These are fitted together into the shape of a letter "A" and the ends secured. Holes about I inch in diameter are made through the logs at intervals of about 5 inches, and teeth made from tree branches cut to uniform 


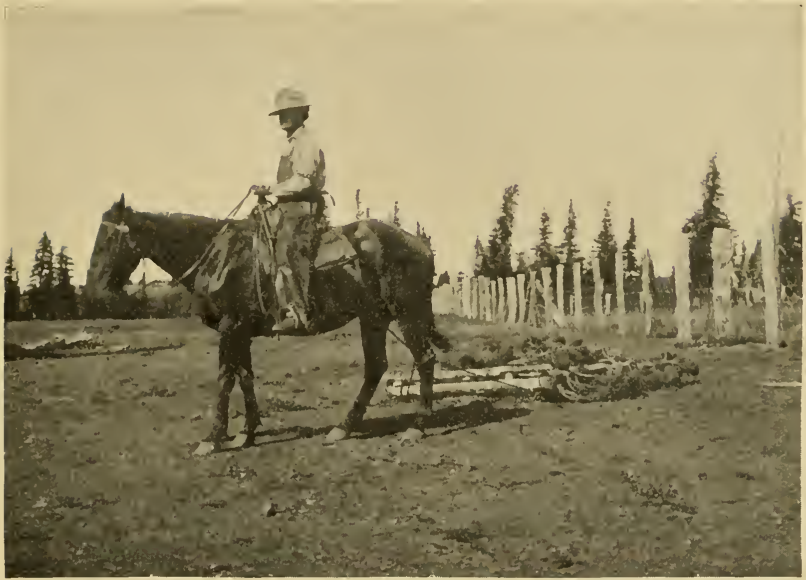

(Forest Service, by the Author.)

FIg. 12.- A BRUSH HARROW IN USE.

This simple implement can be constructed in a short time with materials that are usually available.

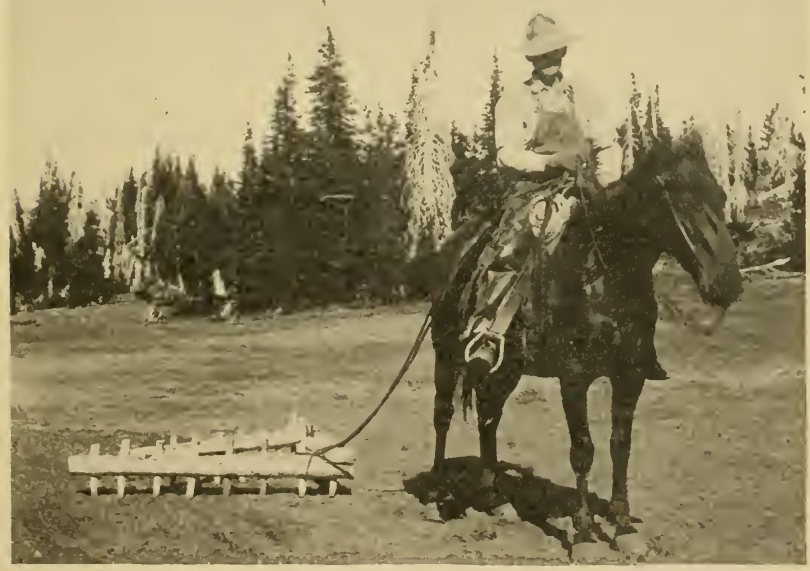

(Forest Service, by the Author.)

Fic. 13. - A WOODEN-PEG "A" HARROW, SUTTED FOR USE ON PACKED SOIL. An ax and a I-inch auger are the only tools needed in its construction. 
lengths of about 6 inches are driven through. The harrow may be dragged over the ground by a rope attached to the saddle horn. An ax and a r-inch auger are the only tools needed in the construction of this harrow.

Sheep are sometimes used to trample in the seed. After close grazing, sheep driven in a compact body two or three times over the seeded area do a satisfactory job of planting. On bunchgrass range, where the tussocks of the native vegetation would be torn asunder by harrowing, sheep are especially recommended for the seed planting. Heavy trampling of the soil during wet weather should, however, be avoided.

Scattering the Seed. - Various inexpensive methods of scattering the seed uniformly over the area have been used. A compact hand seeder is satisfactory, but an experienced man may obtain good seed distribution by scattering the seed by hand. Windy days, however, should be avoided for this operation. It is safest to make double sowings. When this method is employed, half the quantity of the seed is sown by passing up and down the area and the other half by crossing at right angles to the first sowing. If more than one species is being sown, the seed should be thoroughly mixed before it is scattered.

Elevational Limitations of Reseeding. - Because of the temperature and the short growing season, elevation is not uncommonly a limiting factor in range seeding. In the Blue Mountains of eastern Oregon fair stands of timothy, Kentucky bluegrass, and redtop were obtained at elevations as high as 7,800 feet above sea level. At an elevation of about 5,000 feet the plants grew luxuriantly; they not only produced satisfactory height growth but developed an abundance of fertile seed. Above an elevation of about 7,500 feet the height growth and leaf development were greatly reduced, and the yield ratio was approximately $\mathrm{I}$ to 4 as compared with seeding at an elevation of 5,000 feet. This relationship is shown in Figure 14, which pictures the relative development of the fleshy stems and of the roots. Also at the higher elevations the stand was seldom good. Moreover, nonsodding plants, like timothy, are short-lived, 
and, because no fertile seed is produced, the stand usually disappears in a few years.

The elevational limitation in seeding varies appreciably with latitude and is approximately 2,500 feet higher in southern New Mexico than in northern Washington. In the Northwest it

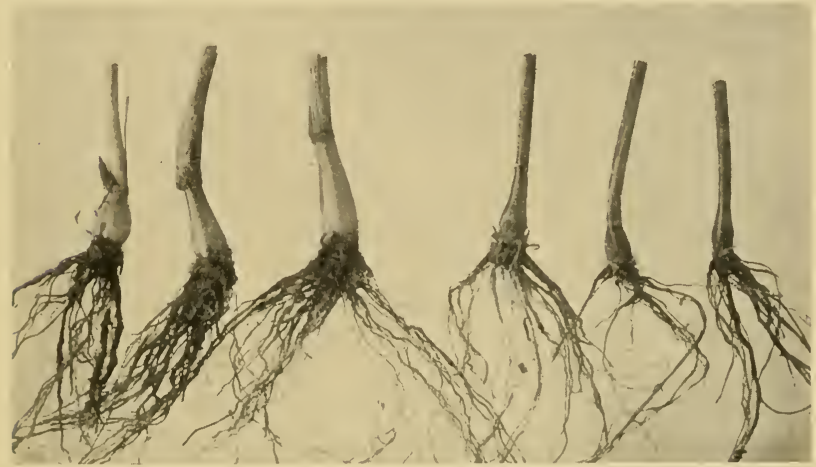

FIG. I4. - RELATION OF YIELD OF TIMOTHY TO ELEVATION.

The three stems to the left represent a stand of timothy produced on range in Oregon at an elevation of 5,000 feet above sea level. The three on the right were grown at an elevation of 7,500 feet. The size of the stems is a direct index of the forage yield.

seldom pays to reseed at elevations in excess of about 7,500 feet above sea level, whereas in southern California good stands have been obtained at an altitude of about 10,000 feet.

The native vegetation itself furnishes the most reliable basis for determining the maximum elevation at which seeding may pay. Where the alpine vegetation becomes scrubby it is evident that the elevation is in excess of that at which seeding is practicable. No seeding to cultivated plants should be attempted above true timberline. In general it may be stated that seeding will not pay within about 1,000 to $\mathrm{I}, 500$ feet of timberline, an elevation at which the timberline trees do not make good development. The effect of elevation on growth is apparent at both extremes. At very high elevations seeding is unsatisfactory because of the short growing season and the low 
temperature; at low elevations, as in the arid-plains region, seeding may fail because of the low rainfall and the frequent periods of protracted drought.

What Grasses to Sow. - In selecting plants for pasture, only those should be used that remain green and palatable so that stock will crop them with relish over a long period. They should make a heavy yield; they should be palatable throughout the season (even after the herbage dries it should be relished and retain its highly nutritive qualities); and they should by all means be well adapted to the soil and climatic conditions peculiar to the locality.

No species has given larger yields, at least for the first two or three seasons, under a diversity of range conditions, than timothy. Furthermore, the cost of the seed is lower than that of any of the more promising species. When once well established, a timothy cover is not readily injured by trampling, but it is much less permanent than that of Hungarian bromegrass, Kentucky bluegrass, Canada bluegrass, white clover, and certain other sod-forming species. The latter-named species may be relied upon to yield heavily for an indefinite period, once they are well established. On the wetter soils redtop yields the most heavily of the plants named. Redtop usually yields well whereever timothy thrives. As it reproduces mainly by rootstocks, its establishment, although slow, is remarkably tenacious.

Among the nongrasses, Alsike and the white clovers yield well. Lands to be seeded to these plants, however, should be carefully selected, as neither species does well on very dry sites, or on cold, saturated, or sour soils.

Amount to Sow and Cost of Seeding. - The methods used in scattering the seed and the soil treatment here recommended make the cost of the seed itself the heaviest item of expense. The cost per hundred pounds of choice seed of the most promising species and the amount of good seed recommended per acre in order to obtain a satisfactory stand on soils of average fertility, follow: 
Amount of Seed and Cost per Acre

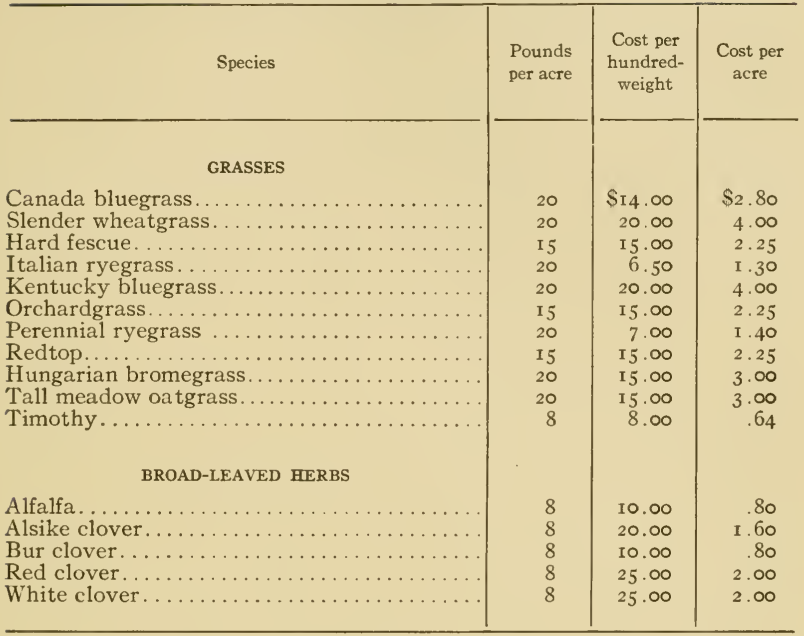

In an estimate of the total cost of a reseeding project, to the cost of the seed itself must be added the expense of transportation, sowing, and soil treatment. The total cost usually ranges from approximately $\$_{2}$ to $\$_{5}$ per acre. An expense of as much as $\$ 5$ per acre is seldom justified.

Moisture Requirements of Cultivated Forage Plants. - A common mistake in range reseeding, as already pointed out, is the failure to select species that are suited to the moisture conditions of the soil. Considering the matter of moisture requirements alone, the following species may be classed as having high, intermediate, and low requirements. The first group refers to plants which grow luxuriantly in wet meadows, and hence where the soil is poorly aërated. The second group includes those species which make the best growth in well-drained soils, but which also do fairly well in both dry and moist habitats. The third group embraces those species which do best on land that is well drained at all times. 
Moisture Requirements of Valuable Plants for Range Reseeding

\begin{tabular}{|c|c|c|}
\hline High & Intermediate & Low \\
\hline $\begin{array}{l}\text { Alsike clover. } \\
\text { Orchardgrass. } \\
\text { Red clover. } \\
\text { Redtop. } \\
\text { White clover. }\end{array}$ & $\begin{array}{l}\text { Alfalfa. } \\
\text { Alsike clover. } \\
\text { Canada bluegrass. } \\
\text { Italian ryegrass. } \\
\text { Japan clover. } \\
\text { Kentucky bluegrass. } \\
\text { Orchardgrass. } \\
\text { Perennial ryegrass. } \\
\text { Red clover. } \\
\text { Tall meadow oatgrass. } \\
\text { Timothy. } \\
\text { White clover. }\end{array}$ & $\begin{array}{l}\text { Alfilaria. } \\
\text { Australian saltbush. } \\
\text { Blue gramagrass. } \\
\text { Bur clover. } \\
\text { Hard fescue. } \\
\text { Mesquitegrass. } \\
\text { Slender wheatgrass. } \\
\text { Hungarian bromegrass. } \\
\text { Timothy. }\end{array}$ \\
\hline
\end{tabular}

Although the above classification should not be considered infallible, it may prove helpful to stockmen in the selection of the proper species. Because of the adaptability of some species to a wide variety of moisture and soil conditions, a single species, as shown in the foregoing table, may fall under two classifications. In addition to the moisture requirements of plants, the physical structure and chemical nature of the soil are sometimes limiting factors in plant growth.

Seeding to a Mixture. - Seeding different species is often a good plan, not only because one species may be better suited to the conditions than another, but because more feed may be produced the season through; moreover, the cost may be less. For example, a mixture of to pounds of Kentucky bluegrass and 4 pounds of timothy per acre - sufficient to produce a good stand - costs only about half as much as does a pure seeding of 20 pounds of Kentucky bluegrass. To obtain a good cover of Kentucky bluegrass requires several seasons. A combined seeding of Kentucky bluegrass and timothy, on the other hand, yields a crop of the latter the first year. Moreover, the timothy crop does not seem to hold in check the development of the bluegrass cover. On western ranges generally, it is seldom profitable to expend more than about $\$ 3$ per acre for seed and planting combined. Where conditions for growth are favorable, a sparse cover, especially of sod plants, is sure to increase 
in density if the lands are not grazed destructively each year, and eventually a complete cover may be obtained.

How to Graze Newly Seeded Lands. - The first year after seeding, the young plants seldom produce much forage, nor do they withstand heavy grazing. Injury to the young cover by grazing and trampling is most severe early in the season of the first year, but even in the autumn moderate grazing should be practiced. On mountain ranges it generally pays to keep stock off the seeded portion during the entire first season. In the autumn or late summer of the second year moderate grazing seldom thins the stand seriously.

Where Seeding Will Pay. - Seeding to cultivated forage plants is warranted only where the soil is fertile, where there is ample moisture, and where the growing season is long enough to permit good growth. If the mountain ranges of the West are taken as a whole, probably only a small part of the area may be economically seeded to cultivated plants. This limitation may be restated as due chiefly to (I) excessive elevation, (2) insufficient moisture, (3) poor soil, and (4) inability of cultivated plants to compete successfully with the native vegetation. Plants that produce a sod are much to be preferred to bunchgrasses which are entirely dependent upon seed for their perpetuation.

It is evident that there is great need for plants as well adapted to mountain range and arid plain as are Kentucky bluegrass and Bermudagrass to certain sections in the humid and semi-humid regions. Neither of these introduced plants nor any other cultivated species thus far tried thrives under the rigorous conditions that obtain over the vast stretches of western grazing grounds. It is significant, however, that most of the cultivated forage plants grown in this country have been introduced from the Old World. In addition to those mentioned, are timothy, redtop, Hungarian bromegrass, various species and varieties of clovers, alfalfa, sorghums, and vetches. Furthermore, there are such semi-domesticated introduced plants as alfilaria (Erodium) and wild oats (Avena), whose forage value on the native 
ranges of the Southwest and the Pacific slope can be only approximately estimated.

Although nearly all of the successful introduced plants are adapted to the humid or semi-humid regions of the United States, it is not improbable that other foreign species might be equally well adapted to mountain lands and arid sections. Until suitable introduced plants are discovered, however, range managers must content themselves with the improvement of the range through the revegetation of the native forage crop. Possibilities along this line have been adequately demonstrated, and the results are highly encouraging.

Reseeding to Native Forage Plants. - Restricted localities are not uncommonly found which have been so severely de-

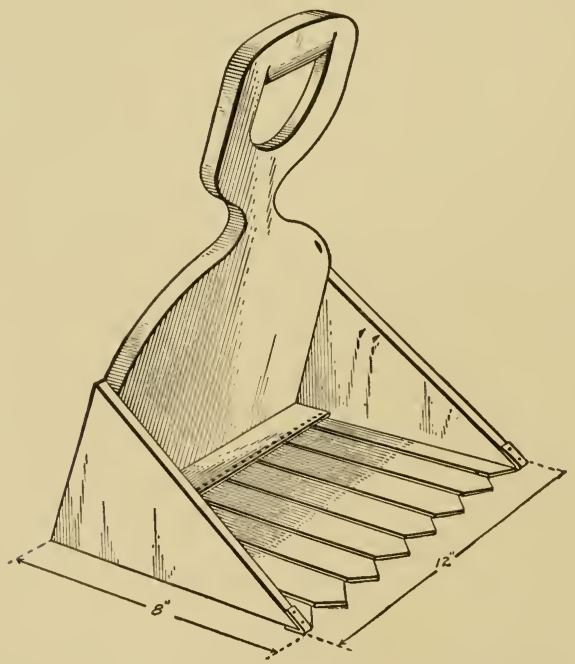

Fig. 15. - COMB SEED STRIPPER, USED IN COLLECTING SEED OF THE NATIVE GRASSES.

pleted that practically no desirable native forage plants remain, and on which cultivated plants will not grow. On such areas revegetation may be hastened appreciably by scattering in 
strategic places seed of the more desirable native plants which once occupied the lands. Collecting seed of native pasture plants, however, is tedious and expensive, and the viability of the seed is often low. For these reasons it seldom pays to seed large areas. In the Wasatch Mountains of Utah large quantities of seed of violet wheatgrass (Agropyron violaceum) have been gathered for 19 cents per pound, and of mountain bromegrass (Bromus carinatus) for 24 cents per pound. A comb seed stripper is used in the collecting (Fig. I5).

A more profitable plan, and one that the author has tried out in many localities in the Great Basin region, is that of "strip" seeding. The area sown is small, often not over 15 or 20 rods long and I or 2 rods wide. Before the sowing, the soil is thoroughly loosened up by harrowing or plowing. The plot is then seeded heavily and the seed carefully covered by harrowing or "brushing."

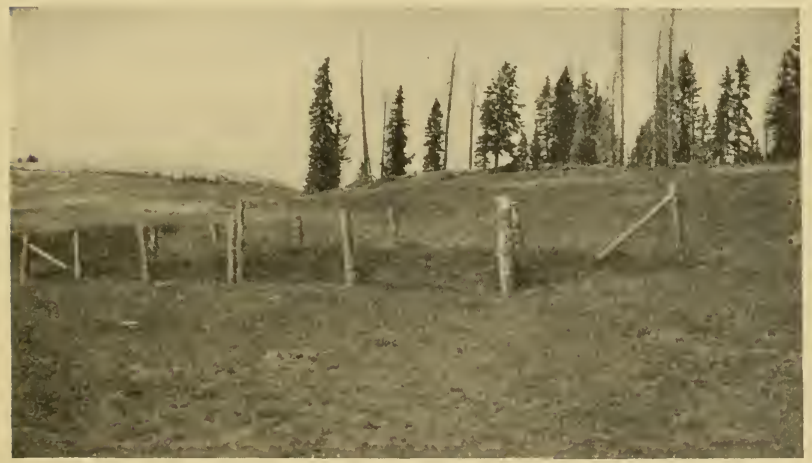

Fig. 16. - A PROTECTION STRIP SEEDED TO NATIVE FORAGE PLANTS.

The luxuriant vegetation produces an abundance of seed which finds lodgment on the adjoining depleted area, thereby aiding nature in replenishing the overgrazed cover.

If the stock is not under control, the seeded strip is fenced, preferably with woven wire or with material which will not break the force of the wind (Fig. I6). If such plots are so located that the wind has full sweep, the seed developed within 
the enclosure is carried for a considerable distance over the adjacent area. In two or three seasons young plants are seen radiating from the central " oases."

Every precaution possible should be taken to avoid the destruction of all the native seed plants. If the lands are denuded of vegetation, nature is put to such a disadvantage that it may be impossible to replace in years what required only two or three seasons to destroy.

\section{QUESTIONS}

1. Discuss the results of plant introduction on arid native western grazing grounds.

2. Discuss the physical conditions peculiar to mountain range lands as related to the growth of cultivated forage plants.

3. Name five plants that are reported to have given the best results in reseeding mountain meadows.

4. When is the best season to sow (a) In the Northwest? Why? (b) In the Southwest? Why?

5. Name five common causes of failure in reseeding mountain land.

6. What cultural implements would you recommend for use in preparing the seedbed and covering the seed?

7. How should the seed be scattered?

8. (a) Why is it important that the seed be covered? (b) How may this best be done on the range?

9. (a) Discuss elevation as a limiting factor in range reseeding. (b) At how great an elevation is it practicable to seed (I) in the Northwest, (2) in the Southwest?

10. Name three important characteristics which a forage plant that is to be seeded on the range should possess.

11. How many pounds should be sown to the acre of $(a)$ Kentucky bluegrass, (b) timothy, $(c)$ white clover, $(d)$ redtop, $(e)$ Canada bluegrass?

12. Discuss the advantages of seeding to a mixture.

13. How would you graze newly seeded land?

14. Discuss the limitations of seeding to cultivated grasses on western range lands generally, and show where such seeding may be expected to pay.

15. Discuss the conditions under which artificial or hand seeding to native forage plants may be justified.

\section{BIBLIOGRAPHY}

Cotron, J. S. The Improvement of Mountain Meadows. U. S. Dept. of Agr., Bur. of Plant Ind., Bul. I27, 1908.

Range Management in the State of Washington. U. S. Dept. of Agr., Bur. of Plant Ind., Bul. 75, I905. 
Griffiths, D. A Protected Stock Range in Arizona. U. S. Dept. of Agr., Bur. of Plant Ind., Bul. 177, г910.

Hastings, S. H. Forage Crop Experiments at the San Antonio Field Station. U. S. Dept. of Agr., Bur. of Plant Ind., Cir. ro6, I9r3.

Hгтснсоск, A. S. Cultivated Forage Crops of the Northwestern States. U. S. Dept. of Agr., Bur. of Plant Ind., Bul. 3r, I902.

Jardine, JAmes T., and Anderson, Mark. Range Management on the National Forests. U. S. Dept. of Agr. Bul. 790, I9I9.

Jones, L. R. Vermont Grasses and Clovers. Vt. Agr. Exp. Sta. Bul. 94, I902.

Kennedy, P. B. Coöperative Experiments with Grasses and Forage Plants. U. S. Dept. of Agr., Div. of Agrost., Bul. 22, 1900.

Smooth Bromegrass. U. S. Dept. of Agr., Div. of Agrost., Cir. I8, I 899 .

McNear, A. D. Lespedeza, or Japan Clover. U. S. Dept. of Agr. Farmers Bul. 44I, I9II.

Montgomery, E. G. Productive Farm Crops. J. B. Lippincott Co., Phila., I9I 5.

Nelson, Elias E. Native and Introduced Saltbushes. Wyo. Agr. Exp. Sta. Bul. 63, 1904.

OAKLey, R. A. The Culture and Uses of Brome-grass. U. S. Dept. of Agr., Bur. of Plant Ind., Bul. ir I, Pt. 5, 1907.

Pearson, G. A. Studies in Artificial Reseeding. U. S. Dept. of Agr., Forest Service, Review of Forest Service Investigations, Vol. 2, ror3.

Sampson, Arthur W. Climate and Plant Growth in Certain Vegetative Associations. U. S. Dept. of Agr. Bul. 700, I9r8.

Plant Succession in Relation to Range Management. U. S. Dept. of Agr. Bul. 791, I9I9.

The Reseeding of Depleted Grazing Lands to Cultivated Forage Plants. U. S. Dept. of Agr. Bul. 4, I9I3.

Scribner, F. Lamson-. Economic Grasses. U. S. Dept. of Agr., Div. of Agrost., Bul. I4, I900.

Thorneer, J. J. The Grazing Ranges of Arizona. Ariz. Agr. Exp. Sta. Bul. 65, r910.

Tracy, S. M. Forage for the Cotton Belt. U. S. Dept. of Agr. Farmers Bul. II 25, 1920.

Vinali, H. N. Meadow Fescue: Its Culture and Uses. U. S. Dept. of Agr. Farmers Bul. 36r, I909.

Wooton, E. O. Carrying Capacity of Grazing Ranges in Southern Arizona. U. S. Dept. of Agr. Bul. 367, rgr6.

Factors Affecting Range Management in New Mexico. U. S. Dept. of Agr. Bul. 21 I, I9I5. 


\section{CHAPTER IV}

\section{NATURAL RESEEDING AND MAINTENANCE OF NATIVE WESTERN PASTURE LANDS}

Inasmuch as only a slight improvement in grazing capacity may be expected, in the light of present researches, from seeding native western ranges to cultivated forage plants, it is very clear that a broad and fundamentally sound plan of revegetation is necessary. Hitherto the grazier has simply taken what nature offered him. This generous offering, however, has been overused to such an extent that nature has been put to a disadvantage. The yield of plants that propagate by seed, as do most of the native herbaceous plants in the West, is not maintained when the leaf blades or seed stalks are eaten down about as soon as they afford a good bite.

The control of the number of stock in accordance with the carrying capacity of the lands will do much to check the evils of overgrazing, but this in itself does not bring about marked forage increment. If, however, the determination of the proper grazing capacity is accompanied by a foraging plan based upon the growth and reproduction requirements of the important forage vegetation, lands with ample seed plants are soon revegetated and restored to their pristine condition. With such a basic, common-sense grazing plan the results appear to be uniformly good on native pasture lands throughout the West. Moreover, it is reasonable to expect good results, for the very presence of native vegetation indicates that it is adapted to the soil and is capable of being sustained by a minimum amount of moisture. Even after the perennial grasses have dried up, as they do in protracted periods of drought, many are capable of quickly resuming growth and succulence.

The maintenance of a maximum forage yield would not be difficult if grazing could be delayed each year until the seed crop had ripened. Since, however, a considerable proportion of the 
feed must be cropped while the vegetation is growing, such a plan is impracticable. Any feasible plan of improving the lands, therefore, demands a grazing system which permits full use of the pasture during the growing season. This is accomplished by alternating the grazing and the resting of the lands in accordance with nature's rules - rules prescribed by the growth requirements of the important vegetation itself.

Migrations of Buffaloes Suggest Revegetation Plan. - The roving habits of buffaloes led them north in the spring and south at the approach of winter. Notwithstanding the enormous numbers of the animals, these migrations caused practically no range deterioration. A proper rotation of grazing and resting pasture lands accomplishes notable results. Although the benefits from intermittent grazing are conspicuous and indisputable, the stockman has been slow to adopt such a plan, either on the public domain or on his own range. Admittedly, resting the pasture throughout one or more seasons is inconvenient and expensive, as it does not fit in with an established meat-producing business. Where the pasture forage is declining rapidly, however, it is necessary to face the facts, and either allow some period of rest or reduce the stock accordingly.

The object of the following discussion is to show how native western pasture lands may be fully revegetated without the loss of a single season's forage crop, and yet how this may be accomplished quite as rapidly as when the areas are closed to grazing. Although this statement may be surprising, the system is built on a thoroughly tested scientific foundation and has been developed in accordance with common sense.

Cost of Overgrazing. - Grazing the pasture to its very maximum year after year can produce only one result - a sharp decline in its carrying capacity. In regions where the climatic conditions are subject to considerable fluctuation, as they are over most of the West, stocking the lands to their maximum as compared with their optimum capacity, is like buying fluctuating stocks on the minimum marginal requirements of the broker, as compared with an outright purchase. When the pressure comes, the investment in cattle (or in stocks) is quickly 
wiped out. Although it is impossible, in the light of our present imperfect knowledge, to declare definitely what the optimum grazing capacity of a given range unit is, the pasture should be so stocked that at the end of an average year a small amount of forage remains. The most successful cattle and sheep growers of today are grazing their lands on an optimum basis. A large proportion of their unsuccessful neighbors, on the other hand, are cropping the pasture each year to the maximum. The ranches owned by the latter men either are mortgaged or are passing into new hands through foreclosure. The financial loss that the stockman suffers because of failure to recognize and meet the requirements of plant growth is so great that it can not be even approximately estimated. Fitting the grazing plan into the growth requirements of the vegetation greatly benefits the stockman and stabilizes the livestock industry; it is favorable to the irrigation farmer because it regulates the streamflow; and it is an essential element in the preservation of soil fertility.

\section{REQUIREMENTS OF PLANT GROWTH}

The most important objects sought in the revegetation of native pastures are a continuous, vigorous growth and ample seed production. The most important points in this connection are: (I) Extent of forage development when the stock is admitted in the spring; (2) seed production and the time when the seed is scattered and planted; and (3) establishment of the seedling plants.

Forage Production in Early Spring. - The vigor of pasture vegetation may be readily determined by the time growth starts and the amount of forage produced in early spring. Any plant that develops an abundance of leafage early in the season had a large amount of food stored in the roots the previous year and, hence, is in a healthy, vigorous condition. When, however, the plant is repeatedly robbed of its green leafage during the summer, not only is growth in the following spring much delayed but the amount of herbage produced is small. ${ }^{1}$ Vegetation

1 Sampson, Arthur W., "Natural Revegetation of Range Lands Based upon Growth Requirements and Life History of the Vegetation." U. S. Dept. of Agr., Jour. of Agr. Research, Vol. 3, No. 2, Pp. IOI-II 5, I9I4. 
in this weakened condition is readily killed by further close or premature grazing.

Sampson ${ }^{1}$ has shown that the removal of herbage several times in a season, especially if the first harvest is made a few days after growth has started, seriously weakens the plant and immediately decreases its forage production. In the Blue Mountains of northeastern Oregon, and again in the Wasatch Mountains of Utah, the writer harvested monthly, for three years in succession, various species of bunchgrasses and other plants, three cuttings being made each year on one plot and once a season on another plot. Most of the plants so treated lived through the period of the experiment, but at the end of the third year only a few weak spears of leafage per plant were produced. Moreover, each season, as the experiment of frequent harvesting progressed, the time at which growth began was correspondingly delayed, until finally no flower stalks were sent up. On the other hand, plants of equal vigor when the test was started, but whose herbage was not clipped until the seed crop had ripened, were approximately I 50 per cent greater in volume at the beginning of the third year of treatment than those harvested three times each season, and the forage yield from them was about 300 per cent greater. Furthermore, the growth of the vigorous plants began in the spring ten to fifteen days earlier than on the frequently clipped plots. Then, too, the leafage was quite as abundant as where the plants were protected yearlong. Nor was the difference in the development of the plants variously treated confined to the aërial growth. Repeated examinations of the roots in the autumn at the.end of the third year of treatment showed that the plants clipped monthly were practically devoid of plant foods, whereas those not harvested until the seed had matured contained a superabundance of food materials (Fig. I 7).

An elaborate series of cropping tests with various forms of bunchgrasses was carried out by the writer at the Great Basin

1 Sampson, Arthur W., "Range Improvement by Deferred and Rotation Grazing." U. S. Dept. of Agr. Bul. 34, p. 3, 1913. 
Experiment Station in the Wasatch Mountains in central Utah. ${ }^{1}$ Plots harvested once each season, just before seed maturity, yielded more than five times as much air-dry forage as those from which the leafage was removed four times each season.
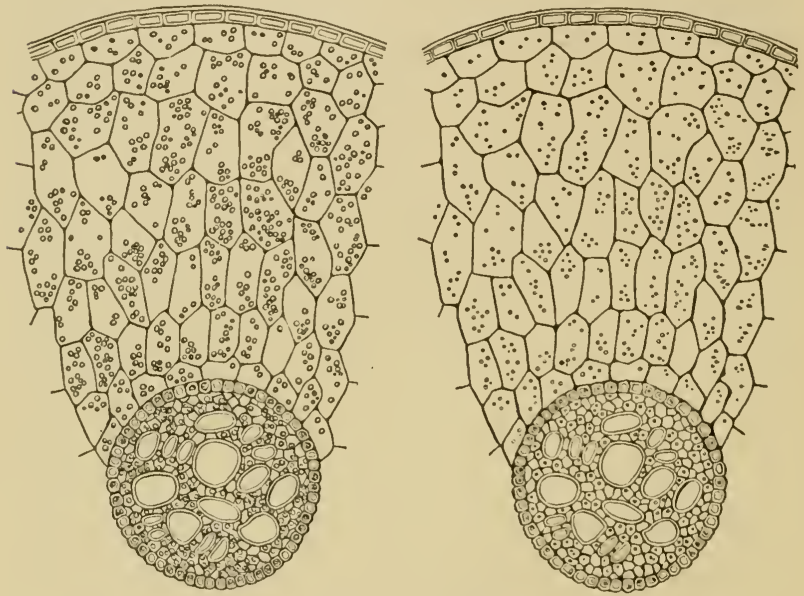

Fig. 17. - THE STORY OF REPEATED GRAZING YEAR AFTER YEAR.

Left. - Thin slice cut across an active root of larkspur. The numerous spherical bodies scattered throughout the tissues are starch grains, an important plant food. The plant had not been molested in any way. It was growing vigorously and was in a normal, healthy condition when the examination was made. Right. - Cross section of a larkspur root similar to that shown on the left. Because the leafage was cut off three times the first year and two times the second year the root section contains only a few small grains of starch. At the end of the second year of cutting the plant died from starvation. Repeated grazing year after year accomplishes exactly this result.

Likewise where two cuttings were made late in the season, the yield was practically the same as where the herbage was removed once, but many times greater than where the plots were harvested four times. It was significant, too, that at the end of the third year approximately 85 per cent of the plants harvested four times had died. They literally starved to death (Figs. I8 and I9).

1 For a more detailed consideration of this subject, see Sampson, Arthur IV., "Livestock Husbandry on Range and Pasture." 


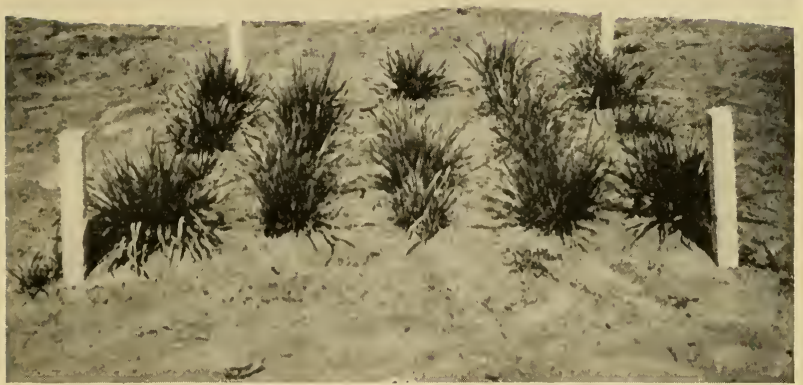

(Forest Service, under direction of the Author.)

Fig. 18. - EFFECT ON VEGETATION OF CROPPING TWICE IN A SEASON.

Plot of violet wheatgrass (Agropyron violaceum) harvested twice each season for two years in succession, the first cutting being made at the time of seed maturity and the second near the end of the growing season. All the plants were vigorous and healthy; they produced a large yield and an abundance of seed of good germination strength. (Photographed in the spring of the third season of the test, prior to harvesting.)

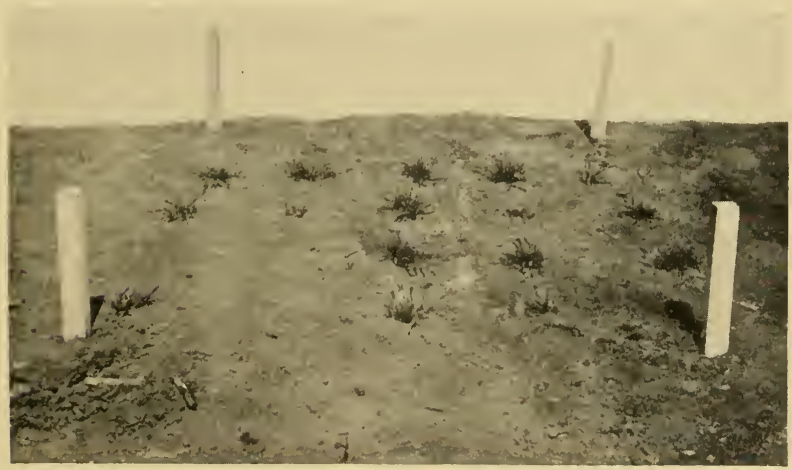

(Forest Service, under direction of the Author.)

FIG. 19. - EFFECT ON VEGETATION OF CROPPING SEVERAL TIMES IN A SEASON.

Plot of violet wheatgrass located adjacent to that shown in Figure 18 . The plot was harvested four times each season at monthly intervals for two years in succession, the first cutting being made two weeks after growth had begun. The yield was approximately five times less than that from the plot shown in Figure 18. At the end of the third year 85 per cent of the plants had died. (Photographed in the spring of the third season of the test, prior to harvesting.) 
The experiments here cited show clearly how utterly dependent is the plant on a reasonable leaf surface for the manufacture of food. Not only is the development of foliage determined largely by the amount of food stored in the plant for future use, but the development of the root system, upon which the plant is dependent for an ample supply of water and soil salts, is also determined by the elaborated food supply.

Seed Production. - The revegetation of native pastures in general and of bunchgrass lands in particular is dependent upon the production of a fertile seed crop. Natural reseeding, therefore, presupposes the maintenance of the seed plants at all times in a high state of vigor. Without vigorous growth few flower stalks are sent up, and these appear so late in the season that little fertile seed is developed.

In the Blue Mountains of northeastern Oregon an area which for several years had been severely overgrazed was fenced against stock, and for five years note was made of the recovery in vigor of the vegetation. During the first year of protection no flower stalks appeared until July 25, although flower stalks of vigorous vegetation of the same species growing under similar conditions started about June 20 . The second season, however, flower stalks on the fenced plot began to appear as early as July ro, although the growing season was no earlier than in the previous year. As the seasons of protection proceeded, the flower stalks appeared earlier in the spring, the seed crop was larger, and the viability of the seed was very much higher. In mountain ranges where the growing season is short, the great struggle of the vegetation is to mature its seed crop. If this is to be accomplished, the vegetation, as shown, must be in a high state of vigor.

Generalizing, it may be stated that vigorous plants, which have not been weakened by overgrazing, produce a large forage yield and a viable seed crop which matures fairly early; that those of average vigor develop a moderate amount of herbage and a small seed crop which matures late; and that seriously weakened plants produce but little forage and usually fail to develop any seed. 
Scattering and Planting the Seed. - Most plants drop their seed as soon as it reaches maturity. This is advantageous in revegetation because it eliminates to a great extent the possibility that the stock will consume much of the seed crop; at the same time it permits the seed to be trampled into the ground when the forage is grazed.

If the lands are not grazed after the seed crop is disseminated, large chaffy seeds, like those of the bromegrasses, fescuegrasses, the wheatgrasses, and numerous others of primary forage value, even though promptly dropped upon reaching maturity, are usually found uncovered in the spring. On the other hand, plants with more or less rounded, heavy seeds, like those of sedges (the leafage of many of which is not highly palatable) are soon worked beneath the surface soil into a favorable seedbed. Needless to say, therefore, plants of the large-seeded species that fail of being planted, often on account of nongrazing, fail likewise to reproduce; whereas, the undesirable forms may increase each year. To insure good results, therefore, the lands should be grazed closely, but not destructively, after the seed crop ripens.

Loss of Seedling Plants from Natural Agencies. - The thoroughness with which the seed is planted in the autumn, the character of the soil, and the favorableness of the climatic conditions are the primary factors in the establishment of the seedling stand. On hard-packed soils, as on bed grounds and stock driveways, a large proportion of the seedlings die because they are unable to extend their roots to sufficient depth to absorb the water necessary for their continued growth. Frequently, also, heavy seedling mortality occurs on exposed, dry situations. If the seedling stand has passed through the forepart of the first season in good condition, it is reasonably sure to develop into a permanent cover. By the end of the second year the young plants have formed fairly deep and elaborate root systems, and their continued growth is practically assured (Figs. 20, 21, 22, and 23).

Destruction of Seedlings by Grazing. - Besides the damage seedlings suffer from natural agencies, their destruction by 


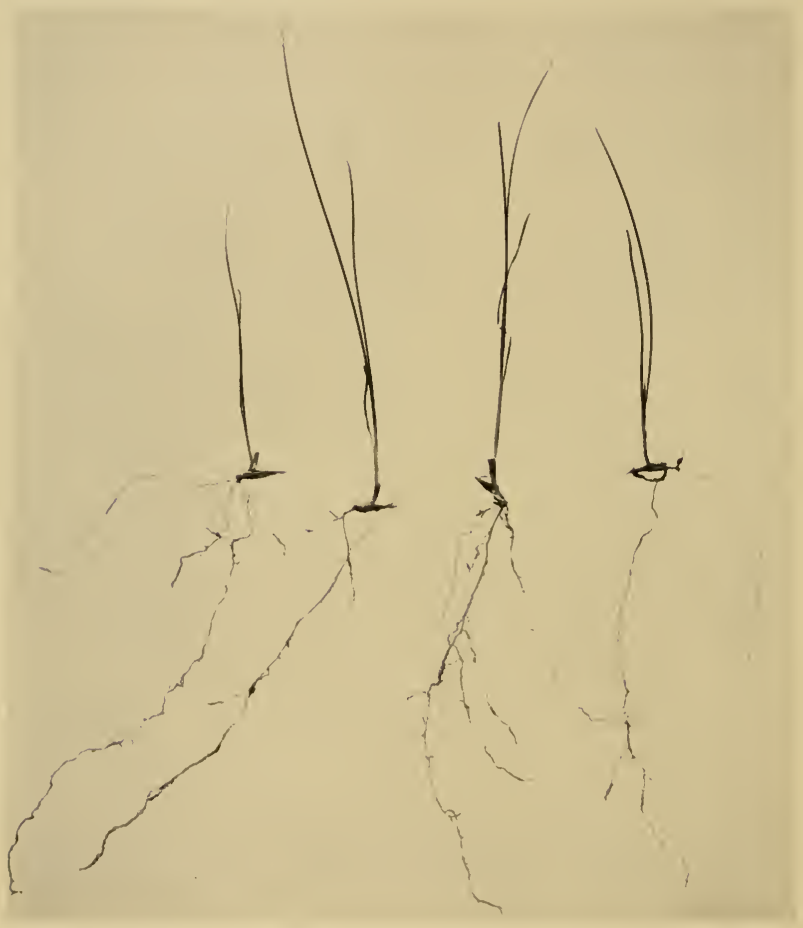

(Forest Serice, by the Auihor.)

FIG. 20. - MOUNTAIN BUNCHGRASS SEEDLINGS AT THE END OF THE FIRST SEASON OF GROWTH.

The average height of the leaf blades is about 3 inches. Because of the meager root system the seedlings are easily destroyed by grazing and trampling, especially early in the season. 


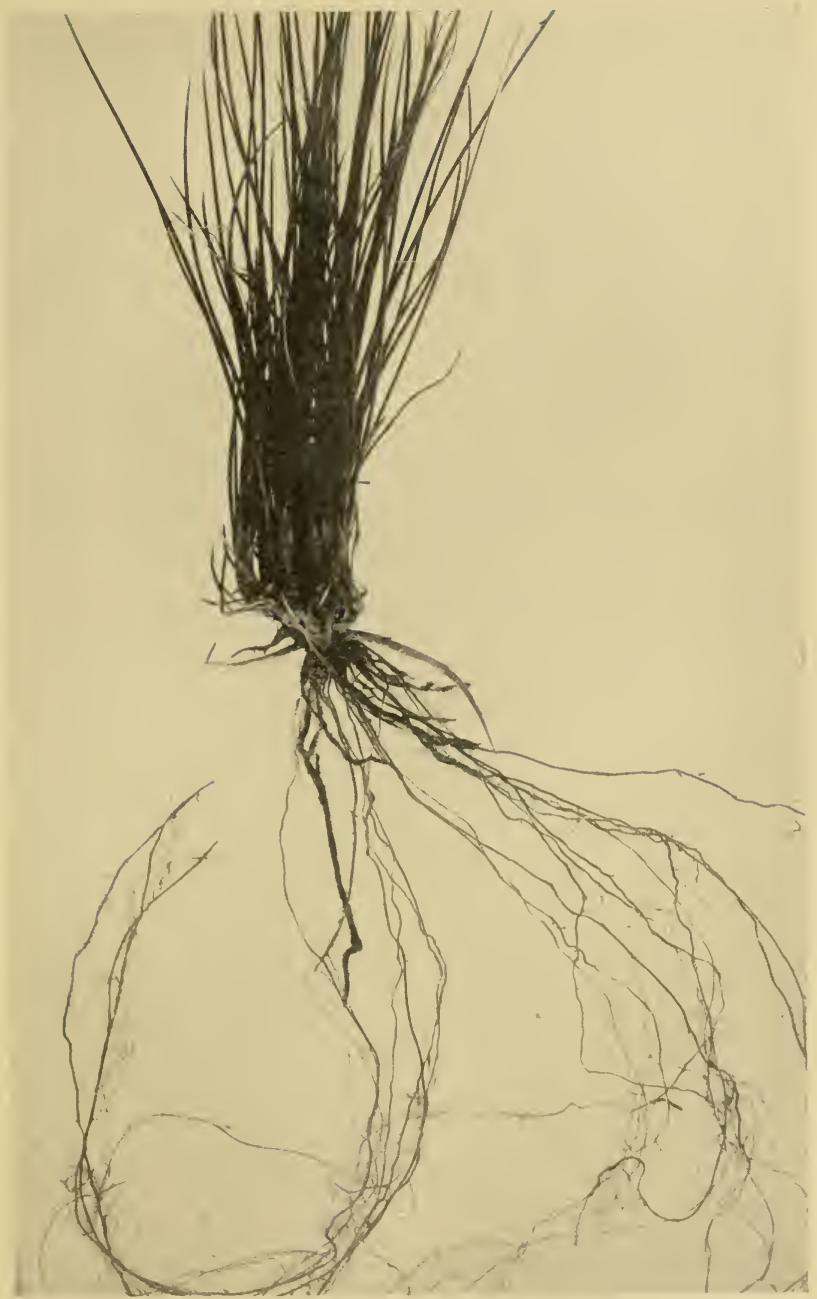

(Forest Service, by the Author.)

Fig. 2r. - MOUNTAIN BUNCHGRASS AT THE END OF THE SECOND SEASON OF GROWTH.

The plant is stocky and has an abundance of basal leafage. A well-formed root was found as deep as ro inches in the soil. Moderate grazing does not appreciably injure the plants at this stage of growth. 


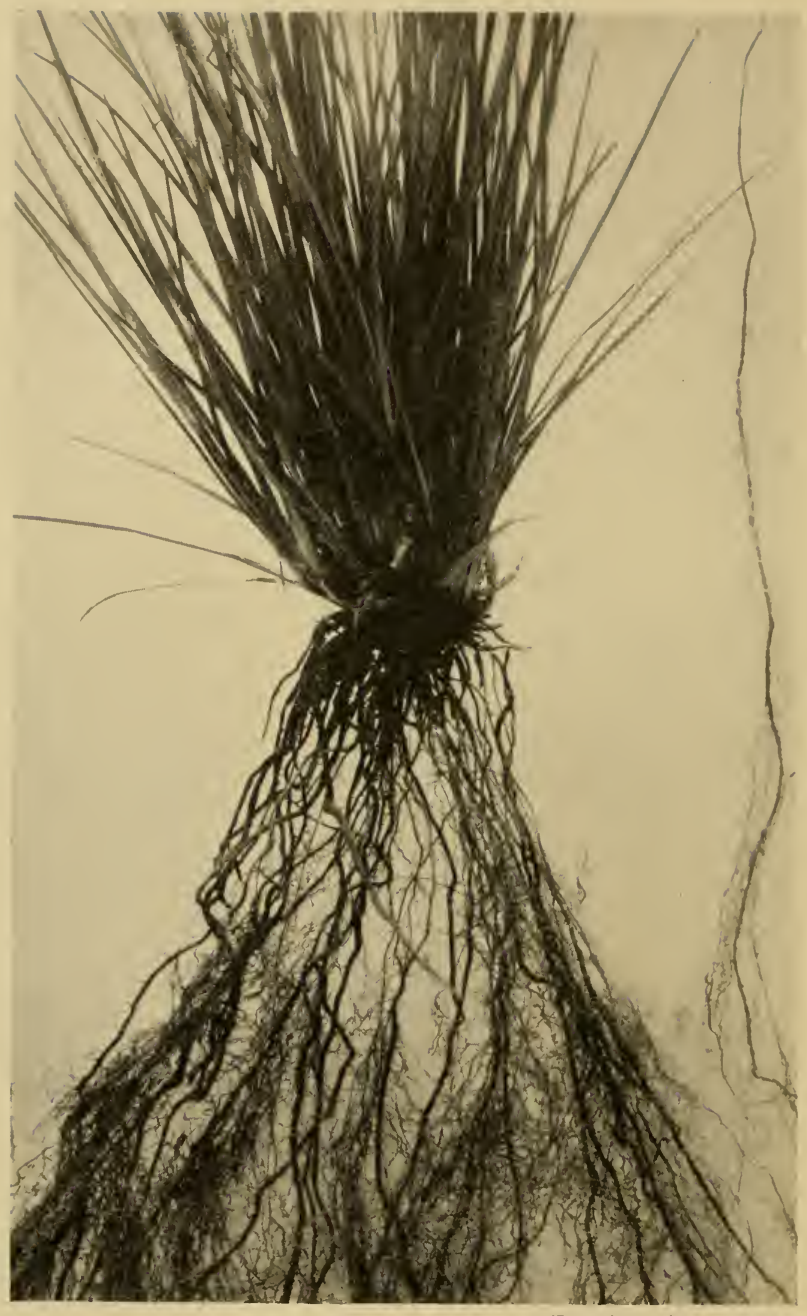

(Forest Service, by the Author.)

Fig. 22. - MOUNTAIN BUNCHGRASS EARLY IN THE SUMMER OF THE THIRD YEAR.

It grows vigorously, producing an abundance of forage. 


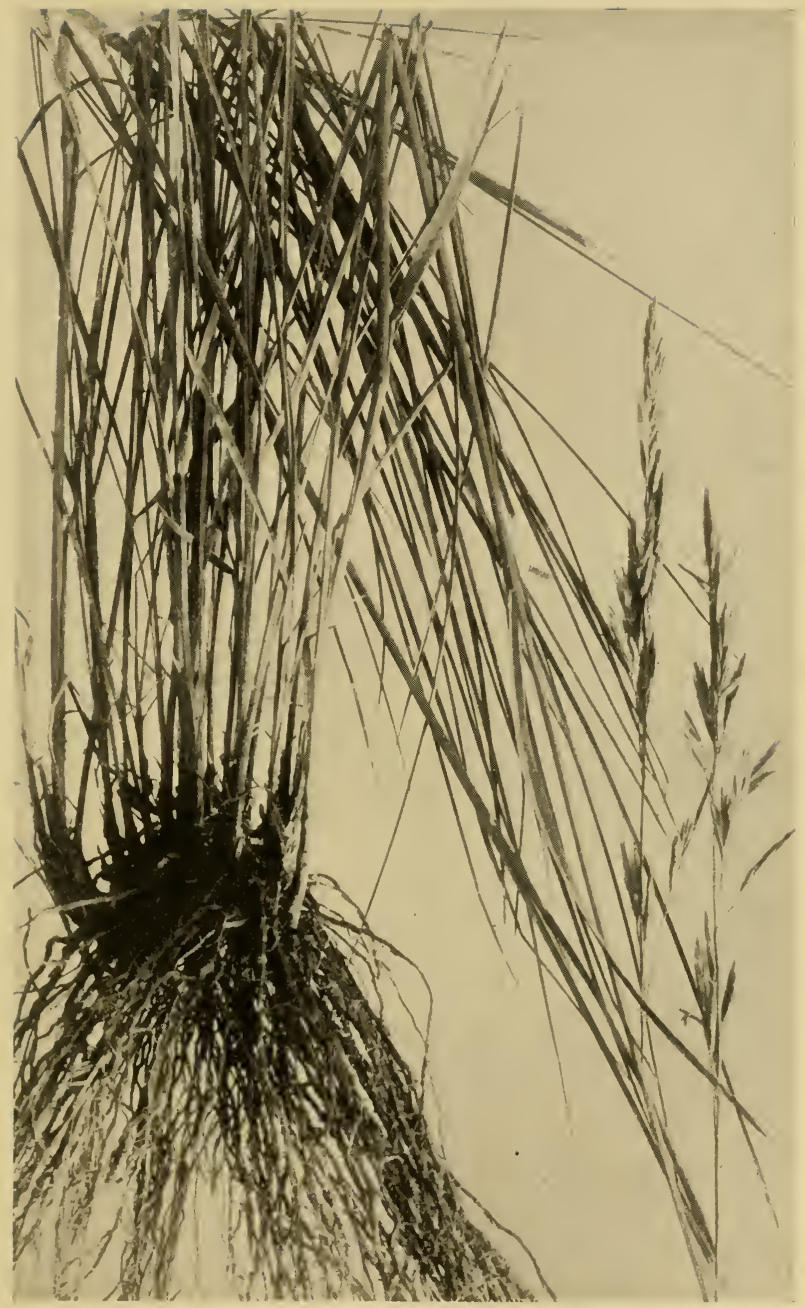

(Forest Service, by the Author.)

Fig. 23. - MOUNTAIN BUNCHGRASS AT THE END OF THE THIRD YEAR.

A few flower stalks and viable seeds are produced. After that the tuft enlarges rapidly. 
grazing may be extensive. Especially is this true where the stand has previously been weakened as a result of drought, where cattle are not properly distributed, or where a band of sheep is too closely herded or handled excessively by dogs. The time at which the reseeding area is grazed, however, is probably the primary factor in the destiny of the seedling stand. A discussion of this point naturally comes in a consideration of the different methods of grazing as related to reseeding.

\section{GRAZING SYSTEMS AND FORAGE PRODUCTION}

If the growth requirements of the principal forage plants, as well as the time when the forage is needed for grazing, are taken into account, it becomes evident that the entire pasture can not be set aside for reseeding in a single year. Grazing as generally practiced in the West may be divided into three more or less distinct systems: (I) Yearlong or season-long grazing year after year; (2) yearlong grazing, with an occasional total exclusion of stock during the entire year with a view to securing forage reproduction; and (3) deferred grazing, or a rotation in the time of using each portion of the range, the plants on one portion being allowed to mature their seed each year before the stock is admitted, and the stock being made to assist forage reproduction by trampling in the seed. These systems will be briefly discussed with a view to outlining a grazing plan which, as a result of many years of practical application, can be recommended as economical and effective in rejuvenating the average depleted native pasture.

Yearlong Grazing. - On much of the public domain, and not infrequently on privately owned pastures, the stock is admitted as soon as the first vestige of green appears in the spring. Often the lands are so heavily stocked that the forage is kept gnawed down throughout the season. The results to the existing vegetation are comparable to the results of the monthly clipping experiments cited. In addition, however, the plant roots are badly damaged by trampling, and the soil is put in poor physical tilth because of heavy packing. Again, as in the clipping experiments, the desirable vegetation is greatly weakened or thinned out; and, because of the entire lack of seed production 
of the palatable vegetation, the grazing capacity drops sharply.

Yearlong or season-long grazing is the most common pasture practice. Not only is the forage as a whole cropped too early in the season, but it is usually grazed again when the second growth is only partly developed. Continued grazing in this way results, as shown, in the failure of the palatable plants to reproduce. In their place there is usually a conspicuous invasion of numerous unpalatable annual and short-lived perennial species.

To sum up the results of continued season-long grazing: ${ }^{1}$ "Where there is enough stock to use all the forage each year the requirements of plant growth are seriously interfered with, the forage crop becomes weakened and is materially decreased, little or no seed is produced, reproduction is therefore prevented, and there is a gradual decline in the carrying capacity of the range."

Revegetation by Yearlong Protection of Pastures. - The fundamentally wrong practice of yearlong or season-long grazing, so far as it concerns the physiological requirements of vegetation, would appear to be overcome by excluding grazing entirely until a depleted pasture is thoroughly revegetated. At first thought it would seem that such a plan of revegetation might be the best and most expedient way to restore a wornout area. As long ago as 1908 a stockman proposed to the writer the total exclusion of foraging animals from an area during the period required for thorough revegetation. The plan was to shift the yearlong protection scheme from one portion of the range to another until the whole area was reseeded. Although this plan required, first of all, a considerable reduction in the number of stock previously grazed, the experiment was initiated.

The study showed conclusively that yearlong protection from grazing restores in a few seasons the vigor of the weakened vegetation and increases appreciably the forage production of the plants already in existence. The system proved a dismal failure, however, in the establishment of seedling plants of the

1 Sampson, Arthur W., "Range Improvement by Deferred and Rotation Grazing." U. S. Dept. of Agr. Bul. 34, p. 9, 1913. 
numerous nutritious grasses, especially species that produce large seeds. On the other hand, annual plants, with their strong seed habits, and especially those with small, round, heavy seeds reproduce exceedingly well. Thus yearlong protection favors the recuperation of only the vegetation already in existence. As this plan fails to accomplish the planting of the seed, it likewise fails to accomplish the reproduction of a large proportion of the most important pasture plants.

In summing up the results of the practice in question, the writer states:1 "Yearlong protection is not an efficient one, because the most valuable perennial species fail to reproduce by seed. While the carrying capacity of the land is increased, this increase is slow and does not compensate for the waste of the forage crop during the long period necessary for revegetation."

Deferred Grazing. - The two grazing systems discussed fail to accomplish revegetation because they are not based upon the growth requirements of the vegetation. What is known as the deferred-grazing system takes into account the requirements of plant growth from the time of the germination of the seed until the seedling plants are thoroughly established. After that it aims to maintain the forage cover at all times in a high state of vigor.

The essential principles of the deferred-grazing system are: (I) An overgrazed area, sufficiently large to supply the forage from the time of seed maturity until the end of the grazing season, is protected from stock until the seed crop has matured. ${ }^{2}$ (2) Upon maturity of the seed crop the forage is grazed closely during the first season, but not to the extent of injuring the seed plants. (3) The same area is protected to about the same date in the second season and longer if necessary, or until the new plants have been thoroughly established. (4) When the area has been satisfactorily reseeded, it is grazed early in the season,

1 Sampson, Arthur W., "Natural Revegetation of Range Lands Based upon Growth Requirements and Life History of the Vegetation." U. S. Dept. of Agr., Jour. of Agr. Research, Vol. 3, No. 2, p. I25, I9I4.

${ }^{2}$ Sod-forming grasses withstand cropping better than do bunchgrasses, yet when sod-forming plants are overgrazed their decline in yield is marked and conspicuous. It is a good practice, therefore, to defer the grazing occasionally on weakened sodforming lands, as elsewhere, until the spring growth is reasonably well advanced. 
and a second area, of sufficient size to accomodate the stock from the time of the ripening of the seed to the end of the grazing season, is protected until the forage has matured. (5) Alternating the grazing after seed maturity from one area to another is continued, not only during the period required for the restocking of each selected area, but even after the deferred portions have been fully revegetated. This plan not only keeps the vegetation vigorous at all times, but results in the formation of an occasional seed crop.

Palatability of Mature Forage. - It is claimed by some that forage on areas where grazing is deferred until after seed maturity is "dry and tough" and can not be utilized to advantage. That this contention is unfounded is seen in the fact that stock of all classes do well on suitable, well-watered winter range, where, after several months of existence on matured forage, the animals are content and in good condition of flesh. Moreover, on the average mountain summer range, very little succulent forage is available in the autumn after the advent of killing frosts. Furthermore, as indicated, there is a distinct advantage in having a reserved area of virgin forage upon which the animals may feed during the latter part of the grazing season. The perennial grasses and the various other plants that are highly palatable when green are generally grazed with considerable avidity after the herbage is air-cured. The leafage of herbaceous plants that is "cured on the ground," however, varies considerably both in palatability and in availability. The leaves of some of the more succulent broad-leaved herbs have a tendency to separate from the stem as soon as they dry up. In grasses, on the other hand, the leaf blades are persistent and generally remain intact, and hence are available for grazing until the plant as a whole undergoes decomposition.

As a rule, lambs do not maintain their plump "baby" condition so well on mature forage as on an abundance of succulent feed; but they harden on dry forage, and therefore hold up well on a drive and in transportation to market. ${ }^{1}$ Western lambs,

1 Douglas, L. H., "Deferred and Rotation Grazing, Hayden National Forest, Wyoming." Nat'l Wool Grower, Vol. 5, No. IO, I9I5. 
however, are usually sold before the forage matures. Furthermore, if range is grazed early in the season and recropped in the fall, uneasiness is usually caused in stock, in so far as there is an insufficiency of the succulent feed which they seek to satisfy the appetite.

In the light of the intensive studies in the Blue Mountains of Oregon, the author summarizes the question of palatability as follows: ${ }^{1}$

"Nearly all the leading range plants, particularly the grasses, are grazed during the autumn with relish. It can not be said, however, that they are eaten with the same gusto after seed maturity as when they are growing vigorously. It was found that the first time a band of sheep passed over a matured range of medium density only about half of the forage crop was grazed off. Not until the range was grazed a second or third time was the crop entirely consumed. The vegetation on similar ranges grazed a month earlier was in most cases entirely consumed the first time the stock passed over it. On ranges grazed after seed maturity the naked flower stalks, rising from leafless tufts of bunchgrass, remained after the stock had passed over them, but on ranges grazed when the forage was succulent and tender no flower stalks were visible after the passage of the stock. No appreciable amount of herbage remained on either area."

Weakened vegetation, when protected by deferred grazing, recovers its vitality quite as rapidly as when the lands are closed to grazing the year through. This protection results in a forage yield practically as large from the existing vegetation as on yearlong protected lands, and in the production of a seed crop quite as satisfactory.

Advantages of Deferred Grazing. - One of the chief advantages of the deferred system of grazing is that no forage is lost while the lands are being reseeded. Stock are not permitted to crop the reseeding area until after seed maturity; but, if the pasture has not been overgrazed, enough feed is available on the

1 Sampson, Arthur W., "Natural Revegetation of Range Lands Based upon Growth Requirements and Life History of the Vegetation." U. S. Dept. of Agr., Jour. of Agr. Research, Vol. 3, No. 2, pp. I44, 145, I9I4. 
larger nonreserved portion. In actual practice it is found advantageous to reserve a portion of the pasture for fall grazing, as it insures ample feed when the average pasture would otherwise be somewhat closely cropped.

Another advantage of deferred grazing is that the planting of the seed insures satisfactory reproduction (Fig. 24). On areas where the deferred-grazing system is applied, seedlings, and later

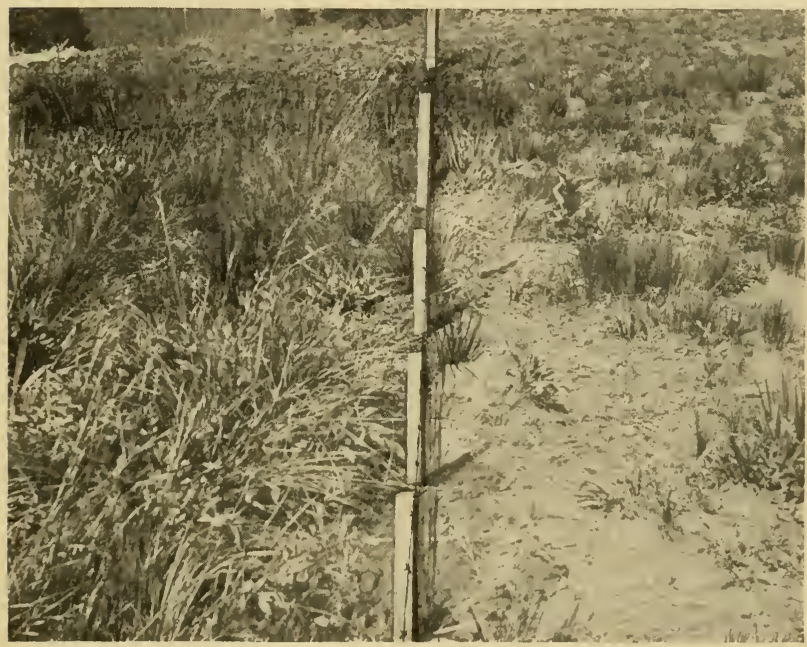

Fig. 24. - DEFERRED CROPPING VERSUS YEARLONG GRAZING.

On the left is shown a bunchgrass pasture where deferred grazing has been strictly applied for three successive years, on the right an area where season-long grazing has been the practice. The vegetation to the left is almost entirely palatable and consists of the best plants of the region. Much of the area to the right is barren or contains poisonous or unpalatable plants.

well-established plants of all species adapted to the area, are found. Not infrequently the stand more than doubles in a single season. Grazing, even late in the autumn, however, thins the young seedling stand; but the damage is seldom serious and is usually insignificant as compared with the damage done on lands grazed early in the season. Moreover, the loss of seedlings from 
fall grazing is largely offset by the planting of an additional seed crop from which seedlings arise in the following year.

In recounting the advantages of the deferred-grazing plan it should not be overlooked that it does away with the fire hazard which is increased by the accumulation of inflammable material on areas protected yearlong.

\section{APPLICATION OF DEFERRED GRAZING}

On range where water is available for livestock in the autumn, deferred grazing can generally be practiced with highly gratifying results. ${ }^{1}$ Ample water must be available for the stock after the herbage dries. In many localities water may be provided with little cost by the construction of dams, by the protection or development of springs, or by the development of wells and the building of windmills. (See Chap. XV.)

Area to be Reserved. - In applying the deferred-grazing system the first points to consider are the time at which the seed of the most important forage plants matures and the length of the grazing period that remains after seed maturity. On high summer ranges, such as those on the National Forests, one-fifth to one-fourth of the grazing season remains between the time of seed maturity and the coming of permanent snows. Accordingly, at least one-fifth of the grazing capacity of the entire pasture or allotment may be reserved annually for deferred grazing. At lower elevations proportionately larger areas may be reserved for reseeding, as the seed crop ripens correspondingly earlier.

General Directions. - When an area is selected for reseeding, it should be strictly reserved for late grazing, and no trespassing by any class of stock should be permitted. The first year the forage should be closely but not destructively utilized. Regardless of the stock grazed, the herder should see to it that the animals pass at least once over the entire area in order to insure planting of the seed. The following season the same area should again be reserved for deferred grazing, for, if the vegetation is much weakened from previous ruthless grazing, two or more

${ }^{1}$ Jardine, James T., "Improvement and Management of Native Pastures in the West." U. S. Dept. of Agr. Yearbook, I91 5, p. 304. 
seasons of deferred grazing will be required to rejuvenate the seed plants and insure the production of ample seed.

It is highly important that grazing be avoided until the young plants are well established. Grazing the second season after the production of a good seed crop should be considerably lighter than in the first year of deferred grazing, for otherwise a large proportion of the seedling stand will be destroyed. On sheep range the herder should avoid massing the band or jamming the animals by the excessive use of dogs. The band should be given the greatest possible freedom at all times.

When the first area selected for deferred grazing is well revegetated, another portion of the pasture in need of reseeding should be selected and handled according to the same plan. This scheme of alternating the deferred grazing will, in time, restore the vegetation over the entire pasture area.

A Specific Case. - As an illustration of the practical application of deferred and rotation grazing, the revegetation of a bunchgrass pasture of $75^{\circ}$ acres may be considered. On the assumption that a stream passes through its entire length, the pasture may be divided by two cross fences into areas of about $25^{\circ}$ acres each, the exact size depending on the type of forage, time of seed maturity, and certain other points of advantage. The grazing plan would then proceed as indicated in the following table.

Plan of Pasturing for Revegetation by Deferred and Rotation GRAZING

\begin{tabular}{|c|c|c|c|}
\hline Year & $\begin{array}{c}\text { Area } \\
A\end{array}$ & $\begin{array}{c}\text { Area } \\
B\end{array}$ & $\begin{array}{c}\text { Area } \\
\text { C }\end{array}$ \\
\hline $\begin{array}{l}1921 \\
1922 \\
1923 \\
1924 \\
1925 \\
1926 \\
1927\end{array}$ & $\begin{array}{l}\text { First } \\
\text { Second } \\
\text { First } \\
\text { Second } \\
\text { Last } \\
\text { Last } \\
\text { Second }\end{array}$ & $\begin{array}{l}\text { Second } \\
\text { First } \\
\text { Last } \\
\text { Last } \\
\text { Second } \\
\text { First } \\
\text { First }\end{array}$ & $\begin{array}{l}\text { Last } \\
\text { Last } \\
\text { Second } \\
\text { First } \\
\text { First } \\
\text { Second } \\
\text { Last }\end{array}$ \\
\hline
\end{tabular}

Area $C$ is the first selected for deferred grazing in $192 \mathrm{I}$, as it is assumed to be most in need of reseeding. This season area $A$ 
is grazed first, and area $B$ second. In order to provide thorough planting of the seed area, area $C$ is cropped closely - much more heavily than areas $A$ and $B$. In 1922, area $C$ is again grazed last, but this time moderately to avoid destruction of the seedling plants; area $B$ is grazed first; and area $A$ second. In 1923 , area $B$ is cropped closely according to the deferredgrazing plan; area $A$ is grazed first; and area $C$ second. In 1924, area $B$ is again reserved for moderate grazing after seed maturity; area $C$ is grazed first; and area $A$ second. In 1925, area $A$ is selected for deferred grazing and is cropped closely; area $C$ is grazed first; and area $B$ second. In 1926 , area $A$ is moderately grazed after seed maturity; area $B$ is pastured first; and area $C$ second. After that, the plan, as indicated in the table, would be repeated, except that in 1927 area $B$ should be cropped first and area $A$ second, in order to foster the establishment of the young seedlings on the latter area.

Although a knowledge of the individual pasture, particularly of the character and density of the vegetation, type of soil, and water facilities, is necessary in order to propose a judicious, farreaching grazing plan, it should not be difficult to apply the principles here laid down. By the use of the plan proposed, all parts of the pasture will be reseeded and the resulting increase in the stand maintained indefinitely.

Deferred Grazing on Range of "Winter Annuals." - The foothill and valley (winter) ranges of California, like those of the Southwest, are admirably adapted to the growth of "winter annuals" - plants like alfilaria, bur clover, and wild oats. Although this type of cover completes its cycle of development in one year, the seed germinates early in the winter, and growth continues throughout the winter and spring. It is the practice generally to begin cropping these lands early in the winter, when the growth is well started, and continue until the herbage dries up in the spring. Where this practice has continued year after year the lands are badly run down, chiefly because of the failure of the more palatable plants to produce seed.

In 1921 tests were initiated on foothill (winter) ranges in various parts of California, the object being to apply the de- 
ferred-grazing system in some practical way. Actual grazing tests have shown clearly that a good seed crop and forage increment may be expected, even when the herbage is closely cropped, if the animals are removed from the range by about the middle of March. Ordinarily the more important annual species mature in the spring and produce viable seed in about six weeks. The plan of deferring or discontinuing grazing sufficiently early in the spring to provide seed gives great promise of effective revegetation of these ranges. The extent of the application of this reseeding plan is determined largely by the possibilities (I) of reserving range in the spring for the animals that are to be removed from the area in need of reseeding, and (2) of producing supplemental roughage for the stock during the time required for the range plants to develop a seed crop, wherever a portion of the range can not be reserved.

Stockmen in California are now adopting this reseeding plan; for, if the area to be reserved is grazed up to about March 15 , there is practically no loss of forage. Moreover, the additional feed originating from the seed produced soon increases appreciably the grazing capacity of the lands, thereby more than offsetting any disadvantage encountered in providing the necessary protection. After one part of the pasture or range unit is reseeded protection during the spring should be applied to another part, and the rotation continued indefinitely as described in applying the deferred-grazing system on the high mountain range.

Reseeding Complications. - If grazing could be deferred for two or three seasons in succession over an entire pasture or range unit, the whole would soon be reseeded. Deferring the grazing to such an extent, however, is clearly impracticable, because, as already pointed out, pasture is in demand throughout the growing season.

Although the deferred-grazing system is applicable generally on all classes of native western pasture, it is not without certain drawbacks. On sheep range, because the animals are constantly under the control of a herder, deferred grazing is readily and effectively applied. Likewise, on fenced cattle pastures the 
system is effectively applied by means of division fences. On unfenced cattle range, however, many complications must be, and usually can be, overcome.

On mountain cattle ranges it is often more difficult to reserve forage until the seed has matured than on the lower, less rugged lands. The situation is complicated by the following conditions: (I) Because of the diversity in elevation and slope all the forage in the mountains does not start to grow at the same time; (2) the character of the forage is widely variable as a result of the different topographic features and the different elevations; (3) water is often unevenly distributed and the supply not infrequently temporary; and (4) the lack of fences makes difficult the control of cattle.

The lower reaches of mountain range furnish ideal spring feed and should be set aside for such use. Lands of medium elevation produce succulent and otherwise desirable forage in midsummer and should not be overrun by stock until the forage is nutritious and has made sufficient growth to withstand grazing. The high mountain lands, whose herbage is seldom sufficiently developed until July to afford economical grazing, furnish superb late summer and autumn feed, and they should not be cropped early in the season.

Cattle have a tendency to drift to the higher lands. Not infrequently they will leave a delicious menu of feed in the lower types for a bit of mountain scenery. Herding does much to prevent this drifting, but herding is expensive at best. The most feasible plan is to fence the spring, midsummer, and late summer and autumn range into large units. The initial cost of fencing is high, but the saving of the herder's wages will often pay for the fence before it has to be replaced. Moreover, a fence is much more effective than herding in the control of cattle. The effective practice of the deferred and rotation grazing system within each seasonal unit, however, requires suitable division fences, or effective herding, or some other control. If there are no cross fences, and if no herder is employed, considerable can be accomplished by properly distributing the stock. This is 
done most effectively by the judicious development of water and the selection of salting stations.

\section{PRACTICAL SUGGESTIONS}

I. Do not overgraze the range. Limit the number of stock to what the pasture as a whole will support in good condition in years of average precipitation and growth.

2. Do not admit the stock in the spring until the herbaceous forage is sufficiently developed to afford a good bite - say, until it averages about 6 inches in height.

3. Avoid overgrazing in early spring when the soil is wet.

4. Fence, herd, salt, or otherwise control cattle so that the animals will be held in the major seasonal grazing units.

5. Secure at all times equitable distribution of the stock within a pasture (seasonal) unit. This can be done most effectively on cattle ranges by cross fencing or by the proper distribution of water and salt, or preferably by a combination of these.

6. Practice deferred grazing on at least one-fifth of the pasture each year. As each selected area is revegetated, rotate the late grazing in order to keep the plant cover as a whole vigorous and productive at all times.

\section{QUESTIONS}

1. Why did not the enormous droves of buffaloes that once roved over the range cause depletion of the native western grazing grounds? Discuss the significance of this fact in connection with revegetation.

2. Discuss the economics of overgrazing.

3. What are the chief points to be considered, so far as the plants are concerned, in revegetating an overgrazed pasture?

4. What is the physiological significance of vigorous plant growth in early spring?

5. Does frequent harvesting of forage plants in a single season increase or decrease the forage yield? Why?

6. Discuss the relation of vigorous growth of bunchgrasses to seed production.

7. What are the chief disadvantages of yearlong grazing as related to revegetation?

8. Show why yearlong protection is not an effective means of reseeding depleted pastures.

9. What are the essential principles of the deferred-grazing system? 
10. Outline a future grazing plan for the revegetation of a pasture fenced off into divisions of equal grazing capacity.

11. Compare the merits of deferred grazing with those of (I) yearlong grazing and (2) yearlong protection.

12. Discuss the palatability of mature native forage characteristic of far western ranges.

13. How would you decide the acreage that may safely be set aside for deferred grazing each year?

14. Discuss the complications encountered in applying deferred grazing on open cattle range. How may these complications be overcome?

15. Name five important conditions to be kept in mind in preventing pasture abuse and in revegetating depleted native pastures.

\section{BIBLIOGRAPHY}

Cotton, J. S. The Improvement of Mountain Meadows. U. S. Dept. of Agr., Bur. of Plant Ind., Bul. I 27, 1908.

Range Management in the State of Washington. U. S. Dept. of Agr., Bur. of Plant Ind., Bul. 75, I905.

Douglas, L. H. Deferred and Rotation Grazing, Hayden National Forest, Wyoming. Nat'l Wool Grower, Vol. 5, No. ro, October, I9r 5.

Griffiths, D. A Protected Stock Range in Arizona. U. S. Dept. of Agr., Bur. of Plant Ind., Bul. I 77, I9ro.

The Reseeding of Depleted Range and Native Pastures. U. S. Dept. of Agr., Bur. of Plant Ind., Bul. I I 7, I907.

Hiтснсоск, A. S. Cultivated Forage Crops of the Northwestern States. U. S. Dept. of Agr., Bur. of Plant Ind., Bul. 31, I902.

JARDINE, JAMES T. Improvement and Management of Native Pastures in the IVest. U. S. Dept. of Agr. Yearbook, I9I5; Yearbook Separate 678 .

JARdine, JAmes T., and Hurtt, Leon C. Increased Cattle Production on Southwestern Ranges. U. S. Dept. of Agr. Bul. 588, I9r 7.

Kennedy, P. B. Coöperative Experiments with Grasses and Forage Plants. U. S. Dept. of Agr., Div. of Agrost., Bul. 22, I900.

Nelson, Elias E. Native and Introduced Saltbushes. Wyo. Agr. Exp. Sta. Bul. 63, I904.

Sampson, Arthur W. Climate and Plant Growth in Certain Vegetative Associations. U. S. Dept. of Agr. Bul. 700, r9r 8.

Important Range Plants: Their Life History and Forage Value. U. S. Dept. of Agr. Bul. 545, I9r 7 .

Natural Revegetation of Range Lands Based upon Growth Requirements and Life History of the Vegetation. U. S. Dept. of Agr., Jour. of Agr. Research, Vol. 3, No. 2, I9I4. 
Sampson, Arthur W. Plant Succession in Relation to Range Management. U. S. Dept. of Agr. Bul. 79I, I9I9.

Range Improvement by Deferred and Rotation Grazing. U. S. Dept. of Agr. Bul. 34, I9r3.

Scribner, F. Lamson-. Economic Grasses. U. S. Dept. of Agr., Div. of Agrost., Bul. 14, I900.

Smпth, J. G. Forage Conditions of the Prairie Region. U. S. Dept. of Agr. Yearbook, I895.

Grazing Problems in the Southwest and How to Meet Them. U. S. Dept. of Agr., Div. of Agrost., Bul. I6, r899.

Thornber, J. J. Alfilaria as a Forage Plant in Arizona. Ariz. Agr. Exp. Sta. Bul. 52, I906.

The Grazing Ranges of Arizona. Ariz. Agr. Exp. Sta. Bul. 65, rgro.

Wooton, E. O. Carrying Capacity of Grazing Ranges in Southern Arizona. U. S. Dept. of Agr. Bul. 367, r9i6.

Factors Affecting Range Management in New Mexico. U. S. Dept. of Agr. Bul. 2I I, r9I 5 . 


\section{CHAPTER V}

\section{IMPROVEMENT AND MANAGEMENT OF FARM PASTURES}

"Show me your pasture and I'll tell you what figures you may place on the note." Thus concluded the country banker to the stockman-farmer who was soliciting funds to be used in the spring planting. The financier was himself a successful farmer, and the correctness of his logic cannot be denied, for good pasture is everywhere concomitant with sound management of the farm as a whole.

Without ample pasture feed of good quality it is quite as impossible to succeed in the production of meats and dairy products as it is to maintain economically the fertility of the soil. The highest type of agriculture is invariably found in those regions where pasture crops and livestock are prominent. A good pasture is an asset and credit to any farm; a poor one may be a distinct liability, and it is a reflection on the owner.

Of the millions of acres of farm pasture lands in the United States, by far the greater portion consists of areas inferior in quality to those under tillage. This, to be sure, is a natural condition. In the settlement of any country the most easily tilled and readily accessible lands - those upon which manual labor is to be expended - are the first to grow the wheat, barley, and corn, and contribute to the bread supply of the nation. The poorly drained portion, or the remote "forty" with a few clumps of willows or other rank-growing vegetation, is selected for the pasture. The possibilities of improvement of such lands are practically unlimited. Drainage alone, for instance, may result in completely replacing a rank, unpalatable cover by edible vegetation; or, indeed, the proper stocking of the lands may so improve their crop production that these "outcast 
acres " may make as good a return as do the higher-priced tilled lands.

What is Good Pasture? - A first-class pasture furnishes the cheapest means of growing livestock. Grazing provides a way of utilizing the feed on the cheaper lands which otherwise could not be harvested. Often the older, properly managed pastures are the most profitable acres on the farm, as the labor cost of pasture management is very low. An acre of good pasture may yield 200 to 450 pounds of prime beef per season.

When the value of pasture land is estimated, the yield per unit of surface, or of a type, is often considered without special reference to the palatability and quality of the vegetation. Generally the quality of the feed is quite as important as is the yield per acre.

The true value of a pasture is best based on its ability to produce mutton, beef, milk, or other animal products. It is desirable, though difficult, to ascertain the "net available nutrients " produced per acre or for the pasture as a whole. Some of the points to be considered in judging the value of a pasture are:

(I) Density, palatability, and digestibility of the plant cover and the permanency of the stand. The density, palatability, and digestibility factors determine the amount and nutrient value of the forage relished by stock. Permanency of the cover has to do with the character of the vegetation, whether it consists of a long-lived hardy perennial cover like Kentucky bluegrass, of biennial forms like sweet clover, or of annual plants such as rape or millet.

(2) Distance the animals must travel to obtain food and water. Animals in high condition of flesh, or those producing an abundance of milk, are not found where they must travel far for food and water any more than they are seen on lean pastures.

(3) The earliness of the feed and its ability to carry the stock through the normal grazing season. The time at which the different forms of plant life begin growth in the spring varies appreciably and often determines the time at which the forage is available for spring grazing. Sodgrasses, though not neces- 
sarily the first to resume growth, withstand early grazing much better than do bunchgrasses. Accordingly, the former are less fluctuating in their yield from year to year than are other forms.

Certain conditions of environment favor the production of a large amount of forage of good quality. A fertile soil, ample moisture, and favorable temperatures are essential to large forage production. Alluvial soils are highly esteemed as pasture land. Certain forage species are much more susceptible to low temperatures or frosts than are others, and their palatability and nutritiousness may change appreciably as the season advances. It is important that a pasture plant shall remain palatable and nutritious after growth has ceased.

Kinds of Pasture. - Pastures are classified as annual, temporary, or permanent, according to the nature of the plant cover and the use made of the lands.

An annual pasture supports vegetation that endures for but one season and is designed to carry stock for such a period only. Annual forage crops are almost invariably cropped before the seed matures. They may furnish feed throughout the growing season or for only a part of it.

A temporary pasture may be sown to annual or short-lived perennial plants. It is used as pasture for more than one season but seldom for several years in succession.

A permanent pasture supports perennial vegetation, which, with a favorable environment, is used for foraging purposes for many years in succession. Sodgrasses are the most desirable, as a good turf does not permit weeds to gain much headway. The forage yield of sodgrasses is usually heavy, and in the humid regions such a cover is not readily injured by early or close grazing. Moreover, because of the mass of ramifying roots, a large proportion of which each year enters into the formation of humus, the fertility of the soil is fairly well maintained. Kentucky bluegrass, redtop, and Hungarian bromegrass are good examples of a desirable permanent sod cover. Less enduring are pastures of timothy, orchardgrass, and red clover.

Why Pastures "Run Out." - Farmers from all sections of the country are asking why pastures deteriorate. The answer 
to the question is not the same everywhere, for various factors may cause a decline in the yield of forage. A declining yield may be due to an excessive amount of weeds, to abnormal climate, to bad handling of the stock, or to various allied conditions.

Natural succession, or a normal tendency in nature to a rotation of crops, as on timberlands, is going on all the time. As choke cherry or aspen are the natural invaders of a cut-over or burned fir type, so useless weeds may occupy grasslands if no effort is made to check them.

Abnormal changes in autumn or winter weather, alternate freezing and thawing, and exposure due to the absence of the usual blanket of snow are injurious to many forms of grasses and other vegetation.

Drought injures forage plants to a very considerable extent. A sudden decline in the water content of the soil may cause the vegetation to wilt beyond recovery with the root system quite intact, or the soil may break and crack and tear the roots asunder. Deep-rooted grasses are usually less liable to injury from drought than are shallow-rooted forms.

Faulty methods of grazing, as pointed out, may seriously thin the stand, particularly of bunchgrass vegetation. The plants are sometimes literally starved to death by too early or close cropping. Then, too, excessively close grazing in the fall destroys the protection otherwise afforded by the forage during the winter. Furthermore, injudicious grazing may change the texture of the soil through heavy packing. The crop-producing power of heavily packed soils falls rapidly until those soils practically cease to support plant life.

Growth Forms of Pasture and Hay Plants. - The habit of growth of the underground parts makes possible a division of forage plants into two distinct forms. Those that spread by rootstocks or rhizomes and form a continuous, more or less extensive sod, like Kentucky bluegrass, are the most desirable and are largely confined to the humid and semi-humid regions. Those whose growth is confined to a tuft or bunch, like slender wheatgrass, and whose perpetuation and spread is dependent 
on seed, are most common in the arid regions. Many cultivated forms, like orchardgrass, also have this habit of growth. The sod forms spread much more rapidly than do those of the bunch habit of growth. The form of growth is determined by the way the new stems or branches develop.

In bunchgrasses the root stems, or " tillers," which originate a short distance below the surface of the soil, grow up inside of the leaf sheath (Fig. 25). In sodgrasses the end of the new branch forces its way through the base of the leaf sheath and spreads to varying distances before coming up. At the point where it ascends a number of anchor and feeding roots usually form (Fig. 26).

In certain humid regions well-established sod pastures are often grazed early and repeatedly year after year without apparent damage; but such repeated grazing of a bunchgrass pasture soon causes its destruction.

The life period of forage plants is not well known. Most perennial grasses in favorable environment are long-lived, but the same species under rigorous conditions may live but a short time. In the Northwest the yield of timothy usually declines sharply after the fifth or sixth year. If, however, a suitable fertilizer is added, timothy may yield satisfactorily for twice that period. A sod cover may endure for a hundred years or more; but, as the stand is continuously renewed by plants originating from the rootstocks or stolons, the entire stand is rejuvenated from time to time.

\section{HOW THE FARMER MAY IMPROVE THE PASTURE}

In some countries the real brains of the farm are devoted to pasture management. While a permanent pasture may continue to produce for many years, it is doubtful if any tillage system requires more careful attention or provision than does the continuous production of a highly nutritious, heavy-yielding forage crop. Choice forage should occupy the entire pasture. Land values are now too high for only a portion of the pasture vegetation to be of use as forage.

Unfortunately, very little experimental work has hitherto 


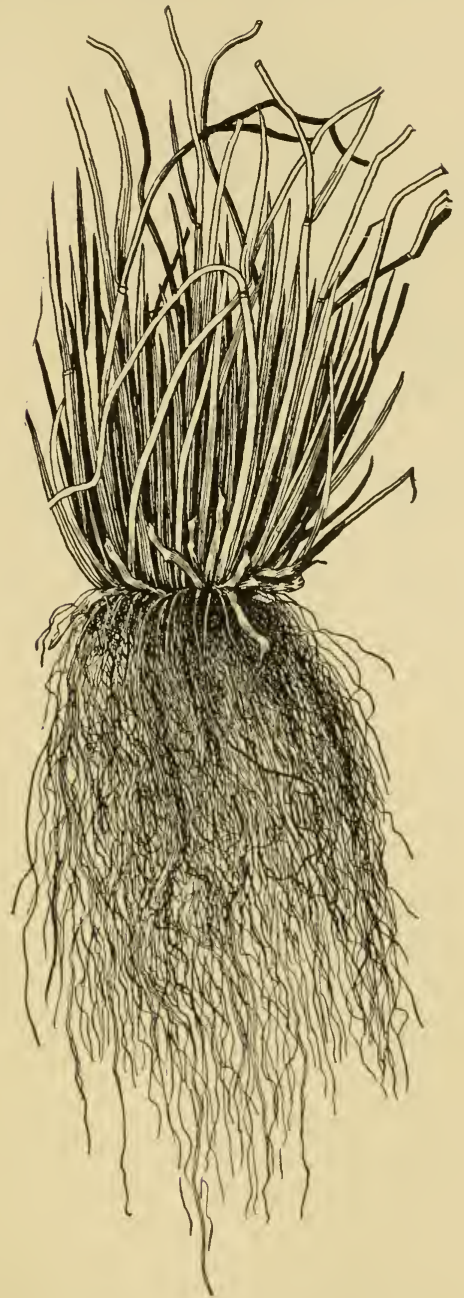

FIG. 25. - A TYPICAL FORM OF BUNCHGRASS.

As the root stems go up inside of the leaf sheath, the roots and basal leaf blades are densely "bunched." 


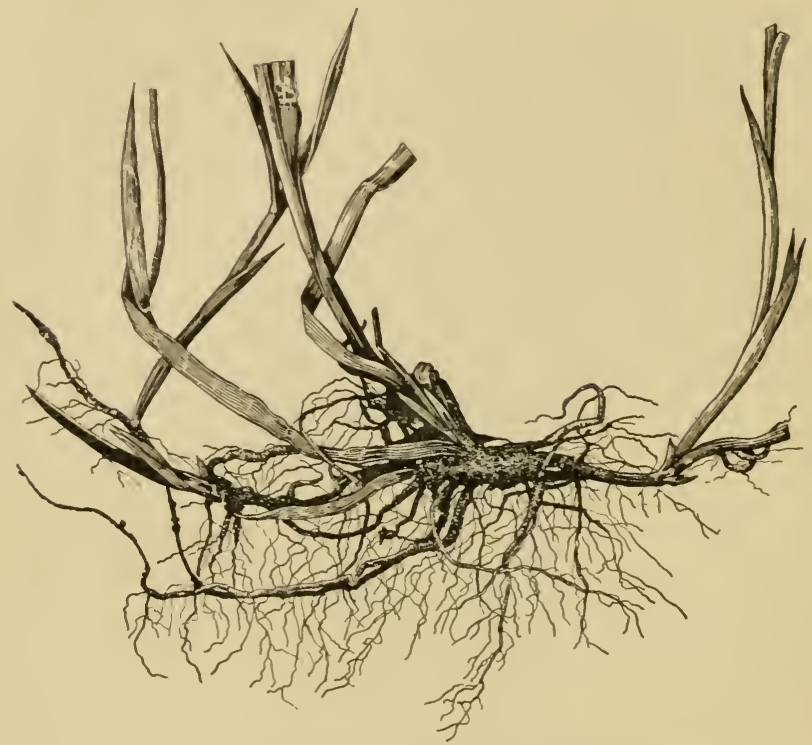

Fig. 26. - A TYPICAL FORM OF SODGRASS.

Because the forming branches force their way through the base of the leaf sheath and grow to a considerable length before turning upward, the stems and leaf blades are often quite remote from the original point of growth.

been done over the pasture region as a whole upon which pasturemanagement plans may safely be based. For this reason the grazing systems ordinarily proposed are largely theoretical. So-called "blanket" recommendations, alleged to apply to all regions, types of vegetation. soils, and climatic conditions, have been made. Often these are liable to be erroneous rather than constructive. The following statements, taken from the current literature on pasture management, are typical of what the farmer is told to do.

I. Let the grass head out before turning stock on it in the spring.

2. Do not let the grass grow tall and get tough before grazing it in the spring. 
3. The kind of plants in the pasture has much to do with its value.

4. There is no relation between botanical composition of the herbage of a pasture and its feeding value.

5. Disk the pasture.

6. There is no need of harrowing the pasture as the ground is pulverized by the grazing of the stock.

7. Keep the weeds out by grazing the pasture with sheep.

8. Sheep should not be used on grassland to destroy weeds, for their sharp noses permit them to seek out and destroy the young sprouting grass.

9. Maintain the productivity of the pasture by applying a top dressing of manure and fertilizers.

Io. Permanent pastures are kept productive because of the droppings from the animals grazed.

II. Reseed the pasture to sod grasses and clovers.

I2. Allow the plants to go to seed in order that the stand may be maintained.

In view of the conflicting directions offered, it is not surprising that the grazing capacity of many a farm paddock is declining sharply. Especially is this true where the sodgrasses do not grow. As a field for investigation, few lines of farm research offer greater possibilities of service than does that of the farm pasture.

It is the aim in the following pages to point out methods of improvement which have been thoroughly tested in practice and are known to be safe.

Management of Bluegrass Pastures. - East of the Great Plains, north of Arkansas and North Carolina, and southward in the cooler mountains, Kentucky bluegrass, sometimes called Junegrass, is the pasture plant par excellence. It is an aggressive species in favorable soils and climate, where it usually forms a complete sod.

Carrier and Oakley, working at the Virginia Station, ${ }^{1}$ conducted fundamental investigations relative to methods of cropping and treating representative selected pasture lots. The plan of study was based on the prevailing practices of farmers of the State and made use of methods developed by the investigators themselves.

1 Carrier, Lyman, and Oakley, R. A., "The Management of Bluegrass Pastures." Va. Agr. Exp. Sta. Bul. 204, I914. 
One pasture was disked once each spring with an ordinary disk harrow. As a check a similar pasture was untreated. The animals were kept in one pasture at a time and every ten days they were changed from one field to the other.

Another area was disked with the ordinary disk harrow, whereas the adjoining area was untreated. The animals grazed were likewise alternated every ten days from the one field to the other.

Still another pasture lot was both disked and harrowed, the treatment being somewhat severe. An untreated field served as a check, and the animals grazed were alternated from the one enclosure to the other every twenty days.

Two paddocks were not treated. These plots were grazed continuously throughout the summer, but the one was cropped from two to three times more heavily than the other.

Additional small plots were established from which the herbage was removed by cutting with a lawn mower, and the dry weight of the harvest was recorded. These plots were harrowed or otherwise treated to correspond more or less with the treatment of the pastured areas.

Alternate versus Continuous Grazing. - Carrier and Oakley point out that the division of pastures with a view to giving each part a rest by alternate cropping during the growing season has long been recommended as a means of increasing their grazing capacity. That such a system works out satisfactorily on bunchgrass lands in the far West has been clearly demonstrated by the writer; ${ }^{1}$ but these findings do not at all prove what may be the results on sodland pastures.

Carrier and Oakley found only a slight difference in the forage yield on bluegrass pasture. They conclude:

While the results of these three years will not settle the question of alternate or continuous grazing for all time, nor for all conditions, they at least show very clearly that the unqualified recommendation of alternate grazing is not justified. We even believe that they strongly indicate the slight value of this method in solving the present pasture problems of Virginia.

1 Sampson, Arthur W., "Range Improvement by Deferred and Rotation Grazing." U. S. Dept. of Agr. Bul. 34, 1913. 
Disking and Harrowing. - Sodgrasses often decline in yield when the surface of the sod becomes tightly bound. Several factors may be responsible for this decline. Generally, however, the growth of the vegetation is held in check because of root competition, the roots in the upper few inches of soil being overcrowded. Moreover, where the soil is deficient in lime the decaying roots may bring about acidity. This is indicated by the presence of moss and other weeds that are adapted to acid lands. Harrowing or otherwise breaking up the tightly bound sod may therefore be beneficial, if for no other reason than that of aërating the soil and improving its physical properties.

The investigators found only a very slight difference in the yield of the disked or harrowed areas as compared with those untreated. On the whole, the cost of the treatment was not justified on the basis of the increase in the yield. Disking or harrowing, no matter how carefully done, tore or cut the sod to some extent. On the other hand, the cultural treatment was found advantageous in that it broke up and distributed the droppings from the animals grazed. This is the statement of Carrier and Oakley:

The indiscriminate recommendation of cultural treatment of pastures is a serious mistake. The experiments at Blacksburg, as a whole, do not necessarily prove the futility of such treatment, but the critical observations made throughout the five years leave no doubt that cultural treatment, by almost any means, must be conducted with care and judgment. In view of the results of its investigations, the Experiment Station cannot at the present time recommend cultural treatment of pastures to the farmer.

Light versus Heavy Grazing. - Overgrazing is without doubt the chief cause of the depletion of bunchgrass or other nonsodded lands. So convincing is this belief over the devastated grazing grounds of the far West that it is commonly accepted as holding generally for bluegrass and other sod pastures. The studies at the Virginia Station, however, emphasize the danger of applying the results of treating one form of plant growth to a very different type.

Comparatively close grazing of well-established bluegrass pasture resulted in the production of many more pounds of beef 
per acre than was produced from the lightly cropped paddock. Furthermore, at the end of the three years' test the sod on the closely grazed area was in much better condition, and there were fewer weeds, than where light grazing was practiced.

The results reported may apply to most bluegrass and possibly to other sodgrass areas, but before generalizations may safely be made the test should be extended to other States and to varied conditions. Quite different results from those recorded would be obtained on bunchgrass lands.

Management of Nonsod Pastures. - Overgrazing is the rule rather than the exception on pastures in which the predominating growth is bunchgrass or such other herbaceous vegetation as does not form a sod.

Number of Stock to Graze. - It is difficult to estimate accurately the number of animals a given pasture will safely carry

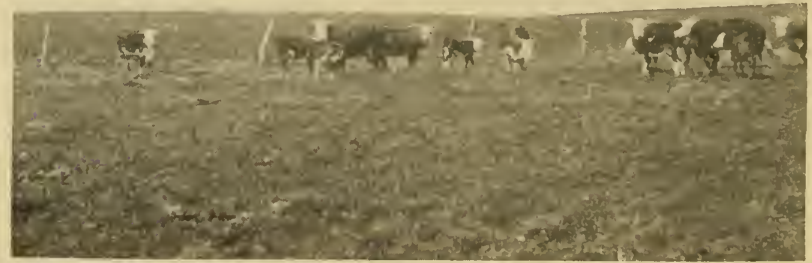

Fig. 27. - A FARM PASTURE IN GOOD CONDITION.

For many years in succession this pasture has been grazed on the basis of one cow and her calf to the acre for six and one-half months.

season after season. Unless one knows approximately how many animals the area has supported in good condition in the past, it is best at the outset to decide on a figure somewhat below what one would expect the area to support in the more favorable seasons (Fig. 27). However, there are exceptions to this statement. For example, very cheap gains may be made by feeding a fairly heavy grain ration to "baby" beeves or steers on 
pasture. More animals may be grazed where forced pasture feeding is practiced in the forepart of the season than the pasture will support throughout the entire grazing period. Accordingly, before the grass is closely cropped - say by July I the "fatted calf" has arrived at the packing house. The pasture may then be allowed to rest for two or three weeks, after which it may be grazed closely, but not destructively, by a new bunch of stocker cattle.

If it is not possible to dispose of part or all of the stock a few weeks after the grazing season begins, and so to give some rest to at least a portion of the pasture, one can not be too cautious in judging the number of stock the pasture will support without injury to the vegetation.

It has been pointed out elsewhere that a young pasture plant needs its green herbage in the spring of the year with which to accumulate food and strength in order to develop normally. Provided the welfare of the plant early in the spring is not overlooked, the plant will not be weakened by moderate grazing later. If, however, the grazing is fairly heavy year after year, the vegetation will require at least a short rest during the growing season. The need of rest will make itself apparent in several ways, as in a delay in the beginning of growth in the spring, lessened foliage production, decrease in stature of the plant, delay in the time of seed maturity, and in a failure to produce a large and fertile seed crop.

Deferred Grazing. - When the more highly relished and desirable nonsodforming pasture plants are not functioning normally, they should be given the required rest. From investigations reported in Chapter IV, it is learned that this can be accomplished without the discontinuance of grazing or without even decreasing the number of stock that this type of pasture will normally support throughout the season. Because of the value of the deferred-grazing plan, a simple example is restated here. The plan corresponds to that reported for use on western grazing lands where bunchgrasses prevail and is recommended only for lands that support vegetation of similar growth habits. 
Let it be assumed that the depleted pasture consists of $\mathrm{I}_{50}$ acres. If watering facilities will permit, it is proposed that the pasture be divided by fencing into three 50-acre tracts. Each enclosure will be grazed during the season, but not simultaneously. If enclosure No. 3 is the most seriously depleted, and No. I is in the best condition, the latter would be grazed first in the spring, No. 2 second, and No. 3 last, but not until the seed of most of the vegetation has reached maturity. Most plants mature their seed early enough in the season so that ample time remains to graze the herbage thereafter. The following season the grazing of the enclosures should be in the same order as the first year, as this arrangement permits the seedlings on area No. 3 to become well established before cropping. The plan of deferred and rotation grazing to be pursued annually follows:

\begin{tabular}{l|l|l}
\hline \multicolumn{1}{c|}{ Area No. I to be grazed } & Area No. 2 to be grazed & Area No. 3 to be grazed \\
\hline Spring, I92I & & \\
\cline { 2 - 3 } Spring, I922 & Summer, I92I & Autumn, I92I \\
Summer, I923 & Summer, I922 & Autumn, 1922 \\
Summer, I924 & Autumn, I923 & Spring, I923 \\
Autumn, I925 & Autumn, I924 & Spring, I924 \\
Autumn, I926 & Spring, I925 & Summer, I925 \\
& Spring, I926 & Summer, I926 \\
\hline
\end{tabular}

After the whole pasture is restocked, the rotation grazing should be continued in order to keep the vegetation physiologically strong at all times.

The grazing system here proposed will usually increase the carrying capacity of bunchgrass pastures without decreasing the number of stock grazed before the partition fences were built. On many western ranges an increase of 50 to more than 200 per cent in the carrying capacity has been obtained within three seasons of such deferred grazing.

Fertilizers for Pasture and Grassland. - Once a grass area is well established, it is seldom given much care or treatment. Grasslands, however, often respond remarkably well to fertilizers, the growth being rapid and the yield large. Pastures can not be expected to maintain their yield permanently unless 
a portion of the plant foods removed by the growing crop is replaced occasionally, for the production and removal of flesh, bone, milk, and wool will sooner or later reduce the supply of plant food in the soil.

If the soil is acid, this condition must first of all be corrected by the addition of lime; otherwise fertilizers will do little good. Acid soils are common in the Northern States, and in Pennsylvania and Ohio. If the rest of the farm needs liming, so do the pasture and other grass areas - possibly more than do the cultivated fields. But before applying lime one should be sure that he is making no mistake. Do the clovers grow well there? If so, there is already enough or nearly enough lime. Is moss or other vegetation common to acid soils appearing? If so, lime is needed. Invariably the famous pasture regions of the world are on soils that contain an abundance of lime. Good results from the application of fertilizers and manure presuppose a dense grass growth, an abundance of feeding roots, and a sweet soil.

Kinds of Fertilizers and Amounts to Apply. - Nitrogen and phosphate are the essential ingredients of fertilizers for grasslands. Of less importance generally is potash.

The need for nitrogen in the soil is indicated by the leaf blades taking on a yellow-green cast. Phosphate is often required on pasture lands and in soils that have long been cultivated. Lands east of the Mississippi, in the South, and in the middle West are often quite as deficient in phosphate as in nitrogen. Potash, on the other hand, is abundant in most soils; but because of its being only slightly soluble the application of it does not always appreciably increase the yield.

In correcting acidity and improving the tilth of the soil, common ground limestone, unburned, is used. From 2 to 10 or more tons to the acre is applied. In Europe basic slag, which is rich in lime and phosphate, is popular. Along the Atlantic seaboard basic slag is used to advantage, but for the interior States its use is impracticable because of the high transportation charges.

For top-dressing, a fertilizer must be readily soluble, or it 
will do little good. Thus, where nitrogen is needed, sodium nitrate and dried blood are best; for phosphate, treated bone and acid phosphate are reliable; and for potash and nitrogen, potassium nitrate is recommended.

It is best to determine by experiment the amount of fertilizer to be applied. The minimum amount of sodium nitrate and acid phosphate to use is roo pounds and 75 pounds per acre, respectively. The minimum amount should be used first, but a larger amount - up to 200 pounds of sodium nitrate and I 50 pounds of acid phosphate - should be tried out on a small area to determine if such application is a paying proposition.

The use of a complete fertilizer is generally recommended. This necessitates the use of potash (muriate of potash) in addition to that of sodium nitrate and acid phosphate. The minimum application of muriate of potash is 25 pounds, and the maximum is 50 pounds.

Fertilizers should be applied in the spring, preferably a week or two after growth starts. The fertilizers should be thoroughly mixed and distributed uniformly over the land.

The top-dressing of pastures with stable manures pays well - often better than on any other land on the farm. Some contend that stock do not crop the forage with relish where manure has been applied. Often the opposite effect is observed, as the grass is more succulent and tender on the manured land. In manuring pastures one rule should not be overlooked: Sheep manure should not be put on sheep pasture, for it may contain stomach worms or other parasites peculiarly injurious to sheep.

One of the best ways to maintain the fertility of pastures is to fatten cattle or sheep on the land, feeding the concentrates as well as the hay and fodder on it. Stock, however, should not be kept on the pasture when the soil is soft and wet, as it often is early in the spring.

The Eternal Battle with Weeds. - The annual growth of weeds on pastures in the United States is enormous. No phase of pasture management needs more serious consideration than does that of weed control. Weeds crowd out the growing palatable crop and keep its development in check. In twelve weeks 
of summer weather some of our choicest pasture plants give off as much as twenty times their own weight in water. Many weeds are equally heavy users of water and mineral matter, both so essential to the proper development of the grass crop. A strong invasion of the pasture by weeds indicates mismanagement of the paddock in some particular. As a rule a heavy weed cover indicates a depleted soil (Fig. 28).

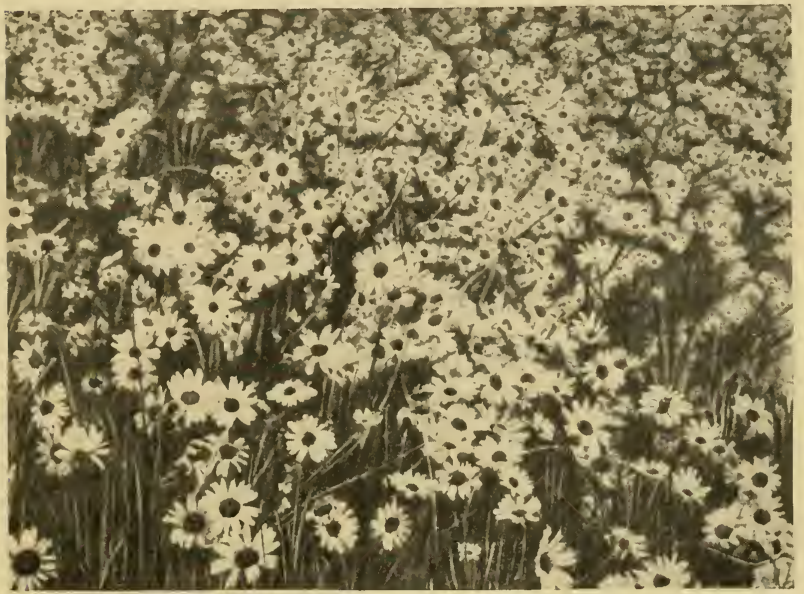

Fig. 28. - INVASION OF A FARM PASTURE BY UNPALATABLE ASTERS, RELIABLE INDICATOR PLANTS OF A DECLINING FORAGE YIELD.

It is highly important to mow the pasture once, or better still, two or three times during the summer, before the weeds ripen their seeds. The work should be done thoroughly, with the use of a mowing machine. The mowing machine should be set to run moderately high, in order not to cut too much of the grass feed. In some pastures this will necessitate some cleaning up and clearing, which in itself makes for better pasture. Mowing prevents the weeds from spreading. It conserves the moisture and mineral matter of the soil for the grass crop, and 
it improves the grazing by rendering the crop of palatable plants more readily available.

Even more desirable than the use of the mower is mixed grazing, as it affords clean, even cropping of the entire pasture. It is a good practice to graze cattle, sheep, and horses in the pasture together. Each class of animals has its choice of feed, the result being that few weeds remain, and the whole pasture is utilized evenly.

Where weeds are a serious pest a top-dressing of a suitable fertilizer should be applied to the pasture. Winter feeding on the poorer spots is also an effective means of improving the grass stand. Where the grass cover is thin or contains denuded spots it should be seeded to the plant or plants known to be adapted to the community. It is well to disk or harrow such areas after the seed is scattered.

\section{QUESTIONS}

1. (a) How are pastures generally classified? (b) Distinguish between an annual and a permanent pasture.

2. Name three factors that determine the value of a pasture.

3. Name and discuss briefly three factors that cause pastures to "run out."

4. Why is it unsafe to recommend the same treatment for the improvement and maintenance of pastures irrespective of their geographic situation?

5. Discuss the results on bluegrass pastures in Virginia with respect to (a) disking, (b) disking and harrowing, (c) lack of cultural treatment, $(d)$ alternate versus continuous grazing, and (e) light versus heavy grazing.

6. Why do not bunchgrass pastures respond satisfactorily to the same grazing practices as pastures that support sod vegetation?

7. How would you determine the number of stock that a pasture may support in good condition throughout the grazing season?

8. On what type of pasture may deferred grazing be expected to give good results?

9. Does it pay to apply fertilizers to pasture lands? If so, what kinds? What amounts should be applied?

10. Why is it unsafe to put sheep manure on sheep pasture?

11. (a) How may the weed pest be controlled in pastures? (b) Under what conditions may cattle, sheep, and horses be grazed together with good results to both stock and pasture? 


\section{BIBLIOGRAPHY}

Carrier, Lyman, and OAkley, R. A. The Management of Bluegrass Pastures. Va. Agr. Exp. Sta. Bul. 204, I9I4.

Hiтснсоск, A. S. Manual of Farm Grasses. Published by the Author, Wash., D. C., I92I.

Hunt, Thomas F. The Cereals in America. Orange Judd Co., N. Y., 1904 .

Kennedy, P. B. Coöperative Experiments with Grasses and Forage Plants. U. S. Dept. of Agr., Div. of Agrost., Bul. 22, I900.

Montgomery, E. G. Productive Farm Crops. J. B. Lippincott Co., Phila., I9r5.

Robbins, Wilfred W. The Botany of Crop Plants. P. Blakiston's Son \& Co., Phila., r9r7.

Sampson, Arthur W. Plant Succession in Relation to Range Management. U. S. Dept. of Agr. Bul. 79r, igr9.

Range Improvement by Deferred and Rotation Grazing. U. S. Dept. of Agr. Bul. 34, I9I3.

The Reseeding of Depleted Grazing Lands to Cultivated Forage Plants. U. S. Dept. of Agr. Bul. 4, r9r3.

Spillman, William J. Farm Grasses of the United States. Orange Judd Co., N. Y., I905. 


\section{CHAPTER VI}

\section{RECOGNIZING AND CORRECTING A DECLINING FORAGE YIELD}

Every plant, whether one of forage value, a noxious weed, or a tree in the deep woods, tells the story of the conditions under which it grows. The rate and luxuriance of its growth and its ability to reproduce are a measure of its response to the particular climate and soil, and indeed to such factors as grazing, competition with other plants, and the like, peculiar to its own little world.

The excellent results obtained on native western range lands through the use of the deferred and rotation grazing system show that plants need time for growth and repair; they must be given a fair chance if they are expected to take up food from the soil and air and convert it into forage. The serious decline in the grazing capacity of range and pasture lands practically everywhere may be traced almost wholly to a failure to recognize the requirements of plant growth.

\section{HOW DESTRUCTIVE GRAZING MAY BE RECOGNIZED}

Old or Empirical Method. - Destructive grazing can not, in fairness to the stockman, be charged entirely to his methods of pasturing. True, the lowered grazing capacity of the native pasture lands is due to faulty livestock management, but in the absence of scientific studies to determine the effects of overstocking the disastrous outcome could not be foretold. Until recently the grazier has had to base his judgment as to the condition of a pasture area on general observations. He has been guided solely by observing the abundance and luxuriance of the plant cover as a whole, and the condition of flesh of the animals grazed.

Any slight or gradual depletion of the forage crop can not be 
recognized by such general observations. Until the carrying capacity of a pasture has been materially reduced, the animals grazed generally come through the season in fair flesh. Likewise, until the plant cover as a whole has been opened up, or a large proportion of the more palatable plants actually killed, the factors responsible for the injury are not recognized. After such serious depletion many seasons of skillful management are required to reëstablish the original forage cover.

New or Scientific Method. - Because of the serious loss to the stockman and the usual injury to important watersheds resulting from destructive grazing, a finer measure than merely observing the density of the plant cover and the condition of the stock pastured must govern the grazing plans. From the viewpoint of proper utilization, the margin between what clearly constitutes overgrazing and what is clearly undergrazing must be reduced to a minimum.

The one reliable, indeed the only direct, scientific way of detecting pasture depletion in its early stages is by observing the succession of the conspicuous vegetation, that is, the replacement of one set or type of plants by another. ${ }^{1}$

Quite different plants occupy soils in the various stages of formation or depletion. Plant life began on the earth with very simple forms. In the early geological ages, largely because of the absence of a deep layer of soil, only simple plant forms or those of low development were in evidence. These forms, through the disintegration of the once consolidated rock, and the gradual accumulation of humus, in the course of time were supplanted by the more specialized forms of plant life. This process continued until the highest kinds of seed-bearing plants came to predominate. Generally it does not require much misuse of grazing lands to deplete the soil, expose the underlying rock, and degrade the vegetation to such an extent that only the lower uneconomical forms of plant life can exist.

If the highly palatable plants on pasture lands are so closely or repeatedly cropped as to weaken or actually kill them, they

1 Sampson, Arthur W., "Plant Succession in Relation to Range Management." U. S. Dept. of Agr. Bul. 79I, pp. I-7, I9I9 
are invariably replaced by certain temporary or short-lived species, corresponding, in a way, to the primitive plant forms, most of which are low or negligible in palatability and nutritiousness. Accordingly, the incoming species are reliable indicators of small departures in the grazing capacity of the pasture; they tell the true story as to whether the pasture is improving, declining, or merely " holding its own " in forage production.

The rate of the replacement of one set of plants by another is determined essentially by the soil texture, the moisture content of the soil, and the compactness of the soil. If the soil is rich in humus so that it may absorb and retain a large amount of moisture for plant growth, the lands will support a stable perennial type of vegetation. The forage yield of such a cover year after year is appreciably larger and less fluctuating than is that of annual or biennial plants, and is therefore the pasture type most desired.

Conspicuous Signs of Overgrazing. - Overgrazing for an extended period will invariably leave its signs of one kind or another. ${ }^{1}$ The accumulated damage may be recognized by the following conditions: (I) Erosion, barrenness, and deeply cut stock trails where the cover was formerly intact. (2) Remnants of dead shoots of palatable woody plants, such as birchleaf mahogany (Cercocarpus), willow (Salix), snowberry (Symphoricarpos), bitterbrush (Purshia), and serviceberry (Amelanchier). Where such shrub growth has been largely destroyed, most of the palatable grasses and weeds have long been killed out. (3) Damage to tree reproduction, including that of most coniferous species, as well as that of broad-leaved forms like aspens. (4) An increasing abundance of unpalatable or, indeed, poisonous plants, such as certain species of butterweed (Senecio), ${ }^{2}$ snakeweed (Gutierrezia), and sneezeweed (Helenium). Areas upon which an abundance of such vegetation grows need very careful management in order to prevent heavy livestock losses. (5) The predominance of annual weeds and short-lived un-

1 Jardine, James T., and Anderson, Mark, "Range Management on the National Forests." U. S. Dept. of Agr. Bul. 790, pp. I6-23, I9r9.

${ }^{2}$ A very few species of Senecio are highly palatable to stock. 
palatable perennials. The conspicuous presence of vegetation of this kind indicates severe overgrazing. It occurs characteristically on badly eroded areas and on long-used sheep trails and bed grounds. The indicators of overgrazing here enumerated are found on lands in the advanced stages of depletion.

Indicators of Slight Departures in Grazing Capacity. - A large number of plants that occur on range and pasture are valuable as indicators of the early or moderate stages of overgrazing. Two sets of plants, however, namely, those that are palatable to stock, and those that are known to occupy inferior soils, are the most reliable indicators. Overstocking or some other form of overgrazing is indicated whenever the highly palatable species are so closely cropped that their luxuriance of growth and ability to reproduce are impaired. The inferior plant forms, or those that characteristically inhabit eroded, heavily packed, or otherwise impaired soils, are valuable as indicators of moderate overgrazing, as well as of serious depletion, because they invariably appear as soon as the original cover of desirable plants is even slightly weakened or opened up. After the destruction of the palatable perennial plants, the annual or shortlived perennial weeds of the lower stage make their appearance. They reproduce abundantly and make good growth because of the larger share of water and light which they receive in the absence of the former cover.

Type Stages of Indicator Plants. - A careful classification of the vegetation up and down the scale of successional development into divisions which can readily be recognized justifies grouping herbaceous pasture vegetation into four stages. In his study of the application of the principles of plant succession to natural range reseeding in the Wasatch Mountains in central Utah, the author classified the developmental stages as follows: ${ }^{1}$ (I) Climax herbaceous stage (the wheatgrass cover); (2) mixed grass and weed stage (the porcupinegrass-yellowbrush cover);

1 Sampson, Arthur W., "Plant Succession in Relation to Range Management." U. S. Dept. of Agr. Bul. 79I, p. 7, I9r9. The principles developed in the investigations reported in this bulletin, covering about thirteen years of study in the West, are applicable to pasture lands generally, and hence are briefly reviewed here. 
(3) second or late weed stage (the foxglove-yarrow-sweet sage cover); (4) first or early weed stage (the annual weed cover).

Although the species concerned in this investigation are not the same everywhere, ${ }^{1}$ the character of growth and the habitat requirements of the plants of the different stages are the same on native pasture lands generally.

\section{CLIMAX HERBACEOUS STAGE}

The wheatgrasses (Agropyron) in the Wasatch Mountains, and generally over their natural range, constitute the climax or highest herbaceous cover. Both the "bunch" wheatgrasses and the turf-forming kinds are characteristic, but generally the bunchgrass forms distinctly predominate (Fig. 29). Usually between the tufts grows a considerable admixture of vegetation. The turf-forming wheatgrasses, on the other hand, usually make so dense a stand in their unhampered development as practically to exclude other plants.

Destruction of the Wheatgrass Cover. - The opening up, by destructive grazing or otherwise, of a well-established stand of wheatgrass immediately stimulates the invasion and establishment of both deep-rooted and shallow-rooted plants. Where the fertility of the soil is not appreciably impaired as a result of the depletion of the wheatgrass cover, yellowbrush (Chrysothamnus lanceolatus) and small porcupinegrass (Stipa minor) are among the first to gain a foothold. Where the tufted or "carpet" form of wheatgrass is permitted to revegetate, this cover again completely reoccupies the area, thus entirely replacing the yellowbrush and porcupinegrass. As shown in Figure 30 , this destruction of the more temporary invaders is due to the network of superficial wheatgrass roots. So completely do these roots occupy the soil that practically all of the available soil water is absorbed. and the soil below, with the deeper roots of the invading plants, like yellowbrush, is left in a state of dryness. Thus any vegetation whose main moistureabsorbing roots extend well below those of the turf-forming

${ }^{1}$ Clements, F. E., "Plant Indicators." Carnegie Institution of Washington, Publication 290, pp. 270-335, 1920. 


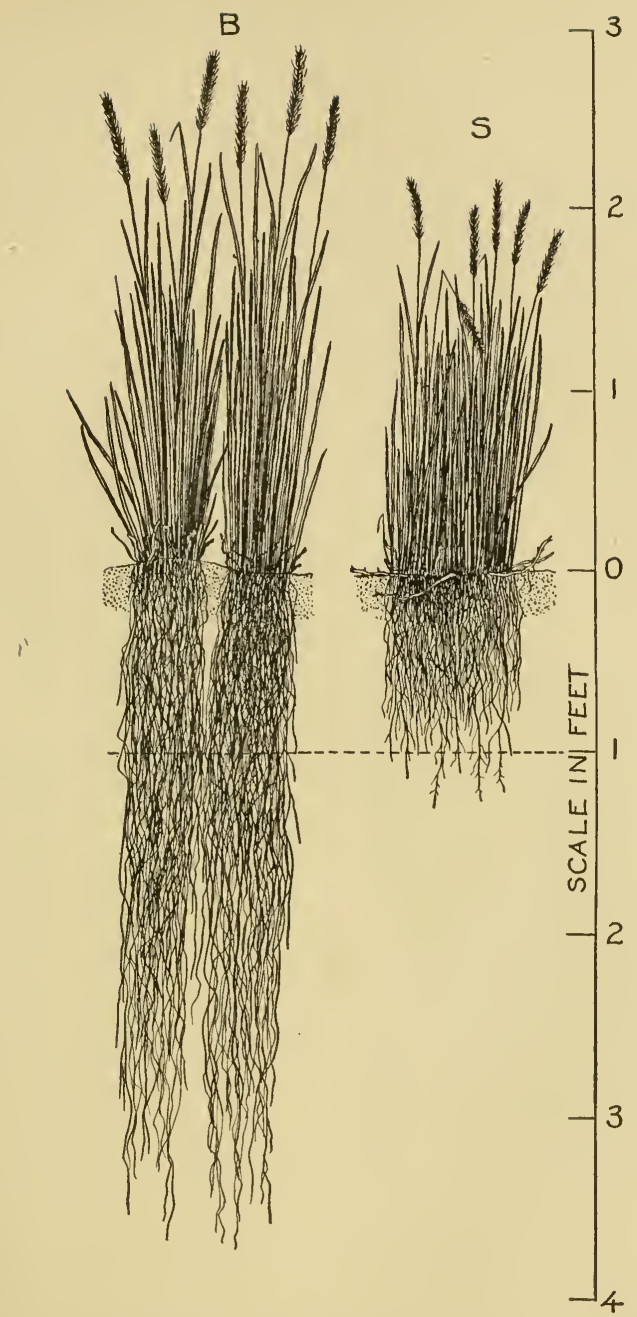

Fig. 29. - RELATIVE HEIGHT GROWTH AND CHARACTER OF ROOT SYSTEM OF TYPICAL WHEATGRASSES OF THE BUNCHED AND OF THE TURFED HABIT OF GROWTH.

B, blue bunch wheatgrass (Agropyron spicatum); S, small wheatgrass (Agropyron dasystachyum). 


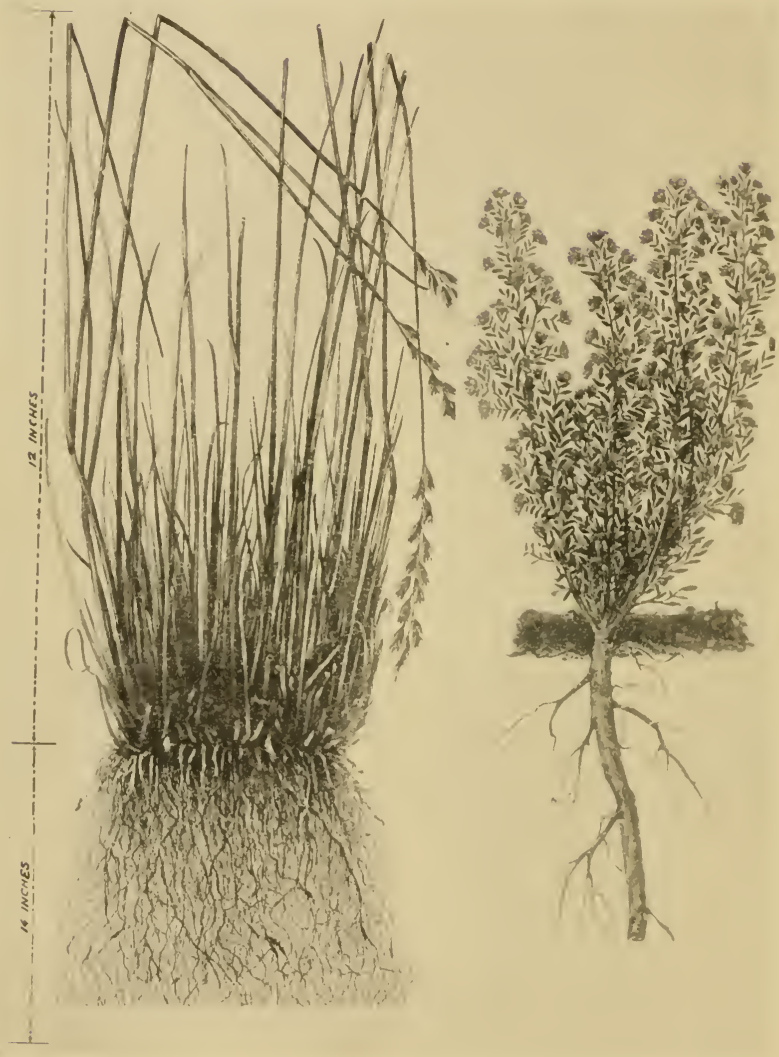

FIG. 30. - PORCUPINEGRASS AND YELLOIIBRUSH ARE THE DOMINANT SPECIES OF THE MINED GRASS AND IVEED STAGE.

They are the first plants to increase in abundance where the wheatgrass cover is declining slightly. 
wheatgrass, is soon killed out. On the bunch wheatgrass lands the invading yellowbrush and porcupinegrass are relatively persistent.

Forage Production. - The wheatgrass cover produces a large amount of forage which is especially well suited to the grazing of cattle and horses. Sheep and goats, however, make better returns on a mixed grass and broad-leaved herb cover, preferably where broadleaves predominate, than on a pure grass type. This statement, however, should not be interpreted to imply that on a highly developed grass cover overgrazing by sheep or goats is justified in order to increase the stand of broad-leaved plants. Such destructive cropping will seriously decrease the forage production of the land for the grazing of cattle and horses. After a few years of full utilization of the wheatgrass cover by cattle and horses, a considerable variety of plants usually appears, thereby increasing the value of the type for the grazing of sheep and goats.

\section{MIXED GRASS AND WEED STAGE}

This vegetative stage, next to the wheatgrass type, corlstitutes the highest and most stable cover. As indicated, where the wheatgrass cover is destroyed gradually, but where the fertility of the soil and its plant water content are not greatly decreased, porcupinegrass and yellowbrush (Fig. 3I) soon gain dominion of the area, and hence signify the waning of the wheatgrass cover. As a great variety of both deep-rooted and shallow-rooted plants makes up the vegetation of the porcupinegrass-yellowbrush type, it is popularly referred to as the "mixed grass and weed " stage. The highest development of this type is indicated by at least a scattered stand of wheatgrasses. A well-established porcupinegrass-yellowbrush cover usually also supports a goodly sprinkling of bluegrasses (Poa) and some fescuegrasses (Festuca). The gradual depletion of this vegetational stage is usually indicated by the invasion and establishment of bromegrasses (Bromus), not uncommonly by an increasing abundance of fescuegrasses, and several species of perennial broad-leaved herbs. Among these, foxgloves, notably 


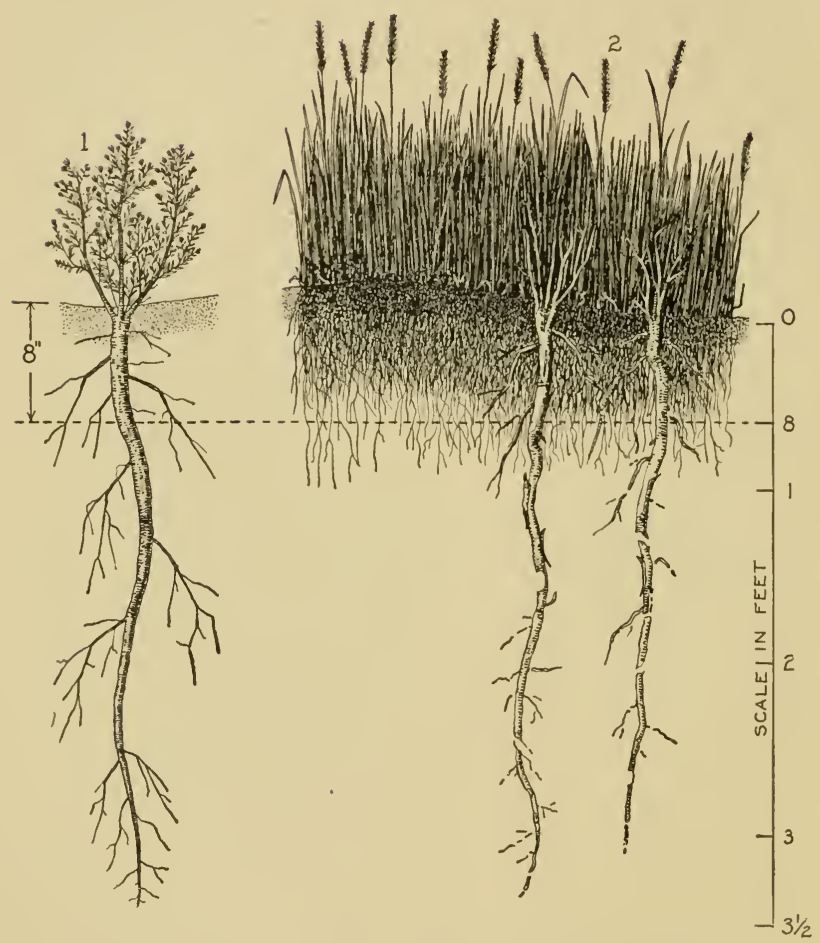

Fig. 3x. - SMALL WHEATGRASS IN COMPETITION WITH YELLOWBRUSH.

r, yellowbrush growing luxuriantly in the open; 2, transverse view of formerly overgrazed area of small wheatgrass where, following controlled grazing, the yellowbrush cover is being killed out by the revegetation of the original wheatgrass stand. 
turf-forming species like blue foxglove (Pentstemon procerus), yarrow (Achillea lanulosa), and sweet sage (Artemisia discolor) predominate.

Destruction of the Porcupinegrass-Yellowbrush Cover. - So long as the porcupinegrass-yellowbrush cover retains its density of stand, or, better still, if it is being replaced by the wheatgrasses, it is perfectly clear that the lands are not being misused. If, on the other hand, the type is being supplanted by bromegrass, or, more seriously still, by foxglove, sweet sage, and yarrow, or other plants of the second weed stage, there is indisputable evidence of the depletion of the area. In a short time the waning forage crop at this stage of depletion will be reflected in the condition of the stock grazed and in the increased erosion of the soil.

Forage Production. - Because of the large variety of palatable plants that are associated with the porcupinegrass-yellowbrush cover, this type in its highest stage of development is probably the most desirable, all classes of stock considered. Since the forage is composed of a mixture of grasses and weeds, with the former distinctly predominating, the highest grazing efficiency is usually obtained through "common use," that is, the combined grazing of cattle, horses, and sheep.

\section{SECOND OR LATE WEED STAGE}

Where unfavorable conditions for the growth of the porcupinegrass-yellowbrush cover have not been such as materially to lower the fertility of the soil, shallow-rooted but often turfforming perennial weeds of the early second weed stage are the natural successors. The most conspicuous and characteristic of these are blue foxglove, yarrow, and sweet sage (Fig. 32). On the other hand, where the porcupinegrass-yellowbrush cover is suddenly destroyed and a considerable portion of the upper dark soil is carried away, the vegetation consists chiefly of annual plants characteristic of the first or early weed stage.

A somewhat large number of species are associated with the foxglove-yarrow-sweet sage type, but they are usually secondary in abundance. They are mostly short-lived, broad-leaved 
perennial herbs. Many of these are entirely dependent upon seed for their reproduction.

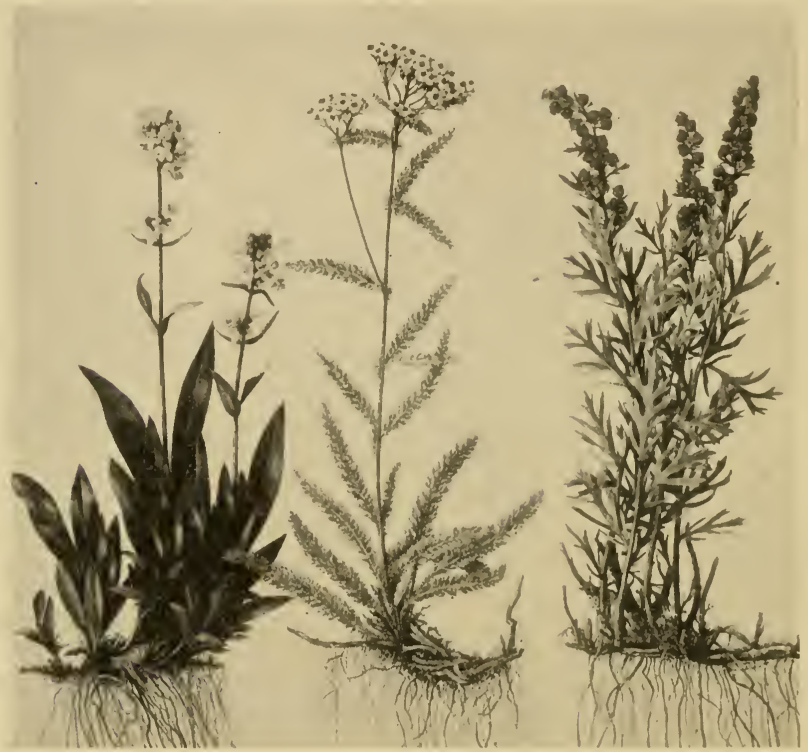

(Forest Service, under direction of the Author.)

Fig. 32, - DOMINANT PLANTS OF THE SECOND OR LATE WEED STAGE, SHOWING HABIT OF GROWTH.

From left to right, blue foxglove (Pentstemon procerus), yarrow (Achillea lanulosa), and sweet sage

(Artemisia discolor). Yarrow is the only one of the trio of any appreciable value as forage.

Destruction of the Foxglove-Sweet Sage-Yarrow Cover. Low peavine (Lathyrus leucanthus), evening primrose (Lavauxia flava), false cymopterus (Pseudocymopterus Tidestromii), Mexican dock (Rumex Mexicanus), and tongue-leaved violet (Viola linguaefolia) are the most reliable and characteristic indicators of the gradual destruction of the more palatable second weed stage cover. With the continued operation of the destructive factors, these relatively short-lived perennials are soon replaced by annual plants. 
Forage Production. - Considerably less forage, generally of an inferior type, is produced on lands in the late weed stage than on the wheatgrass or the porcupinegrass-yellowbrush covers. This is due chiefly to the large number of true (unpalatable) pasture weeds, the presence of poisonous plants, and the small amount of grass forage. Because sheep graze broad-leaved herbs more eagerly than do cattle and horses, the foxglove-yarrowsweet sage type is most economically utilized by the grazing of sheep alone. ${ }^{1}$ The gains sheep make on this type, however, are distinctly less than the gains produced on either of the higher types discussed. Cattle and horses do poorly on this weed type, and as a rule fail to maintain their weight.

\section{FIRST OR EARLY WEED STAGE}

Soils that contain little humus, or have been subject to heavy leaching, or are firmly packed, support virtually the same type of vegetation as badly eroded areas. The cover consists largely of nonpalatable annual weeds. This type is in evidence until enough organic matter has accumulated in the soil to favor the establishment of the second or late weed stage. Some of the more characteristic plants of the first weed stage are lamb'squarters (Chenopodium album), slender-leaved collomia (Collomia linearis), tansy mustard (Sophia incisa), Douglas knotweed (Polygonum Douglasii), and Tolmie's orthocarpus (Orthocarpus Tolmiei) (Fig. 33). These plants complete their cycle of growth in about six weeks after the sprouting of the seed. The seed is then disseminated and the cover dries up and disappears. The seed habits are invariably strong.

Forage Production. - Only a small amount of forage, and that of an inferior quality, is produced by plants of the first weed type. Although a considerable number of species are grazed in a limited way by sheep and goats, very few being palatable to cattle and horses, the type as a whole is well-nigh negligible as forage. Furthermore, this type must be grazed early in the season when the plants are young and succulent, for it is not

1 Sampson, Arthur W., "Bringing Back Overgrazed Range." Nat'l Wool Grower, Vol. Io, No. 4, pp. II, I2, April, I920. 
II6 RECOGNIZING AND CORRECTING DLCLINING FORAGE

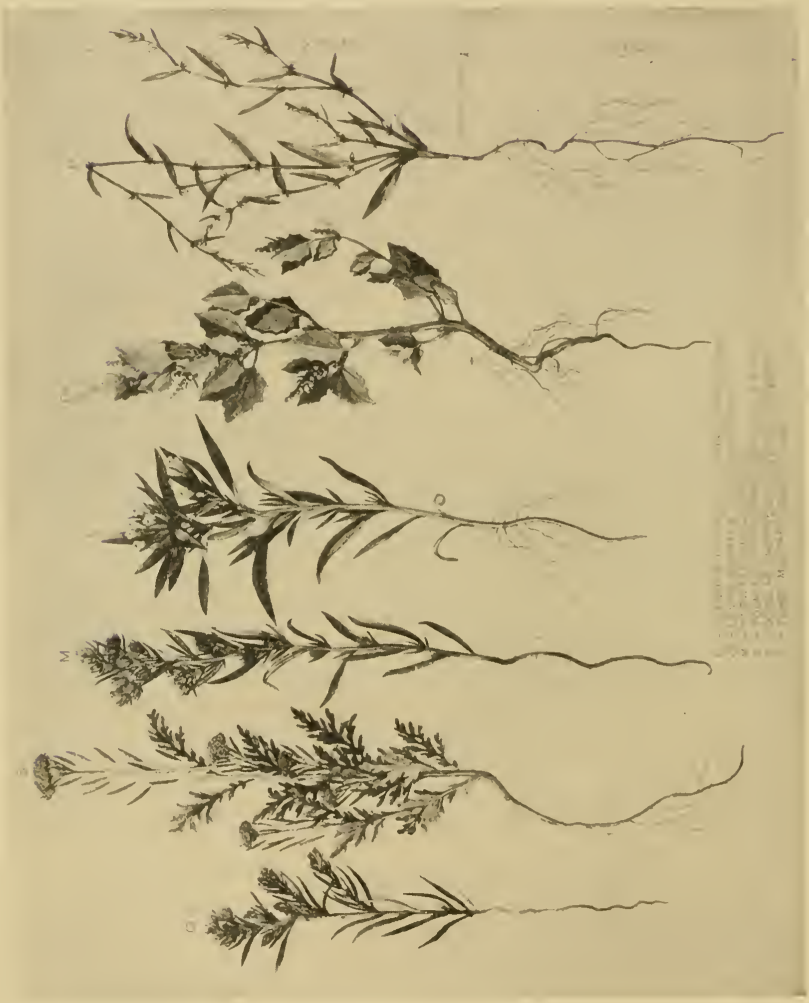

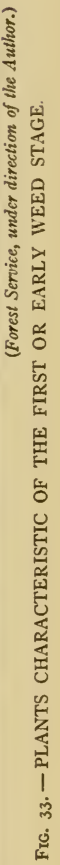


really relished even by sheep. Because of the attending difficulty of utilizing it early enough, much of the forage, poor though it be, is lost each year. Then, too, on account of the restricted taproots of the conspicuous vegetation and the heavy erosion to which the lands are subjected in the absence of an abundance of soil-binding roots, it is essential that stock grazing upon this type be handled in a most careful manner. If serious erosion is to be prevented, the lands should be cropped very little, or better still, not at all, until a good scattering of the second weed stage vegetation has gained dominion over the soil.

\section{EFFECT OF GRAZING ON THE DEVELOPMENT OF VEGETATION}

The statements as to the depletion of the different plant stages make clear the fact that grazing may either retard or promote the development of the plant cover and cause what plant ecologists term vegetative degeneration or progression. The highest grazing efficiency consists in taking the largest amount of forage from a pasture year after year. Therefore any system of pasture management which is responsible for a decline in the forage crop from season to season is destructive. If such a practice is persisted in, the ground cover is soon destroyed, and this condition sooner or later is followed by erosion in one form or another.

A typical case depicting the effects of range depletion and erosion is shown in Figure 34. It will be noted that where the original cover remains intact (section $B$, to the extreme left in the figure) the vegetation is of a desirable forage type and no erosion has occured. Moderate destruction of the vegetation (to the extreme right of $\operatorname{section} B$ ) has brought forth a somewhat inferior type of plant life, and the soil is subject to at least moderate erosion. In contrast to these conditions, serious destruction of the cover (section $A$ ) is associated with heavy washing of the soil. The vegetation on the moderately depleted areas (to the extreme right of section $B$ ) consists chiefly of plants of the second weed stage, but on the badly eroded parts (section $A$ ), the cover is composed either of plants of the first weed stage or of 
II 8 RECOGNIZING AND CORRECTING DECLINING FORAGE

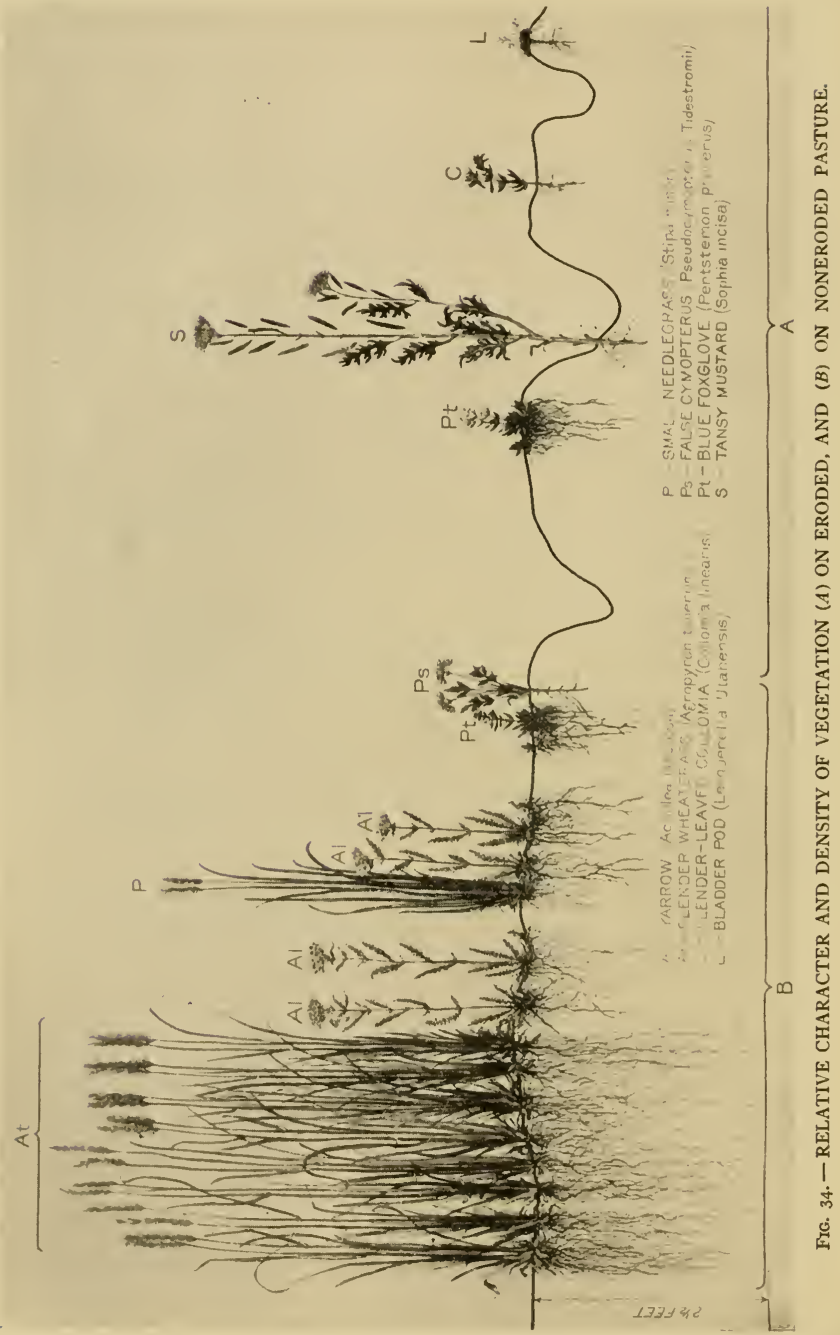


shallow-rooted, short-lived perennials. As would be expected, the vegetation as a whole is most inferior and sparsest on the seriously eroded parts; on the other hand, it is highest successionally and the most desirable and abundant on the noneroded portion.

Vegetation on Driveways and Bed Grounds. - The use for many seasons in succession of established driveways and bed grounds brings about a type of vegetation similar to that found on badly eroded areas - plants that are embraced chiefly in the first weed stage. Not uncommonly such areas represent the most serious destruction of the plant cover that can occur on pasture lands. On long-used bed grounds, for instance, all of the stages of vegetation described are frequently found in belts around the bed ground proper. Figure 35 shows a bed ground that was used for many seasons in succession. The bed ground proper (zone I) is practically circular and covers 22 acres. Because of heavy and repeated use each year not a vestige of vegetation remains. On the basis of the density and palatability of the original cover this area would have supported in good condition I4 sheep, or $3 \frac{1}{2}$ mature cows, for the summer season of Ioo days.

Surrounding the bed ground proper is an area (zone 2) of about 85 acres. Here the vegetation consists entirely of plants of the first or early weed stage. On the basis of the density and palatability of the original cover, this area would have maintained in good condition for the summer season 65 sheep, or 16 cows; whereas it now supports 5 sheep, or $1 \frac{1}{4}$ cows.

Zone 3 comprises about 2 I $_{5}$ acres and has a mixed cover of plants of the first and early second weed stages. If it is assumed that half of the present vegetation is palatable to stock, it may now carry 16 sheep, or 4 cows; whereas it would formerly have furnished feed during the regular grazing season for I30 sheep, or about 32 mature cows.

Zone 4 has a mixed cover of perennial grasses and weeds and comprises an area of approximately $35^{\circ}$ acres. About threefourths of the cover is palatable. It will now carry 105 sheep, or 26 cows; whereas formerly it would have supported not less than 2 Io sheep, or 52 cows. 
In generalizing, the data shows that, if the bedding-out system had been used instead of the established-camp method of handling the band, no less than 280 sheep, or at least 70 cows, could now be pastured on this area during the summer.

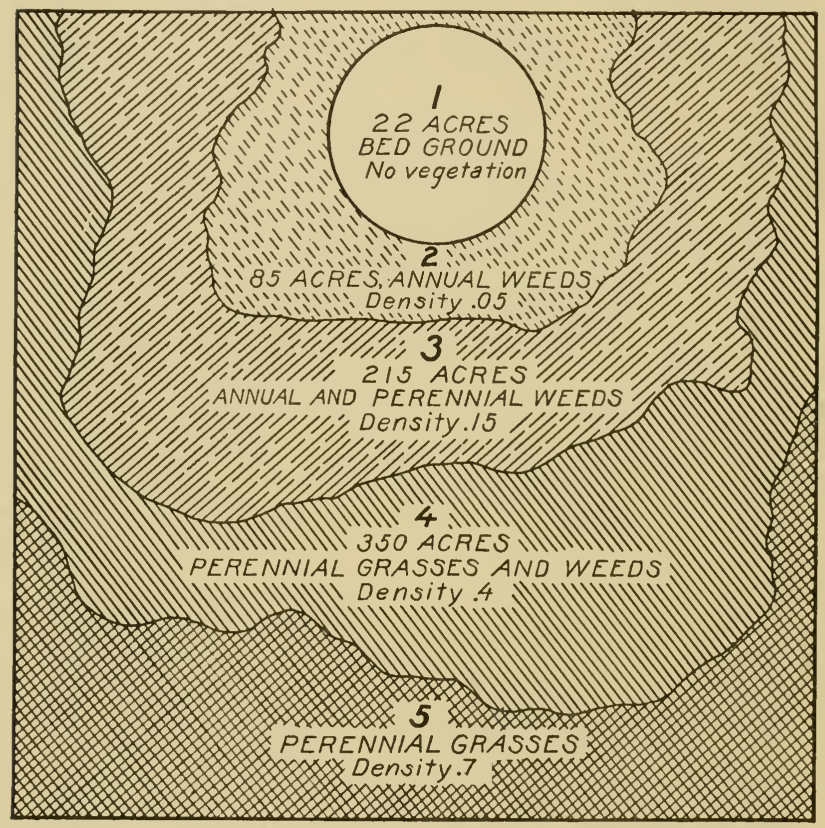

(Forest Service, under direction of the Author.)

FIG. 35. - BED GROUND USED FOR SEVERAL SUCCESSIVE YEARS, SHOWING ZONES OF VEGETATION AND RANGE OF DEPLETION.

If permanent bed grounds are used, it is evident that the carrying capacity of the lands is invariably reduced far below normal. Furthermore, the loss of lambs from poisonous plants is appreciably heavier if regular bed grounds are used.

Revegetation of Bed Grounds. - Many stockmen and others contend that bed grounds will reseed rapidly because of the large accumulation of organic matter. However, some sample 


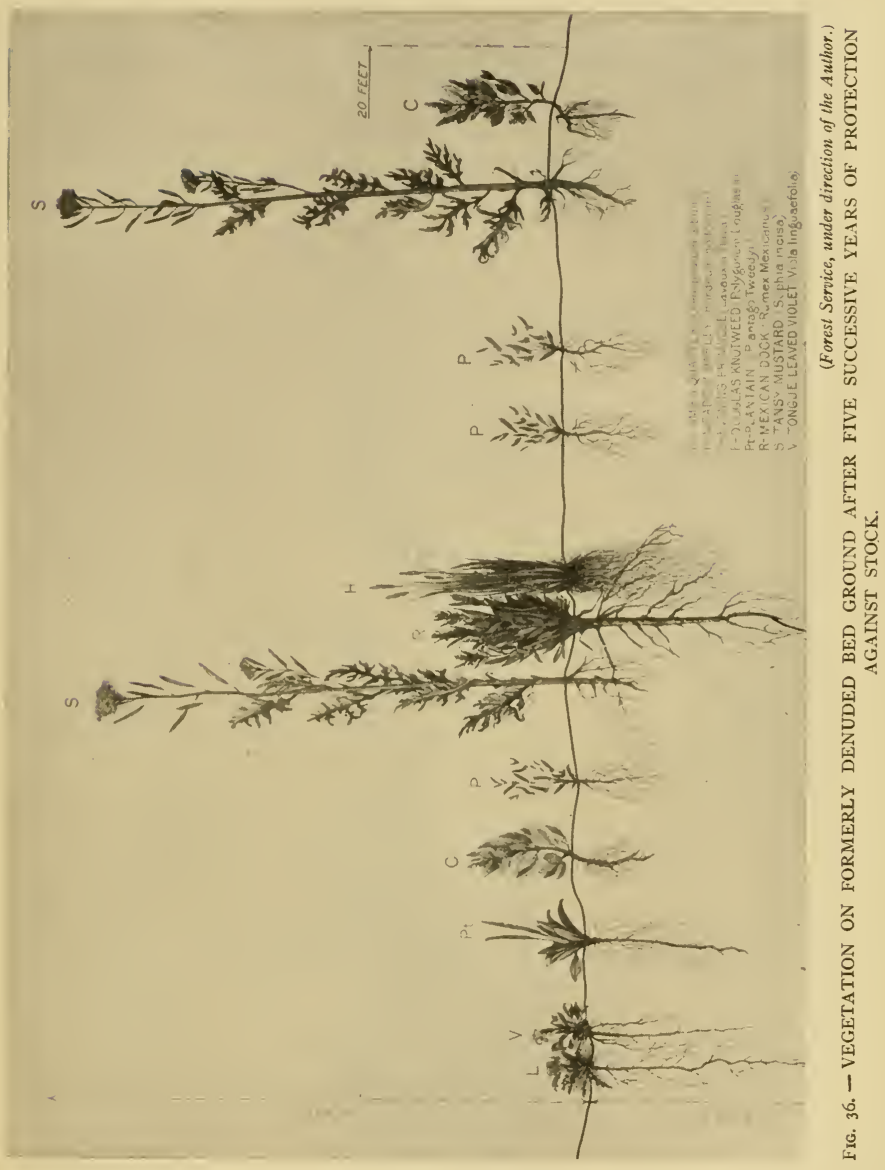


I 22 RECOGNIZING AND CORRECTING DECLINING FORAGE

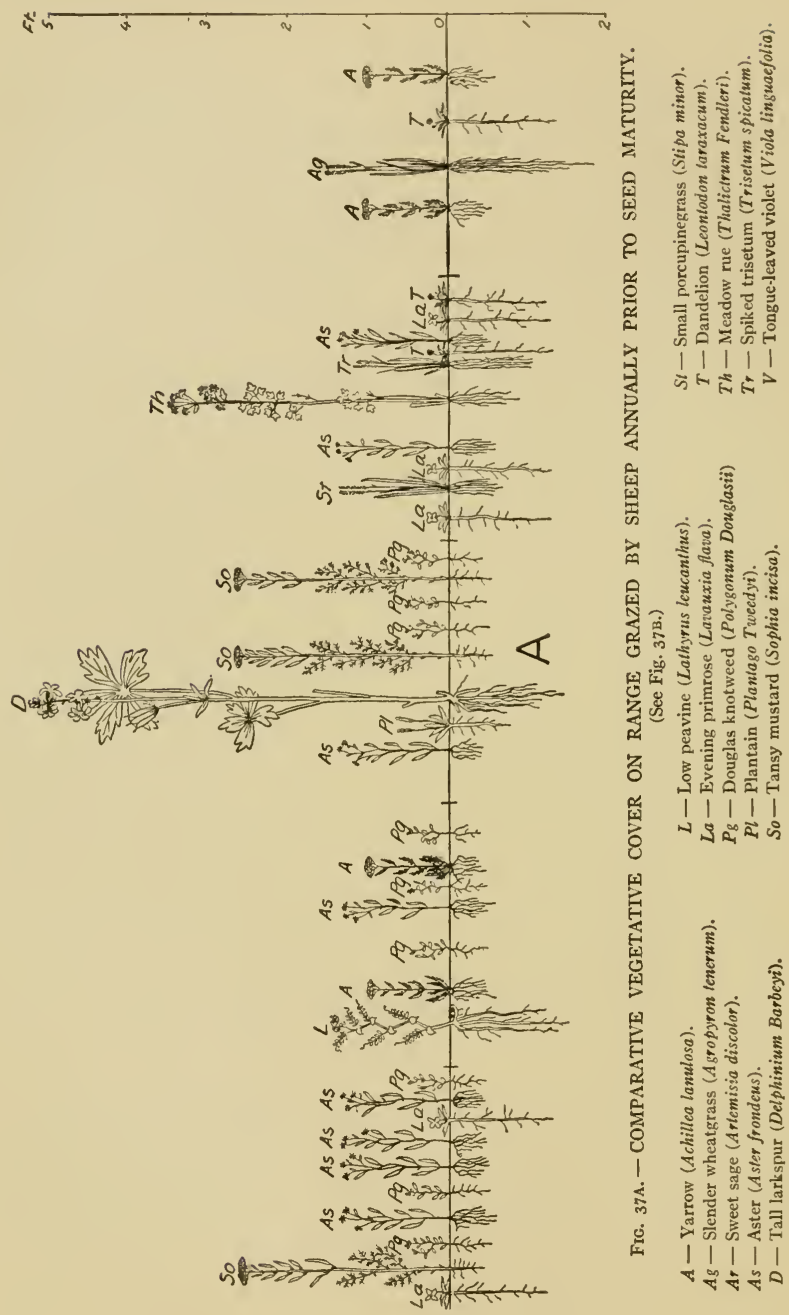




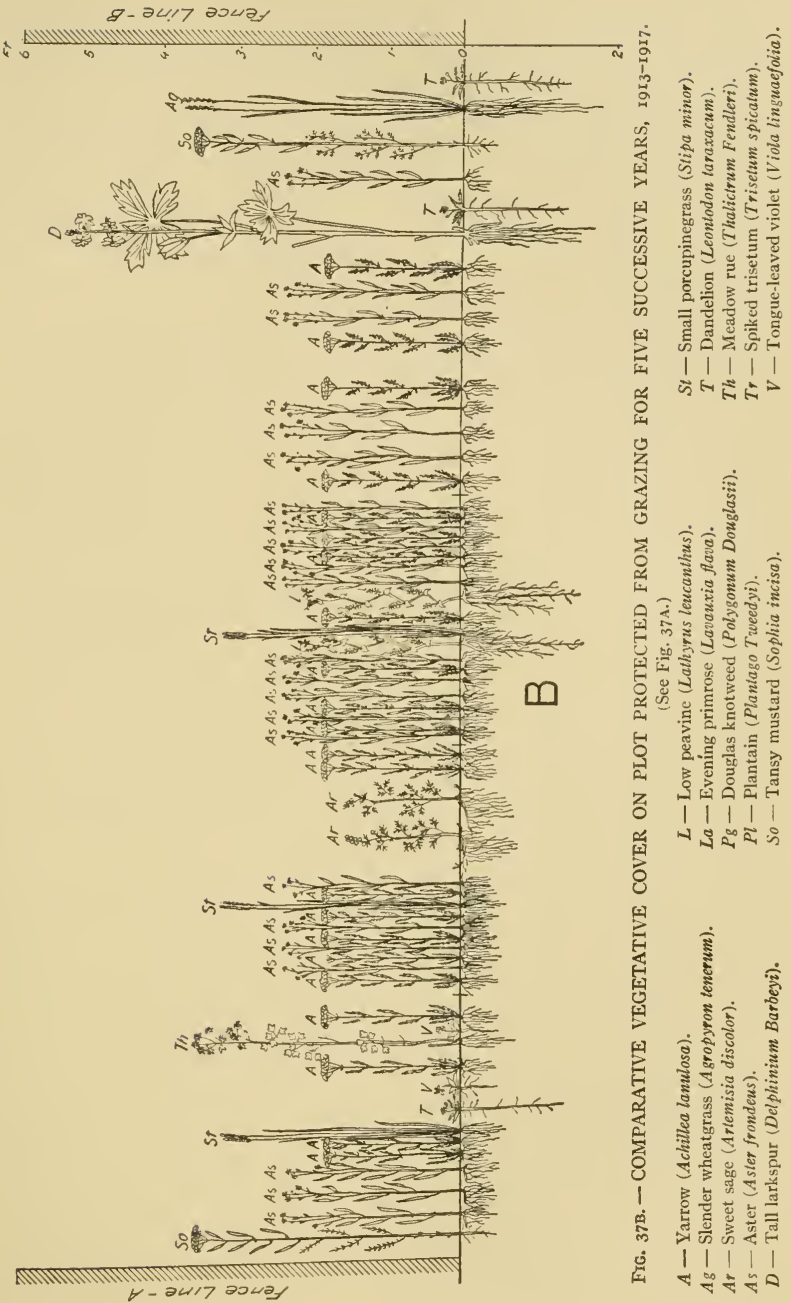


plots of bed grounds that have been fenced against stock for many years have revegetated very slowly indeed. For several years after total protection against stock, only the vegetation of the early successional stages is in evidence (Fig. 36). Such species as Douglas knotweed, lamb's-quarters, tansy mustard, and Mexican dock are often conspicuous. Furthermore, the height growth of the different species, as well as the depth and spread of their root systems, is appreciably less than on areas whose soil has not been heavily packed.

The slow reseeding is due largely to the heavy packing of the soil, for whenever a bed ground is plowed the original cover is soon replaced. So heavily packed is the surface soil on longused bed grounds that it takes the form of a series of laminated "crusts." 1 Therefore, either most of the seed that falls on such areas fails to germinate, or the seedlings die soon after the food stored in the seeds is exhausted.

Revegetation of Lands Grazed Each Year before Seed Maturity as Compared with that of Yearlong Protected Areas. - It has been pointed out that in the somewhat advanced stages of destructive grazing the highly palatable plants are the first to weaken and fail to reproduce. This failure to reproduce is invariably associated with a sharp decline in forage yield; nevertheless the buds at the plant's crown, though they remain dormant, may survive for a considerable period.

Where a considerable portion of the vegetation is alive, though low in vigor, yearlong protection or, indeed, grazing after seed maturity soon rejuvenates the cover and greatly stimulates growth and reproduction. The following table and Figures $37 \mathrm{~A}$ and $37 \mathrm{~B}$ summarize the effect of yearlong protection and of grazing each season before seed maturity. The unprotected portion shown in Figure 37A was grazed moderately by sheep and cattle each year prior to and while the study was in progress and corresponds to the grazing practice to which the protected portion of the area was subject before the initiation of the experiment. When the protected area was fenced, the vegetation was

1 Sampson, Arthur W., "Herding Hints from the Changing Range." Nat'l Wool Grower, Vol. Io, No. 5, pp. 20, 21, May, 1920. 
practically identical in character, vigor, and density with that on the adjacent outside portion.

Comparative Density and Height of Vegetation on a Plot Protected from Grazing for Five Successive Years and on an UnProtected Adjacent Sheep and Cattle Range Grazed Annually, Usually Well Before Seed Maturity ${ }^{1}$

\begin{tabular}{|c|c|c|c|c|c|c|}
\hline \multicolumn{4}{|c|}{ Density per square foot } & \multicolumn{3}{|c|}{$\begin{array}{c}\text { Relative height } \\
\text { (Physiological index) }\end{array}$} \\
\hline Plant & $\begin{array}{l}\text { On pro- } \\
\text { tected plot }\end{array}$ & $\begin{array}{l}\text { On open } \\
\text { range }\end{array}$ & $\begin{array}{l}\text { Percentage } \\
\text { of differ- } \\
\text { ence }\end{array}$ & $\begin{array}{c}\text { On pro- } \\
\text { tected plot }\end{array}$ & $\begin{array}{l}\text { On open } \\
\text { range }\end{array}$ & $\begin{array}{l}\text { Percentage } \\
\text { of differ- } \\
\text { ence }\end{array}$ \\
\hline Yarrow........ & $45 \cdot 6$ & 28.2 & 38 & I. 47 & 0.85 & 42 \\
\hline $\begin{array}{l}\text { Slender wheat- } \\
\text { grass........ }\end{array}$ & I. 6 & I. 4 & 12 & 3.06 & I. 20 & $6 \mathbf{I}$ \\
\hline Androsace.... & $\ldots$. & .7 & $\ldots$ & 3.00 & $\ldots$ & $\ldots 1$ \\
\hline Sweet sage & 3.2 & & 100 & I. 20 & $\ldots \ldots$ & $\ldots \ldots$ \\
\hline Aster.......... & 45.6 & I 6.9 & 63 & I. 90 & 1.03 & 46 \\
\hline Tall larkspur... & .8 & I. 4 & $75^{a}$ & 5.20 & 4.40 & I5 \\
\hline Low peavine... & 3.2 & $2 . I$ & 34 & I. 70 & I. 20 & 29 \\
\hline $\begin{array}{l}\text { Evening prim- } \\
\text { rose......... }\end{array}$ & & & & & & \\
\hline $\begin{array}{l}\text { Douglas knot- } \\
\text { weed........ }\end{array}$ & & 12.7 & & & 1.20 & $\ldots \ldots$ \\
\hline Plantain..... & .8 & I. 4 & $75^{a}$ & & $\ldots \ldots$ & $\ldots \ldots$ \\
\hline $\begin{array}{l}\text { Tansy mustard } \\
\text { Small moun- }\end{array}$ & 4.8 & $4 \cdot 9$ & ${ }_{2}^{a}$ & 2.82 & $2 \cdot 13$ & 24 \\
\hline $\begin{array}{l}\text { tain porcu- } \\
\text { pinegrass }\end{array}$ & I 2.0 & 4.2 & 65 & $2 \cdot 5^{6}$ & 1.18 & 54 \\
\hline Dandelion..... & $7 \cdot 2$ & $3 \cdot 5$ & 51 & & $\ldots$ & $\ldots$ \\
\hline $\begin{array}{l}\text { Meadow rue.. } \\
\text { Spiked tri- }\end{array}$ & 4.0 & .8 & So & 2.92 & 2.92 & $\circ$ \\
\hline $\begin{array}{l}\text { Spiked tri- } \\
\text { setum....... } \\
\text { Tongue-leaved }\end{array}$ & 2.4 & 2.8 & $17^{a}$ & I. 95 & .96 & $5^{I}$ \\
\hline violet...... & 4.0 & I. 4 & 65 & . & $\ldots \ldots$ & $\ldots \ldots$ \\
\hline
\end{tabular}

$a$ Indicates more individuals per square foot on the unprotected area than on the protected portion.

The highly palatable perennial plants are appreciably more abundant on the protected area than on the unprotected plot. Sweet sage, for instance, shows a difference of roo per cent in favor of protection; small mountain porcupinegrass, 65 per cent;

1 The figures here given were compiled from a bisect 16 feet long and I inch wide inside and outside of the protection plot. Owing to the unwieldiness of a sketch of such proportions, only a part of its length is shown in Figures $37 \mathrm{~A}$ and 37 B. 
dandelion, $5^{\mathrm{I}}$ per cent; yarrow, $3^{8}$ per cent; and slender wheatgrass, I 2 per cent. However, the greatest density in four species occurs on the unprotected area. The species concerned are somewhat unpalatable perennials or annuals, such as usually colonize readily on more or less packed soils.

Further interesting contrasts may be observed if the average height growth of the different species on the fenced and the unfenced areas may be used as an index of their physiological vigor or strength. For instance, the relative height growth of the different species is strikingly in favor of the protected area, the percentage being greater in all but one instance. The exception is meadow rue (Thalictrum), a plant which is practically untouched by any class of stock. Being unmolested by grazing animals, the plant is quite as strong physiologically on the unprotected area as on the protected plot. In general the difference in the height growth is roughly in proportion to the palatability of the different species. Moreover, the amount of seed produced, its germination strength, and the height growth of the vegetation are closely correlated. Regardless of whether the vegetation is permitted to regain its vigor by the entire exclusion of stock as a result of deferred grazing, complete physiological recovery results in about three years. Likewise, the decline in the forage yield and seed production of bunchgrass areas, practically to the zero point, is accomplished in approximately three years of abusive grazing.

Possibly the most significant fact brought out in the experiment is the difference in the density of the various species on the protected and on the grazed area. On yearlong protected areas the plants with running rootstocks, like yarrow, low peavine, and sweet sage, increase at a rapid rate by sprouts as soon as sufficient food is elaborated to stimulate the buds to growth. Reproduction from seed, especially by plants of the large-seeded species, like the bromegrasses and fescues, for instance, is strikingly more vigorous on areas where the grazing is deferred until the seed crop has ripened. For good reproduction of plants whose seeds are fairly large, deferred grazing, with the consequent planting of the seed crop by the trampling of stock, is a 
distinct advantage over yearlong protection. Accordingly, deferred grazing has all of the advantages of total protection and none of the disadvantages, such as limited reproduction from seed and waste of forage during the period required for revegetation.

\section{USE OF INDICATOR PLANTS}

The species that are increasing on a pasture area, regardless of whether they are mere weeds or palatable forage plants, reveal one of two facts. If the invading plants are lower in the succession than the original or the predominating vegetation, the area is being misused in one or more respects. If, on the other hand, the incoming vegetation is somewhat higher successionally than the type as a whole, the plan of grazing is satisfactory. If undesirable plants are crowding out the more permanent and palatable ones, remedial measures should be adopted with dispatch.

If the native pasture is not cropped too early in the season, and if its grazing capacity is correctly estimated, the deferred and rotation grazing system may be depended upon to reëstablish the stand, provided enough of the original desirable plants remain for seed production. Lands that have been so seriously depleted, however, that only first weed stage vegetation remains, can not be revegetated satisfactorily by deferred grazing, for such areas can not be grazed without further serious depletion. Lands in the first weed stage had best be entirely closed to stock until the cover is well advanced into the second weed stage.

How to Recognize Pasture Improvement or Depletion. - Although the primary pasture indicators will serve to determine whether a range is being properly handled, it is necessary to adopt some definite means of noting the changes that are taking place in the plant cover. For this purpose, plots representing the area as a whole should be selected. For accurate work it is necessary to make a rough map of the vegetation growing on the selected areas, but in practice a properly recorded accurate estimate of the density and character of the vegetation will suffice. The area should be so located and so carefully staked and labeled 
that it may be reëxamined at any time. The comparative density of the chief indicator species - both the palatable and the unpalatable ones - should be noted. The value of this work is greatly enhanced by collecting and preserving for future reference the main indicator and forage species found on the plot. Photographs showing the density and character of vegetation are also highly valuable.

Reliable Indicator Plants. - Plants as indicators of forage conditions obviously are not the same everywhere. As a rule, however, the same genera will be represented, but the species may be different. Reliable indicators of the various stages of overgrazing in any region may be determined by observing the plants that predominate on and about bed grounds, on livestock trails, and on areas in various stages of depletion. The following list of plants characteristic of the four successional stages, as developed by the writer in the investigation here summarized, will serve more or less perfectly as a check list of indicator plants elsewhere. The list is arranged according to the natural grass or weed stages, and the lowest or more temporary ones are given first, for it is these especially that must be kept in mind in judging the condition of a pasture.

First or early weed stage:

Most characteristic species -

Douglas knotweed (Polygonum Douglasii).

Goosefoot, or lamb's-quarters (Chenopodium album).

Slender-leaved collomia (Collomia linearis).

Tansy mustard (Sòphia incisa).

Tarweed (Madia glomerata).

Tolmie's orthocarpus (Orthocarpus Tolmiei).

Other species of the first weed stage -

Androsace (Androsace diffusa).

Gilia (Microsteris micrantha).

Knotweed (Polygonum aviculare).

Monolepis (Monolepis Nuttalliana).

Peppergrass (Lepidium ramosissimum). 
Second or late weed stage:

Most characteristic species -

Blue foxglove (Pentstemon procerus).

Sweet sage (Artemisia discolor).

Yarrow (Achillea lamulosa).

Other species of the second weed stage -

Aster (Aster frondeus).

Butterweed (Senecio Columbianus).

Cinquefoil (Potentilla filipes).

Evening primrose (Lavauxia flava).

False cymopterus (Pseudocymopterus Tidestromii).

False Solomon's-seal (Vagnera stellata).

Geranium (Geranium viscosissimum).

Horsemint (Agastache urticifolia).

Large mountain bromegrass (Bromus marginatus).

Low larkspur (Delphinium Mensiesii).

Low peavine (Lathyrus leucanthus).

Mexican dock (Rumex Mexicanus).

Mountain dandelion (Crepis acuminata).

Oniongrass (Melica bulbosa).

Porter's bromegrass (Bromus Porteri).

Rubberweed (Hymenoxys floribunda).

Sampson's mertensia (Mertensia Sampsonii).

Scribner's wheatgrass (Agropyron Scribueri).

Showy oniongrass (Melica spectabilis).

Sneezeweed (Helenium Hoopesii).

Tongue-leaved violet (Viola linguaefolia).

Mixed grass and weed stage:

Most characteristic species -

Small mountain porcupinegrass (Stipa minor).

Yellowbrush (Chrysothammus lanceolatus).

Other species of the mixed grass and weed stage -

Blue foxglove (Pentstemon procerus).

Geum (Geum Oregonense).

Junegrass (Koeleria cristata). 
Large mountain bromegrass (Bromus marginatus).

Little bluegrass (Poa Sandbergii).

Low loco (Astragalus decumbens).

Mountain lupine (Lupinus alpestris).

Nevada bluegrass (Poa Nevadensis).

Porter's bromegrass (Bromus Porteri).

Single-flowered helianthella (Helianthella uniflora).

Spiked fescue (Festuca confinis).

Spiked trisetum (Trisetum spicatum).

Sweet sage (Artemisia discolor).

Western fescue (Festuca occidentalis).

Yarrow (Achillea lanulosa).

Climax herbaceous stage:

Most characteristic species -

Small wheatgrass (Agropyron dasystachyum).

Blue bunch wheatgrass (Agropyron spicatum).

Slender wheatgrass (Agropyron tenerum).

Other species of the climax herbaceous stage -

Violet wheatgrass (Agropyron violaceum).

The more species that are made use of as indicators of pasture conditions the safer are the conclusions. For instance, if a type is merging into the early or first weed stage from a higher plant cover, assurance of this fact is found in the increasing abundance of several of the most characteristic "primary" species of the early weed stage, and in the presence here and there at least of the less common forms of that stage.

\section{QUESTIONS}

1. Why can not the waning of a pasture be satisfactorily judged by the condition of the stock grazed?

2. Discuss the theory of plant succession in relation to grazing capacity and range management.

3. Enumerate three conspicuous indications of overgrazing.

4. (a) Name four type stages of native pasture vegetation. (b) Which of these is the highest, and which is the lowest? 
5. How may the waning of the wheatgrass cover be detected in its early stages?

6. Discuss the forage value of the wheatgrass type.

7. What are the most characteristic plants of the mixed grass and weed cover?

8. Compare the grazing value of the mixed grass and weed stage of vegetation with that of (I) the climax herbaceous stage, (2) the second weed stage, and (3) the first or early weed stage.

9. Name seven species common to the second weed stage.

10. Name six species characteristic of the first or early weed stage.

11. What effect does the continued grazing of sheep have on an area in the first weed stage?

12. Discuss the effect of the use of a permanent bed ground on (I) the vegetation and (2) the grazing capacity of the lands adjacent to the bed ground proper.

13. (a) Are the grazing indicator species the same everywhere? (b) How may they be recognized in different localities?

\section{BIBLIOGRAPHY}

Chapline, W. R. Production of Goats on Far Western Ranges. U. S. Dept. of Agr. Bul. 749, I9r9.

Clements, Frederic E. Plant Indicators: The Relation of Plant Communities to Processes and Practice. Carnegie Institution of Wash., Pub. No. 290, 1920.

Plant Succession: An Analysis of the Development of Vegetation. Carnegie Institution of Wash., Pub. No. 242, r9ı6.

Cowles, Henry C. The Physiographic Ecology of Chicago and Vicinity. Bot. Gaz., Vol. 31, Nos. 2 and 3, rgor.

Hole, R. S. On Some Indian Forest Grasses and Their Ecology. Indian Forest Memoirs, Vol. I, No. I, I9I I.

Jardine, James T., and ANDERson, Mark. Range Management on the National Forests. U. S. Dept. of Agr. Bul. 790, r9r9.

Moss, C. E. The Fundamental Units of Vegetation. New Phytologist, Vol. 9, Nos. I and 2, rgro.

Sampson, Arthur IV. Herding Hints from the Changing Range. Nat'l Wool Grower, Vol. Io, No. 5, May, r920.

Plant Succession in Relation to Range Management. U. S. Dept. of Agr. Bul. 79r, I9I9.

Succession as a Factor in Range Management. Jour. of Forestry, Vol. I 5 , No. 5, I917.

Warming, Eug. Oecology of Plants. Clarendon Press, Oxford, Igog. 


\section{CHAPTER VII}

\section{PRINCIPAL INTRODUCED FORAGE GRASSES}

On both temporary and permanent farm pastures of the United States cultivated forage plants are the ones most extensively grown. Many of the species used yield heavily, remain palatable during a long growing season, and withstand cropping well; others fail chiefly because of their unsuitability to the climatic or soil conditions. Therefore it is important to know the climatic, soil, and cultural requirements of the more valuable species.

Classification of Cultivated Plants. - The world over, there are probably not less than 10,000 species of grasses. According to Hitchcock, ${ }^{1}$ about 1,500 species occur in the United States. Of these, however, about 25 , or maybe a few more, species are extensively cultivated, some as cereal crops, and others for the pasture, hay, or fodder which they produce. Not more than five perennial grasses are sown extensively on permanent pastures in this country. These are Kentucky bluegrass, Canada bluegrass, Bermudagrass, Hungarian bromegrass, and redtop. Some of these are drought-enduring; others are well adapted to wet or, indeed, acid soils; and one (Bermudagrass) is well suited to the humid, warm South.

For hay and pasture combined, timothy, orchardgrass, Kentucky bluegrass, and redtop are generally listed as the "big four " - the leaders. Of less importance are such species as tall oatgrass, meadow fescue, Johnsongrass, Sudangrass, the ryegrasses, and certain fescues.

Kentucky Bluegrass. - Kentucky bluegrass (Poa pratensis) is also known as Junegrass, smooth-stalked meadowgrass, or simply bluegrass. It is a perennial which grows in tufts but

${ }^{1}$ Hitchcock, A. S., "The Genera of Grasses of the United States." U. S. Dept. of Agr. Bul. 772, p. 3, 1920. 
produces abundant rootstocks by means of which a firm sod is formed. The panicle is spreading and is 2 to 5 inches long. The spikelets mostly bear from 3 to 5 flowers (Fig. $3^{8}$ ).

Kentucky bluegrass is probably the greatest of all pasture grasses cultivated in America ${ }^{1}$ and is grown extensively in a

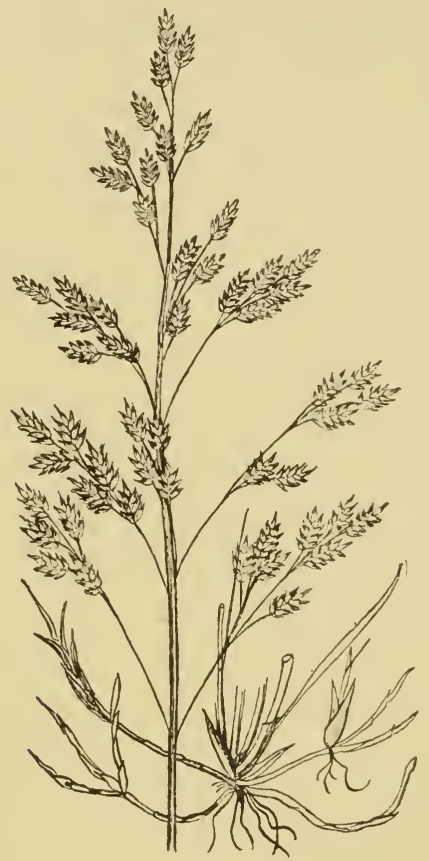

Fic. 38. - KENTUCKY BLUEGRASS (Poa pratensis).

moderately moist, cool climate on limestone or neutral soils. In the cool mountain lands of the South it thrives well, but in

${ }^{1}$ Hitchcock says that forms of $P$. pratensis occur natively north of the United States, in Canada and Alaska, but that all the United States material he has examined and all cultivated material is of the Old World type, and that, as a cultivated plant, Kentucky bluegrass is not American but European. 
the warmer and more humid parts of this region the growth is not vigorous. In acid soils, too, Kentucky bluegrass does not thrive. The conditions in the Plains region are too dry for the successful growth of Kentucky bluegrass. In most localities three years are required for the establishment of a good bluegrass sod. In forage mixtures four or five years are usually required after seeding before the bluegrass clearly predominates. As a hay plant, Kentucky bluegrass does not rank particularly high, the yield being light because of the low stature of the plant. The seed habits are fairly strong, but the viability of the seed is often low; accordingly it is highly important to know the germination strength of the seed before purchasing.

In establishing a pasture, bluegrass seed may be scattered with wheat in the fall or in early spring along with other grasses or with clovers. Seeding in midsummer seldom results in the obtaining of a good stand. For a full stand of Kentucky bluegrass 35 to 40 pounds of seed should be used per acre. Because of the heavy expense, however, 15 to 20 pounds of seed to the acre is usually more economical, as the stand resulting from such seeding is sufficient soon to extend itself over the area. If a small amount of bluegrass seed is used, the seed of other species should be included to provide a temporary pasture while the bluegrass is becoming established.

Fifty years ago Kentucky bluegrass was practically unknown in the middle and far West. Now it is a common roadside grass within its natural climatic region. Growth starts early in the spring, but the plant also matures early. Little growth is made during hot weather; but with ample moisture in the fall an abundance of leafage is produced, and the cover again furnishes excellent grazing. Kentucky bluegrass is one of the most valuable of our grasses for all classes of stock.

Kentucky bluegrass is the ideal lawn grass, as its luxuriant leafage and abundance of rootstocks tend to cover and bind the soil thoroughly. Like most sodgrasses, frequent cutting does not seem to weaken the stand. If white clover is seeded with Kentucky bluegrass, it makes a very satisfactory growth, either in the pasture or on the lawn. 
Canada Bluegrass. - Canada bluegrass (Poa compressa) is known also as English bluegrass, flatstem bluegrass, and Virginia bluegrass. It is a perennial and in appearance closely resembles Kentucky bluegrass ( $P$. pralensis), from which it differs in its lower stature, bluer foliage, flatter stems, and narrower panicles.

Canada bluegrass is a native of Europe, and was among the first of the grasses to be introduced into North America. It is well adapted to cool climates and is especially suited to poor, dry soils, as well as to those of low lime content. The plant is increasing in abundance in the West, but it is much more important in the eastern part of the United States and in Canada.

Although Canada bluegrass is less productive than Kentucky bluegrass, it enjoys an excellent reputation in most quarters as a pasture plant for dairy stock. Scribner ${ }^{1}$ says it is an ideal species for this purpose. It is particularly valuable in the Northeastern States and Canada, but is not a heavy yielder. Remarkably good stands are found on exposed hillsides and knolls where the species produces more heavily than almost any other cultivated grass. When planted for hay or pasture the seed should be scattered with that of other grasses. Canada bluegrass is unusually persistent once it is well established. From 5 to ro pounds of seed to the acre in a mixture is usually sufficient to insure a good stand. It is not generally wise to seed Canada bluegrass where Kentucky bluegrass grows well, but on poor soils it possesses unusual merit. For artificial reseeding of depleted mountain range lands, Canada bluegrass appears to have considerable value. The seed is usually less expensive than that of Kentucky bluegrass, and hence it is not uncommonly used as an adulterant. The seeds of these species are readily distinguished only by a seed expert.

Bermudagrass. - Bermudagrass (Capriola Dactylon) is a native of India and the Mediterranean region. It is thought to have been introduced into this country from Europe about I800. It may now be called the most important pasture grass throughout the southern half of the United States, where it holds much the

1 Scribner, F. Lamson-, "Useful and Economic Grasses." U. S. Dept. of Agr., Div. of Agrost., Bul. 3, pp. 78, 79, 1896. 
same rank as Kentucky bluegrass in the more northerly States. Bermudagrass occurs abundantly throughout the cotton belt and Gulf coast region. In some parts of the South it has been regarded as a pestiferous weed, but it can be held in check or even eradicated by growing on the Bermuda lands such crops as cowpeas, velvet beans, and sorghum, which produce a dense shade. Eradication is also accomplished, after a perfect sod is

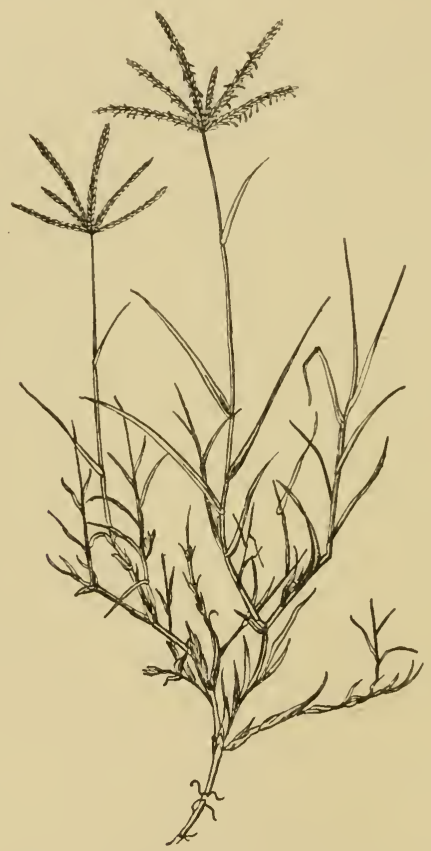

FIG. 39. - BERMUDAGRASS (Capriola Dactylon).

formed, by shallow ploughing, followed by intensive tillage during the dry, hot summer months.

Bermudagrass is a strong perennial with extensive, creeping rootstocks (Fig. 39). In good soils the foliage develops sufficient 
length to warrant cutting it for hay; but on poor lands the leaves and flower stalks are low. Seed production of Bermudagrass, like that of most sodgrasses, is somewhat low. Seed in abundance is produced only in hot, dry weather. Seed production of the species has not yet been widely commercialized.

Although the distribution of Bermudagrass is wide, extending from Massachusetts and southern New York to Florida, Missouri, New Mexico, and Arizona, along the Pacific slope from Washington to California, and south through Mexico and South America to Uruguay, it occurs in economic importance in this country only in the South. This is due to the fact that the aërial growth is readily killed by frost, and the roots die where the soil freezes.

As the seed is expensive, the ground should be thoroughly prepared before sowing. From 4 to 6 pounds of seed is usually sufficient to produce a good stand. It is best to resort to pure seeding because Bermudagrass is intolerant of shade. Not uncommonly the rootstocks, which are unusually persistent, are scattered over the land in order to establish a sod. This is done by breaking up the sod into small pieces and scattering these in furrows 2 to 4 feet apart.

Where Bermudagrass grows luxuriantly, in carrying capacity it ranks very high among the grasses. The palatability remains high almost throughout the season, though, to be sure, in late summer the leafage may become somewhat tough. The plant withstands trampling exceedingly well.

Hungarian Bromegrass. - Hungarian bromegrass (Bromus inermis) is also known as smooth, awnless, Austrian, or Russian brome. It is a long-lived perennial, 2 to 5 feet high, with strong creeping rootstocks by means of which a tough sod is formed. The panicle is loose and open, and from 4 to 6 inches long. The spikelets are erect, flattened, awnless, and about an inch long (Fig. 40). Hungarian bromegrass is a native of the upland plains of eastern Europe, being most abundant in Austria and Russia. The plant was introduced into the United States in the early eighties and is now widely grown throughout the Northern and Western States. It is especially well adapted to the North- 
ern States, and is of considerable importance in the mountains of the arid West.

The species is unusually hardy, being very drought-enduring and resistant to cold. In hot climates the plant does not thrive. The plant is very leafy and under favorable conditions furnishes such a large amount of forage as to obscure the ground com-

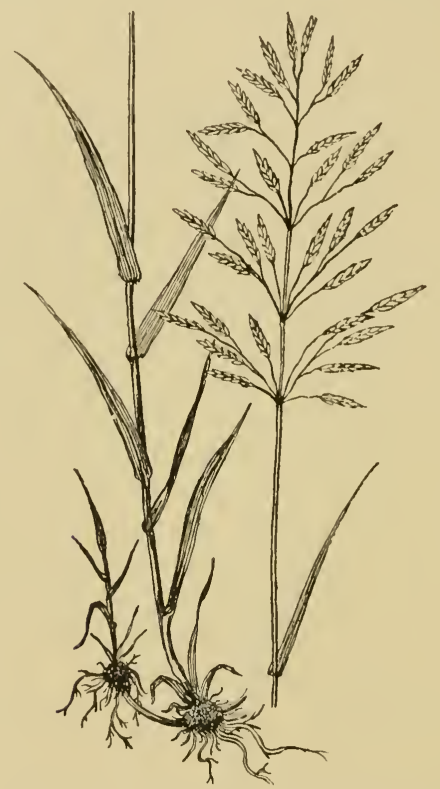

Fig. 40. - HUNGARIAN OR SMOOTH BROMEGRASS (Bromus inermis).

pletely. The strong rootstocks protect the plant from injury by trampling. Although Hungarian brome furnishes an abundance of desirable hay, it is most valuable for pasture. All classes of stock are fond of the leafage, which usually remains succulent and tender from early spring until late in the autumn.

In establishing bromegrass the seed may be scattered either in early spring or early fall, preferably with clover. As the seed is 
light and large, it is usually sown broadcast, preferably by hand. If it is sown pure, about 25 pounds should be used to the acre. Not infrequently the seed is scattered with that of oats, the aim being to sow about one bushel of oats per acre with about 20 pounds of the bromegrass seed. The nurse crop-oats, for example — should be cut early, in order that the bromegrass stand may not be suppressed.

Hungarian bromegrass does well on the lighter, moderately moist soils. The largest yields, however, are obtained on moist, deep, rich, loamy soils. Even under the best conditions bromegrass stands become sod-bound in a few years. Accordingly, it is best to take a few hay crops off the land and then use it for pasture for two or three years. After that the land had best be plowed and used for growing other cultivated crops.

Redtop. - Redtop (Agrostis palustris), formerly known to botanists as $A$. alba, ${ }^{1}$ is also called herd's grass in the southern United States, and bent grass in England. It is a perennial and will be recognized by its reclining or rooting base, the short rootstocks,

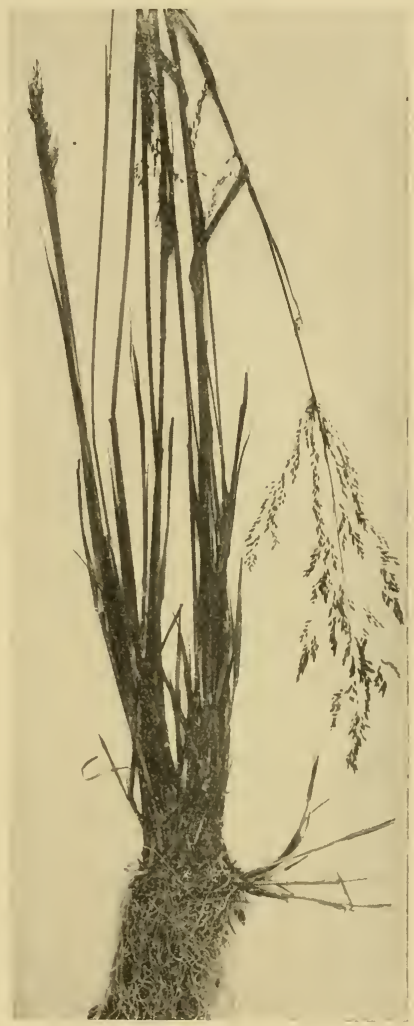

FIg. 4r. - REDTOP (Agrostis palustris). the numerous flat leaves, and the erect, open panicle, 2 to I 2

1 The scientific name of redtop will be found in seed catalogues as Agrostis alba, $A$. alba vulgaris, or $A$. capillaris. 
inches long. The spikelets are commonly red or purple, turning green or brown at maturity (Fig. 4I).

Redtop is a relatively important grass in many parts of the United States. It is more widely adapted to a variety of climatic and soil conditions than timothy, withstands higher temperatures, and is well adapted to wet or boggy soils. On acid lands redtop is commonly the most conspicuous of the grasses, and on very wet lands its yield is unusually heavy. Redtop, however, is not held in so high esteem as timothy, and hence occupies second place where timothy can be grown successfully. However, where timothy fails to produce a good crop, redtop is grown somewhat extensively.

The principal merit of redtop as a pasture or meadow plant is that it will often grow where timothy fails. As pasture the forage is nutritious, yet the leafage is not relished so highly by most classes of stock as is that of the most palatable grasses. A good quality of hay of fairly high palatability is obtained if the grass is cut when young. If, however, the grass is allowed to stand until after it blossoms, the leafage becomes somewhat harsh and woody, and the quality of the hay is impaired. As the quality of redtop hay is not considered to be so high as that of timothy, it is not advisable to seed redtop and timothy together.

Redtop seed is comparatively low in price, and the germination is usually good. Under favorable conditions the seed germinates in 2 to 4 days. When sown pure, Io to 12 pounds of seed to the acre is used, whereas in mixtures 2 to 5 pounds is recommended. The seeding operations, cultural methods, and season of seeding are similar to those of timothy.

Timothy. - The derivation of the name timothy (Phleum pratense) is uncertain. By some it is traced to one Timothy Hanson, who is said to have carried the seed from New York to the Carolinas about I 720 . Timothy is also known as Herd's grass, from a Mr. Timothy Herd of New Hampshire, who is said to have found it in a swamp in that State and to have begun its cultivation. If the latter explanation is authentic, Herd gave both his names to the species. Timothy is a hardy perennial 
with erect stems, bulbous at the base. It forms more or less indefinite tufts or stools as new stalks originate from the crown (Fig. 42).

Timothy occupies more than half of the area upon which forage crops in the United States are grown. It is the chief cultivated hay grass in all regions north of the Ohio River. It is adapted to a great variety of soils, although the best yields are produced on rich, moist loams and clays. The growth is less prolific on sandy soils.

Timothy is valuable for hay rather than for pasture. It is often used in pasture mixtures for early or temporary pasturage, but the stand soon gives way to sodgrasses. Moreover, it does not long withstand close grazing or trampling, and its period of life is not extended. As a meadow grass, however, there is none better. In most localities timothy is grown in a 4 - or 5 -year rotation and is usually seeded with clover in wheat, oats, or rye. In such seeding, clover is much in evidence the first year, but in the second year timothy predominates.

The summer period (August or early September) is the most favorable time to seed timothy. A clean, well-packed, moist seed bed is best. If such land is not available, a nurse crop should be used. Fifteen pounds of timothy seed to the acre is sufficient when seeded pure. When clover and timothy are sown together, a good stand may be obtained by using 6 to 8 pounds of timothy, 7 pounds of red clover, and 3 pounds of Alsike clover. The seed should be harrowed in lightly.

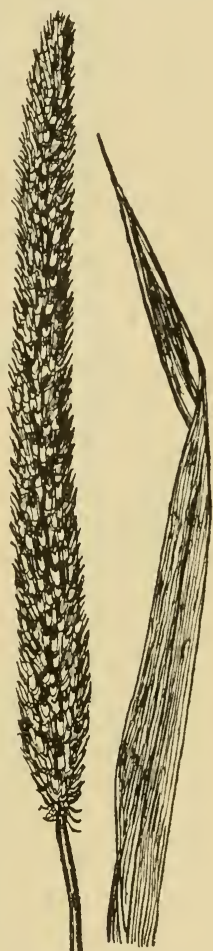

Fig. 42. - TIMOTHY

(Phleum pratense). When scattered with small grain, the seed may be distributed by means of a grass seeder attached to a grain drill which drops the timothy in front of the drill rows. 
The largest yield of the most nutritious hay is obtained if timothy is cut shortly after the blossoms have fallen, but not later than when the seed is in the dough. Yields in excess of $4 \frac{1}{2}$ tons per acre have repeatedly been reported, but $2 \frac{1}{2}$ tons is about the average.

The seed habits of timothy are unusually strong. The yield of seed per acre varies from 5 to 12 bushels. The cutting is done with the ordinary grain or "self" binder, and the bundles are

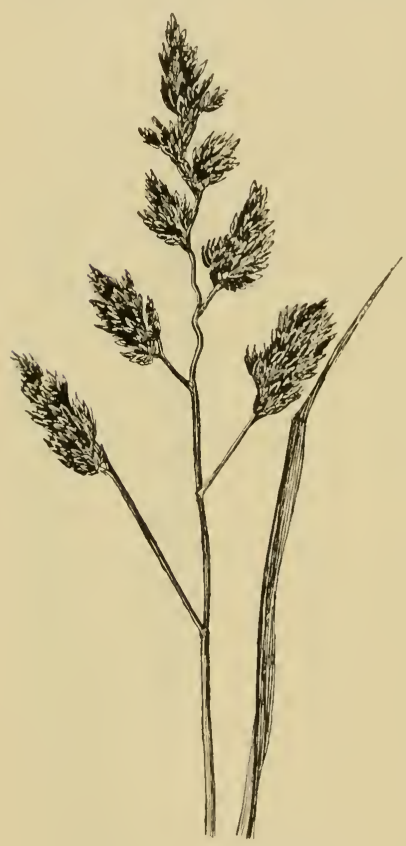

FIG. 43. - ORCHARDGRASS

(Dactylis glomerata). dried in shocks. The seed is separated in the regular grain thresher, special sieves being used.

Orchardgrass. - Orchardgrass (Dactylis glomerata) is known in England as cock'sfoot. It is a hardy perennial, though not so resistant to cold and drought as Hungarian brome. It is without rootstocks and forms dense circular tufts several inches in diameter. The culms are smooth, from 2 to 4 feet high. The panicle is 3 to 6 inches long, bearing a few one-sided clusters of green or purplish spikelets (Fig. 43).

Orchardgrass grows wild throughout the greater part of Europe and in northern Asia. The plant was introduced into the United States about I 740. It is now widely grown as a hay and pasture plant in western Asia, northern Africa, and in various parts of North America.

As the name orchardgrass would imply, the plant is well adapted to grow in shade. It ranks high in nutrient qualities, 
but the leafage is not eaten with so much gusto as is that of Kentucky bluegrass or Hungarian bromegrass. When cut early the plant makes good hay.

Next to Kentucky bluegrass, orchardgrass is one of the earliest to start growth in the spring. Growing, as it does, in tufts, it does not withstand so heavy grazing as sodgrasses; nevertheless, a good stand is remarkably persistent. Severe cutting tests conducted by the author in the mountains of central Utah have brought out the fact that well-established tufts withstand closer cropping than do many native tufted species. Good orchardgrass meadows have been reported to yield heavy crops for as long as i 5 years.

The Ryegrasses. - Two ryegrasses - perennial ryegrass (Lolium perenne) and Italian rye $(L$. Italicum $)$ - are cultivated more or less in this country.

Perennial ryegrass is among the first of the Old World species to be cultivated in this country. Its native home is in temperate Asia and southern Europe. Thus far it has not been extensively cultivated in this country, as it is not well adapted to either a very cold or a very hot climate. It is well suited to wet soils but is a short-lived plant (Fig. 44).

Seed of perennial ryegrass may be scattered in either spring or fall. It is usually sown pure, about 25 pounds of seed to the acre being required. One objection to the use of perennial ryegrass is that the seed is very dear. Practically all of the seed used in this country is grown in Europe.

Italian ryegrass is a native of southern Frg. 44.-PERENNIAL Europe, northern Africa, and western Asia.

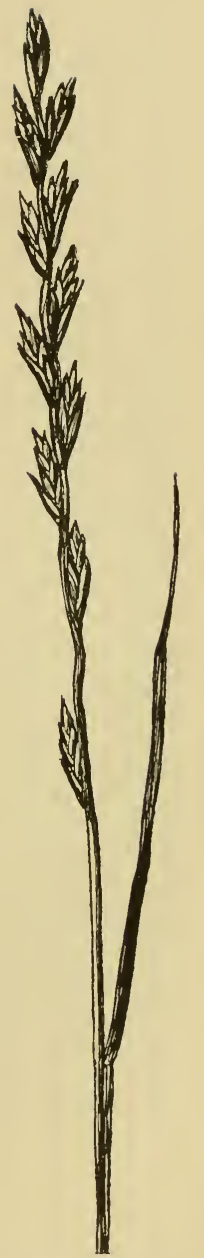
RYEGRASS (Lolium perenne). 
It is not suited to regions where the winters are cold, but in mild climates it makes a strong, vigorous growth. Where the climate is favorable it is an excellent plant for use in temporary pastures. About 30 pounds of seed per acre is required for a full stand. It may be sown in either fall or spring.

Italian ryegrass, like perennial rye, is used extensively in lawn mixtures. Growing rapidly, as it does, and being short-lived, it is an excellent species for seeding with Kentucky bluegrass and white clover.

Johnsongrass. - Johnsongrass (Holcus Halepensis) is a robust, smooth perennial, with stems 3 to 5 feet high, provided with strong, creeping rhizomes. The panicle is open and spreading, 6 to 12 inches long, reddish or purple, and hairy at the base.

Johnsongrass is a native of the Old World but is now extensively naturalized in America. It is a somewhat valuable forage and meadow grass in the South, but on account of its tendency to spread in cultivated fields, and the difficulty of eradicating it, the plant cannot be recommended generally.

The plant is valuable for the hay which it produces. The best growth is procured on heavy soils, preferably those rich in lime. When grazed for more than two seasons the leafage is usually much reduced. Grazing does not destroy the stand, however. On permanent meadows this grass, if its tenacious habits are disregarded, is probably the best hay species in certain parts of the South, notably on the black soils of central Texas, where it reaches its maximum development. Where the crops are to be rotated Johnsongrass has no place. The plant can be eradicated, however, but the process is tedious and expensive.

Unfortunately Johnsongrass occasionally produces toxic symptoms in stock, hydrocyanic acid being formed under certain conditions, especially in second growth. As a poisonous species, however, the plant requires further study.

Sudangrass. - Sudangrass' (Holcus Sorghum Sudanensis), though an annual, resembles Johnsongrass in habit of growth, but is without rootstocks (Fig. 45). It is grown principally as a hay and soiling crop, though in some localities it is used as a 
pasture plant. It grows on a variety of well-drained soils and is relatively drought-enduring.

Sudangrass is sometimes sown broadcast, but is best planted in drills 12 to 18 inches apart. In sections best adapted to its growth Sudangrass may be cut two to four times. The yield is

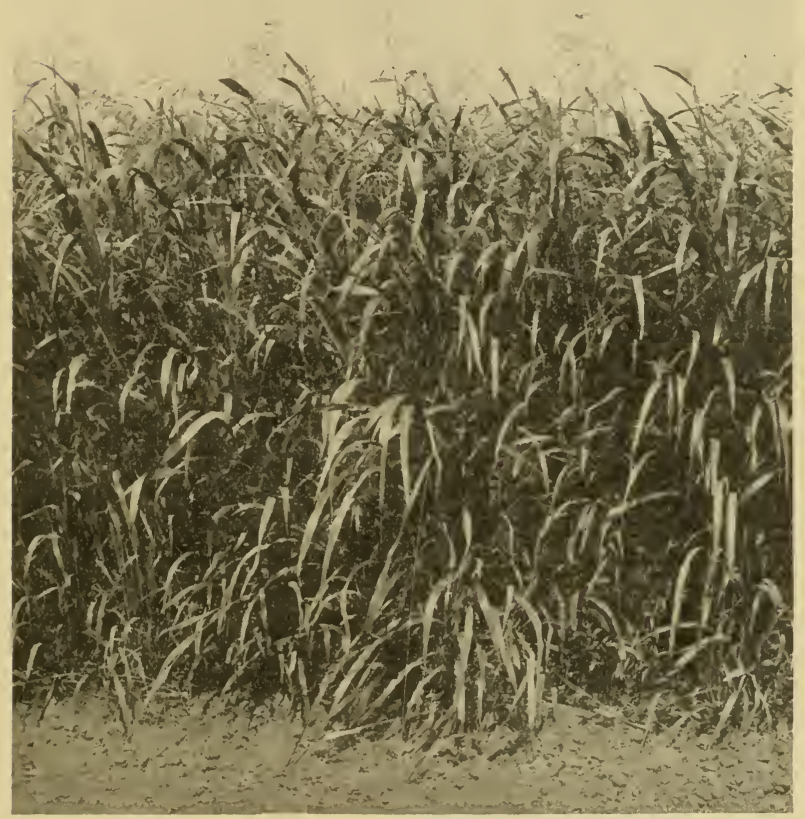

(U.S. Dept. of Agr.)

FIG. 45. - SUDANGRASS (Holcus Sorghum Sudanensis).

3 to 8 tons of excellent hay per acre. It is reported that Sudangrass, grown under irrigation at Chico, California, produced a yield of 9.8 tons of cured hay per acre.

Being a drought-enduring plant it does not do well in regions 
of excessive rainfall, as in parts of Florida and along the Gulf

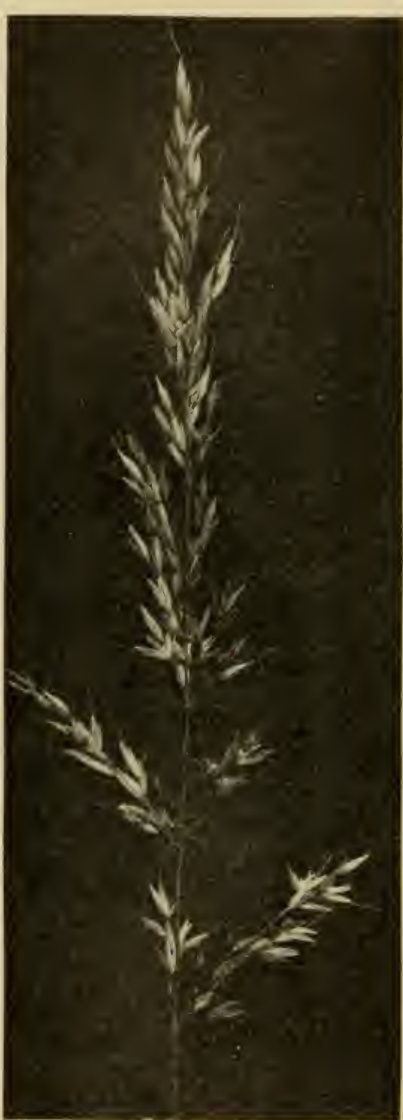

(U.S. Dept. of Agr.)

FIG. 46. - TALL OATGRASS (Arrhenatherum elatius)

coast of Texas. In the central and northern portions of the cotton region and in the drier portions of Texas and Arkansas Sudangrass is a valuable hay plant.

Tall Oatgrass. - Tall oatgrass (Arrhenatherum elatius), also known as Randall grass, is a tall-growing perennial bunchgrass, with narrow panicles resembling the common oat (Fig. 46). It is a native of Europe and is grown to a limited extent for hay and pasture in this country.

As the plant does not form a sod, the best results are obtained when it is sown in combination with other grasses. The most luxuriant growth is enjoyed in mild climates of the South. Here it matures with the earliest of the grasses, and when it is cut early an excellent aftermath of pasture is produced. Also, in the South. as the growth continues late in the fall, the plant furnishes good winter pasture. The seed habits are strong.

For hay the plant is not highly satisfactory because of its low palatability. Tall oatgrass is valued chiefly because of its hardiness and the early pasture feed which it furnishes. 
Meadow Fescue. - Meadow fescue called English bluegrass, and formerly known to botanists as $F$. pratensis, is a tufted, smooth perennial grass which grows from $I \frac{1}{2}$ to 4 feet tall. The tuft is characteristic in being more spreading, loose, and open in habit than that of most bunchgrasses. The leaves have the appearance of those of Kentucky bluegrass but are more stiff and wiry. The panicle is narrow, flat, and somewhat contracted (Fig. 47). Meadow fescue was introduced into the United States from Europe about $18_{5}$ o. It is grown most successfully at the present time in the corn belt region, notably in Missouri and Kansas.

The amount of forage produced is not large, but the grass is rich in nutrients and is relished highly by stock both as pasture and as hay. If it is to be harvested as hay, the cutting should be early, for otherwise the leafage is somewhat tough and wiry. Under favorable conditions an excellent aftermath of pasture leafage is produced, and this remains green and tender until late in the fall.

In general, meadow fescue is not so valuable a plant as orchardgrass or smooth bromegrass. When used either for pasture or as a hay plant, meadow fescue is not long-lived.

In planting meadow fescue, it is best to plow the land and establish a good seed bed. About 30 pounds of seed to (Festuca elatior), also

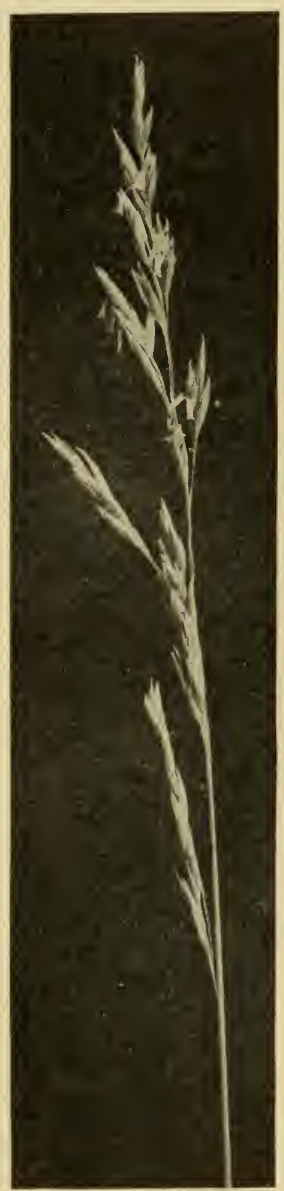

FIG. 47. - MEADOW FESCUE (Festuca elatior). the acre will usually be sufficient to produce a good stand. 


\section{N. C. State College}

148

PRINCIPAL INTRODUCED FORAGE GRISSES

\section{GRASS MIXTURES}

In the foregoing discussion various grass mixtures have been several times suggested. Combinations of grasses and legumes are generally to be preferred to a grass cover of a single species. The advantages are essentially these: Combination stands usually afford more continuous cropping; they yield more; the palatability of the forage throughout the season is higher; and the crop may possibly be a better-balanced ration of food.

In choosing grasses for pasture, one should be careful to select species in such a way that the deficiencies of one may be balanced by the advantages of another; for instance, he should choose species that do not mature at the same time and plants whose seasons of maximum production do not occur simultaneously.

Mixtures for Temporary Pasture. - For temporary pasture, to be used only two or three years, quick-growing grasses and clovers are best. The following combination is popular because of the good results obtained:

\section{Pounds}

Pounds

Alsike clover

Timothy.............. 4

English ryegrass........ I2

Redtop............. 2

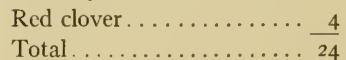

If stock is allowed on the pasture early in the season, the seeding should be somewhat heavier than here recommended, as a goodly proportion of the seedlings is destroyed by trampling. In this combination the ryegrass will produce the earliest and largest amount of forage the first year, but in the second season it will be largely replaced by timothy and redtop.

Mixtures for Permanent Pasture. - Combination seeding especially suited to the bluegrass and timothy region should contain both early-developing and slow-growing species. The following mixture is popular:

\section{Pounds}

Pounds

Kentucky bluegrass....... 6

Timothy.............. 6

Orchardgrass............. 3

White clover........... 2

Red clover............. 3

Redtop............... 3

Total................ 23 
On poor, infertile soils, low in lime content, the following combination is meritorious:

Pounds

Alsike clover........... 3

Canada bluegrass........ 9

Orchardgrass........... 3
Pounds

Redtop............. 3

White clover.......... 2

Total ............... $\overline{20}$

\section{QUESTIONS}

1. (a) Approximately how many native grasses occur in the United States? (b) How many grasses are extensively cultivated? (c) Name the five perennial grasses that are grown extensively on permanent pastures in this country.

2. In what region of the United States does Kentucky bluegrass grow well, and in what region does it fail to produce a good crop?

3. Compare $(a)$ the distribution, $(b)$ the forage value, and $(c)$ the soil requirements of Canada bluegrass and Kentucky bluegrass.

4. (a) Where is Bermudagrass extensively grown? (b) How does the grazing capacity of Bermudagrass compare with that of Kentucky bluegrass?

5. (a) Discuss the habit of growth and forage value of Hungarian bromegrass. (b) How would you establish a pasture of Hungarian brome?

6. Compare $(a)$ the palatability, $(b)$ the yield, $(c)$ the soil requirements of redtop with those of orchardgrass.

7. (a) Is timothy more valuable for hay or for pasture? (b) How many pounds of timothy seed should be sown to the acre, and how should the seed bed be prepared?

8. Discuss the value of $(a)$ ryegrass and $(b)$ Johnsongrass for permanent pastures.

9. How does the palatability of tall oatgrass compare with that of meadow fescue?

10. Discuss the merits of seeding to a mixture of grasses and other species.

\section{BIBLIOGRAPHY}

Ball, C. R. Saccharine Sorghums for Forage. U. S. Dept. of Agr. Farmers Bul. 246, 1906.

Evans, Morgan W. Timothy. U. S. Dept. of Agr. Farmers Bul. 990, I9I8.

PiPer, C. V. Important Cultivated Grasses. U. S. Dept. of Agr. Farmers Bul. I254, 1922.

Piper, C. V., and Carrier, Lyman. Carpet Grass. U. S. Dept. of Agr. Farmers Bul. I I30, I920. 
Piper, C. V., and Hillman, F. H. The Agricultural Species of Bent Giasses. U. S. Dept. of Agr. Bul. 692, I9I8.

Spillman, William J. Farm Grasses of the United States. Orange Judd Co., N. Y., I905.

Tracy, S. M. Natal Grass: A Southern Perennial Hay Crop. U. S. Dept. of Agr. Farmers Bul. 726, revised I922.

Rhodes Grass. U. S. Dept. of Agr. Farmers Bul. I048, I9I9.

Vinall, H. N. Sudan Grass as a Forage. U. S. Dept. of Agr. Farmers Bul. 605 , 1914.

Sudan Grass. U. S. Dept. of Agr. Farmers Bul. I I 26, I920.

Note. - Several of the works listed at the end of Chapter VIII contain material on grasses. 


\section{CHAPTER VIII}

\section{PRINCIPAL INTRODUCED NONGRASSLIKE FORAGE HERBS}

The principal introduced nongrasslike forage plants are members of the pea, pulse, or bean family (Fabaceae, or "Papilionaceae" of the older botanists). This great natural family embraces upwards of 325 genera and 5,000 species of world-wide distribution, and is characterized by its irregular, 5-merous, papilionaceous ("butterfly-like") flowers, the stamens mostly ro and diadelphous, and by the stipulate, usually compound (mostly pinnate or palmate) leaves, though rarely the leaflets are reduced to one. Practically all the older botanists and a few of the modern ones merge the family Fabaceae (under the subfamily or tribal names Papilionoideae, Faboideae, etc.) in what is called by them the legume family (Leguminosae), a group constituting upwards of 10,000 species, whose fruit is the characteristic legume ("pea pod") but whose flowers are, save for the pea-bean group, mostly rotate and never truly papilionaceous. This conception of the family embraces the acacias, sensitiveplants or mimosas, partridge-peas, sennas, and kramerias, with the common garden pea and bean; but this enlarged group most present-day taxonomists prefer to regard as an order, rather than family, and, as such, term it Fabales, or Leguminales.

As a cultivated forage group only the Fabaceae, or restricted pea, bean, or pulse family, are of concern here. Nearly all these plants have nitrogen-fixing bacteria living symbiotically on their roots and hence are rich in proteids. It is natural, therefore, that, generally speaking, this group is highly esteemed by stockmen because of the exceptional nutritive qualities of many of the species.

The most important legumes used as cultivated pasture plants are the true clovers, sweet clover, bur clovers, alfalfa or lucerne, cowpeas, soybeans, vetches, velvet bean, and Japan clover. 
The Clovers. - Stockmen often use the word "clover" to designate various herbaceous plants of several genera of the pea family, but here the term is confined to species of the genus Trifolium. About 275 species of clover have been discovered, yet not more than about half a dozen are extensively cultivated in the United States. They are annual, biennial, and perennial and occur most abundantly in the temperate parts of the Northern Hemisphere. Among those valuable as pasture forage, Alsike clover and white clover are of first importance. Of less pasture value are red clover (Trifolium pratense) and crimson clover (T. incarnatum), but as hay plants they are second to none.

Alsike or Swedish Clover. - Alsike clover (Trifolium hybrid$u m$ ) is a tall, slender-stemmed, long-lived perennial, similar in habit of growth to red clover, except that the stems are more slender and less erect. The main distinction between Alsike and white clover is that the white clover has stolons and "creeps" along the ground. The Alsike does not have these stolons or rooting stems at the nodes or joints of the stems; it is erect or ascending. Alsike also has large, conspicuous stipules at the base of the leaf stalks, whereas those of white clover are small and inconspicuous. The leaflets of Alsike are rounded at the apex, and those of white clover are heart-shaped-notched at the apex (Fig. 48). Alsike clover has long been cultivated in Sweden. The earliest attempts to grow it in the United States were soon after 1839, when the editors of the New Genesee Farmer, of Rochester, New York, brought some seed to this country and distributed it to the readers of that paper. ${ }^{1}$

The best growth is obtained in cool climates on moist or moderately wet soils. It is commonly seeded with timothy and red clover, but sometimes pure stands are grown. When sown alone, 5 to 8 pounds of seed should be used to the acre. Being long-lived and adapted to a variety of soils, Alsike clover is commonly used in pasture mixtures. The leafage is relished by all classes of stock.

1 Pieters, A. J., "Alsike Clover." U. S. Dept. of Agr. Farmers Bul. Ir5I, p. 4,1920 . 
White Clover. - White clover (Trifolium repens) grows wild throughout the temperate regions of Europe and Asia. It appears to have been introduced into the United States about I 747 . Being well adapted to the greater part of the United States and Canada, white clover is now found growing along roadsides, in waste places, and in pastures almost everywhere. White clover is a long-lived perennial but differs from the other cultivated clovers in having stolons. This characteristic, coupled with its high palatability and nutritive qualities, gives the plant remarkable pasture value. Its rate of spread is similar to that of Kentucky bluegrass, a good sod usually being formed. The growth is rapid in warm as well as cool climates; but, being a plant intermediate in moisture requirements, it is not well adapted towet or acid soils. Also the seed habitsof white clover are strong. In forage mixtures white clover is invaluable, especially on bluegrass pasture. For

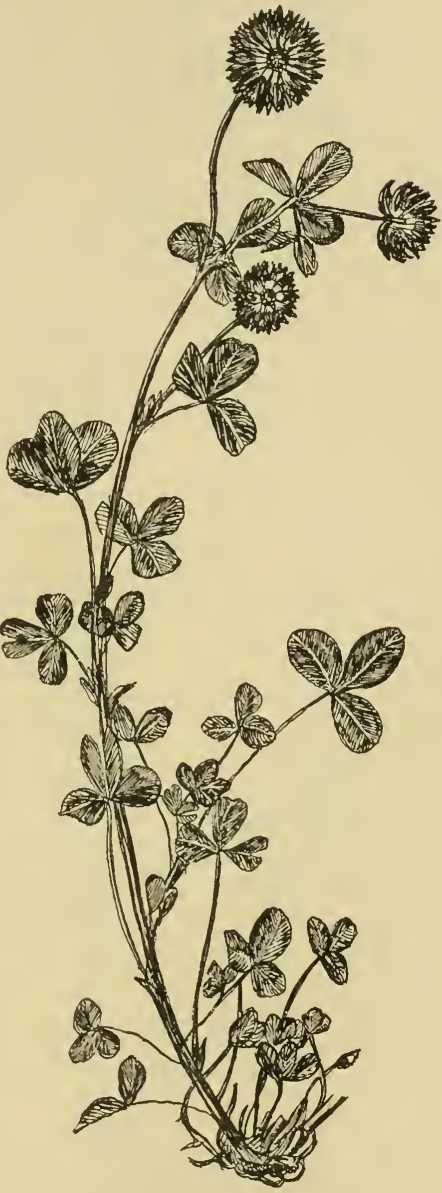

FIG. 48. - ALSIKE CLOVER (Trifolium hybridum). pasture or lawn mixtures 2 to 5 pounds of white clover should 


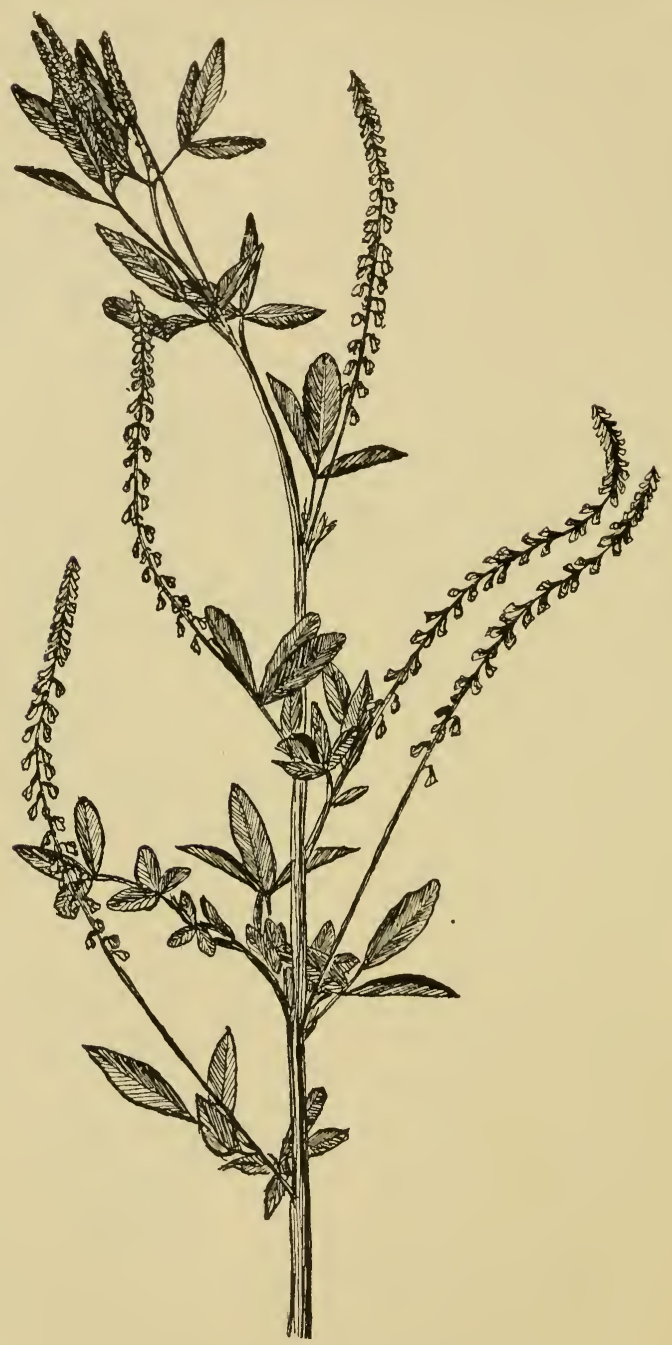

FIG. 49. - SWEET CLOVER (Melilotus alba). 
be used to the acre, but when sown alone 8 to ro pounds is satisfactory.

Sweet Clover. - Sweet clover (Melilotus alba), the most valuable forage species of the genus, is an erect, branching plant, 3 to 8 feet tall, with small white flowers in elongated racemes (Fig. 49). It is a biennial and seldom blossoms the first year. The plant is characterized by a sweet odor, and on this account has been given the common name "sweet clover." It is a native of Europe and Asia and is thought to have been introduced into North America from western Asia about I739.

This species is widely distributed over the United States and Canada, where, along roadsides and in other waste places, it grows with various weeds. Although sweet clover is not uncommonly a pest in cultivated fields, it is largely used as a pasture plant. Sweet clover is unusually cold-enduring, but it is nevertheless well adapted to southern climates.

Except under the most favorable conditions of cultivation the growth of sweet clover is somewhat backward the first season. The second year growth starts early, and the stand usually reaches full height in two to three months. In the Northern States, when the plant is cut early for hay, a luxuriant aftermath is produced. In the Southern States as many as three good cuttings are obtained in a season.

The seed habits of sweet clover are exceptionally strong. In most regions the seed is sown either in early spring or in the fall, often with wheat or rye. About 20 pounds of hulled seed is sown to the acre.

The main objection to the use of sweet clover as a pasture and hay plant is its bitter taste. At first most foraging animals refuse to feed upon it, but in time they become accustomed to the taste, devour the leafage and tender stems with relish, and do well when feeding upon it.

Bur Clovers. - Bur clovers (Medicago) are members of the same genus as alfalfa. They are primarily adapted to regions of mild, moist winters. In the United States this embraces the cotton-growing area of the South and all of the Pacific coast west of the Cascade and Sierra Nevada Mountains. 
Two species of bur clover are common in the United States,

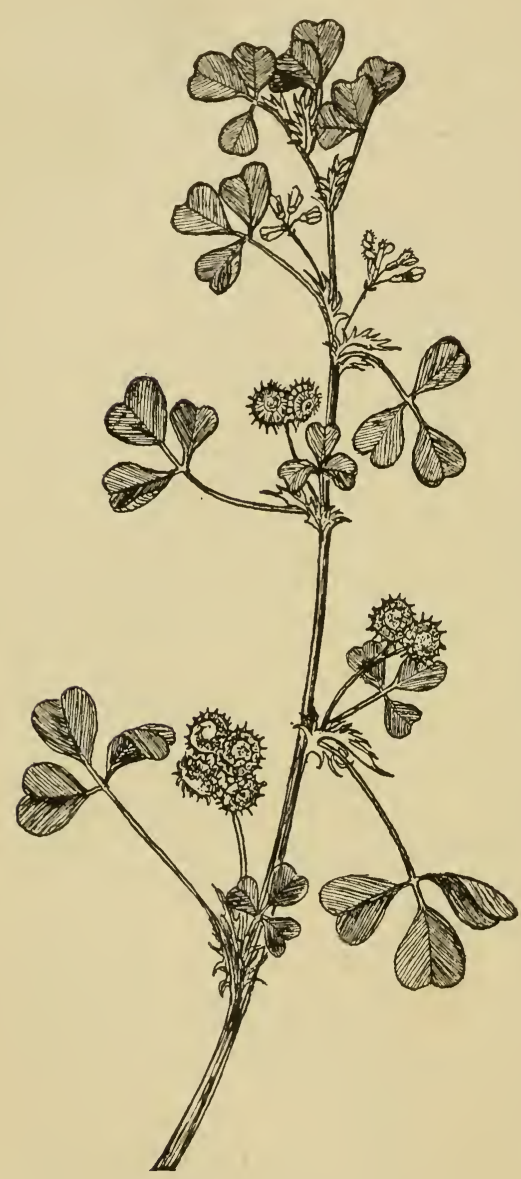

FIG. 50. - TOOTHED MEDIC, OR BUR CLOVER (Medicago hispida). namely, toothed medic, or bur clover (Medicago hispida) (Fig. 50), a highly valuable plant in California and Oregon, and spotted or southern bur clover, known to botanists as M. Arabica.

Spotted bur clover is a much more valuable plant in the South than is toothed bur clover, especially for winter pasture, as it usually grows throughout the entire winter. It does especially well on the sandy soils of the piney - woods region. Here it furnishes good pasture as early as January. Because of its strong seed habits this species maintains itself well when once established. A good combination of seed for use in pasture sowing is spotted bur clover and Bermudagrass, for the reason that the bur clover remains succulent and palatable throughout the winter, whereas the Bermudagrass grows only during the warmer part of the season. 
Toothed bur clover grows luxuriantly on the Pacinc coast, being much more abundant in California than spotted bur clover. It grows on all types of soil, but loam or adobe soils are the best, even though they may be somewhat deficient in lime. On both pasture and cultivated land good stands are often obtained without artificial seeding. Once a stand is established it is maintained indefinitely if the burs are permitted to develop. Both species furnish excellent forage for cattle, sheep, and hogs. Usually the leafage is not relished by horses and mules.

Where the lands do not become seeded naturally, the seeding should be done in the fall, preferably just before the autumn rains begin. About I 5 pounds of the hulled seed should be sown per acre. A light harrowing is the best method of covering the seed.

Alfalfa, or Lucerne. - Alfalfa (Medicago sativa) is thought to be the oldest cultivated forage plant. Growing naturally in the hot, dry regions of Persia and Asia Minor, it yields well in warm, dry climates of the United States but does not do well in humid regions. In the far West it is without doubt the most important of the introduced forage plants. There are several varieties of alfalfa, but the blue-flowered kinds are the most widely cultivated.

It is the general practice to sow alfalfa pure, though sometimes a nurse crop is used. Where ample moisture is available, ro to I 5 pounds of seed per acre should be sown. In drier regions 6 to 8 pounds is sufficient. The seed may be scattered any time during spring or summer.

As hog pasture, alfalfa is second to none. It is not well adapted to the grazing of cattle or sheep because of the tendency to cause bloating. Exception to this general statement is found in the arid regions where bloating is practically unknown. The fact that alfalfa causes bloating of animals in one region and not in another is not understood. Bloating is most troublesome if the animals are very hungry when turned on the alfalfa pasture, or if they graze when the leafage is wet. Alfalfa pasture should never be grazed very closely, as the practice destroys the buds at the crown of the plant and causes the yield to decline sharply. 
Cowpeas. - Cowpeas (Vigna Sinensis) are grown more widely in the cotton region than any other leguminous crop. There are several varieties, some of which produce long, trailing vines,

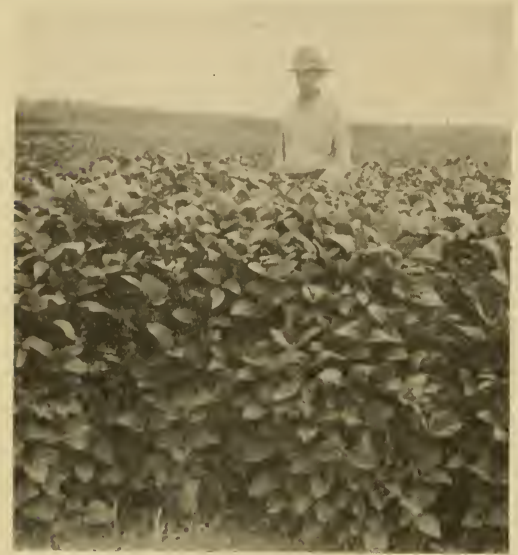

(U. S. Dept. of Agr.)

without tendrils; but others are erect and bushlike. Some varieties reach maturity in two months, and others require nearly six months. They are adapted to all types of soil, but on wet lands they do not thrive. The leaves are trifoliolate and similar in appearance to those of the garden bean; in fact, the cowpea is more closely related to the garden bean than to the garden pea (Fig. 5I).

Fig. 5I. - GENERAL VIEW OF A FIELD OF COWPEAS (Vigna Sinensis).

It is thought that the first cowpea plants were introduced from tropical Africa, where various wild forms abound. The plant is believed to have been under cultivation for more than 2,000 years. Although cultivated in the United States for nearly a century, until recently cowpeas have not been popular in the Northern States. They are not of great importance in States where alfalfa or red clover grows well.

Cowpeas are sown broadcast in pure stand, or in rows 36 to 48 inches apart, or between corn rows, or with certain other widely spaced crops. When sown alone broadcast I to 2 bushels of seed per acre is used; when planted in rows 3 or 4 feet apart 2 to 3 pecks of seed per acre is sufficient. If they are cut for hay, the harvesting should be done as soon as the earliest pods become yellow, for at that stage the vines cure well. For hay the upright varieties should be sown, but for pasture any of the 
trailing forms are satisfactory. The crop may be used to advantage either as hay, as a soiling crop, or as pasture.

Soybeans. - Soybean (Glycine hispida), an annual leguminous plant, is closely related to the cowpea (Fig. 52), and has been cultivated in this country for about a century. There are many varieties and forms, such as those with erect stems and few branches, and the widely branched varieties of a bushy form of growth.

Soybeans are essentially a corn-belt crop. Although the area of their culture in the United States is largely coextensive with that of cowpeas, they may profitably be grown farther north than cowpeas. Soybeans are used for the same purpose as cowpeas, but they have several advantages over the latter. They are erect and without runners; the seed does not shell out readily; the seed crop is larger; and the leafage remains palatable longer after falling to the ground. Soybeans are adapted to a wide variety of soils and are not readily injured either by drought or by abundant moisture.

The time of planting is about the same as for corn. In the cotton region planting any time between April and June gives good results. When the seed is drilled in rows 24 to 36 inches apart, one-half to three-quarters of a bushel of seed should be used to the acre. Soybeans are highly nutritious; they have the highest protein content of any legume that has been analyzed, with the single exception of the peanut. The plant is valuable both for pasture and hay.

Vetches. - Vetches (Vicia) are mostly slender, climbing plants bearing tendrils at the ends of the leaves (Fig. 53). Approximately 125 species have been described, about 24 of which are native to the United States. Of the various species of cultivated vetches, three - hairy or sand vetch (Vicia villosa), common or spring vetch ( $V$. sativa), and the narrow-leaved or Augusta vetch ( $V$. angustifolia), all of which are annuals - are extensively cultivated. 


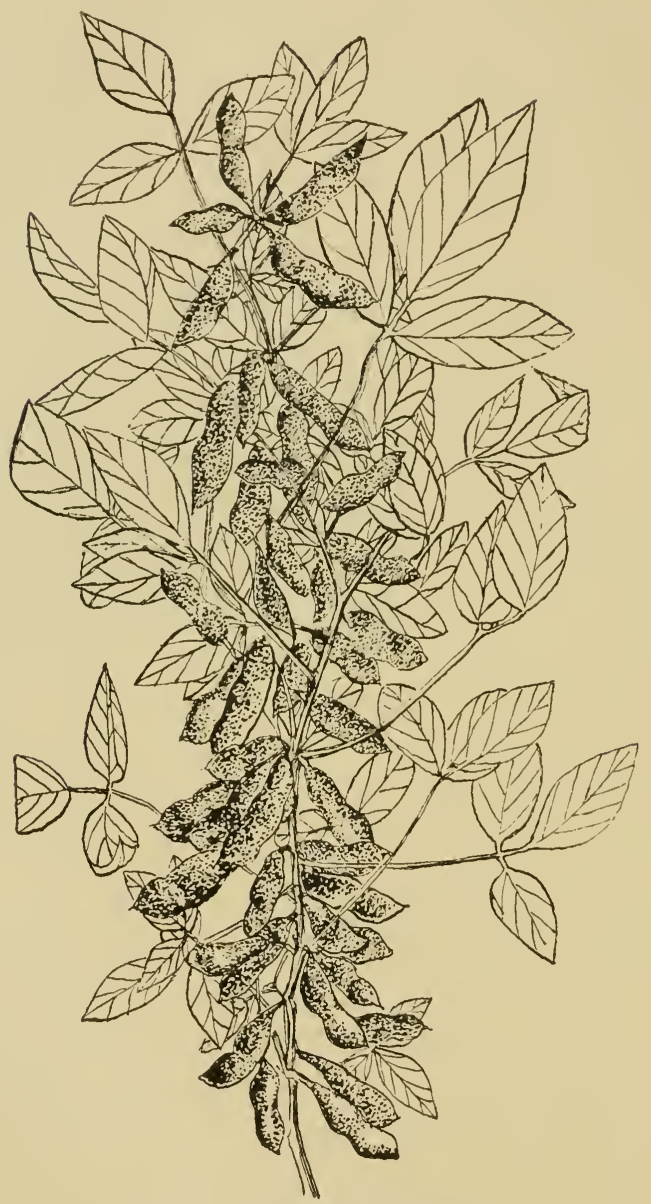

FIG. 52. - SOYBEAN (Glycine hispida). 


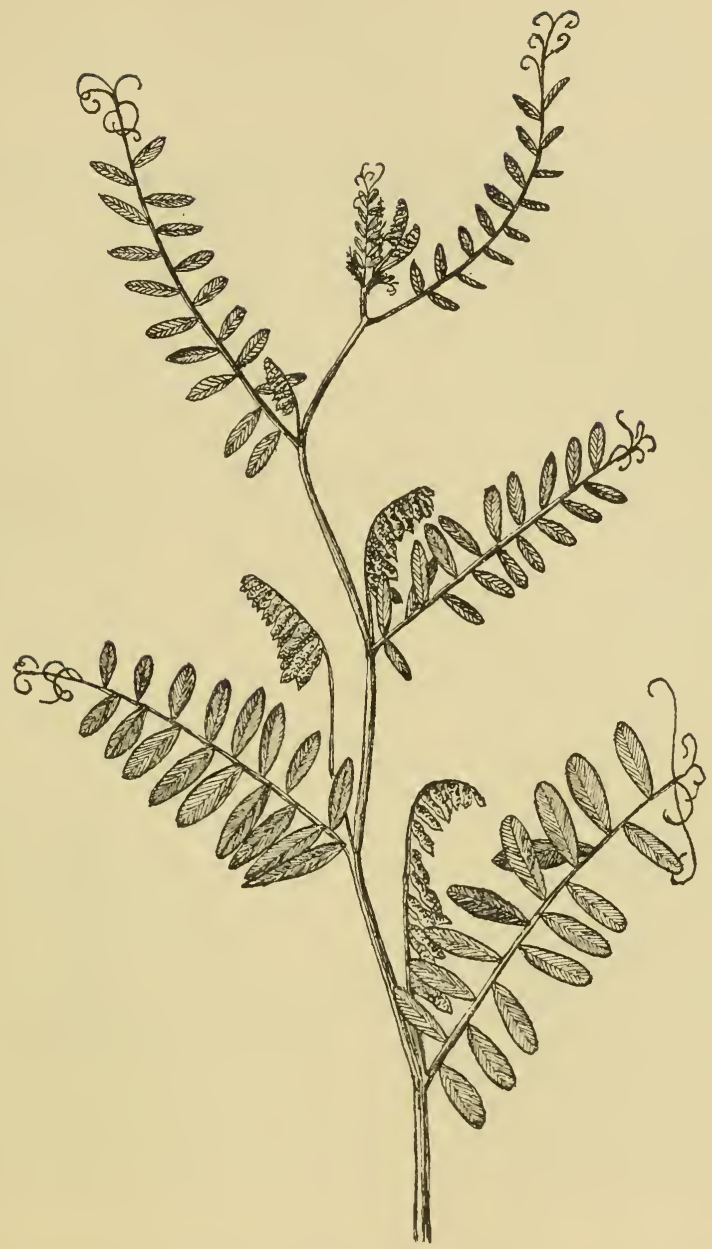

FIG. 53.- HAIRY VETCH (Vicia villosa) 
Hairy vetch is readily recognized by the dense gray hairs which occur on all parts of the plant, and by the crowded clusters of slender, deep-blue flowers. This species is well adapted to both warm and cold climates, seldom winter-killing even in southern

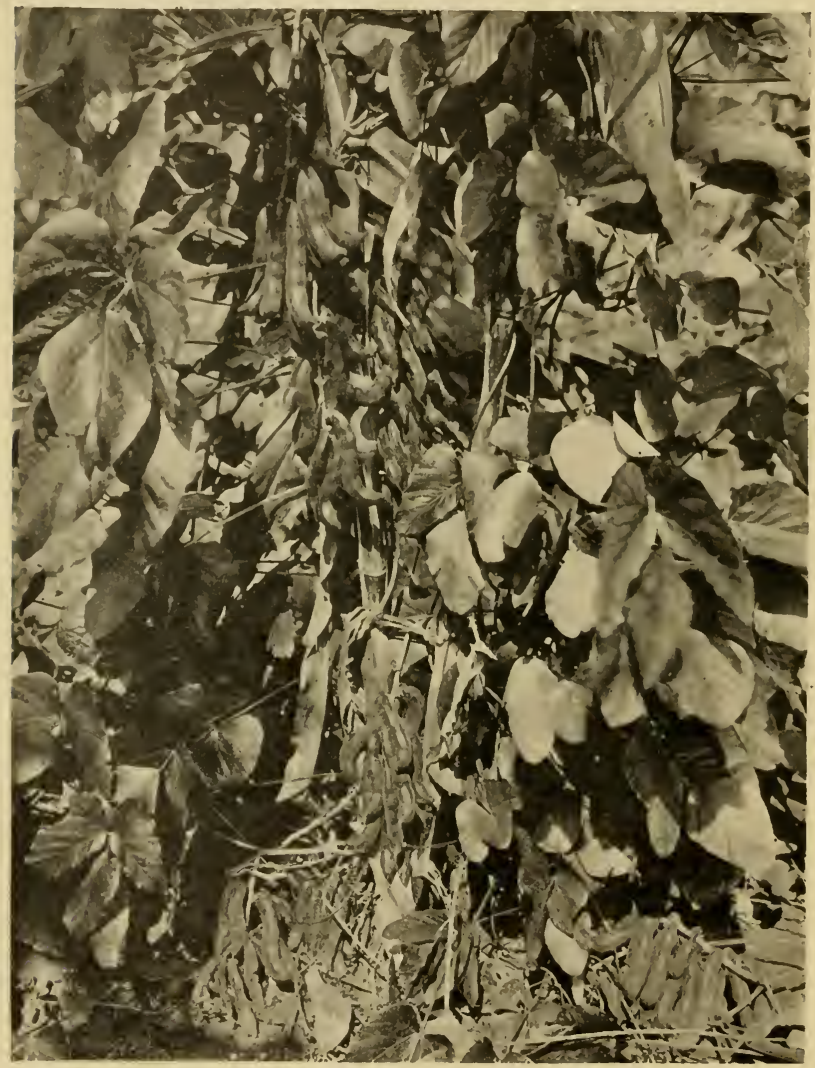

FIG. 54. - VELVET BEAN (Mucuna utilis) IN FULL POD.

Canada. In the South the vetches do well in the black prairie alluvial regions, where they are of ten grown with a nurse crop, 
such as winter oats or rye. About 30 pounds of vetch seed to one bushel of grain is sown to the acre. When sown alone between 50 and 60 pounds of seed to the acre is used. It is a somewhat drought-enduring plant and does well on sandy or clayloam soils.

As stock feed, either as winter pasture or as hay, hairy vetch ranks high, the leafage being readily consumed by all classes of stock. It also makes a satisfactory cover crop and is valuable in improving and maintaining soil fertility.

Common or spring vetch is a viny annual, which grows close to the ground. The cultural requirements of common vetch are the same as those of hairy vetch. Narrow-leaved vetch, as well as the common and hairy vetches, has been used considerably in the cotton region.

Velvet Bean. - Velvet bean (Mucuna utilis) is a native of India and is believed to have been introduced into this country about 1875 . Its growth is confined to the South, the area of successful cultivation being practically the same as for the cultivation of cotton east of Texas. It is an annual twining legume that grows with unusual vigor; but, because it matures late, it is confined to a warm climate (Fig. 54). Along the Gulf coast, in Atlantic coast regions, and as far north as the Coastal Plain of North Carolina, velvet bean is an important constituent of the field crops. It is also an important crop plant in Cuba, Porto Rico, coastal Mexico, and other tropical countries. Some species are dwarfed and bushlike in growth, but others make vines 50 feet or more in length. There are several varieties of velvet bean. Two somewhat distinct types of pods are produced - those covered with dense, black, velvety hairs, and those whose hairs are short, white, or gray. The pods vary in length from 2 to 6 inches.

The cultural methods are practically the same for all varieties. The rate of seeding is determined by the use to be made of the crop. When planted with corn to be harvested for its grain. 2 to 3 quarts of seed per acre is sufficient; but, if a heavy crop of beans is desired, and the corn plants are to be used chiefly as support for the vines, twice as much seed should be sown. If 
the fullest possible stand is desired, as for green manure, a halfbushel or more of seed should be used.

Velvet bean furnishes excellent forage for cattle and hogs in autumn and winter. The plant is not readily injured by exposure and hence furnishes much desirable feed until early spring. No more than half an acre of good cover is required to support a cow for a roo-day period during the winter. This is equivalent to the production of about 300 pounds of beef per acre. The pods and seed are often gathered and ground into meal for feeding to cattle and hogs.

Japan Clover. - Japan clover (Lespedeza striata) is a native of eastern Asia and was introduced into this country about $\mathrm{r} 840$. It is a highly valuable plant in the southeastern part of the United States. As it is adapted to practically all types of soil and grazing conditions, its value is difficult to estimate. Although it is an annual plant, it produces sufficient seed, even under adverse conditions, to reseed itself, and hence it is for practical purposes a perennial in permanency. Being a legume, it is rich in protein. All classes of stock devour the plant with gusto and do exceedingly well upon it.

As it is valuable for soil improvement, and an excellent forage and hay plant, its growth should be widely extended in practically all the pastures of the South, especially the cut-over pine lands of the Coastal Plain. On the rich bottom lands of the Gulf States it produces a large amount of good hay.

In planting, the seed bed should be well prepared. The seed, of which 5 pounds should be sown to the acre, may best be broadcasted over the oat field, after which the seed of both should be harrowed in lightly. The lespedeza does not make much growth until the oats are harvested. A large proportion of the seed of this plant is harvested in Louisiana and Mississippi.

It is estimated that the grazing capacity of great stretches of artificially established pastures in the South has been increased at least 25 per cent by the use of lespedeza. Unlike many leguminous plants, it does not cause animals to bloat.

Good Germination and Purity of Seed Essential. - It is not to be expected that good forage or other crops can be grown 
unless seed of high viability is used. The soil, the seed bed, and the conditions of growth may be ideal; yet all these are as naught if poor seed is planted. Grood seed should be true to name and relatively free from impurities of all kinds; furthermore it should show a high percentage of vigorous germination.

The seed of grasses, legumes, and other forage plants is often poor. Especially is this true of such important pasture plants as Kentucky bluegrass, Hungarian bromegrass, red clover, and Alsike clover. The seed of grasses, too, especially if purchased in a mixture, is often adulterated with cheaper or inferior kinds of seed.

The germination and purity of the seed to be sown should be determined before planting. If it is not possible or convenient to ascertain the value of the seed, through the State Experiment Station or some such public-service organization, it may be tested in some simple homemade germinator, of which there are many kinds.

A satisfactory germination chamber may be made by using two dinner plates. Two or three layers of blotting paper or a half-inch of sand should be placed in the one plate, covered by a piece of heavy cloth. When the sand and cloth have been saturated with water as pure as can be obtained, roo seeds should be placed on the cloth, and the second plate inverted over the first, care being taken that the edges fit so closely as practically to prevent evaporation. Box, "rag doll," and various other types of makeshift germinators are usually satisfactory. The seed should be examined every few days and the results noted. Care must be taken at all times during the test to keep the seed moist and at a proper temperature for growth.

To make sure of obtaining a supply of good and genuine seed the four following precautions should be observed:

I. Require from the seed agent, at the time of purchase, a guarantee of purity, germination strength, and identity.

2. Insist that each species purchased be supplied separately, and always avoid the acceptance of seed mixtures.

3. Purchase the seed with the understanding that if, when 
tested, it fails to come up to the requirements, it is to be returned with no obligation on the part of the buyer.

4. Obtain the seed far enough in advance of the seeding time to ascertain the facts concerning its value.

\section{QUESTIONS}

1. (a) What clovers are especially valuable for pasture? these will probably withstand the heaviest grazing? Why?

(b) Which of

2. What are the objections, if any, to the use of sweet clover as a pasture and hay plant?

3. (a) To what regions are the bur clovers adapted? (b) How many species of bur clover occur commonly in the United States? (c) On what type of soil does toothed medic, or bur clover, grow best? $(d)$ Where the lands are not seeded naturally, how much seed of toothed bur clover should be sown to the acre?

4. (a) Where are cowpeas grown most extensively in this country? (b) How do the various varieties of cowpeas differ in habit of growth? Is the same form equally well suited for the production of hay and for pasturage? If not, why? (c) How are cowpeas usually sown, and how much seed is used per acre?

5. (a) In what States are soybeans grown extensively? (b) Compare the uses of soybeans with those of cowpeas. (c) When should soybeans be planted, how is the seeding done, and how much seed is sown to the acre?

6. (a) How many species of vetch are commonly grown? (b) Are they annual or perennial plants? (c) How much seed of hairy vetch should be sown to the acre (I) when seeded with small grain, and (2) when sown alone? (d) Discuss the value of the vetches as pasture forage and as hay.

7. (a) In what region of the United States is velvet bean successfully grown? (b) Discuss the cultural methods. (c) Discuss the value of velvet bean as a forage and hay plant.

8. (a) When was Japan clover, or lespedeza, introduced into this country? (b) To what region is Japan clover best adapted? (c) Discuss the cultural methods best suited to Japan clover. (d) Discuss the value of lespedeza as a forage plant.

9. (a) What are the requirements of "good" seed? (b) How would you determine the degree of purity of the seed of grasses, clovers, and the like?

10. Describe some simple device for determining seed germination.

11. What precautions in general should be taken to obtain good, genuine seed?

\section{BIBLIOGRAPHY}

Carrier, Lyman. Lespedeza as a Forage Crop. U. S. Dept. of Agr. Farmers Bul. I I43, I920. 
Coburn, F. D. The Book of Alfalfa. Orange Judd Co., N. Y., I 906.

Kephart, L. W. Growing Crimson Clover. U. S. Dept. of Agr. Farmers Bul. II 42, I920.

Livingston, George. Field Crop Production. The Macmillan Co., N. Y., I9I4.

McKee, Roland. Australian Saltbush. U. S. Dept. of Agr. Bul. 6r7, I9I9.

Button Clover. U. S. Dept. of Agr. Farmers Bul. 730, r916.

Purple Vetch. U. S. Dept. of Agr. Farmers Bul. 967, I918.

McKee, Roland, and Ricker, P. L. Nonperennial Medicagos. U. S. Dept. of Agr., Bur. of Plant Ind., Bul. 267, r913.

Morse, W. J. Cowpeas: Culture and Varieties. U. S. Dept. of Agr. Farmers Bul. II 48 , 1920.

Cowpeas: Utilization. U. S. Dept. of Agr. Farmers Bul. II 53, I920.

OAkley, R. A., and Westover, H. L. Commercial Varieties of Alfalfa. U. S. Dept. of Agr. Farmers Bul. 757, I916.

Pieters, A. J. Alsike Clover. U. S. Dept. of Agr. Farmers Bul. II 5 I, I920.

PIPER, C. V. Forage Plants and Their Culture. The Macmillan Co., N. Y., I9I4.

Piper, C. V., McKee, Roland, and Hillman, F. H. Vetches. U. S. Dept. of Agr. Farmers Bul. 51 5, revised 1920.

Shaw, Thomas. Clovers and How to Grow Them. Orange Judd Co., N. Y., 1906.

Tracy, S. M. Forage for the Cotton Belt. U. S. Dept. of Agr. Farmers Bul. I125, revised 1920.

Voorhees, Edward B. Forage Crops for Soiling, Hay, and Pasture. The Macmillan Co., N. Y.. I907.

Wilson, A. D., and Warburton, C. W. Field Crops. Webb Pub. Co., St. Paul, Minn $I^{\wedge} \mathrm{I} 8$ (revised edition). 

PART THREE

RANGE AND PASTURE PROTECTION 



\section{CHAPTER IX}

\section{CONTROL OF EROSION ON RANGE AND PASTURE}

Nearly one-half of the United States - the hilly half - is being seriously impaired by runaway waters. In a relatively short time - a mere moment of time historically considered much of the productive portion of hillside soils has been borne along the "line of least resistance." In our eagerness to work nature overtime we have destroyed the plant cover and prepared the soil for its voyage. The rain furnished the transportation.

Remove the upper dark layer of humus soil, and you have done the same thing as when you skim off the rich film which has accumulated over the surface of a pan of milk; you have taken the cream, the rich, productive part of the land, the part you pay for when you buy the farm.

Erosion is one of the most serious dangers that threaten the farms and pastures of the Nation. On the other hand, a good plant cover, especially on the steep hillsides, would be the safest possible insurance against erosion and consequent damage. And what would such insurance mean? It would mean that approximately one-half of the population of the United States would be more prosperous; that the productivity of about 797,000,000 acres of farm land in this country - not to mention the native pasture and forest lands - with a value of about $\$ 28,500,000,000$, would gradually increase instead of declining. Erosion, the most disturbing single factor in the development of the Nation's lands, is fortunately in a large measure under the control of man. For this reason the principles underlying its control are deserving of careful consideration.

Migration of Rainfall. - Everyone who has been in a dense forest or where other types of vegetation cover the ground, 
knows how thoroughly this ground cover protects the soil and retards or stores the water. The force of the falling rain and the downward pull exerted by gravity after the water reaches the ground are to a certain extent overcome by the vegetation and the litter on the surface. When the fallen rain finally reaches the soil, a part of the water is soaked up by nature's "sponge," a humus layer so rich in organic matter that it will hold several times its own weight in water. The water so held is liberated gradually, and the streams into which this clear, pure water drains vary but little in their flow the season through. Such streams furnish the best water supply for our most valuable irrigated lands.

Every drop of rain that falls on more or less exposed soil, on the other hand, has the power of removing soil particles, and with them the soluble salts essential to plant growth. If the vegetative cover on a drainage area has been largely destroyed, the washing off of the surface soil may remove far more decomposed vegetable matter and soluble plant food in a single season - indeed during one violent storm - than would be deposited by the decay of the vegetation in many years. More than this, the resulting erosion, with its rush of water and debris, frequently ruins the lands where the debris is deposited; and often roads, trails, power plants, and other improvements are destroyed. In many localities the loss of property from this source has been appalling.

Damage by Erosion. - The farmer-stockman who lives in the more arid parts of the far West probably realizes more keenly than those who enjoy an abundance of rainfall that prosperity depends largely upon an adequate water supply for the production of good crops. Water, ample water, and always more water is the real necessity of the West - the essential factor in making the lands pay a reasonable dividend. It is an interesting fact that the prosperity enjoyed from irrigated lands in the West is often directly traceable to the condition of the enormous drainage areas, or watersheds, of the National Forests. The intimate relation that exists between the National Forests and a sustained streamflow for irrigation in the West is 
generally recognized by the stockmen. This is not surprising when it is recalled that not less than 85 per cent of the water used for irrigating the $3,200,000$ acres of western farm lands has its origin in the mountains of the National Forests. Of about I 56,000,000 acres within the boundaries of the National Forests in I92 I, practically all of which contributes in one way or another to agriculture, approximately 8,000,000 acres lie above the altitude of forest growth. Of this acreage about 4,200,000 acres are barren; about I,500,000 acres support a cover of brush; and the remaining $2,300,000$ acres are grassland. The value of the lands at these dizzy heights lies chiefly in their efficiency as watersheds, that is, in the water which they contribute for irrigation. Because of the ruggedness of their surface and their economic relation to the adjoining communities and to agriculture generally, no better opportunity is offered for considering the erosion problem than that afforded on the National Forests. Furthermore, the principles developed in the control of erosion on these lands are applicable to farm and pasture lands generally.

On the National Forests, as elsewhere, the greatest damage from erosion occurs on the lands that have been badly overgrazed and whose ground cover has been destroyed or seriously impaired. After the breaking up of the vegetative cover caused by overstocking during the happy-go-lucky grazing period, many streams that had originally a steady, yearlong flow and teemed with trout became treacherous channels with intermittent flow through which plunged the water from rainstorms. Most of the streams swelled suddenly and subsided as quickly according to the size and frequency of the storms; and many such flows carried so much sediment that fish and similar life could not exist in the water.

The damage is not confined to the decrease in the forage yield of the lands eroded or to the silting over of adjoining agricultural lands to which the torrential floods carried the debris; the efficiency of the watershed in maintaining a permanent flow of irrigation water is also greatly decreased.

Many typical examples of the damage of erosion that have 
come under the observation of the author might be cited, but one will suffice. The incident to be related occurred on the Manti Forest in central Utah, on July 28, I9I2. The rainstorm was confined to an overgrazed belt of about 2 miles between the elevations of 9,000 and 10,500 feet. There was no rain in the valley or on the mountain below approximately 8,000 feet. The fall of .4I of an inch of rain continued intermittently for a period of two hours, but at no time with great violence. A flood of sufficient force developed to reach to the city of Ephraim, Io miles below, covering the streets and some farm land, and filling the basements of many buildings with mud and debris. Laden with silt, logs, vegetable matter, and even with rocks, some of which contained as much as 30 cubic feet of material, the flood destroyed wagon roads, trails, and irrigation ditches (Fig. 55).

The incalculable damage caused by the concentration of waters in the Mississippi River at various times is familiar to everyone. The magnitude of the damage that resulted from the overflow and devastation of the fertile bottom lands baffles comprehension. The losses on some of the river branches have been computed, however, and they serve to show how serious is the situation.

From March I5, 1907, to March 20, 1908, barely more than a year, three floods of the Ohio River caused a direct loss at Pittsburg, Pennsylvania, of about $\$ 6,500,000$. It is estimated that the average annual damage caused by floods of the Ohio River and its tributaries is not less than $\$ 50,000,000$; yet it is believed that there is not a stream emptying into the Ohio River whose flow could not be regulated by reëstablishing and preserving the vegetative cover on the contributing watersheds.

Innumerable instances of the appalling damage caused by erosion could be related; but the results when erosion is permitted free play are, ultimately, the same everywhere - the ruination of soil fertility and the destruction of practically all property found in the path of the deluge. 


\section{KINDS OF EROSION.}

Erosion may be considered in four aspects - gully erosion, sheet erosion, landslides, and river-bottom erosion. Hillside erosion is sometimes included as a distinct type, but such ero-

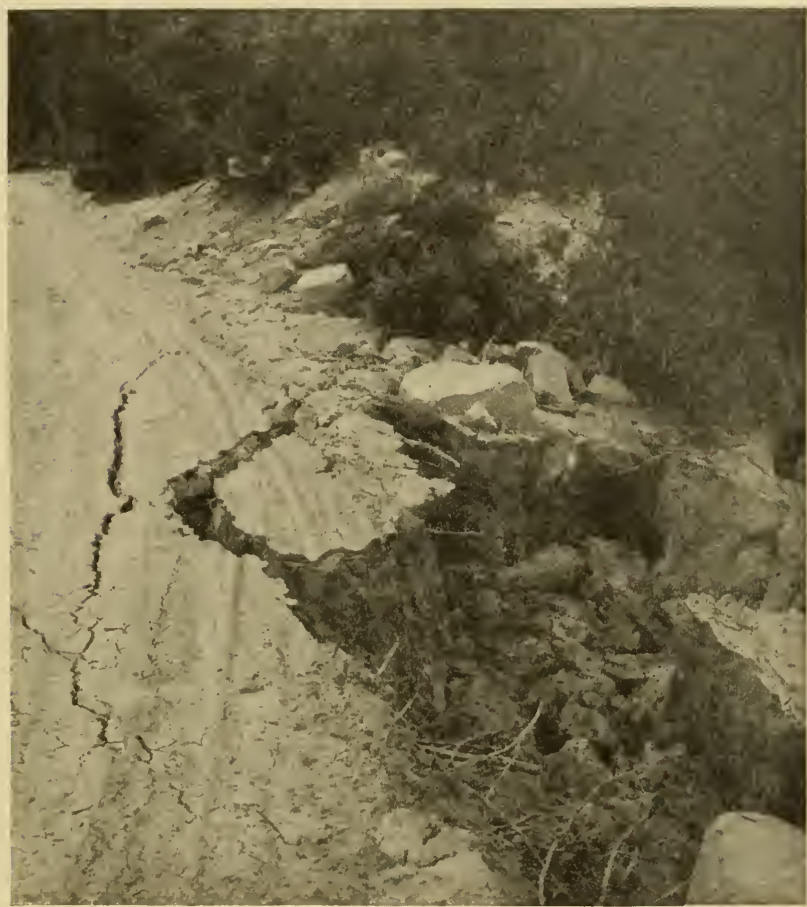

Fig. 55. - A WAGON ROAD ALONG A STREAM UNDERMINED DURING A TORRENTIAL FLOOD.

On account of the poor plant cover there is an erratic run-off of fallen rain after nearly every rain storm. The stream beds at the foot of the mountain, where the force of the water is greatest, are gullied out, and the banks cave in. Most of the loosened silt and rocks is deposited in the valley by subsequent storms.

sion is usually either a form of sheet erosion or of gullying, or a combination of both. 
Gully Erosion. - On lands which are somewhat steep and rolling, well-defined trench channels are readily formed where the plant cover has been destroyed. A large portion of the water from heavy rains finds its way into the channels, and the water, rushing rapidly down, carries away much of the loose soil over which it passes. Gully erosion is much more noticeable than sheet erosion and usually progresses more rapidly. Occasionally numerous small, more or less parallel gullies are formed which are popularly known as "shoestring gullies." They vary in form from sharp-bottomed V-shaped cuts with steep sides to broad depressions with gently rounded sides.

Sheet Erosion. - Sheet erosion is marked by a more or less uniform washing away of the soil over the surface as a whole. The water that is not taken up by the soil runs downward more or less uniformly over the land. With a heavy rainfall the flow down the slope may remove much of the surface soil. This form of erosion not uncommonly causes very serious losses of soil fertility and is difficult to control. Sheet erosion, however, is not confined to the action of water alone, but is caused by wind as well, a stiff wind often depositing considerable loose soil at the base of the slope.

Landslides. - The slipping down of surface soil, usually of a large solid mass, is known as landslide erosion. Such slides occur as a rule where the soil rests on a smooth wet substratum. The soil is usually saturated with water and slips off suddenly from the underlying rock formation. Fires which destroy the deeply ramifying roots that bind the surface soil to the subsoil contribute to the action of landslides. Landslides usually are confined to small areas and, except in restricted localities, are seldom an important factor in the destruction of soil fertility.

River-Bottom Erosion. - Much highly valuable valley land has been destroyed by the wearing away of the river banks or by the formation of new channels. The historic Mississippi floods of almost annual occurrence afford excellent examples of this form of destructive erosion. The enormous amount of debris carried down by the swollen river may be deposited in 
the lower portions and fill up the channels. The water may overflow for a time and then take a new course. The prevention of such erosion lies chiefly in the proper reëstablishment and preservation of the plant cover on watersheds where the flow originates.

\section{FACTORS INFLUENCING EROSION}

Several factors contribute to the action of erosion, the chief of which are (I) steepness of slope (topography), (2) type of soil, (3) rainfall, (4) melting snow, (5) winds, and (6) vegetative cover.

That he might ascertain the effect of the more important of these factors and be able to suggest rational means of preventing and controlling erosion, the author initiated in I9г2 a special erosion study at the Great Basin Grazing Experiment Station, in the Wasatch Mountains of central Utah. ${ }^{1}$ Two areas as nearly similar as possible in topography, soil, climatic conditions, and vegetation were selected. The areas chosen were located at an elevation of 10,000 feet and were on the same slope. The soil was of limestone origin and varied in depth from a few inches to several feet. The area known as $A$, however, had a somewhat steeper slope than the area designated as $B$, and the vegetative cover was less dense than on the latter.

Steepness of Slope. - The steepness of the slope of the lands is one of the most important factors affecting the occurrence of erosion. Under the influence of a given rainstorm lands having a steep slope and a particular kind of plant cover will undergo much more erosion than lands of the same soil type and plant cover that have less slope. Thus, if the established formula is applied, namely, that the transporting power of water varies directly as the sixth power of its velocity, it is evident that, if the velocity of a flow is increased two times, its transporting power is increased 64 times. Then, too, the larger the flow the greater is the velocity of that flow.

1 Sampson, Arthur W, and Weyl, Leon H., "Range Preservation and its Relation to Erosion Control on Western Grazing Lands." U. S. Dept. of Agr. Bul. 675 , I918. 
Type of Soil. - The character of the soil itself often determines to a considerable extent the degree of erosion. The factors determining the extent to which a given soil type may erode are texture, structure, amount of organic matter, pore space, and tenacity.

Texture. - Coarse-textured soils, that is, those having largesized particles like sand, are able to absorb a large amount of rainfall. Accordingly, little water, except on very steep slopes, washes over the surface of such lands, and hence serious erosion seldom occurs. Soils like clay that have small-sized particles hold much less fallen rain than do soils of coarse texture.

Structure. - The particular arrangement of the particles of soil greatly influences the amount of water which is absorbed. When the particles are pressed closely together, as in heavily packed soils, the spaces between the particles are so small that water can be absorbed but slowly. Thus a large portion of the water is carried over the surface of the soil and causes erosion. The structure of any soil is greatly modified by the amount of vegetation which occurs upon it, and, to be sure, by the type of farm operation.

Organic Matter. - Organic matter invariably increases the power of soils to absorb and retain moisture. Accordingly, the amount of organic matter plays an important part in the prevention of erosion both of heavy and of light soils.

Pore Space. - The amount of pore space and the size of the individual pore spaces have an important part in determining the amount of water taken up by a soil and the rate at which it is absorbed. Both the amount of water absorbed and the rate of its absorption are affected by the size of the particles, their arrangement, and the amount of organic matter present.

Tenacity. - The rate at which the stickiness or maximum tenacity of a soil is reached determines to a considerable extent the erosion that may take place. The amount of organic matter, the degree of compactness, and the particular type of soil greatly influence the ability of a soil to absorb moisture, and hence the extent to which the soil may erode. Any method of building 
up the soil so as to increase its ability to absorb and retain moisture, and at the same time decrease its stickiness, helps to lessen its tendency to erode. In general, the greater the tenacity of a soil the less likely is erosion to occur.

Rainfall. - The amount and distribution of the rainfall constitute an important factor in determining the occurrence of erosion. In order that no erosion may occur, the greater portion of the water falling on the land must be absorbed or held back by the soil, temporarily at least. As pointed out, the movement of the unabsorbed water over the soil's surface is largely controlled by the vegetative cover, and, of course, on plowed fields by the character of the tillage and sometimes by terraces.

In the study of the effect of rainstorms of varying intensity on the specially selected areas in the Wasatch Mountains of Utah, ${ }^{1}$ twenty-six rain storms occurred in a single season distributed over four months of the main growing period. Of these only one storm produced run-off. During this storm .70 of an inch of rain fell on each of the areas. The run-off from area $B$, Io acres in size, was 335 cubic feet, and it carried 74 cubic feet of air-dry sediment. As compared with this, the run-off from area $A$, also ro acres in size, was 3 , or 9 cubic feet, and this carried with it $7 \mathrm{I} 7$ cubic feet of air-dry sediment. Not only do these figures show the effect of rainfall on erosion; but, if it is kept in mind that area $A$ has a steeper slope and a less dense plant cover than has area $B$, the effects of the slope and vegetation are also evidenced.

The rate also at which rain falls is an important factor. For instance, a fall of . 36 of an inch of rain, received in 3 hours and 25 minutes, resulted in no run-off on either erosion area. Another storm of .65 of an inch, which was received in 8 hours and 45 minutes, likewise produced no run-off. In contrast to these storms, a fall of .85 of an inch of rain, which was received in 40 minutes, resulted in the deposit from area $A$ of 50,000 pounds

1 Sampson, Arthur W., and Weyl, Leon H., "Range Preservation and its Relation to Erosion Control on Western Grazing Lands." U. S. Dept. of Agr. Bul. 675, pp. II 15 , 1918 . 
(about one carload) of air-dry dirt and rocks of various sizes (Fig. 56).

Melting Snow. - The amount of erosion from melting snow is considerable, especially where gully erosion is in progress. The accumulation of winter snows on each of the two selected areas described ( $A$ and $B$ ) has an average annual water equivalent of about 9 inches. ${ }^{1}$ This accumulation represents approximately 326,000 cubic feet of water awaiting the spring thaw.

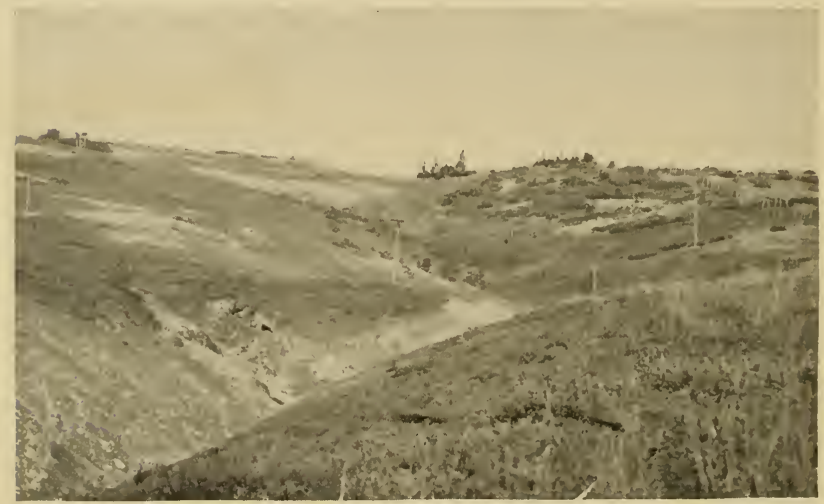

FIG. 56. - EROSION AREA $A$, HEAD OF EPHRAIM CANYON, MANTI NATIONAL FOREST, UTAH.

As a result of the destruction of the plant cover, more than 50,000 pounds, or approximately one carload, of air-dry sediment was carried away from this ro-acre area by a single rainstorm.

Now what becomes of this snow water? It was found that about 292,000 cubic feet, from a total of about 326,000 cubic feet, ran off the steeper area $(A)$ while about 42,000 cubic feet ran off area $B$. A small amount of the snow water evaporates into the air, but the greater portion of that which is not accounted for in the surface run-off is absorbed by the soil. In the fall of the year the gullies contain considerable loose dirt, practically all of which is carried down by the snow water. That melting

1 Sampson, Arthur W., and Weyl, Leon H., "Range Preservation and its Relation to Erosion Control on Western Grazing Lands." U. S. Dept. of Agr. Bul. 675, pp. 9-11, 1918. 
snow is an important factor in causing erosion is evidenced by the fact that for a 5 -year period an average of about 172 cubic feet of soil, expressed on an air-dry basis, was deposited from area $A$ and 82 cubic feet from area $B$. As would be expected, however, there is appreciably less sediment deposit per unit of run-off from melting snows than from summer rain storms.

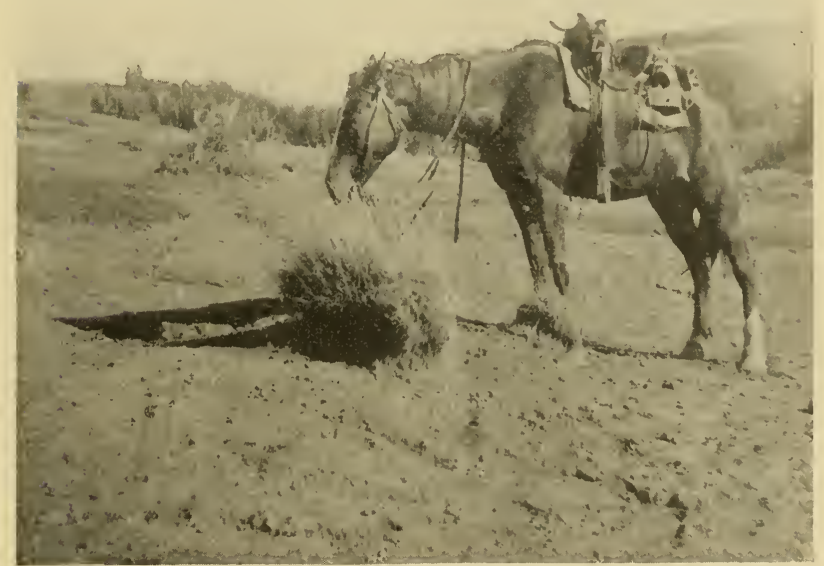

Fig. 57. - RANGE LAND STRIPPED OF ITS GOOD SOIL.

The remaining grass hummocks mark the depth to which the rich surface soil has been removed by wind and water erosion.

Wind. - In addition to the conspicuous action of the gully and "shoestring" type of erosion, the removal of soil caused by the action of the wind is often considerable. After the destruction of the vegetative cover, either entirely or in part, the wind movement becomes highly effective in the translocation of soil (Fig. 57). Almost everywhere the wind is sufficiently strong to carry from one place to another those soil particles that are not firmly bound by vegetation and ultimately to de- 
posit them at the base of the slope. On elevated plateaus the wind often blows in great gales. From places where the surface soil is dry and exposed, such storms transport enormous quantities of soil.

Vegetative Cover. - Although the extent of surface run-off and erosion are determined by the combined action of a number of factors, the vegetative cover is the most important single controllable factor by means of which erosion may be largely prevented. Man has little or no control over climate and topography, and hence the prevention of erosion, especially on pasture lands, must be accomplished chiefly through the improvement and preservation of the vegetative cover. On most of our western range lands the native plant cover must be relied upon to protect the soil from erosion, because the conditions of growth are not favorable to the establishment of cultivated plants.

Obviously, on well-vegetated lands the soil contains a much larger amount of organic matter than on denuded areas. This greatly increases the water-holding capacity of the soil and its power of absorption. Accordingly, on fully vegetated lands practically no erosion occurs except, possibly, during storms of unusual violence, and even then the erosion is seldom serious. On denuded or sparsely vegetated slopes, however, run-off and erosion may occur after relatively light rain storms. Such factors as overgrazing, permitting the animals on the pastures when the soil is wet, fires, and the like, all of which tend to pack the soil or destroy the vegetative cover, increase the damage from erosion (Fig. 58).

\section{EROSION, PLANT GROWTH, AND REVEGETATION}

"Erosion, plant growth, and revegetation" may sound like a curious, unrelated combination; but, as a matter of fact, they are intimately associated. It is a matter of common observation that the native vegetation commonly found on eroded or leached soils is sparse and of relatively low stature. Water washing over the surface of the land may remove a large portion of the small particles of soil, and with that soil are carried the 
valuable plant foods. The coarser portions of the soil which are left are invariably low in plant nutrients.

With a view to determining the cause of the poor plant growth on eroded soils a large number of typical soil types characteristic of the Wasatch Mountains of Utah were examined chemically. ${ }^{1}$

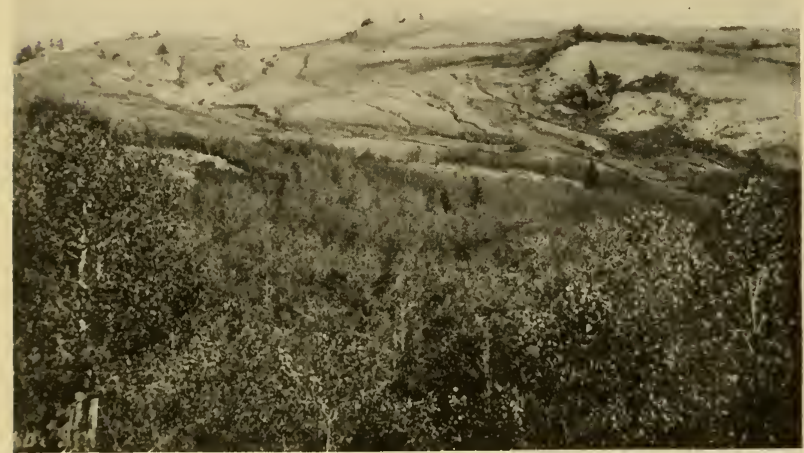

Fig. 58. - RESULTS OF WATER, WIND, AND SHEET EROSION NEAR TIMBERLINE DUE TO OVERGRAZING.

The protective vegetation has been largely removed and the fertility of the soil so seriously impoverished by erosion that few species of plants can exist. It will require decades to revegetate such lands thoroughly, and then it can be done only by the discontinuance of grazing for several years.

The soils studied are typical of those found in the spruce-fir type of the summer sheep range, at approximately 10,000 feet elevation. The soils are of limestone origin and were collected at the same elevation and only a few feet apart. They are therefore comparable in all respects, except that on one soil type the plant cover had been destroyed and erosion had occurred, and on the other the plant cover was intact and the soil was in a good state of fertility.

1 Sampson, Arthur W., and Weyl, Leon H., "Range Preservation and its Relation to Erosion Control on Western Grazing I.ands." U. S. Dept. of Agr. Bul. 675 , pp. 18-22, 1918. 
Plant Foods Contained in Eroded and Noneroded Solls OF THE SAME TYPE

\begin{tabular}{|c|c|c|c|c|c|}
\hline Soil & $\begin{array}{l}\text { Lime } \\
(\mathrm{CaO})\end{array}$ & $\begin{array}{l}\text { Potash } \\
\left(\mathrm{K}_{2} \mathrm{O}\right)\end{array}$ & $\begin{array}{c}\text { Phosphoric } \\
\text { acid } \\
\left(\mathrm{P}_{2} \mathrm{O}_{6}\right)\end{array}$ & $\begin{array}{c}\text { Total } \\
\text { nitrogen }\end{array}$ & $\begin{array}{l}\text { Loss on } \\
\text { ignition } \\
\text { (humus) }\end{array}$ \\
\hline $\begin{array}{l}\text { Eroded soil.... } \\
\text { Noneroded soil }\end{array}$ & $\begin{array}{l}\text { Per cent } \\
\text { I. } 26 \\
\text { I. } 49\end{array}$ & $\begin{array}{c}\text { Per cent } \\
\text { I . } 53 \\
\text { I. } 30\end{array}$ & $\begin{array}{c}\text { Per cent } \\
0.22 \\
0.33\end{array}$ & $\begin{array}{l}\text { Per cent } \\
0.156 \\
0.488\end{array}$ & $\begin{array}{c}\text { Per cent } \\
6.64 \\
14.65\end{array}$ \\
\hline
\end{tabular}

In all of the constituents examined, except potash, the noneroded soil was much the richer. The greatest difference was found in the total content of nitrogen, one of the most important plant foods. A considerable proportion of the nitrogen content was soluble in water and hence was subject to appreciable loss through run-off.

In addition to the decreased fertility of the eroded soil, it was found that this soil had a maximum water-holding capacity of 46.8 per cent, as compared with 76.2 per cent for the noneroded soil. That part of the soil moisture which cannot be absorbed by the roothairs of the vegetation - termed " nonavailable water " - was found to be 15.6 per cent in the eroded soil and I9.3 per cent in the noneroded soil. Accordingly, on the basis of saturation, the noneroded soil was capable of yielding to the vegetation 25.7 per cent more water than was the eroded soil.

Erosion and Plant Growth. - In order to determine the difference, if any, in the crop-producing capacity and water requirements of plants grown on typical eroded and noneroded soils, blocks of these two kinds of soil were sifted and thus freed of the larger pebbles, moistened moderately to the same percentage basis, and tamped firmly into large galvanized-iron cans. In one set of cans containing these selected soils was grown pedigreed Canadian field peas, in another set native bromegrass (Bromus marginatus), and in the third set a pedigreed wheat known as Kubanka. The pots were hermetically sealed and so arranged that all the water removed from the soil had to pass through the plants in the form of transpiration or "evaporation." Water was added from time to time so 
that throughout the experiment the average moisture content was about 30 per cent, an amount ample to produce vigorous growth on both soil types. ${ }^{1}$

The two following tables and Figures 59 and 60 summarize the results as to the vegetative growth and the water require-

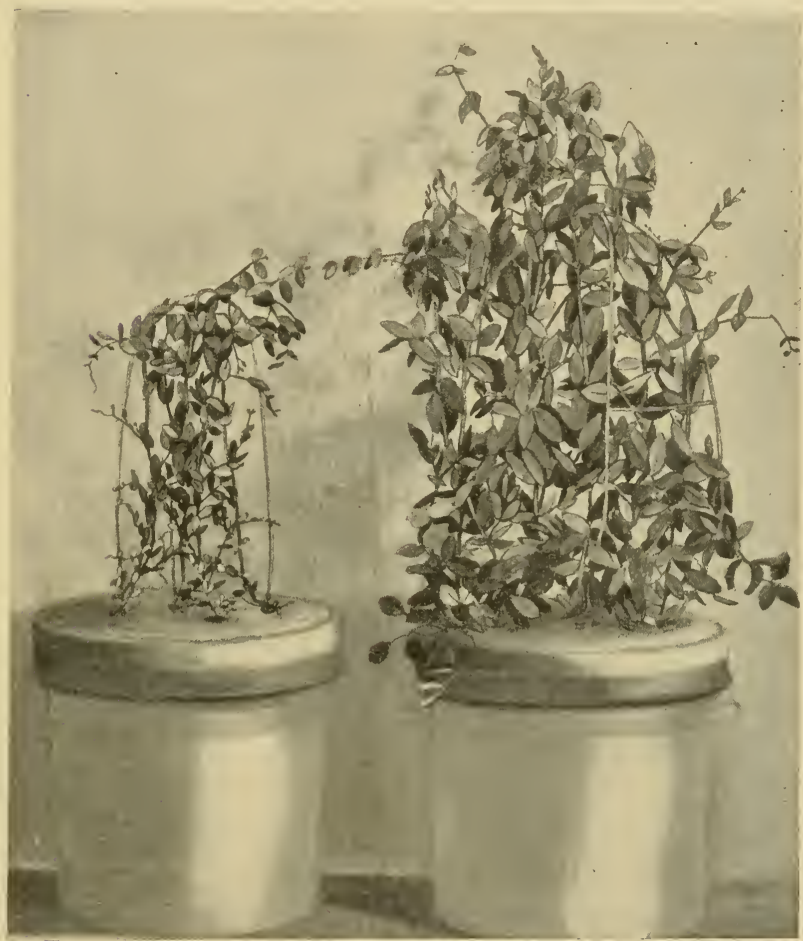

(Forest Service, under direction of the Author.)

FIG. 59. - THE MEANING OF SOIL EROSION.

Canadian field peas (left) grown in poor or eroded soil, and (right) grown in good mellow soil of the same type which had not been subjected to erosion.

1 Sampson, Arthur W., and Weyl, Leon H., "Range Preservation and its Relation to Erosion Control on Western Grazing Lands." U. S. Dept. of Agr. Bul. 675 , pp. 18, 19, 1918. 


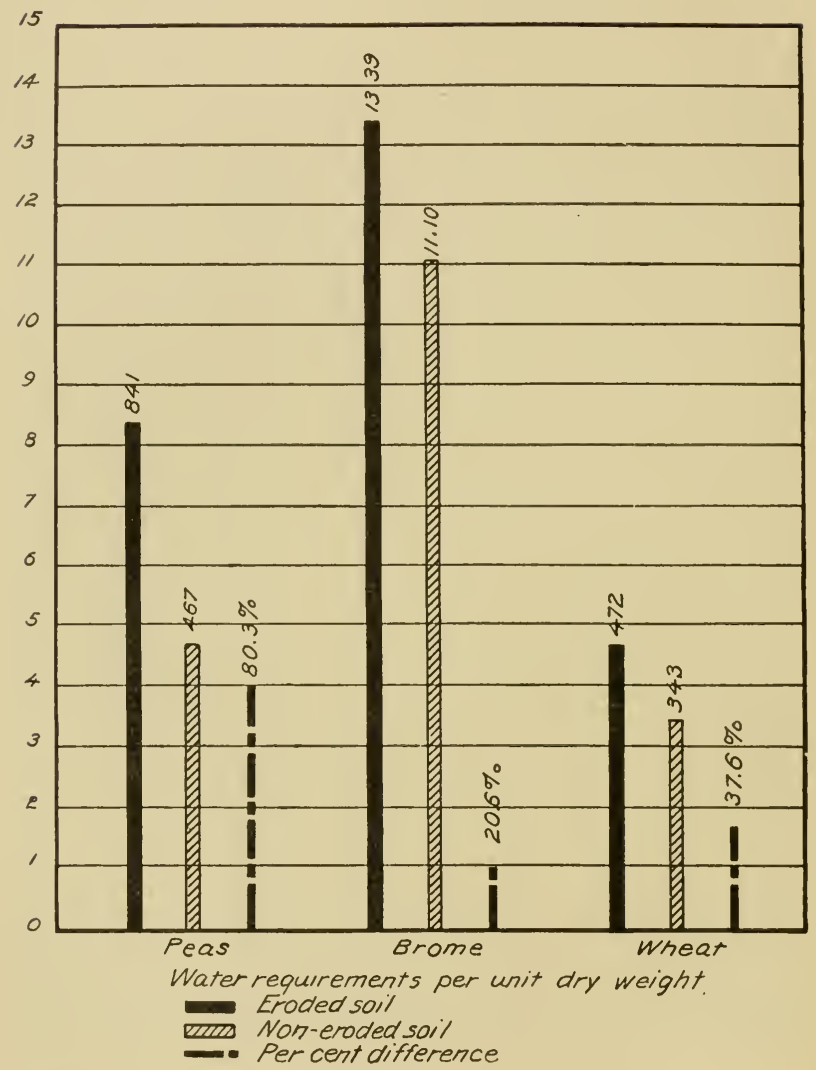

FIG. 60. - RELATIVE WATER REQUIREMENTS PER UNIT DRY WEIGHT FOR PEAS, NATIVE BROMEGRASS, AND WHEAT GROWN IN ERODED AND IN NONERODED SOILS OF THE SAME TYPE. 
ments of the field peas, native bromegrass. and cultivated wheat grown in the two soils.

Pounds of Water Required by Peas, Bromegrass, and Wheat per Pound of Dry Matter Produced

\begin{tabular}{|c|c|c|c|}
\hline Soil and excess water & Peas & Bromegrass & Wheat \\
\hline Eroded......... & $84 \mathrm{I}$ & $\mathbf{I}, 339$ & 472 \\
\hline Noneroded ... & 467 & I, I IO & 343 \\
\hline $\begin{array}{l}\text { Percentage of excess water required } \\
\text { by eroded........................ }\end{array}$ & 80.1 & 20.6 & 37.6 \\
\hline
\end{tabular}

Summary of Plant Growth and Water Requirements of Peas, BromeGRASS, AND WHEAT

\begin{tabular}{|c|c|c|c|c|c|}
\hline Plant and soils & $\begin{array}{c}\text { Number } \\
\text { of } \\
\text { leaves }\end{array}$ & $\begin{array}{l}\text { Leaf } \\
\text { length } a\end{array}$ & $\begin{array}{c}\text { Dry } \\
\text { weight }\end{array}$ & $\begin{array}{l}\text { Water } \\
\text { used per } \\
\text { plant }\end{array}$ & $\begin{array}{c}\text { Water } \\
\text { used per } \\
\text { pound dry } \\
\text { matter } \\
\text { produced }\end{array}$ \\
\hline $\begin{array}{l}\text { Peas: } \\
\quad \text { Eroded soil } \ldots \ldots \ldots \ldots \\
\quad \text { Noneroded soil } \ldots \ldots \ldots\end{array}$ & $\begin{array}{r}42 \\
7 \mathrm{I} 2 \\
\end{array}$ & $\begin{array}{r}\mathrm{Mm} \\
79 \mathrm{r} \\
2,634\end{array}$ & $\begin{array}{l}\text { Lbs. } \\
\circ .79 \\
6.55\end{array}$ & $\begin{array}{r}\text { Lbs. } \\
667 \\
3,05 \mathrm{I}\end{array}$ & $\begin{array}{l}\text { Lbs. } \\
841 \\
467\end{array}$ \\
\hline $\begin{array}{l}\text { Native bromegrass: } \\
\text { Eroded soil ........ } \\
\text { Noneroded soil } \ldots\end{array}$ & $\begin{array}{l}35 \\
84\end{array}$ & $\begin{array}{l}2,902 \\
5,218\end{array}$ & $\begin{array}{l}0.4 \mathrm{I} \\
0.85\end{array}$ & $\begin{array}{l}553 \\
944\end{array}$ & $\begin{array}{l}\text { I, 339 } \\
\text { I, I IO }\end{array}$ \\
\hline $\begin{array}{l}\text { Wheat: } \\
\quad \text { Eroded soil ........... } \\
\text { Noneroded soil ...... }\end{array}$ & $\begin{array}{l}22 \\
47\end{array}$ & $\begin{array}{r}4,474 \\
10,080\end{array}$ & $\begin{array}{r}5.52 \\
12.09\end{array}$ & $\begin{array}{l}2,5 \mathrm{I} 6 \\
3,820\end{array}$ & $\begin{array}{l}472 \\
343\end{array}$ \\
\hline
\end{tabular}

$a$ The length of stem of the peas is given instead of the length of leaf.

The first table shows that a much greater amount of water was required on the eroded than on the noneroded soil for the production of a unit of dry matter of each of the three plants tested. This fact is particularly significant, inasmuch as the eroded soil can retain only a comparatively small amount of water for the growth of vegetation.

Figure 6I was prepared from the data given in the second table and summarizes the vegetative growth and water requirements 


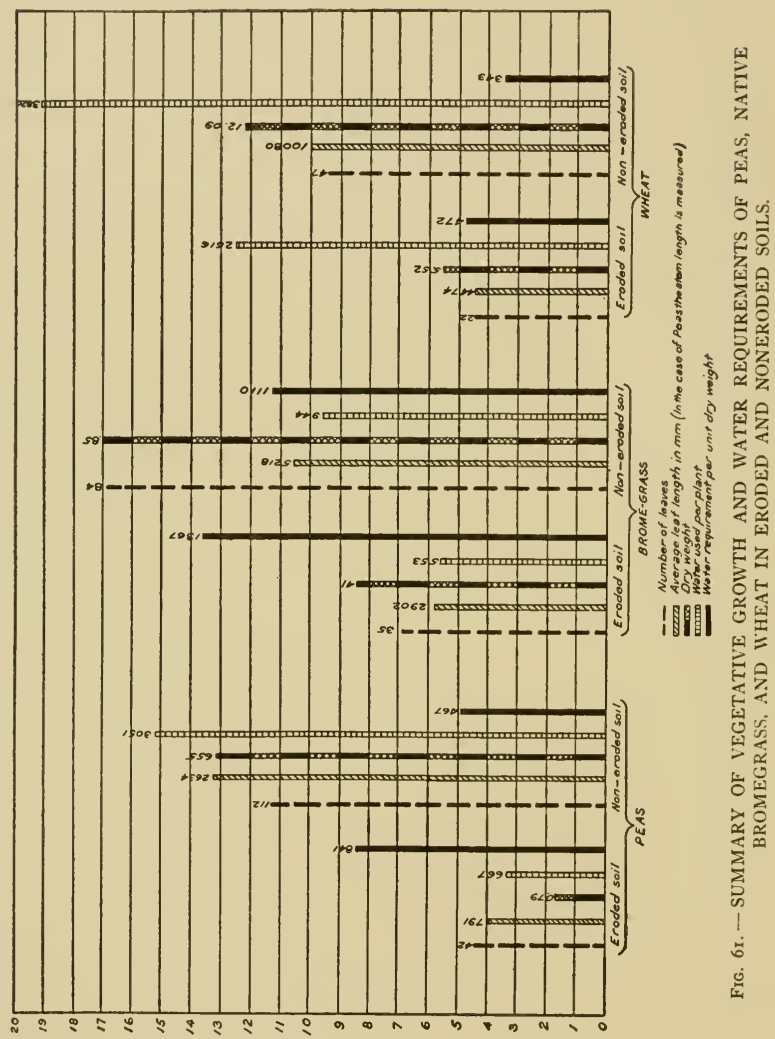


of the plants studied. It shows a remarkable contrast in these functions. In peas, for instance, the numbers of leaves are as I to 27 ; the leaf lengths as I to 3.3 ; the total dry weights produced as I to 8.3; and the water used per plant as I to 4.6 - all in favor of the noneroded soil. In the amount of water used per pound of dry matter produced, on the other hand, the ratio is reversed, being as I.8 to I on the eroded and noneroded soils, respectively. The general development of the plants and the water requirements of native bromegrass and wheat are similar to those of peas. In all the plants, appreciably more leafage and stem growth were produced on the noneroded than on the eroded soil.

Erosion is adverse to plant growth chiefly (I) because eroded soils are so deficient in soil moisture as to prevent the full development and seed production of the vegetation, and (2) because of the lack of adequate plant nutrients in the soil caused by the leaching out of the soluble plant foods. Owing to the deficiencies in the essential nutrients only certain inferior types of vegetation can occupy eroded areas.

Erosion and Revegetation. - The establishment on overgrazed and eroding soils of a dense vegetative cover of the more desirable forage and other deep-rooted, soil-binding species is a most difficult task. The results of (I) the initial and (2) the advanced stages of overgrazing in its relation to erosion, and the attending economic consequences, are summarized in Figure 62, and show the usual steps involved. Revegetation is difficult, in the first place, because of the low moisture content and lowered water-holding capacity of eroded soils; and, in the second place, because of the fact that a large proportion of the plants which do come up die early in the spring, often in the seedling stage. The few that live through the spring usually die before the end of the season. So serious is this loss of seedling plants on eroded areas that it is often possible to predict with much precision not only the rate with which the ground cover may be restored but, as indicated in Figure 62, the particular kinds of plants which will occupy areas in different degrees of depletion. 
On badly eroded lands many years must elapse before the desirable forage species can occupy the site upon which they

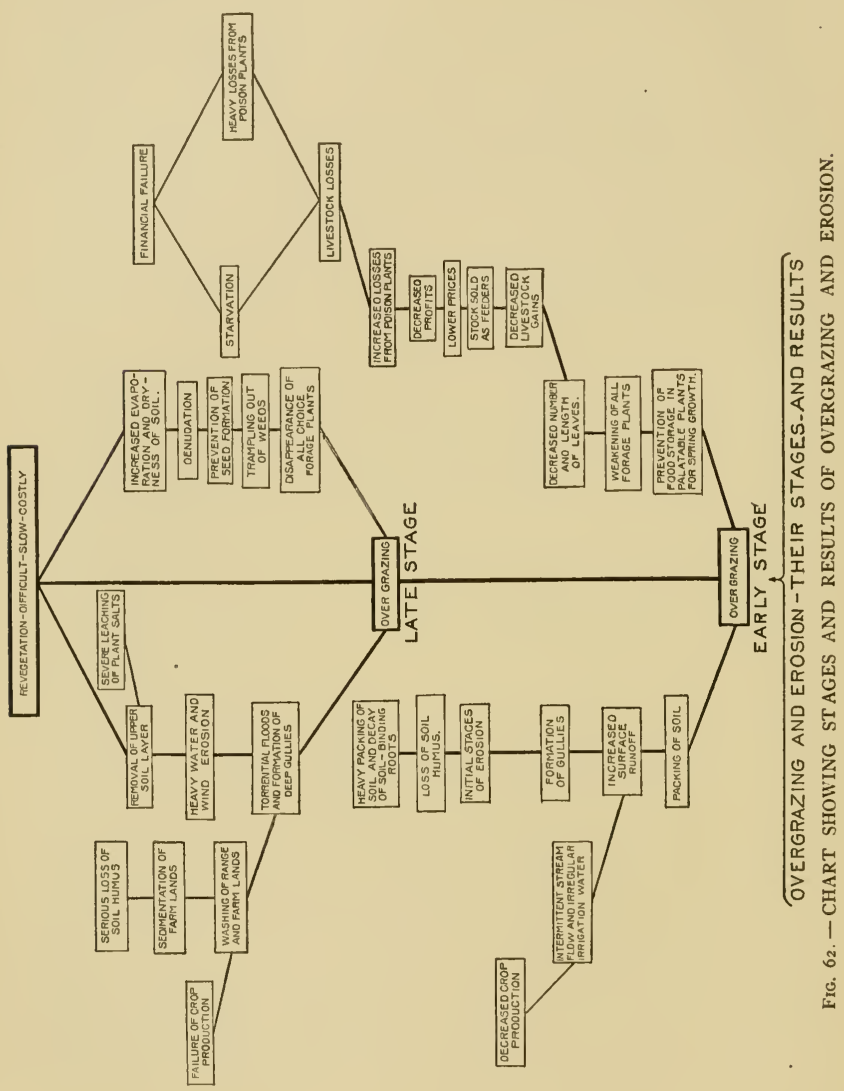

formerly predominated. At first only rapid-growing and early-maturing annual species can occupy such soils. After many years of growth and decay of the vegetation, provided 
erosion is controlled, the more permanent forms slowly make their appearance, until finally the original type of vegetation is again in evidence.

Too much care cannot be exercised in preserving the dark surface layer of the soil, for this humus covering is the very life of the land. Preserving the surface soil is much cheaper than replacing it, and this is not a difficult task if proper precautions are taken when erosion begins.

\section{THE SOLUTION OF THE EROSION PROBLEM ON PASTURE LANDS}

The evidence clearly proves that destructive grazing by any class of stock on lands where the topography, climate, and soil are favorable to washing, will appreciably increase both the run-off and the erosion. The seriousness of the erosion will vary according to the extent to which the plant cover is destroyed.

In order to maintain a good cover of vegetation, recognition of the following conditions is of primary importance: (I) Overgrazing must not take place; (2) too early grazing must be avoided; (3) deferred and rotation grazing should be practiced; (4) proper control and distribution of the livestock are necessary; and $(5)$ in extreme cases it is advisable to terrace the land.

Avoidance of Overgrazing. - The avoidance of overgrazing can best be accomplished by correctly estimating and then adjusting the number of stock that a range or pasture will safely carry. Overgrazing may readily be recognized by the weakened condition and disappearance of the choicest or the most highly palatable forage plants. This is usually accompanied by the appearance of incipient gullies, followed by erosion of varying degrees of seriousness.

Avoidance of Too Early Grazing. - Permitting stock on the pasture too early in the spring when the herbage is very young and succulent, and when the soil is well-nigh saturated with moisture, is a common means of starting serious erosion. At no time in the season is it more essential that a plant be per- 
mitted to develop its leafage - the laboratory for the production of food - than early in the spring. A few days' delay in the time at which the stock are admitted means very little loss in the way of pasturage, for herbage a week to ten days old has but little substance and is deficient in sugars and other foods as compared with forage which has grown twice as long. By avoiding too early grazing the bad effects of trampling over the loose wet soil are largely avoided, and the cover is not injured.

The Practice of Deferred and Rotation Grazing. - Where pastures have been overgrazed to the extent of thinning out the cover of valuable forage plants, merely keeping the number of stock down to the grazing capacity of the lands and preventing too early grazing in the spring are not in themselves effective means of reëstablishing the desired vegetation. The deferred and rotation grazing plan of reserving first one area for grazing and then another, for a season or longer, until the seed crop has ripened, should be adopted. On sheep range this plan can readily be applied, as the animals are under perfect control. On cattle range the deferred-grazing plan can be carried out if the animals are controlled by riding or by the use of drift fences. On fenced pastures division fences are invaluable.

The Control and Distribution of Livestock. - Even if the grazing capacity of the lands has been correctly determined, the season of grazing adjusted, and the deferred and rotation system of grazing adopted, erosion of pasture lands is frequently brought about by poor distribution of stock. This is often due to improper salting and faulty handling of the stock.

The most effective means of holding cattle and horses on the portion of the range desired, as previously shown, are the suitable location of the salt grounds, the proper development of watering places, and the right setting of drift fences.

In addition to improperly estimating the grazing capacity of the lands, three conditions are chiefly responsible for the destruction of the vegetative cover, namely, bedding too long in one place, too close herding, and the excessive use of dogs.

Terracing and Planting. - Areas which have been so seriously depleted through the bad management of livestock that an 
almost complete destruction of the plant cover has resulted, may be reclaimed by terracing and planting after the livestock has been entirely excluded. The gully type of erosion can usually be effectively broken up by the construction of terraces laid out approximately on the contour, but so placed as to allow the water to drain off through their channels. If they are reënforced by an occasional small rock-fill built in the washes, such terraces are effective.

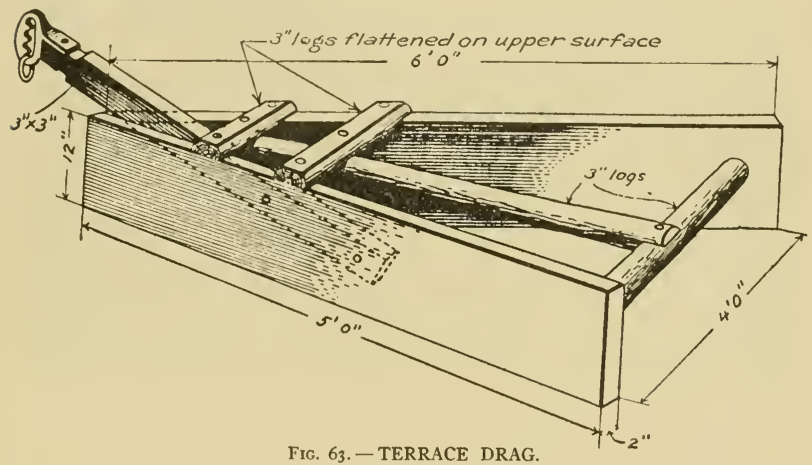

An effective implement used in shaping up terraces to check serious erosion on important watersheds.

The place for successfully attacking the erosion evil is at its source. Accordingly, the first terrace should be built near the head of the gullies. Those established below the uppermost terrace should be placed at intervals of ${ }_{5} 5$ to 30 feet, depending on the steepness of the slope. The terraces should be built about 4 feet wide. This can be done most cheaply by the use of the "terrace drag," which is run over the surface of the soil after plowing (Fig. 63).

After the construction of the terraces it is well to seed down the area, preferably to plants that form a turf. On the native pasture lands seeding to the natural vegetation gives the best results (Fig. 64). Terracing is expensive, however, and should be resorted to only where erosion is very serious and where it is highly important to build up the lands in a short time. 


\section{HOW MORE THAN HALF OF THE EROSION BATTLE IS WON}

In summarizing it may be restated that much more than half of the battle of preserving pasture lands from the devastating effects of erosion is won by the maintenance of a good vegetative

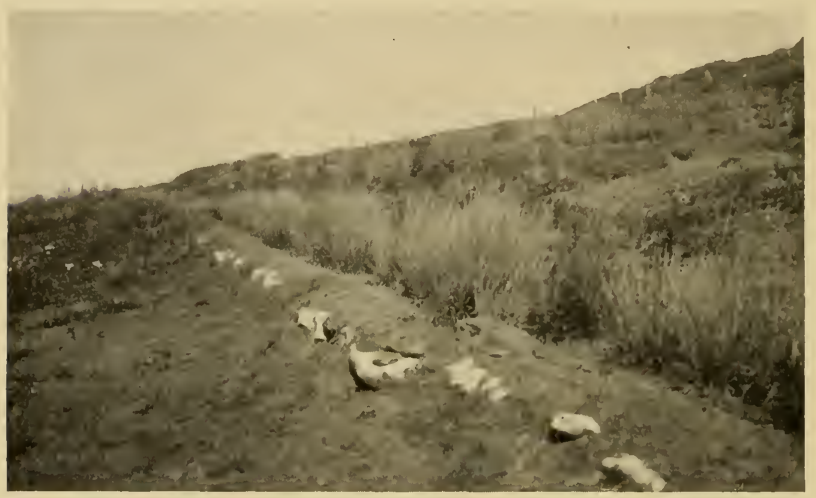

Fig. 64. - A TERRACE SEEDED TO MOUNTAIN BROMEGRASS ON LAND WHICH FORMERLY WAS ERODING SERIOUSLY.

The old shoestring gullies have "rounded out" and can no longer be seen.

cover to prevent the starting of soil washing. The most effective method of doing this involves (I) the avoidance of overgrazing, (2) the avoidance of too early grazing. (3) the application of deferred and rotation grazing, (4) artificial reseeding (in choice sites only), and (5) the proper control and distribution of stock.

Where the depletion of the soil and the formation of longestablished gullies make thorough revegetation impossible, destructive floods and erosion may be controlled by (I) the total exclusion of stock, (2) terracing and planting, and (3) the construction of dams.

\section{QUESTIONS}

1. (a) To what extent do topography, climate, and soil determine the degree of erosion? (b) To what extent does the plant cover influence it? 
2. To what extent may erosion cause damage to (I) crop production, (2) personal and other property, (3) roads, trails, etc.?

3. To what extent may melting snow cause erosion on hilly lands?

4. (a) Is rainfall or the run-off from melting snow more influential in causing erosion? (b) To what extent is the degree of erosion and run-off influenced by the following factors: (I) Rate at which the rain falls, (2) steepness of the slope, (3) presence of well-established gullies, (4) character of the soil. (5) density and character of the vegetation?

5. Since man has little control over climate and topography, by what means is he able largely to control erosion?

6. To what extent do erosion and the depletion of the soil resulting therefrom influence the type of vegetation and the luxuriance of its growth?

7. (a) How does erosion affect the plant foods in the soil? (b) How does erosion influence the potential crop-producing capacity of the soil?

8. (a) Compare the amount of water required for the production of one pound of dry vegetable matter of a given species grown on an eroded soil with that required on a noneroded soil? (b) Compare the amount of water available for plant growth in a given volume of eroded soil with that in a noneroded soil?

9. Name five precautions to be observed in the handling of pasture lands that are subject to more or less serious erosion.

10. Where revegetation through the application of the deferred-grazing system is not effective, what treatment of the lands may prevent erosion?

11. (a) Where terracing and planting are justified to prevent erosion, explain how the terraces should be built and how far apart they should be placed. (b) To what extent should stock be permitted to graze on areas so seriously eroded that terracing is necessary?

\section{BIBLIOGRAPHY}

Baker, W. H. The Soil-Saving Dam. Mo. Agr. Ext. Service Cir. I4, I9I7. Carpenter, John W., and Gross, E. R. The Terrace in Mississippi. Miss. Agr. Exp. Sta. Extension Bul. 9, r9r8.

Clements, Frederic E. Plant Succession: An Analysis of the Development of Vegetation. Carnegie Institution of Wash., Pub. No. 242, I9I6.

Dana, S. T. Farms, Forests, and Erosion. U. S. Dept. of Agr. Yearbook, I916.

Davis, R. O. E. Soil Erosion in the South. U. S. Dept. of Agr. Bul. r8o, I9I 5.

Ramser, C. E. Gullies: How to Control and Reclaim Them. U. S. Dept. of Agr. Farmers Bul. I234, I922.

Reynolds, R. V. R. Grazing and Floods: A Study of Conditions in the Manti National Forest, Utah. U. S. Dept. of Agr., Forest Service, Bul. 9I, I9I I. 
I96 CONTROL OF EROSION ON RANGE AND PASTURE

Sampson, Arthur W., and Weyl, Leon H. Range Preservation and its Relation to Erosion Control on Western Grazing Lands. U. S. Dept. of Agr. Bul. 675, 1918.

Sanford, F. H. Michigan's Shifting Sands: Their Control and Better Utilization. Mich. Agr. Exp. Sta. Special Bul. 79, I9ı6. 


\section{CHAPTER $\mathrm{X}$}

\section{GRAZING ON WOODLANDS AND ITS RELATION TO THE FUTURE TIMBER SUPPLY}

For many years an active and careful study of the best use to which lands of different classes may be put has been made by Federal and State agencies and institutions. Farming, grazing, and timber growing are the principal uses of land for crop production. Farming is the most intensive and timber growing the least, with grazing midway between. In most systems of diversified farming they are combined, especially farming and grazing. Not uncommonly, however, grazing and timber growing are combined, as on the National Forests, on cut-over lands, and on the farm woodlot.

Much has been said and written relative to the wisdom of grazing stock on timbered lands, especially where there is need for tree reproduction. Most of the lands that are now producing a good stand of timber are probably more valuable for a continued production of timber than for any other purpose. In many regions growth is rapid, the quality of the lumber produced is good, natural reproduction after cutting is satisfactory where the lands are properly handled, and the timber crop is generally accessible. However, the livestock industry is of primary importance throughout the timber region of the West, and the greater part of the forest area is utilized as pasture in the spring, summer, or autumn.

The utilization of the forage on the better-timbered areas, especially on important watersheds, has complicated the pasturemanagement plans. Many instances are recorded of the seedling and sapling stand being badly injured by grazing. In some places this has resulted in a depletion of the normal timber growth, in the production of deformed and diseased trees, and in injury to important watersheds. The most serious damage 
has almost invariably occurred on lands cropped by sheep or goats. However, after many years of intensive investigation and wide observation by many specialists in various parts of the West, it has been concluded that practically all serious damage to timber reproduction is caused by too heavy grazing and by faulty handling of the stock.

Although the forage on most areas that are timbered by such species as yellow pine, Douglas fir, aspen, and other hardwood types is probably not superior to that on untimbered lands, it furnishes an enormous amount of good spring and summer feed for all classes of livestock. Indeed, the use of the forage on timbered lands is indispensable to the meat-producing industry in many communities of the West. It is the aim here to point out to what extent injury to forest reproduction may be caused by grazing, under what conditions the damage is most serious, and how such damage may be reduced by improved livestock management.

\section{RESULTS OF INVESTIGATIONS}

Because the policy of the United States Forest Service permits grazing on all of the National Forest range so far as it is consistent with good forestry practice, this bureau has made a very careful study of the effect of grazing on timber reproduction in the West. The study has been so organized as to cover the broader forest types and climatic regions. In the pursuit of this study, detailed investigations were made on the National Forests of Arizona and New Mexico and on certain Forests in California and in central Utah.

Studies in Northern California, Oregon, and Washington. In the Northwest a number of investigations were conducted to determine the effects of grazing on the reproduction of various coniferous and certain other species. Sampson and Dayton ${ }^{1}$ in I9I I initiated a comprehensive study on the Shasta National Forest in northern California to determine the amount and seriousness of injury to timber reproduction caused by grazing,

1 Sampson, Arthur W., and Dayton, William A., "Relation of Grazing to Timber Reproduction, Shasta National Forest." U. S. Dept. of Agr., Review of Forest Service Investigations, Vol. 2, pp. 18-24, I913. 
the season of greatest injury, the relative damage to the various important timber species, the extent of injury both from browsing and trampling, and under what conditions grazing may aid forest reproduction. From the facts ascertained it was hoped to develop a plan of grazing which would prevent serious injury to the young growth.

Based upon three examinations in I9I I and I9 2 of plots containing I I, 040 plants, consisting of sugar pine, white fir, Douglas fir, yellow pine, and incense cedar, all of a size subject to injury by grazing, the following results were recorded of the damage caused by sheep and by cattle, respectively: 38.3 per cent and 8 per cent of the yellow pine reproduction, 2 r. 8 per cent and i9 per cent of the Douglas fir, 48.3 per cent and I I per cent of the white fir, and 26.9 per cent and I 2.5 per cent of the sugar pine. These figures include all types of injury, much of which was so slight that most of the reproduction recovered fully in later years. For the period of observation, only .03 per cent of 1o,888 specimens on the plots were killed by grazing. During this time, I 55 young tree plants were killed by other agencies than stock. The factors chiefly instrumental in the destruction of the stand were drought, disease, and rodents. The only serious injury noted was on goat and sheep ranges, and this was due entirely to faulty management of the stock.

As early as 1897 , Coville ${ }^{1}$ investigated the injuries from sheep grazing on forest growth in the Cascade Mountains of Oregon. It was found that over most of the reserve of 4,493,000 acres, embracing the main ridge of the Cascade Mountains, the actual damage to the growth of timber was confined chiefly to small areas, such as bed grounds and trails. On heavily overgrazed range, where the forage was badly trampled, the stunted growth of pine seedlings was frequently seen.

Working on the National Forest range lands of Oregon generally, Munger ${ }^{2}$ concluded that the timber reproduction was

${ }^{1}$ Coville, Frederick V., "Forest Growth and Sheep Grazing in the Cascade Mountains of Oregon." U. S. Dept. of Agr., Div. of Forestry, Bul. 15, r8g8.

${ }^{2}$ Munger, Thornton T., "Western Yellow Pine in Oregon." U. S. Dept. of Agr. Bul. 418, 1917. 
somewhat exposed to danger from domestic foraging animals, particularly sheep, which, when closely herded, were found to trample a good many scedlings. Where the forage was insufficient or of an inferior quality, sheep were also found to browse on the young tree growth with such intensity as to deform the reproduction permanently. Munger concludes:

If the range is not overstocked and the sheep are properly handled, they do not, in Oregon, do any appreciable damage to yellow pine young growth in the forest at large; trees over 6 feet high are practically immune from damage.

The investigations conducted in Oregon hold equally well for Washington.

Studies in Idaho. - Detailed investigations were conducted by Sparhawk $^{1}$ from I9I 2 to I9I4, on the Payette National Forest in central Idaho. The conditions in this locality are similar to those of the yellow pine forests in the Northwest, and hence the data and conclusions are more or less applicable to the Northwest generally. The livestock industry is important throughout the yellow pine region of the Northwest, and the lands are much used for grazing in spring and summer. In Idaho alone the yellow pine lands will summer at least a million sheep or 200,000 cattle.

Extent of Injury. - On the plots actually grazed the damage to seedlings more than a year old was insignificant, the yearly average being about 2.8 per cent. Of the seedlings less than a year old, however, I 5.4 per cent were killed on the lightly grazed area studied, and 24.9 per cent were destroyed on the heavily pastured sample area. These figures, however, represent the maximum loss which would result if the sheep grazed over every portion of the range. Such intense grazing obviously seldom occurs unless the pasture is heavily overstocked. If the specially selected plots are considered as a whole, some of which were not grazed, I.I per cent of the total stand of young trees were killed each year on the lightly cropped sample area, and 2.5 per cent on the heavily stocked area. Of the seedlings less than a year of age,

1 Sparhawk, W. N., "Effect of Grazing upon Western Yellow Pine Reproduction in Central Idaho." U. S. Dept. of Agr. Bul. 738, 1918. 
on the other hand, 8.8 per cent and $\mathrm{I} 4.8$ per cent were killed each year on the lightly and the heavily grazed areas, respectively. As was to be expected, during the first few years of growth the seedlings were readily killed by only slight injuries. This was because of their small size, the shallow root system, and the presence of only a small amount of woody material in their stems.

Comparative Seasonal Injury. - The percentage of seedlings killed by grazing, notably those less than one year old, was appreciably greater early in the season than it was later. Early in the season, when the soil is wet, the roots are readily trampled out of the ground, and the stems are easily crushed or torn asunder by the sharp, cutting hoofs of the sheep. Towards the end of the season the stems are much tougher, the roots are deeper, and the soil is firmer; hence the injury is usually much less serious than in the spring. In general, however, there is a sufficient number of seedlings left on the moderately grazed lands following a good seed year to make a full stand of timber in spite of the injuries caused

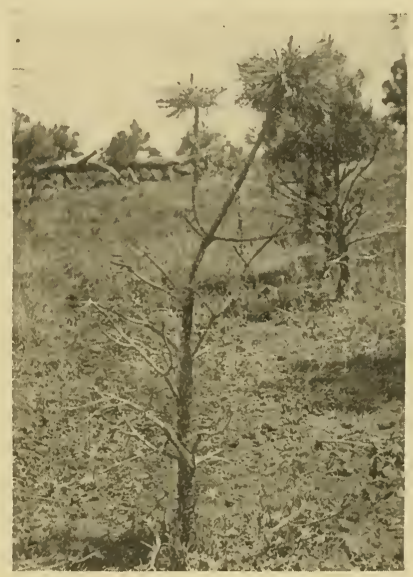

(Forest Service.)

Fic. 65. - A YELLOW PINE 4 FEET TALL, WITH LATERAL BRANCHES SEVERELY BROWSED BY SHEEP ON OVERGRAZED RANGE.

The leader is out of reach of the sheep, and this makes possible the entire recovery of the sapling if destructive grazing is discontinued. by stock. Accordingly, where the stock are carefully handled, a satisfactory stand of reproduction may be expected on practically all lands in the Northwest.

Damage According to Intensity of Grazing and Amount of Forage - Generally, the amount of injury or actual destruction of the reproduction increases with the closeness of the grazing (Fig. 65). Except on bed grounds and trails the damage was 
seldom serious to seedlings more than a year old; and even under the worst conditions only about 4 per cent of the stand more than a year old was killed. Very few seedlings were browsed where the bed ground was used for one night only. On bed grounds used for several nights in succession, on the other hand, most of the leafage of the young growth was devoured, and sometimes even the bark was gnawed off. Where the range was grazed too closely, and the total quantity of feed was too small for the number of stock handled, considerably more injury both from browsing and from trampling occurred than where the forage was ample.

Studies in Arizona and New Mexico. - Hill ${ }^{1}$ made a critical study of the injury caused by the grazing of cattle and sheep to yellow pine reproduction in Arizona and New Mexico in I9ro. The best summer and autumn forage in this region is found in the open stands of yellow pine, mainly at elevations above 6,000 feet. This type constitutes about 6 per cent of the total land area of these States. It is a matter of great importance that the forage crop in the yellow pine type be utilized to the greatest extent possible. It is equally important, however, to interfere as little as possible with the yellow pine reproduction, which is the most important timber of the Southwest.

Average Injury to Reproduction. - Two hundred and fifty representative plots were located on cattle and sheep range, and observations covering a period of three years were made. On these plots 16.7 per cent of the seedlings up to $5^{\frac{1}{2}}$ feet in height were seriously damaged each year; that is, the seedlings were damaged to the extent of interfering more or less seriously with their growth, or of being actually killed. In addition, I6. I per cent of the entire stand was slightly damaged, and on an average 2 I per cent of the seedlings below 6 inches in height were seriously damaged, each year. The injury inflicted gradually decreased with the height growth of the reproduction (Fig. 66).

Season of Injury. - The least injury to the young timber

${ }^{1}$ Hill, Robert R., "Effects of Grazing upon Western Yellow Pine Reproduction in the National Forests of Arizona and New Mexico." U. S. Dept. of Agr. Bul. 580, 1917 . 
stand was recorded during the first few weeks of each growing period, that is, before June 15 . The greatest damage, on the other hand, occurred during the latter half of June and early in July. However, considerable damage was noted throughout the entire grazing season and in the autumn when the forage became dry and somewhat unpalatable.

Injury in Relation to Intensity of Grazing and Character and Abundance of Forage. - Sheep were found to be considerably more destructive to young timber reproduction than were cattle and horses. On overgrazed areas, however, all classes of stock are liable to cause more or less serious damage to reproduction. Under such conditions cat-

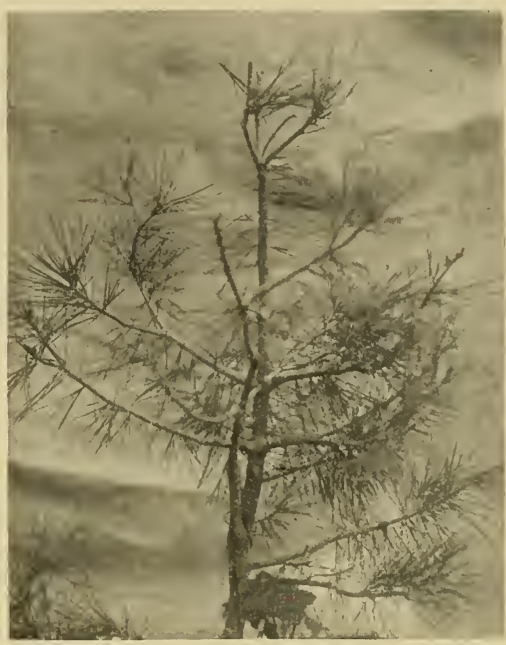

Fig. 66. - YELLOW PINE 5 FEET TALL INJURED BY CATTLE BROIISING AND RUBBING.

Injury to the terminal shoot by the browsing of cattle seldom occurs after the sapling attains a height of $5 \frac{1}{2}$ feet.

tle and horses may injure as much as ro per cent of all tree growth less than $5 \frac{1}{2}$ feet in height (Fig. 67). Under normal grazing, that is, grazing that is not destructive of the forage crop, sheep may injure as much as II per cent of the reproduction under $5^{\frac{1}{2}}$ feet in height. The sheep range studied was about average for the type, and the stock were well adapted both to the character of the forage and to the topographic features. The way in which the stock is handled has much to do with the severity of the grazing injury. Where cattle were permitted to congregate, as much as 22 per cent of the total tree stand between 3 and 6 feet in height was injured in varying degrees 
of seriousness. Likewise, the injury from sheep on established bed grounds was almost invariably heavy.

Both the character and abundance of the forage, and the topographic features determine very largely the extent of damage

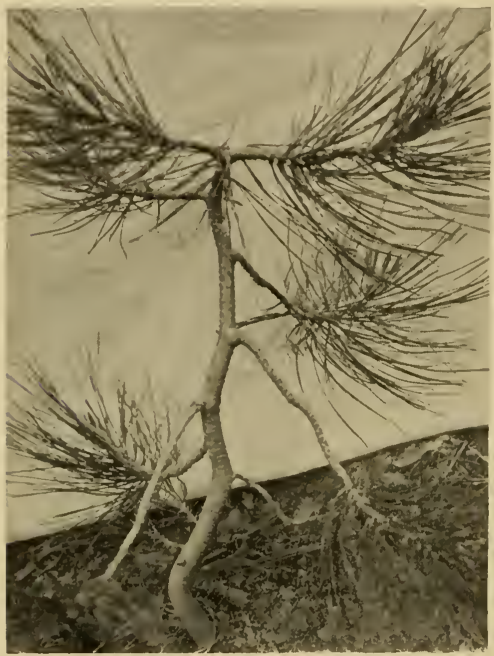

FIG. 67.-FORKED AND OTHERWISE DEFORMED TREES ARE OFTEN THE RESULT OF THE BROWSING OF FORAGING ANIMALS.

Such deformities materially decrease the money value of the merchantable timber. done to the timber reproduction. The injury on bunchgrass range was appreciably higher than that recorded on gramagrass ange, the percentages of injury recorded Jeing 32 and II, respectively. Accordingly, it may be concluded that it is a good deal safer to graze cattle than sheep on the bunchgrass type of range. Considerably less damage to the reproduction was recorded in those years when the supply of succulent and palatable feed was ample than in those seasons when the forage was deficient in quantity or of an inferior quality.

In 1908 , Pearson ${ }^{1}$ initiated a study to determine grazing damage to western yellow pine reproduction on the Coconino Forest in northern Arizona. On the open range the damage to pine seedlings i to 3 years of age was found to vary from ro per cent to 28 per cent, and on established sheep bed grounds and on driveways the damage was even greater. His studies, like those of other investigators, showed that horses and cattle do

${ }^{1}$ Pearson, G. A., "Reproduction of Western Yellow Pine in the Southwest." U. S. Dept. of Agr., Forest Service, Cir. I74, I9ro. 
little damage to the timber stand. Because of the injury inflicted by sheep, it is clear that this class of stock should be excluded from areas on which reproduction is desired.

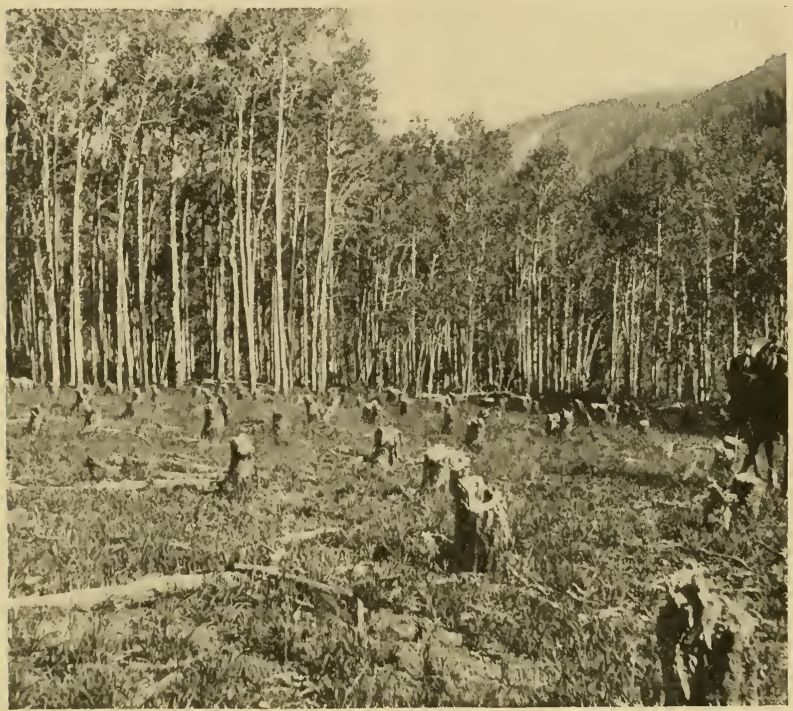

(Forest Service, by the Author.)

FIG. 68. - CLEAR-CUT ASPEN LAND GRAZED BY SHEEP TWICE EACH SEASON FOR THREE SUCCESSIVE YEARS AFTER CUTTING.

A profusion of root and coppice sprouts was produced during the first three years after the cutting, but each season they were gnawed down by the sheep. After the third year no new sprouts were produced, and the area was left without aspen reproduction. (Sce Fig. 69.)

Effect of Grazing upon Aspen Reproduction. - Beneath the aspen, which ordinarily grows in somewhat open stands, is usually a luxuriant understory of grasses, weeds, and browse, which is grazed with relish by all classes of stock. As pasture land, the aspen type is considerably more valuable than either the spruce-fir type at a higher elevation, or the yellow pine or oakbrush type below the aspen. Unfortunately, however, the stock, especially sheep, do not confine themselves entirely to the forage, no matter how abundant and palatable it may be. They 
eat also the leafage and tender twigs of the aspen. Thus the oncoming aspen stand is often badly injured or even killed by grazing animals. This situation usually makes it very difficult to secure a succeeding stand of timber on cut-over lands without some loss in forage utilization.

Effects of Sheep Browsing. - For a period of five years Sampson ${ }^{1}$ made an exhaustive study of the effects of sheep and cattle grazing upon the reproduction of aspen under typical range conditions. It was found that 27.2 per cent of the aspen reproduction under about 40 inches in height was killed by light sheep grazing, 3 г 8 per cent on moderately grazed areas, and 65 per cent on lands closely cropped. One of the silvicultural practices is to clear-cut the aspen stand. Under average conditions where such cutting is done, a dense stand of root sprouts invariably replaces the original cover after the first year of cutting. On clear-cut plots especially established for the grazing study, the damage done by sheep browsing was found to be exceedingly heavy. Three successive years of sheep browsing on clear-cut plots resulted in the complete destruction of the young aspen stand. In other words, at the end of the third year of removal of the sprouts by sheep, the sprouting ceased completely, and the aspen roots were evidently exhausted and died (Figs. 68 and 69). It was concluded that under moderate conditions of grazing, when the sprouts reach a height of about 45 inches, they are practically exempt from injury by sheep browsing. The extent to which the aspen sprouts in standing timber were either killed or injured was found to be in direct proportion to the intensity of the grazing. Although the leaves of the young stand were most relished, the stems, as shown in Figure 70, were nevertheless devoured to a considerable extent. A goodly portion of the young tender twigs was also consumed by sheep in the autumn after the leaves had dropped.

Effects of Cattle Browsing. - The injury to the aspen stand caused by the grazing of cattle, although a factor of some importance in obtaining good thrifty reproduction, was in no sense

\footnotetext{
1 Sampson, Arthur W., "Effect of Grazing upon Aspen Reproduction." U. S. Dept. of Agr. Bul. 74I, I9I9.
} 
very serious where the stock was properly handled. The damage was never so great as that caused by sheep.

As on sheep range, so on cattle range the extent of injury

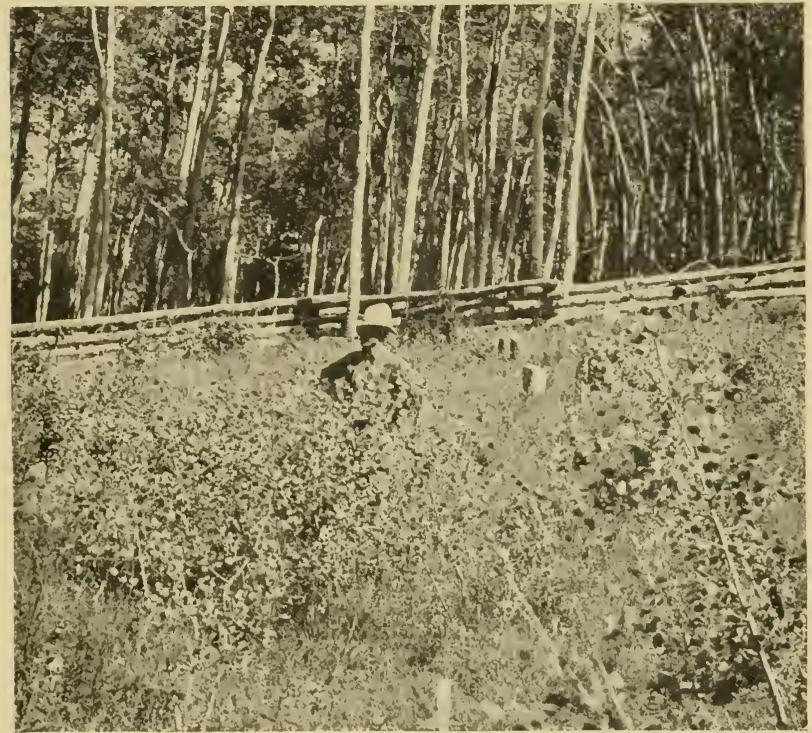

(Forest Service, by the Author.)

Fig. 69. - CLEAR-CUT ASPEN LAND PROTECTED FROM SHEEP GRAZING.

Under such conditions as many as 100,000 sprouts to the acre are not uncommonly produced.

(See Fig. 68.)

varies directly with the closeness of the grazing. The injury is less, indeed practically nominal, on lightly or moderately cropped areas, and relatively heavy (I 7.5 per cent in I9I 5 and 36.I per cent in I9I6) on very heavily grazed areas. Thrifty aspen reproduction of varying size and age is found practically throughout the aspen type where the cover is extensive and where there has been moderate grazing for a number of years by cattle only. This is by no means true of most sheep range in the aspen type. Where only a small amount of aspen occurs on the range, as along 


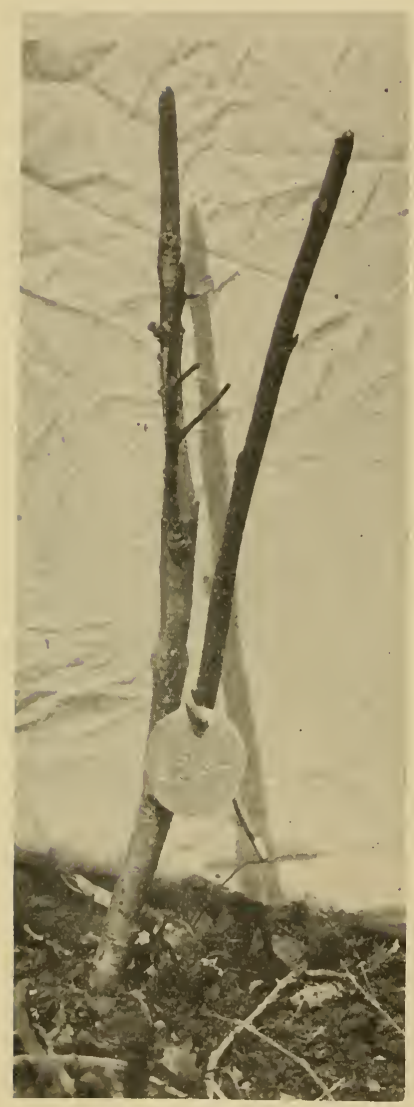

(Forest Service, by the Author.)

Fig. 70. - REMNANTS OF ASPEN SPROUTS ON SHEEP RANGE.

The leafage and tender stems of young aspen sprouts are highly relished by sheep. Such cropping as here shown often results in the destruction of the sprouts in a single season. streams where cattle are inclined to congregate, the aspen reproduction is often seriously injured. Accordingly, it is necessary to protect such lands periodically in order to perpetuate the aspen stand. Where the aspen type extends over large areas, however, if cattle are properly handled. they do not seriously interfere with the perpetuation of aspen timber.

\section{GRAZING FARM WOODLAND}

In the vast central hardwood region of the eastern part of the United States farm woodlands are maintained chiefly for supplying farm timber. This includes fuel wood, posts, poles, rough lumber, ties, and other products. The woodlands are also maintained for the protection which they afford to the farmstead and to growing crops. In the plains region of rich agricultural soils, where the farm timber has mostly been established by planting, protection and shade for livestock are prominent uses of the woodland. Accordingly, it is not probable that in the latter region the farm woodthe production of commercial 
timber. Small areas of a few acres do not lend themselves to the establishment of good forest conditions. The forest floor, for instance, becomes dry, the tops of the trees are often severely damaged by storms, and the trees along the edges of the stand are usually of inferior form. For these and other reasons pasturing is commonly practiced on the small planted woodland. In the extensive hardwood-forest region, with its large farm areas of broken, stony, or poor soils that are in timber, more attention can profitably be given to the growing of trees.

In general, timber production for profit can not compete with the growing of farm crops or pasture forage on lands that have a value of as much as $\$ 30$ or more per acre. In the cattle-raising district where woodlands are grown, such areas are in great demand for pasture. The unpastured woodland is rare. Shade is a distinct asset in the raising of livestock, whether it be of sheep, cattle, hogs, or other animals. While the forage production under the tree growth may not be of the best, it furnishes a considerable amount of feed which the farmer seldom wastes.

Damage Done to Tree Growth by Grazing. - As already mentioned, the damage done by grazing falls into two main classes browsing and trampling. Broad-leaved or hardwood trees, which usually occupy farm woodlands, are generally more palatable to grazing animals than is a stand of coniferous reproduction. The browsing damage may consist of defoliation or of the cropping of the bark and stems in varying degrees of seriousness. Occasionally young seedlings are uprooted and killed. Trampling packs the ground so that reproduction starts with difficulty. Much trampling may not only kill the seedlings, but it may also cause more or less damage to the mature or larger trees by exposing the roots and packing heavily the ground around them. The amount of damage done is generally proportionate to the intensity of the grazing. The damage done by light grazing is practically negligible.

It is evident that, if the production of timber alone is considered, no grazing should be allowed. For general purposes light grazing may be permitted on farm woodlands if other conditions are favorable. So far as the livestock are concerned, 
good results are obtained by the grazing of the woods. This is true quite as much because of the shade afforded to the animals as of the forage which such lands furnish. In any event, if woodlands are to have a permanent place on the farm, the grazing should be light and so handled as to favor the production of timber.

It is a noteworthy fact that farm woodlands are generally in bad condition as a result of grazing; especially is this true where the tenant system of farming is used. The tenant is less particular than is the owner about the damage which the stock do to the young timber and to the protective leaf litter. In this connection it is interesting to recall that over one-third of the farms of the United States are occupied by tenants.

\section{EFFECT OF GOAT GRAZING ON TIMBER REPRODUCTION}

Although the grazing of goats is not a large industry in this country, it plays a relatively important part in many localities. Approximately 60,000 goats are grazed on the National Forests alone, mainly in Arizona and New Mexico. Goats are also grazed on parts of certain Forests in the Northwest. In general, goats are regarded as paragons of catholic taste in that they browse more or less ravenously upon tree reproduction of all kinds regardless of the conditions of the range.

Chapline, ${ }^{1}$ in an unpublished report, points out that goat grazing is a much less serious factor in the establishment of timber reproduction than is generally supposed. On the Gila National Forest in New Mexico, the light grazing of the goat range in the yellow pine type resulted in injury of Io to 13 per cent of the reproduction. These figures included the accumulated injury inflicted after many years of pasturing. On the Alamo Forest in New Mexico, about I 2.5 per cent of the yellow pine reproduction was injured after many years of goat grazing. The injury was generally very slight for yellow pine seedlings under two years of age, nor was it serious for seedlings that had attained a height of 6 inches. Contrary to expectations, the

${ }^{1}$ Chapline, W. R., "Effect of Goat Grazing upon Tree Reproduction." U. S. Forest Service, 1915. 
greatest injury occurred in a stand which had attained a height of $\mathrm{I} \frac{1}{2}$ to $2 \frac{1}{2}$ feet. Piñon pine was only lightly cropped, and full recovery from the injury could nearly always be expected. Juniper, on the other hand, is palatable to goats, and more than half of the stand was browsed. In general, it was found, however, that yellow pine, piñon pine, and Douglas fir were not killed or seriously injured except where the lands were overgrazed or the forage was very closely cropped. Where the timber reproduction was seriously injured, the palatable plants were also disappearing. In some places the coniferous reproduction was somewhat heavily browsed in the winter, evidently because of the absence of other more succulent vegetation.

In general, goats browse upon a larger number of timber species than do other classes of stock. Because much of that vegetation is fairly palatable to goats, they are liable to cause more damage to timber reproduction, other things being equal, than do other classes of domestic foraging animals.

\section{CONCLUSIONS BASED ON INVESTIGATIONS}

The conclusions developed from the studies may be divided into two classes - ( I) those of general application, and (2) those that are applicable to certain regions. ${ }^{1}$

Conclusions of General Application. - I. Overgrazing or bad handling of any class of stock may result in injury to tree reproduction in varying degrees of seriousness. In general, overgrazing by sheep and goats causes greater damage than does destructive cropping by horses and cattle. Injury to the reproduction by horses and cattle is seldom serious.

2. Goats are inclined to browse upon a larger number of timber species than do other classes of stock and may cause more damage than do other domestic foraging animals.

3. Where a good seed crop of the timber stand is produced, large areas often support a good stand of young timber growth notwithstanding moderate grazing each year by the various classes of stock.

1 Jardine, J. T., "Efficient Regulation of Grazing in Relation to Timber Reproduction." Jour. of Forestry, Vol. I8, No. 4, pp. 379-38r, I920. 
4. Topographic features, the season of grazing, the type of forage, and the way in which the animals are handled are the most important factors that determine the degree of injury to tree reproduction.

5. Damage to the tree reproduction and, indeed, to other vegetation must be expected on stock driveways or trails which are used annually as such for several seasons in succession. Accordingly, such driveways should be located where the timber is sparse or inferior, or where they will be of value in protecting the forest from destruction by fires.

Conclusions of Regional Application. - I. Because of the rigorous climatic conditions in the Southwest, notably in Arizona, New Mexico, and southern Utah, the better cut-over forest lands should not be grazed by sheep and goats until a satisfactory stand of reproduction, much of it about $3 \frac{1}{2}$ feet in height, has been secured.

2. As a rule it is safe to graze cattle and horses lightly on cutover or other potential forest lands during the period required for reforestation.

3. In the Northwest, notably in Washington, Oregon, northern California, and Idaho, a satisfactory stand of young timber growth may be expected wherever good grazing management is applied, regardless of the class of stock grazed. The tree reproduction is generally satisfactory in Montana, Wyoming, and Colorado, provided the grazing is not destructive.

4. Where trees have been artificially planted, or where, although the timber reproduction is greatly desired, the stand may be unsatisfactory, the area, regardless of the locality, should be closed to grazing until a satisfactory stand is obtained.

5. From aspen range on which it is desired to perpetuate the aspen cover, sheep and goats should be excluded for at least three years after the cutting. The damage to aspen reproduction from moderate cattle grazing is practically negligible; hence cattle may be grazed on cut-over aspen lands until the sprouts have attained a height growth sufficient to make them exempt from serious injury by sheep grazing. This usually requires three years after cutting. 


\section{APPLICATION OF STUDIES TO GRAZING MANAGEMENT}

In the application of the conclusions set forth it is necessary to take many factors into account. Among these may be mentioned the demand for forage in a given community, the accessibility of and demand for the timber, when the timber may be cut, the condition of the range, and the palatability of the principal timber species to the different classes of stock.

Jardine ${ }^{1}$ has pointed out that, except for total protection from grazing, the judicious management of the forage crop and the protection of tree reproduction are the first essentials of efficient regulation in grazing. In order to apply the conclusions uniformly to actual practice, it is necessary, first, so to standardize grazing use that the terms "light," "moderate," and "close" grazing will have a definite meaning. As yet this has not been done. Because of the variation in grazing capacity and forage types, the lands may vary widely as to the number of stock they will support; hence the provision of a given number of acres per animal can not be the same everywhere. Furthermore, the density of reproduction required for the development of a full stand of timber is not known. The requirement will vary according to the species and the growth conditions.

Although broad unification, both of grazing use and of the requirements for a satisfactory timber cover, is important, those problems are essentially local in character. Proper stocking of the lands, good distribution of the stock, avoidance of too early grazing, and the use of the forage by the proper class or classes of stock will do much to prevent damage to the tree reproduction.

\section{QUESTIONS}

1. (a) To what extent is aspen palatable ( $\mathrm{I}$ ) to sheep, and (2) to cattle? (b) To what extent is yellow pine palatable (I) in the Northwest, (2) in the Southwest?

2. (a) To what extent do sheep injure yellow pine reproduction within their reach (I) on closely grazed range, and (2) on that moderately grazed? (b) To what extent do they injure aspen reproduction?

${ }^{1}$ Jardine, J. T., "Efficient Regulation of Grazing in Relation to Timber Reproduction." Jour. of Forestry, Vol. r8, No. 4, pp. 380, 38r, 1920. 
3. To what height can sheep ordinarily crop tree reproduction, and at what height is the stand exempt from serious injury from sheep grazing?

4. Where the cover is extensive and where there has been moderate grazing for a number of years by cattle only, to what extent has the young growth bcen injured?

5. To what extent does the amount of palatable feed available determine the injury to tree reproduction on cattle range? On sheep range?

6. Under ordinary conditions, is serious injury to tree reproduction on cattle range confined to places where the animals congregate, or is the damage more or less uniform throughout the type?

7. (a) How would you handle the grazing so as to insure a satisfactory stand of reproduction on cut-over aspen lands where sheep are grazed? (b) How would you handle cattle grazing under the same conditions? (c) How would you obtain a satisfactory stand of yellow pine on cut-over bunchgrass lands grazed by sheep?

8. How may grazing and the establishment of stock driveways foster the establishment and protection of a satisfactory stand of timber reproduction?

\section{BIBLIOGRAPHY}

Chapline, W. R. Production of Goats on Far Western Ranges. U. S. Dept. of Agr. Bul. 749, I9r9.

Coville, Frederick V. Forest Growth and Sheep Grazing in the Cascade Mountains of Oregon. U. S. Dept. of Agr., Div. of Forestry. Bul. I 5, I 898 .

Graves, Henry S. Grazing and Fires in National Forests. Amer. Forestry, Vol. I7, No. 7, I9I I.

Hits, Robert R. Effects of Grazing upon Western Yellow Pine Reproduction in the National Forests of Arizona and New Mexico. U. S. Dept. of Agr. Bul. 580, I9r 7.

JARDINE, JAMES T. Efficient Regulation of Grazing in Relation to Timber Reproduction. Jour. of Forestry, Vol. I8, No. 4, 1920.

The Pasturage System of Handling Range Sheep. U. S. Dept. of Agr., Forest Service, Cir. I 78 , I 0 Iо.

Mason, D. T. Utilization and Management of Lodgepole Pine in the Rocky Mountains. U. S. Dept. of Agr. Bul. 234, r9r 5 .

Munger, T. T. Western Yellow Pine in Oregon. U. S. Dept. of Agr. Bul. 418 , 1917 .

Pearson, G. A. Reproduction of Western Yellow Pine in the Southwest. U. S. Dept. of Agr., Forest Service, Cir. I74, I910.

SAMPSON, ARTHUR IV. Effect of Grazing upon Aspen Reproduction. U. S. Dept. of Agr. Bul. 74I, I9I9. 
Sampson, Arthur W., and Dayton, William A. Relation of Grazing to Timber Reproduction, Shasta National Forest. U. S. Dept. of Agr., Forest Service, Review of Forest Service Investigations, Vol. 2, 1913.

Sparhawk, W. N. Effect of Grazing upon Western Yellow Pine Reproduction in Central Idaho. U. S. Dept. of Agr. Bul. 738, I9I8. 


\section{CHAPTER XI}

\section{BURNING OF PASTURE LANDS AND ITS EFFECTS ON FORAGE PRODUCTION}

The grandeur and the awfulness of a great range and forest fire which occurred a few years ago in the Blue Mountains of northeastern Oregon left on the author's mind an impression never to be forgotten. As seen from the summit of a hill the sight surpassed even the stately beauty of virgin forests of pine, spruce, and hemlock. The whole landscape, as far as the eye could reach, was covered with a white sea of smoke clouds. The atmosphere had taken on a golden yellow hue, and in the heavens appeared the pale outline of the lonely sun. One moment the angry flames were carried high above the uppermost branches of the mammoth trees; the next moment all was hidden by the ever-forming clouds of smoke (Fig. 7I). When the smoke had subsided sufficiently to allow the first hazy view of the land, what a panorama of ruin to behold! The transformation that had been effected in a few hours was so complete that nature would require centuries to recover her lost splendor (Fig. 72).

The devastation caused by many of these fires cannot be estimated in a pecuniary way. On heavily forested lands the effects of a single fire are felt for centuries. On range and pasture lands repeated fires generally have quite as serious results as severe overgrazing. On both kinds of lands the fires ultimately destroy the plant cover and are followed by erosion of varying degrees of destructiveness.

History of Burning. - It is probable that nires on prairie and woodland have occurred ever since there was a luxuriant growth of vegetation. Evidence of fires may be found in coal formations, and substances resembling charred wood and other plant parts have been unearthed in the subcarboniferous sandstone in some localities. ${ }^{1}$ There is undeniable evidence from the fire scars on

${ }^{1}$ Plummer, Fred G., "Forest Fires." U. S. Dept. of Agr., Forest Service Bul. 117, p. $7,1912$. 
the California bigtrees, of fires in the eighteenth, sixteenth, and fifteenth centuries, and it also appears that terrific fires occurred there as early as 245 A.D. Occasionally fires originated from falling meteors; many were set by lightning; and in the early days a vast number were started by the Indians, who burned extensive prairie and forest lands before the country was settled

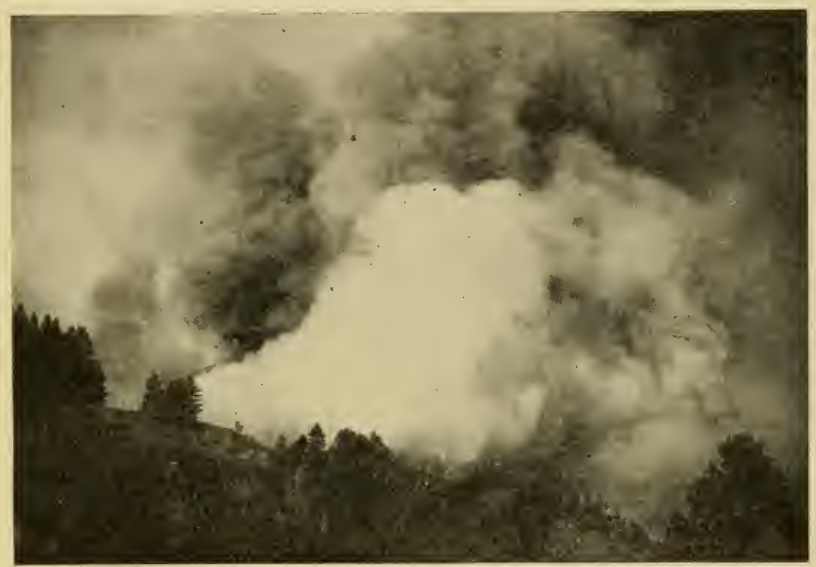

(Forest Service.)

Fig. 71. - A WOODLAND PASTURE FIRE IN NORTHEASTERN OREGON. The whole landscape was covered with white clouds of smoke.

by the white men. ${ }^{1}$ The chief object of the practice appears to have been to bring about a fresh growth of grass in the autumn upon which numerous game animals and wild fowl would gather for feed, thus making it easy for the Indians to secure their winter's meat supply. Fires were also set for the purpose of killing and roasting for food the great quantities of grasshoppers that nearly every year feasted on the tender growth of grass.

Cabeza de $\mathrm{Vaca}^{2}$ states that in Arkansas about I535 "they

1 Sampson, Arthur W., "Concerning Forest Fires." Breeder's Gazette, Sept. I3, I9I I, pp. 429, 430.

2. Narrative of Alvar Nuñez Cabeza de Vaca, "Naufragios, peregrinaciones y milagros," translated by B. Smith, p. 64 , I 85 I. 
[the Indians] take the pasturage from cattle [buffaloes] by burning, that necessity may drive them to seek in such places as it is wished they would go." Bell, ${ }^{1}$ Plummer, ${ }^{2}$ and others ascribe to fires the treelessness and the poor vegetation of certain localities of the Great Plains region and the Middle States. Bonneville ${ }^{3}$ points out that the hunters had the greatest difficulty in starting

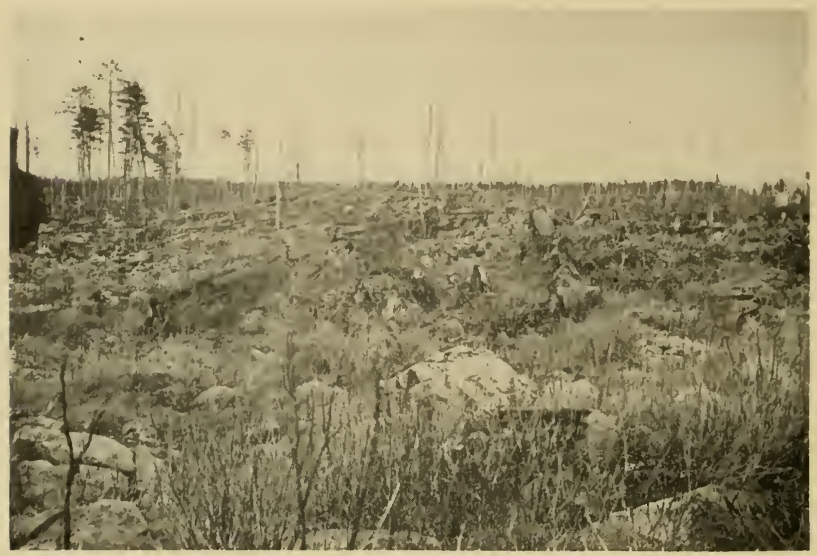

(Forest Service.)

Fig. 72. - THE FIRE-SWEPT AREA IS LEFT PRACTICALLY DEVOID OF PLANT AND ANIMAL LIFE.

Nature cannot recover in centuries the splendor and the money value so soon destroyed.

fires on the meadows along the Platte River because of the sparseness and short stature of the grass. It is recorded of the aborigines in various parts of the West that they kept vast tracts of forest lands denuded of timber as a result of setting fires for hunting. White hunters and trappers continued the practice of setting fires. Later the influx of settlers and the widespread custom of burning over land to get rid of timber, brush, or other

1 "History of California," Vol. I, p. 4I, I7.58.

2 Plummer, Fred G., "Forest Fires." U. S. Dept. of Agr., Forest Service, Bul. I1 7, p. 8, I912.

${ }^{3}$ Irving, Washington, "Adventures of Captain Bonneville," Pawnee Edition, Vol. I, p. 45 
cover, preparatory to cultivation, greatly increased the number of forest and prairie fires which were started. As competition for forage increased and range wars came into existence, fire was used with great effectiveness, both by cattlemen and sheepmen, to drive rival factions out of the country by destroying their range.

It is clear that in the early days burning off the vegetation was a common practice. The fires undoubtedly extended over enormous areas and varied in intensity according to the amount of inflammable material, the velocity of the wind, and certain other conditions. As a result, according to the best available records, the general appearance of the lands and the type of plant life which they supported were greatly changed.

Present-Day Burning. - The rapid settlement of the country and a greater appreciation of the value of forage, as well as an ever-increasing dependence upon the forage, have materially reduced the number of fires and the damage from them on all types of land. Seriously destructive fires, however, still occur in many parts of the country. According to the best available estimates, an average of approximately 13,969,000 acres were burned over annually in I916, I917, and 1918, representing a yearly loss of about $\$ 20,727,000$. Since most of this area supports a considerable amount of forage upon which livestock is grazed, it is apparent that this industry is greatly affected by the fires.

With the exception of certain sections in the South, most of the present-day fires occur on forested lands, where, in the main, they originate by accident. The practice of the willful setting of fires each year is still prevalent in many sections of the South, especially where the grasses and brush make a very robust growth. Burning of heavy growths of brush or chaparral areas is also resorted to more or less in certain parts of the far West, particularly in California.

A Common Delusion. - "Don't let 'em pull the wool over your eyes," was the remark of an experienced and practical farmer-stockman in eastern Nebraska as he "wet blanketed" the flames along a grassy roadside adjacent to his native-grass 
meadow. "This fire isn't goin' to eat up my good old hay land again. For years, as a young farmer, I looked forward with much pleasure to the burnin' job, and for as many years I paid the price for this pastime, and a handsome price it was too. While I was pasturin' the land I didn't realize how every year I was bein' robbed of a good forage crop. It wasn't until I got to puttin' the grass into the haystack and keepin' track of the loads that it dawned upon me that I had been 'pullin' the wool over my own eyes.' Since I quit burnin' off what little second growth there happened to be the yields have been much larger, especially in dry years."

Some of the most persistent beliefs favoring burning are (I) that the character of the herbage and browse is generally much improved by annual firing; (2) that burning brings about early spring growth, and that the forage produced is more palatable than where the lands are not fired; (3) that the productivity of the soil is greatly increased through the liberation of the lime, phosphoric acid, and potash contained in the ash; and (4) that, because of the alleged increased density in the plant cover after a burn, the watershed value of a drainage area is greatly enhanced for irrigation purposes and for navigation. These popular beliefs are in general without foundation.

In the absence of the old growth the first appearance of green vegetation is clearly discernible, and one may readily get the impression that the growth after a fire is not only exceptionally early but that a bumper yield is being produced. This is by no means substantiated by facts.

Some of the other arguments in favor of burning, in the absence of thorough-going investigations, are difficult to disprove. Indeed, in certain restricted localities in the South, periodic burning under some conditions may possibly be justified. However, many a stockman-farmer, like the Nebraskan, has observed that the argument in favor of burning takes into account only the immediate use of the pasture. To consider merely the benefits that may doubtfully be enjoyed - say for one or two seasons obviously is poor economics. Among other things one must keep in mind the effect which fires inevitably have on the pro- 
ductivity of the soil and the continued production of forage; on the perpetuation and healthy growth of the choicest and most valuable plants; and, on mountain lands especially, on the efficiency of the watershed for irrigation and on the supply of water for domestic purposes as well as for navigation.

\section{EFFECTS OF BURNING ON FORAGE PRODUCTION}

The vegetation that remains on the ground at the end of the season performs three important functions. (I) It enriches the soil by the addition of humus and nitrogenous matter made available through the decomposition of the roots and aërial parts of the vegetation. (2) The humus in turn creates a spongelike condition in the upper soil layer which increases its capacity to absorb water as it is received, thus making a maximum amount of water available for absorption by plant life during the dry part of the season. (3) Whatever old vegetation remains after a proper season of grazing, because it acts more or less as a mulch on the soil surface, decreases the evaporation from the soil and thereby conserves the moisture for plant growth. At the same time the semi-decomposed vegetable matter helps to prevent the soil from baking. Hence it acts as a regulator of the temperature and evaporation, both of which are controlling factors in the development of plant life. An area upon which the soil is exposed is sometimes subject to such wide and sudden fluctuations in temperature and moisture content that the vegetation which it supports, being often killed or seriously injured, is replaced by more drought-enduring plants. On the other hand, on areas whose soil fertility is high, and whose surface is partly protected by plant remnants from excessive evaporation, there is found a stable and luxuriant type of vegetation, generally the most profitable type the area is capable of producing.

It is contended that the only way to maintain in the soil the mineral and organic matter absorbed by the plant cover is to return to mother earth in the form of ash, as large a proportion of these constituents as is possible. Burning what vegetation remains at the end of the growing (grazing) season obviously defeats this plan and at once upsets the natural balance between 
the essential plant-food elements in the soil and the physical and chemical requirements of growing vegetation. It is true that close grazing year after year, as compared with nonuse of the lands, also tends to reduce somewhat the elements that would be returned to the soil; but this is largely offset by the fertilizing value of the manure. From 65 to 80 per cent of the nitrogen, phosphoric acid, and potash contained in the forage consumed is returned to the land in this form. ${ }^{1}$ Accordingly, if the forage stand is properly maintained, the soil constituents essential to the proper development of plant growth are always present.

Effect of Burning Grasslands. - Some who advocate the burning of grasslands concede the point that the productivity of the soil cannot be maintained if frequent burning is practiced, yet they insist that the present stand of perennial grasses may be maintained indefinitely. The facts do not bear out this contention. To say that a change takes place in the productive capacity of the soil but not in the surface cover is contrary to some of the most widely tested laws of plant succession and development known to the scientist as well as to the observing practical stockman.

Griffiths, ${ }^{2}$ in a discussion of the effect of burning in the Great Basin region, says: "Fire has a direct influence upon the condition of the feed. Burning is as destructive to the grass of the range as to the trees of the forest."

Burning in the East, Middle IV est, and Far West. - Observations made in various investigations in the East, the middle West, and the far West have convinced the writer that the effect of burning is practically as destructive to the forage cover as to the soil - that the two are virtually inseparable. As a rule, the burning of grasslands is done in the fall or early spring when the vegetation is quite inflammable. Over most of the area the forage cures well on the ground so that it has considerable value as feed throughout the winter. Therefore, the loss of the forage

1 Warren, G. F., "Farm Management," pp. 196-r98. The Macmillan Co., N. Y., r9r3.

${ }^{2}$ Griffiths, David, "Forage Conditions on the Northern Border of the Great Basin." U. S. Dept. of Agr., Bur. of Plant Ind., Bul. 15, p. 31, I902. 
by burning is in itself often serious. The more important loss, however, is in the reduction of the forage yield later.

A large proportion of the more shallow-rooted forage and hay plants, as, for instance, the fescues (Festuca) and the bluegrasses $(P o a)$, is often killed outright by a single fire. Almost invariably highly prized perennial forage plants of this type are replaced for a varying period of time by inferior and unpalatable vegetation. Furthermore, in the absence of the old leafage, which, when present, is cropped as a "filler," there is a tendency to graze the young succulent growth so closely as to injure its later development. Any advantages that may follow the removal of the old growth by burning - as, for example, making the newly developing crop more readily accessible for grazing are, therefore, more than counterbalanced by the disadvantages.

Burning in the Souih. - In many parts of the South where the predominating grasses attain a robust growth the lands have been burned over each year since the country was settled. For instance, the piney-woods region of the Coastal Plain, (which includes South Carolina; Florida; the southern parts of Georgia, Alabama, and Mississippi; the central and northern parts of Louisiana; parts of southern Texas; and southern Arkansas), much of the native range lands, and a large proportion of the privately owned pastures have been burned over each year from the time before the Civil War when the turpentine operations began. To protect the trees from accidental fires the leaf litter and other inflammable material is raked away from the base of the trees and burned under control. Following this operation, the stockmen fire the range according to the time-honored custom.

The practice of burning over the range year after year for so long a time has depleted the potential productivity of the soil to an extent difficult to estimate. By far the most important soil problem in the South is that of maintaining adequate organic matter. In regions with long growing seasons an enormous amount of organic matter is used up in normal decay. To rob the soil by burning off this potential and much-needed vegetable matter further complicates the all-important fertility 
problem and, at the same time, favors that very serious menace to the lands of the South - soil erosion.

If a pasture has been burned year after year, the soil is in about as low a state of productivity as can well be imagined. The forage is not only of an inferior type as compared with that of nonburned areas, but it is much shorter in stature and is appreciably sparser than on the fire-protected and more fertile areas.

Farley and Greene, ${ }^{1}$ as a result of their investigations of pasture management in the piney woods, say:

Another effect of frequent fires on native pasture has been to keep out the desirable pasture grasses and perpetuate the undesirable ones. Wire grass and broom sedge have been able to withstand fires to such an extent that they have almost taken possession of the cut-over lands. These plants, although furnishing most of the grazing, are undesirable because of their short grazing season, and are no better adapted, except in their ability to withstand fire, than carpet grass and lespedeza, the two most valuable pasture plants found on the range.

Although carpet grass is a perennial that stands close grazing, it is very susceptible to fire. The seed is matured late in the fall, and the plant is still growing at the time of fall fires. In the spring, the tender, creeping stocks are not protected to the same degree as are the clumps of wire grass and broom sedge.

The more experienced and successful stockmen of the South have abandoned burning off the grass cover annually. They fully appreciate in terms of production of future crops the loss such practices entail and are doing what they can to build up the fertility of the soil in order to increase, rather than diminish, their grass, timber, and farm crops. Where the grasses produce such a rank cover as seriously to interfere with the grazing of the season's growth, the lands are fired once every three to five years. This rotation allows a considerable part of the vegetable matter to decompose, and at the same time is said to enhance the utilization of the feed. However, even intermittent burning destroys a large portion of carpetgrass and other valuable forage plants. Generally, the less burning done the better is the forage

${ }^{1}$ Farley, F. W., and Greene, S. W., "The Cut-over Pine Lands of the South for Beef-Cattle Production." U. S. Dept. of Agr., Bur. of Animal Ind., Bul. 827, p. 25,1921 . 
stand. Where, however, the timber growth is so luxuriant as to supplant the grass cover, periodic burning appears to be justified.

Annual burning of grasslands has no place in judicious range or pasture management. ${ }^{1}$ It usually requires many years for closely burned and, more especially, for repeatedly burned grasslands to regain their original productiveness and yield their normal type of vegetation. Immediately after a fire, erosion, which follows the destruction of a large part of the soil-binding roots, often causes serious soil depletion. As a consequence the forage production may be materially reduced for an indefinite period.

Effect of Burning Brushlands. - The effect of burning typical brush or chaparral lands has long been a much-mooted point. Many are of the opinion that the firing of a brush field results in materially increasing for years to come the stand of grasses and other herbaceous forage plants. Unfortunately this is rot the case.

Instead of killing off the brush on grazing lands, the ultimate effect of fires is generally to increase it. Although the brush may be burned down, chaparral vegetation usually puts forth an increased number of shoots from the plant's crown, stumps, and roots, and these often occupy more space than did the ones that were killed. In some places ranges which formerly were practically free of brush have become, because of repeated fires, so thick with unpalatable bush growth that from this cause alone their value has greatly decreased. Soon after the firing of a brush field there is usually an appreciable increase in the stand of herbaceous plants, some of which are palatable to stock. Heavily burned chaparral lands in California, for instance, some of which have been fired by the United States Forest Service under careful control, have been invaded by a great variety of annual and perennial herbaceous plants during the first three years or thereabouts following the fire. But these plants gradually die out, and, after about the fifth year, the area is occupied

1 Sampson, Arthur W., "Burning Hay Meadows and Pasture Lands." Breeder's Gazette, p. 352, Aug. 31, rgro. 
by brush, which is usually of a denser stand than that before the fire.

Each summer between 1907 and 1912 the author had occasion, in the Blue Mountains of northeastern Oregon, to observe the development of the plant cover after fires of varying seriousness on different types of range. Notes taken at that time show that as a result of a single fire on densely covered brush areas where willow (Salix), buckthorn (Ceanothus), black sagebrush (Artemisia), mountain mahogany (Cercocarpus), and serviceberry (Amelanchier) predominated, this vegetation, much of which was highly palatable to sheep, was destroyed temporarily, and the grazing capacity was greatly lowered. The first three years after the fire a great variety of herbaceous plants became established, few of which rank high as forage. The following perennials were among the more conspicuous species: Fireweed (Chamaenerion), lousewort (Pedicularis), meadow rue (Thalictrum), mountain bromegrass (Bromus), aconite (Aconitum), goldenrod (Solidago), and everlasting (Antennaria). The cover as a whole was all but useless for grazing purposes. In addition, there were several annuals, among which Douglas knotweed (Polygonum), Androsace, shepherd's-purse (Bursa), and downy bromegrass (Bromus) predominated. Practically all of these plants are relatively drought-enduring and are able to develop and perpetuate themselves on an inferior soil type-a soil whose water-holding capacity, according to tests carefully conducted by the writer, was appreciably reduced by the fire. After the third year the more aggressive and hardy shrubs (in this test, species that were not palatable to stock) rapidly reoccupied the ground. The fifth year after the fire there was, on the whole, an impenetrable tangle of chaparral which had little or no value as browse.

Oftentimes, especially on heavily timbered areas where the heat from the fire was intense, the replacement of the original cover of vegetation probably requires as long a period as where the unchecked action of erosion has left its devastating impression. It is not unusual after a fire to find the soil devoid of the all-important nitrifying bacteria and other life as well as of 
humus content. To such unproductive soil a goodly supply of humus must be added before it can support a permanent and stable type of valuable forage plants.

The burning of brushlands has generally improved neither the palatable herbaceous nor the browse crop. Observations also substantiate the conclusion that what little improvement there may be in the forage following a fire is only temporary. If there is any improvement, it is usually more than offset by the depletion of the soil and the later increased growth and "stemminess" of the original brush plants themselves, as well as by the damage to personal and public property that so often results from the lack of proper fire control.

Goats as Brush Destroyers. - Great success is attained in the destruction of brush if goats are pastured where the brush is not too dense for the animals to work their way through it. If goats are held long on an area whose stand is sufficiently open to afford at least a moderate cover of grass and broad-leaved herbs, they crop the brush so closely as to kill it (Fig. 73). At the same time they make fair economic returns. Like other classes of stock, goats do best on a mixed diet. Browse feed is generally less succulent than herbaceous vegetation, and therefore wethers or dry does use the brush feed to much better advantage than does and kids, for the reason that, if the kids are to make satisfactory growth, the feed must be such as will provide an ample milk supply.

One serious objection to the use of goats, so far as profit from the animals is concerned, is that, after some of the brush has been killed, a considerable part of the mohair is pulled out as the animals work their way through the stiff dry stems and branches. In parts of California, ${ }^{1}$ Virginia, and the Carolinas, and in certain other sections, losses resulting from the destruction of the mohair have been so heavy as to cause stockmen entirely to abandon the use of goats for brush-clearing purposes. Of course, for some weeks after shearing practically no loss of mohair is caused by the brush. If profit from the goats is purely

1 Hatton, John H., "Eradication of Chaparral by Goat Grazing." U. S. Dept. of Agr., Review of Forest Service Investigations, Vol. 2, pp. 25-28, I9r3. 
a secondary matter, these animals may, in general, be depended upon to kill all species of brush whose leafage is palatable to them.

Provided erosion is not started. the disposal of brush by grazing has an advantage over burning in that the soil humus and decay-

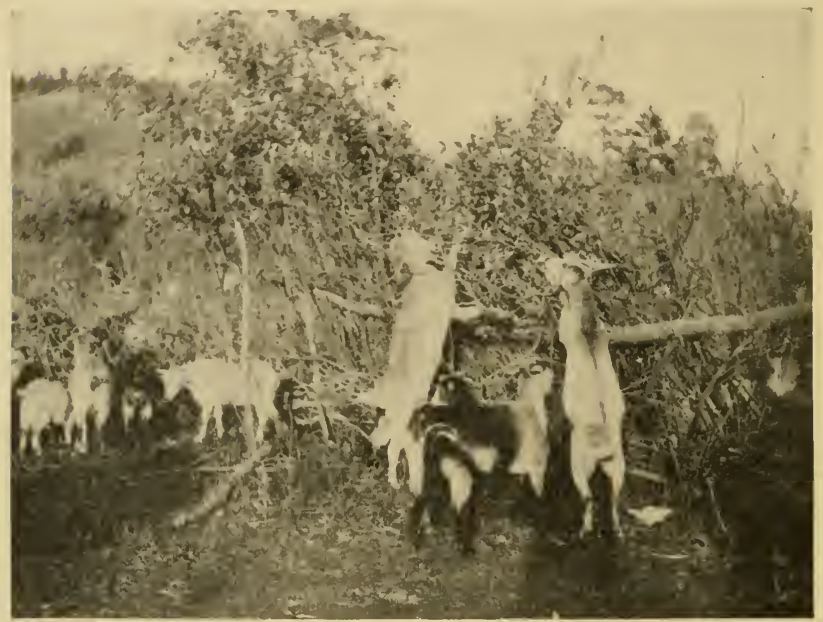

(Forest Service.)

Fug. 73. - GOATS ON PALATABLE BROWSE MAY CROP SO CLOSELY AS TO KILL OUT THE COIER IN TWO OR THREE YEARS.

Not uncommonly the bark of the stems and lower branches is closely consumed.

ing vegetable matter are not destroyed. However, as a rule, the soil on areas overgrazed in this way is heavily packed by trampling. This leaves the soil in bad physical tilth and for a time decreases its forage yield; but, if the cleared area is plowed, the ill effects that would follow packing are prevented.

Effect of Burning Wooded Pastures and Forested Ranges. On wooded pastures and forest ranges fires ordinarily cause much more damage to the timber than to the forage. On mountain range or, indeed, wherever the topography is broken, the timber, in addition to its monetary value, usually is of high importance 
because of the deterrent effect it has upon erosion and as a ground cover to stabilize streamflow. If the timber and undergrowth are killed by fire, not only is the financial loss great but the danger of erosion is much increased. Forest fires vary all the way from light surface fires that consume only the grass and topmost litter to conflagrations that race through the treetops and destroy every vestige of life in the forest. Upon the intensity of the fire depends the relative amount of damage done to both the timber and the forage.

In general, fires are destructive to forest and open pasture lands alike and differ only in degree. Owing to the large amount of fire material in a woodland the effect upon the soil is usually most serious there. Large areas are not uncommon on which the soil is rendered "lifeless" or virtually sterile (devoid of humus, bacteria, and earthworms) and for many years incapable of supporting vegetation except of the most early-maturing and drought-enduring type.

Jacquot, ${ }^{1}$ in discussing the effect of fires on vegetation, says:

The extraordinarily vigorous growth following on the burning of herbaceous and semi-woody plants would, no doubt, tempt many people to a conclusion favourable to fires as stimulators of growth. This exuberance, however, is merely the effect of a temporary stimulus; it is not sustained, and is followed by a depression, which is the reverse of enhancement. Chemical decomposition in operation in the soil provides slowly, but surely and indefinitely, the organic products which the growing stock assimilates every year. The fire, however, at one operation, effects the transformation of the detritus and, so to speak, condenses by anticipation the small but certain interests into an immediately available capital, which stimulates for the moment, but rapidly disappears, leaving to the trees only a minute fraction. The greater portion, swept away by rain, flows into the subsoil out of reach of the absorptive power of the enfeebled roots. In a very few years there remains no particle of the ashes, and as the soil covering has not had time to re-establish itself, the vegetation falls below its original condition.

In rare cases, where deep layers of arid soil overlie the subsoil, the products of combustion supply an excellent alkaline corrective. On the other hand, if the humus is scanty, a fire is disastrous. In any case "fire is ever a dangerous auxiliary."

1 Jacquot, A., "Incendies en forêt." English translation by C. E. C. Fischer, p. 196, I910. 
The monetary loss due to the destruction of the original vegetation is no greater, in all probability, than the loss of the soil's fertility. This fact becomes evident when the low productive capacity of the soil after it is burned and the period required for the reëstablishment of fertility are fully taken into account.

Grazing and Fire Control. - Careful observations and study for many years have convinced the writer that fires ordinarily are

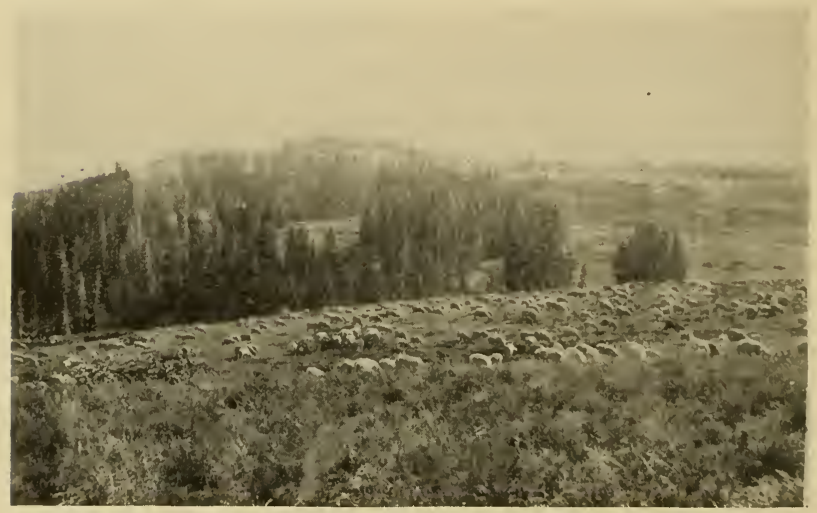

Fig. 74. - JUDICIOUS GRAZING IS HELPFUL IN FIRE CONTROL.

Not only is proper grazing an important factor in the control of fires, but it greatly increases the profits from the land.

fully as destructive to the range as overgrazing. This is particularly true of wooded pastures and forested ranges, where the monetary loss from fires is especially heavy. Proper grazing, however, quite aside from the profits it may directly yield, greatly reduces the liability to fires and the danger therefrom (Figs. 74 and 75). Burning, on the one hand, destroys the forage and makes it unavailable for livestock; grazing, on the other hand, utilizes the forage and prevents it from becoming possible fuel for fires. This latter fact is seldom fully appreciated, especially on the large and valuable timber holdings, in preparing plans for protecting the cover against fires. The beneficial 
effects of grazing in fire control should be taken advantage of to a much greater extent than they are at the present time. The additional revenue derived from the grazing of stock would greatly increase the benefits to be obtained from this means of decreasing the fire hazard.

That the damaging effect of fire on both range and timber

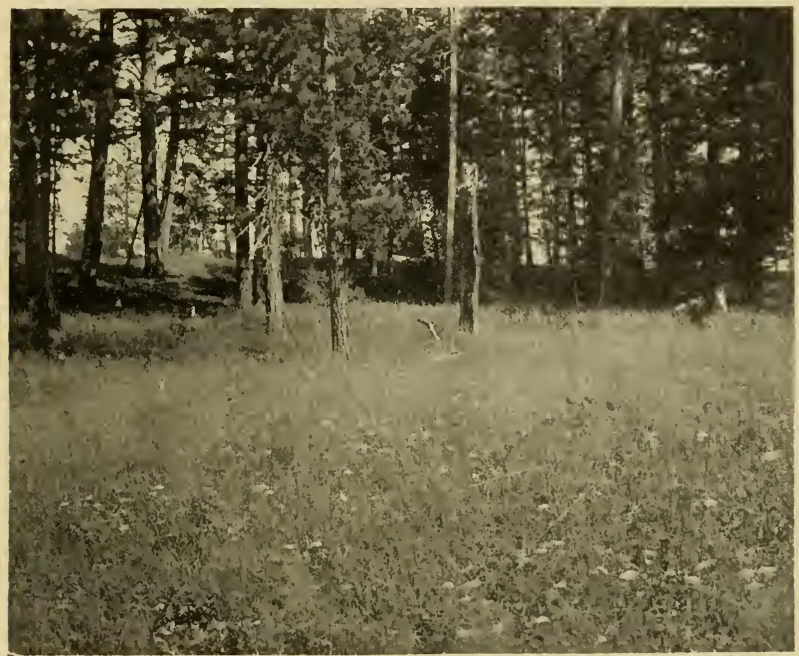

(Forest Service.)

Fig. 75. - A DENSE COIER OF INFLAMMABLE MATERIAL THROUGH WHICH A FIRE GAINS GREAT HEADWAY.

Most of this herbaceous vegetation is highly palatable to foraging animals.

warrants the adoption of the best possible protection against burning can no longer be subject to doubt. It is necessary to provide effective means not only for detecting and fighting fires but for preventing them from occurring. Educating the public to a proper realization of the dangers of setting forest and range fires, although a necessary part of any fire-protection plan, is slow and laborious. Well-regulated grazing, on the other hand, has the immediate effect of reducing the liability of 
fires, of preventing their rapid spread, and of assisting in their control. ${ }^{1}$

In localities where the livestock industry is well developed and the range is in demand, as, for instance, on the National Forests, the liability of fires is considerably lessened. This is because progressive stockmen realize the detrimental effects of fires and know that burning may not only destroy the forage for the season, probably with heavy financial loss to themselves, but that the carrying capacity of the range in future years will be lowered. Although it may be argued that the presence of the stockmen on the timbered range increases the liability of fires, because of carelessness about the camps, actual experience, as well as statistics gathered from a number of different localities, shows that this increased liability is so small that it can be disregarded. On the National Forests, with an area in I92 I of I $36,074,266$ acres (exclusive of Alaska and Porto Rico), upon which 2,056,644 cattle and 7,4I2,4I2 sheep and their lambs were grazed, the presence on the range of a large number of persons interested in the betterment of the forage crop was found to be a distinct advantage. Not only do these men discover and report fires which might otherwise escape notice until a large area had been burned over, but they are a distinct help to the regular protective force in the event of large fires.

As has been pointed out, the damage caused by burning the range depends largely upon the intensity of the fire. This factor is affected by a number of conditions, one of the most important of which is the amount of inflammable material present. It follows, therefore, that where the forage on any area is fully utilized there will be less danger of fires starting; or, if they do occur, they will have less fuel to feed on and consequently will burn more slowly and with less intensity and damage than on areas where the forage is left to "feed the flames." Observations have shown that this is actually the case. On one of the National Forests in California seven fires were started by lightning. Of these, five, which occurred in a country grazed by

${ }^{1}$ Hatton, John II., "Livestock Grazing as a Factor in Fire Protection on the National Forests." U. S. Dept. of Agr. Cir. 134, 1920. 
sheep, needed no attention; but the other two, which were in ungrazed territory, burned until extinguished by Forest officers and stockmen.

The danger from fires is further decreased by grazing, because the trampling of livestock breaks down the litter on the ground and hastens its decomposition. This is particularly true of sheep grazing (Fig. 76).

In controlling the beginning and rapid spread of surface fires,

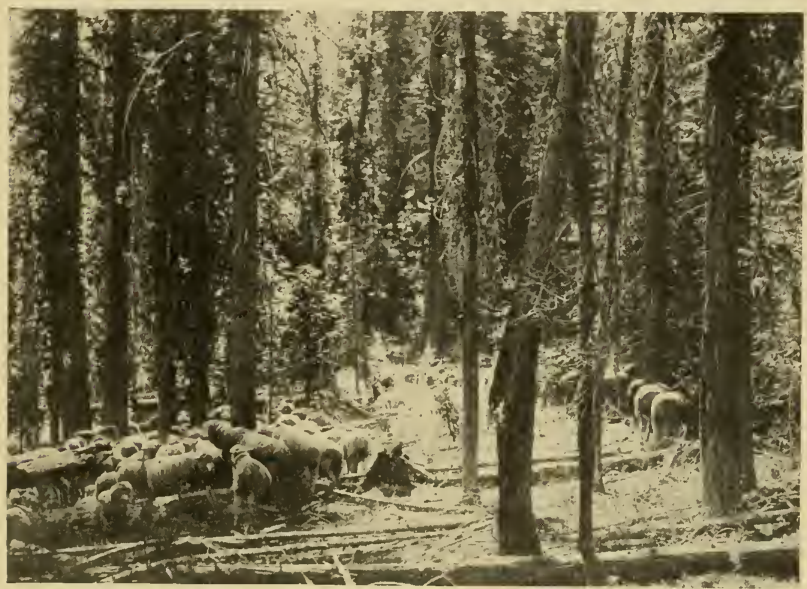

(Forest Service.)

FIG. 76. - GRAZING IN THE WOODLAND TYPE TENDS TO MINIMIZE FOREST FIRES.

The cropping of the herbage on woodland accompanied by the breaking up of the semi-decayed litter on the ground hastens its decomposition, enriches the soil, decreases the danger of fires, and is a distinct help in fire control.

grazing is often of great assistance in preventing the more serious ground and crown fires. In this connection it is well to recognize the three classes of forest fires.

A surface fire is one which consumes only such surface growth as grass, weeds, and other small vegetation. Nearly all forest fires start from surface fires.

A ground fire is a slow fire which burns down into the litter and mold and often follows tree roots underground. It is hotter 
than a surface fire and usually kills all vegetation that is present. Ordinarily a ground fire covers only a few acres.

A crown fire is one which races through the tops of the trees at high speed. It is the most destructive of all, as it kills not only practically all the trees that stand in its path but the herbaceous and brush cover too. Crown fires usually leave the soil sterile, so that for years it is incapable of supporting the higher types of vegetation.

The damage to the large trees caused by surface fires is comparatively small; but, if there is a considerable amount of inflammable material on the ground, the fire gains in intensity, and there is danger that the flames will spread to some low-limbed tree and thence into the tops of the trees and start a crown fire. If the area is grazed by livestock, and if the weeds, grass, and leafage of shrubs have been devoured to a considerable extent, not only is the danger of damaging surface fires reduced, but there is much less opportunity for the starting of the more destructive ground and crown fires.

For the same reason driveways over which large numbers of livestock are moved, and which are almost always closely grazed, tend to prevent fires from spreading to adjacent areas where the forage may not have been closely utilized. The fact that many of these driveways are located on ridges and along roads where lines of defense would have to be established to prevent the spreading of a fire greatly adds to their value for this purpose. It is recorded that many sheep driveways have been sufficient to stop fires which would otherwise have burned unchecked.

Trails made by livestock in going to and from water, salting places, and feeding grounds are likewise valuable for fire-fighting purposes, both because they often check fires, and because they permit men and supplies to be taken into areas where travel would otherwise be difficult if not impossible. Trails, constructed to open up unutilized range, furnish important means of access if fires occur. Likewise the development of stockwatering places in regions where water is scarce often enables fire-fighting crews to establish camp much more advantageously than would otherwise be possible. 
Proper Control of Grazing Essential. - Without question grazing can be successfully employed on most wooded areas for the purpose of reducing the danger from fires. It cannot be emphasized too strongly, however, that unless grazing is carefully regulated its beneficial effects may be outweighed by the damage it causes. This damage consists chiefly in the destruction of the young tree growth and the forage stand, and in the increased liability to serious erosion and floods, followed by the depletion of the soil and watershed.

Overgrazing and other faulty methods of handling stock cause damage to tree reproduction of all kinds, especially to the young, tender coniferous seedlings and the hardwood sprouts, either by browsing or trampling, or by both. There will always be some areas well covered with this class of growth, either from natural reproduction or from hand plantings, from which stock must be excluded long enough to allow the plants to pass beyond the stage in which they are liable to be appreciably damaged. Serious damage to timber production is almost invariably associated with the destruction of the more valuable forage plants, leaving only the unpalatable species to reproduce, if, indeed, it does not result in denuding the area of all or virtually all growth. Continued excessive grazing or other mismanagement of the range causes depletion of the soil almost exactly as fire does; that is, it destroys the natural supply of humus and nitrogen.

It is evident, then, that careful regulation of grazing is necessary in using foraging animals to lessen the danger from forest and range fires. Certain strategic locations, as, for instance, high ridges and areas particularly liable to injury by fires, may properly be grazed closely in order to create firebreaks or to lessen the liability of fires. Ordinarily, the aim should be to graze the forage before it dries up and becomes inflammable. This is especially important on areas of high fire hazard.

Ranges ungrazed because of inaccessibility to stock often afford severe fire nests. Most of the fires on these areas could be prevented or controlled by the construction of trails and by such a development of watering places as would permit the entrance of stock. Wherever the fire hazard is great, stock drive- 
ways should be so located that they will constitute effective firebreaks. On lands which are used exclusively for pasture, and which each year are fully and uniformly utilized, burning is unnecessary, as only a small amount of growth remains at the end of the season.

A little attention directed to the control of fires by judicious grazing will considerably simplify the protection of large bodies of range and woodland, and the profits derived from the livestock will increase the returns from the land.

\section{SUMMARY AND CONCLUSIONS}

From the unmistakable evidence afforded on old "burns" in the forests, from Indian legends, and from the accounts of early explorers it is well established that large areas of our country, both East and West, have been repeatedly swept by fires. Most of these fires were started by Indians and white hunters to control the movements of game. After the country became settled, stockmen and farmers in many parts of the country for a long time continued burning off the forage each year, contending that its removal stimulated early spring growth and that the resulting ash was invaluable as a soil fertilizer. Experience and close observations by scientists as well as by practical men, however, have clearly disproved in general the argument in favor of burning. Nevertheless, firing the lands is still practiced in certain sections in the South and to a lesser extent on unpalatable or otherwise undesirable tangles of brush in the far West. The effect of burning off rank-growing grasslands in the South and the chaparral type in the South and far West has long been a much-mooted question. The conclusions regarding the effects of burning, all types considered, may be summarized as follows:

I. The vegetation that remains on the ground to decay enriches the soil by the addition of humus, nitrogenous matter, and other materials important to plant growth; it increases the waterholding capacity of the soil, thus making a large amount of moisture available to plant life; and it protects the soil from excessive evaporation and the vegetation against injury from 
wide variations in soil temperature, drought, and other similar factors.

2. The safest and most economical way in which to maintain or build up the fertility of the soil is to return to it a goodly portion of its yield of vegetative matter. As is shown by the declining yields on burned-over lands, firing is inimical to the increase or even the maintenance of soil fertility.

3. Most stockmen concede that the fertility of the soil cannot be maintained indefinitely if the plant cover is burned every year or two, but many contend that growth begins earlier in the spring on burned-over areas than on protected lands. The facts indicate that there is probably very little, if any, difference in the time at which the spring growth begins on burned-over lands and on properly grazed nonfired areas. Furthermore, that part of the old stand which still remains somewhat palatable acts as a filler for stock; it has at least some food value and therefore to a certain extent protects the young growing crop from being overgrazed.

4. Burning of grasslands is considered by some careful investigators, as well as by many experienced stockmen, to be quite as destructive to the plant cover as to the fertility of the soil. In the middle West and the far West the writer has observed that some of the valuable shallow-rooted perennial forage and hay plants, such as the blue grasses (Poa) and the fescues (Festuca), for example, have been killed by a single fire. In the Coastal Plain region of the South, carpetgrass and lespedeza, two of the most valuable pasture and hay plants, are readily killed by burning. On the other hand, such inferior plants as "wiregrass" (Aristida spp.) and broomgrass (Andropogon spp.) withstand fires well, so that where the lands are burned annually the latter plants usually become established to the exclusion of the more desirable species.

5. The effect of fires is invariably to throw back the development or successional trend of the vegetation to a lower or more primitive form. The resulting inferior vegetation, most of which is low in forage yield, occupies the soil for an indefinite period.

6. The burning of grassland, chaparral, or timbered pastures 
is destructive to the soil in approximately direct proportion to the amount of inflammable material and the intensity of the heat caused by the fire. A large portion of the superficial roots of most plants is killed, thus leaving the soil exposed to the unhampered action of erosion.

7. Such herbaceous forage plants as may become established after the destruction of the brush are temporary in character. As a rule the brush is fully reëstablished in three to five years after a fire.

8. Generally only parts of the stems and branches of the brush and tree trunks are burned. This condition makes grazing difficult, for animals often become snagged and not uncommonly trapped, and a considerable part of the wool of sheep or the mohair of goats is pulled out by the animals coming in contact with the harsh unburned vegetation.

9. In some localities goats are effectively used in clearing lands of brush. This, however, can best be done where profit from the animals is secondary to the value of ridding the lands of brush.

ı. Carefully regulated grazing is beneficial in preventing destructive fires and is a distinct aid in fire control.

\section{QUESTIONS}

1. According to the present available information, when did range and forest fires first occur in this country? Name the chief originating causes.

2. How does repeated burning of range and pasture compare in destructiveness with severe overgrazing?

3. What effect did the settlement of the country have on the number and frequency of fires?

4. Approximately, what was the average acreage of burned-over lands and the monetary loss resulting therefrom in the United States between 1916 and I9I8, inclusive?

5. To what extent are fires purposely set at the present time in the East, middle West, far West, and South?

6. Name the two chief reasons why many stockmen, more particularly in the South, still favor burning over the range each year? What foundation in fact is there for these reasons?

7. What are the chief functions of the vegetation which remains on the ground and decays? 
8. What effect does burning each year have on the production of herbage on grassland? Why?

9. What effect does burning each year have on the production of herbage and browse vegetation on the chaparral type? On the woodland type? Why?

10. How is the natural trend of plant development or succession influenced by the burning of (I) grasslands, (2) chaparral, and (3) wooded pasture?

11. How does burning in the piney-plains region of the South affect the establishment and spread of (I) broomgrass, (2) carpetgrass, (3) "wiregrass," and (4) lespedeza?

12. How may grazing influence the control of fires? How may grazing be responsible for the starting of fires? Discuss the advantages of livestock trails, watering places, and driveways in the control of fires on forested range.

13. Name and define the different classes of forest fires? Which is the most destructive to the soil? Which is the most common?

14. Assuming for the sake of argument that grazing is an asset in the control of fires on wooded pastures, why is it essential to procure uniform but not excessive use of the forage?

\section{BIBLIOGRAPHY}

Barnes, Will C. Western Grazing Grounds and Forest Ranges. Sanders Pub. Co. (Breeder's Gaz.), Chicago, I913.

Graves, Henry S. A Policy of Forestry for the Nation. U. S. Dept. of Agr., Office of Secretary, Cir. I48, r9r9.

The Principles of Handling Woodlands. John Wiley \& Sons, Inc., N. Y., IgII.

Protection of Forests from Fire. U. S. Dept. of Agr., Forest Service, Bul. 82, 1910.

Griffiths, David. Forage Conditions on the Northern Border of the Great Basin. U. S. Dept. of Agr., Bur. of Plant Ind., Bul. I5. 1902 .

Hatton. John H. Eradication of Chaparral by Goat Grazing. U. S. Dept. of Agr., Forest Service, Review of Forest Service Investigations, Vol. 2, I9r3.

Livestock Grazing as a Factor in Fire Protection on the National Forests. U. S. Dept. of Agr. Cir. 134, I920.

Jacquot, A. Incendies en Forêt. Translated by C. E. C. Fischer. Supt. Govt. Printing, Calcutta, I9ro.

Plummer, Fred G. Chaparral. U. S. Dept. of Agr., Forest Service, Bul. 85 , I9II.

Forest Fires: Their Causes, Extent, and Effects. U. S. Dept. of Agr., Forest Service, Bul. I1 7, I912.

Lightning in Relation to Forest Fires. U. S. Dept. of Agr., Forest Service, Bul, II I, I9I2. 
Sampson, Arthur W. Burning Hay Meadows and Pasture Lands. Breeder's Gaz., Aug. 3r, r9ro.

Concerning Forest Fires. Breeder's Gaz., Sept. I3, I9r.

Sмгтн, B. Narrative of Alyar Nuñez Cabeza de Vaca, I851. 


\section{CHAPTER XII}

\section{STOCK-POISONING PLANTS AND THEIR CONTROL}

Notwithstanding the improved methods of management adopted by stockmen more or less generally in recent years, the livestock industry is nevertheless confronted with some very difficult problems. One of the biggest problems is the enormous annual toll of stock losses due to disease, predatory animals, injurious plants, and accidents of all sorts. Two phases of this problem, outside, of course, of bacterial pathology, come within the domain of botany, viz., (I) the existence of poisonous plants, many of which are devoured by livestock often with fatal effect; and (2) the presence of plants which at some stage in their development cause mechanical injury, not uncommonly weakening the animal seriously and sometimes causing death.

The poisonous-plant problem is most serious in the far West where the losses each year are very heavy - sometimes, indeed, outnumbering the combined losses caused by contagious and infectious diseases and by predatory animals. On the National Forest range alone approximately 8,000 cattle and 20,000 sheep, valued at about $\$ 500,000$, die annually from the eating of poisonous plants; yet the acreage of National Forest range is only a small part of the grazing grounds of the West. Moreover, the percentage of losses from poison on the high mountain Forest range is probably less than on ranges of lower elevation, especially the public-domain lands, most of which are badly overgrazed. Losses in the plains region from loco, for instance, each year vary from 5 to 50 per cent of all the stock grazed.

Stockmen may prevent much of the heavy financial loss now 
caused by the grazing of these dangerous plants if they will familiarize themselves with the more common poisonous species, avoid grazing the stock upon heavily infested areas, check overgrazing, provide sufficient salt, and, at the same time, put into practice certain other improved methods of handling.

The following chapters aim, first, to point out the conditions under which serious poisoning is liable to occur; second, to explain practical, thoroughly tested methods for preventing losses; third, to picture and describe the species which cause the heaviest losses; and, fourth, to note the preventive and remedial measures for each, in so far as they are known.

What is Poison? - By poison is here meant any substance, which, when taken internally, acts in a noxious manner other than mechanical, either causing death or interfering more or less seriously with health. The toxic substances found in the different poisonous plants vary widely both in their poisonous effect upon the animal and in their chemical and physical properties.

The subject of poisonous plants is by no means new. The word "toxicology" is derived from the Greek word toxikon, which referred to the poison in which arrows were dipped. The American Indian and various uncivilized races of Africa and other parts of the world were familiar with numerous poisonous plants long before chemistry had advanced far enough to isolate and identify poisonous plant substances. Numerous interesting illustrated treatises of poisonous plants, prepared by ancient Greek and Latin botanists or " medicine" men, show that many descriptions of the properties of plants given by the early workers have more recently been substantiated by scientific investigations.

Important Families of Poisonous Plants. - Of the many species of poisonous plants occurring throughout the United States, those contained in six genera are probably responsible for at least 75 per cent of all livestock poisoning. These genera are members of four families.

To the bunchflower family (Melanthaceae) belong the wellknown species of death camas (Zygadenus). The plants of this genus are found largely in the western part of America. 
The buttercup family (Ranunculaceae) embraces the larkspurs (Delphinium) which cause such alarming losses among cattle. There are many species of larkspur, a few of which are widely distributed.

The pea or pulse family (Leguminosae), which, next to the grass family, embraces the most economically important pasture and range plants, also includes a number of species that are highly poisonous to livestock. The most troublesome of these are the loco weeds (Astragalus and Oxytropis). Lupines ( $L u$ pinus) are also embraced in this family.

The parsnip family (Umbelliferae), like the pea family, includes a large number of highly palatable and nutritious forage plants, but it embraces toxic species also. Among these is included water hemlock (Cicuta), one of the most deadly poisonous plants in North America.

Interspersed with species of the more common genera of poisonous plants named are many genera whose species contain toxic substances and are more or less troublesome to range livestock.

In addition to the poisonous species of higher plants, only the more prominent of which have been mentioned, powerfully toxic substances occur among some of the bacteria and parasitic fungi. Certain mushrooms and some smuts, like ergot, have been the cause of livestock losses. Like many poisonous flowering plants, the fungi are somewhat variable in the toxic substances present.

Although something may be accomplished in the application of medical remedies to poisoned animals on the range, the main reliance in the control of losses must be upon better range management and improved livestock handling.

Palatability of Poisonous Plants. - The fundamental rule concerning the poisoning of any animal is that a certain amount of the toxic plant substance must be absorbed and circulated by the blood to cause death. The effect upon an animal that consumes a poisonous plant, then, depends not only on the amount devoured but on the rapidity with which the toxic substance is eliminated. The latter varies with different plants and animals, 
and hence some plants known to be poisonous may never cause symptoms of distress in certain animals.

Poisonous plants are not generally grazed as a matter of choice. Accordingly there is a striking relation between scarcity of food and losses by poisonous plants. ${ }^{1}$ The heaviest losses are most liable to occur on ranges that are badly depleted. On such areas the more palatable species produce a weak growth, whereas the poisonous plants, being ordinarily cropped but little, start growth in advance of the choice forage and may constitute a conspicuous part of the early spring vegetation. Not uncommonly livestock losses are heavy on lands which are grazed prematurely. Moreover, vegetation of all kinds is less nutritious early in the spring than later in the season, and this fact tends to widen the selection of leafage consumed by livestock, thus increasing the consumption of poisonous plants. Such overgrazed areas should be revegetated as soon as possible. They should not be grazed too early in the season, and care should be taken not to stock them too heavily.

Range Use and Variation in Poisonous Substances of Plants. It is well known that alkaloids and other toxic substances are not uniformly distributed throughout the tissues of all poisonous plants.

In the toxic lupines poisoning is unknown until the seed pods are well formed; therefore, practically all lupine poisoning occurs in late summer and in the autumn. Accordingly, lupineinfested lands should either be grazed early in the season, before the seeds have developed, or late in the autumn after the seeds have dropped. Although the lupine pods are poisonous, they do not cause deaths unless eaten in large quantities. Sheep are especially subject to lupine poisoning and therefore should not be grazed on lupine areas when the pods contain seed.

The root of the water hemlock contains more deadly toxic properties than do the leaves or stem. Sheep seldom trample out the tubers of this plant, whereas cattle are more liable to do so, and therefore are subject to greater loss from eating them.

1 Marsh, C. Dwight, "Prevention of Losses of Live Stock from Plant Poisoning." U. S. Dept. of Agr. Farmers Bul. 720, r916. 
Then, too, late in the season the leafage and stems of water hemlock become so coarse as to be eaten practically not at all by sheep.

Again, it is good practice to graze on a poison-infested area that class of stock which is immune to the toxic species. Horses and cattle are relatively safe on lands containing death camas and can generally utilize with impunity the feed on such lands, whereas sheep may suffer severely. Stock poisoning from death camas, however, seldom seems to occur after blossoming. While the herbage of death camas may be quite as poisonous after the flowers have dropped as when the plant is young, the leaves are much less palatable than early in the spring. The seed of death camas, which is also poisonous, is seldom eaten, and, as the plant approaches maturity, its palatability is practically lost.

The larkspurs, although poisonous to cattle, are not injurious to horses or sheep (Fig. 77). Horses show symptoms of larkspur poisoning under forced feeding, but they seldom consume the plant on the range. The leafage and stems of larkspur, on the other hand, seem to lose much of their poisonous property about the time of seed maturity, and the plant seldom causes serious losses in cattle late in the autumn.

Sneezeweed is evidently harmful to sheep, but its leafage apparently is not devoured by cattle and horses. Hence, range containing an abundance of this plant may be grazed with impunity by cattle and horses, although it would be dangerous to sheep.

Proper Salting of Stock. - Failure to provide sufficient salt causes foraging animals to develop a perverted appetite. Animals not given sufficient salt become restless and are difficult to handle. At the same time they are unable to eliminate poisons so well as are those supplied with ample salt. The reliance upon alkali licks is generally unsafe, as most alkali outcrops are composed of minerals other than sodium chloride, or true salt. Natural salt licks whose deposits do not contain the essential chlorine element are entirely unsuited to stock and in no way take the place of common salt. If natural licks are to be used, a sample of the salt should be examined by a chemist to determine if chlorine is present. 
In addition to proper salting, the animals should have ample water at all times. Without sufficient water, poisonous substances cannot be readily eliminated.

Eradicating Poisonous Plants. - Various methods of eradi-

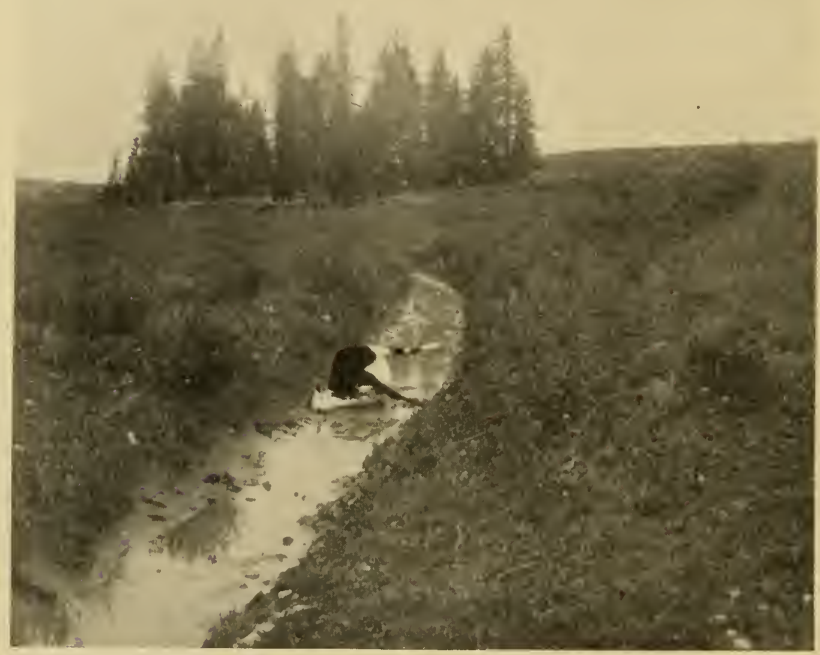

FIG. 77. - YOUNG COW POISONED IN THE SPRUCE-FIR TYPE AT AN ELEVATION OF 10,000 FEET.

The predominating vegetation in the background is tall larkspur. The position of the animal, with the head down the slope, is characteristic of larkspur poisoning. Horses and sheep graze with impunity on the range here shown.

cating plants from the range have been tried. Since all poisonous plants are not injurious to all classes of stock, the toxic species may be weakened or thinned out by close cropping by those animals that are not susceptible to injury. Thus larkspur areas may with impunity be closely grazed by sheep. Complete eradication of larkspur by the grazing of sheep cannot be expected, however, for native larkspurs are perennials and are not 
easily destroyed; and, if they are grazed so closely as to be eliminated, the desirable vegetation is also killed out. Similar results may be expected where other perennial toxic species occur.

It is known that poisonous plants generally increase in abundance where the ranges are overgrazed. As the productivity of the range is increased, many species of poisonous plants will be crowded out by desirable forage species. This appears to be especially true of the low larkspurs, death camas, sneezeweed, and, to a lesser extent, of the locos.

Chemical destruction of poisonous plants has been tried more or less extensively but without great success, because the other vegetation is killed as well. Various chemicals, such as arsenite of soda, common salt, and petroleum may be used to kill poisonous vegetation, but to discover a substance which will act in a selective way upon the undesirable species is difficult.

Grubbing or frequent cutting are the most effective methods thus far developed for destroying poisonous plants. The grubbing of tall larkspur is a conspicuous example of practical eradication. Growing as larkspur does, characteristically in somewhat isolated patches, the grubbing can usually be done at a cost per acre of less than half the value of a two-year-old steer. Again, water hemlock, which occurs commonly in patches on wet land, can also be dug out economically. Less success may be expected in the way of eradication by grubbing of such plants as the locos, death camas, or lupine, on account of their scattered growth. All species can be killed in time by cutting off the plants close to the ground. Usually three or four cuttings are required for complete eradication.

Driving and Herding Stock. - It is often necessary to move sheep considerable distances in changing from one range to another. Some of the most serious cases of poisoning recorded have occurred during these drives. If sheep are driven hastily, they are liable to snatch many plants which they would not devour if they were feeding at leisure. When feeding quietly on the range, tnev exercise considerable choice in the selection of forage; but when they have been driven steadily for a considerable period and are quite hungry, they are apt to nip off 
almost any regetation. This frequently results in astounding losses.

The same bad effects are liable to follow if sheep are bedded for several nights in the same place. As they leave the bed ground the first morning or two they naturally take the best feed. On subsequent mornings they are liable to devour poisonous plants to such an extent as to produce a fatal result. Both as a measure of safety against losses from poisonous plants and as a means of protecting the range, it is much better to use a new bed ground every night. The blanket method of bedding down sheep, and open, quiet herding are by far the safest practices.

If cattle are being moved over a driveway, care should be taken that they do not pass over larkspur areas when they are very hungry. Hungry cattle, like sheep, will snatch eagerly at almost any vegetation along their path, and under such conditions larkspur is tempting. Neither cattle nor sheep should be hurried on the drive. If they are permitted to drift along leisurely, they will spread out and select their food with reasonable care. A large proportion of the losses among cattle and sheep occur because the animals are driven in compact masses over poison areas, whereas there would be practically no losses if the animals were drifted across.

Established driveways are much more liable to contain poisonous plants than are driveways used occasionally. Although it is not always possible to avoid the use of fixed driveways, their use may sometimes be alternated from year to year, and in this way a fair supply of forage may be maintained. If this is not possible, an established driveway should be provided with camps where feed and water are available. The number of camps should be carefully determined on the basis of the number of animals that are to pass over the driveway each season.

\section{QUESTIONS}

1. How do the losses from poisonous plants in the West compare with those caused by diseases and by predatory animals?

2. (a) Approximately how many cattle and sheep die annually on National Forest range from poisonous plants? (b) How do such losses compare with those chargeable to poisonous plants on grazing grounds in the West generally? 
3. Define poison.

4. (a) What families embrace the most poisonous plants? (b) Name the six genera of plants which cause the heaviest livestock losses.

5. (a) To what extent are poisonous plants generally palatable? (b) Discuss the relation of range use and variation in poisonous-plant substances.

6. Discuss salt and salting of livestock as factors in poisonous-plant control.

7. (a) To what extent and under what conditions is eradication of poisonous plants practicable? (b) What methods of plant eradication have been tried, and which have given the best results? Why? $(c)$ What is the cost of plant eradication if one of the more effective methods is employed?

8. Discuss the handling of stock on depleted driveways where poisonous plants occur.

9. What methods of herding and bedding sheep in relation to plant poisoning are most effective and desirable?

Note. - The bibliography for the general subject of stock-poisoning plants is placed at the end of Chapter XIV (page 289). 


\section{CHAPTER XIII}

\section{PRINCIPAL STOCK-POISONING PLANTS}

\section{LOCO PLANTS (Oxytropis and Astragalus)}

Loco plants are members of two genera - Oxytropis and $A s-$ tragalus. The most destructive of these plants is the so-called Lambert's, white, stemless, or rattleweed loco (Oxyiropis Lambertii). It is a perennial herb with stems 12 to 18 inches high, the leaflets of the compound leaves being slender, somewhat hairy, and olive-green in color. The spikes of flowers are commonly white, though the corolla is sometimes streaked with purple. As the calyx is sometimes red, a variety of colors is found. The rattling of the pods as one touches them when the seed is mature resembles the sound of a rattlesnake. Accordingly the name "rattleweed" is in more or less common use (Fig. 78, colored plate).

Woolly, purple, or Texas loco (Astragalus mollissimus) is probably the second most destructive species. It is believed to have been the first member of the genus to be recognized as dangerous to livestock. Woolly loco may be distinguished from Lambert's loco by its more leafy stem, its conspicuously hairy and broader leaflets, blunt instead of sharp-keeled, and often by a deeper purple corolla, and shorter, thicker dark-brown pods. (Compare Figs. 78 and 80 , colored plate.)

Distribution and Habitat. - The amount of destructiveness of white loco is due to its very extended range rather than to an extraordinary degree of toxicity. It often grows very abundantly over large areas and is found from the north to the south of the United States, eastward as far as central Minnesota, western Kansas, and western Texas, and westward to western Arizona and western Montana. Woolly loco, as shown in Figure 79, occurs on the west from southeastern Arizona, central Colorado, and southeastern Wyoming, north to South Dakota, east through 


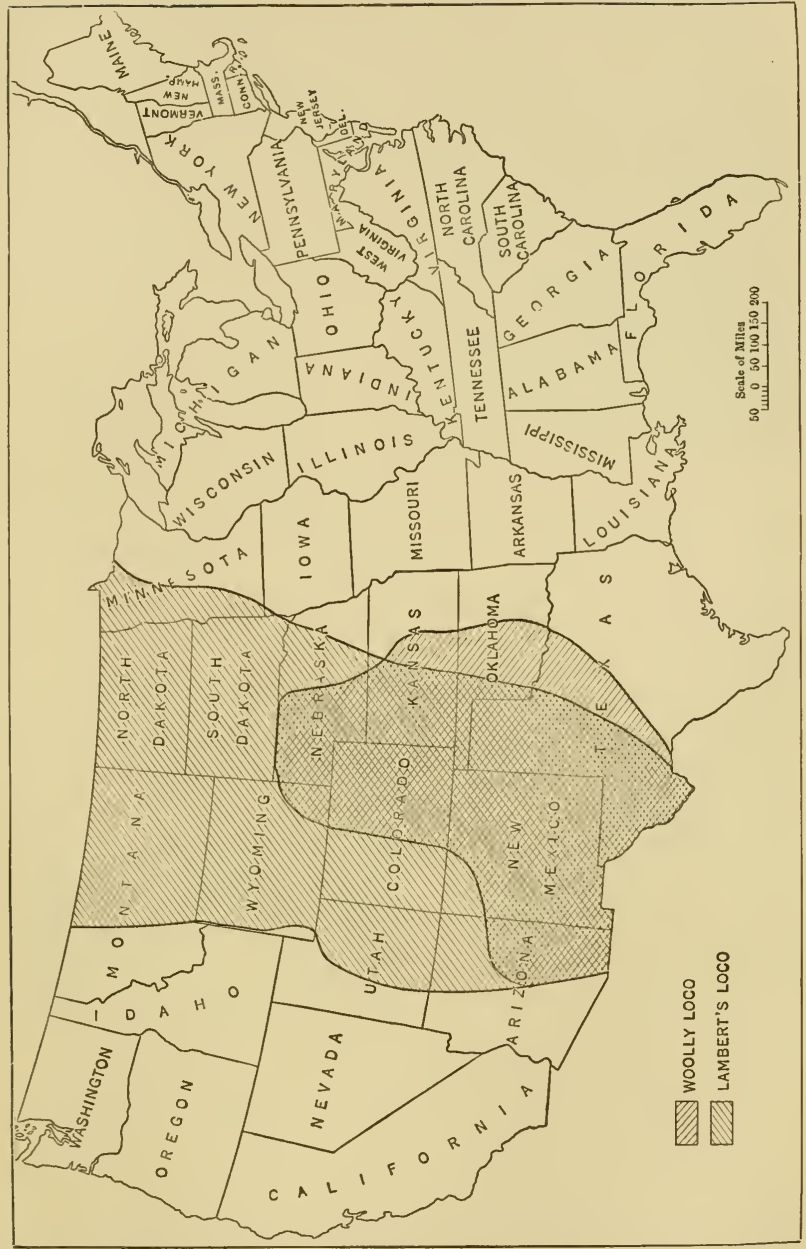

Fic. 79. - DISTRIBUTION OF THE TWO MOST TROUBLESOME SPECIES OF LOCO. 
Nebraska and eastern Oklahoma, and south through Texas, into Mexico. Woolly loco does not usually grow so abundantly as Lambert's or white loco and certain other species, yet it may cover several acres. It grows as a rule in patches, on adobe soil, and in depressions rather than on elevated ground.

Losses of Stock and Animals Poisoned. - Loco weeds are among the most destructive of all the poisonous plants. Losses in regions where purple loco is the only poisonous weed are almost entirely among horses, mules, and sheep. Cattle seldom crop the plant. Horses do not usually eat purple loco if other forage is plentiful, but they may form the habit if forced by lack of good forage. The use of the plant generally results fatally. White loco, on the other hand, is eaten more readily by horses, mules, cattle, and sheep, especially where palatable grass is scarce. Some animals leave loco for grass when the latter becomes green, but others develop a strong liking for loco and continue to eat it regardless of the presence of other feed. They will usually, however, lose their fondness for the plant if kept away from it. The effects of eating loco depend largely upon the individual animal. Some animals eat a limited amount of the plant at certain times of the year for a number of seasons without apparent harm, but others die within a few months or in a few weeks. Losses from loco poisoning are heaviest among young sheep and horses, as older animals rarely acquire the loco habit except where good forage is scarce.

Symptoms of Poisoning. - Loco poisoning may be acute, resulting fatally within a few days, or it may be slow, working for months or even as long as a year. The effects of the poison are cumulative; animals never become immune to it. The first symptoms of loco poisoning are stupidity and general loss of condition. The animals show marked lack of muscular control and become very nervous and excitable. The gait is irregular and staggering, the eyes are glassy, and the sight is impaired or lost altogether. A rough, shaggy coat is characteristic. The loss of muscular control causes the animal to act in an abnormal manner, apparently seeing things incorrectly or as the exact opposite of what they are. For example, a horse will 
leap high over a rut in the road or crouch to pass under an imaginary barrier (Fig. 8I). It shies at nothing and runs up against obstructions. Horses in this condition are very dangerous to ride or drive. Cattle are similarly affected (Fig. 82). They start, tremble, jump, and toss the head violently. They become crazed, lose flesh, and death results from starvation.

The symptoms in sheep and goats are less violent (Figs. 83 and 84 ). They usually become very weak and stupid, and stumble and fall, rising with great difficulty. Locoed sheep are difficult to herd, for they

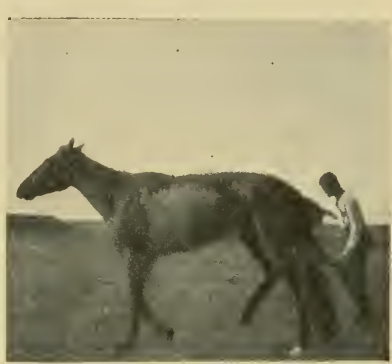

(Bureau of Animal Indusiry.)

Fig. 8r. - THE LANGUID GAIT OF A LOCOED HORSE. tend to stray away from the flock and are often very stubborn. The fleece comes off in patches. The animal is unable to take care of itself and is liable to fall into pools of water and drown.

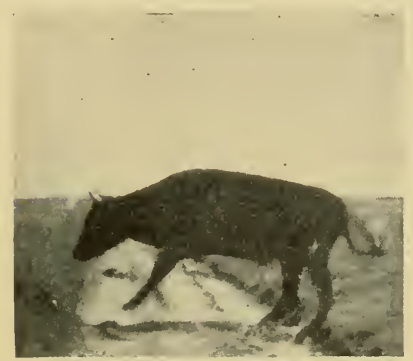

(Bureau of Animal Industry.)

Death results from the exhaustion following the severe convulsions which characterize the later stages of the disease, and from lack of nourishment. Constipation is a general symptom of loco poisoning in all animals.

Remedies. - Because there has been so little understanding of the nature of the loco poison and of its physiological effects upon livestock, no certain cure for it has yet been

FIG. 82, - A LOCOED STEER JUMPING UNNECESSARILY HIGH IN GOING OVER A SLIGHT ELEVATION IN A ROAD.

found. If the disease has not progressed so far that the animals are no longer worth saving, they should be removed from loco-infested range and given proper feed. If sheep are taken away from loco in the early stages of the disease, they may be 
fattened for market, as the poison does not affect the quality of the meat for food. Sheep which do not become fat are worthless except for their hides. Horses very rarely recover from the loco habit.

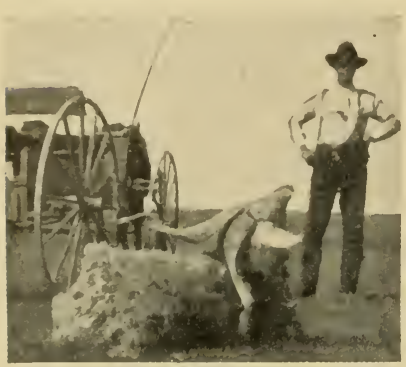

(Bureau of Animal Induslry.)

Constipation may be relieved by Epsom salts. The dose for mature cattle is about I pound, given as a drench; for calves, 2 ounces; for horses, 8 ounces; and for mature sheep, 4 ounces. Food of a laxative character, such as alfalfa and oil meal, should be given. Nervousness in horses may be relieved by 4

Fig. 83.-A GOAT IN THE LATER STAGES OF THE LOCO DISEASE.

to 6 drams of Fowler's solution daily in the grain or drinking water. Strychnine may be administered hypodermically to cattle in very small doses - three-twentieths to fourtwentieths of a grain daily. The treatment for both horses and cattle should be continued for thirty days or more. Recovery cannot be rapid, because the condition is brought on very gradually.

Control and Prevention of Losses. - As loco plants do not reproduce from rootstocks, they may be killed by cutting off the root 2 or 3 inches below the ground. The plants are very stubborn, and the seeds long-lived, producing a continuous crop. These seeds, however, are not carried

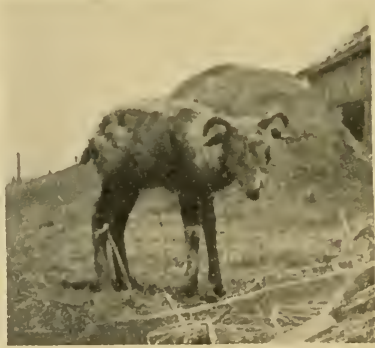

(Bureau of Animal Indusiry.)

Fig. 84. - A MUCII EMACIATED SHEEP IN THE ADVANCED STAGES OF LOCO POISONING. long distances by the wind; hence there is little danger of new plants starting on lands adjoining loco-infested areas. 
Loco plants in a pasture may be destroyed with a spade, but the work must be done two or three times a season and repeated every season. Purple loco is usually easier to eradicate than is white loco, because of its habit of growing in restricted areas, while white loco may cover many acres with a dense growth. The cost in one experiment of eradicating loco weeds was about $\$_{3}$ an acre for the first season, a small percentage of the customary loss from poisoned stock in a single year. Experiments in eradicating loco, however, have not yet been conducted on a sufficiently intensive scale to demonstrate the feasibility of grubbing out the species under general field conditions. Loco should be dug in May or June, while it is blossoming, as the plants are more readily detected and the seeds are not yet ripe.

Special care should be taken to keep young animals away from loco-infested areas, particularly where other forage is scarce. As all domestic animals are more or less imitative, those having the loco habit are likely to teach others the same habit. Therefore locoed animals should be pastured by themselves or, better still, be disposed of. If grubbing out the loco plants is impracticable, either the badly infested areas should be fenced against stock, or the animals should not be herded on those lands. ${ }^{1}$

\section{LARKSPURS (Delphinium)}

Other common names for Delphinium are cow poison and poison weed. A large number of larkspurs, widely variable in size and form, grow in native pasture lands in the West. When in blossom these plants are readily recognized by the conspicuous spur of the flower.

Distribution and Habitat. - There are more than twenty-five native species of larkspur in the United States, but few of these rre widely distributed. Some of the western species, however, ıre found on practically all of the stock ranges from the Rocky Mountains westward, particularly in the more elevated National Forest regions, where they often grow abundantly.

The present systematic status of the larkspurs is admittedly

1 For a detailed review of the loco-weed problem, see Marsh, C. D., "The LocoWeed Disease of the Plains," U. S. Dept. of Agr. Bul. I12, I9०9. 
unsatisfactory, and the genus is much in need of revision taxonomically. The larkspur species of the western ranges, however, may conveniently be divided into two general groups tall larkspur (Fig. 85, colored plate) and low larkspur (Fig. 86 , colored plate). These two groups differ somewhat in their choice of growth sites. The tall species prefer the moist, sheltered gulches and canyons of the higher ranges. Delphinium Barbeyi is the representative tall larkspur species of Colorado, and is also found in the mountains of Wyoming, Montana, and Utah. It grows at altitudes of about 8,000 feet to approximately timberline. The most common species in Montana is D. cucullatum, which is the cause of most of the losses of cattle on mountain ranges in that State.

Low larkspur grows on open hillsides, in drier localities than the tall species, and at somewhat lower elevations. Typical of the low species are D. Menziesii, which grows at elevations of from 4,000 to 10,000 feet, and sometimes spreads over large tracts, and $D$. bicolor, which grows at lower altitudes than $D$. Menziesii and is not so abundant. These species are more or less poisonous to cattle until after the seeds fall.

Both tall and low larkspurs are common in Wyoming, Colorado, Utah, Montana, and New Mexico, and are found in varying abundance in the foothill and mountain pastures over the greater part of the West.

Losses of Stock and Animals Poisoned. - It is probable that more deaths among cattle on western ranges are caused by larkspur than by any other poisonous plant. Serious cases of loss of cattle from this cause are on record. For example, one report states that 35 out of a herd of 500 cattle died within five hours; in another herd 200 out of 3,000 died; and in another, 200 out of a herd of 5,000 . $^{1} \quad$ The estimated money loss of cattle from this cause on the Fishlake National Forest ranges in Utah in I9I 5 was $\$$ I 5,000 .

So far as observations and experiments show, sheep are never poisoned by larkspur; on the contrary, the plants are considered

1 Marsh, C. D., and Clawson, A. B., "Larkspur Poisoning of Livestock." U. S. Dept. of Agr. Bul. 365, p. 12, I916. 
to be good forage for them. Horses are susceptible to the poison if large quantities are fed experimentally; but in feeding on the range at will it is not likely that they would eat enough to cause serious results.

Poisonous Parts of Plant. - All the parts of the larkspur plant above ground are poisonous; most of the trouble is caused by the leaves, but sometimes by the flowers also. The seeds contain more active poison than the rest of the plant, but they hardly ever cause death, as they are readily disseminated upon reaching maturity and are not sought for by stock. After seed maturity, also, the leafage seems to lose much of its toxicity.

The low larkspurs are poisonous as long as their herbage lives, but that generally lasts only through May and June. Moreover, the low species seldom grow densely enough for stock to crop fatal amounts of the herbage. The roots of native larkspurs are never eaten, as they are tough and woody and difficult to get at.

Amount Required to Cause Death. - Experiments with feeding larkspur show that an animal must eat about 3 per cent of its weight in order to be fatally poisoned. Thus, an animal weighing 800 pounds would have to eat about 25 pounds of either tall or low larkspur, although the fatal dose varies with the age of the plant, and with the condition and idiosyncrasies of the animal. On the average, if poisoning has proved fatal, it has been found that the amount of larkspur eaten was 8 to 9 per cent of the weight of the animal. It is evident, therefore, that larkspur is not a virulent poison, and, if taken in small amounts, is not dangerous. If other forage is plentiful, stock may graze without harm on a range on which larkspur is growing. The risk is greater in proportion to the scarcity of good feed.

Symptoms of Poisoning. - Larkspur poisoning always causes constipation, and recovery usually follows if this condition can be relieved. Bloating occasionally occurs, and sometimes death is caused by choking. Animals poisoned by larkspur fall in a peculiar manner; the fore legs give way, and the animal supports itself by its head, and by spreading its hind legs. It usually falls several times, the falls occurring at longer intervals if the 
poisoning is not fatal. Other common symptoms are quivering of the entire body, loss of muscular control, restlessness, stiffness of gait, excessive salivation, weak, rapid pulse, and evidence of pain in the abdomen, probably due to constipation. If pronounced symptoms of nausea occur, death is almost certain to follow. (See Fig. 77.) The symptoms are practically uniform for the tall and low larkspurs. If the case has not developed fatally, recovery from larkspur poisoning is very rapid. The effects usually disappear in two or three days, and no permanent injury is left.

Remedies. - As already said, it is probable that, if constipation could be relieved as soon as the first symptoms of poisoning appear, the poison would not result fatally. Many experiments have been tried with various remedies, such as barium chloride, caffeine, sodium benzoate, strychnine, potassium permanganate, and atropine; but none of these has proved successful.

Apparently favorable results have been obtained from hypodermic injections of physostigmine salicylate, pilocarpine hydrochloride, and strychnine sulphate; but, while more than 96 per cent of the cases treated with this remedy recovered, the total number of tests made was not large enough to give absolute proof of the efficacy of the treatment. It is likely, however, that it would be effective if applied very promptly. The formula for an animal weighing 500 to 600 pounds is as follows: Physostigmine salicylate, I grain; pilocarpine hydrochloride, 2 grains; strychnine sulphate, $\frac{1}{2}$ grain. The formula is to be doubled for an animal weighing $\mathrm{I}, 000$ pounds or more, and the dose is not to be repeated. If the animal shows signs of collapse, hypodermic injections of 20 cubic centimeters of whisky or 50 per cent alcohol may be given. The use of this formula has been tried on the range, as the equipment is not bulky. It may be of practical value where pure-bred cattle are run, but not for grade animals. The Quitman syringe, ro-centimeter size, is the best to use. The needle is inserted in the shoulder. If the animal is down, it should be so placed that the head will lie higher than the 
body, to prevent choking from the gas pressure, and it should be allowed to lie undisturbed. If the case of poisoning is not severe, this treatment alone is usually sufficient. The all-toocommon practice of bleeding has no merit whatever. If an animal is poisoned by larkspur on the range, it is usually dead when found, as a quantity large enough to be fatal acts very quickly.

Control and Prevention of Losses. - Most of the losses of cattle from larkspur poisoning occur in regions where the plant grows in small, dense patches, frequently in gulches into which the animals stray and graze until they have eaten enough to cause poisoning. The best way to eradicate larkspur when it grows in patches is by grubbing. ${ }^{1}$ The highest labor cost of the operation, on the most difficult areas, is never more than $\$ 12$ to \$ I 5 per acre, and the usual cost is not over $\$ 4$ to $\$ 8$. The cost will depend on the rates paid for labor, the cost of transporting laborers' tools and other necessary equipment, the abundance and distribution of the plants, the nature of the soil, and the kind of vegetation growing with the larkspur. The expense per acre is sure to be considerably less than the value of a mature animal. In the grubbing operation the main and side roots of the plant must be cut off at least 6 inches below the ground. The best tool for grubbing is known as the "hazel" hoe (Fig. 87). Any blacksmith who will follow the specifications given in the figure can manufacture this simple device at low expense.

Another effective method of eradicating tall larkspur is by cutting. Extensive studies conducted by the writer in the Wasatch Mountains of central Utah have demonstrated clearly that the densest patches can be killed in three years, and that only four cuttings are required. Two cuttings were made the first year, when the plants attained an average height of about 6 inches, and one cutting was made in each of the two following years. In the first year the initial cutting was made about July ro and in the second about August 20. In the two fol-

1 Aldous, A. E., "Eradicating Tall Larkspur on Cattle Ranges in the National Forests." U. S. Dept. of Agr. Farmers Bul. 826, I917. 
lowing years the plants became so weakened that a height growth of 6 inches was not attained until approximately August I5.

If the soil is free from rock outcrop, trees, and shrubs, the actual cost of cutting is less than that of grubbing. However, because the cutting method requires transporting labor to the

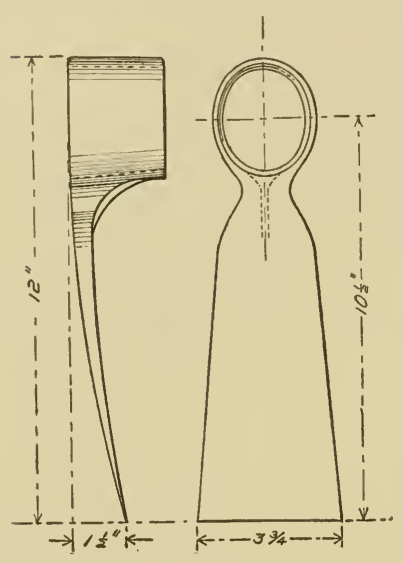

Fig. 87. - HAZEL HOE, USED IN GRUBBING TALL LARKSPUR. area four times instead of once, as the grubbing method requires, the latter appears to be the more practicable. Attempts have been made to destroy larkspur by spraying with plant poisons, but the results have never been satisfactory. A preventive measure which has proved satisfactory under some conditions is that of grazing the larkspur areas with sheep early in the spring, confining the band to the larkspur patches. If larkspur is grubbed or grazed over, the chances of cattle being poisoned are greatly lessened, for a large

amount of the plant is required to cause death.

Very hungry cattle should not be driven over areas on which larkspur grows luxuriantly, and they should be watched with especial care early in the season, as they are likely at that time to be in poor condition, and will eat plants which they do not touch when they are well fed.

The heaviest losses from larkspur usually occur during or immediately after a storm. It is important, therefore, to eradicate or fence larkspur patches where the animals go for shelter during inclement weather. The use of fences is to be recommended only if the area covered by larkspur is too large to be grubbed. Nearly always grubbing is cheaper and more effective than fencing. 


\section{DEATH CAMAS (Zygadenus)}

Other common names for Zygadenus are alkaligrass, hog'spotato, lobelia, mystery-grass, poison sego, soap plant, and squirrel food.

Species belonging to this genus are erect perennial herbs, growing either from rootstocks or, as in the western species, from a tunicated (membranous-covered) bulb, with leafy stems. The leaves are long, narrow, and grasslike; the flowers are green, yellow, or white, borne in terminal elongated or dense racemes or panicles. The perianth is spreading, not dropping when wilted, the sepals bearing one or two glands near the base. The capsule is 3 -lobed, opening to the base at maturity. The species pictured in Figure 88 (colored plate) is Zygadenus elegans. In general appearance it is similar to that of other western species.

Distribution and Habitat. - The species of death camas are widely distributed throughout the United States, and as far north as Alaska. Some species occur in abundance west of the Rocky Mountains to the Pacific Coast and are found at all altitudes at which sheep graze. The plants are somewhat exacting in the matter of site, preferring fairly moist localities into which water seeps slowly, rather than wet, swampy, or very dry ground. They are frequently found in shallow depressions or ravines along the slopes of hills and mountains, and grow either as scattered specimens mingled with other vegetation, or in masses, sometimes covering several acres. Death camas rarely lasts later than July, although the life of its herbage varies with the altitude and the exposure where it grows. The resemblance of death camas to grass before either is headed out, its appearance earlier than most other herbaceous plants, and its wide distribution render it especially dangerous to stock, particularly sheep.

Poisonous Species. - There are about ten species of Zygadenus, all of which are supposed to be more or less poisonous, although none of the recent investigators has offered a systematic revision of the genus. Experiments with the various species prove that $Z$. gramineus is the most virulent species, with 
$Z$. venenosus second, and that $Z$. clegans and $Z$. paniculatus, probably the next two most important species, are only about one-seventh as toxic. ${ }^{1}$

Losses of Stock and Animals Poisoned. - Although it is impossible to estimate, even approximately, the total loss of sheep from death camas poisoning, reports from various localities indicate that it is often very heavy. For instance, in Montana in $1900,3,030$ sheep were poisoned by death camas and 636 of this number died. ${ }^{2}$ Reports from Wyoming record 500 deaths of sheep out of 1,700 poisoned, and it is said that 20,000 sheep died from this cause in 1909 in one county alone. These figures do not include lambs, large numbers of which were poisoned by the milk of the ewes.

Most of the losses of stock from death camas poisoning occur among sheep, but horses and cattle are also sometimes poisoned. Stockmen generally are not familiar with the plant and are therefore likely to attribute to other plants losses of stock which may have been caused by death camas. The heaviest losses from this plant seem to occur in Montana and Wyoming. Heavy losses are also reported in Utah, Oregon, and California. Swine are believed to be unharmed by death camas; indeed, they are said to thrive on the bulb, which is sometimes called hog'spotato. The heaviest losses of sheep occur early in the spring, before other forage plants are abundant, and on ranges which have been overgrazed.

Poisonous Parts of Plant. - Investigators differ as to whether the largest number of cases of poisoning from death camas are caused by the bulb or by the aërial portions of the plant. While the entire plant, including the seeds, is known to be poisonous, the bulb contains a large amount of active poison, though evidently less than the seed. ${ }^{3}$ Whether or not the bulb is eaten

1 Marsh, C. D., Clawson, A. B., and Marsh, H., "Zygadenus, or Death Camas." U. S. Dept. of Agr. Bul. 125, p. 35, I915.

Marsh, C. D., and Clawson, A. B., "The Stock-Poisoning Death Camas." U. S. Dept. of Agr. Farmers Bul. 1273, I922.

${ }^{2}$ Chesnut, V. K., and Wilcox, E. V., "The Stock-Poisoning Plants of Montana." U. S. Dept. of Agr., Div. of Bot., Bul. 26, p. 58, I9or.

${ }^{3}$ Marsh, C. D., Clawson, A. B., and Marsh, H., "Zygadenus, or Death Camas." U. S. Dept. of Agr. Bul. 125, p. 33, 1915. 
by sheep depends upon the condition of the ground and the ease with which the bulb can be pulled up. Ordinarily the bulbs are pulled out of the ground with difficulty.

Amount Required to Cause Death. - The amount of death camas required to cause death depends upon the size and idiosyncrasies of the animal, and whether it is very hungry or not. A mature sheep must eat from $I_{2} \frac{1}{2}$ to 5 pounds of the plant to cause fatal poisoning, and lambs correspondingly less. Experiments have shown that the fatal amount was less when given as a drench or by forced feeding than when mixed with other forage. The amount of the plant required to produce poisoning also depends upon the length of time over which feeding extends. It is likely that sheep are poisoned by a smaller amount when they are grazing in the open than when they are fed in corrals. The poisonous or fatal amount for cattle and horses is practically the same as for sheep, in proportion to the size and weight of the animal.

Symptoms of Poisoning. - The more pronounced general symptoms of death camas poisoning in the higher animals are frothing at the mouth, vomiting, restlessness, weakened heart action, irregular, spasmodic breathing, convulsions, bloating, weakness of the muscles shown in a staggering gait and inability to rise when down, and general paralysis (Fig. 89). The symptoms are not uniform in all poisoned animals, however; they vary according to the manner in which the poison was administered, and with the length of the illness. Animals sometimes lie unconscious for several hours before death.

Remedies. - A large number of logical remedies for death camas poisoning have been tried, and, although some have seemed to be beneficial in experimental treatment under favorable conditions, most of them are not only impracticable for treating a band of sheep on the range, but are more expensive than the animals. Bleeding, a remedy commonly used by herders, is useless. Any antidote is ineffective unless given as soon as symptoms of poisoning appear, for the poison cannot be counteracted after it leaves the stomach. Medical tests carefully conducted by workers in the United States Department of Agri- 
culture have failed to develop an effective antidote against death camas poisoning.

The best means of combating death camas poisoning is prevention. All stockmen should become acquainted with the plant and take every precaution to keep their sheep away from it, especially in early spring before an abundance of nutritious feed is available.

\section{WATER HEMLOCK (Cicuta)}

Other common names for Cicuta are cowbane, beaver poison,

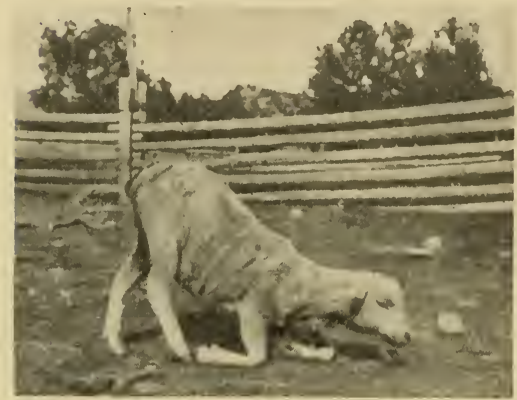

(Bureau of Animal Industry.)

Fig. 89. - ONE OF THE CHARACTERISTIC SYMPTOMS OF SHEEP POISONING BY DEATH CAMAS IS WEAKNESS IN THE FORE LEGS. musquash root, muskrat weed, parsnip, snakeweed, snakeroot, and spotted parsley. The water hemlocks are perennial umbellifers growing from a rootstock, with pinnate leaves and toothed leaflets. There is often an involucre present, but never an involucel. The flowers are white; the fruit ovoid to orbicular, smooth, unwinged but with prominent, flattish ribs, the lateral ones largest; the oil tubes conspicuous and solitary. The seeds are nearly cylindrical. A striking peculiarity of the roots of most species is their characteristic musky odor and horizontal chambered partitions. The species pictured in Figure 90 (colored plate) - Cicuta occidentalis - is a typical western plant, which closely resembles other species of Cicuta found on pasture lands.

Distribution and Habitat. - Water hemlock grows in nearly every country of the North Temperate Zone, and in western North America it usually occurs between elevations of about 
3,000 and 8,000 feet. In the western grazing regions the plant is found from the Black Hills of South Dakota, through Idaho, southward through Colorado and northeastern Nevada as far as New Mexico, throughout the Rocky Mountains, and in the States of the Pacific coast. The growth areas of water hemlock are much restricted. It is found only in moist or wet localities, as along the banks of streams and irrigation ditches, in swamps, and on wild, moist hay land, usually in isolated patches. This habit of growth makes the plant comparatively easy to deal with.

Losses of Stock and Animals Poisoned. - Although there is a considerable difference of opinion among investigators as to the number of animals poisoned by water hemlock, there is no doubt that all of the higher animals, including man, are susceptible to the poison. No reliable facts are available upon which to base an estimate of the losses; but it is known that large numbers of cattle die from this cause every year, though the total loss is much lower than that from loco and larkspur. Reports from Oregon record deaths of 100 cattle in one year, and from Montana, of $5_{5}$ sheep and as many cattle in a single season.

A large proportion of the animals poisoned by water hemlock die, for, unless the animals are treated immediately after the first symptom of poisoning occurs, there is small chance of saving them. Because the toxic principle acts so virulently it is practically impossible to treat a large number of cases at one time.

Poisonous Parts of Plant. - Investigators differ again as to the toxic properties of the stems and leaves of water hemlock. The general opinion, however, is that the whole of the plant is poisonous, at least during the early stages of its growth, although there is much less danger in the part above ground. Usually there are not tops and seeds enough to be harmful when the plant is mixed with hay. Most of the poisonous principle of Cicuta is contained in the root, which is so virulently poisonous that a very small amount appears sufficient to kill any of the higher animals.

Symptoms of Poisoning. - Symptoms of Cicuta poisoning are frothing at the mouth, excessive flow of urine, very violent convulsions, often with more or less opisthotonos, or arching of the 
back, and evidence of severe pain. The breathing is apparently labored and the heart action irregular, although it is difficult to be certain on these last two points, for attempts to handle the animals make the spasms more violent. The action of hemlock poison is very rapid. Cattle have been known to die within fifteen minutes after the appearance of the first symptom of poisoning. Sometimes the animals may live two or three hours.

Remedies. - Antidotes may sometimes be given with success if the symptoms of poisoning are detected at once. It is seldom worth while to resort to treatment, however, as the action of the poison is so rapid and the spasms are so violent that it is almost impossible to administer remedies. Hypodermic injections of morphine as a sedative to quiet the convulsions, in addition to a purgative to carry off the effects of the poison, may be helpful. A drench of lard or bacon grease is also recommended by some investigators. However, most cases of hemlock poisoning are hopeless, and therefore attention should be paid to methods of prevention rather than of cure.

Control and Prevention of Losses. - Because water hemlock grows in wet soil, and the roots are only about 6 inches below the ground, it is comparatively easy to eradicate the plant by grubbing. If for any reason grubbing is impracticable, it is not difficult to fence stock away from infested localities, for water hemlock is almost invariably confined to isolated patches. First of all, it is necessary for stockmen to learn to distinguish the water hemlock plant from harmless species of the same family.

\section{LUPINES (Lupinus)}

The lupines are given many common names. The more common of these are blue bean, blue pea, Indian bean, old maid'sbonnet, Quaker's-bonnet, and sundial. The name loco is used limitedly, but only by persons who are not familiar with the true loco weeds.

Distribution and Habitat. - Lupines are found in practically all western stock-grazing regions. They grow so abundantly in some localities that solid tracts of the blossoms are visible for 
miles. There are only three species in the Atlantic States, and these are neither so widely distributed nor so abundant as in the West, where about twenty-five species are represented (Fig. 9I, colored plate). The species do not usually occur in cultivated soil or in swamps, nor often on river flats. Most of them prefer the slopes of hills, or portions of mountain ranges at moderate elevations. Most lupines are fairly good forage plants if not eaten at the poisonous stage of their growth. Where large tracts of dense stands occur the plants are often cut for hay.

Losses of Stock and Animals Poisoned. - Experiments indicate that practically all animals are more or less susceptible to the toxic substances contained in lupine. Under range conditions, however, lupine may be regarded as almost exclusively a sheep poison, although occasionally horses succumb to the plant. A few cases of lupine poisoning of range cattle have been reported, but they do not appear to be well authenticated. Many heavy losses of sheep from this cause during late summer and fall are on record. One report states that $\mathrm{I} 50$ sheep out of 200 died from lupine poisoning. These animals were very hungry and ate the plant when the pods were developed, but the seeds not entirely ripe.

Lupine hay, or hay that contained as high as 50 per cent of lupine, cut when the plant was in seed, has caused severe losses. In the winter of $1898-99$ over 3,600 sheep died in Montana from this cause; in another band 90 out of 150 sheep died from eating hay which had been cut during the latter half of July; and in still another band of 2,500 sheep 900 died within 48 hours after eating lupine hay. Sheep have often been poisoned by lupine after snowstorms, when it is the only plant remaining above the snow. Out of one band of 2,500 sheep, I, I 50 died from eating lupine under these circumstances. ${ }^{1}$

Poisonous Parts of Plant. - The fruit of lupines is frequently the cause of fatal sheep poisoning. Post-mortem examinations of the stomachs of poisoned sheep which have been found to contain large quantities of the pods and seeds of lupine, prove

1 Chesnut, V. K., and Wilcox, E. V., "The Stock-Poisoning Plants of Montana." U. S. Dept. of Agr., Div. of Bot., Bul. 26, p. I04, Igor. 
conclusively that lupine hay is very dangerous to stock if it is cut when the pods are fully developed and filled with ripe seed. Sheep are especially fond of the green pods of lupine, which, like the fruit of many leguminous plants, have a sweet taste. Bloating may result from eating very large quantities of the green plant, particularly when it is wet.

Amount Required to Cause Death. - The following experiment is on record showing the amount of lupine required to cause fatal poisoning. Two sheep were each fed I 50 mediumsized lupine pods containing nearly ripe seeds. They ate the pods readily, and both showed violent symptoms of poisoning within 45 minutes after eating. Both animals died one hour later. Marsh and Clawson report that $\mathrm{I} \frac{1}{2}$ pounds of fully developed fruit (pods and seed) produced death in a roo-pound sheep. Of empty pods about 3.4 pounds were required to produce similar results. ${ }^{1}$

Symptoms of Poisoning. - Animals poisoned by lupine become crazed, move about with an irregular, staggering gait, froth at the mouth, and butt at any object in their way (Fig. 92). Spasms and falling fits are also characteristic symptoms. The flow of urine is always much increased, and it may contain blood. It sometimes happens that animals poisoned

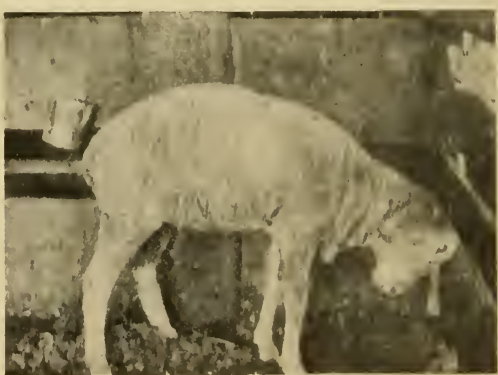

(Bureau of Animal Industry.)

Fig. 92. - SHEEP POISONED BY LUPINE BECOME CRAZED AND BUTT THEIR HEADS AT ANY OBJECT IN THEIR WAY. by lupine do not die until several days after poisoning occurs, the symptoms of the poisoning being less violent. Post-mortem examinations show that the effects of lupine poison on the animal organism

1 Marsh, C. D., Clawson, A. B., and Marsh, H., "Lupines as Poisonous Plants." U. S. Dent. of Agr. Bul. 405, pp. 32 33. 1916. 
are similar to those of acute loco poisoning. The membranes of the brain and lungs are congested, and the small bloodvessels ruptured.

Remedies. - Experiments have thus far shown no effective remedy for lupine poisoning. Bicarbonate of soda administered as soon as the first symptoms appear has been suggested as a possible antidote, but it would have to be administered very promptly in order to be effective. This method might be used in order to save a highly valuable animal, but it is not practicable for common sheep. Bleeding is sometimes practiced by herders, but the value of this procedure is not supported by any scientific evidence.

Control and Prevention of Losses. - Preventive measures are best in this as in other kinds of plant poisoning. Sheep should never be allowed to feed on lupine when the pods contain ripe or nearly ripe seed, especially if the animals are very hungry. Lupine should not be cut for hay until the pods are ripe enough to shed their seed before the hay is stored. This may usually be done after the middle of August; but, if there is any doubt in the matter, one or two sheep should be fed with the hay as a test before it is given to all the flock. The safer way, however, is either to cut the plants when in bloom or not to use lupine for forage until more is definitely known about the time when the plant may be eaten with safety.

\section{SUMMARY OF SYMPTOMS AND TREATMENT OF STOCK POISONED BY PRINCIPAL TOXIC PLANTS}

Those who have not observed the symptoms of stock suffering from having eaten poisonous pasture plants of known identity, often gain the idea that the symptoms are much the same for all genera. As a matter of fact, the symptoms produced by different genera of toxic plants are usually more or less distinctive. It is important to recognize the characteristic symptoms produced by the more common poisonous plants, as such knowledge immediately suggests what precautions should be taken in handling the livestock to minimize or prevent future losses. The following summary of symptoms of poisoning, and of treat- 
ment or prevention for the six most troublesome poisonous genera should be helpful in making comparisons.

\begin{tabular}{|c|c|c|}
\hline Disease & Symptoms & Remedies \\
\hline $\begin{array}{l}\text { Loco } \\
\text { poisoning }\end{array}$ & $\begin{array}{l}\text { Effect cumulative; stupor; } \\
\text { lack of muscular control; de- } \\
\text { fective vision; when excited } \\
\text { animal becomes frenzied, } \\
\text { shies at nothing; sheep dif- } \\
\text { ficult to herd; coat shaggy; } \\
\text { a depraved appetite for loco. }\end{array}$ & $\begin{array}{l}\text { No certain cure; relieve } \\
\text { constipation by giving Ep- } \\
\text { som salts, one pound for ma- } \\
\text { ture cow; also strychnine } \\
3 / 20 \text { to } 4 / 20 \text { of a grain; re- } \\
\text { move animal from loco-in- } \\
\text { fested range to pasture with } \\
\text { forage of laxative character. }\end{array}$ \\
\hline $\begin{array}{l}\text { Larkspur } \\
\text { poisoning }\end{array}$ & $\begin{array}{l}\text { Rapid breathing, pulse fast; } \\
\text { dizziness; weakness of fore } \\
\text { legs; quivering of entire } \\
\text { body; constipation; violent } \\
\text { convulsions in final stages; } \\
\text { heavy bloating immediately } \\
\text { following death. }\end{array}$ & $\begin{array}{l}\text { For mature cow, hypoder- } \\
\text { mic injection of physostig- } \\
\text { mine } 2 \text { gr., pilocarpine hydro- } \\
\text { chloride } 4 \text { gr., and strychnine } \\
\text { sulphate I gr., combined; if } \\
\text { animal is down, have head } \\
\text { higher than body. }\end{array}$ \\
\hline $\begin{array}{l}\text { Death } \\
\text { camas } \\
\text { poisoning }\end{array}$ & $\begin{array}{l}\text { Frothing at mouth; vomit- } \\
\text { ing; restlessness; irregular } \\
\text { gait; weakened heart action; } \\
\text { rapid breathing; motor par- } \\
\text { alysis. }\end{array}$ & $\begin{array}{l}\text { No specific antidote; keep } \\
\text { sheep away from camas-in- } \\
\text { fested lands. }\end{array}$ \\
\hline $\begin{array}{l}\text { Water } \\
\text { hemlock } \\
\text { poisoning }\end{array}$ & $\begin{array}{l}\text { Very severe convulsions } \\
\text { with arching of back, and } \\
\text { evidence of severe pain; di- } \\
\text { lated pupils; irregular heart } \\
\text { action; frothing at mouth; } \\
\text { excessive flow of urine. }\end{array}$ & $\begin{array}{l}\text { Give morphine hypodermic- } \\
\text { ally; wash out stomach with } \\
\text { coffee or whisky, or give } \\
\text { drench of lard or bacon grease. }\end{array}$ \\
\hline $\begin{array}{l}\text { Lupine } \\
\text { poisoning }\end{array}$ & $\begin{array}{l}\text { Animal becomes crazed; ir- } \\
\text { regular, staggering gait; } \\
\text { frothing at mouth; butts } \\
\text { head at any object; later } \\
\text { stupor; loss of appetite; at } \\
\text { first constipation, later diar- } \\
\text { rhea. }\end{array}$ & $\begin{array}{l}\text { No specific antidote; keep } \\
\text { animals off lupine range when } \\
\text { pods contain ripe or nearly } \\
\text { ripe seeds; lupine hay should } \\
\text { not be cut when pods are in } \\
\text { seed. }\end{array}$ \\
\hline
\end{tabular}

\section{QUESTIONS}

1. (a) Compare the livestock losses caused by loco with those of other poisonous plants. (b) Which species of loco causes the heaviest livestock losses? Outline its range of distribution.

2. (a) What are the typical symptoms of loco poisoning? Do the symptoms soon pass off or is the poison cumulative? (b) Discuss remedial and preventive measures in the control of the loco disease.

3. (a) How are larkspurs popularly classified? Give an example of one 
species in each group. (b) To what extent do the larkspurs cause poisoning (I) of cattle and (2) of sheep? On what type of range do larkspurs commonly grow?

4. (a) What parts of the larkspur plant are poisonous to stock, and at what time in the season is poisoning most liable to occur? (b) What amount of larkspur must cattle ordinarily consume to cause death? (c) What are the symptoms of larkspur poisoning? (d) Discuss fully the remedial and preventive measures recommended for the control of larkspur poisoning.

5. (a) How would you recognize death camas? (b) Are all species of Zygadenus poisonous? (c) What parts of the plant are believed to contain toxic substances? (d) What grazing animals are most seriously affected by the grazing of death camas? (e) What amount, by weight, of death camas must be consumed by sheep to cause death?

6. (a) What are the typical symptoms of death camas poisoning? What remedial or preventive measures should be recognized on the range?

7. (a) Describe the characteristics of water hemlock. (b) What is the distribution and habitat of the genus Cicuta? (c) To what extent are grazing animals poisoned by water hemlock? (d) What parts of the plant are poisonous?

8. (a) How would you recognize the symptoms of water hemlock poisoning? (b) Discuss fully the control and prevention of losses from water hemlock on the range.

9. (a) Under what conditions should lupines be listed as poisonous plants? (b) What parts of the lupine plant are to be suspected as poisonous? (c) To what extent are foraging animals poisoned by eating lupine? (d) What amount of the poisonous parts of lupines must be consumed by sheep to cause death? How are cattle affected by grazing on lupine?

10. Discuss fully the symptoms and methods of control of lupine poisoning on pasture lands.

Note. - The bibliography for the general subject of stock-poisoning plants is placed at the end of Chapter XIV (page 289). 


\section{CHAPTER XIV}

\section{POISONOUS AND MECHANICALLY INJURIOUS PLANTS OF SECONDARY OR LOCAL IMPORTANCE}

\section{POISONOUS PLANTS}

Milkweeds (Asclepias). - Certain species of milkweed have long been known to contain toxic properties. Whorled milk-

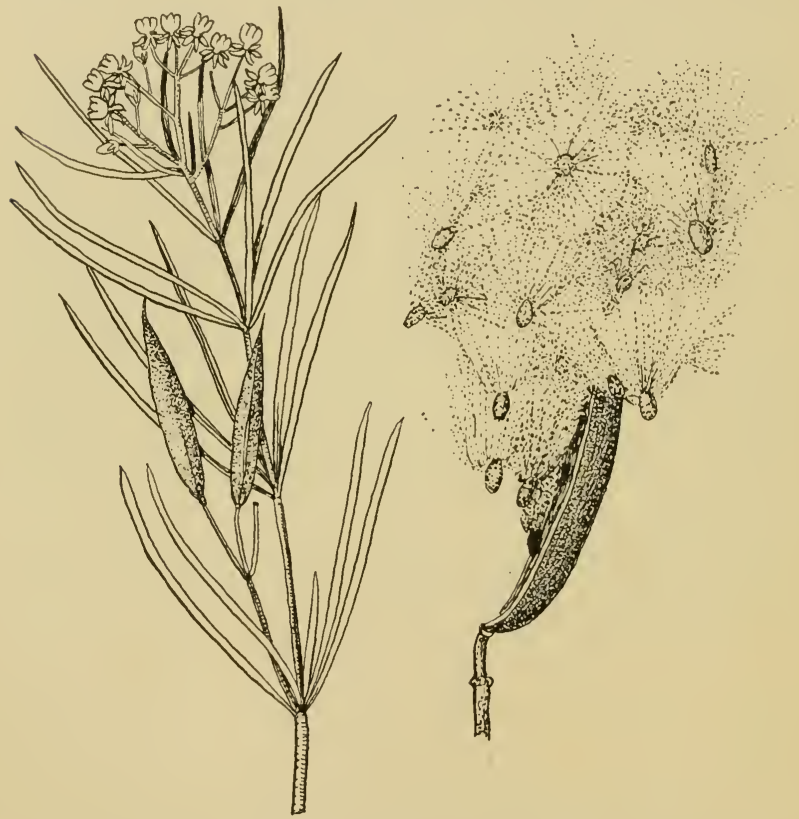

FIG. 93. - WHORLED MILKWEED (Asclepias galioides).

This plant is not cropped by stock where ample good feed is available, but it is eaten under stress of hunger. Losses of shecp, cattle, and horses are caused by it.

weed (Asclepias galioides) has caused losses of sheep, cattle, and horses throughout its range, and in some sections these losses 
have been very great. It occurs on the dry plains and foothills of Arizona, New Mexico, southern and southwestern Colorado, and southwestern Utah. Although animals do not devour the plant under ordinary circumstances, they eat it when they are very hungry. Poisoning usually occurs when stock come upon a patch of milkweed after they have been driven some distance. The plant is sometimes present in hay in sufficient quantity to produce poisoning, and is also sometimes eaten as forage when other plants are covered by snow.

Whorled milkweed is a perennial with horizontal spreading roots. It is very tough and difficult to eradicate. As the seeds are winged, the plant is readily distributed. It grows abundantly along railroads, on the banks of ditches, and in waste places (Fig. 93).

Obviously one who would prevent animals being poisoned from milkweed should learn to recognize the plant and keep hungry animals away from it. If stock must be driven over areas infested by milkweed, either the plants should be cut and burned, or the animals should be well fed before the drive is begun.

Oak (Quercus). - Although no clear-cut results have been obtained from experiments, it is thought that Gambel oak (Quercus Gambelii) and shinnery oak (Q. Havardi) are responsible for most of the cases of so-called oak poisoning. An exclusive diet of the young buds and leaves evidently causes trouble. If, however, oak leaves form only a part of the feed, they are good forage. When eaten alone they are constipating, and this may produce illness or even death. Cattle appear to be the only animals affected.

"Laurels" (Ericaceae). - Heavy losses of sheep from "laurel" poisoning are not uncommon on western ranges where other forage is scarce. These poisonous species may be mentioned: Smooth menziesia (Menziesia glabella), which has caused serious losses in sheep (Fig. 94); black "laurel" (Leucothoë Davisiae), which is extremely toxic to sheep, found commonly in the northern Sierras in California, but not widely distributed (Fig. 95); Labrador tea (Ledum glandulosum), growing in the moun- 
tains of California, Oregon, Washington, Nevada, and in the Rockies, probably the cause of heavy losses of sheep in California (Fig. 96); white "laurel," or azalea (Azalea occidentalis), found in the Coast Range Mountains and in the Sierras, poison-

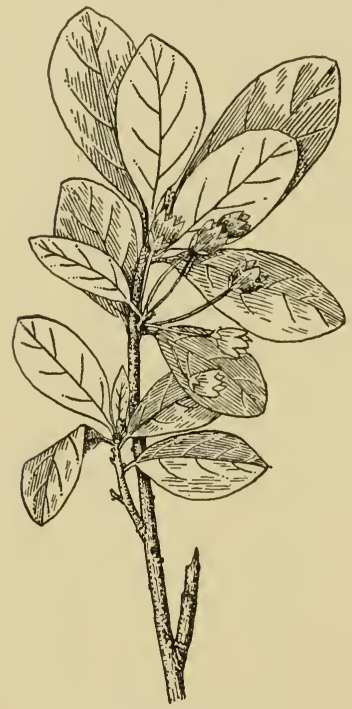

Fig. 94. - SMOOTH MENZIESIA

(Menziesia glabella).

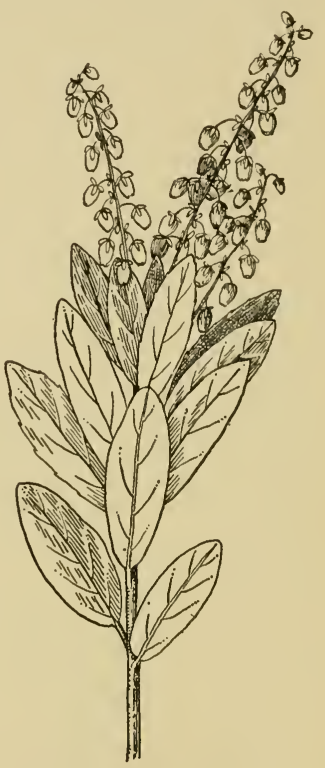

Fig. 95. - BLACK "LAUREL"

(Leucothoë Davisiae).

ous to sheep (Fig. 97); white rhododendron (Rhododendron albiflorum), generally distributed in the mountains of the Northwest, undoubtedly responsible for some livestock losses (Fig. 98); and calicobush, or "mountain laurel " (Kalmia latifolia), which poisons many cattle and sheep in the East and South, its range extending from Canada and New Brunswick to Florida, and through the Gulf States to Louisiana and Arkansas (Fig. 99). Sheep "laurel," or lambkill (Kalmia angustifolia), swamp eubotrys (Eubotrys racemosa), and staggerbush (Neopieris mariana) should be mentioned here, as all these cause a certain amount 
of loss of stock in the spring on eastern ranges, especially the sheep "laurel."

The symptoms of poisoning, which are uniform for all these species of "laurel," are nausea, weakness, salivation, and spasmodic breathing. Poisoned animals usually grate their teeth.

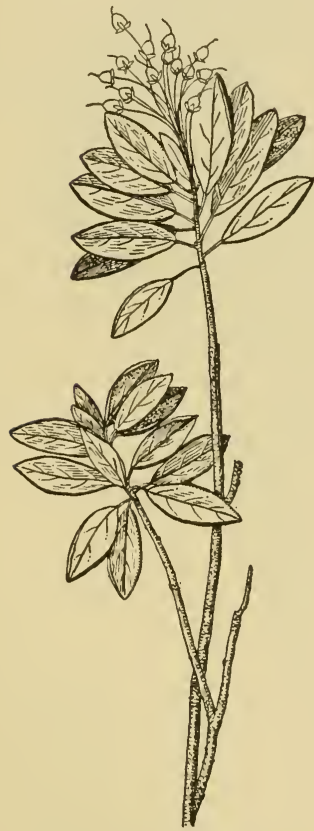

Fig. 96. - LABRADOR TEA

(Ledum glandulosum).

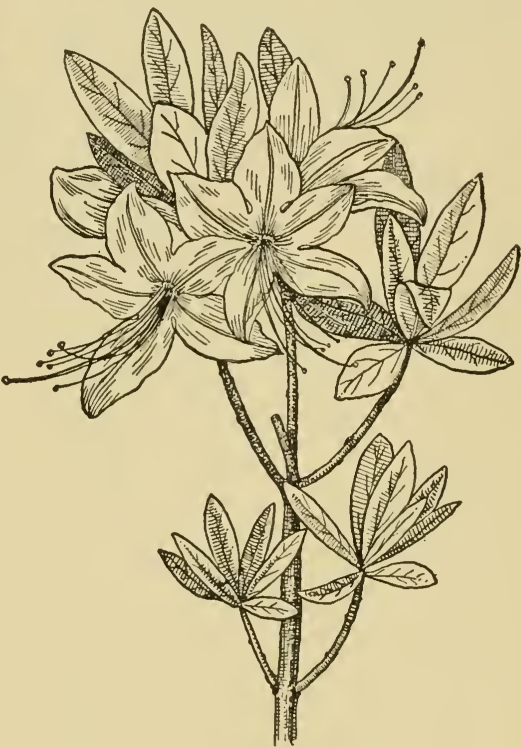

Fig. 97. - WHITE "LAUREL"

(Azalea occidentalis).

No completely effective remedy for "laurel " poisoning has yet been found, but purgatives such as Epsom salts in doses of 4 ounces may give relief. The only safe way is for the one who has the charge of the animals to learn to recognize the plants and keep the stock from eating them.

Woody Aster (Xylorrhiza Parryi). - This plant is found in abundance in Wyoming, and is reported to be the cause of heavy 


\section{POISONOUS AND MECHANICALLY INJURIOUS PLANTS}

losses of sheep. There is no doubt that it is poisonous, but, because of its tough, fibrous quality, sheep are not fond of it and will not touch it unless they have no other forage (Fig. 1oo).

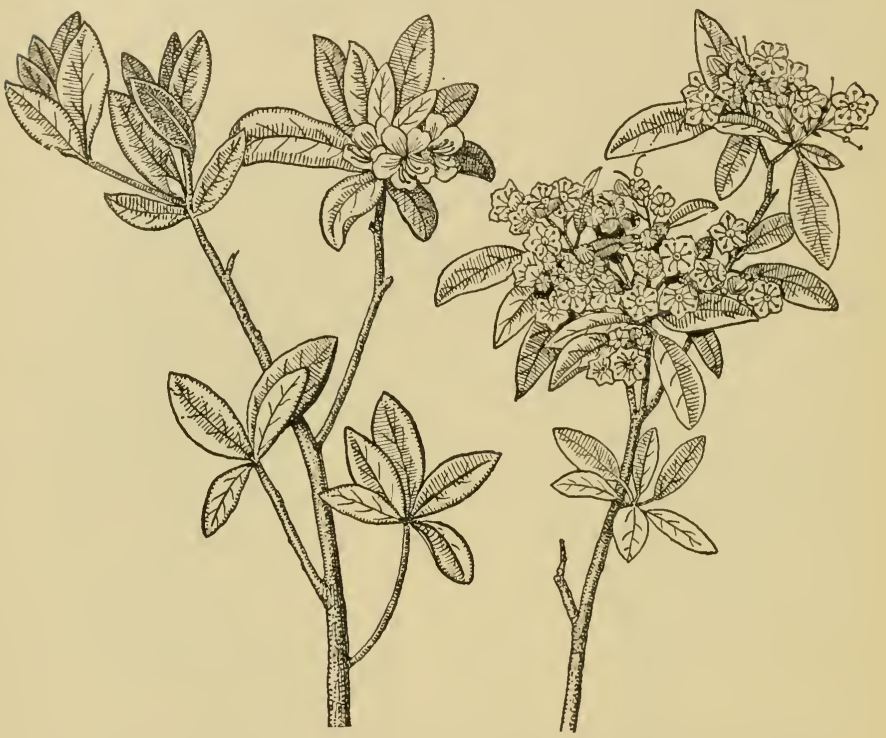

FIG. 98. - WHITE RHODODENDRON (Rhododendron albiflorum).
Fig. 99. - CALICOBUSH, OR "MOUNTAIN LAUREL" (Kalmia lalifolia).

There was once a belief that woody aster caused "grub in the head " in sheep, but it is now known that a fly deposits its eggs on the head of the sheep and the grub (Oestrus ovis) bores in and causes the disease.

Colorado Rubberweed, or Pingué (Hymenoxys floribunda). Experiments have shown that rubberweed is poisonous to sheep. However, sheep eat the plant only when they are at the point of starvation, and never if they are well fed. The plant has asterlike flowers and grows abundantly in some regions of Arizona, New Mexico, Colorado, and Utah (Fig. Ior). 
Western Sneezeweed (Helenium Hoopesii). - Western sneezeweed occurs in the Rocky Mountains, from Wyoming to Arizona and New Mexico, and westward to eastern California. Its range in elevation is from about 6,500 to 10,500 feet. It is a

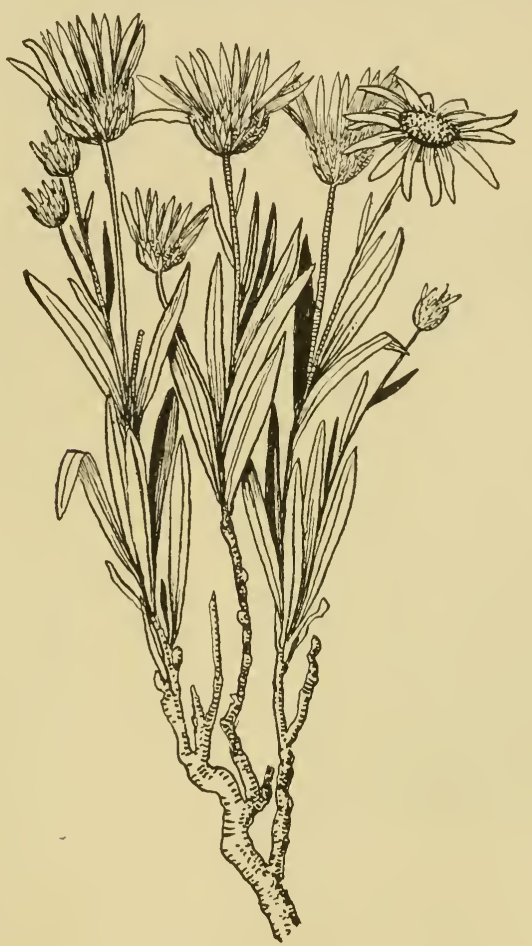

FIg. roo. - WOODY ASTER (Xylorrhiza Parryi).

stout perennial belonging to the sunflower family, the rays of the flower being of an orange color and the disk brownish orange (Fig. IO2).

Experiments in feeding have shown that this plant is the cause of the so-called "spewing sickness" in sheep. Many sheep 


\section{POISONOUS AND MECHANICALLY INJURIOUS PLANTS}

died from this disease during the summer of ${ }_{19} I_{5}$ in the Wasatch Mountains in Utah. Sheep are the principal victims, as horses and cattle do not eat enough of the plant to cause harm under ordinary range conditions. The symptoms of poisoning from

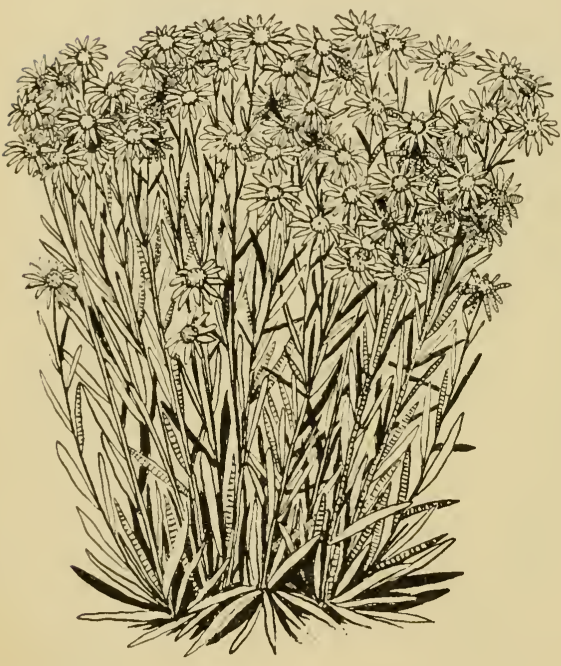

FIG. ror. - PINGUÉ (Hymenoxys floribunda).

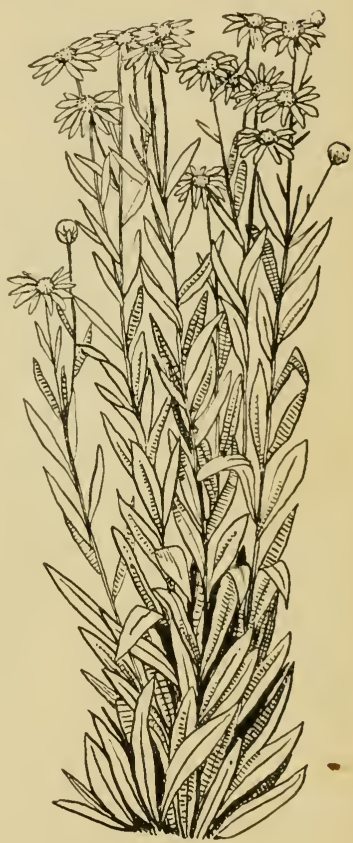

FIG. IO2. - SNEEZEWEED (Helenium Hoopesii).

sneezeweed are nausea, frothing at the mouth, labored breathing, weakened heart action, diarrhea, and bloating.

Acute poisoning from sneezeweed is rare, though it may occur if sheep eat large quantities of the plant when they are hungry. The poison is cumulative and ordinarily acts slowly. Most cases are the result of long-continued feeding.

No remedy can be recommended from experiments thus far 
conducted. Prevention is, therefore, the only reliable method. Depleted ranges often support heavy stands of sneezeweed. As the range is built up this plant is replaced by good forage species.

Aconite (Aconitum Columbianum). - Aconite, or monkshood, is an erect, smooth, single-stemmed plant 2 to 5 feet high, with numerous leaves at the base and a long terminal cluster of conspicuous "hooded" blue flowers (Fig. I03). The plant resembles tall larkspur, with which it is commonly confused, and grows in close proximity to it. It is virtually impossible for the layman to tell aconite and larkspur apart by the leaves alone, but when they are in flower they are readily distinguishable by anyone. The larkspur flower is provided with a conspicuous spur; the aconite flower is without a spur but is conspicuously hooded. The distribution of aconite is approximately the same as that of larkspur, the plant being common in the mountains of Montana, South Dakota, Colorado, Utah, and Arizona, and westward to the Pacific coast.

Aconite is known to contain toxic properties, and probably is more poisonous than its closest relatives, the larkspurs. However, it is not palatable to cattle, and therefore causes no losses to this class of stock. It is doubtful, too, whether sheep are ever fatally poisoned by aconite.

Wild or Choke Cherry (Prunus demissa). - Extensive feeding experiments with wild cherry have proved that the leaves at - times contain the deadly prussic acid and are then extremely poisonous to livestock (Fig. I04). It is well known that animals, particularly sheep, are not infrequently killed on the range by browsing upon this plant. Losses usually occur along driveways, however, where an abundance of wild cherry is found, and where other feed is scarce. The trailing of sheep along closely cropped driveways bordered with wild cherry should be avoided if possible. If it is necessary for the animals to pass along infested driveways, they should be well fed before they start on the trail. Death from wild cherry comes very quickly, and therefore no antidote is recommended.

Fern (Pteridium). - The common bracken fern (Pteridium 


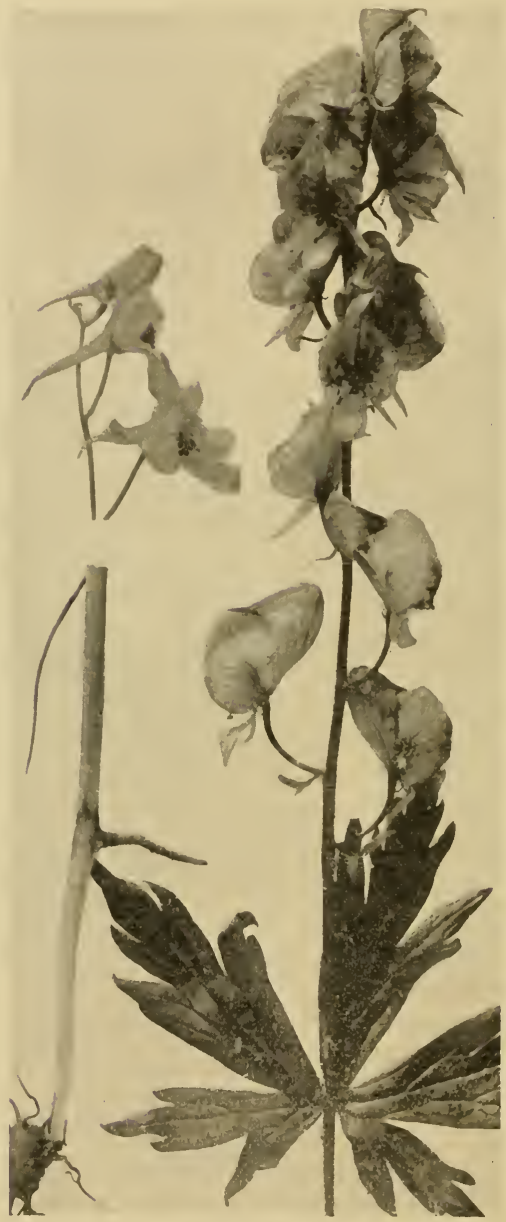

FIG. I0.3. - ACONITE (Aconitum Columbianum).

This plant contains substances toxic to foraging animals, but, not being palatable, it is not a pasture pest. Note the "hooded" flowers of aconite a characteristic which readily distinguishes it from larkspur, whose flowers have a conspicuous spur, as shown by the three blooms to the left in the figure. 
aquilinum), a species widely distributed in North America, should be mentioned as one of the poisonous plants to be reckoned with. Few cases of stock poisoning from fern are on record in the country, but it is likely that all classes of stock would be

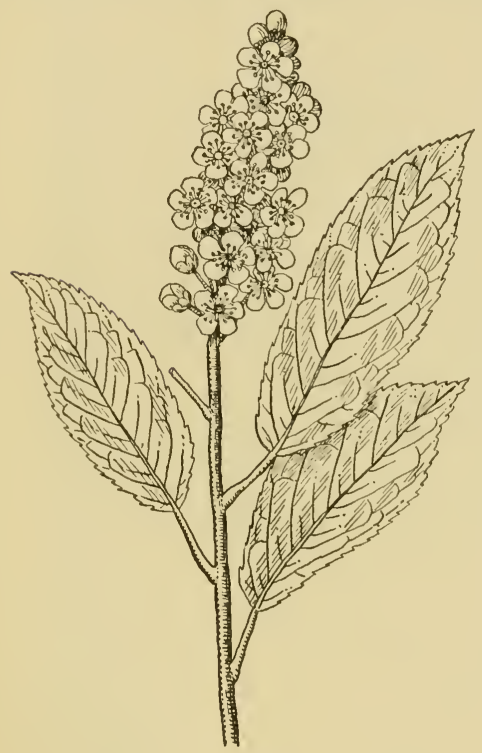

Fig. 104. - WIID CHERRY (Prunus demissa). susceptible to the poison if they were to feed generously upon the plant. Some losses in sheep are reported in the Northwest from the eating of bracken fern (Fig. I05).

Ergot (Claviceps purpurea). - Ergot is a parasitic fungus, having the appearance of a black spur, straight or slightly curved, one-fourth to one-half of an inch in length, which grows in the heads of some grasses. It occurs on a number of host plants, such as wild rye (Elymus), various meadow grasses, bluejoint, couch grass (Agropyron), Junegrass (Koeleria), and others.

It occurs most frequently on wild rye, and may be present wherever that plant grows (Fig. 106). It usually appears in the middle of August and remains until late in the fall.

Ergot produces two forms of poisoning - the nervous form and the gangrenous form. Symptoms in both forms of the disease are fatigue, cold sweat, nervousness, paralysis of the entire body beginning with the tongue and throat, and digestive disturbances. In pregnant animals the poison often causes abortion. The gangrenous form of ergotism is characterized by swelling and the formation of dry gangrene of the hoofs, fol- 
lowed by death from exhaustion. Large quantities of ergot are required to cause fatal results.

As soon as evidence of poisoning appears the animals must be removed from the infected plants. A regular dose of Glauber's

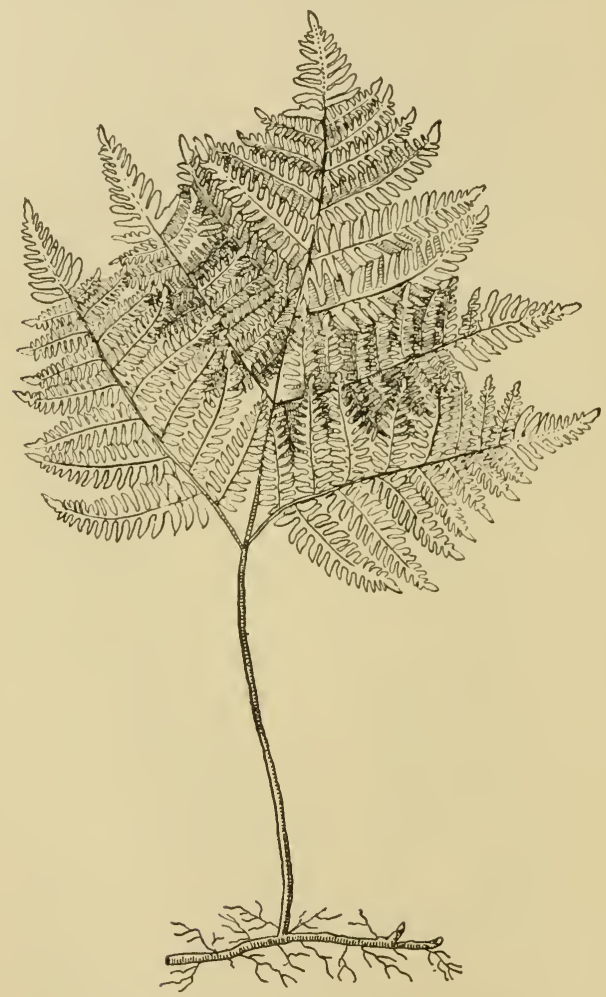

FIG. 105. - BRACKEN FERN (Pleridium aquilinum).

salts should be administered to aid in eliminating the poison. As the poison must be gradually eliminated from the system, the results of treatment are necessarily slow. 


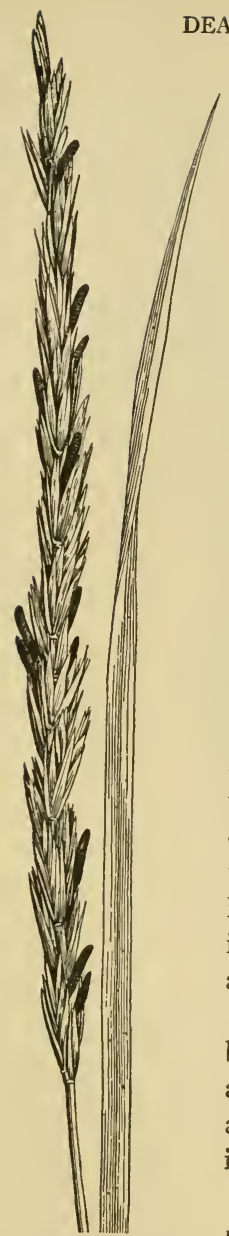

Growth of the ergot fungus may be prevented by mowing the grass during August, September, and October.

Fly Agaric, or Fly Amanita (Amanita muscaria). - This mushroom takes its name from the fact that an extract of it is used for fly poison. It is extremely poisonous and is among the best known of the toxic fungi. Fly agaric is common in the northern and eastern parts of the United States. It is a large fungus, grows singly, and is found commonly in pine groves and in poor, dry soil. The gills and stalk are always white, never pink or purple. The stalk is hollow and bulbous at the base, and has irregular fringed scales on the lower part and a large membranous collar or frill hanging from the upper part. The pileus, or caplike top, is bright yellow, orange, or deep red. The surface is smooth and polished and always bears prominent wartlike scales (Fig. I07). The appearance of fly agaric is so characteristic that it is easy to distinguish it. Notwithstanding this fact, however, the fungus frequently causes poisoning among human beings and sometimes among foraging animals.

The symptoms of poisoning are difficult breathing, depressed heart action, and an abnormal nervous condition. Stupor follows, and death from weakened heart action occurs in eighteen hours to two or three days.

Death Cup, or Deadly Amanita (Amanita

Fig. 106.-BLACK SPURS OF ERGOT (Claviceps purpurea) W1TH WHEATLIKE RYEGRASS (Elymus iriticoides) AS THE HOST PLANT. phalloides).- This fungus is fairly common in Europe and North America. It grows singly in woods and groves and at the edges of fields and pastures, but rarely in the open. It prefers damper, less sandy soil than 
fly agaric. The pileus is shiny white, pale yellow, or olive in color, without distinct scales. When moist it is slightly sticky. The gills and the long, slender stalk are white. The base of the stalk is more bulbous than that of fly agaric, and is bordered by

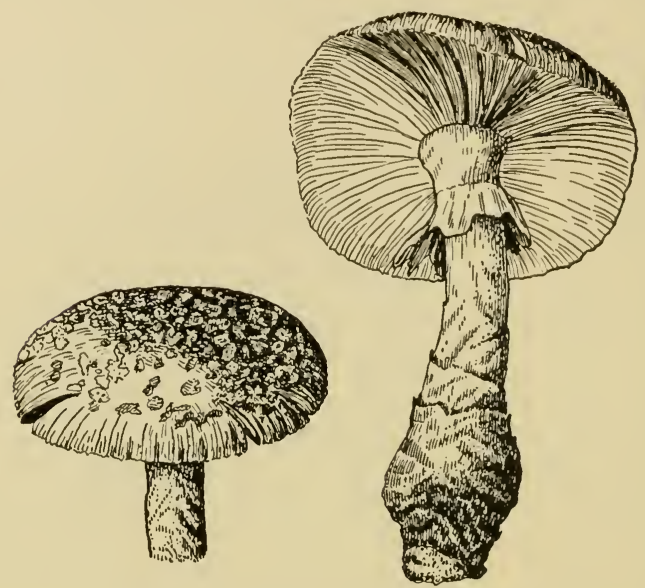

FIG. 107. - FLY AGARIC (Amanita muscaria).

This fungus sometimes causes deaths, both in the human family and among foraging animals. An extract of it is used effectively as fly poison.

a sac-like membrane, often large, but usually only a membranous rim (Fig. I08).

The toxic principle acts directly on the red blood corpuscles, lowering the vitality of the animal. It acts slowly, however, the first symptoms usually appearing from nine to fourteen hours after eating. The symptoms are severe pain in the abdomen. nausea, and diarrhea, followed in two to eight days by coma, and death soon results. There is no known antidote for this poison.

\section{MECHANICALLY IN JURIOUS PLANTS}

A large number of plant genera contain species that cause mechanical injury to stock. Sandburs, cockleburs, and certain cacti need only be mentioned in this connection. Many such 
plants cause considerable annoyance to livestock, the effective plant parts frequently entering into the flesh of the animals and causing inflammation of varying degrees of seriousness. Mechanical injuries caused by plants on range and pasture are in evidence mostly in the fall of the year, about the time of seed

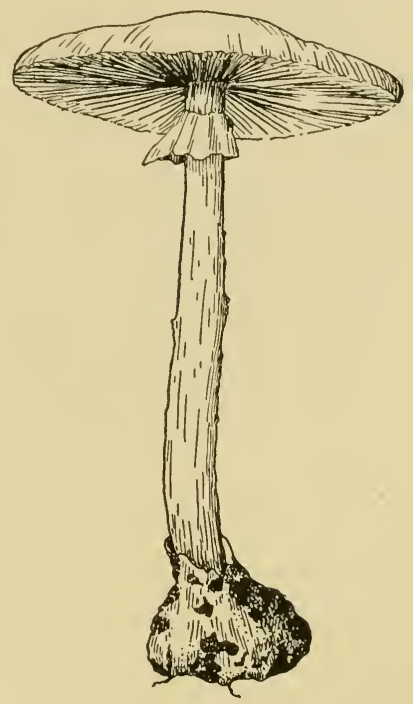

Fig. 108. - DEATH CUP (Amanita phalloides).

maturity. Occasionally, also, mechanical injury occurs from the feeding of hay which contains troublesome seed heads or other parts of the plant that lodge in the eyes, tongue, throat, and hide of foraging animals and cause pain, loss in weight, and sometimes death.

The most serious mechanical injuries brought about by vegetation on range and pasture are caused by grasses. Among these, species embraced in the following genera are the most injurious: Bromegrass (Bromus); barley and squirreltail grasses (Hordeum 
and Sitanion, respectively); needlegrass (Stipa); three-awn (Aristida); and gramagrass (Bouteloua).

Bromegrasses. - Downy bromegrass, sometimes called June brome (Bromus tectorum); hairy bromegrass (B. villosus); and red bromegrass (B. rubens) are the most troublesome species of the genus. The causes of the injury inflicted by these plants are much the same; the injurious effects, likewise, are practically identical. At seed maturity the seed head breaks up readily. As the animal grazes, the florets by means of the sharp calluses, and later the long rough awns, penetrate and cause sores and inflammation of the skin, eyes, lips, teeth, tongue, throat, stomach, and intestines. In the foothills of California red bromegrass in the autumn is often very injurious to cattle, causing " big jaw " and other complications.

Barley and Squirreltail Grasses. - These closely related grasses are probably the most destructive of the physically injurious plants. In many parts of the West the awned spikelets, especially those of squirreltail barley (Hordeum jubatum), (Fig. I09), are very injurious, particularly to sheep, causing severe suffering and heavy losses of ewes and lambs (Fig. I IO). Losses caused to lambing ewes by the feeding of hay containing mature seed heads of squirreltail barley are sometimes very heavy.

Humane considerations, as well as self-interest, should forbid the use of hay in which it [barley grass] makes up any large part of the bulk. This grass is worth little for grazing; and when put up in hay it is dangerous. Fields and meadows on which it grows would be improved by its destruction. No other weed concerns the users and producers of hay for sheep-feeding so much as squirreltail grass. It is dangerous as soon as it heads; when dried and fed in considerable quantities it becomes obnoxious and destructive. ${ }^{1}$

The foregoing statement applies also to wall barley (Hordeum murimum), Pacific barley (H. Gussoneanum), and to all species of squirreltail grass (Sitanion). Of these, however, squirreltail barley is the most troublesome. As many as 600,000 awns are sometimes produced by a single plant.

When a sheep's back, neck, and flanks are densely pierced by

1 Fleming, C. E., and Peterson, N. F., “Don't Feed Fox-Tail Hay to Lambing Ewes." Nev. Agr. Exp. Sta. Bul. 97, 1919. 
innumerable needlelike awns of these grasses, the animal walks about stiffly, with an unnatural gait, and seeks but little food.

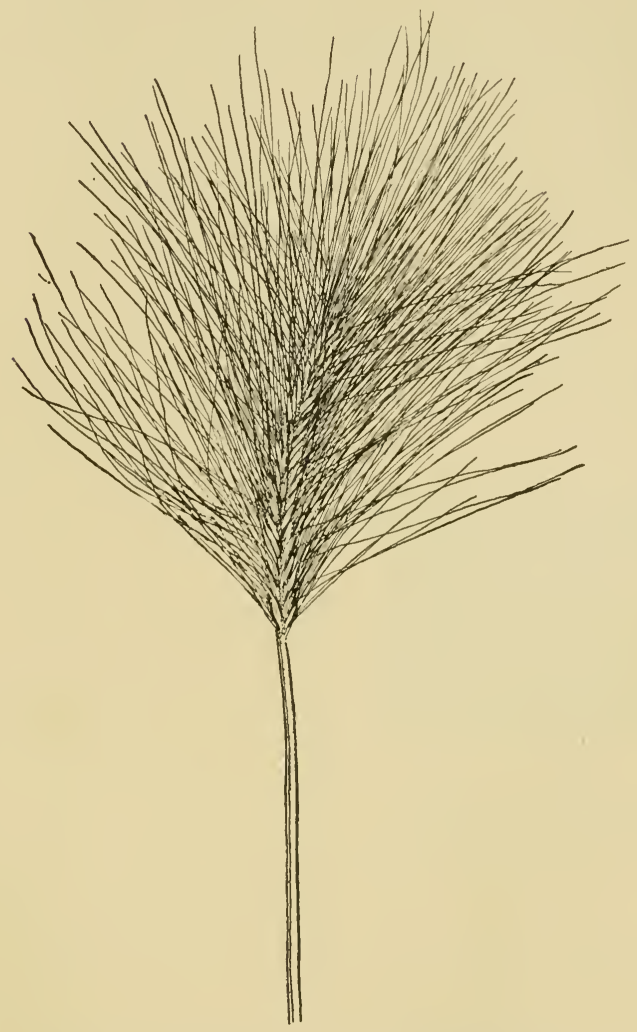

Fig. IOg. - SQUIRRELTAIL BARLEY (Hordeum jubatum).

A very common example of a grass whose awned spikelets are very injurious to foraging animals, especially sheep.

Eventually the skin loses its pliability, and the wool feels harsh and lifeless. Naturally such wool commands a low price on the market. Finally the animal refuses to eat and 
dies from starvation or from some disease resulting from low vitality.

If it is necessary that sheep be fed hay containing much squirreltail or barley grass that has headed out, the hay should be scattered out on the ground rather than fed in racks. This makes it possible for the animals to select their feed somewhat carefully. Also, if that part of the hay in the stack which contains mainly squirreltail or barley grass is not fed, considerable injury to animals or much actual loss may be avoided. When it is possible, it is best to cut the hay on lands that contain an abundance of barley or squirreltail grass or even to use such lands for pasture before the seed heads are sufficiently developed to cause mechanical injury to stock.

Needlegrasses. - Devil's darning needle (Stipa spartea) and needle-and-thread ( $S$. comata) are conspicuous species of the

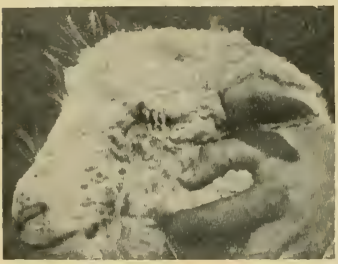

(Nevada Experiment Station.)

Fig. Iro. - THE LAMB HAS BEEN BLINDED AND ITS FACE SHOWS INNUMERABLE ABSCESSES.

The trouble has been caused by the awns of squirreltail barley. genus in the injuries which they inflict upon livestock. The awns of these grasses are several inches long; the spikelets or florets are sharp-pointed and readily bore into the skin and intestines of animals. At maturity the awn bends near the middle and becomes tightly twisted below the first bend. Variation in the humidity of the air causes the awn to twist and untwist, and in this way the sharp-pointed floret penetrates the surface to which it is attached. In range stock serious inflammation and peritonitis are sometimes caused by these grasses. Occasionally, if the spikelets get into the eyes of sheep, blindness is caused and eventually death from starvation.

Three-awn. - Dogtown three-awn (Aristida adscensionis) and Fendler's three-awn (A. Fendleriana) in some localities are troublesome when the seed is ripe. At maturity the seed, with its awn attachment, is blown about by the wind, the sharppointed callus being in advance. These awns work their way 
into the wool and skin of sheep and into the nostrils and eyes of all classes of stock.

Gramagrass. - Needle grama (Bouteloua aristidoides) is probably the only species of gramagrass which is mechanically injurious to foraging animals. The entire spike breaks from the common axis, the segments being provided with a sharp callus point at the base. The effect of these segments on persons is anything but pleasant. The sharp base of the spikes penetrates the stockings and other clothing and then breaks off. The skin is left full of " needle points."

\section{QUESTIONS}

1. (a) To what extent are milkweeds poisonous? (b) How may whorled milkweed be recognized? To what extent does whorled milkweed cause livestock poisoning? Where does it occur? (c) What means of prevention are recommended where whorled milkweed occurs more or less abundantly?

2. Under what conditions may oak poisoning occur?

3. (a) What species of "laurel" sometimes cause livestock poisoning? (b) What are the symptoms of "laurel" poisoning? What remedies are recommended?

4. Is rubberweed poisonous to both cattle and sheep?

5. (a) Where does western sneezeweed occur? Is it poisonous to both sheep and cattle? (b) Discuss (I) the character of sneezeweed poisoning, and (2) the remedy recommended.

6. Discuss aconite as a poisonous plant.

7. Under what conditions does wild cherry cause livestock losses?

8. (a) What are the results to animals that consume considerable quantities of ergot? (b) What treatment is recommended for animals poisoned by ergot?

9. (a) What is fly agaric, and to what extent does it cause livestock losses? (b) Discuss death cup as a plant poisonous to pasture stock.

10. Discuss the ways in which livestock is injured mechanically by vegetation, and the different effects produced.

11. (a) What family of plants is the cause of a large part of the mechanical injuries suffered by livestock? (b) What is the general character of these mechanical injuries? (c) What genera of grasses are conspicuous because of the mechanically injurious species which they embrace?

\section{BIBLIOGRAPHY}

Aldous, A. E. Eradicating Tall Larkspur on Cattle Ranges in the National Forests. U. S. Dept. Agr. Farmers Bul. 826, rgr7.

Chesnut, V. K., and Wilcox, E. V. The Stock-Poisoning Plants of Montana. U. S. Dept. of Agr., Div. of Bot., Bul. 26, г90г. 
Crawford, Albert C. The Larkspurs as Poisonous Plants. U. S. Dept. of Agr., Bur. of Plant Ind., Bul. I I I, Pt. I, I907.

Mountain Laurel, a Poisonous Plant. U. S. Dept. of Agr., Bur. of Plant Ind., Bul. I 21, Pt. 2, I908.

The Poisonous Action of Johnson Grass. U. S. Dept. of Agr., Bur. of Plant Ind., Bul. 9o, Pt. 4, I906.

Fleming, C. E. Range Plants Poisonous to Sheep and Cattle in Nevada. Nev. Agr. Exp. Sta. Bul. 95, I 918.

Fleming, C. E., and Peterson, N. F. Don't Feed Fox-Tail Hay to Lambing Ewes. Nev. Agr. Exp. Sta. Bul. 97, r9r9.

Fleming, C. E., Peterson, N. F., et al. Arrow-Grass, a New StockPoisoning Plant. Nev. Agr. Exp. Sta. Bul. 98, I920.

The Narrow-leaved Milkweed. Nev. Agr. Exp. Sta. Bul. 99, I920.

The Poison Parsnip, or Water Hemlock. Nev. Agr. Exp. Sta. Bul. 100, 1920.

GaIl, F. W., and Hahner, A. R. Some Poisonous Plants of Idaho. Idaho Agr. Exp. Sta. Bul. 86, r9r6.

Glover, G. H., and Robbins, W. W. Colorado Plants Injurious to Livestock. Colo. Agr. Exp. Sta. Bul. 2 I I, I9I 5.

Glover, G. H., Newsom, I. E., and Robbins, IV. IV. A New Poisonous Plant, the Whorled Milkweed. Colo. Agr. Exp. Sta. Bul. 246, I9I 8 .

Hall, H. M., and Yates, H. S. Stock-Poisoning Plants of California. Cal. Agr. Exp. Sta. Bul. 249, I9r5.

Jacobson, C. Alfred. Water Hemlock (Cicuta). Nev. Agr. Exp. Sta. Tech. Bul. 8I, I9I5.

Marsh, C. Dwight. The Loco-Weed Disease. U. S. Dept. of Agr. Farmers Bul. 380 , I909.

The Loco-IVeed Disease of the Plains. U. S. Dept. of Agr., Bur. of Animal Ind., Bul. I 2 , I909.

Menziesia, a New Stock-Poisoning Plant of the Northwestern States. U. S. Dept. of Agr., Bur. of Plant Ind., Leaflet, rgi4.

Prevention of Losses of Live Stock from Plant Poisoning. U. S. Dept. of Agr. Farmers Bul. 720, 19r6.

Stock Poisoning Due to Scarcity of Food. U. S. Dept. of Agr. Farmers Bul. 536, r9r3.

Stock-Poisoning Plants of the Range. U. S. Dept. of Agr. Bul. 575, r9r8.

Marsh, C. Dwight, and Clawson, A. B. The Stock-Poisoning Death Camas. U. S. Dept. of Agr. Farmers Bul. I273, I922.

White Snakeroot, or Richweed, as a Stock-Poisoning Plant. U. S. Dept. of Agr., Bur. of Animal Ind., Leaflet 26, r9r8.

Marsh, C. Dwight, Clawson, A. B., and Marsh, Hadleigh. Cicuta, or Water Hemlock. U. S. Dept. of Agr. Bul. 69, I9I4. 
Marsh, C. Dwight, Clawson, A. B., and Marsh, Hadleigh. Lupines as Poisonous Plants. U. S. Dept. of Agr. Bul. 405, I9r6.

Zygadenus, or Death Camas. U. S. Dept. of Agr. Bul. I 25, r9r 5.

May, W. L. Whorled Milkweed. Colo. Agr. Exp. Sta. Bul. 255, I920.

Pammel, L. H. A Manual of Poisonous Plants. The Torch Press, Cedar Rapids, Ia., Igro-I I.

Swingle, D. B., and Welch, H. Poisonous Plants and Stock Poisoning on the Ranges of Montana. Mont. Agr. Exp. Sta. Cir. 5I, I9I6. 

PART FOUR

PASTURE IMPROVEMENTS AND RESEARCH METHODS 



\section{CHAPTER XV}

\section{DEVELOPMENT OF WATERING PLACES FOR RANGE AND PASTURE STOCK}

From the earliest settlement of the country the availability of water has been a factor of primary consideration. In the stocking of the grazing grounds of the far West the water available for foraging animals was, as it is now, a determining factor in the use of the forage crop. The pioneer stockmen invariably located the center of their operations close to accessible water. Later competition forced them back into the rugged country where, likewise, they laid claim to the lakes and accessible pools. Here water was abundant or scarce according to the amount of rain or snow on the watersheds.

Availability of Water. - Only a portion of the vast arid range of the West has ample water so distributed as to make possible the efficient use of the forage crop year after year and the maintenance of the forage yield even with the proper management of the lands. In many places ample water for livestock is available only early in the season, and, as all of the feed produced cannot be cropped during this short period, a large proportion is lost annually.

No stock range can be efficiently utilized if there is an uneven or inadequate distribution of water. The abundance and distribution of the water supply determines more than any other single factor the time in the season when the forage may be cropped, and hence regulates the value of the range and determines the methods of managing the range as well as the stock.

Fortunately man's control over the distribution of watering places in many localities is far reaching. It is the aim to point out here (I) how and under what conditions stock-watering places may be developed economically; (2) the best-known methods of conserving and amplifying the water supply; and (3) the desirable distribution of water for stock on lands of various types and having different topographic features. 
Water Requirements of Livestock. - In the development of water on range and pasture it is important to consider the individual water requirements of the different classes of stock. The quantity of water an animal will drink varies greatly with the class of feed, the topographic features, and the weather conditions. The requirement of mature cattle or horses during warm weather, especially when cropping upon dry feed, is approximately I Io pounds or I 3 gallons of water for 24 hours, whereas, when feeding on fresh grass, they will consume only about 60 pounds or 7.2 gallons in 24 hours. It is probable that Io gallons of water per day of 24 hours for cattle and horses is slightly in excess of that consumed on high mountain summer range, whereas I 2 gallons per day is ample for mature cattle and horses on the lower, warmer grazing lands. ${ }^{1}$

Mature sheep require from $\frac{1}{4}$ to $\mathrm{I} \frac{1}{2}$ gallons of water daily according to feed and weather. If the forage is green and lush, sheep do well without watering for long periods at a time. ${ }^{2}$ These conditions of succulent forage the herder frequently takes advantage of and does not water oftener than every 8 or Io days, unless the water supply is nearby. Under similar conditions of feed, cattle require only a small amount of water. For water-development purposes generally it is well to estimate Io to $\mathrm{I} 2$ gallons per day for cattle and horses and $\mathrm{I}_{2} \frac{1}{2}$ gallons per day for sheep.

Distribution of Water. - On the cattle range of the plains and mesas reasonably good utilization of the forage is secured if cattle do not have to travel more than $2 \frac{1}{2}$ miles to water. ${ }^{3}$ This would require the presence of watering places 5 miles apart, or a drinking place for approximately 13,200 acres. In the Southwest, where gramagrass occurs in average density, such a tract will carry approximately 500 cattle the year round, averaging 26.4 acres to the head.

1 Barnes, Will C., "Stock-Watering Places on Western Grazing Lands." U. S. Dept. of Agr. Farmers Bul. 592, pp. 2, 3, I9I4.

2 Jardine, J. T., "Grazing Sheep on Range Without Water." Nat'l Wool Grower, Vol. 5, No. 9, Sept., 1915.

8 Jardine, J. T., and Hurtt, L. C., "Increased Cattle Production on Southwestern Ranges." U. S. Dept. of Agr. Bul. 588, pp. 10, 1 1, 191 7. 
Cattle will go a long distance for water on fairly level ground, whereas in a rocky canyon or on a mountain side they will not travel so far. On reasonably level range, where the watering places are not more than 5 miles apart, the grazing, as indicated, is comparatively uniform; but, as the distance between watering places increases above 5 miles, overgrazing invariably takes place for a considerable distance around the watering hole, whereas there is lack of proper utilization farther away (Fig. I I I).

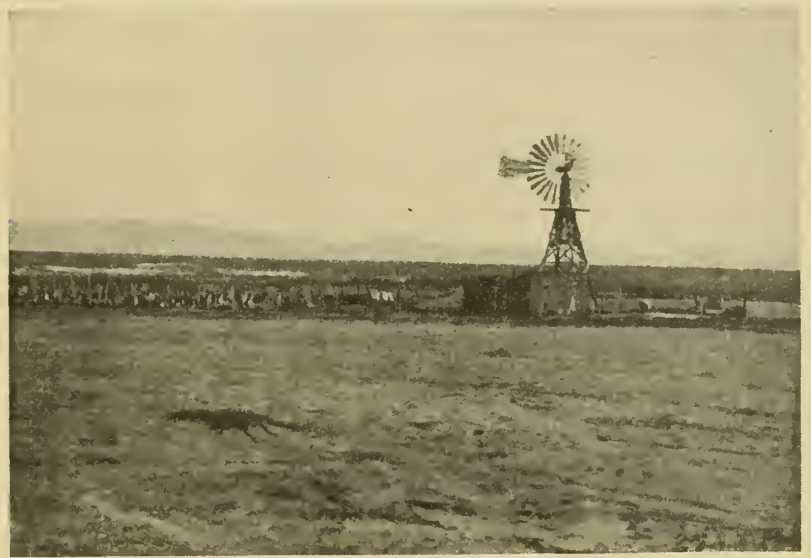

(Forest Service.)

FIG. IIr. - FORAGE HEAVILY OVERGRAZED AND VEGETATION DESTROYED BY THE TRAMPLING OF CATTLE NEAR A WATERING PLACE ON A NEW MEXICO RANGE.

The water-supply stations are more than 5 miles apart. Midway between the watering places the forage is only partly consumed.

On rugged, hilly range good use of the forage is not obtained if the stock have to travel more than about $\mathrm{I}_{2}$ miles for water. For the best forage use it is well to have the watering places not more than a mile apart on lands of irregular topography.

Damage to the range caused by the watering places being too far apart obviously reduces the grazing capacity. It is not uncommon on the plains to see cattle that have been forced to go out several miles for water become so famished that they drop and die. If the animals survive the inadequate water supply, 
their weakened condition is reflected in the retarded growth of the young stock and in the small, inferior calf crop.

The question of water supply is a matter of pasture economics which very largely determines the value of the forage crop, regardless of its luxuriance of growth and palatability.

\section{NATURAL WATERING PLACES}

Springs. - "Springs" and "seeps" are a means of greatly increasing the supply of water on range and pasture. The term "spring " is here used to designate a natural outpour of ground water which finds its way to the surface through some crevice and produces a fairly steady flow. In contrast to this the "seep" produces a small or intermittent flow, often forming merely a wet place on hillside or flat.

It is often possible to improve a spring for the watering of livestock. Not uncommonly a spring may furnish a good flow of water early in the season and then "go dry." This supply may be made permanent by "digging out " the spring. If the digging is continued to bedrock, the steadiest and largest flow is usually obtained. The various openings of the spring should be connected into a single channel.

Cement is the best material to use in curbing or confining the spring. Wood will last only a comparatively short time and must be renewed every few years. Properly selected rocks, well cemented together, last for an indefinite period. Such curbing is invariably the cheapest in the long run. The amount of material needed for cement curbing is small, the cost seldom being more than that for lumber.

If the flow from the spring is small, the surrounding earth is often so badly trampled as to decrease the flow materially. Accordingly it is always best to protect the spring by a substantial fence (Fig. I I 2). Moreover, the prevention of trampling by stock protects the curbing and enhances the life of the spring.

Seeps. - Here and there over the land area the ground water slowly moves from higher to lower levels and ultimately reaches some drainage outlet. This movement is known as "seepage." A seep may be improved in much the same manner as a spring. 
As the flow from a seep is small, it is necessary to dig out a basin

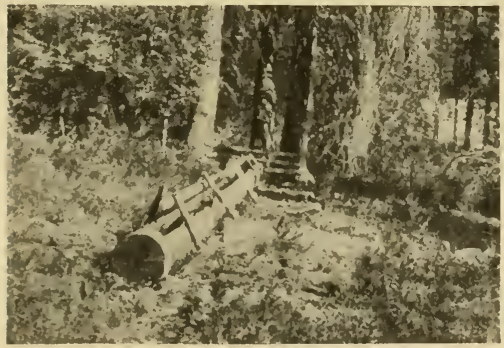

(Forest Service.)

FIG. II2. - THIS SPRING ON A SHEEP RANGE WAS OF LITTLE VALUE IN ITS NATURAL STATE.

After it was "cleaned out," curbed, and fenced, and a trough was provided, it furnished an abundance of clear, fresh water for the band of sheep. The value of the range was greatly enhanced thereby.

in order to secure all the water which the seep will yield. This is done by making open cuts across the wet spot, or by "drifting" into the side of the hill where there is evidence of water. Although the development of a seep is considerably more a matter of chance than is that of a small spring, a slight dribble of water may often be developed into a fairly large, reliable source of supply. As the flow is small, it is necessary to accumulate and store the water.

Swamps. - Swales, or more or less swampy depressions, may often be so developed as to furnish considerable water for stock. The spring or seep from which the water flows is carefully cleaned out and a channel cut across the swamp of sufficient length to allow the flow to drain into a pool or specially constructed reservoir. The channel collects the water which before was unavailable to stock. The practical use of swamp water in this way not only increases the utilization of the forage but also does away with dangerous and annoying bog holes.

Location of Troughs. - Following the improvement of a spring, seep, or bog, the next step is to trough the water. In many places the water is piped for a mile or more from the spring, but ordinarily it is not profitable to pipe water very great distances. Often the trough is not located farther from the spring than the length of an ordinary pipe; sometimes it is not more than 2 to 3 yards from the source of supply.

It is important, wherever possible, to locate the trough on ground that has sufficient fall to carry off the waste and surface 
water and so afford an outlet for the overflow. Piping with a diameter of $I_{2} \frac{1}{2}$ to 2 inches is best. No pipe less than $I$ inch in diameter should be used, as there is always danger of its becoming clogged. If there is more or less travel over the ground, the pipe should be located underground; otherwise it is not necessary to bury or in any way cover it.

Kinds of Troughs. - The particular type and construction of the trough will be determined largely by the character of the surroundings. In deciding on the trough to be constructed the matter of permanency and cost should be kept in mind.

Log Troughs. - The troughs most commonly met with over woodland ranges are hewn out of logs. The availability of the material and the low cost of construction, as well as the slight need of repair and the ease of renewal, account largely for the popularity of the log trough. The average cost of log troughs I 8 to 20 feet long, made from yellow pine or Douglas fir, is about $\$ 8$. The cost will vary according to the skill and energy of the workman, but on the average it will amount to from 20 to 30 cents per cubic foot of opening. Expense in the construction of log troughs may be held down if burning out the material is combined with the process of hewing with the axe. Yellow pine is harder to hew than some other woods, but it burns out well. Such materials as spruce, aspen, yellow pine, lodgepole pine, Douglas fir, and grand fir are hewn into troughs.

Other Wooden Troughs. - Next to the log trough the plank trough is the most common. This type of trough is objectionable because it is short-lived and is difficult to keep tight. Material lighter than 2-inch planks should never be used. Usually plank troughs are rectangular in shape, common dimensions being 12 feet long, 2 feet wide, and 2 feet deep. A trough of this size, built of 2-inch material and properly supported, costs about \$ro.

Wooden troughs should always be thoroughly painted both inside and outside, as this tends to prevent leakage and greatly increases the life of the trough. Wood containing knots should be avoided as far as possible. If knots occur, they should be heavily painted or tarred, and both sides should be carefully covered with tin. 
Circular troughs, constructed of narrow staves of wood bound together by steel rods are probably the most common on farm pastures. The steel rods or hoops, three or four in number, when properly spaced, are drawn tightly about the stave construction, and after a few tightenings the tank becomes impervious to water. These troughs are ordinarily 6 to $\mathrm{I} 4$ feet in diameter. The chief objection to this type of trough is the shrinking of the staves when the tank is empty.

Metal, Cement, and Other Troughs. - After all is said and done the familiar metal trough is generally superior to any other type. Such a trough can be purchased in almost any part of the country. Either it may be received ready to place, or it may come "knocked down." The most popular form of metal trough is half-round in shape and well supported by heavy bands, usually with a wooden rim about the top. Metal troughs are little more expensive than the stave troughs of equal capacity, and they last much longer.

If sand and gravel are readily available, and the cost of cement is not excessive, concrete is excellent material for trough construction. Properly constructed cement troughs are practically indestructible. It is necessary, however, to locate the cement trough permanently, as it cannot easily be removed to another locality. In the construction of cement troughs it is important that the sides and bottom, and especially the corners, be well reinforced with iron rods or heavy wire netting. In finishing the trough, the inner and outer surfaces should be covered with a very rich mixture of sand and cement or of pure cement. This is important in order to close small cracks and seams.

Troughs constructed of dirt in the form of small reservoirs are wasteful and generally unsatisfactory. From the very construction of such troughs it is evident that loss through evaporation and seepage is great. Moreover, the water is always impure. As these troughs cannot well be cleaned, their condition grows worse from year to year.

Trough Foundation. - The life of any form of trough is largely determined by its foundation. Cement or rock sup 
ports are much to be preferred to logs or other materials that are subject to more or less rapid decay. It is best to lay the rock in cement. The foundation should always be deep enough in the ground to avoid freezing and heaving, and it should be made sufficiently wide to prevent settling when the site becomes saturated with water.

Care should be taken to keep the ground about the troughs reasonably dry. The trough should be built fairly low; otherwise, after some use, the ground about the trough is worn away by the animals, and the trough is left so high that only the mature stock can reach the water.

\section{ARTIFICIAL WATERING PLACES}

As the demand for range increased and the better natural sources of water were occupied, "artificial" watering places were developed. A simple device of this kind was that of damming up the water from intermittent streams. This plan, however, was seldom successful, as the reservoir formed was soon filled with silt. Gradually the present-day reservoirs, now so commonly seen on adobe flats in the Southwest, became popular.

Reservoirs. - Small reservoir sites, especially where adobe soil is found, are not difficult to locate. Such reservoirs are usually not costly and are to be depended upon to supplement the natural water supply to a large extent.

If there is a natural slope to the land, as when it is surrounded by hills, comparatively little work is required to elevate the sides by means of a plow and scraper. When the sides and bottom are thoroughly trampled and puddled the reservoir will hold sufficient water to take care of a large number of stock. Drainage into the reservoir is perfected by furrows running diagonally across the slopes, which collect the rainfall or melting snow water and transport it to the storage reservoir.

It is most economical to locate a reservoir site along some natural drainage basin or canyon where the narrowing channel and a substantial earth dam will hold the water. A reservoir so located makes possible the storage of a large amount of water. The danger that the dam may be destroyed by torrential floods 
and the fact that silt is liable ultimately to fill up the depression are great disadvantages in the use of this type of reservoir. To avoid the accumulating of silt in the reservoir a second reservoir, smaller than the main one, may be constructed above the one to be used chiefly for watering the livestock. All of the water drains into it; naturally the silt collects here; and the water is

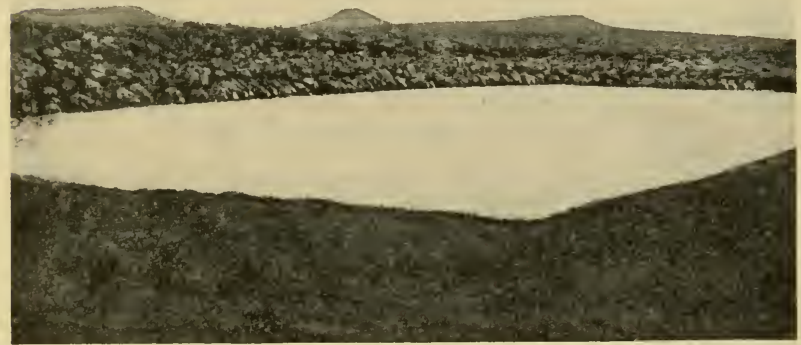

(Forest Service.)

FIG. II3. - AN EARTH RESERVOIR IN NORTHERN ARIZONA BUILT TO COLLECT AND CONSERVE FLOOD WATER FOR WATERING SHEEP.

left reasonably clear as it reaches the second or main reservoir.

A heavy clay or adobe soil is the best type for the construction of reservoirs. The passing of horses to and fro as the reservoir is being built does much to settle the banks. The best way to make the bottom and sides impervious to water is to place salt in the reservoir so that the grazing animals will do the packing themselves. This plan, as shown in Figure $\mathrm{II}_{3}$, is effective where the soil contains sufficient moisture to cause it to puddle.

The cost of building a reservoir is seldom high if the additional forage made available and the benefits derived by the stock are considered. The cost will be determined largely by the character of the soil and the way it can be handled. Barnes ${ }^{1}$ has

1 Barnes, Will C., "Stock-Watering Places on Western Grazing Lands." U. S. Dept. of Agr. Farmers Bul. 592, p. 15, 1914. 
shown that the average cost of eight reservoirs on the Lincoln National Forest, with an average capacity of I,250,000 gallons, was $\$ 506$; of six reservoirs on the Prescott Forest, with an average capacity of 216,000 gallons, was $\$ 18_{3}$; and of seven reservoirs on the Tusayan National Forest, with an average capacity of 473,000 gallons, was $\$ 247$.

Wells. - The essential features of a good well are an ample supply of clear pure water, a location which renders it reasonably free from impurities, and a casing or curbing which is proof against vermin.

Throughout the arid West comparatively few places are found where well water may be obtained at moderate depth. Most wells in the drier regions must be drilled. The best-known region where livestock is watered by means of deep wells is in the Panhandle of Texas. Here water of unlimited quantity is found at depths varying from $\mathrm{I} 50$ to 300 feet. The cost of such wells is from $\$ 350$ to $\$ 500$. To this must be added the cost of a steel or wooden windmill, with pipe, cylinder, and other necessities, which is $\$ 150$ to $\$ 300$; or, if the windmill is not used, the cost of a gasoline engine. Wells so equipped may be relied upon to furnish water for $35^{\circ}$ to 500 cattle throughout the season. On the better improved ranges of the Panhandle region a well is located at approximately the center of every four sections, and the animals are not obliged to travel more than 2 miles in any direction for water, a very satisfactory distance both for stock and pasture.

Nearly the entire western portion of Texas is underlaid by artesian waters ranging from $I 50$ to $I, 500$ feet below the surface. Wherever the drainage slopes are not too precipito us, artificial tanks may be formed across the draws by building dams, and if the bottom of the tank is carried down to hardpan, or is puddled before being filled, a supply sufficient to last through the dry season may be secured at small expense. Such tanks or wells, either artesian or where the water is lifted by windmill pumps, should be provided at least every 4 miles over the range, so that cattle will never have to travel more than a couple of miles to water. Where the wells, waterholes, or tanks are 8 , Io, or more miles apart, as they very frequently are on some of the western ranges, cattle greatly overstock the range in the vicinity of the water, espe- 
cially during midsummer, while the back country is thickly covered with good feed. ${ }^{1}$

In most localities long periods of calm are likely to occur during which the storage supply of water lifted by windmill power is exhausted. For that reason gasoline or oil engines are growing in popularity, especially as supplementary to the windmill. For emergency purposes the engines are so mounted that they can be readily moved from one well to another.

\section{QUESTIONS}

1. Discuss the availability of water on range lands in the far West and its relation to forage utilization.

2. (a) What are the daily water requirements of cattle and horses during warm weather when cropping ( $\mathrm{I}$ ) dry forage and (2) green feed? (b) What are the water requirements of sheep?

3. (a) How far may cattle travel to water and secure good utilization of the forage (I) on plains and mesa range, and (2) on rugged, hilly range? (b) Discuss the effects on both range and stock where the watering places are several miles apart.

4. (a) How may springs be made to furnish a maximum water supply? (b) Discuss curbing and fencing springs.

5. Discuss stock-water improvement by the conservation of water from seeps and swamps.

6. (a) How far is spring or seep water usually piped? (b) Discuss the location of water troughs. (c) What diameter of pipe is recommended for conducting the water from spring to trough?

7. Discuss the advantages or disadvantages in the construction and use of (I) log troughs, (2) plank troughs, (3) circular wooden-stave troughs, (4) metal and cement troughs.

8. (a) What form of foundation is recommended for troughs? (b) In the location of a trough what factors should be kept in mind?

9. (a) Discuss the value of reservoirs as a means of increasing stockwatering places. (b) Where and under what conditions of soil and topography is it most feasible to locate a reservoir site? (c) How may "silting in" of an efficient reservoir be avoided?

10. What are the essential features of a good well?

11. (a) To what extent is the construction of wells practicable in the arid West? (b) What is the usual cost in Texas of an average efficient well, complete with windmill or gasoline engine and other essentials?

1 Smith, J. G., "Grazing Problems in the Southwest and How to Meet Them." U. S. Dept. of Agr., Div. of Agrost., Bul. 16, p. 26, I899. 


\section{BIBLIOGRAPHY}

Barnes, Will C. Stock-IVatering Places on Western Grazing Lands. U. S. Dept. of Agr. Farmers Bul. 592, r9I4.

Coville, Frederick V. A Report on Systems of Leasing Large Areas of Grazing Lands. U. S. Public Lands Commission, Report, 1905.

Forsling, Clarence L. Chopped Soapweed as Emergency Feed for Cattle on Southwestern Ranges. U. S. Dept. of Agr. Bul. 745, I9r 9.

Jardine, James T. Grazing Sheep on Range Without Water. Nat'l Wool Grower, Vol. 5, No. 9, I9I5.

Jardine, James T., and Forsling, Clarence L. Range and Cattle Management During Drought. U. S. Dept. of Agr. Bul. I03I, 1922.

Jardine, James T., and Hurtt, Leon C. Increased Cattle Production on Southwestern Ranges. U. S. Dept. of Agr. Bul. 588, I9I 7.

Potter, Albert F. Questions Regarding the Public Grazing Lands of the Western United States. U. S. Public Lands Commission, Report, 1905.

Surth, J. G. Grazing Problems in the Southwest and How to Meet Them. U. S. Dept. of Agr., Div. of Agrost., Bul. 16, I899. 


\section{CHAPTER XVI}

\section{FORAGE ESTIMATES AS A BASIS FOR THE RATIONAL USE OF GRAZING RESOURCES (GRAZING RECONNAISSANCE)}

According to a well-established principle in economics, the larger pastures, farms, and ranges yield greater returns per acre, other things being equal, than do the smaller holdings. The discussion of the question of profits being reserved for another place, it may be stated that many instances could be cited in which profits on the larger holdings are not commensurate with those realized by the smaller operator.

Some such reversals in the profits may be accounted for by the fact that the resources of the larger livestock concerns are frequently not utilized to the best advantage. Not uncommonly the owner or manager of a pasture does not recognize its true value or understand how to administer it. The high cost of feed and labor now as compared with the cost in the early history of the livestock industry has tended to narrow the margin of profit in livestock production to a point where, for the industry to be really successful, the most approved principles of business and of scientific management must be applied. To do this the forage-producing capacity of the lands must be known, and the problems pertinent to their most economical use must be recognized and solved. While one still occasionally hears the statement, "I am only a stockman," stock breeders and farmers are generally willing to adopt improved methods in the handling of their stock and lands.

\section{GRAZING RECONNAISSANCE}

The introduction of improved methods of harvesting the forage crop as well as of handling the stock grazed presupposes a careful study of all the more important factors that influence forage growth and economic livestock production. On small 
ranges or pastures, say not to exceed a few hundred acres, the outstanding grazing problems can usually be solved without adopting a systematized plan of compiling the various factors that influence the best management and utilization of the resources. On large holdings, however, especially where the surface is rugged and the soil type variable, systematic examination and permanent record-taking are invaluable. A systematized study, designed to secure the data that will lead to permanent improvement in management and to increased profits from the lands, is known as "grazing reconnaissance."

Object of Grazing Reconnaissance. - Grazing reconnaissance aims to secure all the facts essential to the highest possible use of the grazing resources. Indeed, it has been said that grazing reconnaissance is a mere stocktaking of the forage resources. Although one of the chief aims is to record the character, extent, and accessibility of the various forage types, grazing reconnaissance goes much farther than that. It shows not only what the resources are and where they are, but what their true value is and how they may be best utilized and improved. For instance, any overgrazed or underutilized parts of a range are definitely located, and on the basis of the data secured effective methods can usually be proposed to remedy various evils resulting from bad livestock management. Certain areas, however, may require special attention or investigation by experts before they can be appreciably improved.

The problems a grazing reconnaissance seeks to clarify require careful observations as to the topographic features, climatic conditions, need for watershed protection, character and abundance of forage, watering facilities, and certain other factors. In addition, the completed reconnaissance classifies the lands into grazing types and shows the forage value of each. Thus on wooded ranges a combined grazing and timber reconnaissance affords a basis for a working plan embracing all management activities. Broadly speaking, grazing reconnaissance may be intensive or extensive. The facts gathered may be recorded in various ways, the aim being to obtain and compile an inventory, as it were, of the grazing assets and liabilities. 
History of Grazing Reconnaissance. - In practical livestock production there is a limit to the extent to which the details of range and pasture management may be trusted to memory. There is also a limit to the accuracy of individual judgment, even when based on experience, if it is unsupported by actual facts. This is seen to be all the more true if one takes into account the ever-changing personnel in the handling both of private and public pasture lands.

A western ranchman, who had enjoyed more than average success, once told the author that the wealth he had accumulated through livestock production was very largely attributable to the attention he gave to details. Although his pastures were extensive, embracing several thousand acres, and located on a level stretch of country, he had made so intensive a study of the tract as to know with considerable precision where the various forage types were located, their approximate size, their forage value and grazing capacity, what areas were in need of reseeding, what parts had to be grazed early in the season because of lack of water later on, the number of stock the pasture would support indefinitely, and other pertinent facts. In other words, he knew fairly well what his forage resources were and how to utilize the feed to the best advantage.

Practically the only objection to this plan was that the old gentleman carried this valuable information in his memory. If the facts studied so painstakingly had been placed on a map or kept in some tangible and accessible form, his son also, who was then in college, and who soon became heir to the ranch, could have profitably utilized the detailed information gathered by his deceased father. Not only is it convenient in formulating future management plans, but it is also advantageous from a purely business viewpoint, unless the holdings are small, to have at hand a rough sketch at least of all pasture and range lands, and, indeed, of the lands under tillage.

Up to the time of writing (1922) the most extensive and systematic effort that has been made to secure and apply data pertaining to the resources which the land affords has been bestowed upon the National Forests. The average size of the National Forests 
(about $1,000,000$ acres) is so great, and the surface and plant types are so varied, that no person can form a mental picture in sufficient detail of any one National Forest as a whole to serve in the judicious administration of either its grazing or timber crops. Having recognized the value of a systematic compilation of the forest resources, foresters are also fully in agreement with the truism that without such compilations " one cannot see the forest for the trees." It has been shown that when the National Forests were created the greater part of the lands was grazed annually with no regulation of the cropping. Almost everywhere on the heavily grazed Forest ranges there were glaring and sad examples of the ill effects of "free" range. It was clear that in order to protect these vast public interests it was necessary to control the grazing. The adoption of a controlling measure has resulted beneficially in the protection and further development of the livestock industry on lands adjacent to the Forests as well as on the National Forest lands themselves.

When the administration of the National Forests was first undertaken by the Federal Government it was possible to correct only the more glaring misuses of the range and other Forest resources. As time went on, however, the desire for the better protection and conservation of the products of the Forests on the part of the Government and the increased demand for a share in the use of the choice summer range on the part of the stockmen, led to a greatly refined and improved management of the range. It was, of course, essential, both in the interest of the livestock industry and of the Forests themselves, that the grazing lands should be used to the best advantage possible. The only way this could be accomplished without seriously curtailing the grazing was to develop and apply better methods of handling both the stock and the range. In later years this has been greatly assisted by grazing reconnaissance.

The first serious attempt to develop methods in grazing reconnaissance and to organize a party to record data pertaining to the improvement of range management, was in IgI I when the study was initiated on the Coconino National Forest in northern Arizona. The original grazing reconnaissance plans were de- 
veloped and the first party organized by James T. Jardine, then a member of the United States Forest Service. Although the methods of securing, recording, and summarizing the results have passed through a period of evolutionary development, those methods and the plans subsequently proposed by Jardine form the basis for the grazing reconnaissance work pursued by the Forest Service today. Before that time numerous timberreconnaissance parties had been organized. The valuable results obtained by the mapping of the timberlands helped to expedite the development of similar work along grazing lines.

Data and Facts Obtained by Grazing Reconnaissance. - In the administration of the National Forest ranges, as in the most economical management of the larger privately owned pasture units, there are certain primary and perplexing problems which commonly present themselves. In the interest of the maintenance and improvement of the timber, the forage, and, indeed, the watershed, the major questions which reconnaissance aims to clarify are: (I) Adaptability of the range unit to the class of stock grazed; (2) number and distribution of stock grazed; (3) the opening date and the length of the grazing season.

The deciding factors in determining the adaptability of the range unit to the different classes of stock are: (a) Abundance and condition of timber reproduction and immediate need therefor; (b) watershed protection; (c) topography and climate; $(d)$ character and abundance of forage; (e) watering facilities; $(f)$ accessibility of the unit to the different classes of stock.

The number and distribution of stock will be based upon (a) character and density of the vegetation and its palatability and accessibility to the different classes of stock; $(b)$ climatic conditions - total annual precipitation and its seasonal distribution, the length of the grazing period and the period that the forage is available for grazing, and the variation in forage production from one year to another; $(c)$ obstacles to the proper distribution of the stock, as, for instance, barriers and streams; $(d)$ watering places and possibilities of increasing the water supply; $(e)$ need of protection of the range in the interest of timber reproduction and of the forage crop. 
The opening date and the length of the grazing period will be determined largely by (a) climate and elevation, especially as related to the acreage and the productivity of the spring, summer, and winter range; $(b)$ need for revegetation and the maintenance of the more valuable forage cover; $(c)$ permanency and abundance of the watering facilities and type of forage.

To be in a position to apply the important facts to the management of the lands it is first necessary to record the data in tangible form. The object here is to show how the data necessary to the determination of the questions outlined may be collected and arranged for ready use. A complete reconnaissance will comprise the following parts:

I. A topographic map, including all the more important features pertinent to the management of the lands as grazing areas, such as the location of drainage and all stock-watering places, ridges, elevations (usually by roo-foot contour intervals), as well as all the more important cultural features, such as roads and trails, telephone lines, fences, and cabins.

II. A classification of the lands into grazing types, ${ }^{1}$ ro acres or larger in area, except conspicuous landmarks or small meadows of high grazing capacity exceeding 2 acres in area. Of these, ten types are recognized as follows: ${ }^{2}$

I. Open grasslands (other than meadow). This includes bunchgrass areas, gramagrass lands, and other grass cover not meadow in character (Fig. II4).

2. Meadows. This cover embraces both the dry and the wet meadowlands where sedges and rushes and species like tufted hairgrass (Aira caespitosa) predominate, as well as moist meadowlike areas which occur commonly as glades in the timber type (Fig. II5).

3. Weeds. This type includes all untimbered areas where

1 A grazing type as used in reconnaissance consists of an area upon which the cover may be composed of one class of vegetation, as, for instance, a grass cover; or of two or more classes of vegetation, as grass and sagebrush, the more conspicuous of which determines the type designation. Subtypes within the major unit are used to designate the identity of a mixed cover.

${ }^{2}$ In order to avoid complications in field work only the broader types are recognized. 


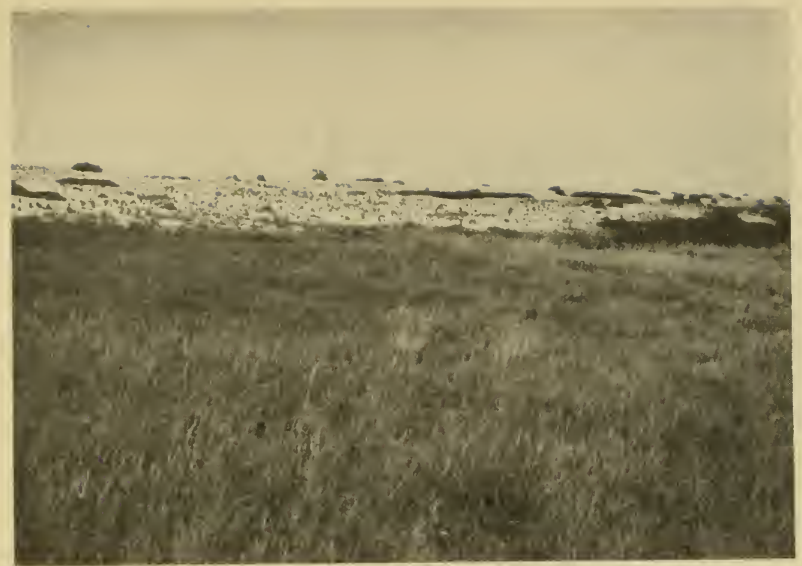

Fig. II4. - OPEN GRASSLAND, NOT MEADOW IN CHARACTER (TYPE I).

The cover is composed of small wheatgrass (Agropyron dasystachyum) and is best suited to the grazing of cattle and horses.

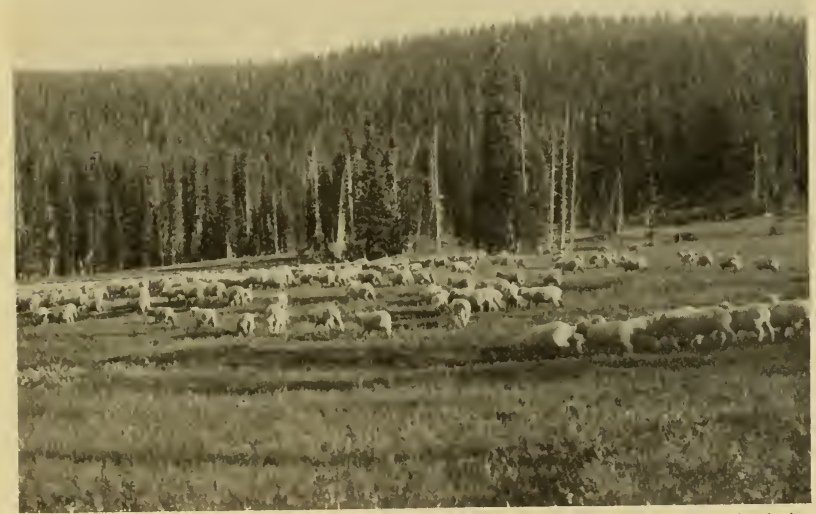

(Forest Service.)

FIG. 115. - MEADOW TYPE (TYPE 2) IN THE FOREGROUND, WITH WASTE RANGE DUE TO DOWN TIMBER (TYPE 7) IN THE BACKGROUND.

The sheep are grazing openly and with contentment. 


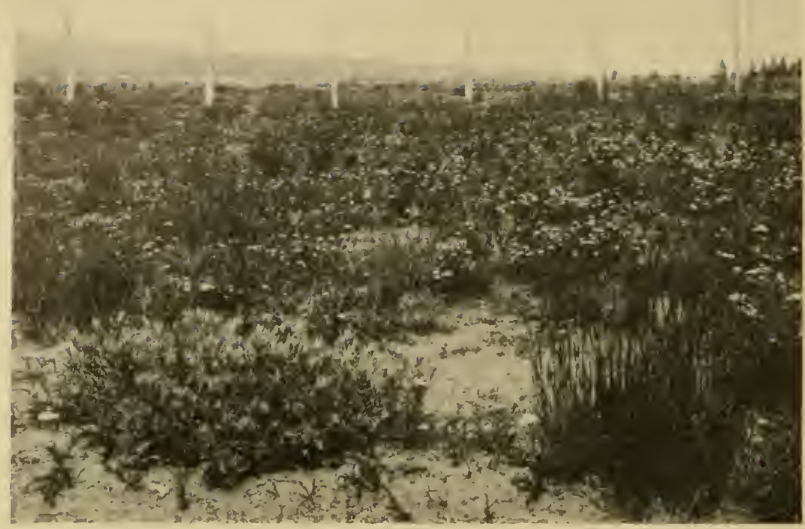

FIG. II6. - WEED TYPE (TYPE 3), WITH BLUE FOXGLOVE (Pen/slemon) AND YARROW (Achillea) PREDOMINATING.

This cover is most efficiently utilized by sheep.

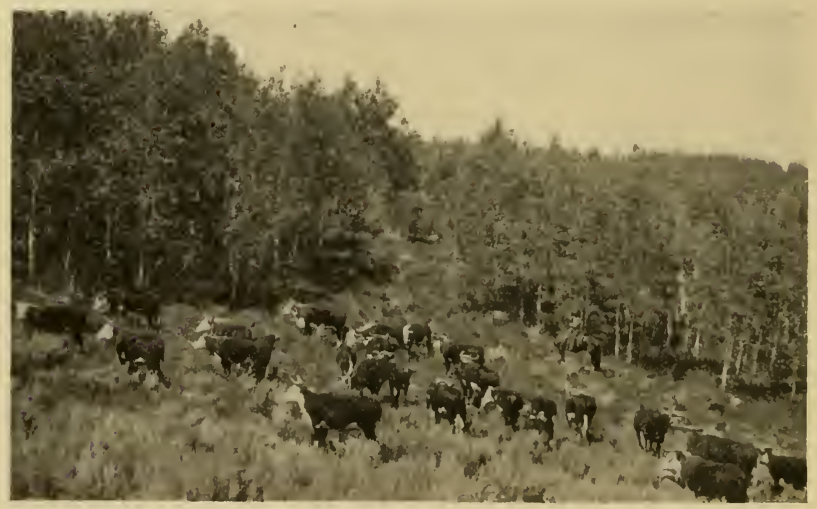

(Forest Service.)

FIG. II7. - SAGE TYPE (TYPE 4 ) IN FOREGROUND AND ASPEN TYPE (TYPE ro) IN BACKGROUND.

The aspen is a very valuable timber cover because of the grazing afforded by the luxuriant understory of palatable, succulent plants. 
plants popularly known as "weeds," that is, broad-leaved herbs, predominate (Fig. I 6 ).

4. Sagebrush. Lands where sagebrush predominates (Fig. II 7 ).

5. Browse. This type includes all lands outside of coniferous timber where browse plants (brush) prevail (Fig. I 8 )

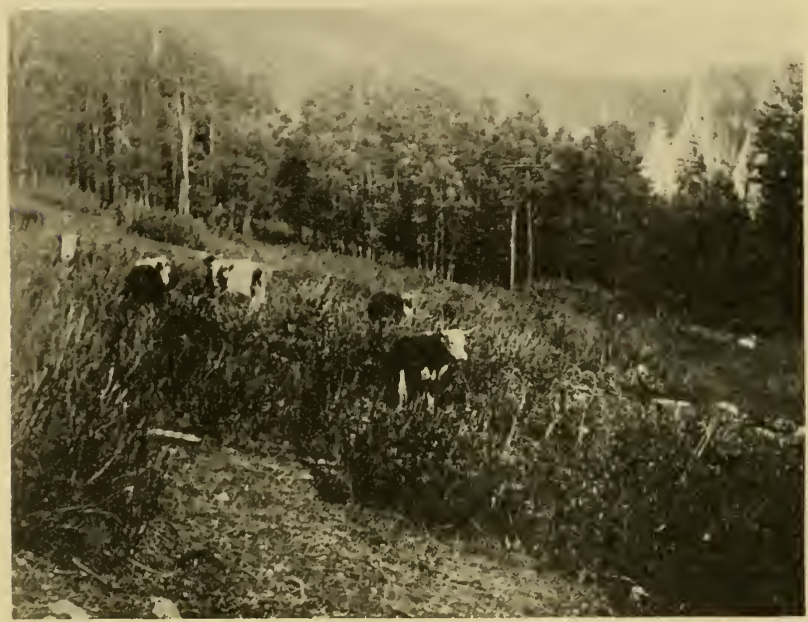

Fig. II8. - BROWSE TYPE, DESIGNATED AS TYPE 5, CONSISTING OF MOUNTAIN ELDER (Sambucus).

Aspen type (Type ro) is seen in the background.

6. Timbered areas. This cover supports a stand of grass, weeds, and browse. It includes all range in coniferous timber (Fig. I I9).

7. Waste lands. This type includes all timbered, brush, and other lands that have no grazing value on account of their inaccessibility (Fig. I I9).

8. Barren lands. All areas potentially incapable of producing the higher (flowering) type of vegetation are classed as barren (Fig. I I9). 


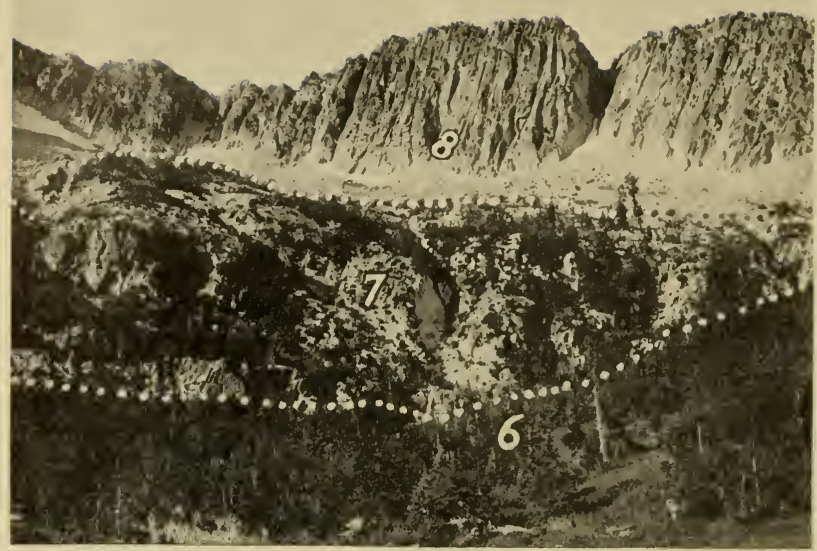

FIG. II9. - A TIMBERED RANGE (TYPE 6) IS SEEN IN THE FOREGROUND. IN THE IMMEDIATE BACKGROUND WASTE OR INACCESSIBLE RANGE (TYPE 7) IS SEEN. In the extreme background the land is not capable of supporting vegetation of value as forage and hence is classed as "barren." It is designated as Type 8.

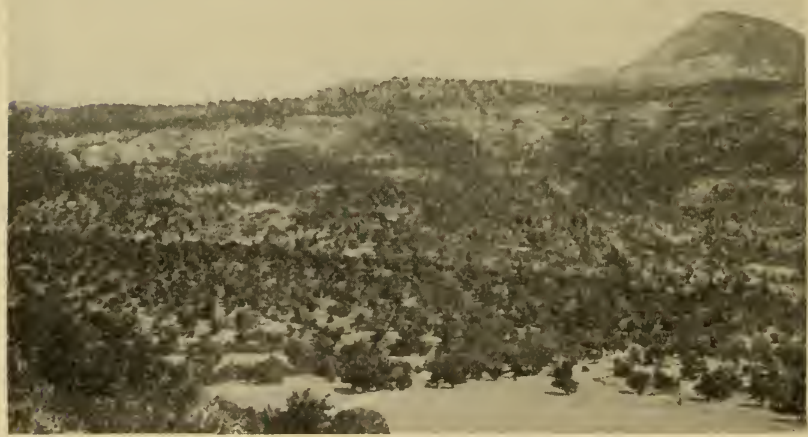

Fig. I20. - WOODLAND COMPOSED OF JUNIPER AND PIÑON PINE, DESIGNATED AS TYPE 9.

This type is characterized by the absence of aspen and the larger coniferous trees. The juniperpiñon type generally receives a small annual precipitation and is low in grazing capacity. 
9. Woodland-Juniper and piñon. A cover so designated supports a variety of vegetation composed of grasses, weeds, and browse in which trees other than aspen and large conifers predominate (Fig. I 20).

ro. Aspen. This type embraces grasses, weeds, and browse, or a cover of any one of these, in a true aspen type (Fig. 12r).

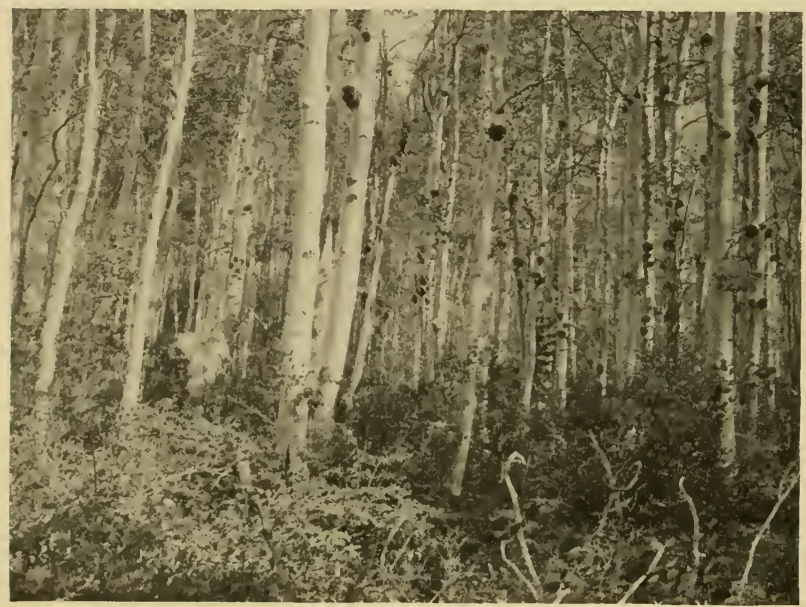

FIG. I2I.- THE TRUE ASPEN TYPE (TYPE IO), WITH THE CHARACTERISTIC UNDERGROWTH OF GRASSES, BROAD-LEAVED HERBS, AND BROWSE.

Obviously various combinations of vegetation that make up the cover are not strictly included in the ten types enumerated. For this reason subtypes are recognized. In such instances the initial letter of the Latin or common name of the predominating species is recorded as the type proper is mapped.

The ten types are represented on the final maps by colors and symbols; but, owing to the inconvenience of carrying crayons in the field, numbers from I to ro, symbolic of the type colors, are employed to designate the types noted in the field mapping. The colors and symbols used for the types above enumerated are (I) yellow, (2) orange, (3) red, (4) olive-drab, (5) brown, 
(6) green, (7) ultramarine, (8) small imperfect triangles, (9) pale green, (10) pink.

In addition to the type designations, features relating to the condition of the range as affected by grazing are also indicated. These data, as will be shown later, are included on a separate map with the topographic and cultural features. Normally grazed areas, for instance, are represented in solid color; overgrazed areas by horizontal hatching in type color; and poorly stocked areas by vertical hatching also in type color.

III. The complete ground cover showing forage species, the percentage of surface supporting vegetation, the density of the ground cover, the percentage of "weeds," grasses, and shrubs, ${ }^{1}$ and the palatability of the cover as a whole. From these data, as will be shown later, the grazing capacity of the range is derived.

IV. A descriptive report of each type (including data which can not be shown on the map), such as the adaptability of the area to the different classes of stock, the soil and climatic conditions, the carrying capacity of the various types, the proper grazing season, the degree of utilization, and other factors pertinent to the management of the lands as pasture areas.

$\mathrm{V}$. A map of the timber showing its types and giving an estimate of the yield, if a timber reconnaissance is made in connection with the typing of the forage resources.

VI. A plant collection, with economic notes of each species showing its value as forage or its undesirable qualities.

Methods Employed in Obtaining the Data: Field Work. Three methods are used in obtaining reconnaissance field data (I) the "gridiron" method, (2) the traverse-sketching method, and (3) the triangulation method. Numerous variations of these are in use, depending on the topographic and other features; but the three methods mentioned nevertheless form the basis of all field mapping.

The gridiron method provides that each man work separately. Where the work is done systematically, with a view to reaching

1 Some, in estimating, include both the percentage of surface supporting vegetation and the density under one factor - density. There may be less chance for personal error if the estimate of the density factor alone is taken into account. Certainly the combining of the two factors under density alone simplifies the compiling of the data. 
a degree of accuracy consistent with a reasonably close utilization of the forage crop, the mapper may pace through each section either on foot or on horseback (usually on foot); or, if the topography is rugged, he may ascend points from which the types may be readily sketched in. In the first instance, the worker passes through each section twice at a distance not greater than half a mile apart, collecting the data as he goes and checking his pacing on surveyed lines if these are available.

In surveyed country the examiner starts from an established Land Office corner, keeping his position located either on a 2- or a 4-inch-scale map. (The U. S. Forest Service provides a special form for this purpose.) The sketching consists in recording the topography, types; and cultural features. In addition, the density of the ground cover and certain other factors are noted on the special form used, and these data are subsequently discussed in the descriptive report. Elevations are recorded by means of an aneroid barometer.

In unsurveyed country traverse lines are run in cardinal directions from a station which is permanently monumented, so that the station may be tied in and the traverses adjusted to later surveys. Along the traverse lines, stakes may be set at intervals of half a mile, these distances being carefully measured. For convenience the stakes are numbered and may carry the elevation where located. The traverse lines being established, the examiner starts from stakes one mile apart and records the data in the manner described for the use of the gridiron method in surveyed country. ${ }^{1}$

The traverse-sketching method is based upon traverse lines so located as to permit the examiner to sketch in the country on each side of the line. Traverse lines may be established in rugged localities by means of compass and chain or by stadia, the method depending upon the topography and the character of the vegetation. These traverse lines may be located along the main streams, roads, ridges, and trails. These data being available, the examiner proceeds in a manner similar to that of

\footnotetext{
${ }^{1}$ In the absence of Land Office corners, traverse lines are extended along ridges, creeks, and trails in the manner described, except that the traverse must be plotted and sectionized.
} 
the gridiron method. Elevations are recorded by means of the aneroid barometer or by stadia calculations.

The traverse-sketching method is not popular because the sketching is not very accurate. It is, however, rapid and inexpensive and serves the purposes of the ordinary grazing reconnaissance, except, possibly, where the forage crop is to be used much more intensively than on most range lands of average productivity. If an accurate topographic map is desired, the telescopic alidade is substituted for the compass; the stadia takes the place of the chain; and instead of the 4-inch section plat the regulation planetable is used.

The triangulation method is best adapted to rugged mountain lands relatively free from vegetation that obstructs the line of sight. The map work is based upon primary stations, secondary stations, and topographic sketch points. The primary triangulation stations are located by means of transit or theodolite; the secondary control points, either by planetable or telescopic alidade; and the sketch points, by the topographic Abney level and the open-sight alidade. Vertical control is computed by means of vertical angles; horizontal control, by horizontal angles. When the sketch points are located and their elevations determined, the topographic and cultural features are sketched. Then one is prepared to proceed with the typing.

The accuracy of the topographic map obtained by triangulation makes it possible to sketch in with reasonable exactness the type boundary lines. When the type boundary lines are located, the examiner proceeds to record for each type such data as are pertinent to its use as forage.

Office Work. - In order to insure accuracy in transcribing the field-map data the camp is provided with the necessary equipment of a draftsman. All the field notes are transcribed in uniform and workable order on township plats, with a scale of 4 inches to the mile. or on a camp map with a scale of 2 inches to the mile, the types being shown in colors. The forage acres ${ }^{1}$ in each type and each unit are then calculated and tabulated. The final compilations are done in regularly established offices where it is possible to record the data in finished form. For office use

1 For definition of "forage acre" see p. 325. 
the map may be drawn on a scale of 2 or 4 inches to the mile. Among other things the map aims to exhibit the following:

I. Total range area.

2. Natural subdivisions of each large grazing unit, showing the location and acreage of spring, summer, autumn, and winter range.

3. Area and location of the surface acres and the forage acres of each type; general description of each grazing type with reference to improvement in its use and management generally; also, necessary improvements, such as the construction of trails, stock driveways, bridges, and water developments, as well as reseeding requirements.

4. The proper period of use for each range division and its exact grazing capacity.

Grazing and Timber Reconnaissance Compared. - Students of forestry familiar with the methods employed in timber reconnaissance may be benefited by a summary of these methods as compared with those of grazing reconnaissance.

I. The methods and application of timber reconnaissance were well established a number of years before grazing was initiated. In a general way, therefore, the methods of timber reconnaissance served as a basis for the methods followed in grazing reconnaissance.

2. In timber reconnaissance accurate control lines are established prior to the location of cruising strips. In grazing reconnaissance control lines may be established, or the elevation and azimuth may be carried along as the work progresses.

3. In timber mapping, in surveyed country at least, every alternate line in one direction is retraced and marked at various intervals to serve as a checking and starting point. In the mapping of the range the lines are seldom retraced but are tied in if possible.

4. In unsurveyed country, both in timber and in grazing reconnaissance, control lines are extended systematically across the area or in the form of " meander " lines.

5. In using the "strip" surveying method, each crew in timber mapping is composed of two men, one of whom acts as a compassman and the other as a cruiser. In the grazing work each man works independently. 
6. In forest mapping, the "strips" are run at least once and usually twice to each 40 -acre area. In range mapping, the strips are never run more than once through a forty, and then only through alternate tiers of 40 acres in each section.

7. In unsurveyed country timber reconnaissance provides that no more than 2 miles of line be run without an accurate "tie-in." In grazing reconnaissance never less than 4 miles and very often 6 miles of line is run before the "tie-in" is established.

8. The scale in timber mapping is 8 inches to the mile; in range mapping it is never more than 4 inches and often only 2 inches to the mile.

9. Timber estimates are determined by actual measurement (diameter breast-high) of all trees on a 66-foot strip. Sufficient measurements are made for the examiner to record the timber production with a high degree of accuracy. In range reconnaissance the estimate of ground cover and forage production is entirely ocular, as the forage resources permit of no definitely measured analysis.

Io. A description of the forest type is made for each 40-acre area. In grazing work the description is made on the basis of a section, though, to be sure, each type within this section is described and its forage value shown.

I I. In timber mapping the descriptive report involves a discussion of the topographic and silvicultural management of each unit area summarized statistically. The same general plan is followed in range mapping, but with such changes or additions as appear to be essential to meet the particular range problem of the community.

12. In timber reconnaissance the final map is on the scale of 4 inches to the mile, the types and other features being colored, and contains all of the data recorded. In grazing reconnaissance the map is presented on a scale of 2 or 4 inches to the mile, the types and other features being colored. A map drawn on a scale of 2 inches to the mile is prepared in atlas form for the Forest as a whole. In timber reconnaissance a crew of two or three men work from one-fourth to one-half of a section per day, at a cost of from io to 5 cents per acre. In grazing reconnaissance 
a man working individually covers one to three sections per day, at a cost of approximately I to 4 cents per acre.

Application of Grazing-Reconnaissance Data to Practical Pasture Management. - The application of grazing-reconnaissance maps and of the descriptive report is so extensive that in themselves they well-nigh serve as a working plan for grazing. Through the use of the maps those concerned with the management or administration of the lands have at their disposal a bird's-eye view of all the more important grazing resources, the timbered areas, and the topographic features, as well as the more important cultural effects and improvements. Then, too, the number of stock that the range will safely carry is determined by the data collected.

While the chief object of a grazing reconnaissance is to furnish information as to the most economical and improved methods of handling livestock and to indicate how the lands may be maintained in a high state of productivity, the data have also an invaluable secondary use. In case of a forest fire, for instance, the topographic map and other features may readily be examined. The presence of certain plant types may determine what methods one is justified in pursuing in attempting to gain control of the fire. Observations of the plant type where the fire is in progress may often be very useful; whereas a fire may spread rapidly over one type, it may be checked or readily controlled on another. Advantage may also be taken of such features as the natural drainage systems, ridges, roads, trails, and stock driveways, which are shown on the map.

Accuracy and Limitations of Grazing Reconnaissance. - The low expense of grazing-reconnaissance work as here discussed is obviously due to the fact that the examiner passes through a section rapidly. For this reason it sometimes happens that certain features are overlooked which are pertinent to the development of a detailed working plan for grazing. Accordingly, the maps cannot serve all the purposes that may be desired. Springs, cabins, fences, and similar features, when not directly in the path of the examiner, may not be located accurately on the map, as their location and distance from the examiner are merely esti- 
mated. ${ }^{1}$ Likewise, the size and location of the different plant types is not exact. However, as the types almost invariably overlap more or less, it would be possible to locate them only approximately, even if the work were done much more accurately than it usually is.

Further, the exact character and density of the type varies according to the time in the season when the examination is made. An area examined in the spring, for example, might show the presence of certain annual plants, such as dog's-tooth violet (Erythronium), Douglas knotweed (Polygonum), and onion (Allium). If the area were examined in the autumn, the annual species would not be noted, as they dry up and disappear early in the summer. However, a good average estimate of the more important permanent constituents of the plant cover is recorded if the mapping is done at any time during the growing season.

Furthermore, the map does not always show the exact conditions when lands are sketched as "poorly stocked," or as having inadequate watering facilities. If land is sketched as poorly stocked, that does not necessarily imply that there is insufficient palatable vegetation. The cover may be ample and of high forage quality; but the area may be so steep or so strewn with down timber, or, indeed, it may be so swampy or otherwise so inaccessible as to be of little grazing value.

Again, areas may be classified as inadequate in water supply if they are examined late in the autumn; whereas, they would be listed as having ample water if they were examined early in the season before the temporary springs and seeps had dried up. Furthermore, a classification of " ample water," reported by the examiner in the spring, might hold for wet seasons; or, the classification of "poorly watered," as listed by the same examiner, might be reliable for dry seasons. Then, too, as the examiner passes rapidly over his course, he may fail to record some spring or watering trough inconspicuously situated and thus show the conditions regarding water more serious than they really are. Therefore it is a good plan to reëxamine, casually at least, all

1 Sometimes these cultural features may be located with the use of maps in the county surveyor's office or in the Land Office. On unpatented claims, of course, no complete maps are available, and the features must be estimated by the examiner. 
lands originally listed as incapable of the highest possible utilization.

The Forage Acre and How it is Derived. - "Forage acre" is the term used in designating the grazing value of a given type. A forage acre may be defined as an acre area having a complete (ten-tenths) cover of palatable vegetation or the equivalent thereof in density and palatability. ${ }^{1}$ Probably the best understanding of the term may be had by considering briefly how the forage acre is derived from the reconnaissance data.

In computing the number of forage acres contained in a given range type the total acreage of the land area is multiplied by the surface (expressed in tenths of the whole) which actually supports vegetation. This figure, in turn, is multiplied by the density of the cover and the percentage of palatable vegetation. Thus we have the formula: Total land area $\times$ Surface supporting vegetation $\times$ Density of cover $\times$ Percentage of palatable forage $=$ Forage acre. For example, let us assume that the type consists of 80 acres (total land area) and that the surface or vegetation cover is $\frac{7}{10}$. Let us say that the vegetation of this $\frac{7}{10}$ surface cover has a density of $\frac{8}{10}$, and that 80 per cent of the cover is palatable to stock. By multiplying the factors mentioned above, namely, the total acreage of the type, by the surface acres which support vegetation, then by the density of the vegetation on the area, and finally by the percentage of the vegetation which is palatable to stock, we have a figure, namely, 36 , or the number of forage acres in the type.

With such known factors as the number of forage acres contained in each type, their accessibility to stock, the time in the season when the herbage should be cropped, and certain other facts, it is possible to determine with reasonable accuracy the number of stock that the range will safely supply during a normal grazing season or any part thereof.

1 The vegetation cover refers only to the surface area which is occupied by vegetation. On an area where the cover is not complete the density of the vegetation is shown by applying the surface-cover factor in tenths, ro/10 being a complete cover. The estimate of density is determined by the comparison of the type under consideration with a similar type having a ro/ o density. 
Comparative Value of a Forage Acre of Different Types. - One of the most puzzling and complicated features experienced by the apprentice grazing examiner is the practical application of the forage acre. This is due to the fact that a forage acre of one type of range does not necessarily have the same pasture value as does a forage acre of quite a different type. Yet this is not an unsurmountable complication among experienced range technicians. However, grazing reconnaissance would be more directly applicable in estimating the grazing capacity of an area which supports various types of vegetation if a forage acre of one type had the same grazing value as that of any other type.

In grazing reconnaissance the use of the term forage acre is comparable to that of a ton of roughage; it is merely a standard measure of comparison. Nobody would argue that a ton of alfalfa hay contains the same feeding value or fattening qualities as does a ton of timothy. Indeed, nobody would contend that a ton of alfalfa hay has the same food value for the different classes of foraging animals. For similar reasons stockmen and pasture experts would not contend that a forage acre of succulent broad-leaved herbs ("weeds"), for example, would furnish as much feed for cattle or horses as for sheep in numbers equivalent to cattle or horses in forage requirement. However, a forage acre of a given type in a given region, like a ton of alfalfa hay, has practically the same forage value for a given class of stock as has the same type of forage acre no matter how remotely located within that region.

To determine the relative grazing capacity of the different types a large number of practical grazing tests with the different classes of stock has been made by the United States Forest Service, and the relative grazing value of a forage acre of many of the important types has been determined with considerable accuracy. Although this work is in its infancy, it is nevertheless possible to estimate somewhat closely on a forage-acre basis the grazing capacity of any portion of the range or of the range as a whole. Thus the actual carrying capacity of a forage acre of a given type takes the place of such a chemical analysis or foodvalue test, for instance, as has been determined for a ton of alfalfa hay. 


\section{QUESTIONS}

1. Enumerate the chief objects of a grazing reconnaissance.

2. What conditions of range and what extent of area justify the expense of making a grazing reconnaissance?

3. Name three problems of high importance to judicious range management that a grazing reconnaissance aims to clarify.

4. How many distinct grazing types are recognized in classifying a range by the reconnaissance method?

5. Discuss briefly the methods employed in obtaining grazing reconnaissance data, taking into account (I) the gridiron method, (2) the traversesketching method, and (3) the triangulation method.

6. Define (I) forage acre, (2) density of vegetation cover, (3) complete ground cover.

7. How would you express a forage type in terms of forage acres?

8. (a) What are the advantages of forage-acre data in making carryingcapacity estimates? (b) Enumerate factors other than the forage-acre data that are important in determining the grazing capacity of a range.

9. Discuss the comparative value of a forage acre of different types.

\section{BIBLIOGRAPHY}

Breed, Charles B., and Hosmer, George L. The Principles and Practice of Surveying. John Wiley \& Sons, Inc., N. Y., I9I7.

Cary, Austin. A Manual for North American Woodsmen. Harvard Univ. Press, Cambridge, 1918.

Chapline, W. R. Production of Goats on Far Western Ranges. U. S. Dept. of Agr. Bul. 749, I9I9.

Clements, Frederic E. Plant Indicators: The Relation of Plant Communities to Processes and Practice. Carnegie Institution of Wash., Pub. No. 290, 1920.

Plant Succession: An Analysis of the Development of Vegetation. Carnegie Institution of Wash., Pub. No. 242, Igr6.

Research Methods in Ecology. Univ. Pub. Co., Lincoln, Nebr., I905.

Forest Service. Grazing Reconnaissance Outline. Unpublished Report Wash., D. C.

Jardine, Jauies T., and Anderson, Mark. Range Management on the National Forests. U. S. Dept. of Agr. Bul. 790, I9I9.

Jardine, James T., and Forsling, Clarence L. Range and Cattle Management During Drought. U. S. Dept. of Agr. Bul. I03I, I922.

SAMpson, ArthuR W. Important Forage Plants: Their Life History and Forage Value. U. S. Dept. of Agr. Bul. 545, I9I 7.

The Quadrat Method as Applied to Investigations in Forestry. Forest Club Annual, Univ. of Nebr., Vol. 6, I9I 5.

Wooton, E. O. Carrying Capacity of Grazing Ranges in Southern Ari zona. U. S. Dept. of Agr. Bul. 367, I9I6. 


\section{CHAPTER XVII}

\section{GRAZING CAPACITY AND PASTURE INSPECTION}

\section{GRAZING CAPACITY}

The grazing capacity of a pasture area may be defined as the number of stock of one or more classes which the area will support in good condition during the time that the forage is palatable and accessible, without decreasing the forage production in subsequent seasons. The determination of the grazing capacity of a pasture area is one of the most difficult yet important tasks that the stockman and pasture technician have to solve. It is hardly necessary to say that the grazing-capacity equation has not been worked out on any range unit with mathematical precision. Furthermore, in view of the numerous variable and uncontrollable factors that present themselves nearly every season, it is not likely that the grazing-capacity factor will ever be worked out to a high degree of scientific accuracy. Many of the variables in forage production, as well as in seasonal grazing and grazing for longer periods, are due to what may be termed "human" factors - factors which may be modified or controlled by human effort. Among such factors may be mentioned: (1) Overgrazing; (2) undergrazing; (3) pasturing by the wrong class of stock; (4) turning the stock on the pasture too early in the spring; (5) methods of handling the stock; (6) condition of flesh in which it is desired to keep the stock; and (7) failure to develop watering places with a view to obtaining the fullest possible utilization of the forage crop over the area as a whole.

Basis for Estimating Grazing Capacity. - In the investigation to determine grazing capacity two distinct methods have been employed. The studies of grazing capacity by the Bureau of Plant Industry of the United States Department of Agriculture - probably the pioneer work along this line in the United States - were confined chiefly to fenced range reserves 
in Arizona and New Mexico. In one series of tests, employing what may be termed the indirect method, the investigation provided for the harvesting of all the herbage that was produced on specially selected plots about 5 by ro feet in size. Some of the plots were fully protected from stock; others were located in special pastures. The herbage was usually harvested in the summer, but from some plots it was removed in the spring. From the weights of dry material obtained, the total productivity in terms of pounds of forage per acre was calculated. From each year's calculations an average for the year was figured, and from the yearly averages an average of all the records was obtained.

In addition to this clear-cutting method of determining the forage per acre, hay was cut on the better parts of the range reserve, and the production of hay per acre was compared with the total amount produced as determined by the collections. With a knowledge of the forage requirements in terms of airdry roughage, the grazing capacity of the area was calculated. Another plan, which may be termed the direct method, employed by the same bureau in determining grazing-capacity estimates, was to keep a record of the animal-days' feed consumed within the individual pastures. Such records were kept for a period of five successive years under the management which is in common practice in that particular grazing region. In order to derive reliable grazing-capacity estimates by the direct method, notably where the animals cannot be under the observation of the investigator at all times. the type should be uniform and relatively pure; the area should be securely fenced if possible; the exact acreage of the area must be known; the departures from the normal in forage production and the closeness of the grazing should be carefully recorded at the end of each grazing season; the dates at which the stock is admitted and removed from the pasture should be noted; and the number, class, and age of the stock used each year in the test should be registered. The test should be continued long enough to include the more striking departures in the annual forage production. 
The chief objection to the above methods of deriving grazingcapacity estimates is that the grazing values of the different types of forage were not strictly taken into account. For this reason the figures obtained cannot well be applied to lands other than those similar to the pastures in which the study was conducted.

The studies of grazing capacity by the United States Forest Service have already been described. In the beginning of studies of this kind the first step is the making of a careful grazing reconnaissance of the area selected. At the completion of this activity the data are tabulated to show, among other things, the forage by types, the forage acres of each type, the accessibility of the forage, and other important conditions. A record is then kept of the number of stock of each class grazed, the length of season grazed, and, as nearly as possiblè, the actual time that the stock are maintained on the different forage types. Weights are usually recorded for a reliable number of the stock of all classes grazed, in order that the all-important matter of losses or gains in weight may be known. A record is kept of the deaths of stock during the grazing-capacity test and the causes thereof, for it is the aim to keep the stock in good growing condition at all times. Careful records are also kept as to the condition of the forage throughout the test period, its utilization, the yield departures from the normal, as well as estimates of the degree of the stocking on the stand and the yield in future.

Grazing Capacity of Ranges and Farm Pastures. - The grazing-capacity figures here given have been developed on the basis of the minimum acreage required to maintain a foraging animal in good, thrifty condition through the grazing season stipulated. For purposes of ready comparison, the data presented in the following table are expressed on a cow-unit basis. ${ }^{1}$

1 Custom varies considerably in the matter of the number of sheep or goats which are taken as the equivalent of a cow in ascertaining the acreage of pasture necessary for each per season or other unit of time. The prevailing proportion in western ranges is four sheep or four goats to one cow. In some Western States, however, five or even six sheep or goats per cow unit is the usage. A horse is usually considered the equivalent of a cow, just as a goat is of a sheep. 
Grazing Capacity of the National Forests in Cow Units from igo7 to I921, INCLUSIVE $a$

\begin{tabular}{|c|c|c|c|c|}
\hline $\begin{array}{c}\text { Fiscal year ending } \\
\text { June } 30\end{array}$ & $\begin{array}{l}\text { Gross area of National } \\
\text { Forests exclusive of } \\
\text { Alaska and Porto Rico }\end{array}$ & $\begin{array}{l}\text { Total cow units of } \\
\text { grazing furnished } \\
\text { (One cow is here con- } \\
\text { sidered the equivalent } \\
\text { of } 5 \text { sheep or } 5 \text { goats) }\end{array}$ & $\begin{array}{l}\text { Gross acreage } b \\
\text { cow unit per y }\end{array}$ & $\begin{array}{l}\text { per } \\
\text { rear }\end{array}$ \\
\hline 1907 & I $45,855,835$ & $2,53 \mathrm{I}, 575$ & 57.6 & \\
\hline rgos & I $55,823,3$ I0 & $2,797,567$ & $55 \cdot 7$ & \\
\hline 1909 & I $67,677,749$ & $3,145,323$ & $53 \cdot 3$ & \\
\hline I910 & I $66,103,621$ & $3,024,2$ I 5 & $54 \cdot 9$ & \\
\hline I9I I & $163,793,443$ & $2,933,32 \mathrm{I}$ & 55.8 & \\
\hline 1912 & $160,591,576$ & $3,008,7$ I 6 & $53 \cdot 4$ & \\
\hline 1913 & I 59,8 O I, 848 & $3, \mathrm{I} 27,4 \mathrm{I} \mathrm{I}$ & $5 \mathrm{I} \cdot \mathrm{I}$ & \\
\hline 1914 & $15^{8,506,402}$ & $3,140,640$ & 50.5 & \\
\hline 1915 & $157,691,1_{5} 2$ & $3,180,991$ & 49.6 & \\
\hline I916 & I $55,009,043$ & $3,434,962$ & $45 . \mathrm{I}$ & \\
\hline 1917 & I 55, I 72,775 & $3,579,273$ & $43 \cdot 4$ & \\
\hline 1918 & I 54,872, I I I & $3,942,45^{2}$ & $39 \cdot 3$ & \\
\hline 1919 & I $53,482,239$ & $3,827,97$ I & 40. I & \\
\hline 1920 & I $59,520,622$ & $3,581,779$ & $44 \cdot 5$ & . \\
\hline 1921 & I $61,04 \mathrm{I}, 305$ & $3,626,855$ & $44 \cdot 4$ & \\
\hline
\end{tabular}

a These data were furnished through the courtesy of the U. S. Forest Service.

$b$ The gross-acreage requirement for a cow unit per year as here given embraces all of the waste and barren lands included in the National Forests.

In 1907 the average required was 57.6 gross or surface acres to support a cow unit as compared with 39.3 acres in 1918 , with a gradual trend towards the minimum during the intervening years. These data are significant in that they show clearly the effect of improved range management in increasing the grazing capacity.

Acreage Required for Cattle. - Jardine and Anderson ${ }^{1}$ have shown that on National Forest range, all the important types and varied topographic features considered, an average of 24 to 30 surface acres, exclusive of inaccessible lands, or about 9.6 forage acres, are required per year for a cow unit. This is equivalent to approximately 12.5 surface acres, or 4.4 forage acres for the usual summer-grazing period on the National Forests of five and one-half months. On the Santa Rita Range Reserve in southern Arizona, an area located in the foothills,

1 Jardine, James T., and Anderson, Mark, "Range Management on the National Forests." U. S. Dept. of Agr. Bul. 790, pp. 27-30, 1919. 
these investigators found that on good grass range I4 gross acres was ample to support a cow unit for a year.

Various miscellaneous data prompt the writer to estimate the average grazing capacity of the public-domain lands remaining in the far Western States in 1923 as between 25 and 35 acres for a cow unit per year. The grazing capacity of these lands on a yearly basis is variously estimated from about 18 to considerably over 100 acres per cow unit (Fig. 122).

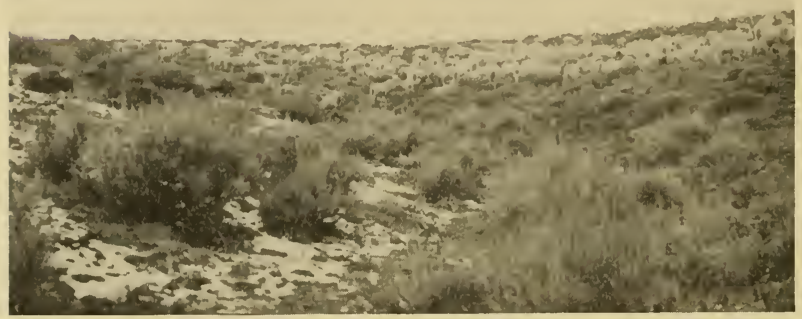

FIG. 122. - WINTER DESERT RANGE OF SAGE AND SHADSCALE IN THE GREAT BASIN REGION.

Here approximately 60 gross acres are required to maintain a cow throughout the year. Compare this cover with that of palatable grassland (Fig. II4), where $I_{4}$ acres are ample to maintain a cow in good condition for a year.

In contrast to the large acreage requirement for the annual support of a cow unit in the drier regions of the West, no more than $I_{2} \frac{1}{2}$ gross acres is required to support a cow for a 5 -month period, or the equivalent of 3.6 acres per year on the betterirrigated farm pastures in the far West or in those middle Western States where the rainfall is such as to stimulate the production of a continued luxuriant growth of forage. Intermediate conditions between the arid West and the humid areas of the middle West are found in Kansas. Hensel's ${ }^{1}$ studies at the Kansas Experiment Station show that for the eastern half of that State from $10 \frac{1}{2}$ to about 12 acres of native pasture land is required per year for a cow unit.

1 Hensel, R. L., Unpublished report, Kansas Agr. Exp. Sta., Manhattan, Kans. 
Acreage Required for Sheep. - The acreage requirements for sheep were determined on National Forest range by Jardine and Anderson. ${ }^{1}$ These determinations covered several years and were made on the basis of fifty-six allotments on typical summer range of all classes and types. An average of 2.5 gross acres, or 0.79 forage acres, was required to support one ewe or two lambs for an average grazing period of 72 days. These writers conclude as follows:

It would appear from close study of the tests conducted, and from similar figures deduced from range reconnaissance surveys, that 0.0 or forage acres per head per day is about right for range suited to sheep grazing. This would be equivalent to about 0.03 surface acres per head per day, exclusive of range having no value for grazing, or about 3 surface acres for a grazing period of Ioo days.

On an annual basis, then, I gross acres, or the equivalent of 3.65 forage acres, would be required per year.

The average yearlong acreage requirement for the support of a cow unit on the National Forest range of 24 to 30 surface acres, or 9.6 forage acres, and the yearlong requirement of about I I surface acres, or 3.65 forage acres, for a sheep, do not necessarily bear any relation to each other. This is due chiefly to the wide variation in the forage relished by these classes of stock. Therefore, when a change is made on the range from one class of stock to the other the carrying capacity of the area in question should be reëstimated for the class of stock to be grazed.

\section{PASTURE INSPECTION.}

Inspection of Range and Farm Pasture. - There is no magic about the production of forage or the harvesting of the pasture crop by foraging animals However, to produce continuously the maximum choice crop of forage that the lands are capable of growing and to harvest it in such a way as to secure the largest continuous economic returns possible is a matter that requires much study and the close inspection both of the stock and the forage resources. Observations as to the conditions of range and

1 Jardine, James T., and Anderson, Mark, "Range Management on the National Forests.” U. S. Dept. of Agr. Bul. 790, p. 28, I9r9. 
farm pastures almost everywhere constitute evidence of the fact that many matters of first importance in continued forage and livestock production are frequently overlooked in determining their future management. Accordingly, an outline is given of the more important considerations in inspecting the range or farm pasture. ${ }^{1}$

I. If a grazing reconnaissance or even a rough field map has been made of the pasture area in question, all data possible should be recorded thereon, as such records are often invaluable. It is especially important that such data as the following be shown on the map: (I) Class or classes of stock grazed; (2) date when the stock may be admitted in the spring; (3) intensity of grazing over different parts of the area; (4) any changes in the boundary or driveways to and from the area; (5) the grazing capacity of each major forage unit; (6) location of salting places, water, and necessary water development; and (7) places where timber reproduction is injured by grazing, where poisonous plants abound, where the range is especially in need of reseeding, and where other improvements are needed. On large range units, especially where cne surface is much broken, a reliable map is almost indispensable to the judicious management of the lands and the stock.

2. Is each range unit being grazed by the class or classes of stock to which it is best suited? Lands which have been used exclusively by cattle for several seasons are liable to become weedy, such vegetation often replacing a large portion of the grass feed. The grazing capacity of many a farm pasture has been much improved for cattle by permitting a few sheep to consume the weeds before they go to seed. Mowing the pasture before the seeds of the weeds ripen is also a good practice.

3. Are the lands being grazed uniformly or are some areas overgrazed and others undergrazed?

4. What is the grazing capacity of the types which are being

1 In preparing this outline on range and pasture inspection use has been made of the work on range inspection by Jardine, James T., and Anderson, Mark, "Range Management on the National Forests," U. S. Dept. of Agr. Bul. 790, pp. 76-79, I9I9. 
grazed (I) too closely and (2) not closely enough? ${ }^{1}$ Such questions can best be answered by consulting the type maps if a reconnaissance has been made. If such data are not available, grazing-capacity estimates must be made ocularly in the field.

5. Is any portion grazed too early, and is any visited by stock so late that the herbage is not palatable? If so, how may such mismanagement be remedied?

6. Is there ample supplemental feed, such as silage, hay, or other roughage, reserved for feeding in the spring in order that injury to the pasture caused by too early grazing may be avoided? If not, cannot supplemental feed of some kind be provided with good results to both the stock and the pasture?

7. Is each class of stock properly handled? Close herding of sheep, the excessive use of dogs, and the use of established bed grounds should be discouraged; cattle should be well distributed at all times.

8. Are there adequate salting grounds for cattle, and are they located properly with respect to water and forage? Do the sheep get all the salt they will eat as often as every ten days?

9. Is the tree reproduction on any area appreciably injured by stock browsing upon it? Would a change in the class of stock or a decrease in the number of the present class remedy the evil?

Iо. Are any areas particularly in need of reseeding, and is any portion denuded to such an extent that erosion is starting? What is the most economical and expedient means of reëstablishing the stand?

II. If there is a gradual decline in the grazing capacity of an area, is it due (I) to overstocking, (2) to too early grazing, (3) to

1 The extent of the utilization of a pasture area by one or more classes of stock is best expressed in percentage. For the sake of uniformity, roo per cent is considered full but not destructive utilization, the forage preferences of the class of stock grazed being considered, so that the growth in future is fully maintained. Accordingly, any grazing beyond roo per cent, or full utilization, may be classed as overgrazing. However, it is exceedingly difficult to determine the extent to which the grazing may be declared Ioo per cent or complete utilization, or I Io per cent, let us say - that is, Io per cent overutilization. The test of overutilization, however, is seen in the decline in the forage production in subsequent seasons. 
poor distribution of the stock, (4) to the need of a fertilizer, (5) to tightly bound sod, or (6) to some other cause? In localities where lime or phosphorus are required various indicators flourish, as, for example, moss, bracken fern, and numerous other acid-tolerant weeds. The addition of lime or some standard phosphate fertilizer readily corrects the soil depletion and fosters the development of the vegetation desired. On the other hand, many a sod-bound pasture is immediately improved by disking or otherwise loosening up the surface.

I2. What are the chief forage species as well as the more objectionable and aggressive weeds? At what time does the seed crop of the best forage plants ripen?

I3. What are the poisonous plant species, and to what!extent and at what time in the season do the livestock losses occur therefrom? Would it be practical to eradicate the plant species causing the losses? If so, how much would it cost, and when could the work be done most effectively?

14. What improvements should be made, and what is the condition of the fences, corrals, and other such features already constructed?

I5. If there are any game animals, what kind and approximately how many are there? Are they increasing or diminishing in number? Is their number so great that they consume an appreciable amount of feed which would otherwise be utilized economically by domestic foraging animals? Where do they range (I) in summer, (2) in winter?

A guide to the answers to the foregoing questions will be found in the preceding chapters.

\section{QUESTIONS}

1. Define grazing capacity.

2. Name several "human" or controllable factors which may influence the grazing capacity of a pasture.

3. Name and discuss two distinct methods which have been employed in determining grazing capacity.

4. How many sheep or goats may be taken as the equivalent of a cow in determining the acreage of pasture required for a given unit of time?

5. What were the gross or surface acreage requirements per cow unit on National Forest range in 1907 , and in 1921 ? 
6. Exclusive of inaccessible range, what is the average (I) surface-acreage and (2) forage-acre requirement on the National Forest for a cow unit per annum? What is the maximum gross-acreage requirement on the poorer public-domain lands?

7. What is (I) the surface-acreage and (2) the forage-acre requirement for the support of a sheep during the summer-grazing period on National Forest range?

8. Name six important questions that should be answered in making an inspection of a range or farm pasture.

9. Discuss the use of the map of a pasture area in making a grazing inspection.

\section{BIBLIOGRAPHY}

Barnes, Will C. Stock-Watering Places on Western Grazing Lands. U. S. Dept. of Agr. Farmers Bul. 592, I9r4.

Farley, F. W., and Greene, S. W. The Cut-over Pine Lands of the South for Beef-Cattle Production. U. S. Dept. of Agr. Bul. 827, I92I.

Forsling, Clarence L. Chopped Soapweed as Emergency Feed for Cattle on Southwestern Ranges. U. S. Dept. of Agr. Bul. 745, I9I9.

Griffiths, D. Range Investigations in Arizona. U. S. Dept. of Agr., Bur. of Plant Ind., Bul. 67, 1904.

The Reseeding of Depleted Range and Native Pastures. U. S. Dept. of Agr., Bur. of Plant Ind., Bul. I1 7, I907.

JARDINE, JAMES T. Range Improvement and Improved Methods of Handling Stock in National Forests. Proc. Soc. Amer. For., Vol. 7, 1912 .

Jardine, James T., and Anderson, Mark. Range Management on the National Forests. U. S. Dept. of Agr. Bul. 790, I9I9.

Jardine, James T., and Forsling, Clarence L. Range and Cattle Management During Drought. U. S. Dept. of Agr. Bul. I031, 1922.

Jardine, James T., and Hurtt, Leon C. Increased Cattle Production on Southwestern Ranges. U. S. Dept. of Agr. Bul. 588, I9r 7.

Nelson, Aven. The Wheatgrasses of Wyoming. Wyo. Agr. Exp. Sta. Bul. 59, Pt. I, 1903 .

Potter, Ermine L. Western Livestock Management. The Macmillan Co., N. Y., I917.

SAmpson, Arthur IV. Climate and Plant Growth in Certain Vegetative Associations. U. S. Dept. of Agr. Bul. 700, I9r8.

Important Forage Plants: Their Life History and Forage Value. U. S. Dept. of Agr. Bul. 545, I9I 7. 
SAMPSON, ARTHUR W. Natural Revegetation of Range Lands Based upon Growth Requirements and Life History of the Vegetation. U. S. Dept. of Agr., Jour. Agr. Research, Vol. 3, No. 2, I9I4.

Plant Succession in Relation to Range Management. U. S. Dept. of Agr. Bul. 791, I9r9.

Sмrтt, J. G. Grazing Problems in the Southwest and How to Meet Them. U. S. Dept. of Agr., Div. of Agrost., Bul. I6, I899.

Woodward, T. E., et al. The Making and Feeding of Silage. U. S. Dept. of Agr. Farmers Bul. 578, revised 1920.

Wooton, E. O. Carrying Capacity of Grazing Ranges in Southern Arizona. U. S. Dept. of Agr. Bul. 367, r916. 


\section{CHAPTER XVIII}

\section{RESEARCH METHODS IN RANGE AND PASTURE REVEGETATION}

It has been shown in Chapter VI that a more or less orderly change is continuously taking place in the composition and density of the plant cover everywhere, regardless of whether the land is utilized by man or remains unclaimed in its virgin state. The methods of cropping on range lands determine whether the plant succession shall be in the direction of improvement or of degeneration in the yield and nutritive value of the forage, regardless of the rapidity of that succession. It seems hardly necessary to call attention to the importance of knowing with a reasonable degree of accuracy the trend, up or down the scale, of the development of vegetation on pasture lands, as this tendency determines the ultimate grazing capacity of the land. Experience - in this matter a very costly teacher has shown without doubt that an occasional ocular examination to determine the condition of the grazing grounds in a given locality is quite unreliable for the noting of slight changes or even the more striking departures in the replacement or succession of pasture vegetation.

In the study of grazing capacity and pasture revegetation it is essential to know with precision (I) the ways of reproduction of the dominant species of the vegetation and their capacity therefor, particularly of the palatable species and of the more aggressive unpalatable intruders; (2) which plant or set of plants is gaining dominion over the soil in response to the different methods of grazing use and also on similar unused lands; (3) the potential or maximum forage yield of the different conspicuous grazing types; (4) the variation in the yield of the different types year after year; and (5) any beneficial effects resulting from a slight change in the methods of handling the 
stock and tending toward a replacement of the undesirable (nonpalatable and poisonous) plants by palatable, nutritious, and heary-yiclding species, preferably perennials.

Only reliable information can be helpful in the development of a rational grazing plan that is to bring about a maximum forage yield, with a minimum of disturbance and loss in the forage use during the revegetational period. This presupposes a detailed knowledge of the successional stages in the development of the vegetation. To obtain such reliable data requires the use of various forms of sample plots so located over the pasture area studied and in such relation to forage types, soils, and topographic features as to show the developmental trend of the vegetation as a whole.

The author feels that a brief summary of his fifteen years of intensive study of the use of sample plots and their establishment, of the various ways of mapping the cover, and of methods of summarizing the data with a view to interpreting the results correctly, may be of value to the junior investigator.

Permanent Sample Plots. - To be of real value sample plots must be so established that future mappings will show clearly what changes have taken place in the plant cover, and hence how much the pasture has increased or decreased in grazing capacity. For such a study the sample plots must be reasonably permanent. Permanency of plots presupposes two conditions: (I) The locating and marking of the plots in such a manner that fires, grazing, and other ordinary destructive factors will not hamper the re-location of the area; and (2) the mapping of the vegetation and the summarizing of the map data in such a way that comparisons may readily be made, and in such detail that satisfactory future relationships may be insured. Permanent sample plots should be available for study by trained investigators at any time during a period of years, possibly a century or more.

Kinds of Plots and Their Establishment. - Sample plots may be of various sizes and shapes; for intensive studies a few square feet (or, indeed, a meter) may suffice, whereas for the more general work many acres may be used. In shape they may 
be square, rectangular, circular, or of irregular dimensions. The square plot, known to ecologists as the "quadrat," is usually the most convenient. If the sample areas are a quarter of an acre or larger, one or more small square plots about 3 feet or one meter in size are established within the larger area for detailed mapping of the vegetation. The information afforded by these small plots supplements the more general data relating to the larger area. The main plot is usually blocked off into convenient segments and the vegetation mapped only in a general way. Such general mapping takes into account (I) the dominant and subdominant species, (2) all the species found on the selected plot, (3) the density of the cover, and (4) the grazing capacity of the plot expressed on an acreage or sectiontract basis of animal-unit capacity. The forage-acre equivalent may be used to advantage if desired. The detailed mapping is done, with variations, according to the quadrat method developed by Clements, the details of which are here summarized under the various headings which follow. ${ }^{1}$

Sample plots are named according to the way the mapping is done. In grazing work, the chart plot, the list plot, and the denuded or depopulated plot are used most extensively.

Chart Plot. - If the changes in the vegetation are to be noted in detail, the chart plot is invaluable. Here ordinarily all of the vegetation within the plot is charted in situ, but in less intensive work the maps show only the species of primary interest in the investigation pursued. If all the vegetation is to be located in position on the map, as shown in Figure 123 , the standard size of quadrat, namely, the meter-square area, is commonly used.

A distinct disadvantage in the extensive use of chart plots is the great amount of tedious work involved in the mapping and in the subsequent crystallization of the data recorded. For this reason the regular chart plot is less popular than formerly, for certain other short-cut methods have been developed in grazing studies which show well the changes in the vegetation.

1 Clements, Frederic E., "Plant Succession: An Analysis of the Development of Vegetation." Carnegie Institution of Washington, Pub. No. 242, pp. 423-442, I916. 
Mapping Chart Plot. - The method of mapping is one in which specially designed tapes are used to divide the plot into squares, which, in the meter plot, are in decimeters. The

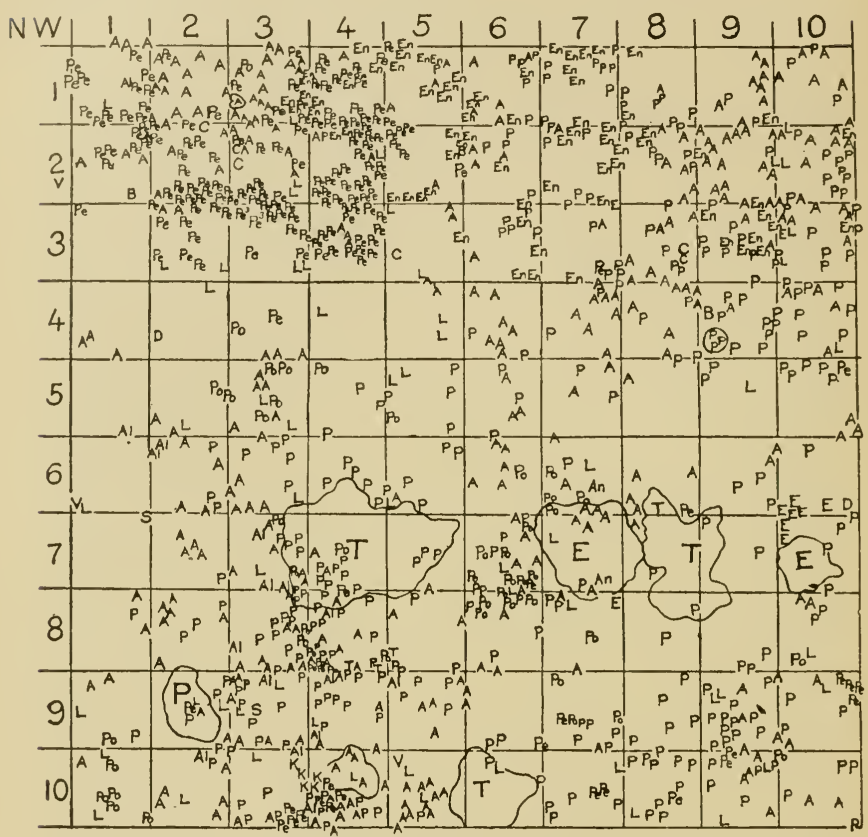

FIG. 123. - CHART PLOT, ALL OF THE VEGETATION BEING LOCATED ON THE MAP TO CORRESPOND WITH ITS POSITION ON THE SELECTED AREA.

$$
\begin{aligned}
& \mathrm{P}-\text { Poa pratensis. } \\
& \mathrm{Pe}-\text { Pentstemon procerus. } \\
& \mathrm{A}-\text { Achillea lanulosa. } \\
& \mathrm{K}-\text { Trisetum spicalum. } \\
& \mathrm{L}-\text { Lathyrus leucanthus. } \\
& \mathrm{Po}-\text { Polygonum Douglasii. } \\
& \mathrm{T}-\text { Leontodon taraxacum. } \\
& \mathrm{E}-\text { Erigcron effusus. }
\end{aligned}
$$
B - Bursa bursa-pastoris.
$\mathrm{C}-$ Crepis acuminata.
$\mathrm{D}-$ Draba cana.
$\mathrm{V}$ - Viola linguaefolia.
$\mathrm{S}-$ Sophia incisa.
An - Androsace diffusa.
Al - Alsine (spp.).
En - Erigeron divergens.

vegetation within each decimeter is mapped on a reduced scale of approximately I to 5, the map scale depending upon the detail desired. In the mapping of permanent chart plots the 
writer has found it convenient more recently to prepare and use a special map form, a reproduction of which is shown in Figure I26. This form on the map side gives the number of the plot, its location, the date of establishment, seasons and dates when remapped, and the species with their map symbols. The map is so ruled off that each square corresponding to a square decimeter of ground surface is divided into four equal parts, an arrangement which facilitates the location of the plant on the chart.

The reverse side of the map form, reproduced in Figure r 24, provides for a statement of the specific object of the plot; the size of the plot; the character of the site and the vegetation; history of the range with respect to grazing, fires, etc., including a statement of its present use; a record of the vigor and life history (reproduction, invasion, and establishment) of the vegetation; and, finally, a summary of the quadrat data, space being so provided for the segregation of the plant record as to make it readily applicable to the range problem under investigation.

Preliminary to charting the plot, care is taken to lay down properly the four boundary tapes, that is, to "square" them up and secure them at each corner by using surveyor's pins extending through the perforated ends of the tapes. The matter of permanent staking is discussed under the heading, "Special Sample-Plot Guide Tapes."

After the four boundary tapes are properly located the two cross tapes are placed in position and held there by means of surveyor's pins through the end holes and through the holes at the decimeter intervals of the boundary tapes. As indicated in Figure I23, the upper and lower sides of the chart are numbered from left to right and the side lines from top to bottom. Accordingly, the mapping is always started at the upper left-hand corner of the chart. The plants found in the first decimeter square of the plot are located on the map by means of symbols placed in the corresponding square of the chart. When the first decimeter strip has been mapped the upper cross tape is moved down one decimeter, where it outlines the second uncharted strip. This strip is now charted as the first one was, 


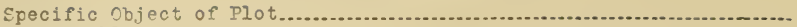

Size of Plot.

Character of Site:

Exposure .......................... Slope and Aspect Elevation Soil

(Origin, depth, humus, texture, indication of erosion, eto.)

Soil moisture content .................. (Spring) (Summer)

(Autumn)

Vegetation:

Type.............. Density.

Associated species Predominating specios............. History of Plot:

Past

(Cut over, grazed, burned, etc.)

Present

(Protected or subject to grazing) (Character of grazing and

class of stock)

History of Range:

$$
\text { class of stock) }
$$

(Grazing season)

Past

(Cut over, grazed, burned, etc.)

Present

(Overgrazed, undergrazed, moderately grazed)

(Dates.of Grazing)

Vigor and Life History of Vegetation:

Growth luxuriant or weak.

Period of growth - From ........................ To

Time of flower stalk production

Time of seed maturity

Size of seed crop

Viability

as grazing advantageous or disastrous to reproduction?........

Was seed planted by stock?...... Were seedlings destroyed?

Symbols

SUMMARY OF PLOT DATA

\begin{tabular}{c|c|c|c|c|c|c|}
\hline 1 \\
\hline 2 \\
\hline 3 \\
\hline 4
\end{tabular}

Total number of specimens.

Total number of forage specimens

Total number of unpalatable specimens.

Total number of species

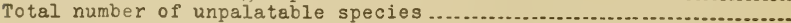
Increase in tufts:....... Palatable species;........ Unpalatable species Per cent of forage specimens ..........................

Per cent increment in all specimens....

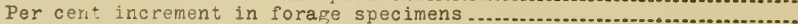

Per cent increment in unpalatable specimens

Per cent increment in tufts

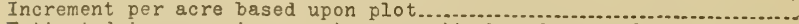
Estimated increase in carrying capacity based upon plot...............

FIG. 124. - REVERSE SIDE OF SAMPLE-PLOT FORM USED IN CHARTING VEGETATION. 
and the shifting of the cross tapes is continued until the charting of the quadrat is completed.

Prior to mapping, and before there has been any abnormal disturbance of the vegetation, a photograph should be taken of the plot. For purposes of future comparison it is highly desirable to establish the exact location of the camera and the direction of the exposure. This is done by placing a stake at the spot where the camera is located and another in line with the angle of the camera. "Position" photographs have proved of much value in comparative studies of plots observed over a period of years.

The Pantograph for Mapping Chart Plots. - The immense amount of painstaking work involved in charting the vegetation in exact position led $\mathrm{Hill}^{1}$ to apply the pantograph, an instrument formerly considered as adapted only for use on a drafting

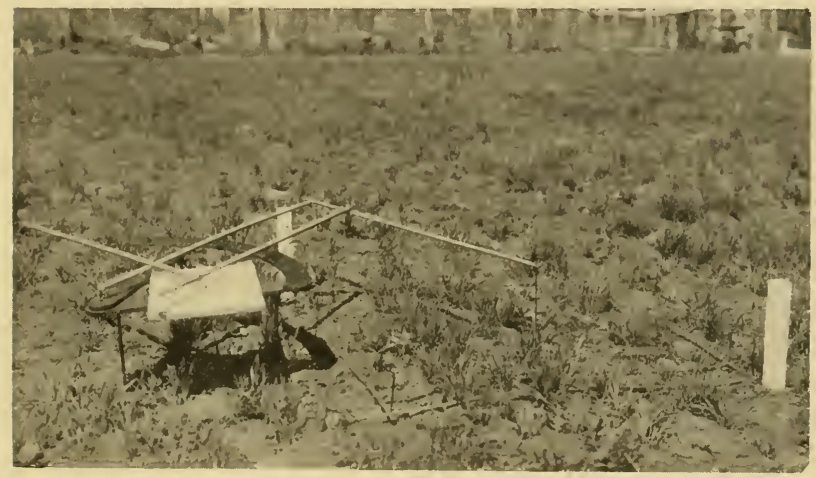

FIG. I25. - THE PANTOGRAPH IN USE ON A CHART PLOT.

The special sample-plot steel guide tapes are in position, and the plot is staked at diagonally opposite corners.

table, to the mapping of vegetation on chart plots. The results from the use of the pantograph are highly satisfactory for reproducing the outlines of tufts of vegetation as well as for

${ }^{1}$ Hill, Robert R., "Charting Quadrats with a Pantograph." Ecology, Vol. I, No. 4, pp. 270-273, 1920. 
locating individual plants. Figure $\mathrm{I} 25$ shows the Hill pantograph with guide and division-plot tapes in use by the author.

The instrument is provided with arms 40 inches long and set to reduce to $\frac{1}{3.75}$, a reduction which, when it is applied to a meter-square plot, makes a map scale of 10.5 inches on a side. A substantial table about 20 inches square, mounted on a pivot at one corner, supports the map and receives the impression. The instrument is supported by a metal leg one inch high with a ball roller, this being so attached to one arm that the arm swings back and forth across the table when the instrument is in use. Also, for the short tracing needle is substituted a steel needle Io inches long for tracing the outline or for locating the vegetation on the plot.

The designer points out that a possible disadvantage in the use of the pantograph is that the services of two persons are necessary to chart successfully. One of these should be familiar with the flora and skilled in charting; the other records the symbols of each species and handles the instrument. Any disadvantage arising from two persons working together, however, appears to be offset by the increased accuracy and speed secured.

The advantages of locating the vegetation in position by means of the pantograph are summarized by Hill as follows:

I. The results are fully as accurate; the pantograph will record as accurately as the skill of the operator in following the outline of plants will permit.

2. The pantograph can be used with entire disregard of the presence of rocks or impenetrable soil - factors very important in using straps.

3. The rank growth of vegetation is even less of an obstacle to accuracy with the pantograph than it is with the strap method, because the foliage can readily be held with one hand while the outline of the plant is traced with the other. Where straps are used the rank foliage is very apt to prevent the straps from lying accurately in position.

4. The work can be done more rapidly with the pantograph and with much less tedium. (Two persons, only one of whom need be skilled, can chart fully three times as many quadrats with the pantograph as one skilled person can chart with straps.)

5. The pantograph is especially efficient in locating individual seedlings or one-stemmed plants and in tracing the outline of crowns of low bushes. 
It is pointed out by the designer that the instrument needs some refinement, and that its further use will doubtless suggest certain minor improvements.

List Plot. - This form of plot is used by most ecologists merely to procure a systematic record of the species which occur within a given plant unit. Such a record in itself, however, affords little data of value upon which to base a rational and judicious plan of pasture study, and its use in successional and distributional studies is often overestimated.

In the more recent natural reseeding studies the writer has made a new application of the method of charting which has greatly popularized the use of the list plot. The method employed is simply a combination of charting and listing.

The former record showing the exact number of individual specimens of a species is substituted for the percentage of the cover which each species produces, and this is recorded per one one-hundredth unit of the plot, as indicated in Figure I26. Each division area of the map shows the species occurring within the unit, regardless of the exact location of the plants, and in addition the percentage of cover formed by each species and the density of cover within each unit. For example: If Polygonum Douglasii composed I 5 per cent of the cover within a given onehundredth unit of the plot, Stipa minor so per cent, and Bromus marginatus 5 per cent, the vegetation would be listed as P-I5, $\mathrm{S}-\mathrm{I}$, and $\mathrm{B}-5$, respectively, one under the other. In the upper right-hand corner of the unit is recorded the density of that unit. Such a record is noted for each unit division of the plot so that its average density may be determined. From these facts the cover may be expressed in terms of forage-acre factor density $\times$ palatability of the cover.

Some of the advantages in the use of the list plot are that the mapping can be done in about one-fifth of the time required for complete "location" charting; that the plan lessens materially the work required in summarizing the data; and that the record furnishes the additional valuable information of the actual density of individual species and of the plot as a whole, factors which are not available where the cover is charted merely in situ 


\section{GREAT BASIN EXPERIMENT STATION, EPHRAIM, UTAH Natural Reseeding}

Protected Plot No. 4

Established September 16, 1916

Mapped by H. E. Malmsten and M. B. Haman Date: September 12, 1921

Season Remapped: 1921
Location: Upper Plot on Bear Creek

\section{Legend}

Symbol Species Symbol

Al....Achillea lanulosa

Av....Agropyron violaceum

Lt... Leontodon taraxacum

Ad... Androsace diffusa

Species
Symbol

Species

Pa...Polygonum aviculare C....Chaenactis spp. Pt.Pseudocymopterus Tidestromii

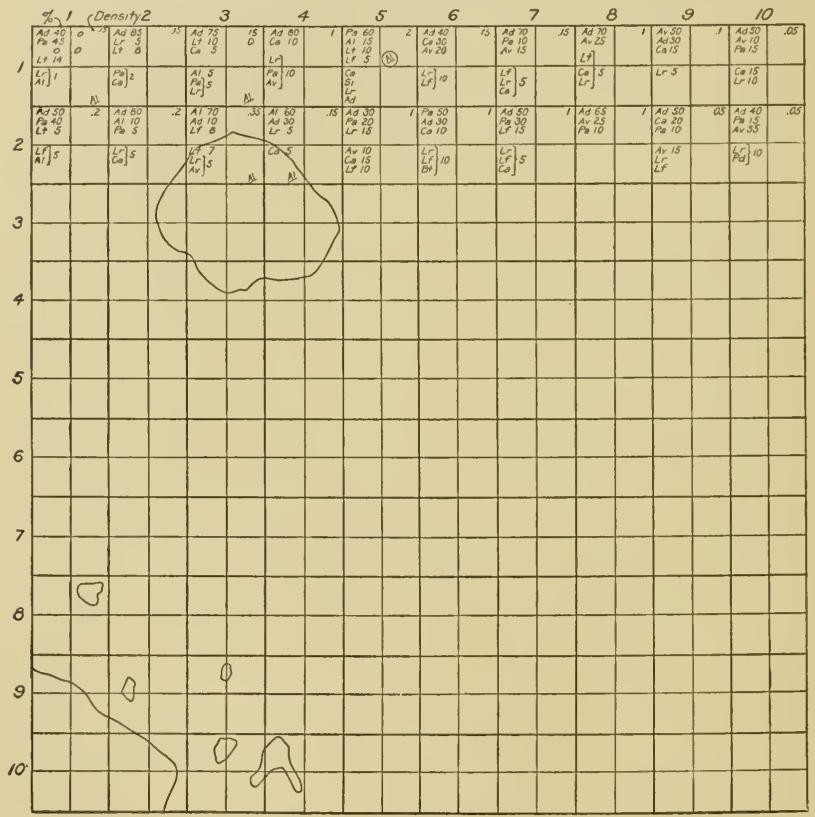

Fic. 126. - THE LIST PLOT.

All the vegetation occurring thereon is charted. 
The same design of sample-plot tapes is used in the listing plan of mapping as for charting. The list plot, because of the rapidity with which the mapping is done, is usually made larger than the chart plot, an additional advantage in securing representative conditions.

Denuded or Depopulated Plots. - The most reliable means of determining the rate of the invasion and establishment of vegetation on badly depleted range is to locate representative sample plots on areas that have been quite or nearly denuded by foraging animals. Artificial depopulation of sample plots has been more or less popular with students of range revegetation in determining the rate of invasion of species. Data as to the rate of the invasion and establishment on artificially denuded plots may furnish some information relative to the rate at which lands denuded by grazing may be built up; but the results are not reliable, because of the absence of a highly influential factor, namely, the packing of the soil. The heavy packing of the soil by livestock, especially the trampling when the soil is wet, has a profound effect upon revegetation. Accordingly, in the natural reëstablishment of the cover on denuded areas those depopulated through excessive or untimely grazing should be selected for study.

The value of the artificially denuded plot in revegetational work lies chiefly in its use for determining the viability of the seed of native vegetation. Here the meter quadrat is valuable. Following the artificial removal of the vegetation, regular quadrat tapes one meter in length, marked off at decimeter intervals, are laid down; then a seed is placed at each decimeter interval, and, if desired, also midway between the intervals, making 100 or 200 seeds to the quadrat according to the spacing. The following spring the plot tapes are replaced, and the results of the germination recorded. This method of determining seed viability is valuable for use on high mountain range where little is known of the temperature requirements and certain other physical stimuli for normal seed germination. ${ }^{1}$

1 Sampson, Arthur W., "The Quadrat Method as Applied to Investigations in Forestry." Forest Club Annual, Univ. of Nebr., Vol. 6, pp. 5, 6, 1915. 


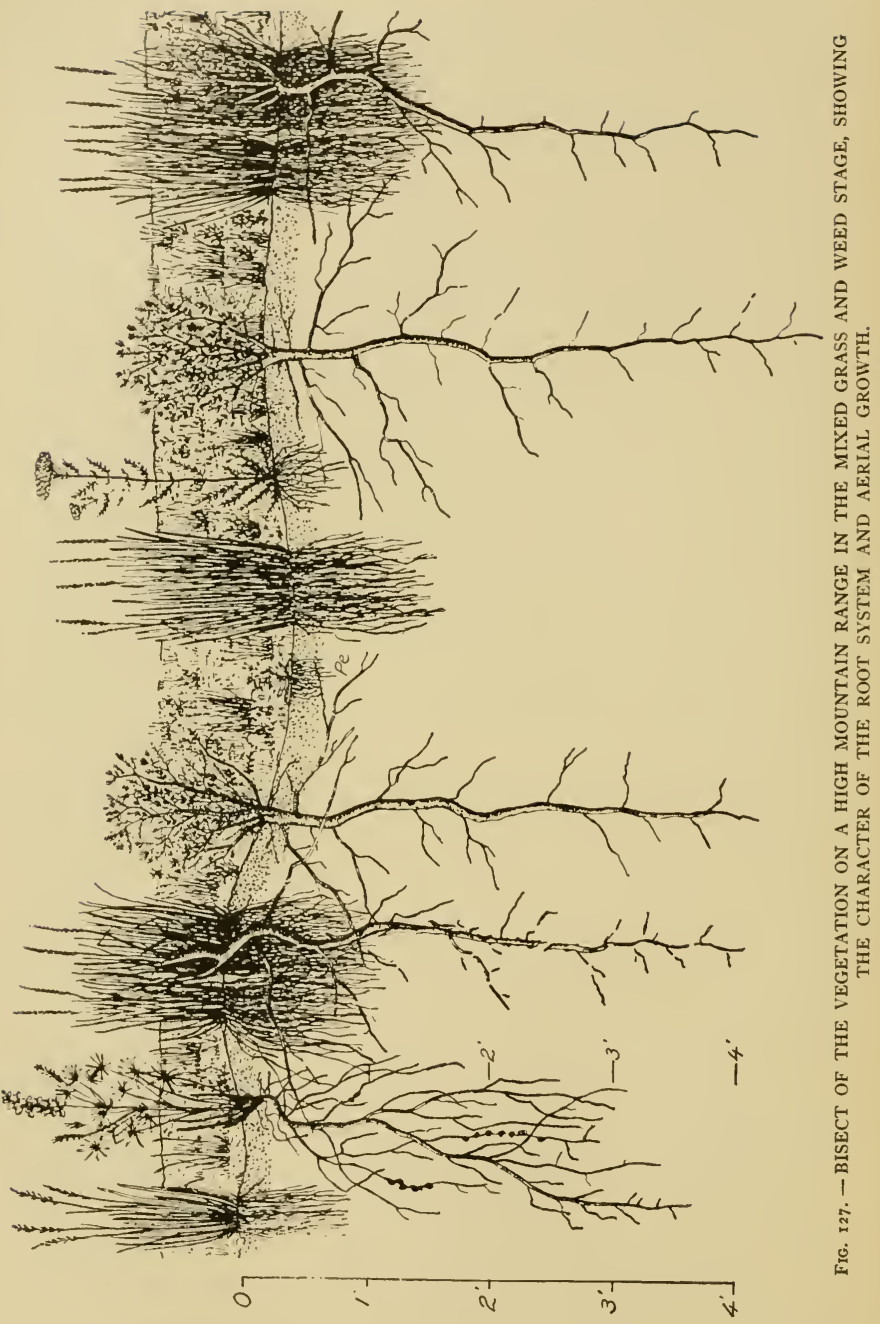


Other Plots. - Strip plots, known as transects and bisects, are sometimes used to advantage in revegetation studies. A transect is merely a narrow, much-elongated sample plot; whereas, a bisect, also much elongated, aims to show the vertical relation or cross-section, as it were, of associated plants, the underground parts as well as the aërial growth often being shown (Fig. 127). The width of the bisect, like that of the transect, is never great, varying from a mere line to a few inches. The advantage in the use of transects and bisects lies in the fact that they may run from one plant community or society into another, or from one exposure or gradient into quite a different one.

The mapping of the transect or bisect is done much the same as that of a chart plot. Special tapes of varying length, conveniently segregated, are used. Because of the great length of the average "belt" transect, that is, one whose width is more than that of a mere line, it is most convenient to map the vegetation in strips or segments on the same sheet. These strips appear on the chart at regular intervals, the first one being placed to the extreme left on the sheet and running from top to bottom, the second to the right of the first, the third to the right of the second, and so on.

Special Sample-Plot Guide Tapes. - Accurately constructed and otherwise satisfactory plot guide tapes are not obtainable on the market. Accordingly special metal tapes have been devised. ${ }^{1}$ Although the sketch (Fig. I28) is designed on the basis of a meter unit, any length desired may be made up according to the following description. Inches and feet may be substituted for the metric scale.

Each set consists of four boundary tapes, as shown by "A," and two division tapes, as shown by "B." The boundary tapes are I $3_{3}$ millimeters wide, and their total length is I.II3 meters. A satisfactory thickness of material is approximately .025 of an inch, as that weight affords the convenience of rolling up the tapes for transportation. To insure ample strength for much

${ }^{1}$ Sampson, Arthur W., "The Quadrat Method as Applied to Investigations in Forestry." Forest Club Annual, Univ. of Nebr., Vol. 6, pp. 7 -10, 19r5. 
longer tapes, it is best to use a somewhat greater width and thickness.

The first perforation of each boundary tape is 5 centimeters from the end of the strap, as shown in the sketch, the diameter being 5 millimeters, a size large enough to permit the insertion of an ordinary surveying pin. The boundary tapes are of such

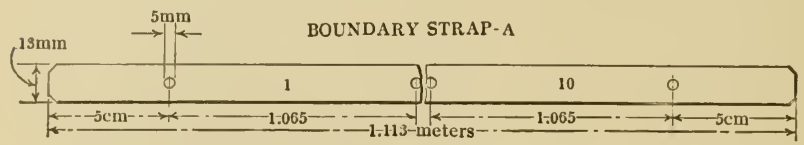

DIVISION STRAP-B

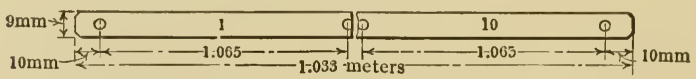

FIG. 128. - BOUNDARY PLOT AND DIVISION TAPES OF SPECIAL DESIGN ADAPTED TO THE MAPPING OF PASTURE VEGETATION.

a length that there is no overlapping of the tape itself upon the meter-square area, a space that is disregarded in mapping when the originally designed tapes are used. Accordingly, the distance between the first and the second perforation is 1.065 decimeters. At each succeeding decimeter a similar perforation appears, marking off a total of exactly io decimeters on each side. To facilitate mapping, each decimeter space carries a number plainly stamped midway between each two decimeter division marks.

The two division straps labeled " B " are 9 millimeters wide and 1.033 meters long. These tapes also are marked off into decimeter lengths, and the intervals are numbered to correspond with the markings on the boundary tapes. Both boundary and division tapes are made of flexible, noncorrosive, nonreflecting steel or other substantial material whose contraction and expansion is slight. In addition to the matter of measuring off an exact unit area, these tapes have an advantage over those ordinarily used in that there is an extension of 5 centimeters from the last perforation to the end of the boundary tape. This 
extension greatly facilitates the accurate placing of the corner stakes, marking the location and exact position of the plot, as the intersection and extension of the tapes indicate precisely where the boundary stakes should be located. The exact lo-

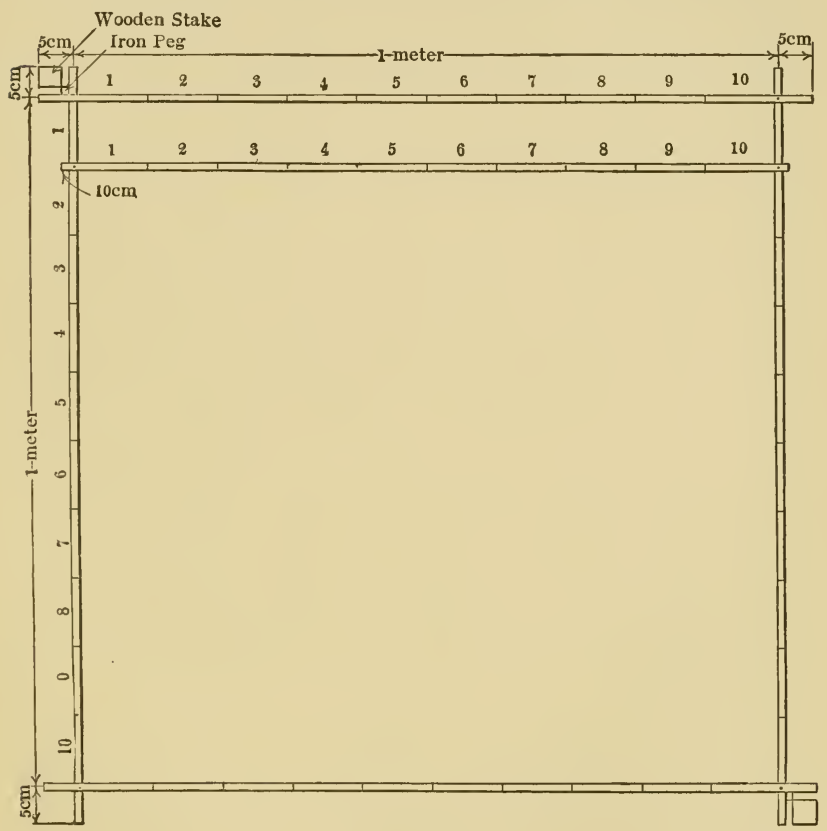

Fig. 129. - A SATISFACTORY AND INEXPENSIVE PLAN OF STAKING PERMANENT SAMPLE PLOTS.

Iron pegs and wooden stakes are used.

cation of the boundary stakes is most important in placing the guide tapes for accurate future mapping.

Nothing should be left undone with respect to the accurate location of permanent sample plots. Obviously wooden stakes are not permanent. Frequently investigators fail to locate small plots, because the wooden boundary stakes have been destroyed 
by fires or ruthless campers, or in some other way. A carefully selected and mapped plot is a good financial investment, and, more important still, has scientific and practical value hardly to be estimated in a pecuniary way. An accurate and inexpensive method of permanent staking of sample plots is shown in Figure I29. The metallic pegs, which are approximately 12 inches long and one inch in diameter, are driven at the corner intersections of the guide tapes, which determine the corner locations. Only two iron pegs, located at diagonally opposite corners, one corner being that from which the mapping was started, are required. They are driven securely into the ground so that only about 2 inches protrudes. As the ends of the protruding iron pegs are blunt, grazing animals will not be injured should they chance to step on them. In order to facilitate ready location of the plot, stakes made from the most durable wood available, about 16 inches long and 2 inches in diameter, are driven close to the metallic pegs. The wooden stakes carry the number of the quadrat, and the label is stamped on the stake located at the corner where the mapping is started.

It is hardly necessary to point out that the location of the quadrat should be shown on as good a topographic or drainage map as is available; in addition, it should be carefully tied in to a section or a quarter-section corner, or to some natural permanent obstacle.

Season and Frequency of Mapping. - On closely utilized range it is important, where possible, to map the vegetation prior to grazing. This is not always convenient, because of the difficulty of identifying species which are neither in flower nor seed. If mapping is done after the range has been grazed, one finds not only that it is difficult to determine the identity of the plants, but that the disturbance by stock has tended to obscure the presence of seedlings and other readily injured and inconspicuous vegetation. Obviously the best time to do the mapping is when the vegetation has reached its maximum luxuriance of growth. On high mountain range August is the best month; in the foothill regions July is best; and in the plains region June is the most desirable. 
The interval between mappings of permanent plots will vary greatly according to ( $\mathrm{I}$ ) the region, elevation, and climatic conditions, (2) the type of vegetation, and (3) the specific object for which the plot was established. In humid and semihumid regions the changes in the cover are rapid and conspicuous, and, in order to procure a record of the more important successional stages, it is best to do the mapping every two years. On desert range or on other lands where the precipitation is low and the invasion and establishment of most of the vegetation is not rapid, mapping at intervals of about five years is sufficient for practical pasture studies. On high mountain range where the precipitation received is from 30 to 40 inches per annum, the mapping should be done at three-year intervals. Where a detailed study of invasion was being conducted the author has sometimes found it necessary to remap as many as three times in a season. In order to obtain the refinement of data ordinarily required, it is not necessary to map more than once in two or three years.

Protection Plots. - Where the water supply is ample the demand for forage, as, for example, on most of the National Forest ranges, is often so great that every little nook is grazed to its maximum capacity each year, and no part of the area is left to develop a maximum cover. In the study of revegetation it is of high importance to know the maximum density of stand under ideal conditions and the species of plants that the soil will support. Without these facts no standard of pasture use is available.

Generally the most valuable pasture lands for cattle and horses are those upon which palatable grasses high in the stage of development have been preserved. The best land for the grazing of sheep, on the other hand, the type which will produce the greatest possible amount of mutton, is that upon which the grass cover has been opened up and the growth of a goodly admixture of grasses, weeds, and even browse has been encouraged. ${ }^{1}$

1 Sampson, Arthur W., "Plant Succession in Relation to Range Management." U. S. Dept. of Agr. Bul. 79I, pp. 20-22, I9I9. 
A reliable method of determining maximum forage production and the composition of such a cover in its highest stages of development is by means of protection plots. For purposes of comparison a plot corresponding with that of the protected area may be established on the open or grazed range. A plot 33 feet on a side, enclosing one-fortieth of an acre, has been found satisfactory. The plot is divided into four equal squares by means of division tapes, the regular sample-plot form as shown in Figure 130 being used. In the upper right-hand corner of each of the four squares is given the density of the vegetation, and, following it, the species occurring on the plot as a whole are recorded and given convenient symbols for charting. The percentages of the respective species which make up the density of the square unit are then recorded, and the palatability of each for cattle and for sheep is noted. The percentage of each species, multiplied by its percentage of palatability for each class of stock, gives the percentage of palatable forage for that species. When the total of the percentage of palatable forage of all species is multiplied by the density of the cover of the unit, the forage-acre factor is derived. In the example given the data are shown only for one of the four units. The forage-acre factor for the entire area is obtained by averaging this factor for the plot as a whole. The vegetation on the unprotected plots is recorded in the same way as in the example given.

Sample-Plot Dimensions. - In field work generally it is convenient, in the establishment both of square and circular plots, and for other purposes, to know the dimension requirements for an acre or a fraction thereof. As a guide for the establishment of sample plots and for general pasture-inspection work the following dimensions for an acre or less are given:

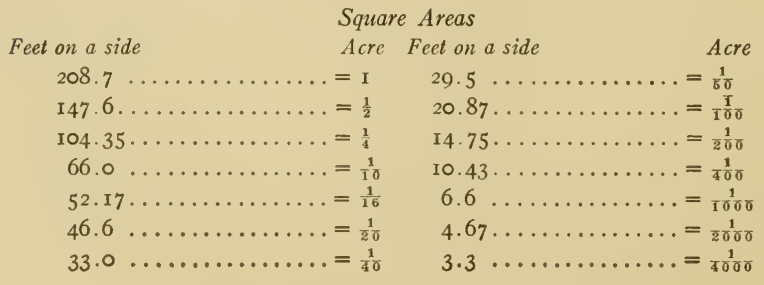


GREAT BASIN EXPERIMENT STATION, EPHRAIM, UTAH Natural Reseeding

Unprotected Plot No 7

Established August 21, 1916

(a)

\section{Legend.}

Symbol Species Symbol Species

A. Agropyron tenerum V-.Vicia Americana

P...Polygonum Douglasii

Al. Achillea lanulosa

Symbol

G.Geranium Richardsonii

S.Stipa minor

L. Leontodon taraxacum

C...Chenopodium album Si.Sophia incisa

Averages for Plot: Density_; Palatability for $C_{6}, S_{3}{ }_{3} ;$ Forage acre Factor for $C_{3}, S_{1}$

Fig. 130. - A 33-FOOT PLOT, DIVIDED INTO FOUR EQUAL PARTS.

The plant cover, following each mapping, is expressed in terms of the "forage-acre factor" for the class or classes of stock grazed. This form of plot is very valuable in the study of natural revegetation. 
Fect radius

I 8

83

59

37

12
Circular Areas

Acre circle

$$
=\mathbf{I}
$$

$=\frac{1}{2}$

$=\frac{1}{4}$

$=\frac{1}{10}$

$=\frac{1}{100}$
Feet exact radius

II $7 \cdot 7$

83.2

58.8

37.2

II 7

Sample plots 33 feet on a side, embracing one-fortieth of an acre, are favored by the writer. If the area is fenced against stock, the fence line should be at least 40 feet on a side in order to prevent animals from snatching vegetation from the plot proper. Woven wire is the best material to use for fencing, as it permits full play of the climatic factors over the plot. Board fences, especially if the boards are placed close together, are the least satisfactory.

\section{QUESTIONS}

1. Why is it important to know the developmental trend of pasture vegetation, and what is the value of sample plots in determining such facts?

2. What kinds of sample plots are used in grazing studies?

3. (a) What is the chart plot, and how is the mapping of such a plot done? (b) Discuss the disadvantages, if any, in the use of the chart plot.

4. What is a pantograph, and how is it used in sample-plot studies?

5. How does the list plot differ from the chart plot, and what are some of the merits of the list plot?

6. Discuss the place of denuded or depopulated plots in natural revegetation.

7. (a) What use is made of (I) the transect, and (2) the bisect in revegetational studies? (b) How is the vegetation in a transect mapped?

8. Describe the design of special sample-plot guide tapes and discuss their nerits.

9. (a) How often should sample plots be remapped under the different conditions? (b) At what time in the season should the mapping be done?

10. (a) What is the value of protection plots on pasture lands? (b) How may the vegetation within protection plots be mapped to show clearly the improvement or decline in the forage cover? 


\section{BIBLIOGRAPHY}

Bates, Carlos G., and Zon, Raphael. Research Methods in the Study of Forest Environment. U. S. Dept. of Agr. Bul. 1059, 1922.

Clements, Frederic E. Plant Indicators: The Relation of Plant Communities to Processes and Practice. Carnegie Institution of Wash., Pub. No. 290, I920.

Research Methods in Ecology. Univ. Pub. Co., Lincoln, Neb., I 905. Hitl, Robert R. Charting Quadrats with a Pantograph. Ecology, Vol. I, No. 4 , 1920 .

Jardine, Jayes T., and Anderson, Mark. Range Management on the National Forests. U. S. Dept. of Agr. Bul. 790, I9r9.

Jardine, James T., and Hurtt, Leon C. Increased Cattle Production on Southwestern Ranges. U. S. Dept. of Agr. Bul. 588, г9г 7.

Mosher, Edna. The Grasses of Illinois. Univ. of Ill. Agr. Exp. Sta. Bul. 205, I9I8.

SAmpson, Arthur W. Climate and Plant Growth in Certain Vegetative Associations. U. S. Dept. of Agr. Bul. 700, r9r8.

Plant Succession in Relation to Range Management. U. S. Dept. of Agr. Bul. 791, 1919.

The Quadrat Method as Applied to Investigations in Forestry. Forest Club Annual, Univ. of Nebr., Vol. 6, I915.

Wooton, E. O. Carrying Capacity of Grazing Ranges in Southern Arizona. U. S. Dept. of Agr. Bul. 367, igr6.

Factors Affecting Range Management in New Mexico. U. S. Dept. of Agr. Bul. 21 I, 1915. 


\section{CHAPTER XIX}

\section{SUGGESTIONS FOR INSTRUCTION IN PASTURE MAN- AGEMENT AND LIVESTOCK PRODUCTION}

Improved methods of handling pasture lands and foraging animals have been somewhat widely adopted by stockmen in this country during recent years. Although the stockmen themselves deserve much credit for this advancement, the leadership in the discovery and application of fundamental principles in this field clearly devolves upon the college-trained investigators of pasture problems. The agriculturalist who succeeds must be trained in all the major lines of rural activities. Agricultural colleges, including forest schools, are making serious efforts to meet the new requirements. It is only recently, however, that some of the colleges have undertaken to offer instruction in pasture and livestock management.

Probably no single agricultural activity exercises so profound and immediate an influence upon our people as that of pasture livestock production. In view of the importance of the subject itself, as well as its relation to all other phases of agriculture, it is surprising that thorough instruction in the management of pasture and foraging animals has not long since been included in the curricula of the leading agricultural colleges and especially of forest schools. Forestry in this country is so closely connected with forage production and livestock handling that it is necessary for the professional forester to understand the handling of stock on woodlands. Failure to include grazing courses in the curricula of agricultural colleges, especially in the West, is no doubt largely accounted for by two conditions - the rapid development in recent years in the science of pasture and livestock handling, and the lack of textbooks on the subject as a whole.

In preparing a syllabus for grazing courses the author has aimed to cover the field for two classes of men - first, the grazing 
experts, and, second, the widely trained agriculturalists and professional foresters. The grazing expert naturally would be expected to cover in detail the entire field of study here outlined, but the general student of agriculture and the forest expert would pursue only such broad grazing subjects as will be mentioned later.

The educational requirements for professional training in pasture and livestock management should be equal to those for other scientific professions. This implies thorough training in auxiliary subjects. The following schedule of auxiliary subjects, including a statement of their application to the management of pasture lands, has been proposed: ${ }^{1}$

Subject

Botany. . . . . . . . . . General management of all forage resources.

Taxonomy......... Recognition of important, objectionable, and unimportant range plants.

Morphology (internal Structure pertinent to the forage value of plants and external)

Physiology.......... Response of growth and functions of plants to annual cropping.

Ecology ........... Relation of invasions and successions to range management.

Plant pathology....... Control of parasitic diseases inimical to forage production.

Zoölogy ............. General conception of animal life, animal relationship, and zoö-dynamics fundamentally essential to the study of entomology, veterinary science, etc.

Bacteriology......... The application of soil flora to soil fertility and crop production.

Entomology........... Classification and life history of insects, especially as related to the genera and species destructive to forage plants.

Chemistry........... Constituents of plants and animals; comparative nutritive qualities of forage plants and concentrates; soil-fertility requirements.

Geology (including soils)... Relation of soils to intensity of grazing, revegetation, erosion, etc.

1 Sampson, Arthur W., "Suggestions for Instruction in Range Management." Jour. of Forestry, Vol. I7, No. 5, pp. 526-528, May, I919. 
Animal husbandry...... Comparative value of feeds, computing rations, and suitability of the different breeds of livestock to the various conditions.

Genetics............. Improvement in animals and plants through the application and control of the laws of heredity.

Veterinary science........ Control of diseases of domestic (range) stock; surgery in connection with livestock production.

Civil engineering........ Fundamentals of surveying, map-making, and typing as related to range use and management.

Meteorology ........... Climatic phenomena in relation to crop production; climatic forecasts and climatic cycles.

Botany probably has the widest possibilities of application. This subject should include a study of the five subdivisions indicated, and these should be preceded by at least one year's study of general (college) botany. A knowledge of botany is sure to have a telling effect ultimately on forage production and hence upon the livestock industry, for the further development and stabilization of the industry is absolutely dependent upon an adequate and permanent supply of choice forage. Recognition of the identity of range species, their internal or external norphology, the laws that control the functions of growth and reproduction, and the ecological requirements of the different forage types is sure to affect the future production of pasture lands. Any plan of range management which aims to improve the carrying capacity of pastures must be based upon the fundamentals of botanical science.

Following the general instruction in zoölogy, a special course should be given in the history of the development of domestic livestock. Such a course should aim also to cover in detail the history of development, relationships, distribution, and life history of the more common predatory and game animals.

The general grounding in entomology should be followed by a special course in applied entomology, and should consider the identity and life history of the genera and species of insects that are commonly detrimental to forage and beef production. Special consideration should be given to such troublesome insects, for instance, as the botfly and to ticks that prey on stock. 
Following the general course in chemistry, which should include qualitative and quantitative analytical and organic work, a special course should be given in the determination of the chemical constituents of feeds and forage crops. While it should not be the aim to make of the student a full-fledged chemist, a course covering, let us say, one credit unit through a semester would suffice to familiarize him with the methods employed in making analyses of feeds and the preparation of forage samples for analysis.

The course in animal husbandry - genetics and veterinary science - should aim to offer special work in the application of principles to improve livestock production. In animal husbandry, for instance, consideration should be given to the relative merits of the different breeds of livestock as related to climate, the temperament of different breeds of stock as affecting their relative adaptability on the range, maintenance-ration requirements of animals, and the suitability of different kinds of concentrate feeds in the different localities, etc. The applied work in genetics should consider especially the question of breeding as related to the creation of improved strains of livestock, such, for instance, as cross-breeding in the development of the mutton type of sheep, the wool type, and the combined mutton and wool type. Likewise the study of veterinary science should include a consideration of the life history and control of diseases common to livestock on the range.

Obviously a thoroughgoing course in civil engineering, including mechanical drawing, is of paramount importance to the range technician.

The meteorological work should consider the vegetative types and the chief crop-producing areas of the United States, followed by a study of the normal temperatures and of the precipitation of these areas, taking into account the barriers and the general trend of the high and low pressure phenomena and their relation to precipitation. Consideration should be given to the study of weather forecasts and to climatic cycles, so far as they influence forage and livestock production, and to the recording and assembling of climatic data, especially with reference to deter- 
mining the relation of climatic factors to plant growth and livestock production. It would probably not be necessary to offer a special course in meteorology, as this work could be given either in connection with the study of plant ecology or some related subject.

\section{OUTLINE OF GRAZING COURSE}

Condensed Outline Suggested for Practical and Professional Instruction in Pasture and Livestock Management

\section{Introductory.}

I. Range and pasture management defined; its object and scope.

2. Need for improved handling of pasture lands and pasture stock.

3. Demand for trained range and pasture technicians.

II. Range History and Livestock Economics.

I. The livestock industry in relation to agriculture and forestry.

$A$. The farm: Economical use of roughages and other feeds; maintenance of soil fertility; diversified farming vs. specialized agriculture.

$B$. The ranch (range).

C. Public domain.

$D$. Woodland pasture.

$a$. National Forests.

$b$. Privately owned woodlots.

c. Unappropriated lands.

2. Meat production and consumption.

$A$. Production of the world.

$B$. Production in the United States.

a. Eastern and Western States.

$b$. The twelve chief range States.

c. Farms.

$d$. National Forests.

C. Meat consumption by different nations. 
$D$. Prospective production, with special reference to the future of the range industry in this country.

3. Classification of pasture lands in the United States.

A. Area.

B. Natural divisions and characteristics of major geographical units.

a. East.

$b$. South.

c. Middle West.

$d$. West.

(I) Great Plains.

(2) Rocky Mountain region.

(3) Great Basin.

(4) Southwest.

(5) Pacific slope.

(6) Northwest.

4. Development of the range industry.

$A$. Buffaloes and their impress on the range.

$B$. Wild horses.

C. Other native herbivorous animals.

$D$. Advent of domestic foraging animals.

$a$. Type and breed; from whence introduced.

$E$. Factors affecting the stocking.

a. Climate; accessibility of the lands to grazing; character of forage; water, etc.

$F$. The lands occupied by different classes of stock.

$G$. Center of livestock production at various periods.

5. Overgrazing and results.

$A$. When and where most serious.

$B$. Results.

a. Sharp decline in forage.

$b$. Decreased animal production and financial failures.

(I) Competition for range.

(A) Range wars.

$c$. Adoption of land grants and leasing systems.

d. Creation of National Forests. 
6. National Forest, State, and private grazing lands.

A. National Forests.

a. Conditions which led to their creation.

$b$. Present area and character of land.

c. Number and classes of livestock grazed.

d. Policy of administration.

(I) Early policy.

(2) Present policy.

(A) Grazing privilege vs. property rights.

(B) The grazing permit.

(3) Policy in other countries.

$e$. Function and results of the Forest Service in regulating grazing.

$f$. Results of regulated grazing.

(I) Improvement in grazing capacity, I905-I922.

(2) Administration responsible for improvement.

$B$. State and private lands.

$a$. Policy leading to acquisition of land grants.

b. Texas leasing system.

c. Wyoming leasing system.

d. Northern Pacific Railroad leases.

e. Other leasing systems.

$f$. Results of leasing systems.

g. Disposition of land-grant areas.

III. Native Pasture Plants.

I. Forage plants.

A. Forage-growth requirements.

a. Characteristics of a good forage plant.

(I) Growth habits and growth requirements.

$b$. Life-history studies and their significance in forage increment. 
(I) Regeneration.

(A) Seed (seed habits).

(B) Vegetative (asexual).

c. Feeding value.

(I) Character of herbage, yield, palatability, nutritiousness, and accessibility.

$B$. Forage preferences of different classes of livestock.

a. Cattle, horses, sheep, and goats.

2. Native grasses.

$A$. Uses.

$B$. Distinctions between true grasses and grasslike plants.

a. Carex, Juncus, etc.

C. Grass family.

a. Importance in forage production.

b. Tribes embracing most important forage species.

D. Wheat and barley grass tribe (Hordeae).

a. Wheatgrasses (Agropyron).

(I) Description and distribution (general).

(2) Economic value (general).

(3) Important species (individually discussed.)

(A) Description and distribution.

(B) Growth requirements.

(C) Life history.

(D) Forage value.

b. Ryegrasses (Elymus).

(Same detail for the following genera and important species which they embrace as under (3) above).

c. Barleygrasses (Hordeum). 
E. Fescue, bluegrass, and bromegrass tribe (Festuceae).

a. Fescues (Festuca).

b. Bluegrasses (Poa).

c. Bromegrasses (Bromus).

d. Melicgrasses (Melica).

e. Lovegrasses (Eragrostis).

f. Mannagrasses (Panicularia).

g. Saltgrasses (Distichlis).

$F$. Oatgrass tribe (Aveneae).

a. Oatgrasses (Avena).

b. Hairgrasses (Aira).

c. Junegrasses (Koeleria).

d. Trisetums (Trisetum).

G. Grama-buffalo tribe (Chlorideae).

a. Gramagrasses (Bouteloua).

b. Buffalograsses (Bulbilis).

c. Bermudagrasses (Capriola).

$H$. Redtop-timothy tribe (Agrostideae).

a. Redtops (Agrostis).

b. Reedgrasses (Calamagrostis).

c. Muhlenbergias (Muhlenbergia).

d. Timothies (Phleum).

e. Dropseedgrasses (Sporobolus).

$f$. Needlegrasses (Stipa).

g. Mountain rice (Oryzopsis).

$h$. Sweet reedgrasses (Cinna).

$i$. The three-awns (Aristida).

$j$. Other genera, possibly of local importance.

I. Comparative forage-value classification of important species of native grasses.

$J$. Ecological classification of important native forage grasses as applied to range management.

3. Grasslike plants.

A. Sedges (Carex).

B. Rushes (Juncus).

$C$. Others. 
4. Broad-leaved pasture plants.

A. Classification.

B. Pasture value (general).

C. Most important families.

D. Plants of the pulse family (Fabaceae). ${ }^{1}$

a. Peavines (Lathyrus).

(I) Important species (individually discussed).

(A) Description and distribution (distribution maps).

(B) Economic value.

(C) Life history.

(D) Forage value.

(2) Other important genera and species.

E. Parsley family (Umbelliferae).

(Same detail for important forage species as under (I) immediately above.)

$F$. Sunflower family (Asteraceae).

$G$. Borage family (Boraginaceae).

$H$. Honeysuckle family (Caprifoliaceae).

I. Buttercup family (Ranunculaceae).

$J$. Rose family (Rosaceae).

$K$. Willow family (Salicaceae).

L. Buckthorn family (Rhamnaceae).

M. Figwort family (Scrophulariaceae).

$N$. Huckleberry family (Vacciniaceae).

$O$. Valerian family (Valerianaceae).

$P$. Goosefoot family (Chenopodiaceae).

Q. Beech family (Fagaceae).

$R$. Geranium family (Geraniaicae).

$S$. Gooseberry family (Grossulariaceae).

$T$. Mallow family (Malvaceae).

$U$. Bunchflower family (Melanthaceae).

$V$. Evening primrose family (Onagraceae).

$W$. Apple family (Pomaceae).

Only those families are here given which embrace species that contribute appreciably to the native forage crop. 
$X$. Comparative forage-value classification of important species of broad-leaved plants.

$Y$. Ecological classification of important broadleaved forage species pertinent to range management.

5. Objectionable plants.

A. Poisonous species.

a. Important families containing most poisonous species.

$b$. Conditions under which serious poisoning occurs.

c. General directions for controlling losses from poisonous plants.

(I) Handling stock, proper class of stock, improved range husbandry, etc.

(2) Eradication of poisonous species.

d. Principal poisonous species.

(I) Discussion of important species embraced in the most troublesome genera, viz., Delphinium, Zygadenus, Cicuta, Lupinus, Astragalus, and Oxytropis.

(A) Distribution and habitat.

(B) Losses of stock and animals poisoned.

(C) Amount required to cause death.

(a) Leafage.

(b) Seed.

(c) Root.

(D) Symptoms, remedies, and control.

$\boldsymbol{e}$. Species of secondary or local importance.

$B$. Mechanically injurious plants.

a. Extent and character of injuries.

$b$. Season of greatest injury, and localities where losses are heaviest. 
c. Most troublesome species.

$d$. Remedial and preventive measures.

6. Collection and preservation of plant specimens.

$A$. What plants to collect.

a. Forage plants.

$b$. Noxious weeds.

c. Poisonous plants.

$B$. How to collect, dry, mount, label, and file specimens.

a. Equipment.

b. Parts to collect.

c. Field notes.

$d$. Drying, mounting, labeling, and filing specimens.

e. Herbarium cases.

IV. Management of Range and Pasture.

I. Importance of proper selection of stock for different classes of range.

2. Suitability of range to different classes of stock.

$A$. Character of forage, topography, water, animal pests, etc.

$B$. Protection of timber and watersheds.

3. Range readiness, grazing period, and grazing capacity.

$A$. Range readiness and grazing periods.

$a$. Premature grazing and results.

$b$. Forage conditions when stock is admitted.

c. Season of grazing.

$B$. Grazing capacity.

a. Grazing capacity defined.

$b$. Factors affecting grazing capacity.

C. Forage (acreage) requirements of stock.

a. Cattle, sheep, goats, and horses.

$b$. Cattle and sheep combined (common use).

c. Requirements according to methods of handling. 
$D$. How to determine grazing capacity.

$a$. Indirect method.

$b$. Direct method.

(I) Estimate of " animal-days" feed.

(A) Grazing reconnaissance.

(B) Actual grazing-capacity tests.

4. Revegetation.

A. The range.

a. Cost of overgrazing.

$b$. Artificial revegetation (cultivated forage plants).

(I) Growth conditions over western native range lands as affecting artificial reseeding.

(2) Results of plant introduction on arid lands.

(A) Cultivated grasses.

(B) Other plants.

(3) Plant introduction on mountain lands in different grazing regions.

(A) Success with various species.

(B) Cultural implements; season of seeding; elevational limitations; causes of failure, etc.

(C) Artificial reseeding to native forage plants.

(a) Collecting seed and cost; methods of sowing; results.

c. Natural revegetation.

(I) Requirements of forage growth.

(A) Life-history studies.

(B) Establishment of seedling plants. 
(2) Grazing systems and forage production.

(A) Yearlong grazing.

(B) Yearlong protection.

(C) Deferred grazing (defined and illustrated).

(a) Palatability of mature forage.

(b) Advantages over other systems.

$B$. The farm pasture.

(c) Practical application.

$a$. Factors which determine the value of a pasture.

(I) Density, palatability, permanency of cover, and digestibility of the forage.

(2) Distance animals must travel for food and water.

(3) Earliness and period of growth of forage.

(4) Distance from market and farm or ranch.

$b$. Kinds of pasture.

c. Why pastures "run out."

d. Pasture improvement.

(I) Management of turfed (sod) pasture lands.

(A) Bluegrass region, etc.

(a) Alternate vs. continuous grazing; results of cultural treatment; effects of light and heavy grazing.

(2) Management of nonsod pasture lands.

(A) Number of stock to graze.

(B) Results of deferred grazing. 
(3) Fertilizers.

(A) Kinds and amounts to apply.

(4) Control of weeds.

C. Recognition and correction of a declining forage yield.

a. Indicators of destructive grazing.

(1) Old (empirical) method.

(A) Serious destruction in forage cover.

(B) Poor condition of stock grazed.

(C) Erosion and floods.

(2) New (scientific) method.

(A) Slight changes in forage cover shown by indicator plants.

(3) Conspicuous signs of overgrazing.

(A) Erosion, barrenness, and prominent stock trails; dead shoots of palatable woody plants; damage to timber reproduction; presence of poisonous plants, etc.

(4) Slight departures in grazing capacity; increase in unpalatable plants.

$b$. Type stages of plants indicating range conditions.

(I) Climax herbaceous stage.

(A) Characteristic species.

(a) Growth habits.

(b) Ecological characteristics.

(c) Forage value.

(2) Mixed grass and weed stage.

(A) Discussion same as $(A)$ immediately above.

(3) Second or late weed stage. 
(4) First or early weed stage.

(5) Denudation.

$c$. Revegetation of driveways and bed grounds.

d. How to recognize reliable pasture-indicator plants.

e. Practical use of indicator plants.

5. Stock-water development.

$A$. Need for water.

a. Water requirement of stock.

$b$. Distance different classes of stock should travel for water.

$B$. Natural watering places and their improvement.

$C$. Artificial watering places and their construction.

6. Control of erosion.

A. Damage.

$B$. Kinds.

C. Factors influencing erosion.

a. Uncontrollable factors - topography; soil type; climatic factors.

b. Controllable factor - vegetative cover.

$D$. Erosion in relation to plant growth and revegetation.

a. Comparative plant foods (salts) and forage production in eroded and noneroded soils.

$b$. Revegetation of eroded lands.

(I) Time required.

(2) Species suited and their forage value.

$E$. Solution of the erosion pasture problem.

a. Control grazing.

$b$. Application of deferred and rotation grazing.

$c$. Terracing and planting (in extreme cases only).

7. Judicious grazing on timberlands.

$A$. History of faulty handling of stock on timber reproduction. 
$B$. Investigations on National Forests.

a. Northwest (northern California, Oregon, and Washington).

(I) Sugar pine, Douglas fir, western yellow pine, incense cedar, etc.

(A) Extent of injury by different classes of stock.

(B) Comparative seasonal injury.

(C) Injury in relation to intensity of grazing and character and abundance of forage.

b. Idaho.

(I) Western yellow pine.

$(A)$ Same as under $(A),(B),(C)$ above.

c. Arizona and New Mexico.

(I) Western yellow pine.

d. Utah.

(I) Aspen.

C. Investigations on farm woodlands.

a. Broadleaves.

b. Conifers.

D. Application of investigations.

a. General.

(I) Overgrazing and bad handling of stock, improper salting, etc.

(2) Moderate, regulated grazing.

(3) Effect of topography, season of grazing, and type and abundance of forage.

b. Regional.

(I) Arid Southwest.

(2) Northwest.

(3) Great Basin.

8. Burning of pasture lands in relation to forage production.

A. History of burning. 
B. Present-day burning.

C. Effect of burning on forage production.

a. Grasslands.

$b$. Brushlands.

c. Woodlands.

$D$. Application of burning tests to forage yield.

a. Relation of decomposed vegetation to soil fertility.

$b$. Relation of burning to plant succession.

(I) Grasslands.

(2) Brushlands.

(3) Timbered lands.

c. Use of goats in clearing brushlands.

9. Destructive pasture rodents and their effective control.

$A$. Value of forage destroyed annually.

$B$. Most destructive species.

a. Prairie dog.

(I) Food habits.

(A) Plants consumed.

(2) Methods of control.

b. Jack rabbits.

(I) Discussion as indicated under (I) and (2) above.

c. Ground squirrels.

d. Gophers.

e. Others.

Io. Grazing reconnaissance.

A. Object.

$B$. Chief problems which reconnaissance aims to clarify.

C. History and development.

$D$. Data and facts obtained.

E. Methods of obtaining data.

$F$. Grazing and timber reconnaissance compared.

$G$. Application to practical range management. a. Direct. 
(I) More efficient use of forage; methods of handling stock; building up range.

$b$. Indirect.

(I) Topographic map, type map, etc.

$H$. Estimating grazing capacity.

$a$. The forage acre.

(I) How derived and basis for estimating.

(2) Application to grazing capacity.

(3) Variation in grazing value.

(4) Requirements for different classes of stock.

$b$. Grazing capacity of range and farm pasture.

(I) National Forests.

(2) Public domain.

(3) Farm pastures.

I I. Inspection of range and farm pasture.

$A$. Factors to record (preferably on map).

$a$. Class or classes of stock grazed; readiness of grazing and grazing intensity; condition of driveways; location of salting places, water, etc.

$B$. Class of stock best suited.

C. Uniformity of grazing.

$D$. Grazing capacity of different types.

E. Extent of areas grazed (I) too early and (2) not early enough.

$F$. Amount of forage reserved for late autumn or spring cropping.

$G$. Proper handling of stock.

$H$. Condition of tree reproduction and watersheds.

$I$. Areas in need of reseeding and causes of depletion.

$J$. Condition of fences, corrals, and other such improvements.

$K$. Game animals.

$a$. Kind, number, reproduction.

b. Where grazed. 
V. Management of Range and Pasture Livestock.

I. Sheep.

A. On range.

a. Establishing the band.

$b$. Equipment (buildings and corrals).

c. Control.

(I) Summer range (National Forest).

(A) Establishment of range sheep units.

(B) Reaching allotment with minimum damage to range and band.

(C) Avoidance of trespass.

(D) Uniform use of range.

(E) Herding.

(a) Bedding-out system.

(b) Established-camp system.

(c) Gathering the sheep for the night.

(d) Selecting the bed ground.

(F) Watering.

(a) Frequency.

I. Season.

2. Character of feed.

(b) Time of day.

(c) Shading up.

(G) Salting.

(a) Kind, amount, how and when fed.

(H) Timely use of forage.

(I) Losses.

(a) Predatory animals.

(b) Poisonous plants.

(c) Disease.

(d) Other causes. 
(2) Winter range (public domain and private lands).

(A) Grazing period.

(B) Location of camps.

(C) Equipment and supplies.

(D) Forage types grazed and conservation of feed during critical periods.

(E) Emergency feed (concentrates) during stormy weather and in adverse seasons.

(F) Losses and their control.

$(G)$ Winter feeding.

(a) Kind and amount of feed.

(b) When and how fed.

(c) Losses.

(3) Breeding, lambing, and marketing.

(A) Breeding.

(a) Season and length of period.

(b) Condition of breeding band.

(c) Number of rams to ewes.

(B) Lambing.

(a) In sheds and tents.

(b) On open range.

(c) Percentage of offspring.

(C) Marking and castrating.

(D) Shearing.

(E) Dipping.

(F) Branding.

$(G)$ Marketing.

$d$. The wool clip.

(I) Wool. 
(A) Production in the United States.

(B) As an article of commerce.

(C) Amount in cloth.

(D) Substitutes.

(E) Structure and properties.

(F) Factors determining its value.

(G) Classes.

(II) Grades.

(2) Shearing.

(A) Methods.

(B) Season.

(C) Tying fleece.

(D) Weight of fleece.

(3) How the producer may increase the profits.

(A) Better handling.

(B) Grading and sorting.

(C) Skirting.

(D) Hard twine for tying fleece.

$e$. Common diseases on range and their control. (Preferably to be offered in veterinaryscience department.)

(I) Principal diseases of sheep.

(A) Important diseases.

(a) Extent of each disease.

(b) Losses.

(c) Nature and symptoms.

(d) How spread.

(e) Treatment and control.

(2) Diseases of secondary importance.

(3) Dipping.

(A) Kinds of dips.

(B) Equipment.

B. On farm.

a. Selecting and establishing the flock.

(I) Size. 
(2) Age and thrift.

(3) Breed and quality.

$b$. Buildings and equipment.

c. Conditioning ewes for mating.

d. Preparing ram for breeding season.

$e$. Number of rams to ewes.

$f$. Breeding ewe lambs.

g. Care of ewes during pregnancy.

$h$. Time and length of breeding season.

$i$. Feed of breeding flock.

j. Dipping.

$k$. Lambing time.

$l$. Care of ewes and lambs.

$m$. The ewes' feed.

$n$. Salt and salting.

$\boldsymbol{o}$. Disorders of udder.

p. Caring for orphan lambs.

$q$. Care of weak lambs.

$r$. Docking and castrating.

s. Marketing the lambs.

$t$. Weaning stocker lambs.

$u$. Handling in hot weather.

v. Shearing and marketing wool (brief).

w. Future of farm flock.

2. Cattle (outline comparable to that for sheep).

3. Goats (outline comparable to that for sheep).

4. Cost of livestock production.

A. Cattle.

a. Eastern States.

$b$. Southern States.

c. Middle Western States.

$d$. Western range States.

B. Sheep.

a. Same detail as in " $a$ " to " $d$ " above.

C. Goats. 
5. Predatory animals and their control.

$A$. Livestock losses.

$B$. Principal destructive animals.

a. Coyote.

(I) General habits.

(2) Foods.

(3) Methods of control.

$b$. Bear.

(I) Same detail as under " $a$ " above.

c. Wolf.

$d$. Wild cat.

e. Mountain lion.

$f$. Sheep-killing dog.

C. Relative destructiveness.

$D$. Methods of control.

VI. Some Research Phases of Range, Pasture, and Foraging Animal Problems.

I. Vegetation.

$A$. Forage preferences of different classes of stock and factors which tend to disturb the forage balance.

a. Forage value.

(I) Individual species.

(A) Chemical analysis.

(B) Actual digestion tests.

$a$. Cattle, horses, sheep, and goats.

(2) Associated or mixed species (major associations).

(A) Same as $(A)$ above.

(B) Same as (B) above.

$b$. Disturbing factors.

(I) Extent of croppang which the various species will withstand.

(A) Early spring. 
(B) Throughout season.

(C) Aftermath (late autumn).

(2) Climatic conditions as affecting forage yield.

B. Creation of new varieties of forage plants.

a. Object: To increase yield, palatability, and reproductive qualities by cross-breeding and selection.

b. Hybridization.

(I) Best related cultivated and native species (crossed).

(2) Best native species.

c. Selection.

d. Grazing tests to determine practical values.

(I) Palatability.

(2) Reproduction under use.

(3) Longevity.

$C$. Causes, trend, and rate of plant succession on range.

a. Object: Recognition of early stages of overgrazing in different localities and time required to revegetate lands in various stages of depletion.

$b$. Factors influencing succession.

(I) Climate.

(2) Soil.

(A) Moisture content and waterholding capacity.

(B) Humus.

(C) Soluble salts.

(D) Micro-organisms, notably nitrifying species.

(3) Vegetational transformations due to grazing.

(A) Successional stages.

(a) Rate and composition. 
(b) Cell-sap density of important species.

(c) Water requirement.

(d) Morphological characteristics of dominant species.

D. Rate of succession (revegetation) of the various ecological plant stages.

a. Plots.

(I) Protected (fenced).

(A) The important forage types that have been grazed with varying intensity.

(2) Unprotected (grazed).

$(A)$ Same as under $(A)$ above.

$b$. Other sample plots.

(I) Denuded.

(2) Undenuded.

E. Period study (beginning and closing of grazing season).

$a$. When range is ready for grazing.

$b$. Division of range into natural-type units.

(I) Yellow pine-oak (Transition zone).

(2) Fir-aspen (Canadian zone).

(3) Spruce-fir (Hudsonian zone).

c. Methods of study.

(I) Phenological observations of important forage species and indicator plants.

(A) On different slopes and exposures for each important type.

(a) Vegetative, flower, and fruit development.

$d$. When grazing should close.

(I) Growth arrested; heavy frosts.

(2) Fruit cast. 
(3) Herbage largely consumed; mostly tough and unpalatable.

(4) Weather inclement; snow.

(5) Other factors.

$F$. Variation in forage yield (seasonal and possibly by climatic cycles).

$a$. Comparative annual yield of specially selected "type" plots in different zones.

$b$. Causes of seasonal variations.

(I) Climate (departures from normal, with data as to frequency).

(2) Utilization.

(A) Earliness of grazing.

(B) Frequency and closeness of the croppings.

c. Methods of study.

(I) "Vigor" plots (artificial harvestings).

(2) Pasture plots (actual grazing tests).

G. Revegetation.

a. Natural reseeding to increase and maintain forage yield.

(I) Life-history studies of forage species.

(2) Deferred and rotation grazing.

b. Artificial reseeding.

(I) Cultivated species.

(2) Native species.

(A) Seed-strip method.

2. Animals.

A. Livestock.

$a$. Grazing-capacity tests (to determine proper stocking).

(I) On different types.

(A) Grass, mixed herbage, browse (composite and composed of a single species).

(2) Animals for study. 
(A) Cattle.

(a) Forage - acre requirements of different types.

(b) Gains on different types, in different seasons, etc.

(c) Marketability.

(B) Sheep, goats, and horses. (Same as under ( $A$ ) above.)

$b$. More and better stock.

(I) Maximum percentage of offspring.

(A) Condition of flesh of breeding herd.

(B) Best age for reproduction.

(C) Definite breeding season.

(D) Strong, ample, and well-bred sires.

(E) Breeding pastures.

(F) Care during gestation period.

$(G)$ Care of offspring.

(2) Improving the grade of stock.

(A) Mating superior sires with best dams.

(B) Culling out inferior animals.

(C) Cross-breeding to improve vigor, size, and fecundity.

(3) Prevention of losses.

(A) Conserving feed for use at different (critical) seasons.

(B) Supplemental feeding (silage, hay, concentrates, etc.).

(C) Control of poisonous-plant pests.

(a) Discovery of toxic species.

(b) Management studies designed to prevent losses. 
$B$. Game animals.

a. Forage requirements.

(I) Grazing capacity.

$b$. Suitable forage types.

(I) Summer.

(2) Winter.

$c$. Forage species relished.

d. Reproduction of different species.

(I) Mating season.

(2) Period of gestation.

(3) Season when offspring is born.

(4) Period required for development.

$e$. Hunting regulations devised to foster reproduction based upon field studies.

C. Winter-range husbandry.

a. Object: To develop improved methods of handling stock on winter range.

(I) Sheep.

(A) Individuals that will withstand rigors of winter with minimum of supplemental feeding.

(a) Condition.

(b) Breed.

(c) Number in band.

(B) Forage types best suited for winter use.

(C) Methods of handling.

(a) Herding.

(b) Losses.

(c) Protection against injury.

I. Poisonous plants, predatory animals, starvation, storms, etc. 
(D) Supplemental feed.

(a) Concentrates.

r. Kinds, amount, how and when fed.

(b) Roughages.

I. Silage, hay, other.

(2) Cattle. (Same as under ( $\mathrm{r}$ ) above.)

(3) Goats.

(4) Horses.

D. Animals of prey.

a. Food habits.

(I) Plants.

(2) Animals.

(A) Domestic.

(B) Rodents and other.

$b$. Life history of different species pertinent to control work.

(I) Mating season.

(2) Period of gestation.

(3) Season when offspring is born.

(4) Period required for full development.

c. Protection against livestock losses.

(r) Most effective protection of pasture stock.

(2) Effective control of predatory animals.

(A) Trapping, hunting, poisoning.

$d$. Improved methods of control based upon life-history studies.

$E$. Range-destroying rodents.

a. Food habits.

$b$. Life-history studies of important species.

(I) (Same as under " $b$ " above).

c. Control.

(I) Effective poisons in different season's.

(2) Other methods of control.

General Instruction in Grazing. - In view of the broad training essential for the professionally trained grazing expert, it would not be possible for students of general agriculture and 
those preparing for professional forestry to cover the field of grazing instruction as proposed in the preceding pages. Only the more important subjects should be pursued by students who desire only a good foundation in this work. The author believes that general rather than detailed instruction in the more important phases of the subject of grazing grouped under the following, should be given: III. Native pasture plants; IV. Management of range and pasture; and $\mathrm{V}$. Management of range and pasture livestock. •

The advice cannot be overemphasized that those who specialize in grazing, especially if they are preparing to enter the United States Forest Service, should avail themselves of the opportunity of taking certain forestry courses. Probably the most important of these subjects are silvics, silviculture, forest utilization, and forest protection.

Schools for Professional Training in Grazing. - While the possibilities of the application of pasture and range management are very great everywhere in this country, it would appear that only a few schools should undertake, during the next few years at least, the development of grazing experts. On the other hand, it would seem that all agricultural colleges should give good general training in the subject of pasture and livestock management. Possibly, full-fledged departments of range management established in two or three of our leading schools would suffice for some years to come. General instruction in grazing might well be coördinated with the departments of botany, agronomy, or, indeed, animal husbandry. For professional training in grazing the department may well be organized in the school of forestry, as it is highly important that the grazing expert become proficient in the art and science of forestry.

Only a part of the grazing outline here given has been developed in the present volume. The forthcoming volumes, "Native American Forage Plants" and "Livestock Husbandry on Range and Pasture," published also by John Wiley \& Sons, Inc., aim to cover in more or less detail the rest of the outline as here given. 


\section{BIBLIOGRAPHY}

Bates, Carlos G., and Zon, Raphael. Research Methods in the Study of Forest Environment. U. S. Dept. of Agr. Bul. ro59, I022.

Clements, Frederic E. Plant Indicators: The Relation of Plant Com. munities to Processes and Practice. Carnegie Institution of Wash., Pub. No. 290, I920.

Plant Succession: An Analysis of the Development of Vegetation. Carnegie Institution of Wash., Pub. No. 242, I9r6.

Research Methods in Ecology. Univ. Pub. Co., Lincoln, Nebr., I905. Jardine, James T., and Anderson, Mark. Range Management on the National Forests. U. S. Dept. of Agr. Bul. 790, I9I9.

REPORT OF THE COMmitee on Standardization of Instruction in Forestry of the Conference of Forest Schools. Forest Quarterly, Vol. ro, No. 3, I9I 2.

Sampson, Arthur IV. Plant Succession in Relation to Range Management. U. S. Dept. of Agr. Bul. 79I, I9I9.

Suggestions for Instruction in Range Management. Jour. of Forestry, Vol. 17, No. 5, 1919. 


\section{INDEX}

A

Acacia, belonging to legumes, 151 .

Accessibility, of range to stock, factor in grazing reconnaissance, $3 \mathrm{II}$; of grazing lands, for study in grazing course, 365 .

Achillea, in weed type, (fig.) 314.

Achillea lamulosa, in second or late weed stage, II3; habit of growth, (fig.) II ; on eroded and noneroded pasture, (fig.) 118 ; on range grazed annually, (fig.) r22; on protected plot, (fig.) 123; indicator plant, 1 29, 130; on chart plot, (fig.) 342 .

Aconite, growth after burning, 226; description and habitat, 279, (fig.) 280; poisonous to stock, 279 .

Aconitum, growth after burning brushland, 226.

Aconitum Columbianum, description and habitat, 279, (fig.) 280; poisonous to stock, 279.

Acreage, required for cattle, 33I; for sheep, 333; requirements of stock, for study in grazing course, $37 \mathrm{I}$.

Adaptability of range unit to classes of stock, 3II.

Agaric, fly, poisonous to stock, 283; habitat and description, 283, (fig.) 284.

Agastache urticifolia, indicator plant, I29.

Agriculture, dependence on use of ranges in National Forests, 26; relation of pasture livestock production to, 360; relation to livestock industry, for study in grazing course, 364 .

Agriculture, Secretary of, letter to Forester, 17.

Agronomy, department of, to include general training in grazing, 390.

Agropyron, highest herbaceous cover, 108; host plant, 281; for study in grazing course, 367 .

Agropyron dasystachyum, height and root system, (fig.) rog; indicator plant, 130; open grassland composed of, (fig.) 313 .

Agropyron Scribneri, indicator plant, I 29.
Agropyron spicatum, height and root system, (fig.) rog; indicator plant, 130.

Agropyron tenerum, in reseeding tests, 43; on eroded and on noneroded pasture, (fig.) I18; on range grazed annually, (fig.) 122; on protected plot, (fig.) 123; on protected plot and on unprotected range, 125 ; indicator plant, 130 .

Agropyron violaceum, collecting seed of, 57 ; effect of cropping, (figs.) 65 ; indicator plant, $\mathrm{r}_{3} \mathrm{O}$.

Agrostideae, for study in grazing course, 368.

Agrostis alba, name for redtop, 139 .

Agrostis palustris, habit of growth, I 39 . Aira, for study in grazing course, 368 .

Aira caespitosa, in meadow type, 312.

Alamo Forest, goat grazing on, 2 10.

Alfalfa, in reseeding tests, 4r, 44; amount to sow and cost, 53; introduced from Old World, 55; cultivated pasture plant, I5I; habitat, I 57; seeding, I57; forage value, ${ }_{57}$.

Alfilaria, winter annual of Southwest, 8 ; in reseeding tests, 40,44 ; moisture requirements, 54 ; semi-domesticated, 55 ; on winter ranges, 80.

Alidade, telescopic, used in field work, 320 ; open-sight, 320 .

Alkaligrass, name for death camas, $26 r$.

Allium, annual plant, 324 .

Alpine fir type of National Forest range, sheep grazing on, (fig.) 19.

Alsine species, on chart plot, (fig.) 342 .

Amanita, deadly, habitat, 283 ; description, 284, (fig.) 285 .

Amanita, fly, poisonous to stock, 283; habitat and description, 283 , (fig.) 284.

Amanita muscaria, poisonous to stock, 283; habitat and description, 283 , (fig.) 284 .

Amanita phalloides, habitat, 283; description, 284 , (fig.) 285 .

A melanchier, sign of overgrazing, ro6; effect of fire on, 226 .

Anderson, Mark, on acreage required, for cattle, 33I; for sheep, 333 .

Andropogon species, in reseeding tests, 43; withstand fire, 237. 
Androsace, on protected plot and on unprotected range, 125; indicator plant, I 28; growth after burning brushland, 226.

Androsace diffusa, indicator plant, I28; on chart plot, (fig.) 342 .

Animals, "living factories," 3; herbivorous, for study in grazing course, 365 ; game, study of, in grazing course, 378,388 ; predatory, for study in grazing course, 383 ; research phases for study of, in grazing course, 386; of prey, study of, in grazing course, 389 .

Annual pasture, 88.

Annual weed cover, ro8.

Antennaria, growth after burning brushwood, 226.

Apple family, for study in grazing course, 360 .

Aristida, mechanically injurious, 286; for study in grazing course, 368 .

Aristida species, withstand fire, 237 .

Aristida adscensionis, injurious species, 288.

Aristida Fendleriana, injurious species, 288.

Arizona, sheep and cattle grazed under permit, 2I; reseeding tests, 40; study of effect of grazing on timber production, $2 \mathrm{O} 2$; study on Coconino Forest, 204; earth reservoir, (fig.) 303; studies of grazing capacity, 329; investigations in, for study in grazing course, 376 .

Arrhenatherum elatius, in reseeding tests, 44; habit of growth, (fig.) 146; value for hay and pasture, 146 .

Arsenite of soda, used in killing poisonous plants, 247 .

Artemisia, effect of fire on, 226.

Artemisia discolor, in depletion of mixed grass and weed stage, II 3 ; habit of growth, (fig.) I I4; on range grazed annually, (fig.) I 22 ; on protected plot, (fig.) 123; on protected plot and on unprotected range, 125 ; indicator plant, I 29, I 30 .

Asclepias, poisonous to stock, 272.

Asclepias galioides, habitat and description, (fig.) $272,273$.

Aspen, type of forest, forage on, 198; area grazed by sheep twice each season, (fig.) 205; effect of grazing on reproduction, 205; area protected from sheep, (fig.) 207; remnants of sprouts on sheep range, (fig.) 208; effect of sheep, goats, and cattle on, 212; for troughs, 300; grazing type, (fig.) 315 , (fig.) $31 \%$; for study in grazing course, 376 .

Aster, invasion of farm pasture, (fig.) IOI; on range grazed annually, (fig.) I 22; on protected plot, (fig.) I 23; on protected plot and on unprotected range, I25; indicator plant, I 29.

Aster, woody, poisonous to stock, 275, (fig.) 277 .

Aster frondeus, on range grazed annually, (fig.) I 22; on protected plot, (fig.) 123 ; indicator plant, I 29.

Asteraceae, for study in grazing course, 369 .

Astragalus, poisonous to livestock, 243; description, 250; for study in grazing course, 370 .

Astragalus decumbens, indicator plant, I 30.

Astragalus mollissimus, description, 250; habit of growth, (fig. frontis.); distribution and habitat, 250 .

Atlantic States, species of lupine found in, 267 .

Atriplex semibaccala, in reseeding tests, 44 .

Atropine, for larkspur poisoning, 258 .

Avena, semi-domesticated, 55; for study in grazing course, 368 .

Aveneae, for study in grazing course, 368.

Azalea, poisonous species, 274.

Azalea occidentalis, poisonous species, 274.

\section{B}

"Baby" beeves, feeding grain ration to, 96.

Bacteria, nitrifying, destroyed by fire, 226; contain toxic substances, 243 .

Bacteriology, auxiliary subject in study of pasture management, $36 \mathrm{r}$.

Barium chloride, for larkspur poisoning, 258.

Barley, meadow, on bed ground, (fig.) I 2 I.

Barley, Pacific, mechanically injurious, 286.

Barley, squirreltail, mechanically injurious, 286, (fig.) 287 ; injury to lamb, (fig.) 288.

Barley, wall, mechanically injurious, 286.

Barleygrass, mechanically injurious, 285,286 ; for study in grazing course, 367.

Barnes, Will C., on cost of reservoirs, 303. 
Barometer, aneroid, used in field work, 319, 320.

Barren lands, grazing type, 315, (fig.) 3 I6.

Bean, blue, name for lupine, 266.

Bean, common garden, belonging to legumes, $\mathbf{I}_{5} \mathrm{I}$.

Bean family, nongrasslike forage plants, I5I.

Bean, Indian, name for lupine, 266.

Bean, velvet, cultivated pasture plant, $15 \mathrm{I}$; in full pod, (fig.) ${ }_{162}$; habitat, 163; habit of growth, I63; seeding, I63; forage value, 164 .

Bear, study of, in grazing course, 383 .

Beaver poison, name for water hemlock, 264.

Bed ground, overgrazing indicated by plants on, 107; vegetation on, 119; zones of vegetation on, (fig.) I 20 ; vegetation on, after five years of protection, (fig.) I $2 \mathrm{I}$; effect of plowing, 124; indicator plants on, I28; injury to timber reproduction, 199, $20 \mathrm{I}, 204$; relation of, to poisoning, 248 ; revegetation of, in grazing course, 375 .

Beech family, for study in grazing course, 360 .

Bell, "History of California," on forest fires, 218 .

Bent grass, name for redtop, 139 .

Bermudagrass, area of growth, 5 ; adapted to humid regions, 55,132 ; introduced from old World, 55, r 35 ; sown extensively on permanent pasture, 132; habitat, 135, 137; habit of growth, (fig.) 1 36,137 ; seeding, I37; with bur clover, 156 ; for study in grazing course, 368 .

Bicarbonate of soda, for lupine poisoning, 269 .

"Big four" for hay and pasture, 132.

Bigtrees, California, evidence of fire scars on, 216.

Binder, grain or "self," I42.

Bisect, of vegetation on high mountain range, (fig.) 350; form of sample plot, 35I.

Bitterbrush, sign of overgrazing, ro6.

Bladder pod, on eroded and on noneroded pasture, (fig.) I1 8.

Bleeding, for larkspur poisoning, 259; for death camas poisoning, 263 ; for lupine poisoning, 269 .

Blood, dried, as fertilizer, roo.

Blue bean, name for lupine, 266.

Blue Mountains, of Oregon, mountain reseeding tests, 44 ; elevational limits of reseeding, 50; experiments in frequent harvesting, 63 ; protection of overgrazed area, 66; studies of palatability of mature forage, 76 ; forest fire, 216; effect of fire on brush, 226.

Blue pea, name for lupine, 266.

Bluegrass, in mixed grass and weed stage, III; often killed by fire, 223, 237; for study in grazing course, 368.

Bluegrass, Canada, in reseeding tests, 43; amount to sow and cost, 53; moisture requirements, 54 ; habit of growth, 135 ; value as pasture plant, I35; mixture for permanent pasture, 149.

Bluegrass, English, name for Canada bluegrass, I35; name for meadow fescue, 147 .

Bluegrass, flatstem, name for Canada bluegrass, 135 .

Bluegrass, Kentucky, in reseeding tests, 4I, 44, 45, 47; elevational limitations, 50 ; yields heavily, 52 ; amount to sow and cost, 53, 134; moisture requirements, 54; in mixed seeding, 54,134 ; adapted to humid regions, 55, 89; introduced from Old World, 55 ; on permanent pasture, $88, \mathrm{I}_{32}$; pasture plant par excellence, 93; for hay and pasture combined, r32; habit of growth, 132, (fig.) 133; lawn grass, 134 ; in mixture for permanent pasture, I48.

Bluegrass, little, indicator plant, 130.

Bluegrass, Nevada, indicator plant, 130 .

Bluegrass, Virginia, name for Canada bluegrass, 135 .

Bluejoint, host plant, $28 \mathrm{r}$.

Bonneville, Captain, Adventures of, on fires along Platte River, 2 I8.

Borage family, for study in grazing course, 360 .

Boraginaceae, for study in grazing course, 360 .

Botany, auxiliary subject in study of pasture management, $36 \mathrm{r}$; application of, 362 ; department of, to include general training in grazing, 390 .

Botfly, to be considered in study of entomology, 362 .

Bouteloua, mechanically injurious, 286 ; for study in grazing course, 368 .

Bouteloua aristidoides, injurious species, 289.

Bouteloua gracilis, in reseeding tests, 40,43 .

Bouteloua hirsuta, in reseeding tests, 40.

Brome, June, name for downy bromegrass, 286. 
Bromegrass, scattering and planting of seed, 67 ; in depletion of mixed grass and weed stage, III; mechanically injurious, 285 ; for study in grazing course, 368 .

Bromegrass, Austrian, name for Hungarian bromegrass, 137 .

Bromegrass, awnless, name for Hungarian bromegrass, 137 .

Bromegrass, downy, growth after burning brushland, 226; mechanically injurious, 286.

Bromegrass, hairy, mechanically injurious, 286.

Bromegrass, Hungarian, in reseeding tests, $4 \mathrm{I}, 44,45,47$; more permanent than timothy, 52; amount to sow and cost, 53; moisture requirements, 54; introduced from Old World, 55; on permanent pasture, 88 , I 32 ; habit of growth, I37, (fig.) I38; value as hay and as pasture, 138 ; seeding, I 38 ; kind of soil, 139 .

Bromegrass, large mountain, indicator plant, I 29.

Bromegrass, mountain, collecting seed of, 57; terrace seeded to, (fig.) I94; growth after burning brushland, 226 .

Bromegrass, native, growth on eroded and on noneroded soil, 184 ; relative water requirements, (fig.) 186; summary of study, (fig.) 188 .

Bromegrass, Porter's, indicator plant, I 29, I30.

Bromegrass, red, mechanically injurious, 286.

Bromegrass, Russian, name for Hungarian bromegrass, 137 .

Bromegrass, smooth, name for Hungarian bromegrass, 137 , (fig.) 138 .

Bromus, in depletion of mixed grass and weed stage, III; growth after burning brushland, 226; mechanically injurious, 285 ; for study in grazing course, 368 .

Bromus carinatus, collecting seed of, 57 .

Bromus inermis, habit of growth, I37, (fig.) 138 ; value as hay and as pasture, I38; kind of soil, 139 .

Bromus marginatus, indicator plant, I 29; growth on eroded and on noneroded soil, 184 .

Bromus Porteri, indicator plant, I29, I30.

Bromus rubens, mechanically injurious, 286.

Bromus tectorum, mechanically injurious, 286.

Bromus villosus, mechanically injurious, 286.
Broomgrass, in reseeding tests, 43; withstands fire, 237.

Broom sedge, withstands fire, 224 .

Browse, grazing type, (fig.) 315 .

Browsing, effect of, on timber reproduction, 199, 200; yellow pine, injured by sheep, (fig.) 201; yellow pine, injured by cattle, (fig.) 203; deformed trees, result of, (fig.) 204; effects of, on aspen reproduction, 206; area protected from sheep, (fig.) 207.

Brush drag, for covering seed, $4 \mathrm{I}$.

Brushland, effect of burning, 225 .

Buckthorn, effect of fire on, 226 .

Buckthorn family, for study in grazing course, 369 .

Buffaloes, migrations of, 61 ; impress on range, for study in grazing course, 365 .

Buffalograss, for study in grazing course, 368.

Buffalograss-gramagrass, in Great Plains, 6.

Bulbilis, for study in grazing course, 368.

Bunchflower family, poisonous plants, 242; for study in grazing course, 369 .

Bunchgrass, in desert range of Great Basin, 7; cropping tests with, 63 ; revegetation of bunchgrass lands, 66 ; seedlings at end of first and of second year's growth, (figs.) 68, 69; early in summer of third year, (fig.) 70 ; at end of third year, (fig.) 71 ; does not withstand early grazing as well as sodgrass, 88; form of growth, 89 , 90; typical form, (fig.) $9 \mathrm{I}$; overgrazing, the rule, 96 ; effect of grazing on timber reproduction on bunchgrass range, 204.

Bunchgrass, mountain, at end of first season of growth, (fig.) 68; at end of second season, (fig.) 69; early in summer of third year, (fig.) 70; at end of third year, (fig.) $7 \mathrm{I}$.

Bureau of Plant Industry, studies of grazing capacity, 328.

Burning, burned-over forest range, (fig.) 46 ; of pasture lands, 216; history of, 216; woodland pasture fire, (fig.) $2 \mathrm{I} 7$; fre-swept area, (fig.) 218; present-day, 219; reasons for, 220 ; effects on forage production, 221 ; effect on grasslands, 222; in the South, 223; favors erosion, 224; periodic, 225; effect on brushlands, 225; effect on wooded pastures and forest ranges, 228; effect on vegetation, 229; study of, in grazing course, 376 . 
Bursa, growth after burning brushland, 226.

Bursa bursa-pastoris, on chart plot, (fig.) 342.

Buttercup, family, poisonous plants, 243; for study in grazing course, 369 .

Butterweed, sign of overgrazing, 106; indicator plant, I 29.

\section{C}

Cacti, mechanically injurious, 284 .

Caffeine, for larkspur poisoning, 258.

Calamagrostis, on burned-over forest range, (fig.) 46; for study in grazing course, 368 .

Calicobush, name for mountain "laurel," 274, (fig.) 276 .

California, sheep and cattle grazed under permit, $2 \mathrm{I}$; test of deferred grazing, 8o; study of effect of grazing on timber reproduction, 198 . Bell's History of, on causes of forest fires, 218; investigations in, for study in grazing course, 376 .

Camas, death, poisonous, 242; when to graze, 245 ; method of eradicating, 247; description, 26r, (fig. frontis.); distribution and habitat, $26 \mathrm{r}$; poisonous species, 26r; losses due to, 262; poisonous parts, 262 ; amount required to cause death, 263 ; symptoms of poisoning, 263; remedies, 263; characteristic sheep poisoning, (fig.) 264 ; summary of symptoms and remedies, 270.

Caprifoliaceae, for study in grazing course, 369 .

Capriola, for study in grazing course, 368.

Capriola Dactylon, introduced from Europe, 135; habitat, 135, 137; habit of growth, (fig.) 1 36,137 .

Carex, study of, in grazing course, 367 , 368.

Carpetgrass, easily killed by fire, 224 , 237.

Carrier, Lyman, investigation of methods of cropping and treating pasture, 93.

Cascade Mountains, study of injury to forest growth by sheep grazing on, I99.

Cattle, thrive on winter annual plants, 8; number grazed on National Forests, 21; increase on National Forests from 1909 to 1919, 22; breed improved by lease plan, 34 ; stocker, grazing by, 97 : injury to yellow pine reproduction in Arizona and New
Mexico, 202; effect of browsing on reproduction of aspen, 206; number grazed on National Forests in I92I, 232; losses due to poisoning, 241; driving and herding, 248; losses from larkspur poisoning, 256; losses from water hemlock poisoning, 265 ; water requirements, 296; most valuable pasture lands for, 355 ; forage preferences of, for study in grazing course, 367 ; forage requirements of, for study in grazing course, 371,387 ; management of, for study in grazing course, 382 ; cost of production, for study in grazing course, 382 ; on winter range, study of, in grazing course, 389 .

Ceanothus, effect of fire on, 226 .

Cedar, incense, injury to, by various agencies, 199; injury to, by stock, far study in grazing course, 376 .

Cellulose, indigestible substance, 3 .

Cement, for curbing springs, 298; troughs, 301.

Cercocarpus, sign of overgrazing, 106; effect of fire on, 226.

Chamaenerion, growth after burning brushwood, 226.

Chaparral land, effect of burning on, 225.

Chapline, W. R., on goat grazing, 210 .

Chart plot, 34I; vegetation on, (fig.) 342 ; pantograph for mapping, (fig.) 345 .

Chemistry, auxiliary subject in study of pasture management, $36 \mathbf{r}$; application of, 363 .

Chenopodiaceae, for study in grazing course, 369 .

Chenopodium album, in first or early weed stage, I15, (fig.) II6; on bed ground, (fig.) I2I; indicator plant, 128.

Cherry, choke, natural invader of cutover or fir type, 89; poisonous to stock, 279, (fig.) 281 .

Cherry, wild, poisonous to stock, 279, (fig.) $28 \mathrm{I}$.

Chlorideae, for study in grazing course, 368.

Chrysothamnus lanceolatus, appears in destruction of wheatgrass cover, I08; indicator plant, 129.

Cicuta, poisonous to livestock, 243; description, 264; distribution and habitat, 264; losses from, 265; poisonous parts, 265 ; symptoms of poisoning, 265; remedies, 266; control and prevention of losses, 266; for study in grazing course, 370 . 
Cicuta occidentalis, western plant, 264, (fig. frontis.).

Cinna, for study in grazing course, 368 . Cinquefoil, indicator plant, 129.

Claviceps purpurea, description and habitat, 28r, (fig.) 283; poisonous to stock, $28 \mathrm{r}$.

Clements, Frederic E., quadrat method developed by, $34 \mathrm{I}$.

Climate, cause of declining forage yield, 89; factor in determining adaptá bility of range to classes of stock, 311 ; study of, in grazing course, 365 .

Climatic cycles in forage yield, study of, in grazing course, 363,386 .

Climatic data, included in study of meteorology, 363 .

Climatic factors, in erosion, for study in grazing course, 375 .

Climax herbaceous stage, 107; value as forage, III; indicator plants, 130; for study in grazing course, 374 .

Clover, cultivated pasture plant, $15 \mathrm{I}$; species and habitat, 152.

Clover, Alsike, in reseeding tests, 44 , 45 ; yields well, 52 ; amount to sow and cost, 53; moisture requirements, 54 ; in mixture for temporary pasture, 148; for permanent pasture, 149; habit of growth, I52; introduced into United States, 152 ; seeding, 152; form of growth, (fig.) 153.

Clover, bur, in reseeding tests, 44; amount to sow and cost, 53; moisture requirements, 54 ; on winter range, 80 ; habitat, I 55 ; species, I 56 ; form of growth, (fig.) 156; kind of soil, 156 .

Clover, Japanese, or Japan, in reseeding tests, 44; moisture requirements, 54; cultivated pasture plant, $1_{51}$; habitat, I64; value, I64; seeding, I64.

Clover, red, in reseeding test, 44; amount to sow and cost, 53; moisture requirements, 54 ; on permanent pasture, 88 ; in mixtures, 148.

Clover, spotted bur, habitat, I 56 ; form of growth, (fig.) 156; in combination with Bermudagrass, 156.

Clover, Swedish, name for Alsike, I 52.

Clover, sweet, cultivated pasture plant, I5I; habit of growth, (fig.) 154, I55; habitat, I55; seeding, I55; objection to, 155 .

Clover, white, in reseeding tests, 44 , $45,47,52$; amount to sow and cost, 53; moisture requirements, 54, I53; seeded with Kentucky bluegrass, I 34 ; mixture for permanent pasture, 148,
I 49; habit of growth, I53; seeding I 53 .

Cocklebur, mechanically injurious, 284 .

Cock's-foot, name for orchardgrass, 142 .

Coconino National Forest, study of grazing damage to yellow pine reproduction on, 204; study of improved methods of range management on, 3 Io.

Collection, plant, for grazing reconnaissance, 318 ; of specimens for study in grazing course, 371 .

Colleges, agricultural, inclusion of courses in pasture and livestock management in curricula of, 360,390 .

Collomia, slender-leaved, in first or early weed stage, II5, (fig.) II6; on eroded and on noneroded pasture, (fig.) I 8 ; indicator plant, 128.

Collomia linearis, in first, or early weed stage, II5, (fig.) II6; on eroded and noneroded pasture, (fig.) Ir8; indicator plant, 128 .

Colorado, sheep and cattle grazed under permit, 2 I.

Comb seed stripper, for collecting seed, (fig.) 56,57 .

Compass, used in traverse sketching, 319.

Coniferous trees, less palatable than hardwoods, 209; damage to seedlings by browsing and trampling, 235; for study in grazing course, 376.

Corn, Kafir, supplemental feed, 34 .

Cost, of seeding, $52,53,54$; of collecting seed, 57 ; of overgrazing, 61 ; of eradicating loco plants, 255; of eradicating larkspur, 259; of troughs, 300 ; of reservoirs, 304 ; of wells, 304 ; of feed and labor, 307; of livestock production, for study in grazing course, 382 .

Cotton, J. S., reseeding experiments, 43. Couchgrass, host plant, $28 \mathrm{r}$.

Coville, Frederick V., study of injury to forest growth from sheep grazing, I99.

Cow poison, common name for larkspur, 255.

Cow unit, meaning of, 330; grazing capacity of National Forests in cow units, 33I; acreage required for cattle, 331; acreage required for sheep, 333 . Cowbane, name for water hemlock, 264.

Cowpeas, cultivated pasture plant, I5I; habit of growth, I58; field of, (fig.) 158; introduced from Africa, 158; seeding, 158 .

Coyote, study of, in grazing coursc, 383 . 
Crepis acuminata, indicator plant, $\mathbf{1 2 9}$; on chart plot, (fig.) 342 .

Crook County Sheep-Shooting Association, I4.

Cropping, tests, 63 ; effect on vegetation, (figs.) 65; deferred, vs. yearlong grazing, (fig.) 77; study of methods, 93 .

Cross-breeding, purpose of, 387 .

Crown fire, 234.

Curbing, for springs, 298; for wells, 304 .

Curricula, of agricultural colleges, inclusion of courses on pasture and livestock management in, 360 .

Cymopterus, false, in foxglove-sweet sage-yarrow cover, II4; on eroded and on noneroded pasture, (fig.) II 8; indicator plant, $\mathrm{I} 29$.

\section{D}

Dactylis glomerata, habit of growth, (fig.) 142.

Dandelion, on range grazed annually, (fig.) I 22; on protected plot, (fig.) I23; on protected plot and on unprotected range, I 25 .

Dandelion, mountain, indicator plant, I 29.

Dayton, William A., study of effect of grazing on timber reproduction, 198.

"Dead lines" in conflicts over range territory, I 5 .

Death camas, poisonous, 242; when to graze, 245 ; method of eradicating, 247; description, 26I, (fig. frontis.); distribution and habitat, 26I; poisonous species, 26r; losses due to, 262; poisonous parts, 262; amount required to cause death, $26_{3}$; symptoms of poisoning, 263 ; remedies, 263; characteristic symptoms of sheep poisoning by, (fig.) 264 ; summary of symptoms and remedies, 270.

Death cup, habitat, 283 ; description, 284 , (fig.) 285 .

Death Valley, below sea level, 7 .

Delphinium, species of poisonous plants, 243; distribution and habitat, 255; for study in grazing course, 370 .

Delphinium Barbeyi, on range grazed annually, (fig.) I22; on protected plot, (fig.) I 23; species of tall larkspur, 256; habit of growth, (fig. frontis.).

Delphinium bicolor, distribution and habitat, 256.

Delphinium cucullatum, species of larkspur, 256.

Delphinium Mensiesii, indicator plant,
I 29; distribution and habitat, 256; habit of growth, (fig. frontis.).

Department of Agriculture, medical tests by, 263; studies of grazing capacity by Bur. of Plant Industry, 328.

Depletion of forage crop, I04.

Denuded or depopulated plots, 349 ; for study in grazing course, 385 .

Desert range, for sheep grazing, (fig.) 7 . de Vaca, Cabeza, fires set by Indians, 217 .

Devil's darning needle, mechanically injurious, 288; description, 288.

Dimensions of sample plots, square areas, 356 , (fig.) 357 ; circular areas, $35^{8}$.

Disking, in experiments in treating pasture lots, 94, 95; after scattering seed, 102.

Distichlis, for study in grazing course, 368.

Dock, Mexican, in foxglove-sweet sageyarrow cover, II4; on bed grounds, (fig.) $12 \mathrm{I}$; on protected bed grounds, I 24; indicator plant, I 29.

Dogs, sheep herding by, 72 ; excessive use of, to be avoided, 79,335 ; sheepkilling, for study in grazing course, 383 .

Dogtown three-awn, injurious species, 288.

Draba cana, on chart plot, (fig.) 342.

Drag, brush, for covering seed, 4I; terrace, (fig.) r 93.

Drawing, mechanical, included in course in civil engineering, 363 .

Drill, grain, I4I.

Driveways, vegetation on, II9; factor in fire control, 234, 235; poisonous plants on, 248; losses from wild cherry poisoning, 279; revegetation of, for study in grazing course, 375 .

Dropseedgrass, for study in grazing course, 368 .

Drought, cause of failure of seeding tests, 48,52 ; destruction of seedlings due to, 72 ; injures forest plants, 89 ; drought-enduring grasses, 138 , 145 ; injury to tree production by, 199 .

Dry farming, in Great Plains, 6; in Great Basin, 7; in the Southwest, 8; success of, ro; on native western range, 39 .

\section{E}

Ecology, auxiliary subject in study of pasture management, $36 \mathbf{I}$.

Elder, mountain, in browse type, (fig.) 315. 
Elymus, host plant, $28 \mathrm{I}$; for study in grazing course, 367 .

Elymus trilicoides, host plant, 283 .

Engine, gasoline, for wells, 304 .

Engineering, civil, auxiliary subject in study of pasture management, 362 ; includes mechanical drawing, 363 .

Entomology, auxiliary subject in study of pasture management, 36r; application of, 362 .

Ephraim, Utah, flood at, I 74; erosion area, head of canyon, (fig.) 180 .

Eragrostis, for study in grazing course, 368.

Ergot, poisonous to livestock, 243, 28I ; description and habitat, 28I, (fig.) 283.

Erigeron divergens, on chart plot, (fig.) 342.

Erigeron effusus, on chart plot, (fig.) 342.

Erodium cicutarium, in reseeding tests, 40, 44; semi-domesticated, 55 .

Erosion, sign of overgrazing, 106; vegetation on eroded and on noneroded pasture, II 7, (fig.) II 8; danger of, I7I; damage by, I72; study of, on National Forests, I 73; kinds of, I75, I 76 ; of wagon road, (fig.) 175; factors influencing, 177 ; study of, in Wasatch Mountains, I77; steepness of slope a factor in, 177 ; influence of soil, I 78; influence of rainfall, I79; influence of melting snow, I80; influence of wind, 181 ; influence of vegetative cover, 182 ; relation of, to plant growth and revegetation, 182,189 ; study of growth on eroded and on noneroded soil, $184 ;$ meaning of, (fig.) 185; overgrazing and erosion, (fig.) Igo; solution of problem, I9I; favored by burning, 224 , 225; study of, in grazing course, 374,375 .

Erythronium, annual plant, 324 .

Eubotrys, swamp, poisonous species of "laurel," 274.

Eubotrys racemosa, poisonous species of "laurel," 274.

European Governments, administration of forests, 23; property rights, $24,26$.

Everlasting, growth of, after burning brushland, 226.

\section{F}

Fabaceae, nongrasslike forage plants, I5I; for study in grazing course, 369.
Fabales, order of plants, $15 \mathbf{I}$.

Faboideac, subfamily name, I5I.

Fagaceae, for study in grazing course, 369.

Farley, F. W., investigation of pasture management in piney woods, 224.

Farm lands, unimproved, extent of, 4.

Feed, supplemental, one reason for increased profits under leasing system, 34 ; to be considered in pasture inspection, 335 .

Fencing, against stock, ro; first step toward pasture and livestock management, (fig.) 33; advantages of, 82 ; to improve depleted pasture, 98; to prevent larkspur poisoning, 260; to protect springs, 298, (fig.) 299; sample plots, 358 .

Fendler's three-awn, injurious species, 288.

Fern, common bracken, poisonous to stock, 279, (fig.) 282 .

Fertility, maintenance of, for study in grazing course, 364 .

Fertilizer, for pasture and grassland, 98; kinds and amounts, 99; for removing weeds, IO2; for study in grazing course, 374 .

Fescue, hard, in reseeding tests, 44; amount to sow and cost, 53; moisture requirements, 54 .

Fescue, meadow, for hay and pasture combined, I32, (fig.) I47; habit of growth, 147; amount to sow, 147.

Fescue, spiked, indicator plant, I30.

Fescue, western, indicator plant, I30.

Fescuegrass, winter annual of Southwest, 8; scattering and planting of seed, 67; in mixed grass and weed stage, III; for hay and pasture combined, I32; often killed by fire, 223, 237; for study in grazing course, 368 .

Festuca, in mixed grass and weed stage, III; often killed by fire, 223, 237; for study in grazing course, 368 .

Festuca confinis, indicator plant, I30.

Festuca duriuscula, in reseeding tests, 44.

Festuca elatior, habit of growth, (fig.) I47; value, I47; amount to sow, I47.

Festuca occidentalis, indicator plant, I3O.

Festuca pratensis, former name for meadow fescue ( $F$. elatior), 147.

Festuceae, for study in grazing course, 368.

Figwort family, for study in grazing course, 369 . 
Fir, alpine, type of National Forest range, sheep grazing on, (fig.) 19.

Fir, Douglas, type of forest, forage on, I98; damage to, by various agencies, 199; effect of goat grazing, $21 \mathrm{I}$; for troughs, 300 ; injury to, by stock, for study in grazing course, 376.

Fir, grand, for troughs, 300 .

Fir, white, injury to, by various agencies, I99.

Fir-aspen, natural-type unit, study of, in grazing course, 385 .

Fire control, relation to grazing, 27, (fig.) 230; cover of inflammable material, (fig.) 231.

Fireweed, on burned-over forest range, 46 ; growth after burning of brushland, 226.

First or early weed stage, 108; characteristic plants, II5, (fig.) II6; forage value, II5; area surrounding bed ground, II9, (fig.) I 20 ; indicator plants, 128 ; for study in grazing course, 375 .

Fishlake National Forest, loss of cattle from poisoning, 256 .

Floods, at Ephraim, Utah, r74; of Mississippi River, I74; of Ohio River, I74; on wagon road, (fig.) I75; ways of controlling, I94; for study in grazing course, 374 .

Forage, palatability of mature, 75; causes of decline in yield, I04; damage to timber according to amount of, 20I, 203, 204; factor in grazin reconnaissance, $3 \mathrm{II}$; character of, for study in grazing course, 365 ; requirements of stock, for study in grazing course, 37I; growth requirements, for study in grazing course, 372 .

Forage acre, calculated from field-map data, 320; defined, 325; how derived, 325 ; comparative value of different types, 325; acreage for cattle, 33I; for shcep, 333; may be used in mapping sample plots, 34I; formula for expressing cover in terms of, 347; determining, on protection plots, 356 ; for study in grazing course, 378,387 .

Forage crop, depletion of, 104; effect of grazing on, II 7 ; improved methods of harvesting, 307 ; variation in, for study in grazing course, 386.

Forage-crop areas, 5; factors that determine, 5 .

Forage plants, moisture requirements, 53; seeding to cultivated plants,
55; introduced from Old World, 55 ; reseeding to native plants, 56 ; seeded protection strip, (fig.) 57; viability of seed, 57 ; two forms, 89 ; life period, 90; introduced grasses, $\mathrm{I}_{32}$; introduced nongrasslike herbs, I5I; for study in grazing course, 366 , 371 ; creation of new varieties, study of, in grazing course, 384 .

Forage production, in early spring, 62 ; results of frequent harvesting, 63; effect of frequent cropping, (figs.) 65 ; by various grazing systems, 72; essentials for, 88; improvement of, 90; of wheatgrass cover, III ; of porcupinegrass-yellowbrush cover, II 3 ; of second or late weed stage, II 5 ; of first or early weed cover, I I 5 ; on eroded and on noneroded pasture, (fig.) II8; affected by burning, 22I; "human" factors, 328; method of determining maximum, 356; variation in, for study in grazing course, 386 .

Forest fires, in Blue Mountains of Oregon, 2I6, (fig.) 2I7; history of, 2I6; fire-swept area, (fig.) 218; present-day, 219; beliefs about, 220; effect on forage production, $22 \mathrm{I}$; liability of, lessened on $\mathrm{Na}$ tional Forests, 232; grazing tends to minimize, (fig.) 233; three classes of, 233.

Forest protection, important forestry subject, 390.

Forest Reserves, authorized, I 7.

Forest Service, area protected by, for five years, (fig.) II; seeks to utilize forage crops, I8; control of grazing, 20; considers use of range a privilege, 26; functions, 28; permits grazing on National Forest range, I98; firing of chaparral lands by, 225; basis of grazing reconnaissance used by, 3II; provides special scale map, 319; grazing-capacity tests by, 326; forestry courses for those who wish to enter, 390 .

Forest utilization, important forestry subject, 390 .

Forester, letter to, from Secretary of Agriculture, I8.

Formula, remedy for larkspur poisoning, 258; for computing forage acres, 325 ; for expressing cover in terms of forage acres, 347 .

Fort Valley Forest Experiment Station, range reseeding experiments: $4 \mathrm{r}$. 
Fowler's solution, for loco poisoning, 254.

Foxglove, blue, in depletion of mixed grass and weed stage, $\mathrm{II}_{3}$; in second or late weed stage, II3; habit of growth, (fig.) II 4 ; on eroded and on noneroded pasture, (fig.) II 8; indicator plant, 129; in weed type, (fig.) 314 .

Foxglove-yarrow-sweet sage cover, I08; follows mixed grass and weed stage, II $x$; associated species, II3; dominant plants, (fig.) I 4 ; destruction of, II 4 ; value as forage, I 5 .

Fungi, parasitic, contain toxic substance, 243.

Fungus, ergot, prevention, 283 ; fly agaric, 283 ; death cup, 283 .

\section{G}

Game animals, for study in grazing course, 378 .

Genetics, auxiliary subject in study of pasture management, 362 ; application of, 363 .

Geology, auxiliary subject in study of pasture management, $36 \mathrm{r}$.

Geraniaceae, for study in grazing course, 369 .

Geranium, indicator plant, $\mathbf{I} 29$.

Geranium family, for study in grazing course, 369 .

Geranium viscosissimum, indicator plant, I 29.

Germany, intensive use of forest in, 23; prescriptive rights, 24 .

Germination chamber, for seed testing, 165 .

Germinators, kinds of, 165 .

Geum, indicator plant, r 29 .

Geum Oregonense, indicator plant, 129.

Gila National Forest, goat grazing on, 210.

Gilia, indicator plant, 128.

Glycine hispida, habitat, 159; habit of growth, 159, (fig.) r6o.

Goats, number grazed on National Forests in 1919 compared with 1909, 22 ; study of effect of grazing on timber reproduction, 210; as brush destroyers, 227; on palatable browse, (fig.) 228; forage preferences of, for study in grazing course, 367 ; forage requirements of, for study in grazing course, $37 \mathbf{1}, 387$; management of, for study in grazing course, 382 ; cost of production, for study in grazing course, 382 ; on winter range, study of, in grazing course, 389.

Goldenrod, growth after burning brushland, 226.

Gooseberry family, for study in grazing course, 369 .

Goosefoot, or lamb's-quarters, indicator plant, 128 .

Goosefoot family, for study in grazing course, 369 .

Gophers, study of, in grazing course, 377.

Grain drill, grass seeder attached to, in seeding timothy, I4I.

Grain thresher, 142 .

Grama, needle, injurious species, 289.

Grama-buffalo tribe, for study in grazing course, 368 .

Gramagrass, winter annual of Southwest, 8; effect of grazing on timber reproduction on gramagrass range, 204; mechanically injurious, 286, 289; for study in grazing course, 368.

Gramagrass, blue, in reseeding tests, 40, 43; moisture requirements, 54 .

Gramagrass, hairy, in reseeding tests, 40.

Grass, bent, name for redtop, I39.

Grass mixtures, I48, I49.

Grass, Randall, name for tall oatgrass, 146.

Grass seeder, attached to grain drill, for scattering timothy seed, $14 \mathrm{I}$.

Grass, squirreltail, mechanically injurious, $285,286$.

Grass, three-awn, in Great Plains, 6; mechanically injurious, 286,288 .

Grasses, in reseeding tests, 43; what to sow, 52 ; introduced, 132 ; number of species, 132; mixtures, 148 , I49; mechanically injurious, 285 ; native, study of, in grazing course, 367.

Grassland, fertilizers for, 98 ; effect of burning on, 222; grazing type, 312, (fig.) 313 .

Grasslike plants, for study in grazing course, 368.

Grazing, on public domain, 4; desert range used for sheep grazing, (fig.) 7 ; on National Forest of yellow pine type, (fig.) 19 ; in alpine fir type, (fig.) 19 ; growth of industry, 20; National Forest policy, 23; regulated, value of, 27 ; permits, 27 ; regulated, results of, 28 ; on newly seeded lands, 55 ; rotation, $6 \mathrm{r}$; result of repeated, (fig.) 64 ; after seed crop ripens, 67 ; destruction of 
seedlings by, 67; systems, 72; yearlong, 72; deferred, 74, 97; deferred, advantages of, 77; deferred cropping vs. yearlong, (fig.) 77; deferred, application of, 78; deferred and rotation, plan for, 79; deferred, on range of "winter annuals," 80 ; reseeding complications, $8 \mathrm{I}$; results of faulty methods, 89 ; alternate vs. continuous, 94; light vs. heavy, 95; number of stock for nonsod pastures, 96; mixed, to remove weeds, IO2; destructive, how to recognize, I04; effect of, on development of vegetation, II7; efficiency, i 7; early, avoidance of, to prevent erosion, I9I; on woodlands, I97; effect of, on timber reproduction, I98; damage according to intensity of, 200 , (fig.) 20I, 203; on farm woodland, 208; damage to tree growth, 209; effect of goat grazing on timber reproduction, 2IO; essentials of efficient regulation, $2 \mathrm{I}_{3}$; affected by fires, 219; advantage over burning in brush disposal, 228; relation to fire control, (fig.) 230 ; tends to minimize fires, (fig.) 233, 235; proper control necessary, 235; on lands infested with poisonous plants, 244; reconnaissance, 308 ; factors determining length of period for, 312; courses of study, 360,364 ; destructive, indicators of, in grazing course, 374; reconnaissance, in grazing course, 377; period of, in grazing course, 385 ; general instruction in, in grazing course, 389 ; subjects for general instruction, 390; schools for professional training in, 390; general instruction in, coördinated with departments of botany, agronomy, and animal husbandry, 390.

Grazing capacity, of native western grounds, 39; optimum and maximum, 62 ; affected by yearlong grazing, 73; amount reserved for deferred grazing, 78; increased by seed production, $8 \mathrm{I}$; decline of, on farms, 93; result of alternate cropping on, 94 ; decline in, due to faulty management, 104; indicators of slight departures in, ro7; data from which derived, 3I8; study of, by Forest Service, 326, 328; defined, 328; steps to be taken in study of, 3.30; of ranges and pastures, 330; of National Forests in cow units, 33I; of public-domain lands in Western States, (fig.) 332; for cattle, improved by sheep grazing, 334; points to be considered in study of, 339; for study in grazing course, $371,372,378$.

Grazing control, 9; by homesteading, Io; by Government, ro; area protected by Forest Service, (fig.) II; by creating National Forests, I7; by European Governments, 23; in India, 26; results of, 28; solution of erosion pasture problem, for study in grazing course, 375 .

Grazing lands, economic importance of, 4; native western, 39; reseeding to cultivated forage plants, 39; study of, in grazing course, 366 .

Grazing permits, 27; for study in grazing course, 366 .

Grazing reconnaissance, objects of, 307,308 ; history of, 309; data and facts obtained by, 3II; parts comprised in, 312; methods of obtaining data, 3I8; compared with timber reconnaissance, $32 \mathrm{I}$; application to pasture management, 323 ; accuracy and limitations of, 323 ; first step in study of grazing capacity, 330; in range and pasture inspection, 334 ; study of, in grazing course, 377. Grazing system, need of, 6r; as practiced in West, 72; yearlong grazing, 72 ; yearlong protection, 73; deferred grazing, 74 ; advantages of deferred grazing, 76; deferred vs. yearlong, (fig.) 77; application of deferred, 78; rotation, 79; limitations of deferred, 8I; "blanket" recommendations, 92; deferred grazing on nonsod pastures, 97; advantage of deferred grazing over yearlong protection, 126; deferred and rotation grazing to prevent erosion, 192 ; study of, in grazing course, 373 .

Grazing types, classification of lands into, 312; represented on maps, 317; descriptive report of each type, 3 I 8 .

Greasewood, on desert range of Great Basin, 7 .

Great Basin, the, 5; location, 6; typical desert range, (fig.) 7 ; native vegetation, 7; irrigation, 8; study of erosion at Grazing Experiment Station, I77; effect of burning, 222; winter desert range, (fig.) 332 ; pasture lands, for study in grazing course, 365 ; investigations in, for study in grazing course, 376 .

Great Plains, the, 5; location, 5; rain- 
fall and water supply, 6; native vegetation, 6; pasture lands, for study in grazing course, 365 .

Greene, S. IV., investigation of pasture management in piney woods, 224.

"Gridiron" method of obtaining data, 3 I 8.

Griffiths, David, tests in seeding native forage plants, 40; discussion of effect of fire in Great Basin, 222.

Grossulariaceae, for study in grazing course, 360.

Ground fire, 233.

Grub, in head of sheep, 276.

Grubbing, for destroying poisonous plants, 247; for eradicating larkspur, 259.

Gully erosion, 176; influence of melting snow, I80.

Gutierrezia, sign of overgrazing, ıo6.

\section{$\mathrm{H}$}

Hairgrass, in meadow type, 312 ; in grazing course, 368 .

Hand seeder, for scattering seed, 50.

Hanson, Timothy, origin of name for timothy, I40.

Hardwood trees, more palatable than coniferous, 209; damage to sprouts by overgrazing, 235 .

Ilarrow, brush, 48, (fig.) 49; woodenpeg " $A$," 48 , (fig.) 49.

Harrowing, in experiments in treating pasture lots, 94; after scattering seed, I02.

Hay, grasses, I32; Kentucky bluegrass, I 34; Canada bluegrass, 135; Bermudagrass, I37; Hungarian brome, I38; redtop, I40; timothy, I4I; orchardgrass, 142; Johnsongrass, I44; Sudangrass, I44; oatgrass, I46; containing squirreltail or barley grass, 288; supplemental feed, 335 .

IIclenium, sign of overgrazing, Io6.

Helenium Iloopesii, indicator plant, 129; habitat and description, 277, (fig.) 278 ; poisonous to stock, 277 .

Helianthella, single-flowered, indicator plant, 130 .

IIclianthella uniflora, indicator plant, 130.

Hemlock, water, poisonous to stock, 243; poison in roots, 244 ; method of eradicating, 247; description, 264, (fig. frontis.); distribution and habitat, 264; losses from, 265 ; poisonous parts, 265 ; symptoms of poison- ing, 265; remedies, 266; prevention and control of losses, 266; summary of symptoms and remedies, 270.

Hensel, R. L., study of acreage per cow unit, 332 .

Herbs, broad-leaved, in reseeding tests, 44; kinds to sow, 52 ; in depletion of mixed grass and weed stage, III; nongrasslike forage, I5I; broadleaved, in study course, 376.

Herd, Timothy, origin of name for timothy, 140.

Herd's grass, name for redtop, I39; name for timothy, 140.

Hilaria Belangeri, in reseeding tests, 44.

Hill, Robert R., study of effect of grazing on yellow pine reproduction, 202 ; use of pantograph by, 345 ; advantages of use of pantograph summarized by, 346 .

Hitchcock, A. S., classification of grasses, ${ }^{2} 3_{2}$; on Kentucky bluegrass, 133 .

Hoe, "hazel," for grubbing, 259, (fig.) 260.

Hogs, number grazed on National Forests in Igro compared with 1909, 22; on forests of Spessart Mountains, 25 .

Hog's-potato, name for death camas, 26 I.

IIolcus IIalepensis, habit of growth, I44; value for hay, I44.

Holcus Sorghum Sudanensis, habit of growth, I44, (fig.) r45; seeding, 145; value for hay, 145 .

Homesteading, in Pacific and Western States, Io.

Honeysuckle family, for study in grazing course, 360 .

IIordeae, for study in grazing course, 367.

IIordeum, mechanically injurious, 285 ; for study in grazing course, 367 .

IIordeum Gussoneanum, mechanically injurious, 286.

IIordeum jubatum, mechanically injurious, 286, (fig.) 287 .

Ilordcum murinum, mechanically injurious, 286.

Hordeum nodosum, on bed ground, (fig.) I 21.

Horsemint, indicator plant, I 29.

Horses, thrive on winter annual plants, 8; number grazed on National Forests in 1919 compared with 1909, 22; breed improved by lease plan, 34 ; water requirements, 296; most valuable pasture lands for, 355 ; wild, 
for study in grazing course, 365 ; forage preferences of, for study in grazing course, 367 ; forage requirements of, for study in grazing course, 371,387 ; on winter range, study of, in grazing course, $3^{89}$.

Host plants, 28r.

Huckleberry family, for study in grazing course, 369 .

Humus, accumulation of, ro5; soil rich in, retains moisture, ro5; soil that contains little, II 5 ; removal of, I $\mathrm{I}$; percentage of, in eroded and in noneroded soil, r 84; preservation of, I9I; added to soil by decomposition of vegetation, 22I; destroyed by fire, 227, 228; destroyed by excessive grazing, 235 .

Husbandry, animal, auxiliary subject in study of pasture management, 362 ; application of, 363 ; winterrange, study of, in grazing course, 388 ; general instruction in grazing coördinated with department of, 390 .

Hydrocyanic acid, formed in Johnsongrass, 144 .

II ymenoxys floribunda, indicator plant, I 29; poisonous to stock, 276; habit of growth, (fig.) 278 .

Hypodermic injections, for larkspur poisoning, 258 .

\section{I}

Idaho, cattle and sheep grazed under permit, $2 \mathrm{I}$; study of effect of grazing on timber reproduction, 200; investigations in, for study in grazing course, 376 .

Ignition, loss on, in eroded and noneroded soil, I84.

Implements, cultural, 48 ; brush harrow, (fig.) 49; wooden-peg " $A$ " harrow, (fig.) 49; for study in grazing course, 372 .

India, grazing practice on forests, 26 .

Indian bean, name for lupine, 266 .

Indicator plants, asters. (fig.) ror; type stages, I07; use, I 27; method of detecting improvement or depletion, 127 ; reliable indicators, 128 ; for study in grazing course, 375 .

Indicators, of moderate stages of overgrazing, ro7.

Injury, mechanical, by plants, 284 ; prevention, 288; seasonal, to timberlands, for study in grazing course, 376.

Inspection, of range and farm pasture,
333; points to be considered, 334; study of, in grazing course, 378 .

Investigations, of methods of cropping, 93; of effect of grazing on timber reproduction, results of, 198 ; of injuries from sheep grazing, r99; on Payette National Forest, 200; conclusions based on, $2 \mathrm{II}$; on $\mathrm{Na}$ tional Forests, 376; on farm woodlands, 376 ; application of, 376 .

Irrigation, of range and pasture lands, 4 ; in Great Basin, 8; dependent on watersheds of National Forests, I 72.

\section{$\mathrm{J}$}

Jack rabbits, study of, in grazing control, 377 .

Jacquot, A., on effect of fires on vegetation, 229.

Jardine, J. T., essentials of efficient regulation in grazing, 213; methods proposed by, form basis for Forest Service grazing-reconnaissance work, 3II; on acreage required, for cattle, 331, for sheep, 333 .

Johnsongrass, for hay and pasture combined, I32; habit of growth, I44; value for hay, 144 .

Juncus, study of, in grazing course, 367,368 .

Junegrass, name for Kentucky bluegrass, 93, 132; indicator plant, 129; host plant, 28I; for study in grazing course, 368 .

Juniper, palatable to goats, $21 \mathrm{r}$; in woodland type, (fig.) 316,317 .

\section{K}

Kafir corn, supplemental feed, 34 .

Kalmia angustifolia, poisonous species, 274.

Kalmia latifolia, poisonous species, 274 ; habit of growth, (fig.) 276 .

Kansas Experiment Station, study of acreage per cow unit, 332 .

Knotweed, indicator plant, 128 .

Knotweed, Douglas, in first or early weed stage, I I5, (fig.) II6; on bed ground, (fig.) I2I; on range grazed annually, (fig.) I22; on protected plot, (fig.) I 23,124 ; on protected plot and on unprotected range, 125; indicator plant, I28; growth after burning brushland, 226; annual plant, 324 .

Koeleria, host plant, 28r; for study in grazing course, 368 .

Koeleria cristata, indicator plant, 129. 
Krameria, belonging to legumes, I5I. Kubanka, species of wheat, 184 .

\section{L}

Labrador tea, poisonous species, 273, (fig.) 275 .

Lambkill, name for sheep "laurel," 274.

Lamb's-quarters, in first or early weed stage, 115 , (fig.) II 6 ; on bed ground, (fig.) I 21 ; on protected bed ground, 124 ; indicator plant, 128 .

Landslide, form of erosion, 176 .

Larkspur, cross section of root, (fig.) 64 ; species of poisonous plant, 243; poisonous until seed maturity, 245; young cow poisoned by, (fig.) 246; distribution and habitat, 256; losses due to, 256; poisonous part, 257; amount required to cause death, 257; symptoms of poisoning, 257; remedies, 258; method of eradicating, 259; summary of symptoms and remedies, 270 .

Larkspur, low, indicator plant, 1 29; method of eradicating, 247; distribution and habitat, 256; habit of growth, (fig. frontis.).

Larkspur, tall, on range grazed annually, (fig.) I 22 ; on protected plot, (fig.) 123; on protected plot and on unprotected range, 125 ; method of eradicating, 247, 259; distribution and habitat, 256; habit of growth, (fig. frontis.).

Lathyrus, study of, in grazing course, 369.

Lathyrus leucanthus, in foxglove-sweet sage-yarrow cover, II4; on range grazed annually, (fig.) I 22 ; on protected plot, (fig.) I 23; indicator plant, I 29; on chart plot, (fig.) 342.

"Laurel," black, poisonous species, 273 , (fig.) 274 .

"Laurel," mountain, poisonous species, 274 , (fig.) 276 .

"Laurel," sheep, poisonous species, 274.

"Laurel," white, poisonous species, 274, (fig.) 275 .

"Laurels," poisonous to stock, 273; habitat, 273 .

Lavauxia flava, in foxglove-sweet sageyarrow cover, II4; on bed ground, (fig.) I2I; on range grazed annually, (fig.) 122 ; on protected area, (fig.) I 23; indicator plant, I 29 .

Leasing system, in Texas, 30 ; in $\mathrm{Wy}^{\mathrm{y}}$ oming, 3I; Northern Pacific Rail- road, 31 ; benefits of, 32,34 ; fencing, following adoption of, (fig.) 33 ; for study, in grazing course, 365 .

Lcdum glandulosum, poisonous species, 273.

Legumes, cultivated pasture plants, I $5 \mathrm{I}$.

Leguminalcs, nongrasslike forage plants, I5 1 .

Leguminosae, or legume family, I5I; includes poisonous species, 243.

Leontodon taraxacum, on range grazed annually, (fig.) I22; on protected plot, (fig.) I 23; on chart plot, (fig.) 342.

Lepidium ramosissimum, indicat or plant, 128.

Lespedeza, valuable pasture plant, easily killed by fire, 224, 237 .

Lespedeza striata, in reseeding tests, 44 ; habitat, I64; value, 164 ; seeding, 164 .

Lesquerella Ctahensis, on eroded and on noneroded pastures, (fig.) i 18.

Leucothoë Davisiae, poisonous species, 273.

Level, Abney, topographic, used in field work, 320 .

Life-history studies, in grazing course, 366,372 .

I.ife period, of forage plants, 90 .

Lightning, fires started by, $217,232$.

Lime, soil deficient in, 95 ; to correct acidity, 99; in eroded and in noneroded soil, I84.

Limestone, fertilizer, 99.

Lincoln National Forest, cost of reservoirs on, 304.

Lion, mountain, study of, in grazing course, 383 .

List plot, 347 , (fig.) 348 ; advantages of, 347 .

Livestock, importance of industry, 4; chief industry on native range lands, $6,7,8$; on National Forests, I8; increase on National Forests from I909 to 1919, 22; control and distribution, factor in preventing erosion, 192; losses from poison and from mechanical injury, 24I; control of losses, 243; driving and herding in relation to poisoning, 247 ; water requirements, 296; methods of handling, chief object of grazing reconnaissance, 323; suggestions for instruction in production of, 360 ; schedule of subjects for studying management of, $36 \mathrm{I}$; course in history of development of domestic, 362; improved handling of, to be 
studied in grazing course, 364 ; economics, to be studied in grazing course, 364 ; center of production, for study in grazing course, 365 ; number and classes grazed, for study in grazing course, 366 ; forage preferences of, for study in grazing course, 367,383 ; suitability of range to, for study in grazing course, $37 \mathrm{I}$; management of, for study in grazing course, 379; cost of production, for study in grazing course, 382 ; reproduction of, for study in grazing course, 387 ; improving grade of, for study in grazing course, 387 ; prevention of losses of, for study in grazing course, 387 ; range and pasture management, general instruction in, 390 .

Lobelia, name for death camas, $26 \mathrm{r}$.

Loco, poisonous to stock, 243; method of eradicating, 247, 254; distribution of two species, (fig.) 25I; symptoms of poisoning, 252; locoed horse, (fig.) 253; locoed steer, (fig.) 253; remedies for poisoning, 253; loco disease in goat, (fig.) 254 , in sheep, (fig.) 254; name for lupine, 266; summary of symptoms and remedies, 270.

Loco, Lambert's, same as white loco, 250.

Loco, low, indicator plant, I3o.

Loco, purple, destructive species, 250 ; losses caused by, 252; eradication of, 255 .

Loco, rattleweed, same as white loco, 250.

Loco, stemless, same as white loco, 250.

Loco, Texas, destructive species, 250.

Loco, white, description, 250; habit of growth, (fig. frontis.); distribution and habitat, 250 , (fig.) 251 ; losses caused by, 252; eradication of, 255 .

Loco, woolly, description, 250; habit of growth, (fig. frontis.); distribution and habitat, 250 , (fig.) 251.

Lolium Italicum, habitat, I43; seeding, I44.

Lolium perenne, in reseeding tests, 44; habitat, I43; habit of growth, (fig.) I43; seeding, I43.

Loss, to stockmen, 62, I05; of seedlings, 67 ; from floods, 174 ; from fires, 219; in forage yield caused by fires, 223; of fertility, caused by fires, 230; from various causes, 24I; from poisonous plants, 24I, 244; from loco, 24I, 252; control and prevention of, $254,259,266,269$; from larkspur, 256; from death camas, 262 ; from water hemlock, 265 ; from lupine, 267; from woody aster, 276 ; from wild cherry, 279 ; from fern, 28I; from mechanically injurious plants, 286; prevention of, in study course, 387 .

Lousewort, growth after burning brushland, 226.

Lovegrass, for study in grazing course, 368.

Lucerne, name for alfalfa, I5I; habitat, I57; seeding, 157 ; value as forage, 157.

Lupine, poisonous to livestock, 243; poison in pods, 244; when to graze, 244; method of eradicating, 247; distribution and habitat, 266; losses from, 267; poisonous parts, 267; amount required to cause death, 268; symptoms of poisoning, 268; sheep poisoned by, (fig.) 268; remedies for poisoning, 269; summary of symptoms and remedies, 270.

Lupine, mountain, indicator plant, 130.

Lupinus, poisonous to livestock, 243 ; distribution and habitat, 266; for study in grazing course, 370 .

Lupinus alpestris, indicator plant, I30; habit of growth, (fig. frontis.).

\section{M}

Madia glomerata, in first or early weed stage, (fig.) 1 6; indicator plant, I 28.

Mahogany, birchleaf, sign of overgrazing, Io6.

Mahogany, mountain, effect of fire on, 226 .

Mallow family, for study in grazing course, 369 .

Malvaceae, for study in grazing course, 369.

Mannagrass, for study in grazing course, 368 .

Manti Forest, rainstorm, I74; erosion area, (fig.) 180.

Manure, application of, 99; as topdressing, Ioo; fertilizing value, 222 .

Map, topographic, for grazing reconnaissance, 3I 2, 320; for timber reconnaissance, 318 ; transcribing fieldmap data, 320; use in forest fires, 323; indispensable in management of lands and stock, 334; form for chart plot, 343, (fig.) 344 ; locating quadrat on, 354 ; use in grazing course, 378 .

Mapping, season and frequency of, 354. 
Meadow, grazing type, 312, (fig.) 313 . Meadowgrass, smooth-stalked, name for Kentucky bluegrass, 132 .

Meat, value of, in diet, 3 ; production, and consumption of, for study in grazing course, 364 .

Mechanical injury, by plants, 284; prevention, 288 .

Mechanically injurious plants, 284.

Medic, toothed, or bur clover, (fig.) 156; habitat, 156, I 57 ; forage value, 157; seeding, 157 .

Iredicago, habitat, 155 .

Medicago Arabiea, habitat, 156.

Medicago denticulala, in reseeding test, 44.

Medicago hispida, habitat, I56, (fig.) $^{44}$ I 56 ; forage value, ${ }_{5} 6$; seeding, 157 .

Medicago sativa, habitat, 157 ; seeding, 157; forage value, 157 .

Melanthaceae, family containing poisonous plants, 242; for study in grazing course, 369 .

Melica, for study in grazing course, 368 .

Melica bulbosa, indicator plant, I 29.

Melica spectabilis, indicator plant, I 29.

Melicgrass, for study in grazing course, 368.

Melilotus alba, habit of growth, (fig.) I54, I55; habitat, I55; seeding, 155 .

Menziesia, smooth, poisonous species, 273, (fig.) 274 .

Menitesia glabella, poisonous species, 273, (fig.) 274.

Mertensia, Sampson's, indicator plant, I 29.

Merlensia Sampsonii, indicator plant, I 29.

Mesa lands, reseeding tests on, 40.

Mesquitegrass, early grass of Southwest, 8 ; in reseeding tests, 44 ; moisture requirements, 54 .

Meteorology, auxiliary subject in study of pasture management, 362 ; application of, 363 .

Methods, for obtaining reconnaissance data, 318; "gridiron," 318 ; traversesketching, 319; triangulation, 320 .

Microsteris micrantha, indicator plant, I 28 .

Milkweed, poisonous to stock, 272 .

Milkweed, whorled, habitat and description, (fig.) 272, 273.

Mimosa, or sensitive-plant, belonging to legumes, I5 1 .

Mississippi River, floods, I 74 .

Mixed grass and weed stage, 107; dominant species, (fig.) IIO; de- velopment of, III; destruction of, II3; value as forage, II3; a rea surrounding bed ground, II9, (fig.) I 20; indicator plants, I 29; bisect of vegetation on high mountain range, (fig.) 350 ; for study in grazing course, 374 .

Moisture requirements of cultivated forage plants, 53 .

Monkshood, name for aconite, 279.

Monolepis, indicator plant, I28.

Monolepis Nuttalliana, indicator plant, I 28.

Montana, cattle and sheep grazed under permit, 21 .

Morphology, auxiliary subject in study of pasture management, $36 r$.

Mowing, prevents weeds from spreading, ror.

Mucuna utilis, in full pod, (fig.) 162 ; habitat, $16_{3}$; habit of growth, $16_{3}$; seeding, I63; forage value, 164 .

Muhlenbergia, in Great Plains, 6; for study in grazing course, 368 .

Muhlenbergia, for study in grazing course, 368 .

Munger, Thornton T., study of effects of grazing on timber reproduction in Oregon, I99.

Mushrooms, poisonous to livestock, 243.

Muskrat weed, name for water hemlock, 264 .

Musquash root, name for water hemlock, 264 .

Mustard, tansy, in first or early weed stage, II5, (fig.) I16; on eroded and on noneroded pasture, (fig.) II 8 ; on bed ground, (fig.) 121 ; on range grazed annually, (fig.) I 22 ; on protected plot, (fig.) I 23 ; on protected bed ground, I 24; on protected plot and on unprotected range, 125; indicator plant, 128 .

Mystery-grass, name for death camas, 261 .

\section{$\mathrm{N}$}

National Forests, area, I 7; object of establishment, I7; policy of administration, 18; livestock on, 18; grazing and timber production in yellow pine type, (fig.) I9; grazing in alpine fir type, (fig.) 19; growth of grazing industry on, 20; grazing policy, 23, 27; administration of, by European Governments, 23; cattle range, moderately grazed, (fig.) 24; use of, a privilege, 26; 
control of, in India, 26; dependence of agriculture on, 26; reseeding experiments on, 43; burned-over forest range, (fig.) 46; relation to irrigation, I72; liability of fires, 232; grazing reconnaissance on, 309 ; acreage required per cow unit, 33I; acreage required for sheep, 333; water supply ample on ranges of, 355; creation of, for study in grazing course, 365,366 ; function and results of, in regulating grazing, for study in grazing course, 366; investigations on, for study in grazing course, 376 .

Needle-and-thread, injurious species, 288; description, 288.

Needlegrass, in Great Plains, 6; mechanically injurious, 286,288 ; for study in grazing course, 368 .

Needlegrass, small, on eroded and noneroded pasture, i 8 .

Neopieris mariana, poisonous species, 274.

New Genesee Farmer, introduced Alsike clover, I 52 .

New Mexico, cattle and sheep grazed under permit, $2 \mathrm{I}$; study of effect of grazing on timber reproduction, 202; overgrazing and trampling near watering place, (fig.) 297; studies of grazing capacity, 329; investigations in, for study in grazing course, 376 .

Nevada, cattle and sheep grazed under permit, $2 \mathrm{I}$.

Nitrifying bacteria, destroyed by fire, 226.

Nitrogen, essential part of diet, 3; ingredient of fertilizer, 99; in eroded and in noneroded soil, I84; percentage returned to soil in manure, 222.

Nitrogenous materials, in the diet, 3 ; in the soil, caused by decomposition of vegetation, $22 \mathrm{I}$.

Northern Pacific Railroad Company, land grants to, 30; leases, 31 ; leasing system, for study in grazing course, 366 .

Northwest, the, pasture lands, for study in grazing course, 365 ; investigations in, for study in grazing course, 376 .

\section{$\mathrm{O}$}

Oak, poisonous to stock, 273.

Oak, Gambel, poisonous species, 273.

Oak, scrub, in desert range of Great Basin, 7.
Oak, shinnery, poisonous species, 273.

Oakley, R. A., investigation of methods of cropping and treating pasture, 93.

Oatgrass, for study in grazing course, 368.

Oatgrass, tall meadow, in reseeding test, 44; amount to sow and cost, 53; moisture requirements, 54; for hay and pasture combined, r32; habit of growth, (fig.) I46; value, I 46.

Oats, wild, semi-domesticated, 55; on winter ranges, 80 .

Oestrus ovis, in sheep, 276.

Ohio River, floods, I74.

Old maid's-bonnet, name for lupine, 266.

Onagraceae, for study in grazing course, 369.

Onion, annual plant, 324 .

Oniongrass, indicator plant, I 29.

Oniongrass, showy, indicator plant, I 29.

Orchardgrass, in reseeding tests, 4I, 44, 45, 47; amount to sow and cost, 53 ; moisture requirements, 54 ; on permanent pasture, 88 ; habit of growth, 90; for hay and pasture combined, I32; habit of growth, (fig.) I42; mixture for permanent pasture, I48, I49.

Oregon, cattle and sheep grazed under permit, 21 ; study of effect of grazing on timber reproduction, I99; investigations in, for study in grazing course, 376.

Orthocarpus, Tolmie's, in first or early weed stage, I I5, (fig.) I I6; indicator plant, I 28.

Orthocarpus Tolmiei, in first or early weed stage, I I5, (fig.) I I6; indicator plant, I 28.

Oryzopsis, for study in grazing course, 368 .

Overgrazing, cause and effect, Io; area protected for five years, (fig.) I I; carrying capacity of pasture, I 2; denuded summer range, (fig.) 13; cost of, 6I; cause of depletion of bunchgrass lands, 95; on nonsod pastures, 96; how to recognize and correct, I04; conspicuous signs of, I06; indicators of moderate, 107; relation to erosion, I73; on Manti Forest, I74; erosion due to, (fig.) I83; overgrazing and erosion, (fig.) Igo; avoidance of, to prevent erosion, I9I; damage to tree reproduction by, 235; cause of soil depletion, 235; cause of loss by poi- 
son plants, 242, 244; affected by distance from watering place, (fig.) 297; for study in grazing course, 365,374 .

Oxylropis, poisonous to livestock, 243; description, 250; for study in grazing course, 370 .

Oxylropis Lamberlii, description, 250; habit of growth, (fig. frontis.); distribution and habitat, 250, (fig.) 25 I.

\section{P}

Pacific slope, pasture lands, for study in grazing course, 365 .

Palatability, of mature forage, 75; studies of, in Blue Mountains of Oregon, 76; factor in good pasture, 87 ; affected by frosts, etc., 88; of primitive plant forms, I06; height growth in relation to, on fenced and on unfenced areas, I 26; of Bermudagrass, I37; of tall oatgrass, 146; of white clover, 153; of bur clover, I 56 ; of poisonous plants, 243; to be considered in study of pasture revegetation, 339, 340; percentage of, on protection plots, 356; for study in grazing course, 373 .

Panhandle, of Texas, use of wells in, 304.

Panicularia, for study in grazing course, 368.

Pantograph, for mapping chart plots, (fig.) 345 ; disadvantage of, 346 ; advantages of, 346 .

Papilionaceae, older name for Fabaceae, I5I.

Papilionoideae, subfamily name, I5I.

Parasites, in sheep manure, 100.

Parsley, spotted, name for water hemlock, 264.

Parsley family, for study in grazing course, 360 .

Parsnip, name for water hemlock, 264.

Parsnip family, includes poisonous species, 243.

Partridge-peas, belonging to legumes, I5I.

Pasture, extent of lands used for, 4; benefits of leasing system on, 33; revegetation, 66; improvement, 86; what is good, 87 ; kinds of, 88 ; reasons for deterioration of, 88; "blanket" recommendations for grazing, 92; experiments on bluegrass, in Virginia, 93; nonsod, 96; farm, in good condition, (fig.) 96; fertility of, maintained by fattening animals, IOO; invasion of, by asters, (fig.)
IOI; depletion of, I04; vegetation on eroded and on noneroded, (fig.) I 18 ; how to recognize depletion or improvement of, 127; mixtures for temporary and for permanent, I48; points to be considered in study of revegetation, 339; importance of pasture livestock production, 360 ; improved handling of, to be studied in grazing course, 364; woodland, for study in grazing course, 364 ; classification of lands, for study in grazing course, 365 ; plants, native, for study in grazing course, 366 ; plants, broad. leaved, for study in grazing course, 369; farm, study of, in grazing course, 373; factors that determine value, 373 .

Pasture management, field for research work, 93; bluegrass pastures, 93; nonsod pastures, 96 ; weed control, IOO; destructive practice, I I 7 ; annual burning, no place in, 225; application of grazing reconnaissance data to, 323; suggestions for instruction in, 360 ; schedule of subjects for studying, 36r; for study in grazing course, $364,37 x$; of sod and nonsod lands, for study in grazing course, 373; general instruction in, 390 .

Pathology, plant, auxiliary subject in study of pasture management, $36 \mathrm{r}$.

Payette National Forest, study of effects of grazing on timber reproduction on, 200.

Pea, blue, name for lupine, 266.

Pea, common garden, belonging to legumes, 15 I.

Pea family, nongrasslike forage plants, 151; includes poisonous species, 243.

Pearson, G. A., reseeding experiments, 4I; study of grazing damage to yellow pine reproduction, 204.

Peas, winter annual of Southwest, 8.

Peas, Canadian field, growth on eroded and on noneroded soil, I84, (fig.) $\mathrm{x} 85$; relative water requirements, (fig.) I86; summary of study, (fig.) 188 .

Peavine, study of, in grazing course, 369.

Peavine, low, in destruction of foxglove-sweet sage-yarrow cover, r14; on range grazed annually, (fig.) 122; on protected plot, (fig.) I 23; on protected plot and on unprotected range, I 25; indicator plant, I 29.

Pedicularis, growth after burning brushland, 226. 
Pentstemon, in weed type, (fig.) $3 \mathrm{I} 4$.

Pentstemon procerus, in depletion of mixed grass and weed stage, II 3 ; habit of growth, (fig.) II 4 ; on eroded and on noneroded pasture, (fig.) I18; indicator plant, I29; on chart plot, (fig.) 342 .

Peppergrass, indicator plant, I 28.

Peritonitis, caused by grasses, 288 .

Permanent pasture, 88; grass mixture for, 148.

Petroleum, used in killing poisonous plants, 247.

Phleum, for study in grazing course, 368.

Phleum pratense, origin of name, 140; habit of growth, I4I.

Phosphate, an ingredient of fertilizer, 99.

Phosphoric acid, in eroded and in noneroded soil, 184; percentage returned to soil in manure, 222 .

Photograph, to be taken of chart plot, 345.

Physiology, auxiliary subject in study of pasture management, 36r.

Physostigmine salicylate, for larkspur poisoning, 258 .

Pilocarpine hydrochloride, for larkspur poisoning, 258.

Pine, lodgepole, for troughs, 300 .

Pine, piñon, cropped lightly by goats, 211 ; in woodland type, (fig.) 316 , 317.

Pine, sugar, injury to, by various agencies, 199; injury to, by stock, for study in grazing course, 376 .

Pine, yellow, type of National Forest, moderate grazing and timber production on, (fig.) 19; on cattle range moderately grazed, (fig.) 24; forage on, I98; damage to, by various agencies, 199; tree severely hrowsed by sheep, (fig.) 20r; effect of grazing on reproduction in Arizona and New Mexico, 202; injury by cattle browsing, (fig.) 20.3; study of grazing damage on Coconino Forest, 204; effect of goat grazing on, 2ro; used for troughs, 300; injury to, by stock, for study in grazing course, 376 .

Pingué, name for Colorado rubberweed, 276 ; (fig.) 278 .

Piñon pine, cropped lightly by goats, $2 \mathrm{II}$; in woodland type, (fig.) 316 , 317.

Piping, spring or seep water, 299.

Pittsburg, floods at, I74.

Planetable, used in field work, 320.
Plant collection, for grazing reconnaissance, 318 .

Plant cover, protection against erosion, I I ; erosion resulting from destruction of, (fig.) I80.

Plant foods, in eroded and in noneroded soils of same type, 184 .

Plant growth, relation of erosion to, I82; study of, on eroded and on noneroded soil, I84; summary of, (fig.) $\mathrm{r} 88$.

Plant Industry, Bureau of, studies of grazing capacity, 328 .

Plant succession, type stages of, 107; study of, in grazing course, 384 .

Plantago Tweedyi, on bed ground, (fig.) I2I; on range grazed annually, (fig.) I 22; on protected plot, (fig.) 123.

Plantain, winter annual of Southwest, 8 ; on bed ground, (fig.) $\mathrm{I} 2 \mathrm{I}$; on range grazed annually, (fig.) 122; on protected plot, (fig.) I 23 ; on protected plot and on unprotected range, I 25 .

Plants, cultivated grasses and other herbaceous, in reseeding tests, 43; cultivated forage, moisture requirements of, 53; introduced, 55; native forage, reseeding to, 56 ; herbaceous, yield of, 60 ; pasture and hay, 89 ; indicator, I07; cultivated, classification of, $\mathrm{r}_{32}$; nongrasslike forage, I5I; herbaceous, growth of, after fire, 226; stock-poisoning, 24I, 250; poisonous and mechanically injurious, 272 ; mechanically injurious, 284; forage, growth requirements, 366; grasslike, distinguished from true grasses, in grazing course, 367 ; broad-leaved pasture, for study, 369; objectionable, in grazing course, 370; poisonous species, for study, 370; collection and preservation of specimens, $37 \mathrm{I}$; forage, new varieties of, in grazing course, 384 ; native pasture, general instruction in, 390.

Plots, sample, permanent, 340 ; kinds of, 340; how named, 34I; chart plot, 34I; mapping chart plot, (fig.) 342 ; list plot, 347 ; advantages of list plot, 347; denuded or depopulated, 349; other, $35 \mathrm{I}$; special guide tapes, 35I; plan for staking permanent, (fig.) 353; season and frequency of mapping, 354; protection, 355; dimensions, 356, (fig.) 357 ; size favored by writer, $35^{8}$; for study in grazing course, 385 . 
Plummer, Fred G., on forest fires, 218. $P o a$, in mixed grass and weed stage, III; often killed by fire, 223, 237; for study in grazing course, 368 .

Poa compressa, habit of growth, 135; forage value, 135 .

Poa Nevadensis, indicator plant, 130.

Poa pratensis, habit of growth, 132; (fig.) I33; resemiles Canada bluegrass, 135; on chart plot, (fig.) 342. Poa Sandbergii, indicator plant, 130 . Poison, definition of term, 242.

Poison sego, name for death camas, 26r.

Poison weed, common name for larkspur, 255.

Poisoning, driving and herding stock, as related to, 247; by loco, symptoms of, 252; locoed horse, (fig.) 253 ; locoed steer, (fig.) 253; remedies, 253; locoed goat, (fig.) 254; locoed sheep, (fig.) 254; control and prevention of loss by, 254, 259, 266,269 ; symptoms of larkspur poisoning, 257; death camas, 262; symptoms, 263; water hemlock, 265 ; symptoms, 265 ; lupine, 267 ; symptoms, 268; summary of symptoms and remedies, 270; milkweed, 273; oak, 273; "laurel," 273; woody aster, 275; rubberweed, 276; sneezeweed, 277; aconite, 279 ; cherry, 279; fern, 28r; ergot, 28I; fly agaric, 283 ; control of, for study in grazing course, 370 .

Poisonous plants, cause of loss of livestock, 24I; ancient knowledge of, 242; families of, 242; palatability of, 243; methods of eradicating, 246 ; driving and herding stock as related to poisoning, 247 ; for study in grazing course, 370,371 ; control of, in grazing course, 387 .

Polygonum aviculare, indicator plant, 128.

Polygonum Douglasii, in first or early weed stage, I I5, (fig.) ir6; on bed ground, (fig.) I $2 \mathbf{I}$; on range grazed annually, (fig.) 122; on protected plot, (fig.) 1 23; indicator plant, 128; growth after burning brushland, 226; annual plant, 324 ; on chart plot, (fig.) 342 .

Pomaceae, for study in grazing course, 369.

Porcupinegrass, small, in mixed grass and weed stage, 108, (fig.) 110; on range grazed annually, (fig.) 122; on protected plot, (fig.) 123; on protected plot and on unprotected range, 125; indicator plant, 1 29 .
Porcupinegrass-yellowbrush cover, 107; succeeds wheatgrass cover, ro8; dominant species, (fig.) Iro; plants that make up type, III; destruction of, $\mathrm{II}_{3}$; value as forage, $\mathrm{II}_{3}$.

Potash, as fertilizer, 99; muriate of, 100; in eroded and in noneroded soil, 184; percentage returned to soil in manure, 222.

Potassium nitrate, as fertilizer, 100.

Potassium permanganate, for larkspur poisoning, 258 .

Potentilla filipes, indicator plant, $\mathbf{1} 29$.

Prairie dog, study of, in grazing course, 377.

Prescott National Forest, cost of reservoirs on, 304.

Primrose, evening, in destruction of foxglove-sweet sage-yarrow cover, II4; on bed ground, (fig.) 12I; on range grazed annually, (fig.) 122; on protected plot, (fig.) 123; on protected plot and on unprotected range, 125; indicator plant, 129; family, for study in grazing course, 369 .

Profits, small operator compared with large operator, 307 .

Protection plots, 355 .

Proteids, Fabaceae rich in, 151.

Protein, content of soybeans, I59; content of Japan clover, 164 .

Prunus demissa, poisonous to stock, 279, (fig.) 281.

Prussic acid, in leaves of wild cherry, 279.

Pseudocymopterus Tidestromii, in destruction of foxglove-sweet sageyarrow cover, 114; on eroded and on noneroded pasture, (fig.) 118 ; indicator plant, I 29.

Pteridium aquilinum, poisonous to stock, 279, (fig.) 282 .

Public lands, location, and extent, 4, I0; homesteading on, I0; for study in grazing course, 364 .

Pulse family, nongrasslike forage plants, I 5 I ; includes poisonous species, 243; for study in grazing course, 369 .

Purshia, sign of overgrazing, Io6.

\section{Q}

Quadrat, form of sample plot, 34I; square meter, 349 .

Quaker's-bonnet, name for lupine, 266.

Quercus, poisonous to stock, 273.

Quercus Gambelii, poisonous species, 273.

Quercus Havardi, poisonous species, 273. 


\section{$\mathrm{R}$}

Rainfall, factor in forage growth, 5; on Great Plains, 6; in Great Basin, 7; in Rocky Mountain region, 8; on native western range, 39 ; migration of, I7I; factor in erosion, I77, I79; factor in determining number and distribution of stock, 3 II.

Rainstorm, on Manti National Forest, 174 ; study of, in Wasatch Mountains, I79.

Range, history, to be studied in grazing course, 364 ; industry, development of, for study in grazing course, 365; division of, into natural-type units, 385 .

Range and pasture lands, extent and location of, 4; five regions, 5; use of, a privilege, 26; leasing system, 3o; reseeding native western range, 39; control of erosion on, I7I; water a necessity, 295; need for grazing control, 310; grazing capacity of, 330; inspection of, 333; management of, for study in grazing course, $37 \mathrm{r}$.

Range land, stripped of good soil, (fig.) I8r; effect of burning, in South, 223; for study, in grazing course, 364 ; suitability of, for different classes of stock, for study in grazing course, $37 \mathrm{r}$.

Range, summer, in the Rockies, (fig.) $9 ;$ denuded of vegetation during "free-for-all" grazing period, (fig.) I3; forage available after frosts, 75 ; seed maturity on, 78 ; study of soil in spruce-fir type, 183.

Range wars, I2; use of fires in, 219; study of, in grazing course, 365 .

Range, winter, in Southwest, 8; deferred grazing on, 80 .

Ranunculaceae, family of poisonous plants, 243; for study in grazing course, 369 .

Rattleweed, name for species of loco, 250 , (fig. frontis.).

Reconnaissance, grazing, object of, 308; history of, 309; data and facts obtained by, 3i I; parts comprised in, 312 ; methods of obtaining data, 318; compared with timber reconnaissance, $32 \mathrm{I}$; application to pasture management, 323; accuracy and limitations of, 323 ; first step in study of grazing capacity, 330; in range and pasture inspection, 334 ; study of, in grazing course, 377 .
Reconnaissance, timber, aid in grazing reconnaissance, 3II; map for, 3I8; compared with grazing reconnaissance, $32 \mathrm{I}$.

Redtop, in reseeding tests, 4I, 43, 44, $45,47,50$; yields well on wet soil, 52 ; amount to sow and cost, 53; moisture requirements, 54 ; introduced from Old World, 55; on permanent pasture, 88, I32; for hay and pasture combined, I32; habit of growth, (fig.) I39; seeding, I40; in mixtures, I48, 149; for study in grazing course, 368 .

Redtop-timothy tribe, for study in grazing course, 368 .

Reedgrass, on burned-over forest range, (fig.) 46; for study in grazing course, 368 .

Reedgrass, sweet, for study in grazing course, 368 .

Regeneration, study of, in grazing course, 367 .

Remedies, for loco poisoning, 253; for larkspur poisoning, 258; for death camas poisoning, 263; for water hemlock poisoning, 266; for lupine poisoning, 269; summary of, 270; for "laurel" poisoning, 275; for sneezeweed poisoning, 278 ; for ergot poisoning, 282 ; for study in grazing course, 370 .

Research, farm pasture, field for, 93; methods, 339; phases of animal problems, for study in grazing course, 383 .

Reseeding, on native western range, 39; tests in southern Arizona, 40; in northern Arizona, 4I; on mountain lands, 42; on National Forest range, 43; results of tests, 45 ; on burned-over forest range, (fig.) 46; season for, 47; seasonal tests on mountain range lands, (fig.) 47; causes of failure, 48; scattering the seed, 50; elevational limitation, 50; what grasses to sow, 52 ; amount to sow, 52 ; cost of, 53,54 ; moisture requirements, 53 ; seeding to a mixture, 54; where seeding pays, 55 ; seeding to native forage plants, 56; "strip" seeding, 57; protected strip, (fig.) 57 ; natural, 6o; by deferred grazing, 78 ; plan adopted by California stockınen, 8I; complications, $8 \mathrm{I}$; of bed grounds, I2O; artificial, to native forage plants, for study in grazing course, 372; natural and artificial, study of, in grazing course, 386 . 
Reservoir, earth, in Arizona, (fig.) 303. Reservoirs, location of, 302; cost of, 303.

Revegetation, by natural reseeding, 60; plan suggested by migrations of buffaloes, $6 \mathrm{I}$; object sought, $6 \mathrm{I}$; by yearlong grazing, 72 ; by yearlong protection, 73 ; by deferred grazing, 74 ; plan for deferred and rotation grazing, 79; of bed grounds, 120; of lands grazed each year before seed maturity compared with yearlong protected areas, I 24 ; relation of erosion to, 182, 189; points to be considered in study of, 339 ; for study in grazing course, 372 , 375,386 .

Rhamnaccae, for study in grazing course, 369 .

Rhododendron, white, poisonous species, 274 , (fig.) 276 .

Rhododendron albiflorum, poisonous species, 274 .

Ricegrass, mountain, in desert range of Great Basin, 7; for study in grazing course, 368 .

Rights, prescriptive, in national forests of European Governments, 24; property, for study in grazing course, 366 .

River-bottom erosion, 176.

Rocky Mountain region, the, 5; location, 8 ; rainfall, 8 ; native vegetation, 8; summer range, (fig.) 9; pasture lands, for study in grazing course, 365 .

Rodents, injury to tree reproduction by, I99; destructive to pasture, for study in grazing course, 377 , 389 .

Root system, of vegetation on high mountain range, (fig.) 350 .

Rosaceae, for study in grazing course, 369.

Rose family, for study in grazing course, 369 .

Roughage, use of, in reseeding plan, $8 \mathrm{I}$; air-dry, 329 ; to be considered in range and pasture inspection, 335; for study in grazing course, 364 .

Rubberweed, indicator plant, 129.

Rubberweed, Colorado, poisonous to stock, 276 ; habitat, 276 .

Rue, meadow, on range grazed annually, (fig.) I 22 ; on protected plot, (fig.) 123 ; on protected plot and on unprotected range, 125 ; untouched by stock, I 26; growth after burning brushland, 226.

Rumex Mexicanus, in foxglove-sweet sage-yarrow cover, II 4 ; on bed ground, (fig.) I $2 \mathrm{I}$; indicator plant, I 29.

Rushes, in meadow type, 312; in grazing course, 368 .

Rye, wild, host plant, 28r.

Ryegrass, for hay and pasture combined, 132; habitat, 143; for study in grazing course, 367 .

Ryegrass, English, mixture for temporary pasture, 148 .

Ryegrass, Italian, in reseeding tests, 4I, 44, 45; amount to sow and cost, 53 , 144; moisture requirements, 54; habitat, 143 .

Ryegrass, perennial, in reseeding tests, 44,45 ; amount to sow and cost, 53, I43; moisture requirements, 54; habitat, (fig.) 143.

Ryegrass, wheatlike, host plant, (fig.) 283.

\section{S}

Sage, on winter desert range, (fig.) 332.

Sage, swcet, in depletion of mixed grass and weed stage, $\mathrm{II}_{3}$; in second or late weed stage, II3; habit of growth, (fig.) I I 4 ; on range grazed annually, (fig.) 122 ; on protected plot, (fig.) I 23 ; on protected plot and on unprotected range, 125; indicator plant, I 29, I30.

Sagebrush, in Great Plains, 6; in desert range of Great Basin, 7; grazing type, (fig.) 314,315 .

Sagebrush, black, effect of fire on, 226 .

Salicaceae, for study in grazing course, 369 .

Salix, sign of overgrazing, ro6; effect of fire on, 226 .

Salt, to prevent poisoning, 245 ; used in killing poisonous plants, 247 .

Saltbush, on desert range of Great Basin, 7 ; in reseeding tests, 41 .

Saltbush, Australian, in reseeding test, 44; moisture requirements, 54 .

Saltgrass, for study in grazing course, 368.

Salting, of stock, to prevent poisoning, 245; for study in grazing course, 376.

Salting stations, aid in deferred grazing, 83 ; location of, a factor in control and distribution of livestock, I92; valuable for fire-fighting purposes, 234; to be shown on map, 334 ; to be considered in range or pasture inspection, 335 .

Salts, Epsom, dose, for loco poisoning, 
254; Glauber's, for ergot poisoning, 282.

Salts, soil, received by plant, dependent on root system, 66; essential to plant growth, I72.

Sambucus, in browse type, (fig.) 3 I5. Sampson, Arthur W., reseeding of mountain lands, 43; effect of removing herbage several times in a season, 63 ; study of effect of grazing on timber reproduction, I 98 ; study of effects of sheep and cattle grazing on aspen reproduction, 206; observations of development of plant cover after fires, 226; intensive study of sample plots, mapping, and summarizing data, 340 .

Sandbur, mechanically injurious, 284 .

Santa Rita Range Reserve, reseeding studies on, 4I; acreage required per cow unit, 33 I.

Saturation of eroded and noneroded soil, I 84 .

Schools, for professional training in grazing, 390.

Scribner, F. Lamson-, on Canada bluegrass, 135 .

Scrophulariaceae, for study in grazing course, 360 .

Second or late weed stage, I08, II3; foxglove-yarrow-sweet sage type, I I3; dominant plants, (fig.) I I4; destruction of, II4; value as forage, II5; area surrounding bed ground, II9, (fig.) I20; indicator plants, I29; for study in grazing course, 374 .

Secretary of Agriculture, letter to Forester, I 7 .

Sedge, scattering and planting of seed, 67; in meadow type, 312 ; in grazing course, 368 .

Sedge, broom, withstands fire, 224 .

Seed, amount and cost per acre, 52, 53; collecting, of native pasture plants, 57 ; viability of, 57 ; production, 66; scattering and planting, 67; essentials of, I64; how to test, I65; how to obtain good, 165 ; collecting and cost of, for study in grazing course, 372 .

Seed habits, of annual plants, 74 ; of plants of first or early weed stage, I 5; of Kentucky bluegrass, I34; of Bermudagrass, I37; of timothy, I42; of white clover, I53; of sweet clover, I 55; of bur clover, I56; for study in grazing course, 367 .

Seeder, grain, I4I.

Seeding, season for, 47 ; amount to sow and cost, 52, 53; to a mixture, 54; where it will pay, 55 ; to native forage plants, 56 ; to Kentucky bluegrass, I34; to Canada bluegrass, I35; to Bermudagrass, I37; to Hungarian bromegrass, I38; to redtop, I40; to timothy, I4I; to perennial ryegrass, 143 ; to Sudangrass, I45; to meadow fescue, I47; to Alsike, I 52 ; to white clover, I 53 ; to sweet clover, 155 ; to bur clover, I57; to alfalfa, I 57 ; to cowpeas, I58; to soybeans, I59; to hairy vetch, I6 6 ; to velvet bean, I63; on terraced area, I93; season for, for study in grazing course, 372 .

Seedlings, loss of, from natural agencies, 67; destruction of, by grazing, 67; mountain bunchgrass, (fig.) 68; at end of second season, (fig.) 69 ; early in third year, (fig.) 70; at end of third year, (fig.) 7I; growth favored by deferred grazing, 77; loss of, on eroded areas, 189 ; damage to, by grazing, 200, 202; comparative seasonal injury to, 20r; damage according to intensity of grazing, 20r; injury to, on farm woodlands, 209; effect of goat grazing on, 210.

Seeds, winged, milkweed, 273.

Seepage, meaning of, 298.

Seeps, distinguished from springs, 298; how to improve, 298.

Sego, poison, name for death camas, $26 r$. Senecio, sign of overgrazing, ro6.

Senecio Columbiamus, indicator plant, 129.

Senna, belonging to legumes, ${ }_{5} \mathrm{I}$.

Sensitive-plant, belonging to legumes, I5I.

Serviceberry, sign of overgrazing, I06; effect of fire on, 226 .

Shadscale, on desert range of Great Basin, 6; on winter desert range, (fig.) 332 .

Shasta National Forest, study of effect of grazing on timber reproduction on, 198.

Sheep, grazing on typical desert range, (fig.) 7; thrive on winter annual plants, 8; grazing on alpine fir type of National Forest, (fig.) I9; number grazed on National Forests, 2I; increase on National Forests from I000 to I9I9, 22; excluded from ranges, 23; used to trample in seed, 50; injury to yellow pine reproduction in Arizona and New Mexico, 202; effect of 
browsing on reproduction of aspen, 206,212 ; on protected aspen land, (fig.) 207 ; remnants of aspen sprouts, (fig.) 208; number grazed on $\mathrm{Na}$ tional Forests in 1921,232 ; losses due to poisoning, 24I; driving and herding, 247; characteristic symptoms of poisoning by death camas, (fig.) 264 ; losses from water hemlock, 265; losses from lupine, (fig.) 268; water requirements, 296; best land for grazing, 355 ; forage preferences of, for study in grazing course, 367 ; forage requirements of, for study in grazing course, 371,387 ; management of, for study in grazing course, 379 ; cost of production, for study in grazing course, 382 ; on winter range, study of, in grazing course, 388 .

Sheep-shooting associations, 14 .

Sheet erosion, 176 ; due to overgrazing, (fig.) 183 .

Shepherd's-purse, growth after burning brushland, 226 .

"Shoestring gullies," 176 ; on seeded terrace, (fig.) I 94.

Silage, supplemental feed, 335; for study in grazing course, 387 .

Silt, in reservoirs, 303 .

Silvics, important forestry subject, 390 .

Silviculture, important forestry subject, 390 .

Silanion, mechanically injurious, 286.

Slag, basic, as fertilizer, 99.

Slope, steepness of, factor in erosion, 177 .

Smuts, poisonous to livestock, 243 .

Snakeroot, name for water hemlock, 264.

Snakeweed, sign of overgrazing, 106; name for water hemlock, 264 .

Sneezeweed, sign of overgrazing, ro6; indicator plant, 129; harmful to sheep, 245; method of eradicating, 247.

Sneezeweed, western, habitat and description, 277; (fig.) 278; poisonous to stock, 277 .

Snow, melting, factor in erosion, 177 , 180 .

Snowberry, sign of overgrazing, ro6.

Soap plant, name for death camas, $26 \mathrm{r}$.

Sod effect of harrowing and disking, 95 .

Sodgrasses, withstand early grazing, 88 ; on permanent pasture, 88 ; form of growth, 90; typical form, (fig.) 92 ; cause of decline in yield, 95 .
Sodium benzoate, for larkspur poisoning, 258 .

Sodium nitrate, as fertilizer, roo.

Soil, in seeding tests, 4I, 44; lack of treatment of, cause of failure of seeding tests, 48; fertile, for seeding to cultivated forage plants, 55; loosened by harrowing or plowing, 57; hard-packed, loss of seedlings on, 67; fertility, requires good pasture feed, 86; fertile, essential for forage production, 88; alluvial, for pasture land, 88; fertility, maintained on permanent pasture, 88; texture changed by injudicious grazing, 89 ; acid, corrected by lime, 99 ; needs fertilizers, 99; fertility, maintained by fattening cattle or sheep on the land, 100; soft and wet, bad for stock, roo; depleted, indicated by weeds, IOI; relation of, to forage production, 106, I $_{3}$; of first or early weed stage, II 5 ; requirements of forage plants, 132 ; for Kentucky bluegrass, 133; for Canada bluegrass, I35; for Hungarian bromegrass, 139; for redtop, 140; for timothy, I4I; for Johnsongrass, 144; for Sudangrass, 145; infertile, grass mixture for, 149 ; effect of erosion on, 171,174 ; type of, factor in erosion, 177 ; types of, 178 ; removal of, by wind, (fig.) $18 \mathrm{r}$; eroded and noneroded, study of, in Wasatch Mountains, I 83 , I 84 ; loose, wet, bad effects of trampling on, 192; washing, prevented by vegetative cover, 194; enriched by decomposition of vegetation, 221; burning destructive to, 222, 229, 230; problem of South, to maintain organic matter of, 223; effect of crown fires on, 234; depletion, caused by excessive grazing, 235; eroded and noneroded, plant foods and forage production in, in study course, 375 .

Solidago, growth after burning brushland, 226.

Solomon's-seal, false, indicator plant, I 29.

Sophia incisa, in first or early weed stage, II5, (fig.) II6; on eroded and on noneroded pasture, (fig.) I 8 ; on bed ground, (fig.) $\mathrm{I} 2 \mathrm{I}$; on range grazed annually, (fig.) I 22 ; on protected plot, (fig.) I 23 ; indicator plant, I 28 ; on chart plot, (fig.) 342 . Sorghum, introduced from Old World, 55 ; growing of, to eradicate Bermudagrass, 136 . 
Southwest, the, 5 ; location, 8 ; vegetation, 8; pasture lands, for study in grazing course, 365; investigations in, for study in grazing course, 376.

Soybean, cultivated pasture plant, I5I; habitat, I59; habit of growth, I 59, (fig.) I60; value, I59.

Sparhawk, W. N., studies on Payette National Forest, 200.

Specimens, collection of, for study in grazing course, 370 .

Spessart Mountains, forest privileges, 25.

Sporobolus, for study in grazing course, 368.

Spotted parsley, name for water hemlock, 264.

Spraying, to eradicate larkspur, 260.

Springs, distinguished from seeps, 298 improving and protecting, 298, (fig.) 299.

Spruce, for troughs, 300.

Spruce-fir, type of summer range, study of soil in, 183 ; young cow poisoned by larkspur in spruce-fir type, (fig.) 246; natural-type unit, study of, in grazing course, 385 .

Squirrel food, name for death camas, $26 \mathrm{I}$.

Squirrels, ground, study of, in grazing course, 377.

Stadia, used in field work, $319,320$.

Staggerbush, poisonous species of "laurel," 274 .

Staking, of chart plot, 353; plan for permanent sample plots, (fig.) 353 .

State and private lands, leasing of, 30 ; in Texas, 30; in Wyoming, 31 ; Northern Pacific Railroad Company, 31 .

Steers, feeding grain ration to, 96 .

Stipa, mechanically injurious, 286 ; for study in grazing course, 368 .

Stipa comata, injurious to stock, 288; description, 288.

Stipa minor, in mixed grass and weed stage, 108; on eroded and on noneroded pasture (fig.) I1 8; on range grazed annually (fig.) I 22; on protected plot (fig.) I 23; indicator plant, I 29.

Stipc spartea, injurious species, 288; description, 288 .

Stock, number to graze on nonsod pasture, 96; driving and herding, 247; factors determining number and distribution, 3II.

Stock trails, sign of overgrazing, I06; indicator plants on, 128 ; injury by sheep grazing confined to, 199; factor in fire control, 234 .
Stocker cattle, grazing on nonsod pasture, 97.

Stocking, factors affecting, study of, in grazing course, 365 .

Strip plots, transects and bisects, $35 \mathrm{r}$.

Stripper, comb seed, for collecting seed, (fig.) 56, 57.

Strychnine, for loco poisoning, 254; for larkspur poisoning, 258. ;

Strychnine sulphate, for larkspur poisoning, 258 .

Sudangrass, for hay and pasture combined, 132; habit of growth, 144, (fig.) 145 ; seeding, 145; value for hay, 145 .

Sugar pine, damage to, by grazing, 199.

Sundial, name for lupine, 266.

Sunflower family, for study in grazing course, 369 .

Supplemental feed, provided under leasing system, 34 ; to be considered in pasture inspection, 335 ; study of, in grazing course, 387 .

Surface fire, 233.

Swales, developing water supply of, 299.

Swamps, developing water supply of, 299.

Sweden, home of Alsike clover, I52.

Symphoricarpos, sign of overgrazing, Io6.

Symptoms, of loco poisoning, 252; of larkspur poisoning, 257; of death camas poisoning, 263; of water hemlock poisoning, 265; of lupine poisoning, 268; summary of, 269; of "laurel" poisoning, 275; of sneezeweed poisoning, 278; of ergot poisoning, 28I; of fly agaric poisoning, 283; of death cup poisoning, 284; of mechanical injury by grasses, 286 , 288; for study in grazing course, 370 .

Syringe, Quitman, for hypodermic injections, 258 .

\section{$\mathrm{T}$}

Tapes, boundary, for charting plots, 343; sample plot steel guide, (fig.) 345; quadrat, one meter in length, on denuded plots, 349; special, for mapping transects and bisects, 35I; special sample-plot guide, 35I, (fig.) $35^{2}$.

Tar weed, in first or early weed stage, (fig.) I 16; indicator plant, 128.

Taxonomy, auxiliary subject in study of pasture management, 361 .

Temperature, factor in forage growth, 5 ; study of, included in course in meteorology, 363 . 
Temporary pasture, 88; grass mixture for, 148 .

Tenants, number occupying farms, 210.

Terrace drag, used in terracing to check erosion, (fig.) 193.

Terracing, to check erosion, 192; terrace seeded to mountain bromegrass, (fig.) 194.

Tests, reseeding, 40, $4 \mathrm{I}$; result of, 45, (fig.) 47 ; causes of failure, 48; yearlong protection of pasture, 73 ; deferred grazing on winter ranges, 80 ; methods of cropping and treating bluegrass pasture, 93 .

Texas, leasing system, 30 ; use of wells in Panhandle, 304; leasing system, for study in grazing course, 366 .

Thalicirum, untouched by stock, 126; growth after burning brushland, 226.

Thalictrum Fendleri, on range grazed annually, (fig.) I22; on protected plot, (fig.) I 23.

Theodolite, used in field work, 320 .

Thornber, J. J., tests in seeding native forage plants, 40.

Three-awn grasses, in Great Plains, 6; injurious species 286,288 ; for study in grazing course, 368 .

Thresher, grain, 142 .

Ticks, to be considered in study of entomology, 362 .

Timber, effects of grazing on reproduction, 198; factors that determine extent of damage to, 204; on farm woodlands, 200; effects of goat grazing on, 210; value of, on mountain range, 228; deterrent effect on erosion, 229; factor in determining adaptability of range to stock, 3 II.

Timber reconnaissance, aid in grazing reconnaissance, 311 ; map for, 318; compared with grazing reconnaissance, $32 \mathrm{I}$.

Timbered areas, grazing type, 315 , (fig.) 316.

Timberlands, grazing on, for study in grazing course, 375 .

Timothy, area of growth, 5 ; in reseeding tests, $4 \mathrm{I}, 43,44,45,47$; elevational limitations, 50 ; relation of yield to elevation, (fig.) $5 \mathrm{I}$; permanency of yield, 52 ; amount to sow and cost, 53 ; moisture requirements, 54 ; mixed seeding, 54, 14I; introduced from Old World, 55 ; on permanent pasture, 88; period of yield, 90; for hay and pasture combined, 132, I4I; origin of name, 140; habits of growth, (fig.) I4I; seed habits,
142; in mixtures, 148; for study in grazing course, 368 .

Topography, factor in erosion, 177; factor in extent of damage to timber reproduction, 204; factor in control of watering places, 295; factor in grazing reconnaissance, $308,3 \mathrm{II}$; for study in grazing course, 371 , 375,376 .

Toxicology, definition of term, 242 .

Trampling, of seed, by sheep, $45,5 \circ$; timothy, not readily injured by, 52 ; injury to newly seeded lands by, 55; injury to plant roots by, 72 ; effect of, on timber reproduction, 199, $200,201,202,235$; on farm woodlands, 209; decreases danger from fire, 233; factor in revegetation, 349 .

Transects, form of sample plot, $35 \mathrm{I}$.

Transit, used in field work, 320 .

Traverse-sketching, method of obtaining forage data, $318,319,320$.

Triangulation, method of obtaining forage data, 318,320 .

Trifolium, species and habitat, 152.

Trifolium hybridum, in reseeding tests, 44; habit of growth, 152, (fig.) 153; introduced into United States, I52; seeding, 152.

Trifolium incarnatum, value as hay, 152.

Trifolium pratense, in reseeding tests, 44 ; value as hay, 152 .

Trifolium repens, in reseeding tests, 44; habit of growth, 153; seeding, I53.

Trisetum, for study in grazing course, 368.

Trisetum, spiked, on range grazed annually, (fig.) I22; on protected plot, (fig.) I 23; on protected plot and on unprotected range, 125 ; indicator plant, 130 .

Trisetum spicatum, on range grazed annually, (fig.) 122; on protected plot, (fig.) I 23; indicator plant, 130; on chart plot, (fig.) 342 .

Troughs, location of, 299; kinds of, 300 ; foundation of, 301 .

Tusayan National Forest, cost of reservoirs on, 304 .

Type stages of native pasture vegetation, 107.

\section{$\mathrm{U}$}

Umbelliferae, embraces poisonous species, 243; for study in grazing course, 368. 
Unimproved land, in the United States, location and extent, 4.

United States, area of, 4 .

Utah, cattle and sheep grazed under permit, $2 \mathrm{I}$; investigations in, for study in grazing course, 376 .

\section{V}

Vacciniaceae, for study in grazing course, 360 .

Vagnera stellata, indicator plant, 129.

Valerian family, for study in grazing course, 369 .

Valerianaceae, for study in grazing course, 360 .

Vegetative cover, on range grazed annually, (fig.) I22; on plot protected from grazing, (fig.) I 23 , (table) I25; relation to erosion, 173; factor in erosion, 177,179 , I82; establishment of, a difficult task, 189; functions of vegetation that remains on ground at end of season, 22I; replacement after fire, 226; study of, in grazing course, 375 .

Vegetative degeneration, II 7 .

Vegetative progression, II 7 .

Vetch, introduced from Old World, 55; cultivated pasture plant, $15 \mathrm{I}$; species, 159.

Vetch, common or spring, one of cultivated species, I59; characteristics, I63.

Vetch, hairy or sand, one of cultivated species, 159; characteristics, (fig.) I61, I62; habitat, I62; seeding, I63; value, 163 .

Vetch, narrow-leaved or Augusta, one of cultivated species, I59; habitat, I63.

Veterinary science, auxiliary subject in study of pasture management, 362 ; application of, 363 .

Viability, of seed of native pasture plants, 57; depends on vigor of plants, 66; of Kentucky bluegrass, I34; essential of good seed, I65; how to test, I65; determined by denuded-plot method, 349 .

Vicia, species, I59.

Vicia angustifolia, one of cultivated species, 159.

Vicia sativa, one of cultivated species, I59.

Vicia villosa, one of cultivated species, I59, (fig.) I6r.

Vigna Sinensis, field of, (fig.) $\mathrm{r}_{5} 8$; habit of growth, 158 .
Viola linguacfolia, in destruction of foxglove-sweet sage-yarrow cover, II4; on bed ground, (fig.) I2I; on range grazed annually, (fig.) I22; on protected plot, (fig.) 123; indicator plant, 129; on chart plot, (fig.) 342 .

Violet, dog's-tooth, annual plant, 324 .

Violet, tongue-leaved, in foxglovesweet sage-yarrow cover, II 4; on bed ground, (fig.) I $2 \mathrm{I}$; on range grazed annually, (fig.) I 22 ; on protected plot, (fig.) I 23 ; on protected plot and on unprotected range, I25; indicator plant, 129.

Virginia, study of methods of cropping and treating bluegrass pastures, 93 .

\section{W}

Wasatch Mountains, height, 7; reseeding tests, 45; collecting seed, 57 ; harvesting experiments, 63 ; study of principles of plant succession, 107; study of erosion in, I77; study of rainstorms in, I79; study of soil types in, I83; study of larkspur eradication in, 259.

Washington, cattle and sheep grazed under permit, 2I; study of effect of grazing on timber reproduction, I98; investigations in, for study in grazing course, 376 .

Waste land, grazing type, 315, (fig.) $316:$

Water, in Great Plains, 6; facilities improved by leasing system, 33; ways of providing supply of, 78 ; aid in deferred grazing, 83; weeds, heavy users of, IOI; necessity of, in the West, 172 ; water erosion, due to overgrazing, (fig.) I 83 ; percentage of "nonavailable," in eroded and in noneroded soil, 184 ; requirements for selected plants per unit dry weight on eroded and on noneroded soil, 186 ; aid in eliminating poisonous substances, 246; factor in utilizing forage crop, 295; availability of, 295; requirements of stock, 296; distribution of, 296; springs and seeps, 298; swamps, 299; wells, 304; factor in grazing reconnaissance, $3 \mathrm{II}$; demand for forage great where supply of, is ample, 355; effect of, on stocking, for study in grazing course, 365 , $37 \mathrm{I}$; development of, for study in grazing course, 375 .

Water hemlock, poisonous to stock, 
243; poison in roots, 244; method of eradicating, 247; description, 264, (fig. frontis.); distribution and habitat, 264; losses from, 265; poisonous parts, 265 ; symptoms of poisoning, 265 ; remedies, 266; summary of symptoms and remedies, 270.

IVatering places, distance between, factor in stocking, 6; factor in fire control, 234; control over, 295; distribution of, 296; overgrazing and trampling near, (fig.) 297; natural, 208; artificial, 302; factor in determining number and distribution of stock, 3II; study of, in grazing course, 375 .

Watersheds, creation of National Forests to protect and improve, I8, 27; injury to, by grazing, 105,197 ; of $\mathrm{Na}$ tional Forests, I72; value of vegetative cover on watersheds contributing to Ohio River, I74; protection of, factor in determining adaptability of range to stock, 311; study of, in grazing course, 378 .

Weed, grazing type, 312, (fig.) 314.

Weeds, annual growth in United States, roo; invasion of farm pasture by asters, (fig.) ror; control of, IOI; indicators of overgrazing, 107; noxious, for study in grazing course, 37I; control of, for study in grazing course, 374 .

Vells, essential features, 304 ; in Panhandle of Texas, 304 .

Wheat, Kubanka, growth on eroded and on noneroded soil, 184 ; relative water requirements, (fig.) 186; summary of study, (fig.) I 88 .

Wheatgrass, scattering and planting of seed, 67; in climax herbaceous cover, I08; height growth and root system, (fig.) 109; in mixed grass and weed stage, III; in competition with yellowbrush, (fig.) I12; for study in grazing course, 367 .

Wheatgrass, blue bunch, height and root system, (fig.) rog; indicator plant, I 30.

Wheatgrass cover, climax herbaceous stage, I07; destruction of, ro8; value as forage, II I.

Wheatgrass, Scribner's, indicator plant, I 29.

Wheatgrass, slender, in reseeding tests, 43; amount to sow and cost, 53; in arid regions, 89 ; on eroded and on noneroded pasture, (fig.) I I8; on range grazed annually, (fig.) 122; on protected piot, (fig.) I 23 ; on protected plot and on unprotected range, I 25 ; indicator plant, 130 .

Wheatgrass, small, height and root system, (fig.) Iog; competition with yellowbrush, (fig.) II2; indicator plant, I30; open grassland composed of, (fig.) 313 .

Wheatgrass, violet, collecting seed of, 57 ; effect of cropping, (figs.) 65 ; indicator plant, I30.

White fir, damage to, by grazing, I99. Wild cat, study of, in grazing course, 383.

Willow, sign of overgrazing, 106; effect of fire on, 226.

Willow family, for study in grazing course, 360 .

Wind, factor in erosion, I77, I8I; erosion due to overgrazing, (fig.) I 83 .

Windmill, water provided by use of, 78; for wells, 304 .

Wiregrass, withstands fire, 224, 237. Wolf, study of, in grazing course, 383 .

Woodland, grazing on, 197; grazing farm, 208; grazing type, (fig.) 316 , 317; pasture, for study in grazing course, 364,376 .

Wooton, E. O., tests in seeding native forage plants, 40 .

Worms, stomach, in sheep manure, 100.

Wyoming, cattle and sheep grazed under permit, 2I; leasing system, $3 \mathrm{I}$; leasing system, for study in grazing course, 366 .

\section{$\mathrm{X}$}

Xylorrhiza Parryi, poisonous to stock, 275, (fig.) 277 .

\section{Y}

Yarrow, in second or late weed stage, I13; habit of growth, (fig.) II4; on eroded and on noneroded pasture, (fig.) 118 ; on range grazed annually, (fig.) I22; on protected plot, (fig.) I 23 ; on protected plot and on unprotected range, 125 ; indicator plant, 129, 130; in weed type, (fig.) 314.

Yellowbrush, in destruction of wheatgrass cover, 108; in mixed grass and weed stage, (fig.) I10, II ; in competition with wheatgrass, (fig.) I1 2; indicator plant, 129 .

Yellow pine, type of National Forest, 
moderate grazing and timber production on, (fig.) I9; on cattle range moderately grazed, (fig.) 24; forage on, I98; damage to, by grazing, 199; tree severely browsed by sheep, (fig.) 201; effect of grazing on reproduction in Arizona and New Mexico, 202; injury by cattle browsing, (fig.) 203; study of grazing damage on Coconino National Forest, 204; effect of goat grazing on, 2I0; used for troughs, 300 .

Yellow pine-oak, natural-type unit, study of, in grazing course, 385 .

Yellowstone Park Reserve, first Forest Reserve created, I7.

\section{Z}

Zones, of vegetation surrounding bed ground II9, (fig.) I20; Transi- tion, Canadian, and Hudsonian, study of, in grazing course, 385 .

Zoölogy, auxiliary subject in study of pasture management, $36 \mathrm{I}$; application of, 362 .

Zygadenus, species of poisonous plants, 242 ; description, 26I; distribution and habitat, 261 ; losses due to, 262; poisonous parts, 262 ; amount required to cause death. $26_{3}$; symptoms of poisoning, $26_{3}$; remedies, 263; characteristic sheep poisoning, (fig.) 264 ; for study in grazing course, 370 .

Zygadenus elegans, poisonous species, 26I, (fig. frontis.).

Zygadenus gramineus, poisonous species, 26 I.

Zygadenus paniculatus, poisonous species, 261 .

Zygadenus venenosus, poisonous species, 26 I. 




